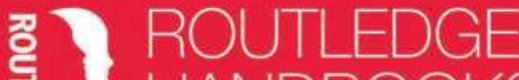 HANDBOOKS}

Temperament theory

$$
\begin{aligned}
& \text { Two-process theory of } \\
& \text { perceived control }
\end{aligned}
$$

Theory of attractive quality

Evolutionary psychology

Space Synfax theory

Biophilia hypothesis

Ecologicalsystems theory

Person-environment

fit theory

theories

Place attachment

Flourish theory

Social constructionism theory

\section{Activity}

theory

Behavioural economics

$$
\begin{aligned}
& \text { Job demands } \\
& \text { resources model }
\end{aligned}
$$
Task-technology fit

Knowledge creation

theory

Action regulation theory

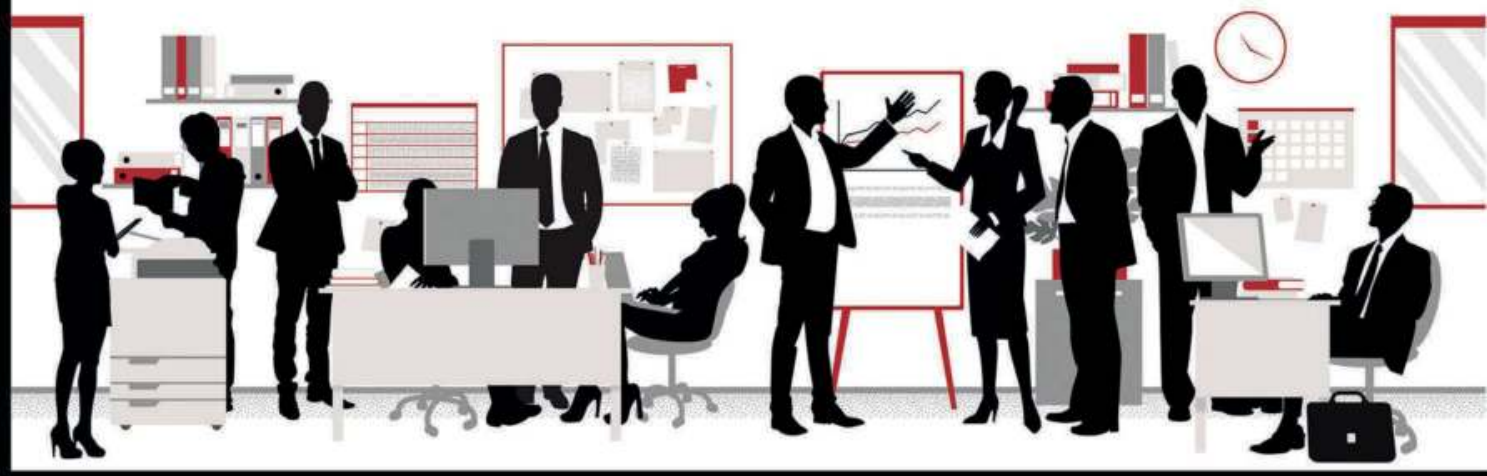

A Handbook of Theories on

Designing Alignment Between

People and the Office Environment

Edited by Rianne Appel-Meulenbroek and Vitalija Danivska 


\title{
A HANDBOOK OF THEORIES ON DESIGNING ALIGNMENT BETWEEN PEOPLE AND THE OFFICE ENVIRONMENT
}

\begin{abstract}
Although workplace design and management are gaining more and more attention from modern organizations, workplace research is still very fragmented and spread across multiple disciplines in academia. There are several books on the market related to workplaces, facility management (FM), and corporate real estate management (CREM) disciplines, but few open up a theoretical and practical discussion across multiple theories from different fields of studies. Therefore, workplace researchers are not aware of all the angles from which workplace management and effects of workplace design on employees has been or could be studied. A lot of knowledge is lost between disciplines, and sadly, many insights do not reach workplace managers in practice. Therefore, this new book series is started by associate professor Rianne Appel-Meulenbroek (Eindhoven University of Technology, the Netherlands) and postdoc researcher Vitalija Danivska (Aalto University, Finland) as editors, published by Routledge. It is titled 'Transdisciplinary Workplace Research and Management' because it bundles important research insights from different disciplinary fields and shows its relevance for both academic workplace research and workplace management in practice. The books will address the complexity of the transdisciplinary angle necessary to solve ongoing workplace-related issues in practice, such as knowledge worker productivity, office use, and more strategic workplace management. In addition, the editors work towards further collaboration and integration of the necessary disciplines for further development of the workplace field in research and in practice. This book series is relevant for workplace experts both in academia and industry.

This first book in the series focuses on the employee as a user of the work environment. The 21 theories discussed and applied to workplace design in this book address people's ability to do their job and thrive in relation to the office workplace. Some focus more on explaining why people behave the way they do (the psychosocial environment), while others take physical and/or digital workplace quality as a starting point to explain employee outcomes such as health, satisfaction, and performance. They all explain different aspects for achieving employee-workplace alignment (EWA) and thereby ensuring employee thriving. The final chapter describes a first step towards integrating these theories into an overall interdisciplinary framework for eventually developing a grand EWA theory.
\end{abstract}

Dr Ir Rianne Appel-Meulenbroek is an associate professor in corporate real estate (CRE) and workplace at the Department of the Built Environment at Eindhoven University of Technology. She is Chair of the Transdisciplinary Workplace Research (TWR) network, co-editor of the Journal of CRE, and a regular speaker at international events. In her research, she approaches workplaces as an important strategic resource for knowledge organizations, studying how they should be managed strategically and how workplace design and use aspects impact employee and organizational outcomes.

Dr Vitalija Danivska is a postdoctoral researcher in the Department of Built Environment at Aalto University, Finland. With a background in real estate economics, she is particularly interested in the real estate business and corporate, facilities management areas. In 2018, she obtained her doctoral degree with her thesis studying the 'Workplace-as-a-Service' concept. She received the EuroFM 2020 Best Paper award, was the runner-up for the 2018 EuroFM Researcher of the Year award, and organized the first TWR conference in 2018 in Tampere, Finland. 
TRANSDISCIPLINARY WORKPLACE RESEARCH AND MANAGEMENT

Series Editors: Rianne Appel-Meulenbroek and Vitalija Danivska

A HANDBOOK OF THEORIES ON DESIGNING ALIGNMENT BETWEEN PEOPLE AND THE OFFICE ENVIRONMENT

Rianne Appel-Meulenbroek and Vitalija Danivska

A HANDBOOK OF MANAGEMENT THEORIES AND MODELS FOR OFFICE ENVIRONMENTS AND SERVICES

Vitalija Danivska and Rianne Appel-Meulenbroek 


\section{A HANDBOOK OF THEORIES ON DESIGNING ALIGNMENT BETWEEN PEOPLE AND THE OFFICE ENVIRONMENT}

Edited by Rianne Appel-Meulenbroek and Vitalija Danivska 
First published 2021

by Routledge

2 Park Square, Milton Park, Abingdon, Oxon OX14 4RN

and by Routledge

605 Third Avenue, New York, NY 10158

Routledge is an imprint of the Taylor \& Francis Group, an informa business

(C) 2021 selection and editorial matter, Rianne Appel-Meulenbroek and Vitalija Danvska; individual chapters, the contributors

The right of Rianne Appel-Meulenbroek and Vitalija Danivska to be identified as the authors of the editorial material, and of the authors for their individual chapters, has been asserted in accordance with sections 77 and 78 of the

Copyright, Designs and Patents Act 1988.

The Open Access version of this book, available at www.taylorfrancis. com, has been made available under a Creative Commons Attribution-Non

Commercial-No Derivatives 4.0 license.

Trademark notice: Product or corporate names may be trademarks or registered trademarks, and are used only for identification and explanation without intent to infringe.

British Library Cataloguing-in-Publication Data

A catalogue record for this book is available from the British Library

Library of Congress Cataloging-in-Publication Data

Names: Appel-Meulenbroek, Rianne, editor. | Danivska, Vitalija, editor.

Title: A handbook of theories on designing alignment between people and the office environment / edited by Rianne Appel-Meulenbroek and Vitalija Danivska.

Description: Abingdon, Oxon ; New York, NY : Routledge, 2021. | Series:

Transdisciplinary workplace research and management | Includes bibliographical references and index.

Identifiers: LCCN 2021002602 (print) | LCCN 2021002603 (ebook) |

ISBN 9780367652999 (hbk) | ISBN 9781003128830 (ebk)

Subjects: LCSH: Work environment. | Work design.

Classification: LCC HD7261 .H345 2021 (print) | LCC HD7261 (ebook) |

DDC $658.3 / 8-\mathrm{dc} 23$

LC record available at https://lccn.loc.gov/2021002602

LC ebook record available at https://lccn.loc.gov/2021002603

ISBN: 978-0-367-65299-9 (hbk)

ISBN: 978-0-367-65308-8 (pbk)

ISBN: 978-1-003-12883-0 (ebk)

DOI: $10.1201 / 9781003128830$

Typeset in Bembo

by Apex CoVantage, LLC 


\section{CONTENTS}

Preface

1 Gathering theories to explain employee-workplace alignment from an interdisciplinary viewpoint

Rianne Appel-Meulenbroek and Vitalija Danivska

2 Person-environment fit theory: application to the design of work environments

Lynne Audrey Armitage and Johari Hussein Nassor Amar

3 Job demands-resources model: its applicability to the workplace environment and human flourishing

Michael Roskams, Eileen McNeely, Dorota Weziak-Bialowolska, and Piotr Bialowolski

4 Task-technology fit theory: an approach for mitigating technostress

Nelda Vendramin, Giulia Nardelli, and Christine Ipsen

5 Action regulation theory

Lukas Windlinger

6 Privacy regulation theory: redevelopment and application to work privacy

Clara Weber, Birgitta Gatersleben, Barbara Degenhardt, and Lukas Windlinger 
7 Information space(s)

Mascha Will-Zocholl

8 Social constructionism theory: constructing the user experience of workplace

Kaisa Airo

9 Ecological systems theory

Eunhwa Yang and Bonnie Sanborn

10 Temperament theory: understanding people in a workplace context Mel Bull

11 Two-process theory of perceived control: changing the workspace and changing the self

Daibin Xie

12 Organisational culture theories: dimensions of organisational culture and office layouts

Kusal Nanayakkara and Sara Wilkinson

13 Theory of attractive quality: occupant satisfaction with indoor environmental quality at workplaces

Quan Jin, Holger Wallbaum, Jungsoo Kim, and Richard de Dear

14 Flourish theory: a model for multisensory human-centric design

Derek Clements-Croome

15 Biophilia hypothesis: the benefits of nature in the workplace Sven Wolf Ostner

16 Place attachment theory

Goksenin Inalhan, Eunhwa Yang, and Clara Weber

17 Evolutionary psychology theory: can I ever let go of my past? Young Lee

18 Behavioural economics theory: masters of deviations, irrationalities, and biases

Young Lee

19 Nudging in the workplace: facilitating desirable behaviour by changing the environment

Tina Venema and Laurens van Gestel 
20 Activity theory: a framework for understanding the interrelations between users and workplace design

Maral Babapour, Antonio Cobaleda-Cordero, and MariAnne Karlsson

21 Space syntax theory: understanding human movement, co-presence and encounters in relation to the spatial structure of workplaces Kerstin Sailer and Petros Koutsolampros

22 Organisational knowledge creation theory and knowledge workplaces Mervi Huhtelin and Suvi Nenonen

23 Towards an interdisciplinary employee-workplace alignment theory Rianne Appel-Meulenbroek, Susanne Colenberg, and Vitalija Danivska 


\section{PREFACE}

This book showcases theories explaining the impact of the office workplace on its users. It was an idea that had been in Rianne's head for some years, before it materialized into the underlying first book of a new book series called Transdisciplinary Workplace Research and Management. It remained only an idea until she shared it with Vitalija at a workplace conference in Hong Kong in 2019, whose enthusiasm to collaborate sparked the first real action to work the idea out into this innovative book series. Much has already been written on the strategic, tactical, and operational management of office workplaces and their impact on employees by researchers from many different disciplinary backgrounds. However, this book is unique in showcasing theories that provide researchers and practitioners with a structure for asking the right questions and sharing knowledge on methodologies across disciplinary boundaries.

Due to the spread of workplace research across disciplines, we knew we could not oversee all relevant theories ourselves, with just our own respective engineering and economic backgrounds. Therefore, we soon decided to put out a call for potentially relevant theories in our networks and across social media platforms to see what would come forward. The response was so extensive that it felt a bit overwhelming at first. We received ideas for almost 60 different chapters. But after the initial shock wore off, we decided not to produce one book but to start a book series instead. There were clearly even more theories available than we realized that could help advance both workplace design and management research and practice.

When the full draft chapters came in for about 40 theories, our enthusiasm reached a new high. Although of course we had aimed for inspiration from other disciplines, the level of inspiration and new knowledge blew our minds. Clearly, a lot of knowledge is lost between disciplines, as so many theories were new to us and stemmed from many different disciplines. The described application of each theory to our own field was valuable for us and appeared an important road to advance our field further as a real science.

Looking through the list of theories, we soon saw two main 'categories' of theoretical topics coming forward, which we used to divide the theories over two books. On the one hand, it was suggested to include theories in our series on aligning the work environment to the office employee at the individual level, towards increasing individual outcomes such as satisfaction, wellbeing, and performance (which became the first book). On the other hand, we received suggestions for many theories and models focused on the workplace management process and strategy development and alignment as part of it (which became the second book). Hopefully, 
future books in the series will embrace even more angles, and we are open for suggestions if you have an idea for it. Workplace research and management methods is one idea that we are thinking of for the third book.

This first book in the series explains 21 theories, in 21 equally set-up chapters, that provide important insights for achieving employee-workplace alignment towards support of employee thriving (happy, healthy, and productive employees). In addition, we have taken these insights to the next level towards a real 'transdisciplinary' viewpoint. Transdisciplinary means that the knowledge from the theories is not only linked, but that it is also used to create an overall system without disciplinary boundaries. It was quite a challenge to develop such a shared conceptual framework, but we managed through a joint effort with all the 41 authors in this book. This made it possible to take a bold first step in the final chapter of this book towards developing a grand theory of employee-workplace alignment (EWA).

Thanks to the institutions of several authors and a crowdfunding project that we started on GoFundMe, we were able to make the e-book versions of these first two books open access to all (meaning there are no costs to download the book chapters from routledge.com). Besides the 54 donors who contributed to this crowdfunding initiative on an individual note, we specifically want to acknowledge the large donations we received from the Kardham Group, the Sonneborgh group, IVBN (Association of Institutional Property Investors in the Netherlands), and CREME (Dutch end-user platform for corporate real estate managers), as well as donations from Buck Consultants International, Fakton, and the Dutch branch of CBRE global investors.

We hope you enjoy reading the book. The books are aimed at both researchers and practitioners, because all chapters clearly explain a theory, then apply it to the workplace, discuss research methods and limitations for researchers, and discuss implications for workplace management in practice. Hopefully, they thus help advance the academic research field and help transfer scientific knowledge to practice. You can read the book from front to back, but you can also start in the end with the grand theory and then visit the individual theories afterwards in the order of your own interest. We wish you lots of inspiration and wonderment from reading all the knowledge gathered in this book.

Rianne Appel-Meulenbroek and Vitalija Danivska 


\section{CONTRIBUTORS}

Dr Kaisa Airo works as a senior lecturer in Laurea University of Applied Sciences, in which she teaches service design and facility management to master's and bachelor's students. Previously she worked as a researcher in Aalto University in Finland, where she completed her doctoral dissertation about user experience of workplaces in 2014. She has been working with several industrial partners in developing workplaces, shopping centres, business parks, and learning environments, both in higher and basic education. In her research, she is applying theories from sociology and sociolinguistics to workplace management. She is enthusiastic about storytelling and visual language, which she actively applies to her teaching. Laurea University of Applied Sciences, Finland ORCID: 0000-0002-9530-0916

Dr Ir Rianne Appel-Meulenbroek is an associate professor in corporate real estate (CRE) and workplace at the Department of the Built Environment at Eindhoven University of Technology. She is Chair of the Transdisciplinary Workplace Research (TWR) network, co-editor of the Journal of CRE, and a regular speaker at international events. In her research, she approaches workplaces as an important strategic resource for knowledge organizations, studying how they should be managed strategically and how workplace design and use aspects impact employee and organizational outcomes. Eindhoven University of Technology, The Netherlands ORCID: 00000003-3877-4004

Dr Lynne Audrey Armitage, Associate Professor, Urban Development, Bond University, Australia, has worked extensively in corporate property advisory roles in private and public sectors in the UK and Australia. Leading undergraduate and postgraduate property programs in four universities in three countries - Australia, Papua New Guinea, and Thailand - her research centres on property markets in mature and emerging markets with a particular interest in the modifying characteristics of legislative and societal developments. She has published and presented widely in international refereed journals and conferences and authored four books in the areas of commercial real estate, property valuation, and built heritage conservation. Bond University, Australia ORCID: 0000-0002-9273-9392

Dr Maral Babapour is a design researcher at Division Design \& Human Factors at Chalmers University of Technology and the Institute of Stress Medicine, Region Västra Götaland. 
Maral applies user-centred design methodology to study the adoption of workplace innovations which cover products, services, systems, or environments. Her research approach is interactive and interpretative and engages multiple stakeholders. The goal is to inform the design of resource-efficient and health-promoting workplace solutions that make work and life fulfilling and meaningful for users. Maral's work includes developing methods and tools for (re-)designing workplaces and addressing occupational health and safety issues in the workplace. Chalmers University of Technology, Sweden Institute for Stress Medicine, Sweden ORCID: 0000-0002-8620-2329

Dr Piotr Bialowolski (PhD, dr hab.) specializes in applied economics and quantitative methods for applied research in the areas of household financial behaviour, workplace relations, and wellbeing. Before joining the Sustainability and Health Initiative at the Harvard T.H. Chan School of Public Health, PB was a researcher at the Institute for Quantitative Social Science at Harvard University. His research interests and publications focus on the following research topics: (1) application of micro-level data for the impact evaluation of financial behaviours and workplace relations on wellbeing and health, (2) financial wellbeing with application of composite scales, (3) segmentations, and (4) survey design, biases, and forecasting with survey data. Harvard University, USA ORCID: 0000-0003-4102-0107

Dr Mel Bull is the Director for Executive and Professional Education at the University of Sheffield and teaches across the MBA and executive education programmes. She has previously worked as the MBA Director at Sheffield Hallam University, teaching across all the MBA programmes including the MBA in facilities management. Her research interests focus on workplace and facilities management, organizational behaviour, leadership, and communication. University of Sheffield, UK ORCID: 0000-0002-7443-4026

Prof Derek Clements-Croome (Reading University) previously worked in industry. He chairs the CIBSE Intelligent Buildings Group and is a coordinator for the CIB W098 Commission. He researches health, wellbeing, and using wearables in the workplace (British Council for Offices). He was a commissioner on air quality and biodiversity in London and a contributor to the World Green Building Council Reports 'Health and Wellbeing in Homes 2016' and 'Health and Wellbeing in Offices 2014'. Books include Creating the Productive Workplace, Routledge 2018 and Designing Buildings for People: Sustainable Liveable Architecture, Crowood Press 2020. TWR Board member ORCID: 0000-0001-5116-8821

Antonio Cobaleda-Cordero is a PhD student at Division Design \& Human Factors, Chalmers University of Technology. His background is in design engineering, and his research focuses on the experiences of users working in flexible office environments, in which they must often share artefacts and spaces that were designed for individual use. This research aims to understand how these artefacts and spaces might be (re-)designed to improve the user experience (UX) at flexible offices. His research work intends to support the design and development of office products, services, and spaces for positive UX, thus contributing to office user wellbeing. Chalmers University of Technology, Sweden ORCID: 0000-0001-6734-7584

Ir Susanne Colenberg has a degree in both organizational psychology (Leiden University) and interior architecture (Royal Academy of Arts, The Hague). After working for over 20 years as a researcher and workplace consultant, she currently is a $\mathrm{PhD}$ candidate at the Department of Human-Centered Design, Faculty of Industrial Design Engineering, Delft University of Technology, studying the relationship between workplace design and social wellbeing at work. She is 
a guest lecturer of environmental psychology at the University of Amsterdam. Delft University of Technology, the Netherlands ORCID: 0000-0003-4835-4572

Dr Vitalija Danivska is a postdoctoral researcher in the Department of Built Environment at Aalto University, Finland. With a background in real estate economics, she is particularly interested in the real estate business and corporate, facilities management areas. In 2018, she obtained her doctoral degree with her thesis studying the 'Workplace-as-a-Service' concept. Besides research and teaching, she is also a board member of the IFMA (International Facility Management Association) Finland chapter. Aalto University, Finland ORCID: 0000-0001-9984-7487

Prof Richard de Dear is Director of the Indoor Environmental Quality Laboratory at the University of Sydney. He has previously worked at Macquarie University, National University Singapore, and Technical University of Denmark. Since 1981 de Dear's research has focused on building occupants' thermal comfort, health, productivity, and the relationships of these factors with broader contextual features of architecture and climate. De Dear holds ASHRAE's Nevins Award and is a member of the International Society of Indoor Air Quality's Academy of Fellows. In 2016 he received the Windsor Award for his contribution to thermal comfort research. University of Sydney, Australia ORCID: 0000-0002-3414-290X

Dr Barbara Degenhardt is Managing Director of Irchel Campus Usage Management and workplace consultant at the University of Zurich. She is founding head of the private Institut für nutzerInnengerechte Bauten und Landschaftsgestaltung (INBL) and guest lecturer at the Center for Urban Real \& Estate Management (CUREM) in Zurich. In her work she focuses on the environmental, work, and health psychological basics of good work and recovery, which she applies to the evidence-based and user-centred design or improvement of work and recreation environments. University of Zurich, Switzerland ORCID: 0000-0002-6327-4477

Dr Birgitta Gatersleben is a reader in environmental psychology at the University of Surrey, where she runs the Environmental Psychology Research Group and MSc. She has been working in the field for over 20 years and has published numerous papers on a range of people-environment topics. Most of her work focuses on understanding the wellbeing benefits of engagement with natural environments and on promoting sustainable lifestyles. University of Surrey, UK ORCID: 0000-0002-5841-0577

Mervi Huhtelin is a doctoral student, and her research topic is 'places supporting knowledge co-creation' in Tampere University, Finland. She works also in University Properties of Finland Ltd. (SYK) as a business development analyst. Her research interest is in campus development, innovation platforms, and workplace concepts, supporting academic research as well as product development. University of Tampere, Finland ORCID: 0000-0001-6440-4862

Dr Johari Hussein Nassor Amar has been a property academic, researcher, and consultant for over 10 years. Commencing as a land economist for Knight Frank Tanzania, she was responsible for managing commercial and residential portfolios. Currently a lecturer in property economics at the Queensland University of Technology (QUT), Australia, Johari has published internationally in refereed journals and conference proceedings. Her research interests include commercial real estate, valuation, PE-fit theory, built heritage, and affordable housing. Johari holds a $\mathrm{PhD}$ in sustainable development, Bond University; MSc Real Estate Management, KTH Royal Institute of Technology Sweden; and BSc (Hons.) Land Management and 
Valuation, University of Dar es Salaam Tanzania. Queensland University of Technology, Australia ORCID: 0000-0002-1751-6009

Dr Goksenin Inalhan works as an associate professor in the Architecture Department at Istanbul Technical University. She earned her PhD from Reading University, Urban Studies, Construction Management in England. She has researched in the areas of environmental psychology, accessibility, design for everyone, environmental design for the elderly and the disabled, the changing workplace, and post-occupancy evaluation in the workplaces. Her work has been published in leading workplace and facility management journals. Istanbul Technical University, Turkey ORCID: 0000-0003-4995-8431

Dr Christine Ipsen is an associate professor and head of the Implementation and Performance Management group at the Technical University of Denmark (DTU). She also has an affiliation with the University of Massachusetts-Lowell, US, and is a visiting senior fellow at Nottingham Trent University, UK. She has led a number of research projects focusing on developing participatory intervention programs supporting the implementation of preventive changes, and her research is published in books and papers. Her present research focus is on distance management, working from home, and in particular the role of new digital technologies and how to manage organizational performance and employee-wellbeing in tandem. Technical University of Denmark, Denmark ORCID: 0000-0002-2394-5571

Dr Quan Jin is a senior researcher in the sustainable research group at the Department of Architecture and Civil Engineering at Chalmers University of Technology. She is core member of REHVA Technical and Research Committee, editorial board member of the journal Intelligent Buildings International, and commission member of CIB W098. She was awarded the SCANVAC prize for Young Researcher 2019. In her research, she focuses on indoor environmental quality concerning occupant comfort, health, and productivity from multiple disciplinary perspectives, studying what the key factors are, how they interact with occupants, and their impact on building energy efficiency and sustainability. Chalmers University of Technology, Sweden ORCID: 0000-0003-4331-7983

Prof MariAnne Karlsson is a professor (chair) in Human-Technology Systems at Division Design \& Human Factors, Chalmers University of Technology. Her research focuses on the complex, multidimensional relationship between people and technical artefacts and how new solutions are adopted into everyday life. The overall purpose is to contribute with knowledge to support a user- and use-centred development of technical products and systems. Chalmers University of Technology, Sweden ORCID: 0000-0001-6336-3878

Dr Jungsoo Kim is a senior lecturer in building science in the School of Architecture, Design and Planning. He received his $\mathrm{PhD}$ from the University of Sydney, and his $\mathrm{PhD}$ project focused on occupant satisfaction with indoor environmental quality (IEQ) in office buildings. His current research interests include human thermal comfort, occupant adaptive behaviour, cognitive performance, and building energy efficiency. He is also an active member of international research groups under the International Energy Agency's Energy in Buildings and Communities Programme (IEA-EBC). University of Sydney, Australia ORCID: 0000-0003-4012-1600

Petros Koutsolampros is a $\mathrm{PhD}$ researcher in the Space Syntax laboratory, focusing on the effects of spatial configuration on movement and interaction in workplaces. He is an architect 
by training but has since diverged towards spatial analysis and computation. He has experience working with and teaching building and urban analytic techniques, agent-based modelling, and mixed reality in various languages and frameworks. Petros was previously a knowledge transfer partnership associate with Spacelab and UCL and currently works at Space Syntax Ltd. on the development of novel spatial analytic methods. He is also the primary maintainer of the opensource spatial analysis software depthmapX and its accompanying $\mathrm{R}$ package, rdepthmap. University College London, UK ORCID: 0000-0003-2842-9899

Dr Young Lee (LEED AP, WELL AP, Fitwel). Trained in indoor environment design/engineering, sustainable building research, and workplace strategies for over two decades, Young's focus in research and practice resides in health/wellbeing-enhanced workplaces, indoor environmental quality, and user experiences. As the creator of open source workplace analytics CAPTIW ${ }^{\mathcal{O}}$ : Workplace Innovation Performance and PROWELL ${ }^{\mathcal{C}}$ : Workplace Health \& Wellbeing Performance, Young has been pioneering evidence-based practice in workplace design and management. Integrating her analytical research background to workplace design/management strategies, she continuously pursues her belief in health and wellbeing, sustainability, and workplace thrivingness by understanding human factors. Innovative Workplace Institute, USA University College London, UK ORCID: 0000-0002-5778-9095.

Dr Eileen McNeely is Founder and Executive Director of SHINE, the Health \& Sustainability Initiative at the Harvard T.H. Chan School of Public Health. She has extensive experience in the areas of environmental epidemiology, occupational and community health, health promotion, and health services management and policy. Her experience spans numerous industries. She has consulted both nationally and internationally on the impact of work on wellbeing and has authored many publications on this topic. Her research is currently focused on work as a platform to improve wellbeing, putting people and health at the centre of corporate sustainability and business culture. Harvard T.H. Chan School of Public Health, USA ORCID: 0000-0002-4797-9995

Dr Kusal Nanayakkara (BProp (Hons), BSc EMV (Sp) (Hons), HNDA, MAAT) recently completed his $\mathrm{PhD}$ in built environment. His $\mathrm{PhD}$ research focused on how organizational culture would be influenced by changing office layouts and designs. It examined the issue from the perspectives of management, employees, and workplace specialist consultancy and design firms. Kusal's research interests are in the areas of new ways of working and their impact on workplaces and organizational culture, corporate real estate-related issues, and property markets in developing countries. He has been working as a casual academic and had industry experience as a property analyst for six years. University of Technology Sydney, Australia ORCID: 0000-0003-2634-1834

Dr Giulia Nardelli is an associate professor at DTU Management, Implementation and Performance Management research group. She holds a $\mathrm{PhD}$ in innovation management in services. In close collaboration with industry, she is currently researching implementation aspects of innovation digitalization by applying process methods. Giulia combines the emphasis on human factors, IT, and implementation to study a variety of contexts, for example services, manufacturing, and energy providing. She has published peer-reviewed articles in the Service Industries Journal, the International Journal of Innovation Management, the International Journal of Information Systems in the Service Sector, and the Journal of Facilities Management. Technical University of Denmark, Denmark ORCHID: 0000-0002-0487-216X 
Dr Suvi Nenonen is a workplace developer in both practice and research. She is an adjunct professor at Universities of Tampere and Turku with research interests and projects focused on digital, physical, and social spaces and realities. Her background is in social sciences, and her doctoral thesis, 'The Nature of the Workplace for Knowledge Creation', was conducted in the Department of Real Estate Management at Aalto University (former HUT), Finland. She has an extensive European network. She is the Specialist of Future Working and Learning Environments in SYK, University Properties of Finland Ltd. Her passion there is to support and facilitate co-commitment processes in small- and large-scale changes all over Finland. She is also coordinating the RDI-activities in the company. Universities of Tampere and Turku, Finland ORCID: 0000-0002-0347-524

Dipl.-Ing. architect Sven Wolf Ostner, MSA EUA, studied architecture and international project management in Germany and London. After some years of work experience in both countries, he started his own architectural practice in Stockholm. With experience from over 140 different projects, he is now working as a senior business developer and strategist for office projects. In the last six years, his projects have been based on scientific findings, combining an array of different research disciplines. This approach builds a bridge between theory and design and helps to shape a new understanding of the build environment. AWL Arkitekter, Sweden ORCID: 0000-0001-6108-6790

Michael Roskams is a PhD student in environmental psychology at Sheffield Hallam University. His research explores the effects of the workplace environment on employee wellbeing and productivity. In particular, his research interests include theoretical approaches to the workplace and the use of modern Internet of Things technology to improve workplace practice. Sheffield Hallam University, UK ORCID: 0000-0003-4956-0335

Dr Kerstin Sailer is Associate Professor in Social and Spatial Networks at the Bartlett School of Architecture at University College London. She investigates the impact of spatial design on people and social behaviours inside a range of buildings such as offices, laboratories, hospitals, and schools. An architect by training, her research interests combine complex buildings, workplace environments, and space usage with social networks, organizational theory, and organizational behaviour. Her research has been funded by both industry and research councils, including the Engineering and Physical Sciences Research Council, the Arts and Humanities Research Council, Innovate UK, and Google. University College London, UK ORCID: 0000-0001-6066-7737

Bonnie Sanborn is an anthropologist and environmental psychologist who serves as Design Research Leader for the integrated design firm DLR Group, where they support clients and design teams through practice-based research. B has an Evidence-Based Design accreditation from the Center for Health Design and is a member of the EDAC Advisory Council. B is active in organizations that seek to connect research to design, including the Environmental Design Research Association, the Design Futures Initiative, and as a National Allied Member of the AIA. DLR Group, USA ORCID: 0000-0002-3306-3222

Laurens van Gestel is a $\mathrm{PhD}$ candidate in social psychology at Utrecht University. He has published field studies on nudges' effectiveness as well as fundamental work on the working mechanisms of these nudges. He particularly focuses on the role of dual processes and motivation in nudges' effectiveness across several behavioural domains such as health and sustainability. Utrecht University, The Netherlands ORCID: 0000-0002-2461-4301 
Nelda Vendramin, MSc, is a PhD candidate from the Technical University of Denmark, DTU Management. Her PhD project focuses on digitalizing knowledge work and investigates the involved processes, drivers, and enablers of digitalization in knowledge-intensive organizations. She is interested in the role of digital technology and their effects in knowledge-intensive organizations. Her work addresses the transition from co-location to dispersed and virtual work, focusing on technostress, distance management, and the dynamics in dispersed, hybrid, and virtual workplaces. Technical University of Denmark, Denmark Orchid: 0000-0002-7291-2952

Dr Tina Venema received her PhD in psychology from Utrecht University in 2020. Her dissertation 'Preferences as Boundary Condition of Nudge Effectiveness. The Potential of Nudges under Empirical Investigation' was part of the multidisciplinary consortium WINK (Welfare Improvement through Nudging Knowledge). In 2016 she received the Louis Bonduelle young researcher award. Her research interests revolve around the positive and negative influence of the environment on human decision-making. She currently works as a postdoctoral researcher at Aarhus University. Aarhus University, Denmark ORCID: 0000-0002-3939-2828

Prof Holger Wallbaum has been Full Professor in Sustainable Building at Chalmers since 2012. Earlier he was an assistant professor in sustainable construction at the Department of Civil and Environmental Engineering at ETH Zurich, Switzerland. Holger's research is related to ecological and economic life-cycle assessment of construction materials, buildings, and infrastructures, sustainability assessment tools for buildings, social-cultural and climate-adapted design concepts, as well as energy and material resource-based building stock modelling and its visualization. $\mathrm{He}$ has built up a strong research environment that does research on comfort and wellbeing and their effect on occupants' productivity in non-residential buildings. Chalmers University of Technology, Sweden ORCID: 0000-0001-5809-9400

Dr Clara Weber is a senior research associate at the Institute of Facility Management (IFM) of the Zurich University of Applied Sciences (ZHAW) and a visiting researcher at the Environmental Psychology Department at University of Surrey. Clara is an expert in work environments research, particularly in intersections between work environments and socio-environmental needs such as privacy. She is a regular speaker at international conferences and has published on these topics in leading workplace and environmental psychology journals. Zurich University of Applied Sciences, Switzerland ORCID: 0000-0002-8813-3689

Dorota Weziak-Bialowolska ( $\mathrm{PhD}, \mathrm{dr}$ hab.) is a research scientist at the Department of Environmental Health, Harvard T.H. Chan School of Public Health and a research fellow at the Human Flourishing Program at the Institute of Quantitative Social Science, Harvard University. She received her master's degree in quantitative methods, her doctoral degree in economics, and her postdoctoral degree (habilitation) in sociology. Her research interests are in methodology, including psychometrics and impact assessment and evaluation. Her recent empirical research is on human flourishing, wellbeing, and health promotion. She has published 63 papers in peer-reviewed journals, seven book chapters, and two books. Harvard University, USA ORCID: 0000-0003-2711-2283

Prof Sara Wilkinson (BSc, MA, MPhil, PhD, FRICS, AAPI) is a chartered building surveyor and Australia's first female Professor of Property. Her transdisciplinary research program sits at the intersection of sustainability, urban development, and transformation, with a focus on green cities and preparing our urban environments for the challenges of climate change. 
Sara works with academics and industry partners in engineering, science, health, and business to deliver building adaptation, sustainability and resilience, and green infrastructure projects. Sara has produced nine books, 29 book chapters, 59 refereed journal and 105 refereed conference papers, and eight keynote presentations. University of Technology Sydney, Australia ORCID: 0000-0001-9266-1858

Prof Mascha Will-Zocholl is a professor for social sciences in the Department of Public Administration at Hessian University of Police and Administration in Wiesbaden (Germany). She received her doctoral degree from Technische Universität Darmstadt and worked as a postdoc at the Goethe-University Frankfurt. With a sociology background, she focuses on relations between work, technology, and organization. Her research concentrates on the digitization of the world of work: changing work processes, employees' practices, and qualification and competence issues. Further, she examines trust in cooperation and social perceptions of meaningful work. In her current publication project, she focuses on topologies of work. Hessian University of Police and Administration, Germany ORCID: 0000-0003-1647-8060

Prof Lukas Windlinger is a professor at the Institute of Facility Management (IFM) of the Zurich University of Applied Sciences (ZHAW). He has been active in workplace management since 2005 and represents this discipline in the bachelor, master, and continuing education programs of the IFM. Together with his team, Lukas conducts applied research and consultancy projects on the design and management of work environments by focusing on the integration of spatial, human, and organizational factors. Zurich University of Applied Sciences, Switzerland ORCID: 0000-0001-9762-8504

Dr Daibin Xie is a workplace researcher and workplace strategy consultant. He is an anthropologist at heart with great interests in cultural phenomena, yet has trained as an architect in China, where he completed his bachelor's and master's degree in architecture. He finished his $\mathrm{PhD}$ research, 'Cultural Influences in Chinese Workplaces', at University College London. His current research work focuses on the cross-cultural comparison of workspace design and workplace behaviours, as well as their underlying motivations. University College London, UK ORCID: 0000-0002-1074-8413

Dr Eunhwa Yang is an assistant professor in the School of Building Construction at the Georgia Institute of Technology. Her scholarly passion lies in integrating work, workers, workplace, and technology through the lens of environmental psychology, organizational behaviour, programming and design, and engineering. She views workplace strategies and facility operation as a catalyst for users' physical, social, and mental health and wellbeing, ultimately affecting organizational vitality. Her work has been published in leading workplace and facility management journals. Georgia Institute of Technology, USA ORCID: 0000-0001-5946-7703 

Taylor \& Francis http://taylorandfrancis.com 


\title{
1 \\ GATHERING THEORIES TO EXPLAIN EMPLOYEE- WORKPLACE ALIGNMENT FROM AN INTERDISCIPLINARY VIEWPOINT
}

\author{
Rianne Appel-Meulenbroek* and Vitalija Danivska
}

\section{Introduction}

In a way, the field of office workplace management was born with the first introduction in society of dedicated buildings to perform work away from the home environment. Nonetheless, for centuries the attention on physical workplaces was purely focused on providing shelter from outside forces, without thinking much of how this work environment fitted people's needs, preferences and activities. Much later, large companies started to assign the task of workplace management to dedicated managers, and it became a profession. However, the background training of these early workplace managers was often not in real estate but in the core business of the company, and their focus remained on efficiency and timely provision of square metres, rather than on optimally supporting the people that had to use the office. During the '90s of the 20th century this changed, when workplace management started to become a topic of academic and practice-based research. It became clear that corporate real estate management (CREM), facility management (FM) and other workplace-related management professions needed to improve their ad hoc and operational way of working towards a more strategic and context-specific approach. Also, real estate programs started to appear at universities on bachelor and master levels, although for a long time these also focused mostly on the financial management of real estate, instead of the real estate users (Epley, 2006). Training on the users' experience of work environments was 'confined' to different, much older traditions such as psychology and sociology. It was not until the past decade that knowledge from such disciplines started to slowly penetrate the workplace management profession, partly by increased joint approaches to the work environment with human resource management (HRM) and other departments, as well as interdisciplinary research projects by academics.

Since the '90s, much has been written on workplace design and management and how this supports or hinders employees, by researchers from many different disciplinary backgrounds. Both field studies and experiments and controlled laboratory experiments have shown that people are affected by their work environment in many ways (see Appel-Meulenbroek, Clippard, \&

*Corresponding author: h.a.j.a.appel@tue.nl 
Pfnür, 2018 for a scoping review of evidence), and thus it is important to align the workplace to the employee's needs. Also, more and more proof came forward that designing a more optimal fit between employees and their work environment could increase not only their comfort and satisfaction, but also task performance, health and commitment to the company.

So far, the term alignment in the context of workplace design and management research has been used largely on the strategic organisational and corporate real estate portfolio level (e.g. Heywood \& Arkesteijn, 2017), departing from theories in the field of strategic management. Alignment between a person and the environment on the individual level is generally called 'fit', referring to person-environment (PE) fit theories (see Chapter 2) stemming from psychology. But judging from the definition of alignment in the MacMillan dictionary, "the organization of activities or systems so that they match or fit well together", the terms alignment and fit are closely related. For this book, the editors have therefore chosen for the term employee-workplace alignment (EWA) instead of PE-fit, to emphasise the focus on the physical work environment, thus following other recent works in the workplace field that have done so (e.g. Roskams \& Haynes, 2019). As Roskams and Haynes (p. 282) put it, "a workplace environment which is perfectly aligned to the occupants is one which is free of demands and abundant in resources." The importance of PE-fit, generally focused on the psychosocial work environment, has been proven across many different contexts, by researchers from many different disciplinary backgrounds. Although only a few studies explicitly apply PE-fit theory to the physical work environment (e.g. Hoendervanger, Van Yperen, Mobach, \& Albers, 2019), it would seem that EWA is thus also important.

For sure, nowadays many organisations and their workplace managers are looking for evidence on how to align office design solutions to their workforce more optimally, so they believe in the importance of EWA. Their end goal is happy, healthy, productive and engaged employees; also called thriving (Kleine, Rudolph, \& Zacher, 2019). But here they often run into problems. Workplace research is quite fragmented and spread across multiple disciplines in academia, each having their own focus on parts of the mechanisms behind the P-E fit equation (AppelMeulenbroek et al., 2018). Because of this fragmentation, a lot of knowledge is lost between disciplines and many insights do not reach workplace managers in practice. Psychologists present their workplace-related research at psychology conferences and in psychology journals and business magazines, while real estate academics stick to real estate conferences and outlets, ergonomists to the ergonomic counterparts, etc. This causes a lack of integration of knowledge into an overall theoretical framework.

\subsection{A complex problem}

Traditionally, an academic discipline is an area of study with its own vocabulary, theories, strategy and techniques for replication and validity (Donald, 2002). However, workplace design is typically a field of 'complex problems' that needs input from many different disciplines. Like other complex systems, a key property is "that the whole is greater than the sum of all the parts" (Bernstein, 2015). Looking from one discipline only will never capture the whole picture. For example, Zhang and Shen (2015) showed that when dealing with complex, real-world problems that require knowledge from multiple disciplines, students may suffer from isolated knowledge and discipline-specific reasoning and problem-solving. The same is likely to be true for more advanced researchers. Because of the fragmentation of knowledge, workplace researchers are not aware of all the angles from which workplaces are studied, nor can they oversee all the theories and methodologies that are used by other disciplines on the same complex problem.

An optimal EWA can probably even be considered a so-called wicked problem, because as Kreuter, De Rosa, Howze, and Baldwin (2004) describe wicked problems, they are difficult to 
pin down and influenced by a constellation of complex social and political factors that change over time. Especially regarding environmental health, they sum up four characteristics that make problems wicked, and all four clearly apply to reaching EWA:

1 The nature of the problem is viewed differently depending on the perspectives and biases of those with a stake in the problem.

2 Multiple stakeholders are involved which disagree about the problem and the optimal solution.

3 It is unclear when the problem is actually solved.

4 What works in one context does not necessarily work in another similar context.

While several other books and journals are dedicated to workplace design and management, only very few open up a theoretical discussion across multiple theories from different disciplines. Also, no overall interdisciplinary framework ties such theories together and as such gives a more holistic view of improving EWA. Therefore, closing that research gap is the goal of this book. It will provide the necessary insights into the (potential) application of 21 theories from multiple disciplinary fields to optimise alignment between people and their work environment. Each chapter will address one theory (or a set of related theories) in the context of better, humanfocused workplace design. It will explain the theory's assumptions, its implications for the workplace field, relevant research methodologies to study this further, and the theory's relevance for workplace managers in practice. To start an interdisciplinary integration of all these theoretical assumptions, the last chapter ties the 21 theories together into an overall interdisciplinary framework as a first step towards a grand theory on EWA. The setup of this framework is based on an empirical concept-mapping study, involving the authors of the different chapters as respondents (see Chapter 23 for more details).

The next sections of this introductory chapter will now explain the concept of inter- and transdisciplinarity, plus the different disciplines that are represented in some way in this book. It also discusses the logic of the chapter order in the book. This is followed by a brief discussion of terminologies, in order to prevent cross-disciplinary confusions on terms. First, this regards the differences between terms like a theory, model or framework. Then, terms from the workplace field itself are treated (e.g. workplace versus workspace), discussing their meaning and use. Last, the setup of the series and the broad disciplinary background of the 41 authors of this first volume are described.

\section{Transdisciplinarity}

Transdisciplinarity is proven to be effective in fields like architecture, where social, technical, and economic developments interact with elements of value and culture (Klein, 2004). Therefore, this is the essence of this book series and its books. It is a relatively young term, first coined by the Swiss philosopher and psychologist Jean Piaget (1896-1980) (Nicolescu, 2006). Piaget (1972, as cited in Nicolescu, 2006) described transdisciplinarity:

Finally, we hope to see succeeding to the stage of interdisciplinary relations a superior stage, which should be 'transdisciplinary', i.e. which will not be limited to recognize the interactions and or reciprocities between the specialized researches, but which will locate these links inside a total system without stable boundaries between the disciplines.

Many mark the 1970 OECD Conference 'Interdisciplinarity: Problems of Teaching and Research in Universities' and the contribution by Erich Jantsch (1972a, 1972b) as the birth of the discourse 
about transdisciplinarity (Jahn, Bergmann, \& Keil, 2012). Another key date in its further development was the Charter of Transdisciplinarity (1994) which was adopted by the participants of the First World Congress of Transdisciplinarity in Portugal (Nicolescu, 2014). Although there is no real consensus on an exact definition of transdisciplinarity, two aspects of the term are essential to capture it:

1 "Transdisciplinarity, more than a new discipline or super-discipline is, actually, a different manner of seeing the world, more systemic and more holistic" Max-Neef (2005). It is said to be "a common system of axioms for a set of disciplines" and the science and art of discovering bridges between different areas of knowledge, both 'hard' and 'soft' sciences (Klein, 2004).

2 Transdisciplinarity involves both cooperation between various disciplines as well as cooperation between science and society, with a focus on demand-driven research of real-world problems (Jahn et al., 2012). Science for complex problems needs contextualisation, also called mode-2 knowledge production, including public debate (Nowotny, Scott, \& Gibbons, 2001). Only then can the produced knowledge be really shared with practice, as there is a common process of making sense of it all. This is what distinguishes interdisciplinary from transdisciplinary (Jahn et al., 2012).

Max-Neef (2005) attempts to describe the continuum from a single discipline to transdisciplinary:

- Disciplinarity is about mono-discipline (specialisation in isolation).

- Multidisciplinarity approaches a problem from multiple disciplines without real integration or cooperation.

- Pluridisciplinarity implies cooperation between disciplines, without coordination.

- Interdisciplinarity adds coordination but only for different groups of disciplines on different levels.

- Transdisciplinarity is the result of coordination/integration between all hierarchical levels.

As he adds, this continuum is not intended to be a hierarchical order of value. Transdisciplinarity is meant to complement the disciplinary approaches, and all approaches are just as valuable.

As transdisciplinarity transcends disciplinary boundaries and develops shared conceptual and methodologic frameworks (Jahn et al., 2012), integration of knowledge is thus a very important term. Such synthesis cannot be achieved through combining different brains in joint teams but must occur inside each of the brains (Max-Neef, 2005). This is visible in several definitions of the term integration. Repko (2012, p. 263) defined it in the context of interdisciplinarity as "the cognitive process of critically evaluating disciplinary insights and creating common ground among them to construct a more comprehensive understanding". Jahn et al. (2012, p. 3) transformed this definition to the transdisciplinary context: "the cognitive operation that establishes a novel, hitherto non-existent connection between distinct entities of a given context". Precisely, this joint cognitive process of integration is what is attempted by the empirical research described in the last chapter of this book, towards an overall framework for creating EWA that integrates the different theories.

\section{Selecting theories}

This book aims to support academics and practitioners in getting a grip on the complexity of EWA and to inspire them with the many different concepts and theories that can be applied 


\section{Gathering theories}

towards more optimal workplace solutions. Many theories have been identified as relevant for P-E fit, of which extensive overviews have been made (e.g. Edwards, 2008). However, most theories discussed in such reviews are focused on the organisational, psychosocial environment (e.g. personnel recruitment, training-task fit, job satisfaction). On the contrary, this book has collected theories that could help explain EWA from a physical work environment point of view. It thus identifies a very different list of theories that might contribute to workplace management in practice and academic research.

When thinking of designing better alignment of the physical workplace to the workforce, several disciplines from the social sciences and humanities field come forward as potentially relevant to this complex, wicked problem, such as psychology, ${ }^{1}$ sociology ${ }^{2}$ and anthropology. ${ }^{3}$ The theories in this book mainly stem from psychology and sociology, but they also include some theories from more quaint fields. Because of the interdisciplinary nature of workplace research, this book does not dare claim to be exhaustive in its selection of theories, as the nature of the EWA 'problem' and its boundaries are endless, and neither can the editors oversee all potential theories that could contribute. Therefore, the selection of theories happened in an uncontrolled, open manner; namely, the editors solicited suggestions for theories and accompanying authors from their networks and on social media (e.g. LinkedIn). The proposed contributions present an interesting first selection of theories from several relevant fields:

- Psychology

- Environmental psychology (Chapters 2 and 16).

- Work and organisational psychology (Chapters 3, 5, 12 and 22).

- Social psychology (Chapters 6 and 20).

- Personality psychology (Chapter 10).

- Behavioural psychology (Chapters 11, 18 and 19).

- Positive psychology (Chapter 14).

- Evolutionary psychology (Chapters 15 and 17).

- Sociology:

- Information space theory (Chapters 7, 8 and 9).

- Other disciplines:

- Information systems (Chapter 4).

- Quality management (Chapter 13).

- Human geography (Chapter 21).

Although the chaotic spread of the chapter numbers in this bullet list may suggest otherwise, there is of course a logical reading order in the book. On purpose, the (sub)disciplines were not used to group the chapters, but instead the chapters were ordered based on a logical flow of their contents. The book starts by presenting person-environment fit theory, explaining how to interpret the degree to which individual employees and their environmental characteristics need to match on several levels to prevent stressed and dissatisfied employees. Then, the job demands-resources model explores EWA further, through the assumption that, in general, strain is a response to imbalance between demands on the individual and the available (workplace and personal) resources to deal with those demands. Next, several chapters look at more specific aspects of alignment between people and their work environment. The task-technology fit theory chapter dives into how the functionality of technology and the tasks it aims to support should 
match with the individual abilities of users, in order to achieve EWA and prevent so-called technostress. Action regulation theory and privacy regulation theory show, respectively, how more general and more specific regulation problems at work lead to undesired outcomes of a misfit, such as stress, lower satisfaction and decreased productivity. The information space theory adds the additional challenges that need to be faced because of rising digitalisation, adding virtual workspace and placelessness.

As emphasised in $\mathrm{P}-\mathrm{E}$ fit theory, the perception of the workplace is just as important as the quality of the place itself in determining how employees experience their work environment. The next set of theories in the book therefore dives more deeply into this subjective experience of the workplace. The social constructionism theory chapter discusses how people attach meaning to places. The ecological systems theory chapter adds that the fit of a workplace can best be understood in nested systems beyond the single setting to which individuals are subject. This is followed by a chapter on temperament theory, showing how personality can influence the experience and use of the workplace, and a chapter on the two-process theory of perceived control, which shows that the national cultural setting can also influence expectations and how people attempt to gain control of the alignment of their workplace with their preferences. The chapter on organisational culture theories discusses alignment between workplaces and organisational culture on a higher, organisational level.

Next follows a set of theories that help to identify important aspects for providing a highquality, supportive workplace. First, the chapter on the theory of attractive quality explains the Kano model on how support of specific user preferences might or might not increase employee satisfaction, with a focus on indoor environmental quality (IEQ). The next chapter on flourish theory introduces the flourish model to go beyond more traditional views of IEQ and comfort. Then, one of the aspects in this model that has only more recently gained attention in workplaces is addressed more in depth in the chapter on the biophilia hypothesis. The last chapter of this section, on place attachment theory, discusses the temporal dimension of workplace quality, explaining how an emotional bond grows between people and their environment and that feelings of loss can be experienced in times of workplace changes.

Finally, several theories provide important insights into why employees behave in workplaces in the way they do, as this can also help or hinder EWA. The first chapter, on evolutionary psychology theory, starts by looking at our brains as they developed in our ancestral environment as hunter-gatherers, because this still determines certain behaviours at the office. Next, behavioural economics theory further explains why we do not always make rational choices when we are at the office. The nudging theory chapter shows how workplace managers might try to influence these decisions without impairing autonomous decision-making or changing financial incentives. And last, the chapter on activity theory provides further insights into the overall system of purposeful interactions between employees and their workplace. This behavioural section ends with two theories that discus how certain employee behaviours at the office are connected to spatial configuration and design. The chapter on space syntax theory shows why certain spatial configurations trigger certain types of behaviours in general, while the chapter on knowledge creation theory specifically addresses how space and services can support different forms of knowledge-sharing behaviour.

Despite this flow throughout the book, there is no need to read the book from front to end. It is just as interesting to pick a theory at random that catches your attention and start reading there. As you will see, many chapters link to other chapters in the book, so in the end you will likely have read all the chapters this way as well. Or you could start with the last chapter, to read first about the overarching framework across the theories, and then pick individual theories that specifically interest you. However, know that especially those chapters that do not draw your 
attention at first might be the most inspiring in the end. The next two sections of this chapter dive into academic discussions of definitions of some terms used in this book. If you are not interested in that, you can go straight to Section 5, to find out how the chapters in this book are set up and who wrote them.

\section{What is a theory, model or framework?}

The first volumes in this new book series provide an interdisciplinary overview of theories that are (or could be) applied to workplace research. However, theoretical models are also included. The discussion on what a theory really is has been present for ages and, unfortunately, there is no uniform agreement in the scholarly world. Three common classifications of theories from the philosophy of science are the syntactic, semantic and pragmatic views (Winter, 2016). According to the syntactic view of the logical positivists, theories are a logical and related set of axioms, presented by clear logical languages from metamathematics only. The semantic view, on the other hand, sees theories as a collection of models representing empirical generalisations (see e.g. Reynolds, 2015). The pragmatic view holds that mathematics are not necessary or sufficient to characterise a theory and that there is no one-size-fits-all structure of scientific theories (Winter, 2016). The first two views have received criticism, the first for concentrating too much on the language and technicalities (see e.g. Van Fraassen, 1980) and the second for being deformalised and imprecise (Halvorson, 2012). As the more recently developed pragmatic view appears to embrace internal pluralism and the importance of external contexts, it seems the most fitting interpretation for this book. Nevertheless, the editors of this book series are not philosophers of science and thus will leave further argumentation about the 'best' approach to the philosophers.

More generally, academics define theory as a way to describe a specific realm and explain how it works (e.g. Bunge, 2012; Kivunja, 2018; Lynham, 2002; Wacker, 1998). A theory should be able to help in predicting or examining why certain elements lead to certain outcomes. Edwards (2008, p. 171) stated,

a theory should select and define constructs of interest, describe how the constructs relate to one another, explain why the focal constructs were chosen and why they relate as predicted by the theory, and specify boundaries that denote the conditions under which the predictions of the theory should hold.

The chapters in this book have tried to do all this on different levels of depth and in different ways. The final chapter provides an overall selection of constructs of interest and defines them, as a first step towards EWA theory development.

A theory can be assigned to multiple levels based on the level of abstraction, generalisability and role, namely meta-, grand, mid-range and micro- (Higgins \& Moore, 2000). While metatheories represent more of a world view on the nature of knowledge and grand theories describe broad theoretical perspectives instead of a working theory, the mid-range theories are the ones social researchers usually understand as 'real' theories. They deal with specific aspects of human behaviour. Last, microtheories explain a certain phenomenon within a limited scope, often with a limited possibility to generalise. More often, such explanations are more likely to be considered as descriptions of a certain observation, which some academics argue are better called models. For example, Nilsen (2015) explains that the difference between a model and a theory might be very limited as these two are closely related. He states that models are theories with a more narrowly defined scope of explanation, which is descriptive and not as explanatory as a theory. Except for the meta- level, all other levels of theories can be found in this book. 
Another closely related (and often misused) term is 'framework'. Frameworks are most often used to describe factors that might have an effect on the outcome, but they provide a more systematic overview of a phenomenon (Nilsen, 2015). They do not provide explanations but describe phenomena by fitting them into a set of categories. This is what is produced in the last chapter of this book as a first step towards a grand EWA theory.

\section{Relevant terminologies}

This book incorporates several terms that are commonly used by researchers who study issues related to the (physical) workplace, people and achieving alignment between them through strategic workplace management. Even though some of them have official definitions, the scope of the definition and the focus sometimes differ in various disciplines and countries and/or due to historical reasons. Without aiming to pick the 'best' definitions for each term, this section intends to provide a brief discussion of the most relevant terms and their interpretations to provide some context for the following chapters. But those chapters will use the terms as they see fit from their own disciplinary background and experience.

To begin, there is no one definition that is widely used for workplace management. In a report for IFMA (the International FM Association), workplace management is broadly defined as "the management of all resources needed to design \& maintain appropriate, effective and economical workplace experiences that align to strategic business objectives and support people in doing their best work every day, wherever they are" (Jervis \& Mawson, 2014, p. 10). Others give a similar definition for workplace strategy as

the alignment of the organisation's workplace with the business strategy in order to optimise the effectiveness of its people and achieve its strategic business goals. It takes into account different dimensions of a company, its physical and virtual work environments, culture, business processes, technologies and other resources.

(Redlein, Höhenburger, \& Turnbull, 2020, p. 179)

In practice some see workplace management as the task of human resource management, others of facility management and again others of the corporate real estate management department. However, Redlein et al. (2020) correctly stress that workplace management needs a collaboration of HRM, FM and CREM, and also finance, marketing, IT, business unit leaders, employee advocates and the C-suite to be able to create a workplace that is effective, representative for the organisation and healthy for the employees. So, there seems to be agreement that workplace management is a collaborative task towards aligning the workplace with the organisation and the employees using it. For a discussion of definitions for CREM and FM and an overview of theories on how to manage physical workplaces, please refer to Volume 2 of this series, titled A Handbook of Management Theories and Models for Office Environments and Services.

The support of people as part of the overall alignment process of workplace management is the focus of the book you have started reading now. Chapter 2 extensively describes what is meant by alignment between a person and his/her work environment, so at this point only the essence of the description that the authors (Armitage and Amar) provide is repeated: the quality of 'fit' depends on the interaction between person and environment and thus should be assessed by comparing characteristics of both and determining whether there is a match. Workplace management has been portrayed as an input-throughput-output-outcome process model (Jensen, 2010). In light of EWA specifically, one could say that input, throughput and output show characteristics of the environment, while the people-based outcomes (and eventually thriving) show the success 
of achieving true alignment. Appel-Meulenbroek et al. (2018) tried to provide classifications for inputs and for outcomes, but no overall agreement on distinctive categories exist for either side of the EWA mechanism. From their scoping review, they distinguished indoor environmental quality, office layout, design quality, accessibility, services and the psychosocial conditions created inside the building for the input side of EWA, while as potential outcomes they found studies on satisfaction, performance/productivity, health, emotional state, attitude, comfort, concentration, privacy and communication; with subcategories for most of these inputs and outcomes. The chapters in this book discuss detailed theories addressing many of these aspects.

From those chapters, it will become clear that there is another cross-disciplinary debate necessary on the meaning of the terms 'workplace' and 'workspace'. You will see that they are used differently, interchangeably and as definitions of different scale levels of the work environment. This might be a result of disciplinary differences in training or in basic theories, although there is no proof for such an assumption, as the debate is yet to start. A quick scan of literature shows that researchers in physical design (e.g. Wineman \& Barnes, 2018) and also some dictionaries (e.g. Princeton's WordNet and the Oxford dictionary) define workplace as the overall place where work is done and workspace as the physical space allocated for the work to be done. So here, workspace appears to be the physical component of a workplace. This interpretation is expanded by literature on the digital work environment, which refer to online spaces as part of the workplace as well (e.g. Wang, 2010), thus letting go of the physical delineation but still seeing spaces as parts of a broader workplace term. Others see the workspace as a smaller subset within the physical building, where the physical workplace would be the entire office building (e.g. Roskams \& Haynes, 2019), so both space and place are physical here. Nonetheless, all these researchers appear to see a place as created through human experiences with spaces (e.g. Seamon \& Sowers, 2008). However, in the field of sociology, researchers seem to interpret both terms in a very different way. Some sociologists see place as a physical spot, which could be an entire office building but also a specific workstation within it, that exists through the meaning attached to it by people. As Gieryn (2000, p. 465) puts it, "place is space filled up by people, practices, objects, and representations" (see Chapter 8 Social Constructionism Theory). This still suggests that at least there is an ordering of space as a subset of place, but there is no distinction between a building and a smaller-scale space. And even more opposing to the previously discussed meanings of these terms, other sociologists (see Löw, 2008 for a discussion) have mentioned places to be a subset of space (so flipping the hierarchical order of both terms), and that space does not only contain a physical place (called materiality) but is constituted in interaction by its users (so flipping the terms in the sense of how people create one from the other). Some real estate researchers seem to follow a similar line of reasoning (e.g. Hills \& Levy, 2014), where the term workspace is relating to the building and the social elements, while workplaces are used to indicate a smaller-scale level, where individual and group needs must be satisfied. Last, some even use both workplace and workspace interchangeably throughout their papers (e.g. McGregor, 2000). As this book contains authors from all mentioned disciplines, the editors did not want to force terminology definitions on them, so both terms are used in different ways across the different chapters. More general terms like work environment or workstation are also used.

\section{Setup and authors of the chapters}

Each of the following chapters in this book start with a brief explanation of the theory's origin (often born in a totally different field than workplace design or management) and essence in Section 1 . Then the authors discuss its applicability to the physical workplace in Section 2. Sections 3 and 4 are particularly aimed at researchers, as they address relevant research methodologies and possible 
limitations in this theory's application to workplace research. Section 5, on the other hand, discusses implications for practice. So, practitioners could skip Sections 3 and 4 and continue reading in Section 5 if they are not interested in research methods. All chapters end with some suggestions for further reading, in case you are so inspired that you would like to read more about this theory.

In Table 1.1 you can find an overview of all the researchers that contributed to this book, plus their current institution. Many authors work in Europe, but also in Australia, and USA-based authors have contributed as well. The authors represent 19 different universities and three practicebased organisations, in 11 different countries, and a vast number of different disciplinary fields.

Table 1.1 An overview of the different authors

\begin{tabular}{|c|c|c|c|c|}
\hline \multicolumn{2}{|c|}{ Chapter } & \multirow{2}{*}{$\begin{array}{l}\text { Authors } \\
\text { Rianne Appel-Meulenbroek } \\
\text { Vitalija Danivska }\end{array}$} & \multirow{2}{*}{$\begin{array}{l}\text { Country } \\
\text { Netherlands } \\
\text { Finland }\end{array}$} & \multirow{2}{*}{$\begin{array}{l}\text { University/organisation } \\
\text { Eindhoven University of } \\
\text { Technology } \\
\text { Aalto University }\end{array}$} \\
\hline 1 & Introduction & & & \\
\hline 2 & $\begin{array}{l}\text { Person-environment } \\
\text { fit theory }\end{array}$ & $\begin{array}{l}\text { Lynne Audrey Armitage } \\
\text { Johari Amar }\end{array}$ & Australia & Bond University \\
\hline 3 & $\begin{array}{l}\text { Job demands- } \\
\text { resources model }\end{array}$ & $\begin{array}{l}\text { Michael Roskams } \\
\text { Eileen McNeely } \\
\text { Dorota Weziak-Bialowolska } \\
\text { Piotr Bialowolski }\end{array}$ & $\begin{array}{l}\text { UK } \\
\text { USA } \\
\text { USA } \\
\text { USA }\end{array}$ & $\begin{array}{l}\text { Sheffield Hallam University } \\
\text { Harvard T.H. Chan School } \\
\text { of Public Health }\end{array}$ \\
\hline 4 & $\begin{array}{l}\text { Task-technology fit } \\
\text { theory }\end{array}$ & $\begin{array}{l}\text { Giulia Nardelli } \\
\text { Nelda Vendramin } \\
\text { Christine Ipsen }\end{array}$ & Denmark & $\begin{array}{l}\text { Technical University of } \\
\text { Denmark }\end{array}$ \\
\hline 5 & $\begin{array}{l}\text { Action regulation } \\
\text { theory }\end{array}$ & Lukas Windlinger & Switzerland & $\begin{array}{l}\text { Zurich University of } \\
\text { Applied Sciences }\end{array}$ \\
\hline 6 & $\begin{array}{l}\text { Privacy regulation } \\
\text { theory }\end{array}$ & $\begin{array}{l}\text { Clara Weber } \\
\text { Barbara Degenhardt } \\
\text { Birgitta Gatersleben } \\
\text { Lukas Windlinger }\end{array}$ & $\begin{array}{l}\text { Switzerland } \\
\text { Switzerland } \\
\text { UK } \\
\text { Switzerland }\end{array}$ & $\begin{array}{l}\text { Zurich University of } \\
\text { Applied Sciences } \\
\text { University of Zurich } \\
\text { University of Surrey } \\
\text { Zurich University of } \\
\text { Applied Sciences }\end{array}$ \\
\hline 7 & $\begin{array}{l}\text { Information space } \\
\text { theory }\end{array}$ & Mascha Will-Zocholl & Germany & $\begin{array}{l}\text { Hessian University of Police } \\
\text { and Administration }\end{array}$ \\
\hline 8 & $\begin{array}{l}\text { Social } \\
\text { constructionism } \\
\text { theory }\end{array}$ & Kaisa Airo & Finland & $\begin{array}{l}\text { Laurea University of } \\
\text { Applied Sciences }\end{array}$ \\
\hline 9 & $\begin{array}{l}\text { Ecological systems } \\
\text { theory }\end{array}$ & $\begin{array}{l}\text { Eunhwa Yang } \\
\text { Bonnie Sanborn }\end{array}$ & USA & $\begin{array}{l}\text { Georgia Institute of } \\
\text { Technology } \\
\text { DLR group }\end{array}$ \\
\hline 10 & Temperament theory & Mel Bull & UK & University of Sheffield \\
\hline 11 & $\begin{array}{l}\text { Two-process theory } \\
\text { of perceived } \\
\text { control }\end{array}$ & Daibin Xie & UK & University College London \\
\hline 12 & $\begin{array}{l}\text { Organisational } \\
\text { culture theories }\end{array}$ & $\begin{array}{l}\text { Sara Wilkinson } \\
\text { Kusal Nanayakkara }\end{array}$ & Australia & $\begin{array}{l}\text { University of Technology } \\
\text { Sydney }\end{array}$ \\
\hline 13 & $\begin{array}{l}\text { Attractive quality } \\
\text { theory }\end{array}$ & $\begin{array}{l}\text { Quan Jin } \\
\text { Holger Wallbaum } \\
\text { Jungsoo Kim } \\
\text { Richard de Dear }\end{array}$ & $\begin{array}{l}\text { Sweden } \\
\text { Sweden } \\
\text { Australia } \\
\text { Australia }\end{array}$ & $\begin{array}{l}\text { Chalmers University of } \\
\text { Technology } \\
\text { University of Sydney }\end{array}$ \\
\hline
\end{tabular}




\begin{tabular}{|c|c|c|c|c|}
\hline \multicolumn{2}{|c|}{ Chapter } & \multirow{2}{*}{$\begin{array}{l}\text { Authors } \\
\text { Derek Clements-Croome }\end{array}$} & \multirow{2}{*}{$\begin{array}{l}\text { Country } \\
\mathrm{UK}\end{array}$} & \multirow{2}{*}{$\begin{array}{l}\text { University/organisation } \\
\text { University of Reading }\end{array}$} \\
\hline 14 & Flourish theory & & & \\
\hline 15 & Biophilia hypothesis & Sven Wolf Ostner & Sweden & ÅWL Arkitekter \\
\hline 16 & $\begin{array}{l}\text { Place attachment } \\
\text { theory }\end{array}$ & $\begin{array}{l}\text { Goksenin Inalhan } \\
\text { Eunhwa Yang } \\
\text { Clara Weber }\end{array}$ & $\begin{array}{l}\text { Turkey } \\
\text { USA } \\
\text { Switzerland }\end{array}$ & $\begin{array}{l}\text { Istanbul Technical } \\
\text { University } \\
\text { Georgia institute of } \\
\text { technology } \\
\text { Zurich University of } \\
\text { Applied Sciences }\end{array}$ \\
\hline 17 & $\begin{array}{l}\text { Evolutionary } \\
\text { psychology theory }\end{array}$ & Young Lee & USA \& UK & $\begin{array}{l}\text { Innovative Workplace } \\
\text { Institute \& University } \\
\text { College London }\end{array}$ \\
\hline 18 & $\begin{array}{l}\text { Behavioural } \\
\text { economics theory }\end{array}$ & Young Lee & USA \&UK & $\begin{array}{l}\text { Innovative Workplace } \\
\text { Institute \& University } \\
\text { College London }\end{array}$ \\
\hline 19 & Nudging theory & $\begin{array}{l}\text { Tina Venema } \\
\text { Laurens van Gestel }\end{array}$ & $\begin{array}{l}\text { Denmark } \\
\text { The Netherlands }\end{array}$ & $\begin{array}{l}\text { Aarhus University } \\
\text { Utrecht University }\end{array}$ \\
\hline 20 & Activity theory & $\begin{array}{l}\text { Maral Babapour } \\
\text { MariAnne Karlsson } \\
\text { Antonio Cobaleda-Cordero }\end{array}$ & Sweden & $\begin{array}{l}\text { Chalmers University of } \\
\text { Technology }\end{array}$ \\
\hline 21 & Space syntax theory & $\begin{array}{l}\text { Kerstin Sailer } \\
\text { Petros Koutsolampros }\end{array}$ & UK & $\begin{array}{l}\text { The Bartlett, University } \\
\text { College London }\end{array}$ \\
\hline 22 & $\begin{array}{l}\text { Knowledge creation } \\
\text { theory }\end{array}$ & $\begin{array}{l}\text { Mervi Huhtelin } \\
\text { Suvi Nenonen }\end{array}$ & Finland & $\begin{array}{l}\text { University Properties of } \\
\text { Finland } \\
\text { Tampere University of } \\
\text { Technology }\end{array}$ \\
\hline 23 & $\begin{array}{l}\text { Towards an } \\
\text { interdisciplinary } \\
\text { EWA theory }\end{array}$ & $\begin{array}{l}\text { Rianne } \\
\quad \text { Appel-Meulenbroek } \\
\text { Susanne Colenberg } \\
\text { Vitalija Danivska }\end{array}$ & $\begin{array}{l}\text { Netherlands } \\
\text { Netherlands } \\
\text { Finland }\end{array}$ & $\begin{array}{l}\text { Eindhoven University of } \\
\text { Technology } \\
\text { Delft University of } \\
\text { Technology } \\
\text { Aalto University }\end{array}$ \\
\hline
\end{tabular}

The last chapter of the book is based on an empirical concept mapping analyses of all theories treated in this volume. With the help of the authors of the chapters, an interdisciplinary framework is created from the basic assumptions of the individual theories. It is a first attempt towards a more systemic and holistic approach to developing a grand EWA theory, that hopefully inspires more research on the topic. We hope you will be as inspired by the book as we were after receiving all the draft and final chapters.

\section{Notes}

1 According to Wikipedia: "the science of mind and behaviour. Psychology includes the study of conscious and unconscious phenomena, as well as feeling and thought."

2 According to Wikipedia: "the study of human behaviour. Sociology refers to social behaviour, society, patterns of social relationships, social interaction, and culture that surrounds everyday life."

3 According to Wikipedia: "the scientific study of humans, human behaviour and societies in the past and present." 


\section{References}

Appel-Meulenbroek, R., Clippard, M., \& Pfnür, A. (2018). The effectiveness of physical office environments for employee outcomes: An interdisciplinary perspective of research efforts. Journal of Corporate Real Estate, 20(1), 56-80. https://doi.org/10.1108/JCRE-04-2017-0012

Bernstein, J. H. (2015). Transdisciplinarity: A review of its origins, development, and current issues. Journal of Research Practice, 11(1), 1-20. Retrieved from http://jrp.icaap.org/index.php/jrp/article/view/510/436

Bunge, M. (2012). Scientific research II: The search for truth. Berlin, Germany: Springer Science \& Business Media.

Donald, J. (2002). Learning to think: Disciplinary perspectives. San Francisco, CA: Jossey-Bass.

Edwards, J. R. (2008). Person-environment fit in organizations: An assessment of theoretical progress. Academy of Management Annals, 2(1), 167-230. https://doi.org/10.1080/19416520802211503

Epley, D. R. (2006). New ranking of decision-making subject areas for corporate real estate executives. Journal of Real Estate Research, 26(1), 43-68. Retrieved from https://ssrn.com/abstract=954784

Gieryn, T. F. (2000). A space for place in sociology. Annual Review of Sociology, 26(1), 463-496. Retrieved from www.jstor.org/stable/223453

Halvorson, H. (2012). What scientific theories could not be. Philosophy of Science, 79(2), 183-206. https:// doi.org/10.1086/664745

Heywood, C., \& Arkesteijn, M. (2017). Alignment and theory in corporate real estate alignment models. International Journal of Strategic Property Management, 21(2), 144-158. https://doi.org/10.3846/16487 15X.2016.1255274

Higgins, P. A., \& Moore, M. S. (2000). Levels of theoretical thinking in nursing. Nursing Outlook, 48(4), 179-183. https://doi.org/10.1067/mno.2000.105248

Hills, R., \& Levy, D. (2014). Workspace design and fit-out: What knowledge workers value. Property Management, 32(5), 415-432. https://doi.org/10.1108/PM-02-2014-0011

Hoendervanger, J. G., Van Yperen, N. W., Mobach, M. P., \& Albers, C. J. (2019). Perceived fit in activitybased work environments and its impact on satisfaction and performance. Journal of Environmental Psychology, 65, 101339. https://doi.org/10.1016/j.jenvp.2019.101339

Jahn, T., Bergmann, M., \& Keil, F. (2012). Transdisciplinarity: Between mainstreaming and marginalization. Ecological Economics, 79, 1-10. 10.1016/j.ecolecon.2012.04.017

Jantsch, E. (1972a). Inter- and transdisciplinary university: A systems approach to education and innovation. Higher Education, 1, 7-37. https://doi.org/10.1007/BF01956879

Jantsch, E. (1972b). Towards interdisciplinarity and transdisciplinarity in education and innovation. In Organisation for Economic Cooperation and Development, Paris (France). Centre for Educational Research and Innovation (Ed.), Interdisciplinarity: Problems of Teaching and Research in Universities. Washington, DC: OECD Publications Center. Retrieved from https://eric.ed.gov/?id=ED061895

Jensen, P. A. (2010). The facilities management value map: A conceptual framework. Facilities, 28(3/4), 175-188. https://doi.org/10.1108/02632771011023131

Jervis, G., \& Mawson, A. (2014). The workplace management framework. IFMA. Retrieved from https:// community.ifma.org/cfs-file/_key/telligent-evolution-components-attachments/13-467-00-00-0105-79-18/2017_5F00_The-Workplace-Management-Framework_5F00_Research.pdf

Kivunja, C. (2018). Distinguishing between theory, theoretical framework, and conceptual framework: A systematic review of lessons from the field. International Journal of Higher Education, 7(6), 44-53. https:// doi.org/10.5430/ijhe.v7n6p44

Klein, J. T. (2004). Prospects for transdisciplinarity. Futures, 36(4), 515-526. https://doi.org/10.1016/j. futures.2003.10.007

Kleine, A.-K., Rudolph, C. W., \& Zacher, H. (2019). Thriving at work: A meta-analysis. Journal of Organizational Behavior, 40, 973-999. https://doi.org/10.1002/job.2375

Kreuter, M. W., De Rosa, C., Howze, E. H., \& Baldwin, G. T. (2004). Understanding wicked problems: A key to advancing environmental health promotion. Health Education \& Behavior, 31(4), 441-454. https://doi.org/10.1177/1090198104265597

Löw, M. (2008). The constitution of space: The structuration of spaces through the simultaneity of effect and perception. European Journal of Social Theory, 11(1), 25-49. https://doi.org/10.1177/1368431007085286

Lynham, S. A. (2002). The general method of theory-building research in applied disciplines. Advances in Developing Human Resources, 4(3), 221-241. https://doi.org/10.1177/1523422302043002

Max-Neef, M. A. (2005). Foundations of transdisciplinarity. Ecological Economics, 53(1), 5-16. https://doi. org/10.1016/j.ecolecon.2005.01.014 


\section{Gathering theories}

McGregor, W. (2000). The future of workspace management. Facilities, 18(3/4), 138-143. https://doi.org/ 10.1108/02632770010315698

Nicolescu, B. (2006). Transdisciplinarity: Past, present and future. In B. Haverkort \& C. Reijntjes (Eds.), Moving worldviews: Reshaping sciences, policies and practices for endogenous sustainable development (pp. 142166). Leusden: ETC/COMPAS.

Nicolescu, B. (2014). Methodology of transdisciplinarity. World Futures, 7(3-4), 186-199. https://doi.org /10.1080/02604027.2014.934631

Nilsen, P. (2015). Making sense of implementation theories, models and frameworks. Implementation Science, 10(1), 53-79. https://doi.org/10.1186/s13012-015-0242-0

Nowotny, H., Scott, P., \& Gibbons, M. (2001). Re-thinking the relations between texts and contexts in science. Science \& Public Policy, 28(6), 484-486. https://doi.org/10.1093/spp/28.6.484

Redlein, A., Höhenburger, C., \& Turnbull, P. (2020). Workplace management. In A. Redlein (Ed.), Modern facility and workplace management. Cham, Switzerland: Springer International Publishing.

Repko, A. F. (2012). Interdisciplinary research: Process and theory (2nd ed.). Thousand Oaks, CA: Sage.

Reynolds, P. D. (2015). Primer in theory construction: An A\&B classics edition. London: Routledge.

Roskams, M., \& Haynes, B. (2019). Employee-workplace alignment: Employee characteristics and perceived workplace requirements. Facilities, 38(3/4), 282-297. https://doi.org/10.1108/F-09-2018-0105

Seamon, D., \& Sowers, J. (2008). Place, and placelessness. In P. Hubbard, R. Kitchen, \& G. Vallentine (Eds.), Key texts in human geography (pp. 43-51). London, UK: Sage.

Van Fraassen, B. (1980). The scientific image. Oxford: Oxford University Press.

Wacker, J. G. (1998). A definition of theory: Research guidelines for different theory-building research methods in operations management. Journal of Operations Management, 16(4), 361-385. https://doi. org/10.1016/S0272-6963(98)00019-9

Wang, Q. (2010). Using online shared workspaces to support group collaborative learning. Computers E Education, 55(3), 1270-1276. https://doi.org/10.1016/j.compedu.2010.05.023

Wineman, J. D., \& Barnes, J. (2018). Workplace settings. In A. S. Devlin (Ed.), Environmental psychology and human well-being: Effects of built and natural settings (pp. 167-192). London, UK: Academic Press.

Winter, R. G. (2016). The structure of scientific theories. In E. N. Zalta (Ed.), The Stanford encyclopedia of philosophy (Winter 2016 ed.). Retrieved from https://plato.stanford.edu/archives/win2016/entries/ structure-scientific-theories/

Zhang, D., \& Shen, J. (2015). Disciplinary foundations for solving interdisciplinary scientific problems. International Journal of Science Education, 37(15), 2555-2576. https://doi.org/10.1080/09500693.2015. 1085658 


\title{
2 \\ PERSON-ENVIRONMENT FIT THEORY
}

\section{Application to the design of work environments}

\author{
Lynne Audrey Armitage* and Johari Hussein Nassor Amar
}

\section{Background}

When did person-environment fit theory emerge? According to Wang and Wang (2018), P-E fit theory is set in behavioural, psychology and motivational studies and originates from Frank Parsons's (1909) Choosing a Vocation. In his book, Parsons (1909) argued that a good fit between the work environment and an employee's abilities would lead to increased performance and productivity. A crucial part of Parsons's theory is the use of a trait-factor approach which, as Hartung and Blustein (2002) explain, facilitates organisational work processes by matching a person's traits with occupational requirements. Naturally, Parsons's trait-factor approach was faced with public criticism related to the oversimplified psychometric testing used to assess an individual's behaviour, personality and psychology in a workplace (Spokane, 1985). Despite criticisms, Parsons's theoretical foundation is considered fundamentally significant, as it generated many correlational studies related to the dynamics of person and environment fit (P-E fit) on workplace productivity and performance (Follmer, 2016; Spokane, 1985). As such, Chartrand (1991, p. 519) states, "the PE-fit approach is viewed as a direct descended [sic] of trait-and-factor model."

Such a new perspective led to development of P-E fit theory in the areas of vocational choice and adjustment to give a starting point for further discussion (Edwards, 2008; Walsh, Craik, \& Price, 2012). Most notably, Holland's theory of vocational choice represents that people choose a workplace environment that is congruent with their personality/interest type (Holland, 1966, 1985; Nauta, 2010), and the theory of work adjustment posits that there is no perfect fit between a person and environment, resulting in behaviour adjustment in order to satisfy their work abilities and values (Dawis \& Lofquist, 1984; Rounds, Dawis, \& Lofquist, 1987; Van Vianen, 2018). The interaction between person and environment is ascribed to the quality of 'fit' underpinned by three basic concepts.

Kristof-Brown and Billsberry (2013, p. 1) define 'fit' as "assessed by the explicit comparison of person and environment characteristics to determine whether or not there is a match". Whereas, summarised from Edwards, Caplan, and Harrison (1998), the basic concepts include:

1 The interaction between person (e.g. values, abilities) and environment (e.g. supplies, demand) is reciprocal and can be summarised as a person influences the environment and the environment influences a person.

*Corresponding author: larmitag@bond.edu.au 
2 The fit between the person (P) and environment (E) can take an objective or subjective construct - objective fit is where PE attributes are derived from other sources and subjective fit is where PE attributes are derived from employee's perception (van Vianen, 2018).

3 Requires a commensurate demands-abilities and needs-supplies fit. According to Kristof (1996), the former occurs when the employee has abilities required by the organisational work processes and the latter occurs when the environment satisfies employee preferences.

The breadth of P-E fit theory cannot be fully addressed within this chapter but has been comprehensively represented in its entirety by Dipboye (2018), Walsh et al. (2012) and Edwards (2008). Kristof-Brown and Billsberry (2013) state that P-E fit theory has been broadly defined because its key concepts are dynamically connected with each other and characteristics can change in many ways, vacillating between fit and misfit across time (Follmer, 2016). As Sekiguchi (2004, p. 178) states, "Whether a good fit will be a good fit tomorrow depends on the stability of the variables on which matches are made." This brings us to the next discussion, which explores the application of $\mathrm{P}-\mathrm{E}$ fit theory in workplace research.

\section{Applicability of P-E fit theory to workplace studies}

Although P-E fit is considered as a new connection to the design of the work environment (Leonard, 2013), over a century ago human-environment principles (Becker, 1991) - a similar concept to P-E fit - was used to design physical workplaces that articulated individual and organisational values (Baldry, 1999). Taylor (1911) and Weber (1947) were the first to recognise that the psychology and behaviour of the workspace were significantly crucial to performance and productivity. However, although these scholars recognised the connection between workspace environment and individual behaviours in the workplace, their relationship was not well documented due to less-direct common outcomes (Baldry, 1999). Previous studies of workplace design followed a traditional approach that focused on just one aspect of the functional space - consistency and efficiency versus costs (Gibson, 2003), while human relations focused on employee productivity - psychology and behaviour versus performance (Çelik \& Ozsoy, 2016). Nevertheless, the literature on workplace design that incorporates person-centric strategies has shown a growing area of interest since World War II. In recent decades, organisational cultures have undergone continuous transformation due to diversity, cost-cutting trends and technology (Scully-Russ \& Torraco, 2020; Rajan \&Wulf, 2006; Becker, 1991). Kupritz (2002) discusses how, in order to manage these conditions, different organisations implemented a change process that resulted in the development of the work environments required by users with demandsabilities fit and/or needs-supplies fit. These two terms are detailed by Appel-Meulenbroek, Le Blanc, and De Kort (2019) and Edwards (2008). From the 1960s to 1980s, it was realised that the concepts of environment and people are inextricably linked, thus cannot be applied to workplace design in isolation (Baldry, 1999; Becker, 1991). As Vischer (2008) notes, each triggers the other on matters concerning productivity and performance.

For example, Hobstetter (2007) observes, the 1960s' workplace layouts were windowless and heavily illuminated by fluorescent lighting. These layouts admitted little sunlight and natural ventilation, with the exception of corner offices. While artificial light was believed to minimise distraction and reduce operational costs such as rental, purchase and fit-out costs (Hills \& Levy, 2014), Court, Pearson, and Frewin (2010) assert that this layout harmed productivity and psychological wellbeing as a result of eyestrain, headaches and a decreased level of happiness (Wilkins, Nimmo-Smith, Slater, \& Bedocs, 1989). This, in turn, expanded debate on the relationship between a person and their environment to research on building-related illness and 
sick building syndrome (Ghaffarianhoseini et al., 2018). P-E fit has contributed to the transformation of workplace design, which has evolved since the 1960s (Peteri, Lempiäinen, \& Kinnunen, 2020) from cubicles to open plan and, recently, activity-based flexible spaces that bring together the physical and digital workplace. The application of human-environment practice in workplace design was - and continues to be - modelled by Eberhard and Wolfgang Schenelle's Bürolandschaft (office landscape). Much the same as $\mathrm{P}-\mathrm{E}$ fit, it is widely recognised by its aim to create an egalitarian workplace (Dzidowski, 2016) that offers flexibility and collaboration (Peteri et al., 2020) and allows for humane working environments with positive psychophysiological outcomes (Nieuwenhuis, Knight, Postmes, \& Haslam, 2014). However, Dzidowski (2016) notes that Bürolandschaft was short lived, as it fostered subtler 'silo mentality' caused by functional and operational structures created by the matrix-organisational approaches. The solution, Dzidowski (2016) says, was to alter the work environment to 'cubicle farms' that can be adapted to meet the need of individuals in a workplace. This form of workplace design was popular in the 1970s and 1980s but slowly declined in the late 1990s and had virtually disappeared by the 2000s.

Several factors mediated the demise of cubicles. They were linked to a loss of productivity through absenteeism and presenteeism (Lee \& Brand, 2005; Quelch \& Knoop, 2018) and reduced turnover due to increased property costs related to matching human-environment needs (Hills \& Levy, 2014; Vischer, 2008). This is relatively unsurprising given that, as Court et al. (2010, p. 4) state, a "human being spends between $80 \%$ and $90 \%$ of their lives indoors"; thus, it is undeniable that people affect and are affected by their environment (Appel-Meulenbroek et al., 2019). As discussed in Section 1, work-related threats or stressors are increasingly evident in the workplace, with many employees exposed to psychophysiological and psychosocial risks. These risks have become common in today's knowledge-based economy (Appel-Meulenbroek et al., 2019; Nieuwenhuis et al., 2014). To understand how people adapt to the environment, AppelMeulenbroek et al. (2019) posit that research on how to create a workplace setting nuanced with $\mathrm{P}-\mathrm{E}$ fit has grown. The workplace design trends that have come and gone across sectors provide evidence of this (for example: Peteri et al., 2020); as Friedman (2014, p. 33) remarks, "Cubicles are depressing. Private offices are isolating. Open spaces are distracting." But, one thing is certain, organisations rely on the complementarity between demands-abilities fit and needs-supply fit to design a workplace capable of driving - among other needs - creativity, wellbeing, efficiency and productivity (Appel-Meulenbroek et al., 2019; Friedman, 2014).

The key to success lies in the ability of workplace design to capture diverse work styles and experiences: first internally, with the organisational workforce, and second externally, with visitors, clients and customers (Jensen \& Van der Voordt, 2020). In order to do this, organisations take technology into account when designing workspaces (Baldry, 1999; Lee \& Sirgy, 2019). For example, the workplace of many organisations such as Google, Macquarie Group (Sydney), Deloitte and WeWork, among others, emphasises the need for P-E fit in response to the fastchanging work environment. This kind of design understands the organisational workplace as being composed of two elements: the physical and the digital. The physical workplace is commonly referred to as "spaces where people are physically situated to engage in work activities" (Byström, Ruthven, \& Heinström, 2017, p. 2), while the digital workplace is defined by M. Attaran, S. Attaran, and Kirkland $(2019$, p. 4) as a "collection of all the digital tools in an organization that allow employees to do their jobs. Those tools include intranet, communication tools, email, CRM, ERP, HR system, calendar and other enterprise processes." Efficient and effective workplace design must balance out different personalities and behaviours in order to ensure maximum creativity and productivity (Baldry, 1999). The workplace literature can be broadly divided into one of these two streams as discussed in the following sections. 


\subsection{Physical workplace}

The first broad stream of workplace literature considers the physical workspace. This literature examines how the design of the physical workplace can enable work processes (Kupritz, 2002) by meeting the expectations of individuals, both actual and perceived (McCoy \& Evans, 2005), of their workspace attributes/hubs (Vischer, 2008). According to Wohlers, Hartner-Tiefenthaler, and Hertel (2019), the critical design variable of the physical workplace is the centralisation of workspace attributes to accentuate effective collaboration and reduce sedentary behaviour. For example, Nieuwenhuis et al. (2014) report that employees spend at least two-thirds (or 65\%) of a day on average seated to complete work tasks, which is considered a workplace health and safety issue. Supporting this, systematic reviews of literature by Biswas et al. (2015) found that this prolonged sitting causes chronic diseases, including cardiovascular disease, diabetes, obesity, cancer and eventual premature deaths.

In contrast, studies have shown that the use of activity-based flexible work (A-FOs) design can alleviate both mental and physical health issues and boost performance and productivity. The A-FO design of the physical workspace incorporates open-plan centralised hubs with ergonomics and biophilics (see also Chapter 15 The Biophilia Hypothesis) (Candido et al., 2019; Botting, 2016; Vischer, 2008), designed to provide a more significant opportunity for personal reflection, collaboration through the sharing of knowledge and task efficiency as well as encouraging movement.

Likewise, the findings from U.S. Workplace Survey 2019 by Gensler Research Institute (2019) indicated that $79 \%$ of employees reported having excellent work experience due to the availability of a variety of work settings, which resulted in higher business performance and profit. Gensler surveyed more than 6,000 office employees across a variety of industries and demographics. Additionally, the report by Leesman (2017), published in partnership with IFMA Sweden, stated that $52 \%$ of respondents reported that A-FOs encourage them to select the workspace hub that was the best fit for their activity and needs. Leesman's study involved 70,000 employees, 11,000 of whom described their workplace as activity-based working.

Despite the benefits of a well-designed physical workplace for employee wellbeing and productivity, some research has found that A-FOs are associated with decreased P-E fit. Generally speaking, the common features have been reducing performance and productivity through presenteeism (Ferreira, da Costa Ferreira, Cooper, \& Oliveira, 2019). For instance, the system review of advantages and disadvantages of A-FOs conducted by Engelen et al. (2019) revealed a negative perception of functional workspace and indoor climate. Nonetheless, in 2014, Steelcase/ Ipos published a three-year meta-analysis of 10,500 workers in Europe, North America and Asia, which stated that organisations lose 86 minutes of employee productivity because employees were not able to concentrate due to distractions, for example time spent finding privacy or avoiding a workspace exhibiting social dynamic tension and distrust (Sander, 2019). Another significant observation from Ferreira et al. (2019) is that A-FOs are used as cost-saving mechanism - to monitor employee performance and organisation productivity (Leesman, 2017) - rather than ensuring a match between the person and their work environment.

\subsection{Digital workplace}

As previously stated, implementation of the digital workplaces such as teleworking and telecommuting (Hoornweg, Peters, \& Van der Heijden, 2016) have recently gained popularity as organisations have sought to address the shifts associated with the physical environment and employee 
work outcomes (Attaran et al., 2019). Within this second broad stream of the workplace literature, research into digital workplaces (see also Chapter 7 on information spaces) has yielded a diversity of definitions, theories and methodological approaches to the person-environment relationship (Byström et al., 2017). This is likely due in part to the reconceptualisation of work processes in the knowledge-based economy (Hejduk, 2005). However, even different digital workplace literature shares important commonalities: that is, the work environment is tailored to meet and adapt to the work style demands of workforce demographics related to work-life balance (Lee \& Sirgy, 2019), work-life fit (Sweet, James, \& Pitt-Catsouphes, 2015) and work-life integration (Kreiner, 2006). These three dimensions reduce psychosocial risks such as depression and anxiety caused by making trade-offs between working and quality life. From the perspective of productivity, the World Health Organization (WHO, 2019) confirms that depression and anxiety cost the global economy approximately USD 1 billion annually, and that every USD 1 spent on improving wellbeing would return USD 4 due to reduction of absenteeism and increased productivity. This brings the discussion to the critical aspects of the digital workplace, namely flexibility and telecommuting (Lee \& Sirgy, 2019).

Flexibility allows tasks to be performed at a time that fits with an employee's schedule so long as work targets are completed within the allotted time. According to Moen et al.s (2016) longitudinal study of 867 information technology workers in a Fortune 500 corporation, this work style accounted for $19 \%$ of increased job satisfaction and $23 \%$ of decreased psychological distress. Telecommuting allows employees to perform tasks away from the typical physical workplace, for example working from home, in co-working spaces and in hotels. The work style has a positive association with increased performance outcomes due to the effective allocation of time for work and non-work obligations (e.g. commuting, distracting lifestyle) (Lee \& Sirgy, 2019). A nationwide survey of over 580 Australians on the benefits on flexibility and teleworking conducted by McCrindle Research (2013) found that 52\% of respondents reported higher productivity working in places other than the office, and introverts were $30 \%$ more productive than extroverts when working out of the office. According to the post-COVID Global Workplace Analytics Survey of 2020, 69\% of nearly 3,000 employees reported that they had improved wellbeing when working outside of the office, with $54 \%$ eating more healthily and $48 \%$ involved in exercise, actions which may alleviate health issues.

The benefits of the digital workplace on employee performance and productivity are clear; however, at the same time, its design does not suit all workforce demographics. One of the many challenges presented by the 2017 report from EuroFound and the International Labour Organisation (ILO) is that employee stress and anxiety were related to juggling between personal and work matters. On the one hand, teleworking creates irritability, uneasiness and guilt due to reduced support and feedback from peers (Appel-Meulenbroek, Van der Voordt, Aussems, Arentze, \& Le Blanc, 2020). On the other hand, it promotes work intensification caused by pressure to respond to work requests outside work hours (Hoornweg et al., 2016). From a P-E fit perceptive, digital workplace issues can be narrowed down to the technostress phenomenon (see also Chapter 4 Task Technology Fit Theory), described by Ayyagari, Grover, and Purvis (2011) as lack of fit between the task assigned to an employee (often requiring high cognitive and adaptive skills) and technology (related to ICT information overload and intrusiveness). As a result, technostress may negatively impact innovation, decreases employee satisfaction and lower higher turnover rates (Wang \& $\mathrm{Li}, 2019$ ).

Despite the extensive research in this area, workplace design is still considered to be an ongoing and serious problem, as organisations continuously need to churn the work environment which was traditionally limited to the physical workplace but later also incorporated the digital workplace - to adapt to workforce demographics and experiences. The distinctive characteristics 
of the two workplaces tend to suit some employees but disadvantage others, as explained previously. The key to success, therefore, lies in the effective implementation of a P-E fit strategy capable of driving actual change from drawing on the unique perspectives of digital and physical workplaces as a whole and not as separate organisational work environments. The bottom line thus far when it comes to designing a work environment, far from the theory of P-E fit but relevant to this review, is that strategy has been implemented as a cost-saving measure that can support ever-changing business processes (Gibson, 2003). However, the literature on workplace design has scant research that, on the one side, focuses on employee wellbeing and productivity assessed using subjective wellbeing, and, on the other side, the work environment operation and performance assessed using the post-occupancy evaluation tool. These are presented in the next section.

\section{P-E fit methodology/research approach}

While the implementation of $\mathrm{P}-\mathrm{E}$ fit theory to workplace design sounds deceptively easy due to the comprehensive literature on positive outcomes, it usually takes several months and sometimes even years to collect enough empirical data to assess how organisations can better adapt their workplaces to meet the needs of their employees. The focus needs to be on employees and their needs as they are affected by the work environment and the flow-on effects of employee's wellbeing on performance and productivity. In this research, post-occupancy evaluations and subjective wellbeing measures are employed to explore how P-E fit theory determines the 'fit' with workplace design as a consequence of a person's behaviour.

\subsection{Post-occupancy evaluations (POEs)}

In the broadest sense, POEs are undertaken after a work environment has been built and occupied to assess whether its workplace features/facilities are functioning adequately and support employees in completing their job and tasks effectively. Preiser, Rabinowitz, and White (2015) describe the POE mechanism as linked to the relativity of person-environment relationships and, as Van Vianen (2018) notes, characterised as a mutual transactional process, similar to the concepts of P-E fit theory. Several researchers, including Preiser et al. (2015), consider that the POE methodology is based on the premise that the technical (e.g. safety), functional (e.g. layout) and behavioural (e.g. feelings) attributes of a workplace affect worker/employee satisfaction and productivity. Organisations carry out POEs to monitor the fit between workspace and people and, if necessary, adapt the work environment to individual/organisational values (Preiser et al., 2015; Vischer, 2008). There are two primary approaches to POEs: quantitative and qualitative. These are intended to evaluate the contribution of workplace design to productivity and performance. The distinctions between the two approaches to POEs are offered here.

In Preiser et al. (2015), quantitative POEs assess the effects of workspace features, such as lighting, acoustics, thermal comfort and privacy (see also Chapter 6 Privacy Regulation Theory), on employees' performance. For example, the POE results from a survey of 9,794 Australian employees of 77 open-plan offices by Göçer, Candido, Thomas, and Göçer (2019) reported that poor acoustics and privacy are two major reasons for employee dissatisfaction resulting in reduced performance and productivity. Qualitative POE analyses reflect on the influence of workplace design features such as aesthetics and quality on employee experience (Preiser \& Vischer, 2005), talent retention and the reduction of business costs (Coster \& Govan, 2015). The findings from Gensler, Leesman and Steelcase/Ipos discussed in the previous section suggest that workplace aesthetics and quality are strongly correlated with optimal human functioning. 
As such, workplaces with better aesthetics are associated with less staff turnover, as it is a source of employee motivation (Schell, Theorell, \& Saraste, 2011).

Over the years, organisations have used specific POEs to identify errors in workplace design that could reduce the performance and productivity of employees (Sanchez Leitner, Christine Sotsek, \& de Paula Lacerda Santos, 2020). Within each methodology, different categories guide the POE assessment when collecting information related to person and environment attributes and tools for evaluation. In practice, there are over 52 rating tools worldwide, each of which uses different metrics to evaluate the relationship between people and environment and its implications on performance and productivity (World Green Building Council, n.d.). Based on P-E fit theory, many rating tools certify buildings that implement sustainable and green designs that boost the health and productivity of the work environment (McArthur \& Powell, 2020). However, in research of P-E fit theory, several studies have used various quantitative methods including, but not limited to, linear regression (Lauver \& Kristof-Brown, 2001), polynomial regression (Van Vianen, De Pater, \& Van Dijk, 2007), stepwise regression (Hoendervanger, Ernst, Albers, Mobach, \& Van Yperen, 2018), and logistic and hierarchical regression (Tak, 2011). According to Edwards et al. (1998), regression analysis is the principal method for P-E fit analysis as it allows in-depth consideration of the interaction between person and environment concepts within a workplace.

\subsection{Subjective wellbeing (SWB) measures}

Current workplace research, particularly in the field of cognitive psychology, has shifted away from employee satisfaction and productivity to understanding employees' affective state (e.g. sad, happy, relaxed, angry, etc.) and productivity (Bellet, De Neve, \& Ward, 2019; Tenney, Poole, \& Diener, 2016). In SWB methodology, employees are required to keep a daily time-use diary (Beattie \& Griffin, 2014) or use a wearable device (Moore \& Piwek, 2017) that records their emotional state during work hours, enabling organisations to monitor and address any issues in order to ensure higher performance and productivity (Bellet et al., 2019). The study by Oswald, Proto, and Sgroi (2015) found that employees tend to allocate more time to work tasks perceived as interesting and that they are more creative and innovative in a content work environment (Ferreira et al., 2019). Furthermore, this is achieved by maximising positive experiences through creating a work environment that fits the employee's psychosocial and psychophysiological attributes, as detailed in the previous section. Several methods are used to study the subjective wellbeing of employees, two of which are briefly discussed next.

Diener and Tay (2014) state that the conceptual underpinning of an experience sampling method (ESM) can be narrowed down to understanding the actual feelings that people ('employee' for this chapter) experience when performing a daily activity. This is a momentbased assessment requiring employees to record the location, activity and associated emotions as they occur (Kahneman, Krueger, Schkade, Schwarz, \& Stone, 2004; Lucas, Wallsworth, Anusic, \& Donnellan, 2020) to minimise memory recall biases, which may cause over- or underestimating feelings (Diener \& Tay, 2014). The daily reconstruction method (DRM) utilises the same approach as ESM by prompting participants to record location, activity and associated feelings (Kahneman et al., 2004). However, unlike ESM, DRM requires participants to reconstruct the previous day into episodes such as breakfast, work, the commute and so forth (Lucas et al., 2020). The two methodologies enable an organisation to use feedback drawn from both qualitative and quantitative tools to create a better P-E fit (Srivastava, Angelo, \& Vallereux, 2008). For example, a 2019 survey conducted by Airtasker in the US reported that 505 of employees working remotely said they spent an additional 1.4 days every month compared to those who 
work in an office, of whom 54\% felt emotional stress and 37\% procrastinated on tasks. As such, organisations have been investing in the creation of a work environment that makes all employees feel valued and enables them to focus. Yet, there is little further development of P-E fit theory in the workplace design and related to corporate real estate management (CREM) and facilities management (FM) strategies. This may be because workplace literature tends not to see the work environment as a significant component of the work process (Baldry, 1999).

It has been several decades now since researchers, academics and practitioners have been urging employers to exercise social justice in the work environment (Cornelius, 2002). Today, social justice in the workplace is imperative for organisations to have competitive advantages in a world economy increasingly reflecting the benefits of migration, technological change, change of family and flexible gender roles. Two key principles of social justice that organisations are using to design a work environment perceived to fully fit employees' needs from different backgrounds are diversity and inclusion (Mor Barak, 2000). As such, these two principles have become congruent with modern workplace design, in addition to underpinning a moral and legal responsibility to provide an inclusive workplace (Agarwal, 2018) which contributes to the evolution of effective workplace design. Contemporary work environments that integrate both digital and physical workplaces, such as A-FOs, are considered as workplaces that are fit for all. As discussed previously, the efficacy of the workplace design continues to be subject to debate. For example, the inclusive workplace has been successful in fitting people with different personalities, disabilities, family obligations and ages in the work environment. However, it lags when it comes to supporting a P-E fit relating to cultural and religious spirituality (Botting, 2016) and the accessibility of transgender and nonbinary people to some facilities. for example access to bathrooms in the workplace (Schuster, Reisner, \& Onorato, 2016). This lack of P-E fit can reduce satisfaction, cause poor wellbeing due to stress and unhappiness and potentially decrease employee productivity and performance.

\section{Limitations}

While P-E fit theory is widely used in the workplace to design a work environment that suits the needs of its people, several researchers have noted that its conceptual framework has several limitations, as summarised next. Edwards et al. (1998) mentions that P-E fit theory has failed to specify the content of person and environment explicitly, thus, researchers and practitioners define the two constructs based on the other information sources such as Maslow's hierarchy of needs, the Work Preference Inventory (WPI), the Rokeach Value Survey (RVS) and the Fleishman Job Analysis Survey (FJAS). De Cooman, Mol, Billsberry, Boon, and Den Hartog (2019) explain that the operationalisation concepts may inflate or limit the effects of $\mathrm{P}-\mathrm{E}$ fit, especially when interpreting results with a perceived fit variable. Such a variable may contain bias and a high level of manipulation of data. Van Vianen (2018) states that P-E fit theory may not be applicable to an environment that exhibits power-distancing culture - for example Western versus Eastern context detailed by Abdalla, Al-Zufairi, Al-Homoud, and Muhammad (2019); often needs-supplies fit tends towards social conformity rather than individual autonomy.

\section{Relevance of P-E fit to practice}

Insight from the earlier listed principles enables organisations to reconfigure the work environment to suit different psychological, behavioural and motivational needs of employees (Van Vianen, 2018). According to Appel-Meulenbroek et al. (2019), organisations have attempted to align PF-fit with CREM and FM strategies. Several researchers (e.g. Armitage, Murugan, \& 
Kato, 2011; Langford \& Haynes, 2015) assert that such property strategies contribute added value to organisational objectives as they identify/measure which physical and behavioural aspects of real estate enhance performance and productivity. Thus far, a review of the literature of corporate real estate has discovered three models that attempt to integrate the basic principles of $\mathrm{P}-\mathrm{E}$ fit theory and, partially, CREM and FM strategies. These are the ' $10 \mathrm{P}$ alignment model' by Haynes, Nunnington, and Eccles (2017); the workspace design and fit-out framework by Hills and Levy (2014); and, the '3-30-300 rule' by Jones Lang LaSalle (JLL) (2016). The underlying conceptual framework of these models puts psychology at the centre of CREM since, as identified by Haynes et al. (2017), the analogy of 'one size fits all' previously used to create work environments is flawed, as it fails to take into account interpersonal differences in the workplace design.

\section{Further reading}

- Carnevale, J. B., \& Hatak, I. (2020). Employee adjustment and well-being in the era of COVID-19: Implications for human resource management. Journal of Business Research, 116, 183-187.

- De Cooman, R., Mol, S. T., Billsberry, J., Boon, C., \& Den Hartog, D. N. (2019). Epilogue: Frontiers in person-environment fit research. European Journal of Work and Organizational Psychology, 28(5), 646-652.

- Stich, J., Tarafdar, M., \& Cooper, C. (2018). Electronic communication in the workplace: Boon or bane? Journal of Organizational Effectiveness, 5(1), 98-106.

\section{References}

Abdalla, I., Al-Zufairi, A. M., Al-Homoud, M., \& Muhammad, A. H. (2019). Fitting in: Different types of person-environment fit as drivers of career self-management in Kuwait. International Business Research, 12(9), 29-42. https://doi.org/10.5539/ibr.v12n9p29

Agarwal, P. (2018). How do we design workplaces for inclusivity and diversity? Retrieved from www.forbes.com/ sites/pragyaagarwaleurope/2018/07/19/how-inclusive-is-your-organisation-here-is-how-to-use-inclusivedesign/?sh=16d6ee $944 \mathrm{~d} 18$

Airtasker. (2019). The benefits of working from home: Comparing the productivity, spending and health of remote vs. in-office employee. Retrieved from www.airtasker.com/blog/the-benefits-of-working-from-home/

Appel-Meulenbroek, H. A. J. A., Le Blanc, P. M., \& de Kort, Y. A. W. (2019). Person-environment fit: Optimizing the physical work environment. In R. Ayoko \& N. Ashkanasy (Eds.), Organizational behaviour and the built environment (pp. 251-267). Abingdon: Routledge Taylor \& Francis Group. Retrieved from www.crcpress.com/Organizational-Behaviour-and-the-Physical-Environment/Ayoko-Ashkanasy/p/ book/9781138053533

Appel-Meulenbroek, R., van der Voordt, T., Aussems, R., Arentze, T., \& Le Blanc, P. (2020). Impact of activity-based workplaces on burnout and engagement dimensions. Journal of Corporate Real Estate, 22(4), 279-296. https://doi.org/10.1108/JCRE-09-2019-0041

Armitage, L., Murugan, A., \& Kato, H. (2011). Green offices in Australia: A user perception survey. Journal of Corporate Real Estate, 13(3), 169-180. https://doi.org/10.1108/14630011111170454

Attaran, M., Attaran, S., \& Kirkland, D. (2019). The need for digital workplace: Increasing workforce productivity in the information age. International Journal of Enterprise Information Systems, 15(1), 1-23. Retrieved from www.igi-global.com/article/the-need-for-digital-workplace/220396

Ayyagari, R., Grover, V., \& Purvis, R. (2011). Technostress: Technological antecedents and implications. MIS Quarterly, 35(4), 831-858. Retrieved from www.jstor:stable/41409963

Baldry, C. (1999). Space-the final frontier. Sociology, 33(3), 535-553. https://doi.org/10.1177/S00380385 99000346

Beattie, L., \& Griffin, B. (2014). Day-level fluctuations in stress and engagement in response to workplace incivility: A diary study. Work \& Stress, 28(2), 124-142. https://doi.org/10.1080/02678373.2014.898712

Becker, F. (1991). Workplace planning, design, and management. In E. Zube \& G. Moore (Eds.), Advances in environment, behavior and design. New York: Plenum Press. https://doi.org/10.1007/978-1-4684-5814-5 
Bellet, C. S., De Neve, J. E., \& Ward, G. (2019). Does employee happiness have an impact on productivity? SSRN Electronic Journal, 67, 671-677. https://doi.org/10.2139/ssrn.3470734

Biswas, A., Oh, P. I., Faulkner, G. E., Bajaj, R. R., Silver, M. A., Mitchell, M. S., \& Alter, D. A. (2015). Sedentary time and its association with risk for disease incidence, mortality, and hospitalization in adults: A systematic review and meta-analysis. Annals of Internal Medicine, 162(2), 123-132. https://doi.org/10. 7326/M14-1651

Botting, S. (2016). Commercial office space: Time for a workplace intervention. Corporate Real Estate Journal, 5(2), 171-179. Retrieved from www.ingentaconnect.com/content/hsp/crej/2016/00000005/00000002/ $\operatorname{art} 00007$

Byström, K., Ruthven, I., \& Heinström, J. (2017). Work and information: Which workplace models still work in modern digital workplaces? Information Research, 12(1). Retrieved from http://hdl.handle. net/10642/5135

Candido, C., Thomas, L., Haddad, S., Zhang, F, Mackey, M., \& Ye, W. (2019). Designing activity-based workspaces: Satisfaction, productivity and physical activity. Building Research and Information, 47(3), 275289. https://doi.org/10.1080/09613218.2018.1476372

Çelik, A., \& Ozsoy, N. (2016). Organisational change: Where have we come from and where are we going? International Journal of Academic Research in Accounting, Finance and Management Sciences, 6(1), 134-141. Retrieved from https://EconPapers.repec:RePEc:hur:ijaraf:v:6:y:2016:i:1:p:134-141

Chartrand, J. (1991). The evolution of trait-and-factor career counseling: A person x environment fit approach. Journal of Counseling and Development, 69(6), 518-524. https://doi.org/10.1002/j.1556-6676.1991.tb02635.x

Cornelius, N. (2002). Building workplace equality: Ethics, diversity and inclusion. London: Thomson Publishing. Retrieved from www.cengage.co.uk/books/9781861525857/

Coster, S., \& Govan, C. (2015). Does workplace design affect employee attraction? Melbourne: Hassel. Retrieved from www.hassellstudio.com/uploads/20191212_WorkplaceDesignAttraction.pdf

Court, A. D., Pearson, A., \& Frewin, D. A. (2010). The effects of exposure to natural light in the workplace on the health and productivity of office workers: A systematic review protocol. JBI Library of Systematic Reviews, 8(16), 1-19. https://doi.org/10.11124/jbisrir-2010-574

Dawis, R. V., \& Lofquist, L. H. (1984). A psychological theory of work adjustment. Minneapolis, MN: University of Minnesota Press. Retrieved from https://catalogue.nla.gov.au/Record/917196

De Cooman, R., Mol, S. T., Billsberry, J., Boon, C., \& Den Hartog, D. N. (2019). Epilogue: Frontiers in person-environment fit research. European Journal of Work and Organizational Psychology, 28(5), 646-652. https://doi.org/10.1080/1359432X.2019.1630480

Diener, E., \& Tay, L. (2014). Review of the Day Reconstruction Method (DRM). Social Indicators Research, 116(1), 255-267. https://doi.org/10.1007/s11205-013-0279-x

Dipboye, R. (2018). The Emerald review of industrial and organizational psychology. Bingley: Emerald Publishing Limited. https://doi.org/10.1108/978-1-78743-785-220181002

Dzidowski, A. (2016). Form follows fun: The workspace as a playground. In 4th international biennial of interior design INAW, 11-7 March. Krakow, Norway. Retrieved from www.researchgate.net/ publication/311369539_Form_follows_fun_the_workspace_as_a_playground

Edwards, J. R. (2008). Person-environment fit in organizations: An assessment of theoretical progress. Academy of Management Annals, 2(1), 167-230. https://doi.org/10.5465/19416520802211503

Edwards, J. R., Caplan, R. D., \& Harrison, R. V. (1998). Person-environment fit theory: Conceptual foundations, empirical evidence, and directions for future research. In C. L. Cooper (Ed.), Theories of organizational stress (pp. 28-67). Oxford: Oxford University Press. Retrieved from http://public.kenan-flagler. unc.edu/faculty/edwardsj/Edwardsetal1998.pdf

Engelen, L., Chau, J., Young, S., Mackey, M., Jeyapalan, D., \& Bauman, A. (2019). Is activity-based working impacting health, work performance and perceptions? A systematic review. Building Research and Information: The International Journal of Research, Development and Demonstration, 47(4), 468-479. https:// doi.org/10.1080/09613218.2018.1440958

EuroFound and the ILO. (2017). Working anytime, anywhere: The effects on the world of work. Luxembourg: Publications Office of the European Union. Retrieved from http://ilo:global/publications/books/ WCMS_544138/lang-en/index.htm

Ferreira, A. I., da Costa Ferreira, P., Cooper, C. L., \& Oliveira, D. (2019). How daily negative affect and emotional exhaustion correlates with work engagement and presenteeism-constrained productivity. International Journal of Stress Management, 26(3), 261. https://doi.org/10.1037/str0000114

Follmer, E. (2016). What we do to fit in: Personality, coping and person-environment fit [Doctoral thesis]. University of Iowa, Iowa, USA. https://doi.org/10.17077/etd.ebd2lt9f 
Friedman, R. (2014). The best place to work: The art and science of creating an extraordinary workplace. New York: Perigee. Retrieved from www.ignite80.com/the-book

Gensler Research Institute. (2019). U.S. workplace survey 2019. USA: The Gensler Research Institute. Retrieved from www.gensler.com/uploads/document/614/file/Gensler-US-Workplace-Survey-2019.pdf

Ghaffarianhoseini, A., AlWaer, H., Omrany, H., Ghaffarianhoseini, A., Alalouch, C., Clements-Croome, D., \& Tookey, J. (2018). Sick building syndrome: Are we doing enough? Architectural Science Review, 61(3), 99-121. https://doi.org/10.1080/00038628.2018.1461060.

Gibson, V. (2003). Flexible working needs flexible space? Towards an alternative workplace strategy. Journal of Property Investment and Finance, 21(1), 12-22. https://doi.org/10.1108/14635780310468275

Global Workplace Analytics. (2020). Global work-from-home experience survey: Report final. Houston: IFMA. Retrieved from https://globalworkplaceanalytics.com/global-work-from-home-experience-survey

Göçer, Ö., Candido, C., Thomas, L., \& Göçer, K. (2019). Differences in occupants' satisfaction and perceived productivity in high-and low-performance offices. Buildings, 9(9), 199. https://doi.org/10.3390/ buildings 9090199

Hartung, P. J., \& Blustein, D. L. (2002). Reason, intuition, and social justice: Elaborating on Parsons's career decision-making model. Journal of Counseling \& Development, 80(1), 41-47. https://doi.org/10.1002/j. 1556-6678.2002.tb00164.x

Haynes, B., Nunnington, N., \& Eccles, T. (2017). Corporate real estate asset management: Strategy and implementation (2nd ed.). London: Routledge. Retrieved from www.taylorfrancis.com/books/e/9781315690445

Hejduk, I. K. (2005). On the way to the future: The knowledge-based enterprise. Human Factors and Ergonomics in Manufacturing \& Service Industries, 15(1), 5-14. https://doi.org/10.1002/hfm.20010

Hills, R., \& Levy, D. (2014). Workspace design and fit-out: What knowledge workers value. Property Management, 32(5), 415-432. https://doi.org/10.1108/PM-02-2014-0011.

Hobstetter, D. (2007). Daylighting and productivity: A study of the effects of the indoor environment on human function. Retrieved from www.mihalovich.com/articles/hobstetter200703.php

Hoendervanger, J. G., Ernst, A. F., Albers, C. J., Mobach., M. P., \& Van Yperen, W. (2018). Individual differences in satisfaction with activity-based work environments. PLoS One, 13(3), 1-15. https://doi. org/10.1371/journal.pone.0193878

Holland, J. L. (1966). The psychology of vocational choice: A theory of types and model environments. Waltham, MA: Blaisdell Publishing. Retrieved from https://psycnet.apa:record/1966-12652-000

Holland, J. L. (1985). Making vocational choices: A theory of vocational personalities and work environments. Englewood Cliffs, NJ: Prentice-Hall. Retrieved from https://psycnet.apa:record/1997-08980-000

Hoornweg, N., Peters, P., \& Van der Heijden, B. (2016). Finding the optimal mix between telework and office hours to enhance employee productivity: A study into the relationship between telework intensity and individual productivity, with mediation of intrinsic motivation and moderation of office hours. In J. De Leede (Ed.), New ways of working practices: Antecedents and outcomes (pp. 1-28). Bingley, UK: Emerald Group Publishing. https://doi.org/10.1108/S1877-636120160000016002

Jensen, P., \& van der Voordt, T. (2020). Typology of value adding FM and CREM interventions. Journal of Corporate Real Estate, 22(3), 197-217. https://doi.org/10.1108/JCRE-09-2019-0042

JLL. (2016). A surprising way to cut real estate costs. Retrieved from www.us.jll.com/en/trends-and-insights/ workplace/a-surprising-way-to-cut-real-estate-costs

Kahneman, D., Krueger, A., Schkade, D., Schwarz, N., \& Stone, A. (2004). A survey method for characterizing daily life experience: The day reconstruction method. Science, 306(5702), 1776-1780. https:// doi.org/10.1126/science.1103572.

Kreiner, G. E. (2006). Consequences of work-home segmentation or integration: A person-environment fit perspective. Journal of Organizational Behavior, 27(4), 485-507. https://doi.org/10.1002/job.386

Kristof, A. L. (1996). Person-organization fit: An integrative review of its conceptualizations, measurement, and implications. Personnel Psychology, 49(1), 1-49. https://doi.org/10.1111/j.1744-6570.1996.tb01790.x

Kristof-Brown, A., \& Billsberry, J. (2013). Organizational fit: Key issues and new directions. Chichester, UK: Wiley-Blackwell. https://doi.org/10.1002/9781118320853

Kupritz, V. W. (2002). The relative impact of workplace design on training transfer. Human Resource Development Quarterly, 13(4), 427-447. https://doi.org/10.1002/hrdq.1042

Langford, L., \& Haynes, B. (2015). An investigation into how corporate real estate in the financial services industry can add value through alignment and methods of performance measurement. Journal of Corporate Real Estate, 17(1), 46-62. https://doi.org/10.1108/JCRE-06-2014-0015

Lauver, K. J., \& Kristof-Brown, A. (2001). Distinguishing between employees' perceptions of person: Job and person-organization fit. Journal of Vocational Behavior, 59(3), 454-470. https://doi.org/10.1006/jvbe.20 01.1807 
Lee, D. J., \& Sirgy, M. J. (2019). Work-life balance in the digital workplace: The impact of schedule flexibility and telecommuting on work-life balance and overall life satisfaction. In M. Coetzee (Ed.), Thriving in digital workspaces: Emerging issues for research and practice (pp. 355-384). Cham: Springer. https:// doi.org/10.1007/978-3-030-24463-7

Lee, S. Y., \& Brand, J. L. (2005). Effects of control over office workspace on perceptions of the work environment and work outcomes. Journal of Environmental Psychology, 25(3), 323-333. https://doi.org/10.1016/j. jenvp.2005.08.001

Leesman (2017). The rise and rise of activity based working: Reshaping the physical, virtual and behavioural workspace. London: Leesman and IFMA Sweden. Retrieved from www.leesmanindex.com/The_Rise_and_ Rise_of_Activity_Based_Working_Research_book.pdf

Leonard, P. (2013). Changing organizational space: Green? Or lean and mean? Sociology, 47(2), 333-349. https://doi.org/10.1177\%2F0038038512441280.

Lucas, R. E., Wallsworth, C., Anusic, I., \& Donnellan, B. (2020). A direct comparison of the day reconstruction method and the experience sampling method. Journal of Personality and Social Psychology. Advance online publication. https://doi.org/10.1037/pspp0000289

McArthur, J. J., \& Powell, C. (2020). Health and wellness in commercial buildings: Systematic review of sustainable building rating systems and alignment with contemporary research. Building and Environment, 171, 106635. https://doi.org/10.1016/j.buildenv.2019.106635

McCoy, J. M., \& Evans, G. W. (2005). Physical work environment. In J. Barling, E. K. Kelloway, \& M. R. Frone (Eds.), Handbook of work stress. Thousand Oaks, CA: Sage.

McCrindle Research. (2013). Teleworking in Australia: Latest trends and perceptions. Bella Vista: McCrindle. Retrieved from https://mccrindle.com.au/insights/blogarchive/teleworking-in-australia-latest-trendsand-perceptions/

Moen, P., Kelly, E., Fan, W., Lee, S., Almeida, D., Kossek, E., \& Buxton, O. (2016). Does a flexibility/ support organizational initiative improve high-tech employees' well-being? Evidence from the work, family, and health network. American Sociological Review, 81(1), 134-164. https://doi.org/10.1177/000 3122415622391

Moore, P., \& Piwek, L. (2017). Regulating wellbeing in the brave new quantified workplace. Employee Relations, 39(3), 308-316. https://doi.org/10.1108/ER-06-2016-0126

Mor Barak, M. (2000). The inclusive workplace: An ecosystems approach to diversity management. Social Work, 45(4), 339-353. https://doi.org/10.1093/sw/45.4.339

Nauta, M. M. (2010). The development, evolution, and status of Holland's theory of vocational personalities: Reflections and future directions for counseling psychology. Journal of Counseling Psychology, 57(1), 11-22. https://doi.org/10.1037/a0018213

Nieuwenhuis, M., Knight, C., Postmes, T., \& Haslam, S. A. (2014). The relative benefits of green versus lean office space: Three field experiments. Journal of Experimental Psychology: Applied, 20(3), 199-214. https://doi.org/10.1037/xap0000024

Oswald, A. J., Proto, E., \& Sgroi, D. (2015). Happiness and productivity. Journal of Labor Economics, 33(4), 789-822. https://doi.org/10.1086/681096

Parsons, F. (1909). Choosing a vocation. Boston: Houghton Mifflin. Retrieved from https://archive:details/ choosingvocation00parsiala

Peteri, V., Lempiäinen, K., \& Kinnunen, M. (2020). From cubicles to open space: An analysis of gendered meanings of workspace. European Journal of Cultural Studies. https://doi.org/10.1177\%2F1367549420902792

Preiser, W., Rabinowitz, H., \& White, E. (2015). Post-occupancy evaluation. London: Routledge. https:// doi.org/10.4324/9781315713519

Preiser, W., \& Vischer, J. C. (Eds.). 2005. Assessing building performance. Oxford: Elsevier. https://doi. org/10.4324/9780080455228

Quelch, J. A., \& Knoop, C. I. (2018). Compassionate management of mental health in the modern workplace. Cham: Springer. https://doi.org/10.1007/978-3-319-71541-4

Rajan, R. G., \& Wulf, J. (2006). The flattening firm: Evidence from panel data on the changing nature of corporate hierarchies. The Review of Economics and Statistics, 88(4), 759-773. https://doi.org/10.1162/ rest.88.4.759

Rounds, J. B., Dawis, R. V., \& Lofquist, L. H. (1987). Measurement of person-environment fit and prediction of satisfaction in the theory of work adjustment. Journal of Vocational Behavior, 31, 297-318. https:// doi.org/10.1016/0001-8791(87)90045-5

Sanchez Leitner, D., Christine Sotsek, N., \& de Paula Lacerda Santos, A. (2020). Postoccupancy evaluation in buildings: Systematic literature review. Journal of Performance of Constructed Facilities, 34(1). https://doi. org/10.1061/\%28ASCE\%29CF.1943-5509.0001389 
Sander, L. (2019). Hot-desking and activity-based work not so good for employees: Research. Retrieved from www.commercialrealestate.com.au/news/hot-desking-and-activity-based-work-not-so-good-foremployees-research-37677/

Schell, E., Theorell, T., \& Saraste, H. (2011). Workplace aesthetics: Impact of environments upon employee health? Work, 39(3), 203-213. https://doi.org/10.3233/WOR-2011-1182

Schuster, M. A., Reisner, S. L., \& Onorato, S. E. (2016). Beyond bathrooms: Meeting the health needs of transgender people. The New England Journal of Medicine, 375(2), 101-103. https://doi.org/10.1056/ NEJMp1605912

Scully-Russ, E., \& Torraco, R. (2020). The changing nature and organization of work: An integrative review of the literature. Human Resource Development Review, 19(1), 66-93. https://doi.org/10.1177\%2F1534484 319886394

Sekiguchi, T. (2004). Toward a dynamic perspective of person-environment fit. Osaka Keidai Ronshu, 55(1), 177-190. Retrieved from www.i-repository.net/il/user_contents/02/G0000031Repository/ repository/keidaironshu_055_001_177-190.pdf

Spokane, A. R. (1985). A review of research on person-environment congruence in Holland's theory of careers. Journal of Vocational Behavior, 26(3), 306-343. https://doi.org/10.1016/0001-8791(85)90009-0

Srivastava, S., Angelo, K., \& Vallereux, S. (2008). Extraversion and positive affect: A day reconstruction study of person: Environment transactions. Journal of Research in Personality, 42(6), 1613-1618. https:// doi.org/10.1016/j.jrp.2008.05.002

Sweet, S., James, J. B., \& Pitt-Catsouphes, M. (2015). Discussing work-life fit: Factors that predict managerial promotion of flexible work arrangements. Research in the Sociology of Work, 26, 301-330. https:// doi.org/10.1108/S0277-283320150000026018

Tak, J. (2011). Relationships between various person-environment fit types and employee withdrawal behavior: A longitudinal study. Journal of Vocational Behavior, 78(2), 315-320. https://doi.org/10.1016/j. jvb.2010.11.006

Taylor, F. W. (1911). The principles of scientific management. New York: Harper \& Brothers. Retrieved from https://archive: stream/principlesofscie1911 tayl? $\mathrm{ref}=\mathrm{ol}$

Tenney, E. R., Poole, J. M., \& Diener, E. (2016). Does positivity enhance work performance? Why, when, and what we don't know. Research in Organizational Behavior, 36, 27-46. https://doi.org/10.1016/j. riob.2016.11.002

Van Vianen, A. (2018). Person environment fit: A review of its basic tenets. Annual Review of Organizational Psychology and Organizational Behavior, 5(1), 75-101. https://doi.org/10.1146/annurev-orgpsych-032117104702

Van Vianen, A., De Pater, I., \& Van Dijk, F. (2007). Work value fit and turnover intention: Same-source or different-source fit. Journal of Managerial Psychology, 22(2), 188-202. https://doi.org/10.1108/026839 40710726438.

Vischer, J. C. (2008). Towards an environmental psychology of workspace: How people are affected by environments for work. Architectural Science Review, 51(2), 97-108. https://doi.org/10.3763/asre.2008.5114

Walsh, W., Craik, K., \& Price, R. (2012). Person-environment psychology: New directions and perspectives (2nd ed.). New York: Routledge. Retrieved from www-taylorfrancis-com.ezp01.library.qut.edu.au/ books/9781410605771

Wang, K., \& Wang, Y. (2018). Person-environment fit and employee creativity: The moderating role of multicultural experience. Frontiers in Psychology, 9, 1-11. https://doi.org/10.3389/fpsyg.2018.01980

Wang, X., \& Li, B. (2019). Technostress among teachers in higher education: An investigation from multidimensional person-environment misfit. Frontiers in Psychology, 10, 1791. https://doi.org/10.3389/ fpsyg.2019.01791

Weber, M. (1947). The theory of social and economic organization. In A. M. Henderson \& T. Parson (Eds.), Translation. New York: Oxford University Press. Retrieved from https://archive:details/in.ernet. dli.2015.6054/page/n45/mode/2up

WHO. (2019). Mental health in the workplace. Retrieved from www.who.int/mental_health/in_the_work place/en/

Wilkins, A. J., Nimmo-Smith, I., Slater, A. I., \& Bedocs, L. (1989). Fluorescent lighting, headaches and eyestrain. Lighting Research \& Technology, 21(1), 11-18. https://doi.org/10.1177\%2F096032718902100102

Wohlers, C., Hartner-Tiefenthaler, M., \& Hertel, G. (2019). The relation between activity-based work environments and office workers' job attitudes and vitality. Environment and Behavior, 51(2), 167-198. https://doi.org/10.1177\%2F0013916517738078

World Green Building Council. (n.d.). About green buildings. Retrieved from www.worldgbc:rating-tools 


\title{
JOB DEMANDS-RESOURCES MODEL
}

\section{Its applicability to the workplace environment and human flourishing}

\author{
Michael Roskams*, Eileen McNeely, Dorota Weziak-Bialowolska, \\ and Piotr Bialowolski
}

\section{Background}

The job demands-resources (JD-R) model (see Figure 3.1; Demerouti, Bakker, Nachreiner, \& Schaufeli, 2001; Bakker \& Demerouti, 2014, 2017) is one of the most popular and influential models of work stress in the literature. The model can be summarised in a series of simple yet compelling propositions. All jobs share common characteristics that can be classified as 'demands' or 'resources', based on their effect on an employee. Demands instigate a health impairment process characterised by strain and exhaustion, eventually leading to burnout and other negative work outcomes. Resources stimulate work engagement, leading to higher motivation and other positive work outcomes. As such, the challenge for those tasked with job design is to minimise demands whilst maximising resources.

The JD-R model has become immensely popular in the two decades following its inception, inspiring hundreds of empirical articles and being used within thousands of organisations worldwide (Demerouti, Bakker, \& Xanthopoulou, 2019). As a result of its broadness and generalisability, it has been found to be equally applicable across a range of ostensibly diverse professional environments (Demerouti et al., 2019). The strength of the model lies in its ability to move beyond surface-level differences and identify the common characteristics that are universally associated with work outcomes.

The chapter is structured as follows. Firstly, the JD-R model is outlined in more detail. Secondly, a domain-specific extension of the JD-R model, termed the environmental demandsresources (ED-R) model, is presented and evaluated. Finally, the chapter concludes with a discussion of how the ED-R model ties in with theories of human flourishing and can be used to support a salutogenic (i.e., health-promoting) approach to well-being in the workplace.

\subsection{Outline of the JD-R model}

The JD-R Model assumes that every job shares common risks and opportunities for impaired or enhanced well-being and functioning. These characteristics can be divided into two broad categories: job demands and job resources.

*Corresponding author: mjroskams@googlemail.com 


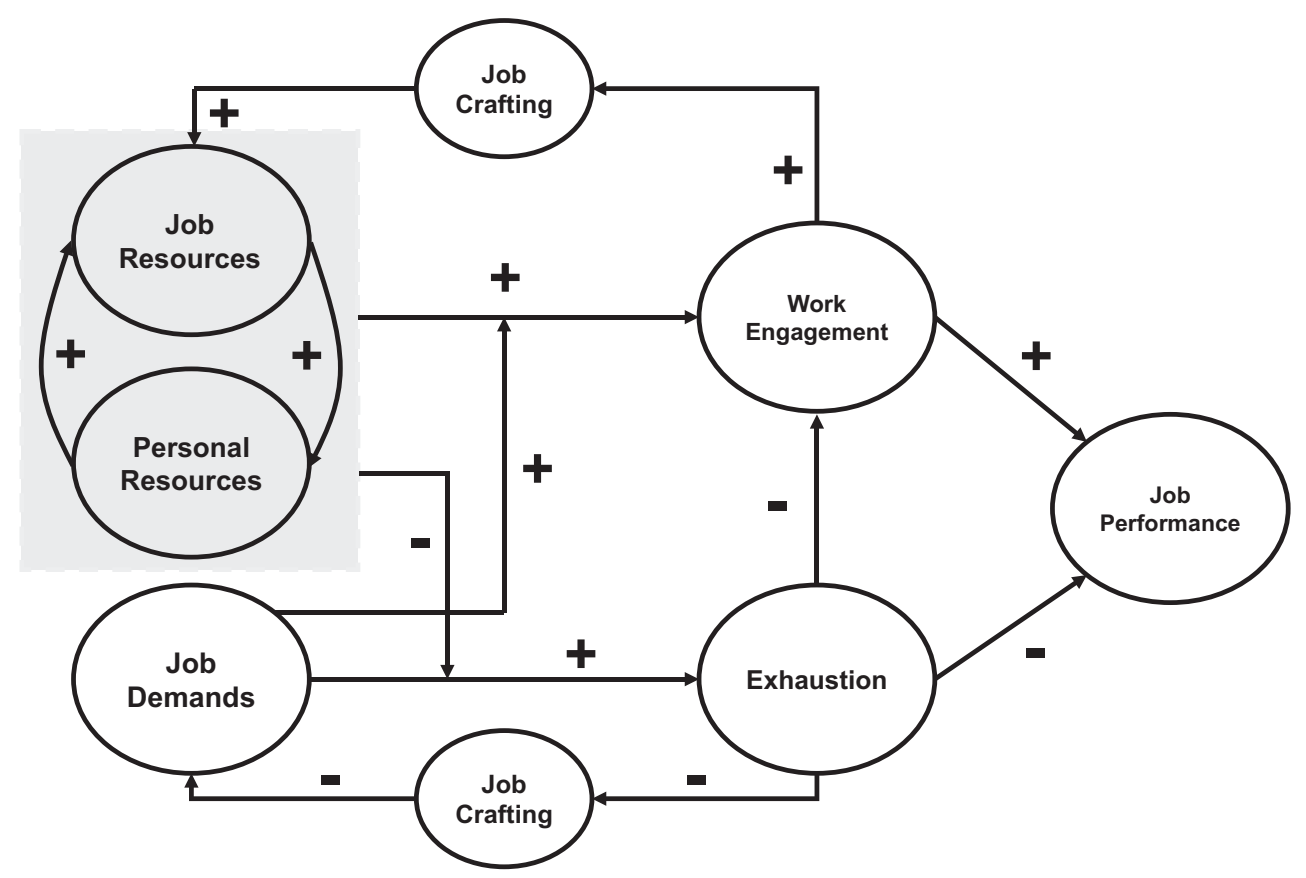

Figure 3.1 The job demands-resources model (Bakker \& Demerouti, 2014)

Job demands are defined as "those physical, social, or organizational aspects of the job that require sustained physical or mental effort and are therefore associated with certain physiological and psychological costs" (Demerouti et al., 2001, p. 501). Importantly, demands should be valued negatively by the employee (as opposed to difficult but positively valued challenges, which provide an opportunity to develop mastery and personal growth; Schaufeli \& Taris, 2014). Examples of such demands might include an irregular work schedule and demanding interactions with clients, amongst others.

Conversely, job resources are defined as "those physical, social, or organizational aspects of the job that may do any of the following: (a) be functional in achieving work goals; (b) reduce job demands and the associated physiological and psychological costs; (c) stimulate personal growth and development" (Demerouti et al., 2001, p. 501). Examples here could include organisational factors such as supervisor support and goal clarity, but they can also be widened to include personal resources such as resilience and interpersonal skills (Xanthopoulou, Bakker, Demerouti, \& Schaufeli, 2007).

Job demands and resources affect numerous work outcomes through two mediating pathways. First, the process of exhaustion is instigated by high demands and few resources. Chronic job demands require the employee to expend high levels of energy to achieve their work-related goals, with insufficient time for recovery. Eventually, this leads to a state of exhaustion. Similarly, a lack of job resources leads to a state of disengagement whereby the employee loses the motivation to expend effort to complete work. The combination of exhaustion and disengagement is symptomatic of burnout, which is in turn associated with various negative outcomes (e.g., absenteeism, impaired physical and mental health).

Whilst the absence of job resources causes demotivation, their presence can trigger a separate pathway termed work engagement. Job resources are intrinsically motivating because they satisfy 
fundamental human needs, thus engendering an engaged state of mind characterised by vigour (i.e., high levels of energy and mental resilience whilst working), dedication (i.e., a sense of significance, enthusiasm and challenge), and absorption (i.e., high levels of focus and feeling engrossed in one's work). In turn, work engagement is then associated with numerous positive outcomes (e.g., higher productivity, extra-role performance, positive affect at work).

Finally, the JD-R model also highlights the role of job crafting, which refers to proactive strategies taken by employees to alter the nature of their work (task crafting), their relationships with colleagues and clients (relationship crafting), and/or their appraisal of their work (cognitive crafting) (Wrzesniewski \& Dutton, 2001). When given the autonomy to do so, employees can thereby attempt to reduce perceived job demands and enhance job resources, thereby making the work more enjoyable and meaningful.

Altogether, the JD-R model has received good empirical support in the literature. Synthesising the large evidence base, different meta-analyses have confirmed the positive associations between job resources and work engagement (Christian, Garza, \& Slaughter, 2011; Crawford, LePine, \& Rich., 2010; Halbesleben, 2010) and between job demands and burnout (Alarcon, 2011; Crawford et al., 2010). Furthermore, research also supports the propositions that work engagement is positively associated with dedication and commitment (Halbesleben, 2010; Christian, Garza, \& Slaughter, 2011), whereas burnout is negatively related (Alarcon, 2011). A meta-analysis including only longitudinal research also supports the claims of the model (Lesener, Gusy, \& Wolter, 2019), providing more rigorous evidence to suggest that the concepts are causally related to one another, as opposed to being merely associated.

Overall, therefore, the JD-R model is a simple, yet effective, framework for representing the nature of work. In particular, it highlights three ways in which jobs can be adapted to improve employee well-being and productivity: (i) through the mitigation of job demands; (ii) through the enhancement of job resources; and (iii) through the facilitation of job crafting.

\section{Applicability to workplace studies}

Although the original conceptualisation of the JD-R model by Demerouti et al. (2001) acknowledges that an unfavourable physical work environment could be considered a job demand, the empirical JD-R literature has largely neglected the role of the physical environment as a potential source of job demands and resources (instead focusing on personal, social, and organisational factors). Correspondingly, the physical environment literature has tended to suffer from a lack of theory, where individual studies are typically segmented by discipline and unconnected to any conceptual framework (Ashkanasy, Ayoko, \& Jehn, 2014; Sander, Caza, \& Jordan, 2018; Weziak-Bialowolska, Dong, \& McNeely, 2018).

However, research from a variety of built environment disciplines (e.g., indoor environment quality, environmental psychology, corporate real estate, facilities management) clearly demonstrates that many aspects of the workplace environment have the same effects as other job demands and resources, and that many common behaviours within the workplace can be considered as examples of crafting. This can be presented separately as the ED-R model (see Figure 3.2).

\subsection{Environmental demands}

Environmental demands can be defined as aspects of the workplace environment that require an additional and sustained exertion of physical and/or mental effort, resulting in physiological and/or psychological strain. 


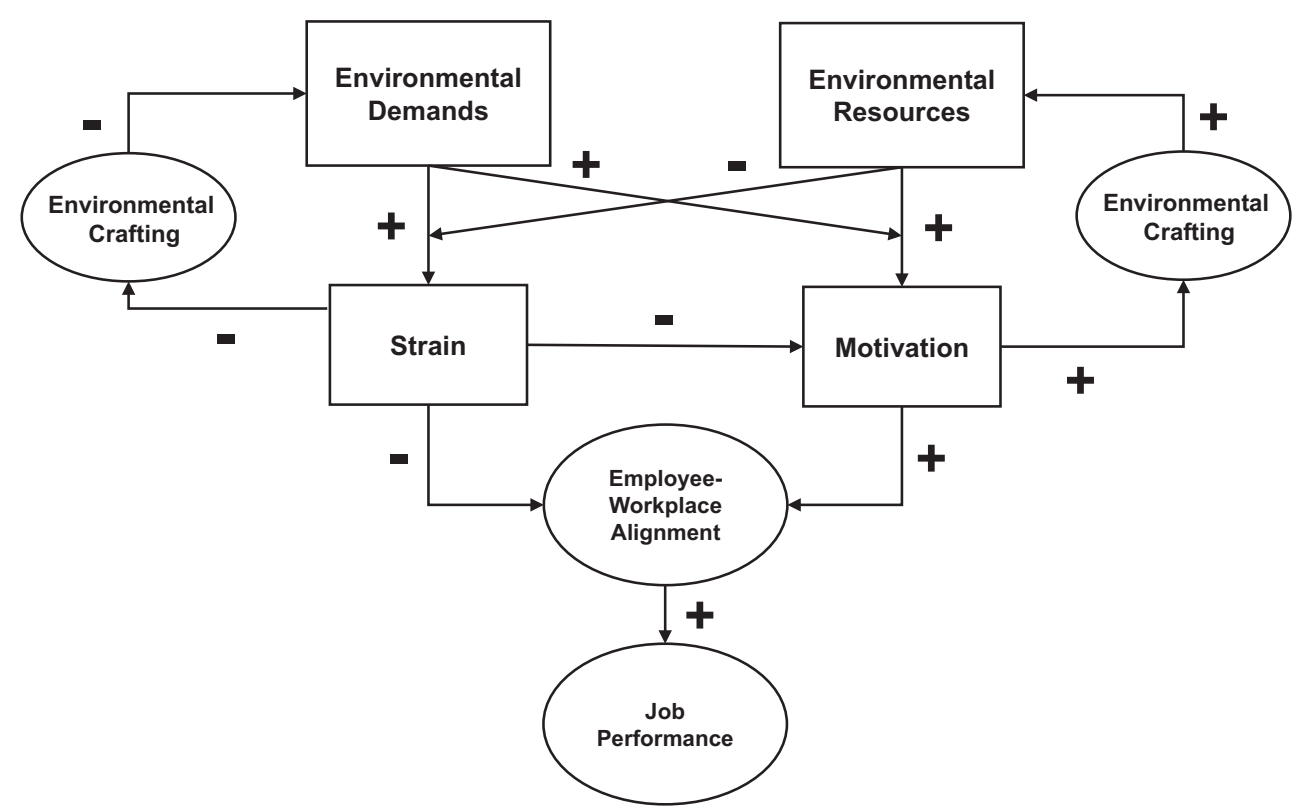

Figure 3.2 The environmental demands-resources model (Roskams \& Haynes, 2019)

For example, polluted indoor air can be considered an environmental demand, as it has a negative impact on cognitive performance (Allen et al., 2015; Satish et al., 2012, Zhang, Wargocki, Lian, \& Thyregod, 2016) and contributes to the development of 'sick building syndrome' symptoms, such as headaches, tiredness, and respiratory difficulties (Seppänen, Fisk, \& Mendell, 1999; Tsai, Lin, \& Chan, 2012). Other environmental factors which could deplete employees' energetic reserves might include uncomfortable temperatures (Rupp, Vásque, \& Lamberts, 2015; Wyon \& Wargocki, 2006), inadequate lighting (Boyce et al., 2006), and insufficient exposure to daylight (Jamrozik et al., 2019) (see also Chapter 13 The Theory of Attractive Quality).

Environmental demands may be particularly prevalent in modern open-plan offices, compared with traditional private offices. In shared workspaces, employees are frequently exposed to distraction by irrelevant background speech (Bodin Danielsson \& Bodin, 2009; Haapakangas, Hongisto, Eerola, \& Kuusisto, 2017; Mak \& Lui, 2012), leading to an estimated tenfold increase in acoustic complaints (Pejtersen, Allermann, Kristensen, \& Poulsen, 2006) and a doubling in the amount of time wasted due to noise (Kaarlela-Tuomaala, Helenius, Keskinen, \& Hongisto, 2009) relative to enclosed offices. Open-plan offices also increase perceptions of crowding and low privacy (Sundstrom, Burt, \& Kamp, 1980), leading to emotional exhaustion (Laurence, Fried, \& Slowik, 2013) and lower job satisfaction (Weziak-Bialowolska et al., 2018) amongst employees.

\subsection{Environmental resources}

Environmental resources can be defined as aspects of the workplace environment whose presence is associated with an enhanced ability to cope with demands and/or higher levels of work engagement.

For example, certain features of the workplace environment are effective in promoting recovery from stress. In particular, 'biophilic' design strategies (i.e., the integration of nature and natural analogues into the indoor built environment; see also Chapter 15 The Biophilia Hypothesis) have 
received significant research attention, building upon research that demonstrates that exposure to nature reduces psychological and physiological stress (Hartig, Mitchell, de Vries, \& Frumkin, 2014). When nature is brought into the office environment, most typically through interior plants, benefits include not only lower subjective stress but also higher health and job satisfaction, improved information processing and management, greater attention capacity, and higher self-rated productivity (Kaplan, 1993; Lohr, Pearson-Mims, \& Goodwin, 1996; Nieuwenhuis, Knight, Postmes, \& Haslam, 2014; Raanaas, Evensen, Rich, Sjøstrøm, \& Patil, 2011; Smith \& Pitt, 2009). In line with the definition that resources should be inherently engaging, biophilic design has also been observed to have an instorative effect (i.e., a positive impact on energy even in the absence of prior ego depletion; Beute \& De Kort, 2014).

The objects of workspace personalisation also serve as important environmental resources. Up to $90 \%$ of employees personalise the workspace with personally meaningful objects, such as photos of loved ones or artwork, if they have an opportunity to do so (Wells \& Thelen, 2002). This imbues the workplace with a sense of meaning (Brunia \& Hartjes-Gosselink, 2009) and helps to accelerate the development of personal identity in the workplace (Ashkanasy et al., 2014). In this way, the objects of personalisation act as visual stimuli which remind the employee of the deeper purpose of their work, which in turn helps to foster engagement and increased effort in the face of demands.

\subsection{Environmental crafting}

Finally, there is also good evidence to suggest that many behaviours within the workplace can be understood as examples of environmental crafting, in that they are directly motivated by a desire to improve one's working environment, through the mitigation of demands and/or the enhancement of resources.

For example, if they have the ability to do so, employees act in various ways to reduce discomfort in the workplace environment. In response to the demand of distracting background noise, it is common for employees to use headphones to improve acoustic comfort (Oseland \& Hodsman, 2018). In response to the demand of uncomfortable temperatures, employees might use personal fans or heaters to improve thermal comfort (Rupp et al., 2015). If the workplace environment is perceived as stale and corporate, then the act of personalisation is another example of environmental crafting, motivated by the desire to have easy access to resources at one's workspace.

Employees working in offices with flexible working arrangements often have an even greater ability to craft their working environment. By providing more freedom over where and when to work (referred to as spatial crafting and time crafting, respectively; Wessels et al., 2019), employees become better able to ensure that their working environment has few demands and abundant resources.

\subsection{Relationship to human flourishing}

Overall, the presence of demands and resources (relative to each individual's idiosyncratic needs and preferences) determines the level of 'alignment' between the employee and the workplace. In turn, more aligned workplaces will have a more positive impact on human flourishing (see also Chapter 14 Flourish Theory). As such, the ED-R model can be used to support a regenerative culture of well-being within organisations, in line with wider initiatives towards sustainable development goals (McNeely, 2018; Serafeim, Rischbeith, \& Koh, 2020; Wahl, 2016).

Essentially, flourishing can be understood as a state of fulfilment which arises when universal human needs are met. Specifically, the concept of human flourishing is conceptualised as a 
general construct with five distinct but interrelated components: life satisfaction and happiness; mental and physical health; meaning and purpose; character strengths; and close social relationships (VanderWeele, 2017; VanderWeele, McNeely, \& Koh, 2019). By systematically identifying and mitigating demands whilst enhancing resources, an environment more conducive to flourishing is provided.

Indeed, the ED-R model is congruent with more general frameworks for human flourishing within organisations. For example, the SHINE (Sustainability and Health Initiative for Net-Positive Enterprise) model (see Figure 3.3) developed at the Harvard T.H. Chan School of Public Health draws from a rich bank of literature in the social, psychological, management, and health sciences to identify key elements associated with human need fulfilment, resiliency, work performance, and engagement (Braunchli, Jenny, Fullemann, \& Bauer, 2015; Grossmeier et al., 2020; Jenny, Bauer, Vinje, Vogt, \& Torp, 2017; Kaufman, 2020; Medvedev \& Landhuis, 2018; Roskams \& Haynes, 2019, Weziak-Bialowolska, Bialowolski, Leon, Koosed, \& McNeely, 2020c). These key elements support flourishing precisely because they constitute specific resources or assets needed for employees to mitigate demands. The data thus far confirm the importance of these work arrangements for driving performance at work and overall flourishing in life and therein reaffirm the overall premise of the ED-R model (Bialowolski, McNeely, VanderWeele, \& Weziak-Bialowolska, 2020; Gale, Mordukhovich, Newlan, \& McNeely, 2019; Weziak-Bialowolska, Koosed, Leon, \& McNeely, 2017; Weziak-Bialowolska et al., 2018; WeziakBialowolska, McNeely, \& VanderWeele, 2019a; Weziak-Bialowolska, Bialowolski, \& McNeely, 2019c, 2020a; Weziak-Bialowolska, Bialowolski, Sacco, VanderWeele, \& McNeely, 2020b; Weziak-Bialowolska et al., 2020c).

Most importantly for this chapter, the SHINE model highlights the importance of physical working conditions as a key component of a regenerative work environment (alongside more general psychosocial job characteristics). In line with the salutogenic perspective and towards the overall aim of providing jobs which enhance rather than detract from well-being, the ED-R model can be used for the specific purpose of optimising the workplace environment.

\section{A Systems Approach to Well-being and Flourishing}

\begin{tabular}{|c|c|c|c|c|}
\hline \multicolumn{3}{|c|}{$\begin{array}{c}\text { REGENERATIVE } \\
\text { WORK ENVIRONMENTS }\end{array}$} & \multicolumn{2}{|c|}{ INDIVIDUAL FLOURISHING } \\
\hline & $\begin{array}{l}\text { CARING } \\
\text { CULTURE }\end{array}$ & & & $\begin{array}{l}\text { IN } \\
\text { LIFE }\end{array}$ \\
\hline $\begin{array}{l}\text { Access to Healthy } \\
\text { Nutrition }\end{array}$ & $\begin{array}{l}\text { Physical working } \\
\text { conditions }\end{array}$ & Recognition & \multirow[t]{2}{*}{ Happy } & life satisfaction \\
\hline Job Autonomy & $\begin{array}{l}\text { Manageable } \\
\text { Workload }\end{array}$ & $\begin{array}{c}\text { Supportive } \\
\text { Relationships }\end{array}$ & & \multirow{2}{*}{ Meaning and purpose } \\
\hline & & Work/Life & \multirow[t]{2}{*}{ Healthy } & \\
\hline Job Security & Fair Wages & Integration & & Social connectedness \\
\hline Zero Harassment & $\begin{array}{l}\text { Learning and } \\
\text { Growth }\end{array}$ & $\begin{array}{l}\text { Meaningful } \\
\text { Job }\end{array}$ & Engaged & Character strength \\
\hline
\end{tabular}

Figure 3.3 SHINE work and well-being model 


\section{Methodological/research approaches}

A variety of research methodologies can, and should, be used to empirically validate the propositions of the ED-R model. The model is in a nascent stage, and it will be necessary to confirm the assumed relationships between environmental demands and strain, between environmental resources and motivation, and between employee-workplace alignment and flourishing.

Firstly, recognising the fact that the majority of workplace environment research has focused largely on pathogenic factors, more research is needed to test the relationship between different environmental resources and different components of flourishing. The flourishing index (FI), which is embedded in the overarching SHINE model and has shown good psychometric properties (Weziak-Bialowolska et al., 2019a; Weziak-Bialowolska, McNeely, \& VanderWeele, 2019b), can be a suitable tool for this type of research. Using this framework, research(ers) would assess the ways in which a comprehensive, yet not exhaustive, set of different workplace demands and resources can affect general life satisfaction and happiness, mental and physical health, meaning and purpose, social connectedness, and character strengths of overall flourishing.

Secondly, researchers must resist the urge to restrict their inquiries solely to their own specialisms and instead to consider the entirety of environmental forces acting upon office occupants. A workplace intervention might successfully achieve a reduction in one environmental demand but inadvertently increase other demands and/or decrease resources, resulting in a worse working environment. The need to evaluate a comprehensive set of workplace factors across various work settings prompted the development of the SHINE model. To advance knowledge in the field, researchers should apply a consistent and broad set of workplace factors in longitudinal cohorts and use rigorous methods, such as pre-/post-intervention studies, ideally with a control group, to test assumptions of causality within the ED-R model. Further, qualitative techniques such as interviews and focus groups might be useful for identifying important demands or resources which have not yet been considered by the researchers.

Finally, to provide practitioners with more useful insight, it would be important to link employees' perceptions with objective assessments of environmental conditions. By comparing subjective and objective data, it would help confirm which conditions are associated with better or worse outcomes, such as work performance, engagement, and flourishing. The challenge for the aggregation of both subjective and objective information is that both environmental conditions and subjective perceptions are liable to momentary fluctuation, which can result in a lack of concordance or measurement accuracy of the intended condition or outcome. For example, the perception of poor air quality could be missed by employees completing a survey shortly after a momentary mechanical failure of the ventilation system. Instead, it may be more suitable to use either longitudinal survey data linked with continuous objective measurements of working conditions or repeated random experience sampling to assess employee-workplace interactions on a moment-by-moment basis (e.g., Roskams \& Haynes, 2020).

\section{Limitations}

The ED-R model shares the limitations of the JD-R model (e.g., Schaufeli \& Taris, 2014). Specifically, the generalisability of the model comes at the cost of limited specificity; no predictions are made within the ED-R model about the strength of the relationships between different demands, resources, and outcomes. It also remains unclear whether combinations of different demands and/or resources are additive or multiplicative in their effects. Hence, whilst 
the ED-R model can be viewed as a comprehensive meta-theory for the workplace environment, it would also be necessary to apply other frameworks, such as the SHINE model, to explain the numerous specific factors and relative relationships in the model with greater detail and predictive power.

\section{Theory relevance to practice}

This chapter explored the conditions for 'healthy work' by exploring the JD-R model in relation to the workplace environment and then examining how this approach aligns with the more general SHINE model for flourishing at work. Evidence-based approaches to workplace practice should be contextualised within these theoretical frameworks and explicitly guided towards connecting workplace resources directly to performance and overall flourishing.

Specifically, workplace practitioners can apply the ED-R model to practice by implementing top-down strategies such as identifying and mitigating environmental demands (e.g., monitoring and reducing airborne pollutants) and increasing the presence of environmental resources (e.g., using biophilic design within the office). This process can be supported by a typology of environmental demands and resources, derived from previous research (see Roskams \& Haynes, 2021). Practitioners should have a good understanding of the various environmental factors which may impact an employee's well-being and productivity and aim to ensure that the workplace is designed and maintained in such a way that it will continue to provide physical, functional, and psychological comfort for users.

However, it should also be recognised that significant inter-individual variability exists between different individuals and different types of work, and the strategies required to provide an optimal working environment may vary depending on these circumstances. Interventions delivered at the group level are likely to be welcomed by some employees but considered unhelpful by others. Hence, the top-down strategies should be complemented with bottom-up, user-directed strategies designed to facilitate the individual process of environmental crafting (e.g., implementing flexible workplace policies). This will allow the workplace users themselves to ensure that their working environment is free of demands and abundant in resources.

By applying these strategies, the hidden arrangements at work which give rise to both harms and benefits can be made visible. The approach presented in this chapter emphasises a holistic model of well-being in which work systems can be optimised to address specific human needs, such as social connectedness, or designed to affect multiple outcomes simultaneously. By uncorking the user experience of work in relation to their well-being, it becomes possible to gain new insights and opportunities to build a regenerative workplace that fits with the goals of sustainability and societal well-being.

\section{Further reading}

- Bakker, A. B., \& Demerouti, E. (2017). Job demands-resources theory: Taking stock and looking forward. Journal of Occupational Health Psychology, 22, 273-285. https://doi.org/10. 1037/ocp0000056

- Bodin Danielsson, C., Bodin, L., Wulff, C., \& Theorell, T. (2015). The relation between office type and workplace conflict: A gender and noise perspective. Journal of Environmental Psychology, 42, 161-171. https://doi.org/10.1016/j.jenvp.2015.04.004

- Khazanchi, S., Sprinkle, T. A., Masterson, S. S., \& Tong, N. (2018). A spatial model of work relationships: The relationship-building and relationship-straining of workspace design. Academy of Management Journal, 43(4), 590-609. https://doi.org/10.5465/amr.2016.0240 
- Roskams, M., \& Haynes, B. P. (2019). Salutogenic workplace design: A conceptual framework for supporting sense of coherence through environmental resources. Journal of Corporate Real Estate, 22(2), 139-153. https://doi.org/10.1108/JCRE-01-2019-0001

- Weziak-Bialowolska, D., Dong, Z., \& McNeely, E. (2018). Turning the mirror on the architects: A study of the open-plan office and work behaviors at an architectural company. Frontiers in Psychology, 9, 2178. https://doi.org/10.3389/fpsyg.2018.02178

\section{References}

Alarcon, G. M. (2011). A meta-analysis of burnout with job demands, resources, and attitudes. Journal of Vocational Behavior, 79, 549-562. https://doi.org/10.1016/j.jvb.2011.03.007

Allen, J., MacNaughton, P., Satish, U., Santanam, S., Vallarino, J., \& Spengler, J. (2015). Associations of cognitive function scores with carbon dioxide, ventilation, and volatile organic compound exposures in office workers: A controlled exposure study of green and conventional office environments. Environmental Health Perspectives, 124(6), 805-812. https://doi.org/10.1289/ehp.1510037

Ashkanasy, N., Ayoko, O., \& Jehn, K. (2014). Understanding the physical environment of work and employee behavior: An affective events perspective. Journal of Organizational Behavior, 35(8), 1169-1184. https://doi.org/10.1002/job.1973

Bakker, A. B., \& Demerouti, E. (2014). Job demands-resources theory. In C. Cooper \& P. Chen (Eds.), Wellbeing: A complete reference guide (pp. 37-64). Hoboken, NJ: Wiley-Blackwell.

Bakker, A. B., \& Demerouti, E. (2017). Job demands-resources theory: Taking stock and looking forward. Journal of Occupational Health Psychology, 22, 273-285. https://doi.org/10.1037/ocp0000056

Beute, F., \& de Kort, Y. (2014). Natural resistance: Exposure to nature and self-regulation, mood, and physiology after ego-depletion. Journal of Environmental Psychology, 40, 167-178. https://doi.org/10.1016/j. jenvp.2014.06.004

Bialowolski, P., McNeely, E., VanderWeele, T. J., Węziak-Białowolska, D. (2020). Ill health and distraction at work: Costs and drivers for productivity loss. PLoS One, 15(3), e0230562. https://doi.org/10.1371/ journal.pone. 0230562

Bodin Danielsson, C., \& Bodin, L. (2009). Difference in satisfaction with office environment among employees in different office types. Journal of Architectural and Planning Research, 26(3), 241-257. Retrieved from www.jstor.org/stable/43030872

Boyce, P., Veitch, J. A., Newsham, G. R., Jones, C. C., Heerwagen, J., Myer, M., \& Hunter, C. M. (2006). Lighting quality and office work: Two field simulation experiments. Lighting Research E Technology, 38(3), 191-223. https://doi.org/10.1191\%2F1365782806lrt161oa

Braunchli, R., Jenny, G., Fullemann, D., \& Bauer, G. (2015). Towards a job demands-resources health model: Empirical testing with generalizable indicators of job demands, job resources, and comprehensive health outcomes. Biomedical Research International, 959621. https://doi.org/10.1155/2015/959621

Brunia, S., \& Hartjes-Gosselink, A. (2009). Personalization in non-territorial offices: A study of a human need. Journal of Corporate Real Estate, 11(3), 169-182. https://doi.org/10.1108/14630010910985922

Christian, M. S., Garza, A. S., \& Slaughter, J. E. (2011). Work engagement: A quantitative review and test of its relations with task and contextual performance. Personnel Psychology, 64, 89-136. https://doi. org/10.1111/j.1744-6570.2010.01203.x

Crawford, E. R., LePine, J. A., \& Rich, B. L. (2010). Linking job demands and resources to employee engagement and burnout: A theoretical extension and meta-analytic test. Journal of Applied Psychology, 95, 834-848. https://doi.org/10.1037/a0019364

Demerouti, E., Bakker, A. B., Nachreiner, F., \& Schaufeli, W. B. (2001). The job demands-resources model of burnout. Journal of Applied Psychology, 86, 499-512. https://doi.org/10.1037/0021-9010.86.3.499

Demerouti, E., Bakker, A. B., \& Xanthopoulou, D. (2019). Job demands-resources theory and the role of individual cognitive and behavioral strategies. In T. Taris, M. Peeters, \& H. de Witte (Eds.), The fun and frustrations of modern working life: Contributions from an occupational health psychology perspective (pp. 94-104). Kalmthout, Belgium: Pelckmans Pro.

Gale, S., Mordukhovich, I., Newlan, S., \& McNeely, E. (2019). The impact of workplace harassment on health in a working cohort. Frontiers in Psychology, 10, 1181. https://doi.org/10.3389\%2Ffpsyg.2019.01181

Grossmeier, J., Castle, P., Pitts, J., Saringer, C., Jenkins, K. R., Imboden, M., . . \& Mason, S. (2020). Work place wellbeing factors that predict employee participation, health and medical cost impact, and perceived support. American Journal of Health Promotion, 34(4), 349-358. https://doi.org/10.1177/0890117119898613 


\section{Michael Roskams et al.}

Haapakangas, A., Hongisto, V., Eerola, M., \& Kuusisto, T. (2017). Distraction distance and perceived disturbance by noise: An analysis of 21 open-plan offices. The Journal of the Acoustical Society of America, 141(1), 127-136. https://doi.org/10.1121/1.4973690

Halbesleben, J. R. B. (2010). A meta-analysis of work engagement: Relationships with burnout, demands, resources, and consequences. In A. B. Bakker \& M. P. Leiter (Eds.), Work engagement: A handbook of essential theory and research (pp. 102-117). Hove, UK: Psychology Press.

Hartig, T., Mitchell, R., de Vries, S., \& Frumkin, H. (2014). Nature and health. Annual Review of Public Health, 35, 207-228. https://doi.org/10.1146/annurev-publhealth-032013-182443

Jamrozik, A., Clements, N., Hasan, S. S., Zhao, J., Zhang, R., Campanella, C., . . . \& Bauer, B. A. (2019). Access to daylight and view in an office improves cognitive performance and reduces eyestrain: A controlled crossover study. Building and Environment, 165, 106379. https://doi.org/10.1016/j. buildenv.2019.106379

Jenny, G. J., Bauer, G. F., Vinje, H. F., Vogt, K., \& Torp, S. (2017). The application of salutogenesis to work. In M. B. Mittelmark, S. Sagy, M. Eriksson, G. F. Bauer, J. M. Pelikan, B. Lindström, \& G. A. Espnes (Eds.), The handbook of salutogenesis (pp. 197-210). New York: Springer.

Kaarlela-Tuomaala, A., Helenius, R., Keskinen, E., \& Hongisto, V. (2009). Effects of acoustic environment on work in private office rooms and open-plan offices: Longitudinal study during relocation. Ergonomics, 52(11), 1423-1444. https://doi.org/10.1080/00140130903154579

Kaplan, R. (1993). The role of nature in the context of the workplace. Landscape and Urban Planning, 26(1/4), 193-201. https://doi.org/10.1016/0169-2046(93)90016-7

Kaufman, S. B. (2020). Transcend: The new science of self-actualization. New York: TarcherPerigee.

Laurence, G., Fried, Y., \& Slowik, L. (2013). "My space": A moderated mediation model of the effect of architectural and experienced privacy and workspace personalization on emotional exhaustion at work. Journal of Environmental Psychology, 36, 144-152. https://doi.org/10.1016/j.jenvp.2013.07.011

Lesener, T., Gusy, B., \& Wolter, C. (2019). The job demands-resources model: A meta-analytic review of longitudinal studies. Work \& Stress, 33(1), 76-103. https://doi.org/10.1080/02678373.2018.1529065

Lohr, V., Pearson-Mims, C., \& Goodwin, G. (1996). Interior plants may improve worker productivity and reduce stress in a windowless environment. Journal of Environmental Horticulture, 14(2), 97-100. https:// doi.org/10.24266/0738-2898-14.2.97

Mak, C., \& Lui, Y. (2012). The effect of sound on office productivity. Building Services Engineering Research and Technology, 33(3), 339-345. https://doi.org/10.1177\%2F0143624411412253

McNeely, E. (2018). Following footprints: What corporate health can learn from environmental sustain ability. American Journal of Health Promotion, 32(4), 1146-1150. https://doi.org/10.1177/08901171187 65037

Medvedev, O. N., \& Landhuis, C. E. (2018). Exploring constructs of well-being, happiness and quality of life. PeerJ, 6, e4903. https://doi.org/10.7717/peerj.4903

Nieuwenhuis, M., Knight, C., Postmes, T., \& Haslam, S. (2014). The relative benefit of green versus lean offices space: Three field experiments. Journal of Experimental Psychology: Applied, 20(3), $199-214$. https://doi.org/10.1037/xap0000024

Oseland, N., \& Hodsman, P. (2018). A psychoacoustical approach to resolving office noise distraction. Journal of Corporate Real Estate, 20(4), 260-280. https://doi.org/10.1108/JCRE-08-2017-0021

Pejtersen, J., Allermann, L., Kristensen, T., \& Poulsen, O. (2006). Indoor climate, psychosocial work environment and symptoms in open-plan offices. Indoor Air, 16(5), 392-401. https://doi.org/10.1111/j.16000668.2006.00444.x

Raanaas, R., Evensen, K., Rich, D., Sjøstrøm, G., \& Patil, G. (2011). Benefits of indoor plants on attention capacity in an office setting. Journal of Environmental Psychology, 31(1), 99-105. https://doi.org/10.1016/j. jenvp.2010.11.005

Roskams, M., \& Haynes, B. P. (2019). Salutogenic workplace design: A conceptual framework for supporting sense of coherence through environmental resources. Journal of Corporate Real Estate, 22(2), 139-153. https://doi.org/10.1108/JCRE-01-2019-0001

Roskams, M., \& Haynes, B. P. (2020). Testing the relationship between objective indoor environment quality and subjective experiences of comfort. Building Research \& Information. Advance online publication. https://doi.org/10.1080/09613218.2020.1775065

Roskams, M., \& Haynes, B. P. (2021). Environmental demands and resources: A framework for understanding the physical environment for work. Facilities, ahead-of-print.

Rupp, R., Vásquez, N., \& Lamberts, R. (2015). A review of human thermal comfort in the built environment. Energy and Buildings, 105, 178-205. https://doi.org/10.1016/j.enbuild.2015.07.047 
Sander, E., Caza, A., \& Jordan, P. (2018). Psychological perceptions matter: Developing the reactions to the physical work environment scale. Building and Environment, 148, 338-347. https://doi.org/10.1016/j. buildenv.2018.11.020

Satish, U., Mendell, M., Skekhar, K., Hotchi, T., Sullivan, D., Steufert, S., \& Fisk, W. (2012). Is CO2 an indoor pollutant? Direct effects of low-to-moderate CO2 concentrations on human decision-making performance. Environmental Health Perspectives, 120(12), 1671-1677. https://doi.org/10.1289\%2Fehp.1104789

Schaufeli, W. B., \& Taris, T. W. (2014). A critical review of job demands-resources model. Implications for improving work and health. In G. Bauer \& O. Hammig (Eds.), Bridging occupational, organizational and public health (pp. 43-68). New York: Springer.

Seppänen, O., Fisk, W., \& Mendell, M. (1999). Association of ventilation rates and CO2 concentrations with health and other responses in commercial and institutional buildings. Indoor Air, 9(4), $226-252$. https://doi.org/10.1111/j.1600-0668.1999.00003.x

Serafeim, G., Rischbeith, A., \& Koh, H. (2020). Sustainability, business, and health. Journal of the American Medical Association, 324(2), 147-148. https://doi.org/10.1001/jama.2020.8714

Smith, A., \& Pitt, M. (2009). Sustainable workplaces: Improving staff health and well-being using plants. Journal of Corporate Real Estate, 11(1), 52-63. https://doi.org/10.1108/14630010910940552

Sundstrom, E., Burt, R., \& Kamp, D. (1980). Privacy at work: Architectural correlates of job satisfaction and job performance. The Academy of Management Journal, 23(1), 101-117. https://doi.org/10.5465/255498

Tsai, D., Lin, J., \& Chan, C. (2012). Office workers' sick building syndrome and indoor carbon dioxide concentrations. Journal of Occupational and Environmental Hygiene, 9(5), 345-351. https://doi.org/10.10 $80 / 15459624.2012 .675291$

VanderWeele, T. J. (2017). On the promotion of human flourishing. Proceedings of the National Academy of Sciences of the United States of America, 114(31), 8148-8156. https://doi.org/10.1073/pnas.1702996114

VanderWeele, T. J., McNeely, E., \& Koh, H. (2019). Reimagining health-flourishing. Journal of the American Medical Association, 321(17), 1667-1668. https://doi.org/10.1001/jama.2019.3035

Wahl, D. (2016). Designing a regenerative culture. Bridport, UK: Triarchy Press.

Wells, M., \& Thelen, L. (2002). What does your workspace say about you? The influence of personality, status, and workspace on personalization. Environment and Behavior, 34(3), 300-321. https://doi.org/1 $0.1177 \% 2 \mathrm{~F} 0013916502034003002$

Wessels, C., Schippers, M., Stegmann, S., Bakker, A., van Baalen, P., \& Proper, K. (2019). Fostering flexibility in the new world of work: A model of time-spatial job crafting. Frontiers in Psychology, 10(505). https://doi.org/10.3389/fpsyg.2019.00505

Weziak-Bialowolska, D., Bialowolski, P., \& McNeely, E. (2019c). Worker's well-being: Evidence from the apparel industry in Mexico. Intelligent Buildings International, 11(3-4), 158-177. https://doi.org/10.108 0/17508975.2019.1618785

Weziak-Bialowolska, D., Bialowolski, P., Leon, C., Koosed, T., \& McNeely, E. (2020c). Psychological climate for caring and work outcomes: A virtuous cycle. International Journal of Environmental Research and Public Health, 17, 7035. https://doi.org/10.3390/ijerph17197035

Weziak-Bialowolska, D., Bialowolski, P., \& McNeely, E. (2020a). The impact of workplace harassment and domestic violence on work outcomes in the developing world. World Development, 126(C), 1-12. https://doi.org/10.1016/j.worlddev.2019.104732

Weziak-Bialowolska, D., Bialowolski, P., Sacco, P. L., VanderWeele, T. J., \& McNeely, E. (2020b). Wellbeing in life and well-being at work: Which comes first? Evidence from a longitudinal study. Frontiers in Public Health, 8, 103. https://doi.org/10.3389/fpsyg.2019.00505

Weziak-Bialowolska, D., Dong, Z., \& McNeely, E. (2018). Turning the mirror on the architects: A study of the open-plan office and work behaviors at an architectural company. Frontiers in Psychology, 9, 2178. https://doi.org/10.3389/fpsyg.2018.02178

Weziak-Bialowolska, D., Koosed, T., Leon, C., \& McNeely, E. (2017). A new approach to the well-being of factory workers in global supply chains: Evidence from apparel factories in Mexico, Sri Lanka, China and Cambodia. In OECD, HEC Paris, \& SnO centre (Eds.), Measuring the impacts of business on well-being and sustainability (pp. 130-154). Paris: OECD and HEC Paris/SnO centre.

Weziak-Bialowolska, D., McNeely, E., \& VanderWeele, T. J. (2019a). Human flourishing in cross cultural settings: Evidence from the US, China, Sri Lanka, Cambodia and Mexico. Frontiers in Psychology, 10, 1269. https://doi.org/10.3389/fpsyg.2019.01269

Weziak-Bialowolska, D., McNeely, E., \& VanderWeele, T. J. (2019b). Flourish index and secure flourish index: Validation in workplace settings. Cogent Psychology, 6, 1. https://doi.org/10.1080/23311908.2019. 1598926 
Wrzesniewski, A., \& Dutton, J. E. (2001). Crafting a job: Revisioning employees as active crafters of their work. Academy of Management Review, 26, 179-201. https://doi.org/10.5465/amr.2001.4378011

Wyon, D., \& Wargocki, P. (2006). Room temperature effects on office work. In D. Clements-Croome (Ed.), Creating the productive workplace (pp. 181-192). Milton, UK: Taylor \& Francis.

Xanthopoulou, D., Bakker, A. B., Demerouti, E., \& Schaufeli, W. B. (2007). The role of personal resources in the job demands-resources model. International Journal of Stress Management, 14, 121-141. https://doi. org/10.1037/1072-5245.14.2.121

Zhang, X., Wargocki, P., Lian, Z., \& Thyregod, C. (2016). Effects of exposure to carbon dioxide and bioeffluents on perceived air quality, self-assessed acute health symptoms, and cognitive performance. Indoor Air, 27, 47-64. https://doi.org/10.1111/ina.12284 


\title{
4 \\ TASK-TECHNOLOGY FIT THEORY
}

\section{An approach for mitigating technostress}

\author{
Nelda Vendramin*, Giulia Nardelli, and Christine Ipsen
}

\section{Background}

\subsection{Task-technology fit}

The task-technology fit (TTF) theory postulates the relationship between digital technology (hereafter technology) and the tasks it aims to support. TTF is a variance theory describing the interrelationship between three components - technology functionality, task requirements, and individual abilities - at a specific point in time (Goodhue, 1995; Goodhue \& Thompson, 1995).

The TTF perspective stems from information systems research (e.g., Bere, 2018; Gebauer, Shaw, \& Gribbins, 2010; Vanduhe, Nat, \& Hasan, 2020) and has been applied in different domains. For example, knowledge work (Kuo \& Lee, 2011), managerial decision-making (Goodhue, Klein, \& March, 2000), team performance (Fuller, 2009), virtual teams (Zigurs \& Khazanchi, 2008), and education (McGill \& Klobas, 2009). The concept of task-technology fit was developed by Goodhue and Thompson (1995) and Zigurs and Buckland (1998). While Goodhue and Thompson (1995) focus on the fit between the technology, task, and individual, Zigurs and Buckland (1998) place the focus on how task and technology interact to enhance group performance.

Goodhue (1995) and Goodhue and Thompson (1995) proposed the TTF as an evaluation construct defined within a theoretical perspective, which assesses certain aspects of technology and seeks to understand how the use of technology affects performance impacts. The TTF perspective assumes that users can appropriately evaluate the level of TTF as they use the technology for performing their work tasks, and that an evaluation of TTF may predict the performance. TTF is measured through assessment of user experience based on different dimensions such as quality of data, usability, and reliability of the technology. However, the assumption is that users evaluate both the functionality of the technology and the degree to which the technology assists them in task accomplishment and suits their abilities (Dishaw, 1999).

According to TTF theory, a higher fit between technology, task requirements, and individual abilities will contribute to a better performance, that is, will lead to more efficient task accomplishment (Goodhue, 1995). When users acknowledge that technology improves the execution of a task, it leads to higher adoption and use and, in turn, to improved performance (Figure 4.1).

*Corresponding author: neol@dtu.dk 


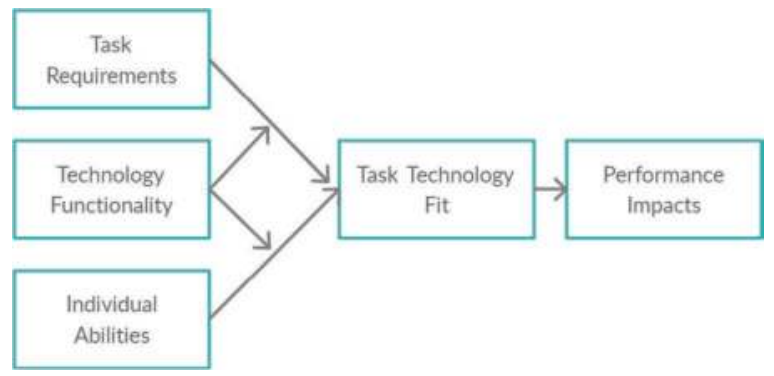

Figure 4.1 Interacting elements of TTF

The improved performance arises from an optimal TTF: when technology matches the task characteristics it aims to support and the individual abilities of the users, users may execute their tasks more smoothly (Lee, Cheng, \& Cheng, 2007; Spies, Grobbelaar, \& Botha, 2020).

Figure 4.1 illustrates the interacting elements of TTF. The task requirements represent the physical and cognitive actions individuals carry out to turn inputs into outputs in a specific environment (Goodhue, 1995; Goodhue \& Thompson, 1995). A task may contain different levels of detail and requirements relating to the technology supporting the task. The technology functionality element refers to the tools that individuals use to perform tasks or use to assist them in performing their tasks. Technologies may include computer systems (hardware, software, and data) and support services (training, HR policies, and IT support). The technology functionality relates to the environment where technology is used and what tasks it aims to support. This is the moderating element, as to achieve an improved performance the individuals need to use the technology to perform the task. Furthermore, the individual abilities represent the different characteristics of an individual that may influence how proficiently they use the technology to perform work tasks. This element relates to a person's internal resources, for example motivation, experience, and training in the use of different technologies (Goodhue \& Thompson, 1995).

The TTF component refers to the level to which technology assists users in accomplishing their work tasks. The task requirements, technology functionality, and individual abilities contribute to the level of TTF. The performance impacts represent the task accomplishment of an individual. A higher performance assumes a mixture of improved efficiency and effectiveness, and/or improved overall quality of the outputs (Goodhue \& Thompson, 1995).

\subsubsection{Utilisation}

Figure 4.1 represents the basic relationship between task, technology, individual abilities, tasktechnology fit, and performance, yet it does not involve the utilisation construct. Goodhue and Thompson (1995) suggest that the TTF perspective may gain from combining the TTF focus with utilisation, as this combination would allow pinpointing relevant aspects of technology impacts influencing the performance. Focusing solely on TTF excludes that technology needs to be used before reaching performance impacts, whereas focus placed only on utilisation would limit the understanding on how the technology influences performance (Goodhue \& Thompson, 1995).

However, utilisation is a complex aspect as elements other than TTF may influence it, and it may differ across organizations. Utilisation refers to the user behaviour, that is, frequency of use and the diversity of functionality applied when accomplishing tasks using a certain technology, and it considers user attitudes and beliefs when predicting the use of the technology. However, increased utilisation does not equal better performance. For example, utilisation of an 
unsupportive technology may still occur due to habits, social norms, ignorance, and other factors affecting the users, even when the use of technology is voluntary. Frequently, the utilisation of technology is a requirement of the job function rather than due to its functionality. In these situations, the utilisation construct does not need consideration as the performance impacts will highly depend on the TTF. A higher level of TTF may increase utilisation and lead to improved performance because the technology meets the needs of the task and the individual (Goodhue \& Thompson, 1995). On the contrary, in situations where the fit is poor and the technology does not support users while accomplishing tasks, the individuals will face distress and frustration with their performance (Goodhue, 1995). The inability to accomplish work tasks effectively when using technology may lead to distress tied to technology use, in other words, technostress (Ayyagari, Grover, \& Purvis, 2011).

Research has attempted to extend and combine the TTF model with other models to explain utilisation. For example, TTF has been extended using attitude and behaviour models which intend to explain user acceptance of technology (Kuo \& Lee, 2011). Dishaw (1999) suggests combining TTF with the technology acceptance model (TAM). While the two perspectives have overlapping properties, the TAM perspective focuses on user attitudes (i.e., perceived usefulness and ease of use) towards the use of a specific technology, which the TTF perspective does not consider. On the other hand, TTF includes a view on task characteristics, which the TAM perspective excludes. The combination of TTF and TAM may offer a more comprehensive understanding of the user attitudes towards a specific technology and the fit between technology functionality and the characteristics of the tasks than each of these perspectives taken separately (Dishaw, 1999). The combined perspectives have been widely used in research (e.g., Shih \& Chen, 2013; Pagani, 2006).

Furthermore, Strong, Dishaw, and Bandy (2006) argue for extending the TTF with a computer self-efficacy construct (CSE), where CSE is added as an individual characteristic. As a result, combining CSE and TTF would increase the explanatory power related to the utilisation of a specific technology. While the TTF perspective considers individual characteristics, CSE is linked to computer literacy (Strong et al., 2006). However, individual characteristics involve other aspects, for example experience, innovativeness, creativity, and willingness to try new things. The suggested CSE construct refers to an individual's judgement of own ability and competence when employing technology (Compeau, 1995) and claims that the users' judgement influences the utilisation of the technology (Strong et al., 2006). For example, a higher self-efficacy means that the individual has a high perception of their ability and might imply that the individual is willing to place more effort in task completion. Low self-efficacy, on the other hand, might affect the performance negatively and contribute to experiencing technostress.

\subsection{Technostress}

Technostress conceptualises the distress associated with the need to adapt to and use new digital technologies (Brod, 1984; Gaudioso, Turel, \& Galimberti, 2017; Vuori, Helander, \& Okkonen, 2019). Elevated technostress may contribute to dissatisfaction at work, job burnout, and poor performance (Fuglseth \& Sørebø, 2014; Gaudioso et al., 2017). Technostress stems from the presence and severity of factors contributing to technostress (i.e., techno-stressors), which to some degree are present in all organizations that engage technologies in accomplishing work tasks (Gaudioso et al., 2017; Srivastava, Chandra, \& Shirish, 2015). Techno-stressors - factors that contribute to technostress - are

1 Techno-invasion, i.e., mixing work and private time due to technology-supported connectivity.

2 Techno-overload, i.e., demands on working more and faster when using technology. 
3 Techno-complexity, i.e., steeper learning curve due to multifaceted and continuously changing technology.

4 Techno-insecurity, i.e., nervousness and insecurity in using and interacting with technologies due to lack of experience and training.

5 Techno-uncertainty, i.e. technology adoption in an organization leading to process reorganization or job replacement.

(Gaudioso et al., 2017; Tarafdar, Tu, Ragu-Nathan, E Ragu-Nathan, 2007)

Even though using technology may contribute to technostress, achieving an optimal fit between the technology functionality, tasks, and individual abilities would alleviate it (Ayyagari et al., 2011). Technology that enables individuals at work and promotes employee self-motivation and well-being will boost productivity and job satisfaction (Cascio \& Montealegre, 2016). On the contrary, in situations where the TTF is poor and technostress is present, individuals may engage in a coping process to minimise the distress. Transactional theory of stress and coping explains the process of appraisal and coping.

\subsection{Transactional theory of stress and coping}

The transactional theory of stress and coping (TTSC) explains the dynamic interplay of appraisal and coping processes when dealing with a situation where the placed demands are higher than the individuals' capacities to deal with them (Lazarus, 1966; Lazarus \& Folkman, 1984; Lazarus \& Folkman, 1987). The TTSC is among the most influential stress theories and has been applied in areas such as occupational safety and health (Brough, Drummond, \& Biggs, 2018), organizational change (Rafferty \& Griffin, 2006), organizational performance (Li, Chen, \& Lai, 2018), and work organization (Espedido, Searle, \& Griffin, 2020).

According to the TTSC, stress emerges in interactions between individuals and the environment. When an individual has trouble dealing with the demands, the interaction may cause a stress response. On the contrary, if an individual appraises the demands as manageable, they do not experience a stress response. The stress response lies in the individuals' subjective interpretation and in their ability to cope with the situation (Lazarus, 1966; Lazarus \& Folkman, 1984; Lazarus \& Folkman, 1987).

As presented in Figure 4.2, when the environment, for example the workplace, places demands that the individual perceives as too troublesome, their primary appraisal evaluates them as a potential threat to their well-being. The assessment of a potential threat engages the secondary appraisal, where the individual evaluates options for dealing with the situation. Depending on the appraisal, individuals experience a different emotional response, such as anger, worry, or excitement. The primary appraisal continuously informs the secondary appraisal and vice versa.

To respond to the environmental demand and minimise stress, individuals engage in a coping process informed by the secondary appraisal. In some situations, coping may not lead to an outcome or may take a maladaptive form. If individuals cannot reach an outcome, they may engage in a reappraisal process where they reframe their viewpoint on the demands, or otherwise, the individual may need external support such as training or coaching.

\subsubsection{Coping with unsupportive technology}

If individuals perceive the technology to be unsupportive in their task accomplishment and, as a result, impeding their work outcomes, they may face distress and appraise the situation as a 


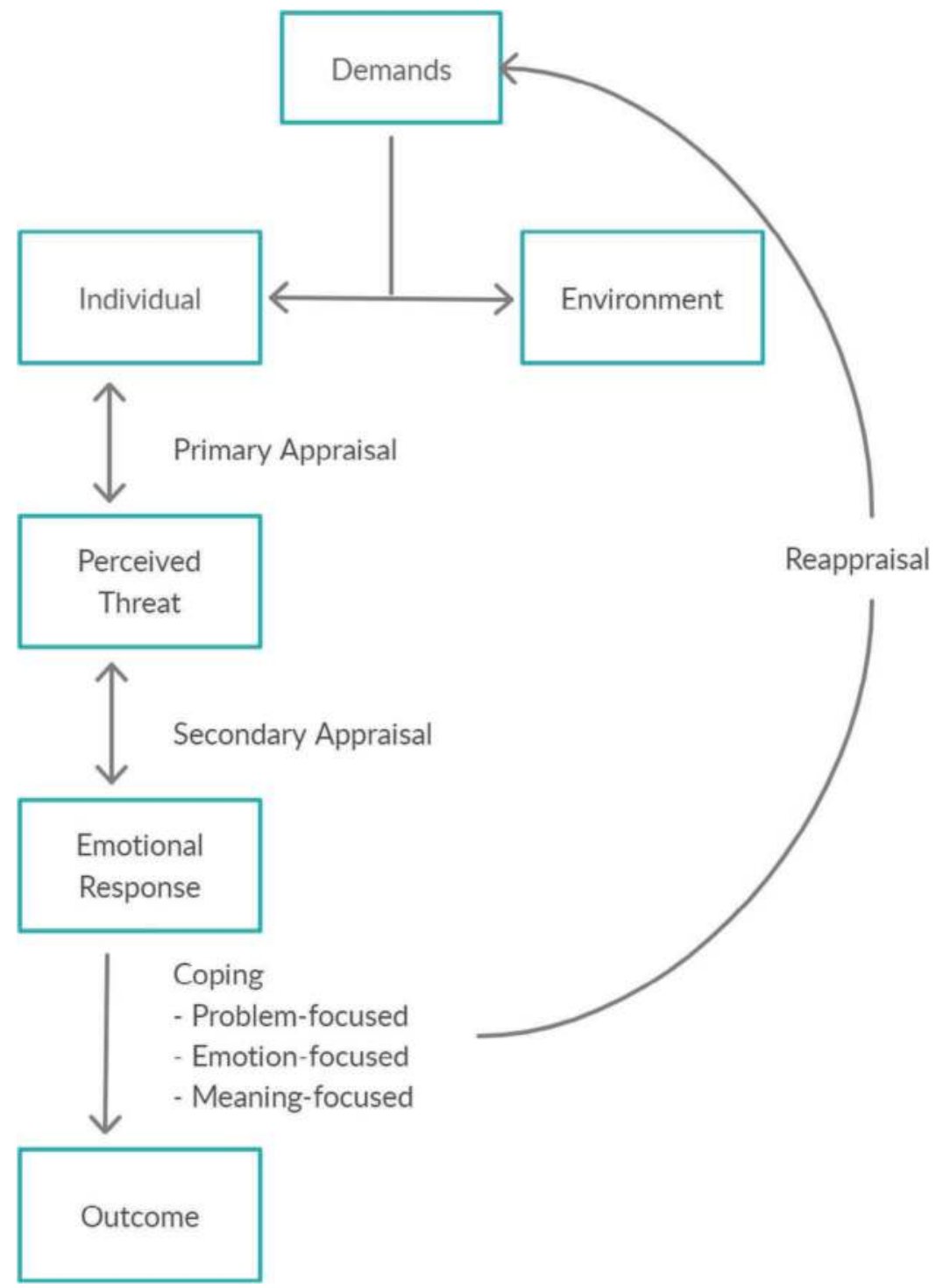

Figure 4.2 Elements and processes in the TTSC

potential threat to their well-being at work (Fuglseth \& Sørebø, 2014). In turn, the perception of a threat will initiate the coping process to alleviate distress.

The appraisal of a threat is more likely in those situations in which individuals have assigned high personal significance yet have low control over the circumstances (e.g., cannot accomplish work tasks other than by using the specific technology, see also Chapter 11 Two-Process Theory of Perceived Control). Dissatisfaction and the appraisal of a threat may trigger an emotional response, such as fear, worry, anxiety, and anger. On the contrary, if individuals assign high personal significance yet have high control (e.g., can select other means for accomplishing tasks), 
the situation is appraised rather as a challenge and individuals instead may experience feelings of excitement and eagerness (Folkman, 2013; Lazarus \& Folkman, 1987).

The appraisal of a threat, challenge, or harm initiates coping behaviours, that is, individuals exhibit behavioural and emotional effort to find potential options and resources for dealing with the demanding situation (Gaudioso et al., 2017; Lazarus \& Folkman, 1984; Tarafdar et al., 2007). Coping can take adaptive or maladaptive forms. For example, reaching out to colleagues to ask for help in learning the functions of the unsupportive technology classifies as adaptive coping. Whereas avoiding the use of technology, complaining, and blaming others classify as maladaptive coping (Gaudioso et al., 2017). The way individuals cope depends on their psychological, social, environmental, and material resources, as well as on the nature of the situation, and whether the individual has control over the outcomes or has to accept what is happening (Folkman, 2013).

When engaging with unsupportive technology, individuals may use different coping strategies. There are three main types of coping - problem-focused, emotion-focused, and meaningfocused - that individuals apply in troublesome situations (Folkman, 2013; Lazarus \& Folkman, 1987). Problem-focused coping attempts to alter the situation, emotion-focused coping seeks to regulate emotions, and meaning-focused coping concerns situations that cannot be changed and require reappraisal, that is, accepting the circumstances or seeking to have a more positive outlook (see Table 4.1). People tend to use multiple coping strategies interchangeably and at the same time, and tailor them to a specific task or goal to reach the desired outcome. Coping is contextual, and the ways of coping may change over time as a situation evolves in the environment or due to internal changes (Folkman, 2013; Lazarus, 1993).

The appraisal, coping, and reappraisal processes persist until the stressful situation is addressed, resolved, or terminated (Gage, 1992) or the individual has reassessed the situation and reframed thoughts about the demands (i.e., sees the situation in a different light) to reframe the emotional impact (Gross, 1998; Troy, 2013). This sequence repeats once another stressful event is anticipated or encountered. These processes vary from one person to another due to differences in their internal and external resources, for example one person may perceive working with an unsupportive technology as more stressful than another may perceive it, even when the occurring situation is the same for both (Ipsen \& Jensen, 2012). The outcome of the appraisal and

Table 4.1 Overview of coping types

\begin{tabular}{|c|c|c|c|}
\hline & Problem-focused coping & $\begin{array}{l}\text { Emotion-focused or cognitive } \\
\text { coping }\end{array}$ & Meaning-focused coping \\
\hline Purpose & $\begin{array}{l}\text { To change the relationship } \\
\text { between the affected } \\
\text { person and the } \\
\text { environment }\end{array}$ & $\begin{array}{l}\text { To regulate emotional } \\
\text { distress }\end{array}$ & To sustain well-being \\
\hline $\begin{array}{c}\text { Adaptive and } \\
\text { maladaptive } \\
\text { strategies }\end{array}$ & $\begin{array}{l}\text { Information gathering, } \\
\text { learning, advice seeking, } \\
\text { relying on previous } \\
\text { experiences, negotiation, } \\
\text { problem-solving, } \\
\text { intellectualisation }\end{array}$ & $\begin{array}{l}\text { Distancing, humour, seeking } \\
\text { social support, avoidance, } \\
\text { denial, escaping the } \\
\text { situation, resignation, } \\
\text { blaming others, venting, } \\
\text { aggression, suppression }\end{array}$ & $\begin{array}{l}\text { Focusing on values, } \\
\text { beliefs, and goals, } \\
\text { reappraising situations } \\
\text { more positively, } \\
\text { appreciating positive } \\
\text { moments daily }\end{array}$ \\
\hline Use & Controllable situations & $\begin{array}{l}\text { Situations that have to be } \\
\text { accepted }\end{array}$ & $\begin{array}{l}\text { Situations that are } \\
\text { chronic and not } \\
\text { resolvable }\end{array}$ \\
\hline
\end{tabular}


Table 4.2 Approaches to stress interventions

\begin{tabular}{|c|c|c|c|}
\hline Level & Primary & Secondary & Tertiary \\
\hline Goal & $\begin{array}{l}\text { Removing risk factors } \\
\text { leading to stress and/or } \\
\text { reducing the intensity of } \\
\text { the risk factors }\end{array}$ & $\begin{array}{l}\text { Helping employees to modify } \\
\text { challenges and understand } \\
\text { how to respond to stress } \\
\text { symptoms }\end{array}$ & $\begin{array}{l}\text { Treating stress and reducing } \\
\text { damaging consequences } \\
\text { by helping to cope } \\
\text { efficiently }\end{array}$ \\
\hline Focus & Organization & $\begin{array}{l}\text { The interplay of individual } \\
\text { and organization }\end{array}$ & Individual \\
\hline Examples & $\begin{array}{l}\text { Redesign in work processes, } \\
\text { alterations in the work } \\
\text { environment, supportive } \\
\text { processes, new incentive } \\
\text { systems, role clarification, } \\
\text { recognition }\end{array}$ & $\begin{array}{l}\text { Stress management, wellness } \\
\text { programs, training in } \\
\text { coping strategies }\end{array}$ & $\begin{array}{l}\text { Return-to-work programs, } \\
\text { therapy, counselling, } \\
\text { medicine }\end{array}$ \\
\hline
\end{tabular}

Source: (Cooper, Dewe, \& O’Driscoll, 2001)

coping for a particular person in one situation may predict their appraisal and coping tendencies in another situation (Folkman, 2013).

Dedicated stress interventions can help individuals cope with the demands placed upon them and prevent and minimise work-related stress, including technostress (Ipsen \& Jensen, 2012). Prevention of work-related stress includes three levels (see Table 4.2). Primary intervention strategies focus on organizational changes and are the most appropriate when aiming to reduce work-related stress with a long-term preventative approach. Secondary strategies seek to adjust to challenges by acting on the interplay between individuals and organizations. Finally, tertiary intervention strategies are reactive as they focus on fixing stress outcomes instead of acting upon the basic organizational stressors.

\section{Applicability to workplace studies}

The introduction of new digital technologies has offered possibilities for finding new ways of working, new products, and services. Digital technologies allow knowledge workers to work flexibly and remotely thanks to practices such as telework, commuter hubs, and virtual teams, by combining distance work and management across time and geography. While a well-designed and -managed flexible and remote workplace can have a positive influence on employee wellbeing (Arnold et al., 2016; Dickson-Swift, Fox, Marshall, Welch, \& Willis, 2014; Hoeven \& Zoonen, 2015), the ability to implement new work practices is not always straightforward. When not managed appropriately, flexible and remote workplaces can be a source of workrelated stress and harm individuals, organizations, and the economy as a whole through, for example, productivity losses, presenteeism, and absence (Arnold et al., 2016; Cooper et al., 2001; Ipsen, Karanika-Murray, \& Nardelli, 2020). Furthermore, the lack of exploration of the TTF may contribute to wasted resources on underutilised technology (Dishaw, 1999).

On the one hand, the TTF theory aims to support organizations in investigating the factors affecting the effective adoption of technology they are planning to implement in their organization. Workplace management researchers have also employed the theory to investigate how to implement, manage, and maintain technology with positive results in terms of organizational performance and individual well-being (e.g., Cameron \& Webster, 2005; Chen, Zhao, Zhang, Wang, \& Guo, 2015; Hung, Duyen, Kong, \& Chua, 2008). 
On the other hand, workplace research can apply the TTSC in assisting individuals and equipping them with skills and resources that would allow them to cope better with stressors at work. Across professions, individuals experience different demands that affect their well-being with consequences for their psychological and physical health. These demands may relate to high workload, tight deadlines and time pressure, working with complicated or unsupportive technology, the blurring of boundaries between work and private life due to constant connectivity, the level of control in one's job, and relations to colleagues and organizational climate, which are all potential stressors. The heterogeneity in the stressors that different professions experience is related to the characteristics of the tasks they need to perform and of the overall work situation.

The TTSC explains why some individuals are more effective than others are when dealing with environmental demands. However, while people tend to have different responses to demands, organizations are responsible for providing support and training in both technology use and adaptive coping strategies to reach more positive work outcomes. Therefore, we propose to apply and test the conceptual framework in Figure 4.3 through action research to investigate how organizations do and should handle technostress. To do so, workplace action researchers should start by identifying the risk of technostress in the workplace they are investigating. They should then investigate the nature and significance of technostress within each context to generate scientific insight on technostress management. At the same time, workplace action researchers should develop concrete interventions with organizations to provide technical support and training workshops, while cultivating collaboration and knowledge sharing among team members.

While the TTSC focus on the individual responses to stress, the TTF theory focuses on establishing a fit between the task, the technology, and its users. Therefore, by combining the two theories, we propose to take an organizational perspective to investigate how organizations can prevent technostress independently of individuals' ability to cope with it. Furthermore, we propose to adopt a collaborative approach to test how the combined theories help to deal with workplace management issues, such as technostress. In combination, the TTF theory and TTSC can help to investigate the implementation of new technologies in workplaces to minimise technostress (Figure 4.3).

In Figure 4.3, the implementation of new technology in a workplace creates a demand in the interactions between the environment (workplace) and the individual (employee). If the use of the new technology is crucial for employees to perform and accomplish tasks (their primary appraisal may detect a potential threat, and they may feel threatened or challenged by the change or it may remind them of a loss experienced in the past) (Arnold et al., 2016; Mayes \& Ganster, 1988). For example, employees may foresee the specific demands that the new technology places on them (i.e., techno-stressors) and struggle to cope with both the requirements and the advancing technologies, thereby experiencing technostress (Mahapatra \& Pillai, 2018).

\section{Methodology/research approach: action research}

Research within applied areas such as workplace research embeds the complexity of the practical world of organizations and people. Applied researchers thus face the challenge of finding appropriate ways to create value for both academia and practice, bridging the gap between scientific validity and practical relevance (Van de Ven, 2007). Action researchers can close this gap by establishing a close collaboration with industry and emphasising real-life issues as research topics (Coughlan, Draaijer, Godsell, \& Boer, 2016). Through the active interaction between researchers and practitioners, action research focuses on both facilitating organizational solutions to concrete problems and generating scientific knowledge (Cirella, Guerci, \& Shani, 2012). 


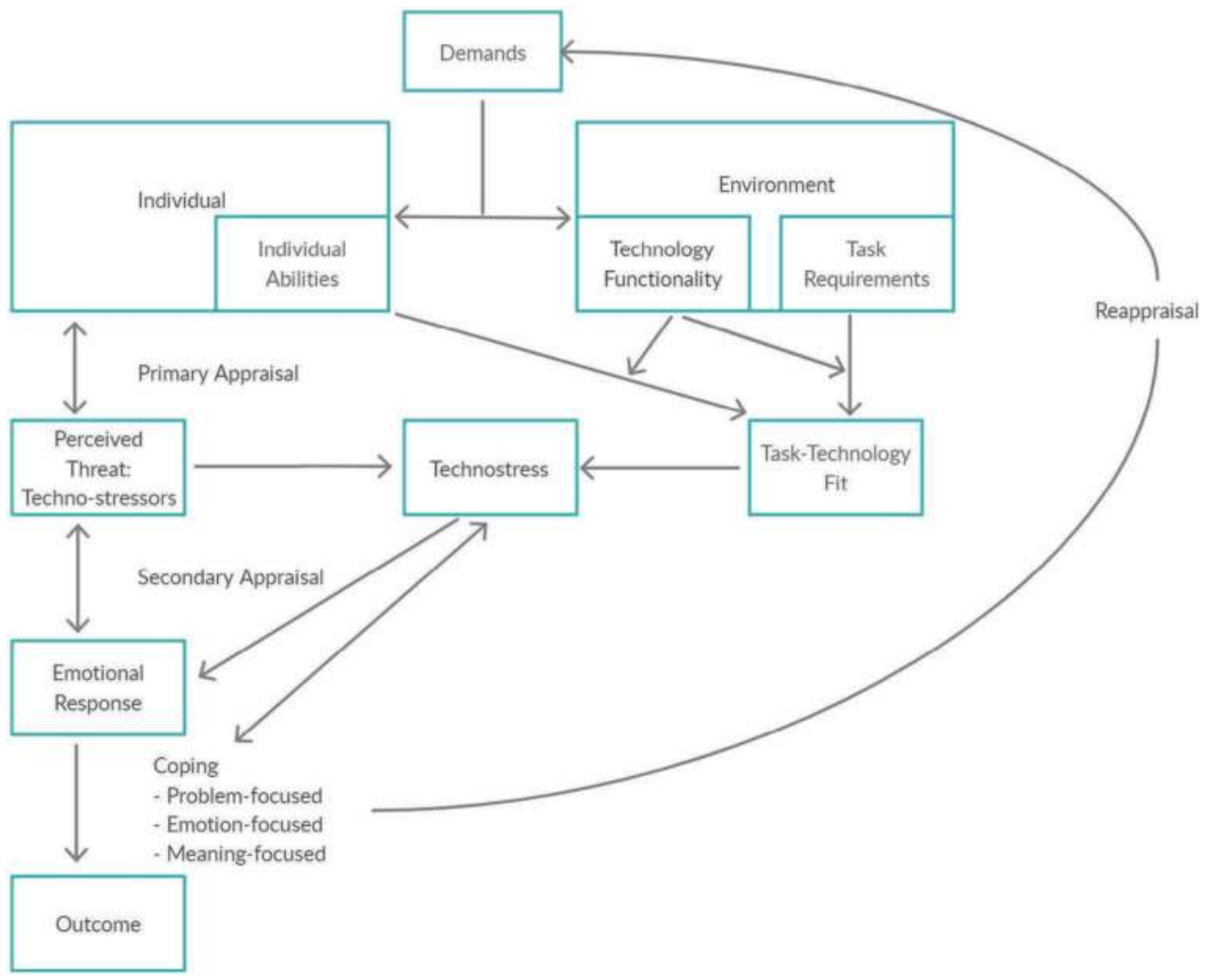

Figure 4.3 Conceptual framework combining TTF with the TTSC

Action researchers enable system changes and/or support new initiatives in organizations through interventions that they plan and implement together with organizational participants. The role of action researchers is threefold: (1) to facilitate the inquiry process by feeding scientific knowledge into the interventions; (2) to facilitate the ongoing learning process through reflection exercises; and (3) to establish and maintain ongoing engagement with the senior management of the organization (Cirella et al., 2012). Action researchers collect data from multiple sources, from participant observation to interviews and workshops with multiple organizational actors, and interpret them by creating shared meaning with fellow researchers and research participants (Coughlan et al., 2016).

Action researchers participate in collaborative communities with practitioners on equal terms. To develop actionable solutions that are both theoretically and practically relevant through engagement with practice, action research combines theory and practice with action and reflection (Bergman, Hellström, Lifvergren, \& Gustavsson, 2015). For example, insider action research involves interventions that either aim at pragmatic outcomes (e.g., the management of change and problem resolution) or at studying the inquiry process to change it (e.g., through increasingly intensive learning in action) (Coghlan, 2001, 2003).

In workplace research, action research can enable combining the TTF with the TTSC theory for studying the effects of implementing new technologies on employee well-being. Combining the two theories in the conceptual framework enables workplace researchers to investigate 
how organizational decision-making on new technology implementation affects employee wellbeing. Yet dedicated empirical research should investigate the processes and interrelationship between variables that we propose in the combined framework as they occur in praxis.

Although emphasising that organizations can influence individual stress and coping processes, the framework that we propose in this chapter does not include change management variables, such as managerial expectations of employee behaviour, communication of demands, and consequent employee reactions. Future workplace research should look at how managerial expectations and communication of demands affect experienced technostress and employee well-being in general. Furthermore, while the chapter emphasises technostress as a workplace issue, this is just one aspect of the work-related stress that knowledge workers experience. Future research should look into the intertwining of technostress with other types of work-related stress and their effects on employee well-being and organizational performance.

\subsection{Participatory changes in the daily practices}

Involving employees in the research process can promote organizational learning and catalyse change from within an organization (Rosskam, 2009; Schnall, Dobson, \& Rosskam, 2009). Thus, we suggest participatory action research (PAR) as an alternative approach to examining workplaces as opposed to viewing employee health outcomes as the outcome of individual behaviours or as the result of single work tasks or exposures from new technologies.

PAR is an action research approach centred on the interaction between researchers and practitioners. This approach incorporates a systematic effort to generate knowledge about specific conditions that can influence changes in each situation and aims at lessening psychosocial risks in the workplace, especially if they result from managerial and employee disagreements (Dollard, Le Blanc, \& Cotton, 2008). PAR involves the participants in all phases of the change project and acts as a suitable method to overcome challenges through a continuous dialogue.

By adopting a PAR approach while investigating how organizational decision-making on new technology implementation affects employee well-being, workplace researchers can strengthen the interaction between researchers and practitioners, generate knowledge that is both valid and relevant, and have a tangible effect on technostress in organizations.

\section{Limitations}

The main limitation of the TTF theory refers to it addressing the present moment of fit. Tasks may become more demanding over time, and the technology might not have the required functionality to assist the users, which can promote technostress. Since TTF does not address changes over time, it limits the predictive potential of a specific technology in the workplace (Fuller, 2009). As a result, the TTF needs continuous reassessment, yet the optimal frequency of evaluations is not evident.

The appraisal and coping process represented by the TTSC vary from one person to another and may not always be visible and thus recognised. Identifying and recognising the appraisal and coping processes in individuals requires close management attention and the ability to empathise with individuals and their situation. Acknowledging how individuals react to a situation and whether they engage in the coping process may be covert unless shared openly. Coping processes may look different in different situations, which means that it would be presumptuous to assign patterns and assume a certain response informed by the past. Furthermore, coping in a demanding situation may not always be the solution; sometimes there may be a need for management interference to minimise stressors in the workplace. 


\section{Theory relevance to practice}

Knowledge workers largely rely on digital technology use for knowledge sharing, yet managers tend to forget to consider the effects of technologies on employee well-being (Cascio \& Montealegre, 2016). The proposed conceptual framework and action research approach can benefit practitioners by highlighting three concrete actions that organizations and workplace managers can implement to prevent and minimise technostress and improve user satisfaction: (1) building awareness, (2) reducing techno-stressors, and (3) embracing adaptive coping mechanisms.

\subsection{Building awareness}

Organizations should (1) acknowledge that technostress affects individuals and organizations alike, yet in different ways; (2) assess the degree to which technostress is present in their organization, for example by using scale items suggested by Gaudioso et al. (2017); and (3) consider techno-stressors both individually and in combination (Brivio et al., 2018; Gaudioso et al., 2017; Tarafdar et al., 2007). Additionally, managers should pay special attention to people affected by the implementation of new technology in workplaces and design the technology implementation process accordingly. Managers should map employees who use the new technology to accomplish important work tasks, their abilities, and the tasks they need to perform. These employees, in fact, are especially at risk of experiencing technostress as the newly implemented technology directly affects their work.

\subsection{Reducing techno-stressors}

Although reducing techno-stressors in workplaces may be a difficult task, organizations can implement multiple methods and approaches to minimise technostress effects and support employee well-being. Mitigation strategies include adequate training, assigning time for learning to use new technologies, and providing a high-quality help desk (Fuglseth \& Sørebø, 2014). Managers should also consider not overwhelming employees with more new tools to work with at the same time as it may contribute to technostress (Gaudioso et al., 2017).

Furthermore, organizations may consider assessing the fit between the task, the technology, and the individual abilities before implementing new technology in workplaces as well as measuring TTF over time. By applying the TTF theory, organizations can assess the impact of technology and thus foresee employee responses to the new technology. For example, organizations can evaluate the TTF of technology by assessing eight TTF components (Table 4.3) to predict the performance and effectiveness of a specific technology. This process allows highlighting the problem areas more thoroughly, and it informs the management of potential corrective action (Goodhue, 1995; Goodhue \& Thompson, 1995).

Goodhue and Thompson (1995) expand further on the task-technology measures organized around the eight components presented in Table 4.3. Responding to these measures will allow pinpointing the degree of TTF of a specific technology used for task accomplishment.

\subsection{Embracing adaptive coping mechanisms}

Employees may also minimise possible negative outcomes by reducing their maladaptive coping strategies and adopting coping strategies that focus on proactive problem-solving instead. For example, employees can focus on learning how to use the new technology, asking colleagues for help, and searching for instructions that are specific to their abilities and assigned tasks. 
Table 4.3 TTF measurement components

\begin{tabular}{ll}
\hline Focus & Components of measuring TTF \\
\hline Meeting task needs for using data in decision-making & Data quality \\
& Data locability \\
& Authorisation \\
& Data compatibility \\
& Usability and training \\
Meeting daily operational needs & Timeliness in meeting (scheduled) operations \\
Responding to shifting business needs & Systems reliability \\
\hline
\end{tabular}

Organizations and managers may assist employees in embracing adaptive coping mechanisms by introducing initiatives that focus on explaining technostress, techno-stressors, and relevant adaptive coping strategies. Moreover, organizations and managers should explain how and in which situations to adopt these strategies. Managers can teach adoption of these strategies through initiatives, such as employee training, job redesign, reward mechanisms, and interventions focusing on reducing techno-stressors (Gaudioso et al., 2017). Furthermore, organizations may analyse what type of coping strategies could be most optimal for different situations and technologies and seek to train employees to adopt these strategies through incentive systems or training programs.

\section{Further reading}

- Ayyagari, R. (2012). Impact of information overload and task-technology fit on technostress. SAIS 2012 Proceedings. Retrieved from https://aisel.aisnet.org/sais2012/4

- Tarafdar, M., Pullins, E. B., \& Ragu-Nathan, T. S. (2015). Technostress: Negative effect on performance and possible mitigations. Information Systems Journal, 25(2), 103-132. https:// doi.org/10.1111/isj.12042

- Tarafdar, M., Tu, Q., \& Ragu-Nathan, T. S. (2010). Impact of technostress on end-user satisfaction and performance. Journal of Management Information Systems, 27(3), 303-334. https:// doi.org/10.2753/MIS0742-1222270311

- Zhao, X., Xia, Q., \& Huang, W. (2020). Impact of technostress on productivity from the theoretical perspective of appraisal and coping processes. Information $\&$ Management, 103265. https://doi.org/10.1016/j.im.2020.103265

\section{References}

Arnold, J., Randall, R., Randall, F., Silvester, J., Robertson, I., Harris, D., . . \& Axtell, C. (2016). Work psychology: Understanding human behaviour in the workplace (6th ed.). Pearson Education.

Ayyagari, R., Grover, V., \& Purvis, R. (2011). Technostress: Technological antecedents and implications. Management Information Systems Quarterly, 35(4), 831-858. https://doi.org/10.2307/41409963

Bere, A. (2018). Applying an extended task-technology fit for establishing determinants of mobile learning: An instant messaging initiative. Journal of Information Systems Education, 29(4), 239-252.

Bergman, B., Hellström, A., Lifvergren, S., \& Gustavsson, S. M. (2015). Rejoinder. Quality Engineering, 27(1), 41-43. https://doi.org/10.1080/08982112.2015.968045

Brivio, E., Gaudioso, F., Vergine, I., Mirizzi, C. R., Reina, C., Stellari, A., \& Galimberti, C. (2018). Preventing technostress through positive technology. Frontiers in Psychology, 9. https://doi.org/10.3389/ fpsyg.2018.02569

Brod, C. (1984). Technostress: The human cost of the computer revolution. Reading, MA: Addison-Wesley. 
Brough, P., Drummond, S., \& Biggs, A. (2018). Job support, coping, and control: Assessment of simultaneous impacts within the occupational stress process. Journal of Occupational Health Psychology, 23(2), 188-197. https://doi.org/10.1037/ocp0000074

Cameron, A. F., \& Webster, J. (2005). Unintended consequences of emerging communication technologies: Instant messaging in the workplace. Computers in Human Behavior, 21(1), 85-103. https://doi. org/10.1016/j.chb.2003.12.001

Cascio, W. F., \& Montealegre, R. (2016). How technology is changing work and organizations. Annual Review of Organizational Psychology and Organizational Behavior, 3(1), 349-375. https://doi.org/10.1146/ annurev-orgpsych-041015-062352

Chen, G., Zhao, Y., Zhang, N., Wang, F., \& Guo, X. (2015). Task-technology fit in workplaces: Theoreti$\mathrm{cal}$ framework and empirical analysis in the context of mobile government. International Journal of Mobile Communications, 13(5), 455. https://doi.org/10.1504/IJMC.2015.070960

Cirella, S., Guerci, M., \& Shani, A. B. (Rami). (2012). A process model of collaborative management research: The study of collective creativity in the luxury industry. Systemic Practice and Action Research, 25(3), 281-300. https://doi.org/10.1007/s11213-011-9220-x

Coghlan, D. (2001). Insider action research projects: Implications for practising managers. Management Learning, 32(1), 49-60. https://doi.org/10.1177/1350507601321004

Coghlan, D. (2003). Practitioner research for organizational knowledge: Mechanistic- and organisticoriented approaches to insider action research. Management Learning, 34(4), 451-463. https://doi. org/10.1177/1350507603039068

Compeau, D. R. (1995). Computer self-efficacy: Development of a measure and initial test. Management Information Systems Quarterly, 19(2), 189-211. https://doi.org/10.2307/249688

Cooper, C., Dewe, P., \& O’Driscoll, M. (2001). Organizational stress: A review and critique of theory, research, and applications. Thousand Oaks, CA: SAGE Publications, Inc. https://doi.org/10.4135/9781452231235

Coughlan, P., Draaijer, D., Godsell, J., \& Boer, H. (2016). Operations and supply chain management: The role of academics and practitioners in the development of research and practice. International Journal of Operations \& Production Management, 36(12), 1673-1695. https://doi.org/10.1108/ IJOPM-11-2015-0721

Dickson-Swift, V., Fox, C., Marshall, K., Welch, N., \& Willis, J. (2014). What really improves employee health and wellbeing: Findings from regional Australian workplaces. International Journal of Workplace Health Management, 7(3), 138-155. https://doi.org/10.1108/IJWHM-10-2012-0026

Dishaw, M. T. (1999). Extending the technology acceptance model with task-technology fit constructs. Information and Management, 36(1), 9-21. https://doi.org/10.1016/S0378-7206(98)00101-3

Dollard, M. F., Le Blanc, P. M., \& Cotton, S. J. (2008). Participatory action research as work stress intervention. In The individual in the changing working life (pp. 353-379). Cambridge: Cambridge University Press. https://doi.org/10.1017/CBO9780511490064.017

Espedido, A., Searle, B. J., \& Griffin, B. (2020). Peers, proactivity, and problem-solving: A multilevel study of team impacts on stress appraisals of problem-solving demands. Work \& Stress, 34(3), $219-237$. https://doi.org/10.1080/02678373.2019.1579767

Folkman, S. (2013). Stress: Appraisal and coping. In M. D. Gellman \& J. R. Turner (Eds.), Encyclopedia of behavioral medicine (pp. 1913-1915). New York: Springer. https://doi.org/10.1007/978-1-4419-1005-9_215

Fuglseth, A. M., \& Sørebø, Ø. (2014). The effects of technostress within the context of employee use of ICT. Computers in Human Behavior, 40, 161-170. https://doi.org/10.1016/j.chb.2014.07.040

Fuller, R. M. (2009). Does fit matter? The impact of task-technology fit and appropriation on team performance in repeated tasks. Information Systems Research, 20(1), 2-17. https://doi.org/10.1287/ isre.1070.0167

Gage, M. (1992). The appraisal model of coping: An assessment and intervention model for occupational therapy. American Journal of Occupational Therapy, 46(4), 353-362. https://doi.org/10.5014/ajot.46.4.353

Gaudioso, F., Turel, O., \& Galimberti, C. (2017). The mediating roles of strain facets and coping strategies in translating techno-stressors into adverse job outcomes. Computers in Human Behavior, 69, $189-196$. https://doi.org/10.1016/j.chb.2016.12.041

Gebauer, J., Shaw, M. J., \& Gribbins, M. L. (2010). Task-technology fit for mobile information systems. Journal of Information Technology, 25(3), 259-272. https://doi.org/10.1057/jit.2010.10

Goodhue, D. L. (1995). Understanding user evaluations of information systems. Management Science, 41(12), 1827. https://doi.org/10.1287/mnsc.41.12.1827

Goodhue, D. L., Klein, B. D., \& March, S. T. (2000). User evaluations of IS as surrogates for objective performance. Information E Management, 38(2), 87-101. https://doi.org/10.1016/S0378-7206(00)00057-4 
Goodhue, D. L., \& Thompson, R. L. (1995). Task-technology fit and individual performance. Management Information Systems Quarterly. https://doi.org/10.2307/249689

Gross, J. J. (1998). The emerging field of emotion regulation: An integrative review: Review of General Psychology. https://doi.org/10.1037/1089-2680.2.3.271

Hoeven, C. L. ter., \& Zoonen, W. van. (2015). Flexible work designs and employee well-being: Examining the effects of resources and demands. New Technology, Work and Employment, 30(3), 237-255. https:// doi.org/10.1111/ntwe.12052

Hung, Y.-T. C., Duyen, N. T. T., Kong, W.-C., \& Chua, A.-L. (2008). Reexamining media capacity theories using workplace instant messaging. IEEE Transactions on Professional Communication, 51(4), 352-368. https://doi.org/10.1109/TPC.2008.2007861

Ipsen, C., \& Jensen, P. L. (2012). Organizational options for preventing work-related stress in knowledge work. International Journal of Industrial Ergonomics, 42(4), 325-334. https://doi.org/10.1016/j. ergon.2012.02.006

Ipsen, C., Karanika-Murray, M., \& Nardelli, G. (2020). Addressing mental health and organisational performance in tandem: A challenge and an opportunity for bringing together what belongs together. Work and Stress, 34(1), 1-4. https://doi.org/10.1080/02678373.2020.1719555

Kuo, R.-Z., \& Lee, G.-G. (2011). Knowledge management system adoption: Exploring the effects of empowering leadership, task-technology fit and compatibility. Behaviour E Information Technology, 30(1), 113-129. https://doi.org/10.1080/0144929X.2010.516018

Lazarus, R. S. (1966). Psychological stress and the coping process. New York: McGraw-Hill.

Lazarus, R. S. (1993). From psychological stress to the emotions: A history of changing outlooks. Annual Review of Psychology, 44(1), 1-22. https://doi.org/10.1146/annurev.ps.44.020193.000245

Lazarus, R. S., \& Folkman, S. (1984). Stress, appraisal, and coping. New York: Springer Publishing Company.

Lazarus, R. S., \& Folkman, S. (1987). Transactional theory and research on emotions and coping. European Journal of Personality, 1(3), 141-169. https://doi.org/10.1002/per.2410010304

Lee, C.-C., Cheng, H. K., \& Cheng, H.-H. (2007). An empirical study of mobile commerce in insurance industry: Task-technology fit and individual differences. Decision Support Systems, 43(1), 95-110. https://doi.org/10.1016/j.dss.2005.05.008

Li, F., Chen, T., \& Lai, X. (2018). How does a reward for creativity program benefit or frustrate employee creative performance? The perspective of transactional model of stress and coping. Group E Organization Management, 43(1), 138-175. https://doi.org/10.1177/1059601116688612

Mahapatra, M., \& Pillai, R. (2018). Technostress in organizations: A review of literature. European Conference on Information Systems (ECIS 2018) [Research Papers]. Portsmouth, UK. Retrieved from https:// aisel.aisnet.org/ecis2018_rp/99

Mayes, B. T., \& Ganster, D. C. (1988). Exit and voice: A test of hypotheses based on fight/flight responses to job stress. Journal of Organizational Behavior, 9(3), 199-216. https://doi.org/10.1002/job.4030090302

McGill, T. J., \& Klobas, J. E. (2009). A task: Technology fit view of learning management system impact. Computers \& Education, 52(2), 496-508. https://doi.org/10.1016/j.compedu.2008.10.002

Pagani, M. (2006). Determinants of adoption of high speed data services in the business market: Evidence for a combined technology acceptance model with task technology fit model. Information and Management (Amsterdam), 43(7), 847-860. https://doi.org/10.1016/j.im.2006.08.003

Rafferty, A. E., \& Griffin, M. A. (2006). Perceptions of organizational change: A stress and coping perspective. Journal of Applied Psychology, 91(5), 1154-1162. https://doi.org/10.1037/0021-9010.91.5.1154

Rosskam, E. (2009). Using participatory action research methodology to improve worker health. In Unhealthy work: Causes, consequences, cures (pp. 211-228). New York: Baywood Publishing Co.

Schnall, P. L., Dobson, M., \& Rosskam, E. (2009). Unhealthy work: Causes, consequences, cures. New York: Baywood Publishing Co.

Shih, Y.-Y., \& Chen, C.-Y. (2013). The study of behavioral intention for mobile commerce: Via integrated model of TAM and TTF. Quality \& Quantity, 47(2), 1009-1020. https://doi.org/10.1007/ s11135-011-9579-x

Spies, R., Grobbelaar, S., \& Botha, A. (2020). A scoping review of the application of the task-technology fit theory. In M. Hattingh, M. Matthee, H. Smuts, I. Pappas, Y. K. Dwivedi, \& M. Mäntymäki (Eds.), Responsible design, implementation and use of information and communication technology (pp. 397-408). Cham: Springer International Publishing. https://doi.org/10.1007/978-3-030-44999-5_33

Srivastava, S. C., Chandra, S., \& Shirish, A. (2015). Technostress creators and job outcomes: Theorising the moderating influence of personality traits. Information Systems Journal, 25(4), 355-401. https://doi. org/10.1111/isj.12067 


\section{Task-technology fit theory}

Strong, D. M., Dishaw, M. T., \& Bandy, D. B. (2006). Extending task technology fit with computer selfefficacy. ACM SIGMIS Database: The DATABASE for Advances in Information Systems, 37(2-3), 96-107. https://doi.org/10.1145/1161345.1161358

Tarafdar, M., Tu, Q., Ragu-Nathan, B. S., \& Ragu-Nathan, T. S. (2007). The impact of technostress on role stress and productivity. Journal of Management Information Systems, 24(1), 301-328. https://doi. org/10.2753/MIS0742-1222240109

Troy, A. S. (2013). A person-by-situation approach to emotion regulation: Cognitive reappraisal can either help or hurt, depending on the context. Psychological Science, 24(12), 2505-2514. https://doi.org/10.1177/ 0956797613496434

Van de Ven, A. H. (2007). Engaged scholarship: A guide for organizational and social research. Oxford: Oxford University Press.

Vanduhe, V. Z., Nat, M., \& Hasan, H. F. (2020). Continuance intentions to use gamification for training in higher education: Integrating the technology acceptance model (TAM), social motivation, and task technology fit (TTF). IEEE Access, 8, 21473-21484. https://doi.org/10.1109/ACCESS.2020.2966179

Vuori, V., Helander, N., \& Okkonen, J. (2019). Digitalization in knowledge work: The dream of enhanced performance. Cognition, Technology \& Work, 21(2), 237-252. https://doi.org/10.1007/s10111-018-0501-3

Zigurs, I., \& Buckland, B. K. (1998). A theory of task/technology fit and group support systems effectiveness. MIS Quarterly, 22(3), 313-334. https://doi.org/10.2307/249668

Zigurs, I., \& Khazanchi, D. (2008). From profiles to patterns: A new view of task-technology fit. Information Systems Management, 25(1), 8-13. https://doi.org/10.1080/10580530701777107 


\title{
5 \\ ACTION REGULATION THEORY
}

\author{
Lukas Windlinger*1
}

\section{Background}

The Hawthorne experiments (Roethlisberger \& Dickson, 1939) are a milestone in social science. ${ }^{2}$ The investigators set out to understand the effects of illumination on workers' performance. A group of selected employees moved to a specially prepared space and worked under varying lighting conditions. The results were surprising: regardless of the direction and magnitude of change in lighting, the work output of the employees increased. These results led to a seminal series of studies concerning the relationships between employers and employees. The investigators realised that the special experimental setup and effects of the social situation, such as informal relationships between employees and investigators, were crucial for the understanding of the results. The focus of the investigations thus was shifted from the work environment to the social relations. It was concluded that the physical environment at work was relatively unimportant regarding workers' performance.

This conclusion, however, is based on the oversimplified assumption that there is a direct cause-and-effect relationship between physical conditions and human behaviour. Because workers' output was not improved by changes in lighting levels but by social relations, the investigators assumed that light levels were irrelevant to performance. Psychologists now know that there are complex cognitive processes that mediate the effects of physical conditions on human behaviour (Frese \& Zapf, 1994; McGrath, 1976; Miller, Galanter, \& Pribram, 1960).

Action theory is concerned with the processes that intervene between environmental input and behaviour: the regulatory functions of cognition (Frese \& Zapf, 1994). Human action is regarded as regulated by goals in a cybernetic control loop (Miller et al., 1960). A general model of human action can be described as an action cycle that consists of the following steps (Frese \& Zapf, 1994; Norman, 2013):

- $\quad$ perception of the environment,

- interpretation,

- appraisal and goal development,

- plan generation,

- decision, and

- execution and monitoring of the plan.

*Corresponding author: wind@zhaw.ch 
In its more general formulation this approach assumes causal relations between the environment and individual reactions (see Figure 5.1). It assumes that individuals react to features of the environment perceptually, affectively, and behaviourally. The three components of this model form the basis of much applied research in industrial and organisational psychology (e.g. Spector, 1992) and environmental psychology (e.g. Bell, Greene, Fisher, \& Baum, 2001). Outcomes in this model may consist of behaviour (e.g. performance), attitudes (e.g. satisfaction), cognitive results (e.g. learning), or emotional reactions (e.g. mood). There is considerable evidence for this general causal chain (Spector, 1992).

A more detailed account of the effects of the work environment on work activities and worker's experience based on the action cycle (as described earlier) is provided by the action regulation theory.

\subsection{Basic principles of the action regulation theory}

Action regulation theory has a long history in German work and organisational psychology (Hacker, 1998; Volpert, 1982, 2003). The basic tenet of this theoretical approach is that work is goal directed. Action regulation theory emphasises the cognitive regulation of actions. It "relates remarkably well to current cognitive models of human activity" (Roe, 1999, p. 238) and integrates several theoretical approaches.

Action regulation theory allows the independent definition of demands (regulation requirements), resources (regulation possibilities), workload factors (regulation problems), and health (Ducki, 2000). Furthermore, action regulation theory focuses on the interplay between the objective world and subjective reactions and experience. For these reasons, action regulation theory is considered as particularly well suited for the analysis of human-environment interactions.

Additionally, human activity is considered as integrated in physical environments and societal contexts since individuals regulate their actions based on information they receive from the environment and modify their environment through action. Despite this consideration of context, physical environments and conditions of action are hardly addressed from the perspective of action regulation theory. As an explanatory framework it is useful, because action regulation theory addresses principally all forms of environmental demands. Research and application related to this theory, however, have mainly focused on the design of work tasks and learning (Hacker, 2003), work and stress (Frese \& Zapf, 1994), proactive work behaviour, and entrepreneurship (Zacher \& Frese, 2018).

In this chapter, the focus will be on the basic elements of the theory as they relate to the work environment.

\subsection{The hierarchical-sequential model of action regulation}

Miller et al. (1960) introduced the concept of cybernetic regulation in action psychology and developed a model that forms the basis of current action regulation theories, such as the German action regulation theory (Frese \& Zapf, 1994). According to Miller et al. (1960), an actor

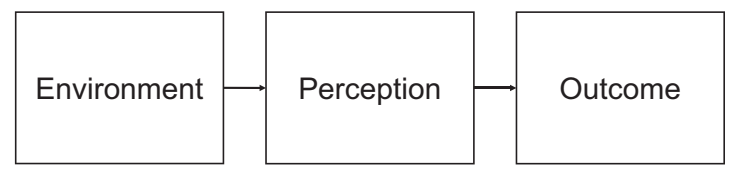

Figure 5.1 Traditional model of individual responses to organisational conditions (Morgeson \& Campion, 2003; Spector, 1992) 
compares situations or stimuli with expectation parameters or plans. In the case of incongruence, he tries to reach congruence through action. He then compares the new situation with his plans and decides whether new action is needed in order to produce congruence. Such comparison processes are modelled as cybernetic TOTE (test-operate-test-exit) units (Figure 5.2, left) that can be nested hierarchically (Figure 5.2, right). The cybernetic theory of action regulation models the translation of goals into plans, and the execution of plans through action and feedback.

On the basis of the cybernetic theory of action regulation, the hierarchical-sequential model of action regulation was proposed by German work psychologists (Frese \& Zapf, 1994; Hacker, 1998; Volpert, 1982). It is based on the assumption that human activity can be characterised as goal-oriented and conscious. Action is oriented towards a mentally anticipated result and deliberately regulated towards this goal.

The hierarchical-sequential model of action regulation describes action from a process and a structural point of view. The process component focuses on the sequential aspects of action and the structural component refers to its hierarchical organisation.

The core unit of action regulation is a cyclical unit comparable to the TOTE units developed by Miller et al. (1960): As a function of goal setting, series of transformations of the environment are produced. In work contexts, goals are defined by work tasks (as they are understood and interpreted by the worker). The sequence of transformations is defined through a preliminary run before performance (i.e. the execution of a series of transformations) begins; the transformations are queued to be worked through (Volpert, 1982). Then feedback takes place and the degree of goal attainment is examined. If differences remain, transformations are repeated and adapted, or the goal is modified.

Figure 5.3 shows Volpert's (1982) model of the cyclical unit. The descending arrow and the straight arrows from left to right show the generating process of transformations (based on goal
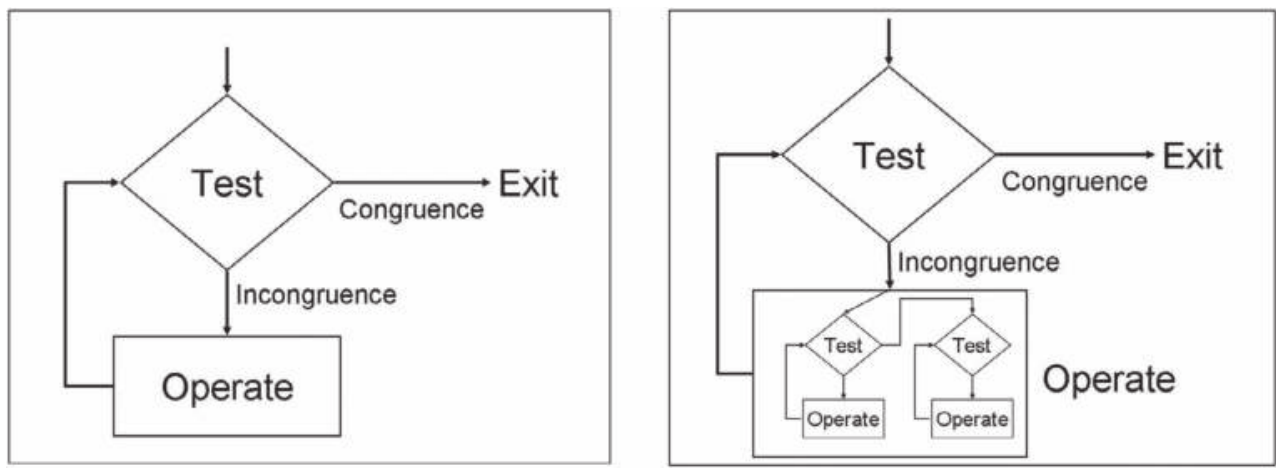

Figure 5.2 Basic test-operate-test-exit (TOTE) unit (left) and hierarchical structure of TOTE units (right) (Miller et al., 1960)

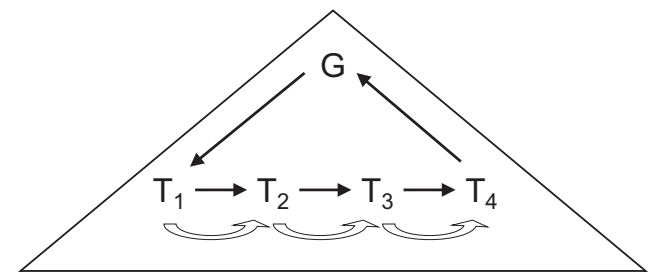

Figure 5.3 The cyclical unit (Volpert, 1982): goal is reached through a sequence of transformations 
G transformations, T1 to T4 are generated). These transformations are sequentially worked through when the generating process is finished (curved arrows). After the last transformation is performed, feedback about goal attainment follows (ascending arrow). If the achieved state corresponds to the goal, the cyclical unit is completed.

Every cyclical unit is part of a system that is composed of multiple interlaced cyclical units. Complex action structures emerge when multiple cyclical units are connected in a hierarchical order (see Figure 5.4). On the lowest level, base units represent directly performable operations, and on the highest level a peak unit represents a hypothetical general goal. In principle the number of levels and the number of transformations is arbitrary, but there are psychologically substantiated reasons to assume only three levels (Frese \& Zapf, 1994; Hacker, 1998): (1) a level of stereotyped and automated movement sequences which are executed without conscious attention (as long as they remain undisturbed by external circumstances); (2) a level of flexible action patterns where execution happens by means of operation sequences learned before, guided by perception of signals that have been learned before; and (3) an intellectual level, where situations are analysed, and action sequences planned. Actions concerned with problem-solving are regulated on this level in the form of analysis of goals and environmental conditions, decisionmaking, and planning. Regulation on this level is laborious and resource limited. It works in a serial mode, and feedback is interpreted step by step (Frese \& Zapf, 1994). Regulation on the intellectual level is necessarily conscious.

The hierarchical-sequential model of action regulation can be described as a model of interlaced cyclical units: a cyclical unit can be the transformation part of a higher unit. Reversely, the transformation parts of a cyclical unit can be described in its structure as a cyclical unit. In a context of occupational activities, the starting point for actions is the work task (Hackman, 1969). With complex actions higher-order goals are formed and partial goals and sub-goals are derived. Thus, a hierarchical action plan in the form of goals and transformations develops. The execution of actions occurs sequentially in the form of operations that change the environment. Goal attainment is fed back to the next higher level. The sub-goals are worked through in a sequential order (Figure 5.4).

In the action process initially only a rough planning of partial goals takes place (Frese \& Zapf, 1994). The generation of more detailed subunits occurs successively. This implies that disturbances can be corrected on the level where they occur and thus do not necessarily negatively impact higher-order goals. Therefore, unexpected environmental changes or errors in planning

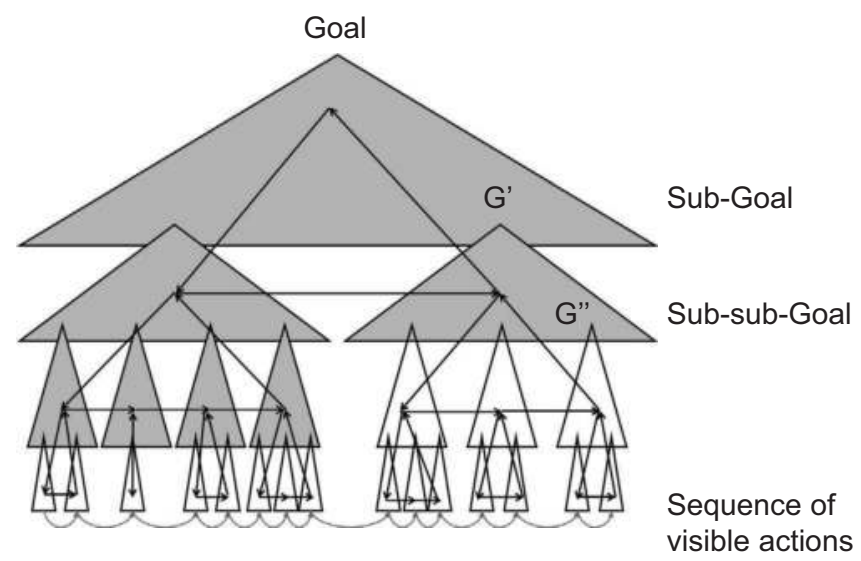

Figure 5.4 The hierarchical-sequential organisation of action (Frese \& Zapf, 1994; Volpert, 1982) 
or execution of transformations do not lead to disruptions of the pursuit of a higher-level goal but to modifications or repetitions of lower-level cyclical units. Thus, the model of hierarchicalsequential organisation regulation allows the explanation of stable long-term goal-oriented and at the same time flexible actions.

\subsection{Regulation requirements and regulation possibilities}

Dealing with simultaneous multifactorial requirements in work contexts, workers must decide how they want and can deal with these requirements in order to work effectively and efficiently. The regulation requirements are related to properties of the hierarchical-sequential organisation of action (Frese \& Zapf, 1994). The main regulation requirement is complexity. Complexity describes a set of decision necessities. Tasks and goals with a high complexity require a high degree of regulation. Complexity is understood as an interactive term and refers to a person's skills in relation to the necessities of the situation (Frese \& Zapf, 1994). Decision necessities are based on the number of different goals, plans, and feedbacks that have to be regulated and organised in time and the nature and number of relationships within and between goals, plans, and feedback (Dörner \& Schaub, 1994).

In contrast to industrial regulation, in human actors often multiple goals are active simultaneously (Hockey, 2000). Switching between goals during a workday is thus a characteristic feature of human action. However, in order to attain important goals, this flexibility has to be regulated by maintaining goals as anticipated future states in the feedback process and to adapt behaviour according to the differences of the feedback process.

Goal-oriented behaviour always implies the overcoming of the natural tendency to switch to other goals (Hockey, 2000). This process implies regulation costs (i.e. regulation efforts). The maintenance of performance under unfavourable conditions is connected with extra regulation because the effort to reduce differences of the feedback process increases (greater difference or more difference) and the distraction through multiple goals has to be tackled. A constant effectiveness of action can be accompanied by reduced cognitive and emotional efficiency. Unfavourable conditions do not normally influence the effectiveness of actions, but efficiency deteriorates because unfavourable conditions require compensatory control (Hockey, 1997). Compensatory control is a performance protection strategy - an adaptive regulation process that supports goals with high priority at the expense of goals with lower priorities. Compensatory control is a response to external threats (e.g. stressors) by increasing effort and concentrating more on goals considered important. The cost of this regulation may be decrements in non-focal aspects of tasks and a neglect of personal needs and other goals.

Control describes the possibilities available for an actor to have an impact on the conditions and on his/her own activities in relation to the goals (Ganster \& Fusilier, 1989). In contrast to complexity as a set of decision necessities, control describes a set of decision possibilities (i.e. a resource).

Classes of regulation problems can be distinguished which act as stressors because they disturb the regulation of action (Frese \& Zapf, 1994; Greiner \& Leitner, 1989) (see Figure 5.5). They can be subdivided into regulation obstacles, regulation uncertainty, and overtaxing regulation (Frese \& Zapf, 1994). Regulation obstacles or barriers directly influence action regulation and require short-term reactions. Regulation overtaxing in contrast is related to continuous conditions that reduce mental and physical performance over longer periods (e.g. the workday) (Greiner \& Leitner, 1989).

Regulation obstacles are conditions that hinder the accomplishment of work results because they make it harder or impossible to pursue a goal and to regulate an action. Regulation obstacles 


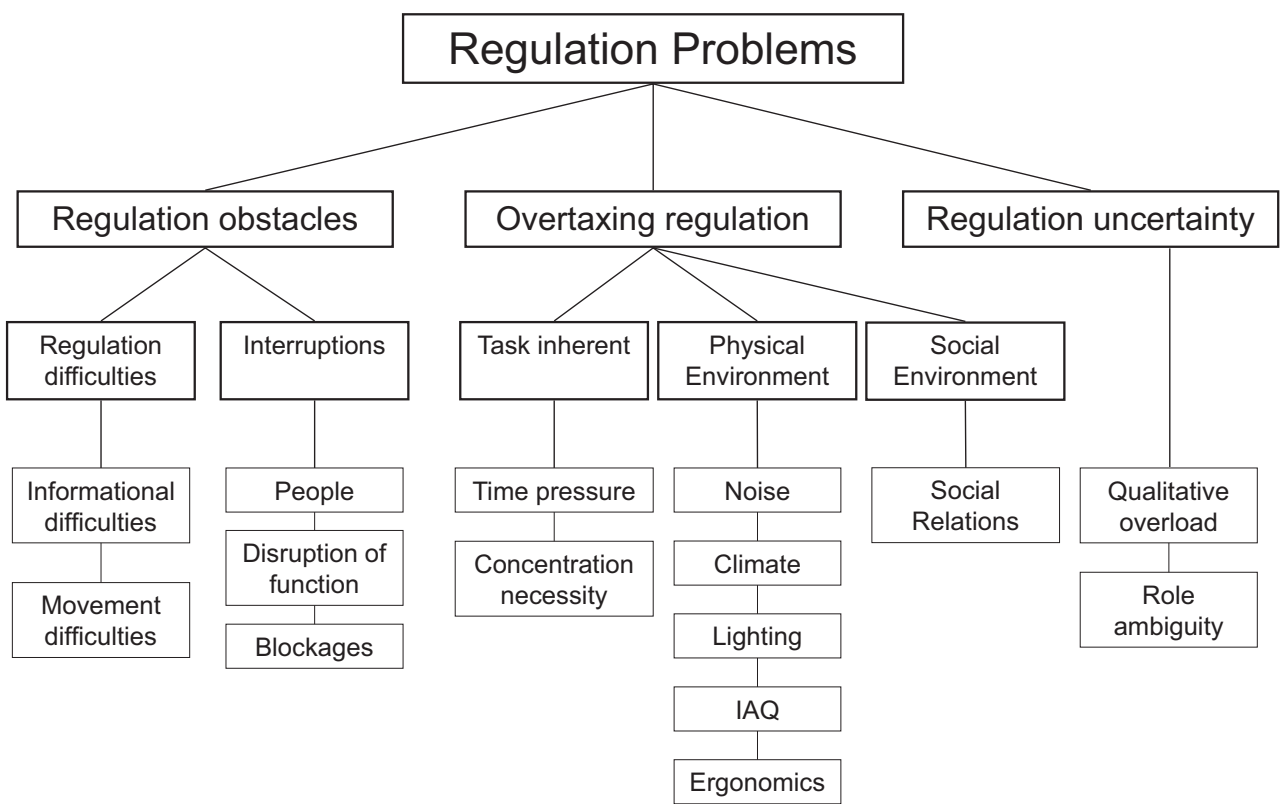

Figure 5.5 Classification of regulation problems (based on Frese \& Zapf, 1994; Greiner \& Leitner, 1989; Leitner, 1999)

are stressors because they require additional effort for task completion. They necessitate repetition of the action, the making of detours, and/or use up regulation capacity that is then subtracted from the main task.

Regulation obstacles can be subdivided into interruptions and regulation difficulties (Figure 5.5). Interruptions are unpredictable outside events (such as a computer breakdowns or phone calls) that disrupt an ongoing activity. Interruptions are regulation obstacles because they force the actor to restart a task or because, due to interruptions, parts of the task already completed may be lost. Regulation difficulties are conditions that impede efficient execution of tasks. They appear when access to task-relevant information is unnecessarily difficult or when movements need extra effort, for example due to inadequate tools. Regulation obstacles may have their roots in organisational problems (e.g. lack of supplies) or the social environment.

Regulation uncertainty describes a state in which the actor is confused about how to achieve a goal because he's unable to determine which kinds of plans are useful or what feedback can be trusted (Semmer, 1984). In this case a lack of information is not the cause, but rather the inconsistency or ambiguity of information.

Overtaxing regulation describes a state of overload due to overstimulation related to required speed and intensity of regulation. Time pressure or quantitative overload of the working memory or concentration, for example, is a typical stressor. In order to complete a task, more processing resources have to be allocated to regulation and thus more effort is expended. For this class of regulation problems, permanent conditions of time pressure or bound attention are characteristic, as are environmental conditions that do not constrain working activities (like regulation obstacles do) but exceed human performance capacities.

Social stressors such as hostile colleagues, conflicts with colleagues or supervisors, unfair treatment by colleagues or supervisors, and a negative group climate can be considered as overtaxing 
regulation because they divert attention from the main tasks to thoughts and worries about social relations. Thus, social stressors consume regulation capacity (Dunckel, 1991).

Action regulation theory assumes that human beings actively deal with their environment. Regulation requirements (complexity) and corresponding regulation possibilities (control) lead to positive effects (i.e. satisfaction) because they address human needs such as a feeling of competence or pride over achievement (Zapf, 2002). On the other hand, regulation problems do not address needs and impede goal-directed acting. Regulation problems thus act as stressors.

\subsection{Action regulation and stress}

The transactional view of stress (Lazarus, 1966; Lazarus \& Folkman, 1984) describes a process linking stressors, strain, and coping: stress arises from perceived environmental demands that exceed a person's perceived resources and capacity. Appraisal of a situation and personal resources starts coping behaviour. Coping behaviour refers to two things: first, it refers to the stress-generating problem, for example the handling of an additional task. Second, it refers to dealing with the emotions activated in this process. Thus, coping takes effort and thereby produces fatigue and consumes resources. According to Hockey's (1997) compensatory control model, individuals use performance-protection strategies when dealing with environmental stressors. Performance protection is realised through increased subjective effort (psychological process) and/or sympathetic activation (physiological process). The greater the activation, the greater the costs for the individual. Short-term effects of compensatory control in the regulation of performance under stress consist in inefficient strategies. Long-term effects may be a draining of energy and a state of exhaustion.

According to the transactional view, stress is seen as a product of the complex and dynamic transaction between the person and the environment, rather than a product of one of these components on its own. In order to keep these transactions manageable in research, the transactional model is often reduced by the concept of stressors. Stressors are job or work features that increase the probability of stress reactions and stress-related outcomes (Kahn \& Byosiere, 1992, Semmer, McGrath, \& Beehr, 2005). Stressors are not defined on the individual level but on the level of populations. Each individual perceives the same objective environment somewhat differently, and stressors do not lead to stress reactions in every individual. Like some people are more resistant to infections than others are, some are more resistant to certain stressors. Stressors therefore are considered as risk factors and not as determinants of stress reactions and outcomes. Stress reactions are indicated in one or more of the following signs: verbal reports of being stressed or overtaxed or the like; observable behaviour, and physiological signs (Semmer et al., 2005).

While in cognitive theories of stress (e.g. Lazarus \& Folkman, 1984) the concept of appraisal is central for the examination of the relationship between the person and their work environment, the tradition of work and job design emphasises objective ${ }^{3}$ characteristics of jobs. The reasons for this emphasis on objectivity are twofold: first, it is rooted in the theoretical tradition of action regulation theory that aims at contributing to job design. Second, there is empirical evidence of correlations between objective work characteristics and individual health and wellbeing. From a practical point of view, the reason for emphasising the objective nature of work and work environments is that work and environmental design is usually accomplished without taking individual factors into consideration (Zapf, 1993). While individual appraisal is obviously unique, it is not idiosyncratic (Semmer et al., 2005). It is therefore possible to identify patterns in the way people appraise specific work conditions. This is particularly so with patterns that relate to the way the workplace is seen to threaten a person's health and well-being.

In terms of action regulation theory, stressors are equalised with regulation problems (Frese \& Zapf, 1994; Greiner \& Leitner, 1989). Regulation problems act as stressors and impair work 
performance because they require extra regulation efforts. This additional regulation effort in turn can lead to overtaxing of regulation and lead to stress reactions and stress-related outcomes.

This approach allows for a conceptualisation of stressors that is not dependent on worker appraisal but does not omit mental processes in general. Stressors are conditions that interfere or are incompatible with mental regulation processes such as information processing, planning, and movement execution.

\section{Applicability to workplace studies}

The concept of psychological stress allows for an extension of the job and work design literature towards the analysis and design of the physical environment. It encompasses not only short-term stress episodes but also emphasises long-term impacts on health and well-being. Furthermore, it acknowledges the possible influence of moderating variables such as control (e.g. job decision latitude or environmental control) and social support.

Research on work and stress has focused on psychosocial, organisational, and job design aspects but largely ignored the potential effects of the physical environment (Vischer, 2007).

Environmental stressors interfere with mental regulation processes and/or consume resources that otherwise would be used for task-related activities. In terms of the action regulation theory described previously, environmental stressors act as regulation problems because they impede goal-directed regulation. Therefore, environmental stress leads to frustration and dissatisfaction. Endangering the fulfilment of accepted tasks has been found to be experienced as stressful and tends to correlate with psychosomatic symptoms (Greiner, Ragland, Krause, Syme, \& Fisher, 1997; Leitner \& Resch, 2005; Semmer, Zapf, \& Greif, 1996). Evidence of the (small) negative effects of situational constraints (i.e. regulation problems) on performance and satisfaction is reported by O'Connor et al. (1984).

Action regulation theory has mainly been applied in order to study negative aspects of work, specifically stress. Action regulation theory, however, also considers positive aspects such as learning and individual development through acting (and therefore values the complexity of work tasks highly). The two foci on stress and learning do not allow the assessment of positive effects of the physical work environment. The theoretical framework therefore has to be completed with an approach that permits the study of environmental impacts that lead to higher well-being, better health, or higher performance. The absence of regulation problems or stressors does not fulfil human needs. Workers not only need freedom from regulation problems but also want environmental support for the activities they perform. The concept that captures these aspects is environmental comfort (Vischer, 2005, 2007). Environmental comfort contains the satisfaction with the relationship between individual goals and physical, functional, and psychological aspects of the physical work environment. It links the assessments of office environments by their users to outcomes such as performance and well-being.

The experience of comfort is understood as guided by similar regulatory mechanisms as stress. Comfort is thus a physiology-oriented concept not of neutral sensation (sensu Fanger, 1970) but of neutral regulatory demands from the physical environment. Comfort is thus conceived as a psychological concept. The measurement of comfort should focus on satisfaction with comfort because the concept of satisfaction should relate to longer periods than sensation does. Thus, while sensation may be an adequate measure in laboratory studies, satisfaction is considered more appropriate in field studies. Satisfaction with aspects of environmental comfort includes the possibility of individual adaptation to environmental conditions in order to achieve comfortable levels (Nicol \& Humphreys, 2002). Furthermore, conceptualising comfort as satisfaction considers the multidimensional nature of comfort. For example, an empirical study 
found that seating comfort is based on a sense of well-being, relief, and relaxation, as well as on the appearance of the chair (Zhang, 1996).

From the theoretical perspective of action regulation, stressors are defined as regulation problems. The general taxonomy of regulation problems (Figure 5.5) can be translated into a taxonomy of regulation problems for office work that is related to the physical office environment (see Figure 5.6).

Regulation obstacles are conditions that make it harder or impossible to pursue a goal or to regulate an action. The subcategory of regulation difficulties refers to conditions that impede efficient task execution. In office work such conditions are noise (Leitner et al., 1993), ineffective design of workspaces, and crowding (Schultz-Gambard, Feierabend, \& Hommel, 1988). Noise requires higher concentration, for example for an individual's own telephone calls. Ineffective workspace may impede task execution on the level of movements (spatial barriers, dysfunctional arrangements). Crowding is associated with excessive stimulation, scarce resources, and behavioural constraints and aggravated action regulation.

The second subcategory of regulation obstacles refers to interruptions. In office settings, the main source of interruptions and distractions are other people (Baethge, Rigotti, \& Roe, 2015; Jett \& George, 2003).

Overtaxing regulation refers to speed and intensity of regulation and the risk of physiological and psychological overload. Conditions belonging in this category are time pressure and concentration necessity (Zapf, 1993) as task inherent factors. Furthermore, environmental factors such as noise, climate, lighting, indoor air quality, and ergonomics are task unspecific risk factors for overload or overstimulation (e.g. Sundstrom, 1986). In relation to the social environment, problematic social relations due to conflicts may overtax regulation. Social density is a second factor of the social environment that is relevant for overtaxing regulation. Social density is associated with overstimulation and impairs focusing and concentrating abilities (Oldham \& Rotchford, 1983).

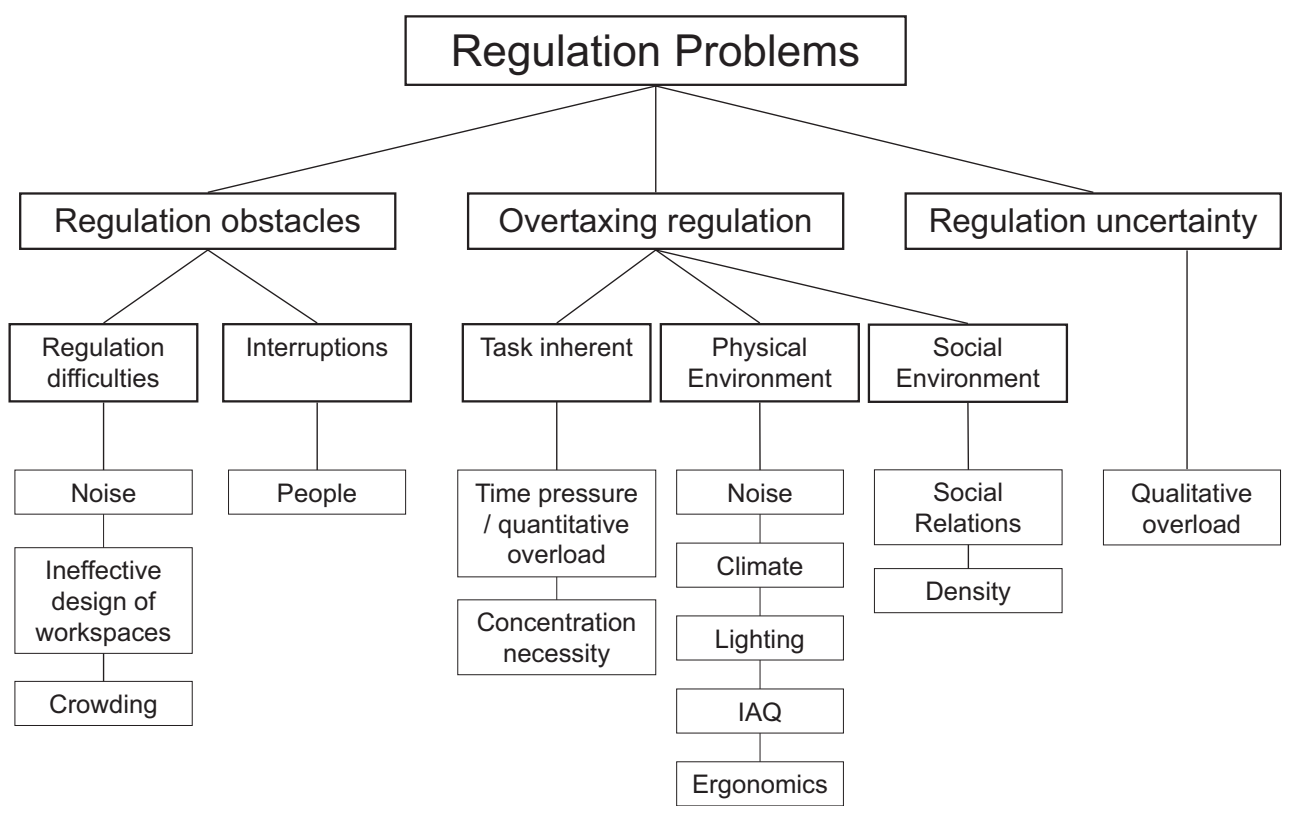

Figure 5.6 Regulation problems in office work 
Noise appears as a stressor in two different ways. First, noise acts as a regulation difficulty for specific tasks requiring extra effort. Second, noise may overtax regulation as a task unspecific stressor that leads to cognitive overstimulation. Task unspecific stressors do not require extra regulation effort but must be borne by the job incumbents.

Regulation uncertainty describes a state in which an actor is confused about how to achieve a goal because s/he is unable to determine which kinds of plans are useful or what feedback can be trusted (Semmer, 1984). This concept is strongly associated with qualitative overload, a state that is characterised by excessive requirements on working memory as much as too many pieces of information must be kept in memory simultaneously and for too-long periods of time.

From the perspective of action regulation theory, the far most important resource is control. Control describes the amount of regulation possibilities an individual worker has (see also Chapter 11 Two-Process Theory of Perceived Control). A second resource is social support, a concept that has been shown to buffer negative effects of work stressors in many studies (Kahn \& Byosiere, 1992; Van der Doef \& Maes, 1999). Although social support is not derived from action regulation theory (which has an individualistic cognitive focus), it is usually considered in action regulation-based research on work stress, well-being, and health (Frese, 1995). Considering the physical environment, further resources can be identified. Privacy (see also Chapter 6 PrivacyRegulation Theory) and control over one's own physical environment are two facets of autonomy that are likely to act as instrumental resources (De Croon, Sluiter, Kuijer, \& Frings-Dresen, 2005). Furthermore, comfort may play a role as an intrinsically valued resource.

By understanding environmental conditions as regulation problems or regulation possibilities, action regulation theory serves as a micro-theory that relates environmental demands with experience of stress, that is, a theoretical approach that allows explanations of why certain (environmental) conditions may act as demands or stressors (regulation problems) or resources (regulation possibilities). Action regulation theory thus allows for a better identification and understanding of environmental influences, as part of work conditions, on employees.

\section{Methodology/research approach}

Action regulation theory has been applied in many fields (Frese \& Zapf, 1994; Hacker, 2003; Zacher \& Frese, 2018), and many research methods are used. Work-related research based on action regulation theory tends to take place in (field) experimental settings and field studies (Hacker, 2003), and some researchers attempted to combine objective with subjective measurements (e.g. Greiner et al., 1997; see also Hacker, 2003).

The observational interview is a method that is more frequently used in research based on action regulation theory than in other approaches. This method combines elements of observation and enquiry since the research focus often lies on thinking processes. With observational interviews, person-independent work analyses are carried out. These analyses combine external characteristics of activities with an understanding of the work processes and action structures of work activities (cf. Leitner \& Resch, 2005).

Generally, the action regulation theory provides a framework of how a person deals with tasks, including objects and the environment. This framework comprises the generation of action plans, the execution of actions and monitoring of goal achievement, and how cognitive resources are activated. This framework can be further developed for the analysis of effects of the work environment, for example it allows the definition and identification of demands and resources as well as regulation problems. More knowledge on the interplay between the objective world and subjective reactions and experience can serve as a basis for the development of theory-based instruments for the assessment of work environments in terms of their 
health-impairing or -promoting function and the analysis of action strategies of execution regulation, that is, coping with environmental demands and using environmental resources to achieve goals and maintain health and well-being.

\section{Limitations}

A limitation of the action regulation theory is its disregard of person-variables (such as individual preferences, personal taste, and individual dispositions) and social influences. These aspects should not be neglected when the main aim of research consists in explaining certain behaviour as it relates to work environments. Generally, however, it is assumed that social influences will be balanced over a sample of organisations analysed and that person-related effects will be balanced in the sample of participants. ${ }^{4}$

\section{Theory relevance to practice}

Action regulation theory combines motivational regulation and execution regulation of actions. Thus, it emphasises the role of the environment for work activities. Furthermore, it provides a basis for differentiating between different forms of regulation problems and their measurement or assessment. Action regulation theory refers to the resource limitation of intellectual (conscious) regulation and stipulates that well-practiced routines are regulated by less effortful modes. However, information from the environment may trigger mindful processing, for example when barriers or opportunities relevant to one's work appear. Changes in the environment may therefore require more conscious processing. This effect can be deliberately used by modifying the environment to create signals, for example when managing work safety. On the other hand, practitioners must be aware that any change in the environment may lead to conscious processing and with that to positive or negative reactions of the affected workers.

\section{Further reading}

- Frese, M., \& Zapf, D. (1994). Action as the core of work psychology: A German approach. In H. C. Triandis, M. D. Dunnette, \& L. M. Hough (Eds.), Handbook of industrial and organizational psychology (2nd ed., Vol. 4, pp. 271-340). Palo Alto, CA: Consulting Psychologists Press.

- Zacher, H., \& Frese, M. (2018). Action regulation theory: Foundations, current knowledge and future directions. In D. S. Ones, N. Anderson, C. Viswesvaran, \& H. K. Sinangil (Eds.), The SAGE handbook of industrial, work \& organizational psychology: Organizational psychology (pp. 122-144). Thousand Oaks, CA: Sage.

\section{Notes}

1 This chapter is largely based on parts of the theory sections of my unpublished PhD thesis.

2 Although the scientific value of the Hawthorne studies is disputed (e.g. Carey, 1967; Parsons, 1974) and they have never been published in scientific journals, they are noteworthy because they stand for a paradigm shift in the history of social science.

3 Objective characteristics of jobs are not necessarily physical characteristics. Rather, objective characteristics are conceived as independent of a specific person's cognitive and emotional processing and are inter-individually agreed physical or social facts (Frese \& Zapf, 1988).

4 In statistical terms this assumption is known as the central limit theorem. It states that with sufficiently large samples sizes, sampling distributions of means are normally distributed (Tabachnick \& Fidell, 2007). 


\section{References}

Baethge, A., Rigotti, T., \& Roe, R. A. (2015). Just more of the same, or different? An integrative theoretical framework for the study of cumulative interruptions at work. European Journal of Work and Organizational Psychology, 24(2), 308-323. https://doi.org/10.1080/1359432x.2014.897943

Bell, P. A., Greene, T. C., Fisher, J. D., \& Baum, A. (2001). Environmental psychology. Mahwah, NJ: Lawrence Erlbaum Associates.

Carey, A. (1967). The Hawthorne studies: A radical criticism. American Sociological Review, 32(3), 403-416. https://doi.org/10.2307/2091087

De Croon, E., Sluiter, J., Kuijer, P. P., \& Frings-Dresen, M. (2005). The effect of office concepts on worker health and performance: A systematic review of the literature. Ergonomics, 48(2), 119-134. https://doi. org/10.1080/00140130512331319409

Dörner, D., \& Schaub, H. (1994). Errors in planning and decision-making and the nature of human information processing. Applied Psychology: An International Review, 43(4), 433-453. https://doi. org/10.1111/j.1464-0597.1994.tb00839.x

Ducki, A. (2000). Diagnose gesundheitsförderlicher Arbeit. Eine Gesamtstrategie zur betrieblichen Gesundheitsanalyse [Diagnosis of health-promoting work: An overall strategy for occupational health analysis]. Zürich: vdf, Hochschulverlag an der ETH Zürich.

Dunckel, H. (1991). Mehrfachbelastung und psychosoziale Gesundheit [Multiple exposure and psychosocial health]. In S. Greif, E. Bamberg, \& N. Semmer (Eds.), Psychischer Stress am Arbeitsplatz (pp. 154167). Göttingen: Hogrefe.

Fanger, P. O. (1970). Thermal comfort: Analysis and applications in environmental engineering. New York: McGraw-Hill.

Frese, M. (1995). Stress factors and health: A multicausal relationship. In O. Svane \& C. Johansen (Eds.), Work and health: Scientific basis of progress in the working environment. Proceedings of the International Conference, February 1993, Copenhagen (pp. 19-26). Copenhagen/Brussels: European Commission, Directorate-General of Employment, Industrial Relations, and Social Affairs.

Frese, M., \& Zapf, D. (1988). Methodological issues in the study of work stress: Objective vs subjective measurement of work stress and the question of longitudinal studies. In C. L. Cooper \& R. Payne (Eds.), Causes, coping and consequences of stress at work (pp. 375-411). Chichester: John Wiley \& Sons.

Frese, M., \& Zapf, D. (1994). Action as the core of work psychology: A German approach. In H. C. Triandis, M. D. Dunnette, \& L. M. Hough (Eds.), Handbook of industrial and organizational psychology (2nd ed., Vol. 4, pp. 271-340). Palo Alto: Consulting Psychologists Press.

Ganster, D. C., \& Fusilier, M. R. (1989). Control in the workplace. In C. L. Cooper \& I. T. Robertson (Eds.), International review of industrial and organizational psychology (pp. 235-280). Chichester: John Wiley \& Sons.

Greiner, B. A., \& Leitner, K. (1989). Assessment of job stress: The RHIA instrument. In K. Landau \& W. Rohmert (Eds.), Recent developments in job analysis (pp. 53-66). London: Taylor \& Francis.

Greiner, B. A., Ragland, D. R., Krause, N., Syme, S. L., \& Fisher, J. M. (1997). Objective measurement of occupational stress factors: An example with San Francisco Urban Transit operators. Journal of Occupational Health Psychology, 2(4), 325-342. https://doi.org/10.1037/1076-8998.2.4.325

Hacker, W. (1998). Allgemeine Arbeitspsychologie: Psychische Regulation von Arbeitstätigkeiten [General work psychology: Psychological regulation of work activities]. Bern: Huber.

Hacker, W. (2003). Action regulation theory: A practical tool for the design of modern work processes. European Journal of Work and Organizational Psychology, 12(2), 105-130. https://doi.org/10.1080/1359 4320344000075

Hackman, J. R. (1969). Toward understanding the role of tasks in behavioral research. Acta Psychologica, 31 , 97-128. https://doi.org/10.1016/0001-6918(69)90073-0

Hockey, G. R. J. (1997). Compensatory control in the regulation of human performance under stress and high workload: A cognitive-energetical framework. Biological Psychology, 45, 73-93. https://doi. org/10.1016/S0301-0511(96)05223-4

Hockey, G. R. J. (2000). Work environments and performance. In N. Chmiel (Ed.), Introduction to work and organizational psychology: A European perspective (pp. 206-230). Oxford: Blackwell.

Jett, Q. R., \& George, J. M. (2003). Work interrupted: A closer look at the role of interruptions in organizational life. Academy of Management Review, 28(3), 494-507. https://doi.org/10.2307/30040736

Kahn, R. L., \& Byosiere, P. (1992). Stress in organizations. In M. D. Dunnette \& L. M. Hough (Eds.), Handbook of industrial and organizational psychology (2nd ed., Vol. 3, pp. 571-650). Palo Alto, CA: Consulting Psychologists Press. 
Lazarus, R. S. (1966). Psychological stress and the coping process. New York: McGraw-Hill.

Lazarus, R. S., \& Folkman, S. (1984). Stress, appraisal, and coping. New York: Springer.

Leitner, K. (1999). Kriterien und Befunde zu gesundheitsgerechter Arbeit - Was schädigt, was fördert die Gesundheit? [Healthy work. Criteria and evidence] In R. Oesterreich \& W. Volpert (Hrsg.), Psychologie gesundheitsgerechter Arbeitsbedingungen. Konzepte, Ergebnisse und Werkzeuge zur Arbeitsgestaltung (S. 63-139). Bern: Huber.

Leitner, K., Lüders, E., Greiner, B., Ducki, A., Niedermeier, R., \& Volpert, W. (1993). Analyse psychischer Anforderungen und Belastungen in der Büroarbeit. Das RHIA/VERA-Büro-Verfahren. Handbuch und Manual [Analysis of psychological requirements and strain in office work: The RHIA/VERA-office-method. Handbook and manual]. Göttingen: Hogrefe.

Leitner, K., \& Resch, M. G. (2005). Do the effects of job stressors on health persist over time? A longitudinal study with observational stressor measures. Journal of Occupational Health Psychology, 10(1), 18-30. https://doi.org/10.1037/1076-8998.10.1.1

McGrath, J. E. (1976). Stress and behavior in organizations. In M. D. Dunnette (Ed.), Handbook of industrial and organizational psychology (pp. 1351-1395). Chicago: Rand McNally.

Miller, G. A., Galanter, E., \& Pribram, K. H. (1960). Plans and the structure of behavior. New York: Holt, Rinehart and Winston.

Morgeson, F. P., \& Campion, M. A. (2003). Work design. In W. C. Borman, D. R. Ilgen, \& R. J. Klimoski (Eds.), Handbook of psychology (pp. 423-452). Hoboken, NJ: John Wiley \& Sons.

Nicol, J. F., \& Humphreys, M. A. (2002). Adaptive thermal comfort and sustainable thermal standards for buildings. Energy and Buildings, 563-572. https://doi.org/10.1016/S0378-7788(02)00006-3

Norman, D. (2013). The design of everyday things (revised and expanded ed.). New York: Basic Books.

O’Connor, E. J., Peters, L. H., Pooyan, A., Weekley, J., Frank, B., \& Erenkrantz, B. (1984). Situational constraint effects on performance, affective reactions, and turnover: A field replication and extension. Journal of Applied Psychology, 69(4), 663-672. https://doi.org/10.1037/0021-9010.69.4.663

Oldham, G. R., \& Rotchford, N. L. (1983). Relationships between office characteristics and employee reactions: A study of the physical environment. Administrative Science Quarterly, 28, 542-556. https:// doi.org/10.2307/2393008

Parsons, H. M. (1974). What happened at Hawthorne? Science, 183(4128), 922-932. https://doi.org/10.11 26/science.183.4128.922

Roe, R. A. (1999). Work performance: A multiple regulation perspective. In C. L. Cooper \& I. T. Robertson (Eds.), International review of industrial and organizational psychology (Vol. 14, pp. 231-335). Chichester: John Wiley \& Sons.

Roethlisberger, F. J., \& Dickson, W. J. (1939). Management and the worker. New York: Wiley.

Schultz-Gambard, J., Feierabend, C., \& Hommel, B. (1988). The experience of crowding in real-life environments: An action oriented approach. In D. Canter, J. C. Jesuino, L. Soczka, \& G. M. Stephenson (Eds.), Environmental social psychology (pp. 94-105). Dordrecht: Kluwer.

Semmer, N. K. (1984). Stressbezogenen Tätigkeitsanalyse. Psychologische Untersuchungen zur Analyse von Stress am Arbeitsplatz [Stress related work analysis: Psychological examination for analysing stress at work]. Weinheim: Beltz.

Semmer, N. K., McGrath, J. E., \& Beehr, T. A. (2005). Conceptual issues in research on stress and health. In C. L. Cooper (Ed.), Handbook of stress medicine and health (2nd ed., pp. 1-43). Boca Raton: CRC Press.

Semmer, N. K., Zapf, D., \& Greif, S. (1996). "Shared job strain": A new approach for assessing the validity of job stress measurements. Journal of Occupational and Organizational Psychology, 69, 293-311. https:// doi.org/10.1111/j.2044-8325.1996.tb00616.x

Spector, P. E. (1992). A consideration of the validity and meaning of self-reports measures of job conditions. In C. L. Cooper \& I. T. Robertson (Eds.), International review of industrial and organizational psychology (Vol. 7, pp. 123-151). Chichester: John Wiley \& Sons.

Sundstrom, E. (1986). Work places: The psychology of the physical environment in offices and factories. Cambridge: Cambridge University Press.

Tabachnick, B. G., \& Fidell, L. S. (2007). Using multivariate statistics (5th ed.). Boston, MA: Allyn \& Bacon.

Van der Doef, M., \& Maes, S. (1999). The Job Demand-Control(-Support) Model and psychological well-being: A review of 20 years of empirical research. Work $\mathcal{E}$ Stress, 13(2), 87-114. https://doi. org/10.1080/026783799296084

Vischer, J. C. (2005). Space meets status: Designing workplace performance. London: Routledge.

Vischer, J. C. (2007). The effects of the physical environment on job performance: Towards a theoretical model of workspace stress. Stress and Health, 23, 175-184. https://doi.org/10.1002/smi.1134 


\section{Action regulation theory}

Volpert, W. (1982). The model of the hierarchical-sequential organization of action. In W. Hacker, W. Volpert, \& M. V. Cranach (Eds.), Cognitive and motivational aspects of action (pp. 35-51). Berlin: Hüthing Verlagsgemeinschaft.

Volpert, W. (2003). Wie wir handeln - was wir können. Ein Disput als Einführung in die Handlungspsychologie [How we act - what we can do: A dispute as an introduction to the psychology of action] (3., vollständig überarbeitete Auflage). Sottrum: Artefact Verlag.

Zacher, H., \& Frese, M. (2018). Action regulation theory: Foundations, current knowledge and future directions. In D. S. Ones, N. Anderson, C. Viswesvaran, \& H. K. Sinangil (Eds.), The SAGE handbook of industrial, work \& organizational psychology: Organizational psychology (pp. 122-144). Thousand Oaks, CA: Sage.

Zapf, D. (1993). Stress-oriented analysis of computerized office work. The European Work and Organizational Psychologist, 3(2), 85-100. https://doi.org/10.1080/09602009308408580

Zapf, D. (2002). Emotion work and psychological well-being. A review of the literature and some conceptual considerations. Human Resource Management Review, 12, 237-268. https://doi.org/10.1016/S10534822(02)00048-7

Zhang, L., Helander, M. G., \& Drury, C. G. (1996). Identifying factors of comfort and discomfort in sitting. Human Factors, 38(3), 377-389. https://doi.org/10.1518/001872096778701962 


\title{
PRIVACY REGULATION THEORY Redevelopment and application to work privacy
}

\author{
Clara Weber*, Birgitta Gatersleben, Barbara Degenhardt, \\ and Lukas Windlinger
}

\section{Background}

Increasing empirical evidence indicates that the fulfilment of privacy needs in the workplace is important for productive and healthy work (e.g., Kim \& de Dear, 2013; Kupritz, 1998; Laurence, Fried, \& Slowik, 2013; Sundstrom, 1986; Weber, 2019). However, theoretical perspectives on privacy vary greatly (for reviews see, e.g., Altman, 1975; Bates, 1964; Kupritz, 2000; Margulis, 1977; Newell, 1995; Westin, 1970), making it difficult to come to clear conclusions about its relevance for different groups of workers in different jobs and environmental contexts.

Most privacy definitions relate to an interaction between the person and the socio-physical environment, with varying foci on different elements:

- The person: Privacy is seen as a state of being (e.g., being private; Bailey, 1979; Fischer, 1971; Schoeman, 1984);

- The environment: Privacy is defined as quality of space (e.g., architectural privacy; Webster, 1979) or an attitude towards the environment (e.g., solitude, anonymity, intimacy; e.g., Pedersen, 1979, 1999; Westin, 1970); or

- The person-environment transaction: Privacy is a transactional person-environment regulation process (e.g., Altman, 1975; Kupritz, 1998, 2000; Margulis, 1977). It emphasises the unity of person and environment, rather than regarding both as independent entities which interact (e.g., linearly) with each other.

Despite the variety of definitions, two central themes can be distinguished (Weber, 2019). The first theme is a form of input control: it is the personal control over input from people and stimuli outside the self (including access to the self and being available to others; e.g., Altman, 1975; Bates, 1964; Beardsley, 1971; Ittelson, Proshansky, \& Rivlin, 1970; Marshall, 1972; Sundstrom, 1986). The second theme is a form of output control over personal information of varying degrees (Beardsley, 1971; Justa \& Golan, 1977; Kelvin, 1973; Margulis, 1977; Shils, 1966; Westin, 1970). The regulation of social interaction, sometimes mentioned as a third theme (e.g., Kupritz, 1998, 2000; Le Poire, Burgoon, \& Parrott, 1992), has been conceptualised as a meta-theme by others (e.g., Altman, 1975); in this construction, input control of access and stimuli and output control of information are nested.

*Corresponding author: weec@zhaw.ch 
This conceptual structure is largely in line with the prevalent privacy conceptualisation by Altman $(1975,1976)$, which is widely used within people-environment studies across a range of disciplines. Altman's privacy regulation framework is grounded in person-environment $(\mathrm{P}-\mathrm{E})$ fit theory (cf. Edwards, Caplan, \& Harrison, 1998, see also Chapter 2 Person-Environment Fit Theory) that describes a transactional person-environment relationship shaping a person's subjective appraisal of the environmental condition. Altman (1975, p. 11) defined privacy as "selective control of access to the self or to one's group ... an input and output control process; people and groups attempt to regulate contacts coming from others and output they make to others". Altman did not specify any particular context (e.g., workplace or home environments). Therefore, his framework relates to privacy in general. His framework has six specifications to privacy that in this particular composition are unique to his theory:

1 Differentiation between a person's desired and achieved levels of privacy.

2 Level of fit, which describes congruence between levels of desired and achieved privacy.

3 Cases of having too much privacy (if achieved $>$ desired) and too little privacy (if achieved $<$ desired).

4 Differentiation between levels of input and output that a person desires or can achieve.

5 Privacy regulation as an optimisation process as people attempt to achieve optimal fit.

6 Dynamic privacy desires that change constantly and are influenced by personal (e.g., mood), interpersonal (e.g., closeness to others), and situational (e.g., work task) factors.

Altman's model translates to the following ecological P-E fit equation: ${ }^{1}\left[P R B=f\left(D, A, D^{\star} A\right)\right]$, where privacy-regulating behaviour $(P R B)$ is a function $(f)$ of privacy desires $(D)$, actual privacy $(A)$, and the congruence or privacy fit of privacy desires $(D)$ with actual privacy $(A)$ (represented by the interaction term $D^{\star} A$ ). In a successful privacy-regulation system, there is congruence or privacy fit $\left(D^{\star} A\right)$ between the actual levels of privacy $(A)$ and the desired levels of privacy $(D)$. In an unsuccessful privacy-regulation system, there is incongruence or poor privacy fit which is thought to motivate privacy-regulating behaviour ( $P R B$; such as territorial behaviour).

\section{Applicability to workplace studies}

The following section gives an overview on prior work privacy conceptualisations, highlights some of their limitations (2.1), and presents a new conceptualisation of work privacy by Weber (2019) (2.2). Subsequently, this section argues the applicability and relevance of work privacy theory by providing an overview on empirical evidence on the predictors of work privacy fit (2.3), on the consequences of poor privacy fit (2.4), and on predictors of individual differences in privacy desires resulting in nonuniform requirements to workplace design (2.5).

\subsection{Prior conceptualisations of work privacy}

Overall, prior perspectives and conceptualisations of work privacy vary greatly in their content, depth, and conceptual grounding (cf. Weber, 2019). The following list of work privacy types used across past studies in various combinations indicates their overlap in content and inconsistencies in conceptualisation.

1 Global work privacy refers to the assessment of privacy by using one global item without further explanation of what work privacy refers to or what the attributes of work privacy are. For example, the assessment might ask participants to rate the degree of general privacy 


\section{Clara Weber et al.}

in their office on a scale ranging from 'not private' to 'private' (Sundstrom, 1986). Another example is to ask participants to rate their satisfaction level with the privacy provided in their workspace (O’Neill \& Carayon, 1993).

2 Speech privacy, sometimes called conversational or communication privacy, refers to the possibility of having conversations at work without others overhearing them (Cavanaugh, Farrell, \& Hirtle, 1962; Oldham, 1988; Sundstrom, 1986). Speech privacy can include the possibility of having conversations without disturbing others (Oldham, 1988; Sundstrom, 1986) as well as not being heard and seen while conversing (Crouch \& Nimran, 1989).

3 Visual privacy captures visual exposure, but not only in regard to work processes (Kim \& de Dear, 2013; Sundstrom, 1986). Occasionally, visual privacy also includes protection from visual distractions (e.g., people passing by; Zalesny \& Farace, 1987). Confusingly, visual privacy has also been referred to as architectural privacy (Rashid \& Zimring, 2008), which in turn is often used to describe architectural qualities of space (e.g., solid walls, soundabsorbing partitions; Goodrich, 1982).

4 Acoustical privacy captures, on the one hand, having conversations that are not overheard, and on the other hand protection from intruding sounds (e.g., Zagreus, Huizenga, Arens, \& Lehrer, 2004).

5 Task privacy encompasses the ability of being able to focus on work. It includes the ability to work with few distractions and interruptions, as well as outcomes of distractions and interruptions such as concentration difficulties or reduced attention; e.g., Oldham, 1988).

\subsection{New conceptualisation of work privacy by Weber (2019)}

Building on Altman's (1975) transactional privacy regulation framework, Weber (2019) proposed a four-dimensional conceptualisation of work privacy to overcome the limitations of previous conceptualisations (cf. 2.1.) She defined work privacy as

a control process of input and output of information and social stimuli in the work environment. Workers attempt to regulate stimuli coming from their colleagues and output they make to their colleagues. Workers strive to achieve the best possible fit between their actual and desired levels of input and output.

(Weber, 2019, p. 28)

This new work privacy conceptualisation follows the six principles of Altman's framework, mentioned earlier. As such, it

- differentiates between work privacy desire, actual work privacy, and work privacy fit;

- includes inputs and outputs in a social work environment system; and

- acknowledges the dynamic nature of privacy desires that can change over time and with different circumstances.

Consequently, it puts forward four distinct work privacy dimensions from the perspective of an individual:

1 distractions (non-directed stimuli/input from others);

2 interruptions (directed social stimuli/input from others);

3 task privacy (visual output to others); and

4 conversation privacy (acoustical output to others). 
Further, Weber (2019) put forward a redevelopment of Altman's privacy framework and applied it to work privacy. In addition to postulating the use of Altman's transactional understanding of privacy fit, she proposed that the conceptualisation and assessment of work privacy fit ought to incorporate an individual's subjective priority of privacy desires (Weber, 2019). This postulation is grounded in Kahana's (1982) empirical P-E work, which informed the assumption that not all aspects of (privacy) desires are equally important within the range of desires and between individuals. Poor privacy fit could be acceptable for some privacy dimensions that are less important to the individual, whereas good or poor privacy fit are expected to be exceptionally important for dimensions that are salient to the individual. This new understanding of privacy fit incorporating subjective priority results in a weighted work privacy fit. This translates to the following new ecological equation: $\left[P R B=f\left(D, A, D^{\star} A \star P r\right)\right]$. Here, privacy regulating-behaviour $(P R B)$ is a function $(f)$ of privacy desires $(D)$, actual privacy $(A)$, and the congruence or privacy fit of privacy desires $(D)$ with actual privacy $(A)$ that is relative to subjective priority $(P r)$ (represented by the interaction term $\left.D^{\star} A \star P r\right) . D^{\star} A \star \operatorname{Pr}$ is a composite variable multiplying the individual's assessment of privacy fit $\left(D^{\star} A\right)$ by the priority of desires $(P r)$ appraised by the individual, comprising a weighted privacy fit.

\subsection{Predictors of work privacy fit}

The exploration and testing of predictors of privacy fit, especially architectural predictors, have been a predominant research topic in work privacy research. However, a large quantity of evidence amounts to outdated findings referring to office concepts that have fallen out of fashion, such as open-plan offices with cubicles. Evidence on more recent office concepts, such as activitybased working $(\mathrm{ABW})$, are scarce, yet researchers have speculated that such concepts support privacy regulation in terms of their particular design and cultural makeup (Engelen et al., 2019). In the following, a summary is given on design and social factors, as it has been postulated that both factors have to complement each other for successful workplace design (Weber, 2019).

\subsubsection{Design and social factors}

Design features that support privacy fit are rooms or stand-alone environmental barriers such as single walls, partitions, planters, and columns (Duvall-Early \& Benedict, 1992; Johnson, 1991; Leder, Newsham, Veitch, Mancini, \& Charles, 2016; Sundstrom, 1986). Although postulated to be of key importance to privacy fit, findings on numbers of partitions enclosing a workspace are conflicting (Weber, 2019). Single findings concern atmospheric properties (light levels, Goodrich, 1982; olfactory elements, Davis, 1990; calmness, Weber, 2019), the symbolic value of spatial elements that suggest privacy (Johnson, 1991), the shape of rooms (Zeisel, 1984), lines of sight (Mehrabian, 1977), spatial density (Oldham, 1988), workstation size (Leder et al., 2016), and seating arrangements (workspaces located away from the main traffic flow, Johnson, 1991; Weber, 2019).

Evidence on social factors that support privacy regulation at work, while minimal, includes policy support and social support (Kupritz, 2000). Policies at work refer to institutionalised social rules and can include elements that facilitate privacy regulation, such as access policy, autonomy over confidential files (Kupritz, 2000), and policies on working from home. Social support refers to any implicit social rules and norms in the social work environment, for example accepted volume of speech (Justa \& Golan, 1977; Steele, 1986). It has been acknowledged that social norms at work can be steered with protocols on how to use different types of office spaces correctly (e.g., Oseland, 2009), and some empirical evidence supports the usefulness of 
protocols in decreasing disturbances by colleagues (Brennan, Chugh, \& Kline, 2002; Bellingar, Kupritz, \& Haworth, 2006; Hedge, 1982; Kupritz \& Haworth, 2005).

\subsubsection{Design and social factors in activity-based working environments}

The design of ABW offices has been suggested to give manifold opportunities to regulate privacy and achieve privacy fit because of the variety of work setting designs provided and the implicit autonomy to use them flexibly (Flynn, 2014; Keeling, Clements-Croome, \& Roesch, 2015; Oseland, 2009). ${ }^{2}$ However, little empirical evidence supports the usefulness of task-based settings for privacy regulation, as most studies have not specifically investigated the link between the office design and privacy fit (Weber, 2019). The little evidence available suggests that perception of setting variety is a positive predictor for privacy fit (e.g., Flynn, 2014). This was confirmed with Weber's (2019) new privacy fit operationalisation in a field experiment, as a move from a standard open-plan office to an ABW office with increased setting variety predicted increased privacy fit.

Social principles particular to ABW that have been suggested to be supportive of privacy regulation and increased privacy fit include location autonomy and protocols (e.g., Flynn, 2014; Oseland, 2009). However, empirical evidence on their impact is mixed. Location autonomy, which is the choice over work location, has been found to be useful to regulate interpersonal interaction and therewith increase privacy fit in some accounts (Robertson, Huang, O'Neill, \& Schleifer, 2008; Weber, 2019), but other accounts have reported an increase in autonomy whilst simultaneously reporting on a decrease in privacy fit in ABW (Medik \& Stettina, 2014). The use of protocols has been found to foster helpful social norms, make the different ABW settings more effective, and therewith support privacy regulation and increase privacy fit (e.g., Bellingar et al., 2006; Brennan et al., 2002; Hedge, 1982; Kupritz \& Haworth, 2005). This was confirmed with Weber's (2019) new privacy fit operationalisation in a field experiment; an increase in adherence to protocols amongst colleagues predicted increased privacy fit.

\subsection{Consequences of poor privacy fit}

The following overview gives evidence on the relationship between privacy and work attitudes (satisfaction); cognitive, emotional, and psycho-physical strain or stress; and work behaviour (performance) when work privacy (mis)fits workers' needs.

\subsubsection{Satisfaction}

There is ample empirical evidence associating privacy fit with job satisfaction and workplace satisfaction. This finding is consistent across studies using different operationalisations of privacy. Examples include general privacy (Sundstrom, 1986); acoustical and visual privacy (Kim \& de Dear, 2013; Klitzman \& Stellman, 1989; Stokols \& Scharf, 1990; Zalesny \& Farace, 1987); speech privacy and task privacy (Oldham, 1988); general privacy, speech privacy, and interruptions (Sundstrom, 1986); acoustical privacy, interruptions, and visual privacy (Leder et al., 2016; Veitch, Charles, Farley, \& Newsham, 2007); general privacy, speech privacy, and visual privacy (O'Neill \& Carayon, 1993); and the new conceptualisation by Weber (2019). Scholars have acknowledged that frequent disturbances, interruptions, and the feeling of being observed can hinder workflow and increase arousal as well as cognitive load, which creates additional demands for the worker, resulting in dissatisfaction (Brennan et al., 2002; Brill, Margulis, Konar, \& BOSTI, 1984; Geen \& Gange, 1977; Haynes, 2007; Kim \& de Dear, 2013; Kupritz, 1998; Laurence et al., 2013; Sundstrom, 1986). 


\subsubsection{Stress, negative affect, and emotional exhaustion}

Health-related outcomes of poor privacy fit have been found concerning various forms of stress, negative affect, and emotional exhaustion (e.g., depleted emotional capacities).

As for stress-related consequences, there is qualitative evidence suggesting that perceived work stress can relate to visual privacy (e.g., feeling visually exposed) and to distractions that hinder task completion (Goodrich, 1982). Similarly, quantitative evidence points to associations between psychosomatic stress (distress) and visual privacy ('other people can see into my workspace'; O’Neill \& Carayon, 1993), as well as distractions and human noise (e.g., Brennan et al., 2002; Raffaello \& Maas, 2002).

As for affect-related consequences, qualitative accounts suggest that noise and interruptions can relate to feelings of anxiety, powerlessness, invasion, annoyance with colleagues (Goodrich, 1982), and other forms of negative affect (Klitzman \& Stellman, 1989; Zijlstra, Roe, Leonora, \& Krediet, 1999). In addition, it has been reported that aspects of visual privacy (e.g., feeling observed), speech privacy, and task privacy (keeping conversations and work content confidential) relate to feelings of vulnerability (Goodrich, 1982).

As for exhaustion-related consequences, quantitative evidence points to an association between poor privacy fit at work and emotional exhaustion (Laurence et al., 2013), which was confirmed with Weber's (2019) four-dimensional operationalisation of privacy fit.

\subsubsection{Work performance and mental fatigue}

Performance reduction due to hindered work processes and mental fatigue (e.g., depleted cognitive capacities) because of a poor privacy fit has often been suggested (e.g., Cohen, 1978; Laurence et al., 2013; Sundstrom \& Sundstrom, 1986). However, empirical evidence which considers multiple dimensions of work privacy is limited, as the majority of evidence concerns the two privacy dimensions distractions and interruptions.

Some studies have shown that distractions and interruptions can affect work on complex tasks (e.g., Goodrich, 1986; Wallis, Steptoe, \& Cole, 2006), lead to concentration difficulties (e.g., Haynes, 2007; Hedge, 1982; Veitch, Bradley, Legault, Norcross, \& Svec, 2002), and result in attention reduction and increased task errors (e.g., Cohen \& Spacapan, 1978; Goodrich, 1986; Kupritz, 1998). Further, studies have reported on associations between distractions and interruptions and difficulties in decision-making processes (Hedge, 1982) as well as task motivational deficits (Evans \& Stecker, 2004). Additionally, self-rated reduction in performance has been reported (e.g., Banbury \& Berry, 1997, 1998; Brill et al., 1984; Kupritz, 1998; Wallis et al., 2006). Further, scholars have made the theoretical assumption that speech and/or task privacy could create additional attentional demands for workers, resulting in reduced cognitive performance (Geen \& Gange, 1977; Laurence et al., 2013; Sundstrom, 1986).

As for evidence that considers multiple dimensions of work privacy, there is first crosssectional and longitudinal evidence on the association between poor privacy fit and mental exhaustion, as assessed with Weber's (2019) four-dimensional operationalisation of privacy fit.

\subsection{Predictors of individual differences in privacy desires}

As Weber (2019) has pointed out, work privacy fit ought to be relative to an individual's priority of privacy desires (i.e., weighted fit). In fact, empirical evidence indicates significant individual response variance in workplace studies (Hoendervanger, Ernst, Albers, Mobach, \& Van Yperen, 2018), leading to nonuniform requirements for workplace design. Various predictors of privacy desires have been suggested that could explain the variance of an individual's priority of desires. 


\section{Clara Weber et al.}

These include personal characteristics (personality, past history and experiences, momentary physiological and psychological state), interpersonal characteristics (relationship to others), and situational factors (job type and role, job task, physical features of settings, and social density; Altman, 1975, Kupritz, 2000; Sundstrom, 1986). The following overview focuses on the most commonly reported predictors of privacy desires, which are job type and task, as well as workers' traits and abilities.

\subsubsection{Job type and task}

There is ample evidence that the nature of a worker's job informs their desire for privacy. As for job tasks, studies show that those who work on highly complex tasks are more likely to experience distractions, are less likely to be satisfied in dense workplaces, and have an increased requirement for limited visual and acoustical distractions as well as interruptions (Fried, Slowik, Ben-David, \& Tiegs, 2001; Oldham, Cummings, Mischel, Schmidtke, \& Zhou, 1995; Seddigh, Berntson, Bodin Danielsson, \& Westerlund, 2014). Further, those who predominantly do group work have been found to experience a better person-environment fit in open-office configurations than those who predominantly do individual work (Haynes, 2008).

As for job types, early research on individuals' privacy needs has significant limitations, as workers' flexibility in being able to regulate privacy at work drastically differed by job type, for example managers were working in private offices whereas administrative staff worked in openplan areas (Sundstrom, Herbert, \& Brown, 1982). The assumption was made that if privacy needs were the same for all job types, they would benefit from the same type of design solution (Kupritz, 2011). However, Kupritz's (2011) newer ethnographic research has indicated that although privacy needs might be shared across job types, the associated environmental solutions can differ significantly. For example, her study showed that managers and technical professionals shared the desire for minimal visual and acoustical distraction as well as minimal interruptions. For managers, the preferred design solution was visual panels for individual work to reduce accessibility and the provision of private rooms for group work ('total enclosure', p. 303); whereas for technical professionals, the preferred design solution was solid walls to reduce sound to a minimum for concentration purposes.

\subsubsection{Traits and abilities}

Individuals' traits and abilities that have been reported to be associated with types of desired work privacy are introversion or extraversion and sensory-processing sensitivity. There is some evidence on the relationship between introversion or extraversion and human noise, in that introverts appear to be more quickly aroused and disturbed by noise than are extroverts (Belojevic, Slepcevic, \& Jakovljevic, 2001; Cassidy \& MacDonald, 2007; Dobbs, Furnham, \& McClelland, 2011; Geen, 1984). Studies on cognitive abilities have also shown that those with high sensory processing sensitivity (weak screening skills or inhibitory ability) have difficulties in coping with socioenvironmental stimuli (Mehrabian, 1977). They have been found to exhibit the lowest self-rated performance, satisfaction, and privacy when working in offices with high social density and with few enclosures; satisfaction and performance were particularly poor when they performed highly complex tasks (Maher \& von Hippel, 2005; Oldham, 1988; Oldham, Kulik, \& Stepina, 1991).

\section{Methodology: assessment methods of work privacy}

This methodology section gives an overview on the predominant quantitative and qualitative methods used in work privacy research and highlights the strengths of each approach. Qualitative 
studies are concerned with 'what' privacy means to people and 'why', while quantitative studies tend to be concerned with 'how much' privacy fit or desire a person experiences in a given context.

\subsection{Quantitative methods}

Work privacy research appears to favour quantitative methods in the form of surveys. However, most of the employed instruments are conceptually and methodologically weak (cf. 2.1). Points of critique include lack of systematic measure development, lack of theoretical grounding of questionnaire items, scale not matching the theory, assessing work privacy globally with a single item instead of assessing types of work privacy, metric inequivalence, poor item construction (e.g., double-barrel items), and inclusion of correlates (e.g., adjustable workspace) or outcomes of privacy (e.g., concentration difficulties).

Based on her new, transactional conceptualisation of work privacy fit (cf. 2.2), Weber (2019) developed the new four-dimensional 'privacy at work' (PAW) measure. PAW uses a weighted fit score $\left(D^{\star} A \star P r\right)$ that reflects subjective prioritisation of privacy requirements. For example, participants' ratings of how often they wanted to 'work without others seeing what they were working on' $(D)$ was correlated with how often participants were able to do so $(A)$ when they wanted to $(P r)$. Initial empirical tests with workers from the construction industry in standard open-plan and ABW office settings have validated the reliability and validity of these conceptually separated but empirically correlating dimensions (Weber, 2019). An in-depth analysis of PAW's reliability (internal consistency, construct reliability, and longitudinal stability) and construct validity (convergent, discriminant, criterion, predictive and nomological validity, and cross-population equivalence) supports the psychometric properties of the measure (Weber \& Gatersleben, in preparation).

\subsection{Qualitative methods}

Qualitative methods for the study of privacy seem to have fallen out of fashion in recent research, whereas they appear to have been popular in early works (e.g., Altman, 1975, 1977; Goodrich, 1982; Justa \& Golan, 1977). The strength of qualitative methods is that because of their indepth analysis they can be used to discover new knowledge, challenge preconceived assumptions (e.g., uniform workplace requirements, Kupritz, 2011), and explore complex inter-relationships between variables (Flyvbjerg, 2006). Predominant qualitative works in the domain of work privacy are those by Kupritz (e.g., 1998, 2011), who took an ethnographic approach by using data triangulation and heuristic elicitation methodology (HEM). The HEM approach relies on different methods of inquiry staged along elicitation phases (Harding \& Livesay, 1984). This process begins with phase 1 , domain definition, which includes a specific in-depth interview process to elicit participants' languages and shared meanings as well as gather first data on the research question (e.g., design features facilitation for job tasks, Kupritz, 2011). In phase 2, beliefs matrix, employees give answers to questions along a binary matrix (e.g., comparing design features to job activities, Kupritz, 2011); the item wording is informed by results of phase 1. To supplement HEM data, Kupritz (e.g., 1998, 2011) used archival records (floorplans, site plans, and background information), descriptive interviews with staff and HR personnel, and field observations with photo documentation at the studied offices. Apart from increasing validity, the merit of using HEM and triangulating qualitative data lies in its usefulness to investigate complex socio-physical issues, such as privacy, that are particularly influenced by contextual (office design and office culture) as well as individual factors (job type and individual traits of personnel) (e.g., Denzin \& Lincoln, 2003). 


\subsection{Research gaps}

Person-focused research on privacy fit could be extended by, firstly, investigating predictors of privacy requirements, while differentiating between job-related predictors (such as job tasks) and individual ability-related predictors (such as sensory processing sensitivity). Secondly, after further testing, employing the PAW measure to facilitate comparable research on privacy fit at work (i.e., privacy fit as a personal outcome and as a potential cause of a variety of work-related effects). Thirdly, exploring mediators that relate privacy fit and stress, such as comfort factors in the environment or coping abilities (and the interaction of both).

Context-focused research about privacy fit could be extended by, firstly, systematically comparing work privacy fit in different office concepts using the same, psychometrically validated tool, and drawing on large-scale data sets. Secondly, investigating how workplace design and culture together can create a work environment conducive to both privacy and togetherness (cf. Weber, 2019). Thirdly, employing gold standards in intervention design (e.g., longitudinal intervention testing using control conditions) to advance this field of research methodologically. These insights would aid the development of non-generic, inclusive work environments.

\section{Limitations}

This section first gives an overview of the main limitations of privacy regulation theory in general and on quantitative work privacy research to date. Secondly, limitations of the new model and measure by Weber (2019) are specified.

Predominant limitations of privacy regulation theory concern its transactional and contextspecific nature. As such, the specifications and measures of work privacy are bound to the work domain and cannot be readily transferred to other contexts, such as the home; the meaning of privacy varies by context. Further, meanings of privacy cues, such as design elements or behaviours, also differ across contexts, work cultures, and national cultures (e.g., Altman, 1975; Justa \& Golan, 1977).

The main limitation in quantitative work privacy research concerns the lack of comparability of results. This is because of the variety of privacy conceptualisations and measures employed (cf. 2.1), the inconsistency in academic standards, and the different terminology used to describe workplaces across different countries and eras (open-plan offices in North America typically include cubicles, but they do not in the EU). Further, most of the present research lacks in-depth understanding of privacy requirements on the individual level (Kupritz, 2011; Weber, 2019).

Limitations of Weber's (2019) new conceptualisation and corresponding measure (PAW) concern the measure's focus on privacy in the life domain of work in distinction to general notions of being private at work (private life in work domain, e.g., making a 'private' phone call to arrange a medical appointment). In addition, the items are cognitive-focused as opposed to affect-focused (e.g., feeling exposed, feeling watched), which focuses but also narrows the scope of assessment. Further, there is a requirement for additional further psychometric testing (e.g., temporal stability or cross-population equivalence using larger samples) and potentially refinement of the measure, for example by adjusting the number of items to achieve conceptual equivalence across the dimensions. In addition, a short version for practice is still in development.

\section{Theory relevance to practice}

Workplace research suffers from comparing apples with oranges because of the lack of theoretically sound, psychometrically valid, and consistently applied measures used for key levers of productive, healthy, and creative work behaviour. Consequently, the decision about an appropriate 
workplace design often relies not on the basis of evidence but on anecdotal experiences of architects, office trends triggered by entrepreneurial efforts to save recognisable fixed costs for 'hard' facts (e.g., scope of rental properties, infrastructure of new buildings), product marketing to open up new sales markets (e.g., for office furniture), and so forth.

Individual work privacy needs have been identified as such key levers (cf. 2.3, 2.4) in spite of the applied conglomerate of assessment instruments. In fact, empirical evidence indicates that generic recommendations which do not take the individuals' work privacy needs into account can lead to investment errors with regards to the equipment and organisation of workspaces; workers' task type and mental abilities, amongst other factors, determine their required level of privacy to work productively (cf. 2.5). Whereas participative user-centred approaches in developing workplace concepts should be employed to overcome this problem, these user-centred assessments ought to differentiate between the four privacy dimensions as they result in different workplace strategies.

A broad use of the newly introduced PAW measurement (Weber, 2019) would help to (a) advance our understanding of the relevance of privacy fit on work-relevant parameters such as work engagement, health, or organisational commitment; (b) simplify the quality assessment of various office concepts; and (c) support the planning and design of cost-efficient inclusive work environments for different user groups.

\section{Further reading}

- Bellingar, T. A., Kupritz, V. W., \& Haworth, Inc. (2006). Privacy matters. Haworth Research Paper.

- Gifford, R. (2016). Research methods for environmental psychology. Chichester: John Wiley \& Sons.

- Kupritz, V. W., \& Haworth, Inc. (2005). Ethnographic assessment of individual and group privacy needs: Phase I and II studies. Haworth Research Paper.

\section{Notes}

1 Lawton and Nahemow's (1973) original equation as well as Lawton's (1987) further development was built on Lewin's (1951) first $\mathrm{P}-\mathrm{E}$ fit model. Lawton's (1987) ecological equation was [B $\left.=f\left(P, E, P^{\star} E\right)\right]$, 'where behaviour $(B)$ is a function $(f)$ of the personal characteristics $(P)$ and environmental characteristics $(E)$, together comprising a 'subjective appraisal' by which the individual perceives the life condition not only through the present situation but through future expectations as well as through past experience ... [The interaction term $\mathrm{P}^{\star} \mathrm{E}$ represents $\mathrm{P}-\mathrm{E}$ fit as] 'the congruence of needs with available environmental supports' (Cvitkovich \& Wister, 2001, p. 3).

2 An environmental principle of ABW environments is the provision of a variety of work settings that differ in their designs to support various work tasks (cf. Keeling et al., 2015). A workplace that supports ABW typically has settings that range from modular project spaces that support interactive collaborative work to sheltered spaces, such as a room-in-room concept, to support highly concentrated individual work. Naturally, these settings vary in their degree of connectedness with people. Often ABW environments are characterised as non-territorial workplaces without, or with only, some allocated seating, but where workers are seated in neighbourhoods allocated to a team (e.g., Engelen et al., 2019). Desks and other work settings are mostly shared among employees (Appel-Meulenbroek, Groenen, \& Janssen, 2011; Wyllie, Green, Nagrath, \& Town, 2012).

\section{References}

Altman, I. (1975). The environment and social behavior: Privacy, personal space, territory, crowding. Monterey, CA: Brooks/Cole.

Altman, I. (1976). Privacy: A conceptual analysis. Environment and Behavior, 8(1), 7-29. https://doi.org/10. 1177/001391657600800102 


\section{Clara Weber et al.}

Altman, I. (1977). Privacy regulation: Cultural universal or culturally specific? Journal of Social Issues, 33(3), 66-84. https://doi.org/10.1111/j.1540-4560.1977.tb01883.x

Appel-Meulenbroek, R., Groenen, P., \& Janssen, I. (2011). An end-user's perspective on activity-based office concepts. Journal of Corporate Real Estate, 13(2), 122-135. https://doi.org/10.1108/14630011111136830

Bailey, G. W. S. (1979). Privacy and the mental. Amsterdam: Rodopi N.V.

Banbury, S., \& Berry, D. C. (1997). Habituation and dishabituation to speech and office noise. Journal of Experimental Psychology: Applied, 3(3), 181-195. https://doi.org/10.1037/1076-898X.3.3.181

Banbury, S., \& Berry, D. C. (1998). Disruption of office-related tasks by speech and office noise. British Journal of Psychology, 89, 499-517. https://doi.org/10.1111/j.2044-8295.1998.tb02699.x

Bates, A. P. (1964). Privacy: A useful concept? Social Forces, 42(4), 429-434.

Beardsley, E. L. (1971). Privacy: Autonomy and selective disclosure. In J. R. Pennock \& J. W. Chapman (Eds.), Nomos XIII: Privacy (pp. 56-70). New York: Atherton Press.

Bellingar, T. A., Kupritz, V. W., \& Haworth, Inc. (2006). Privacy matters. Haworth Research Paper.

Belojevic, G., Slepcevic, V., \& Jakovljevic, B. (2001). Mental performance in noise: The role of introversion. Journal of Environmental Psychology, 21(2), 209-213. https://doi.org/10.1006/jevp.2000.0188

Brennan, S. A., Chugh, J. S., \& Kline, T. (2002). Traditional versus open office design. Environment and Behavior, 34(3), 279-299. https://doi.org/10.1177/0013916502034003001

Brill, M., Margulis, S. T., Konar, E., \& BOSTI. (1984). Using office design to increase productivity. Workplace Design and Productivity. Buffalo, NY: Workplace Design and Productivity Buildings/IAQ.

Cassidy, G., \& MacDonald, R. A. R. (2007). The effect of background music and background noise on the task performance of introverts and extraverts. Psychology of Music, 35(3), 517-537. https://doi.org/10. $1177 / 0305735607076444$

Cavanaugh, W. J., Farrell, W. R., \& Hirtle, P. W. (1962). Speech privacy in buildings. Journal of the Acoustical Society of America, 34(4), 475-492.

Cohen, S. (1978). Environmental load and the allocation of attention. In A. Baum \& S. Valins (Eds.), Advances in environmental psychology (pp. 1-29). Hillsdale, NJ: Lawrence Erlbaum Associates.

Cohen, S., \& Spacapan, S. (1978). The aftereffects of stress: An attentional interpretation. Environmental Psychology \& Nonverbal Behavior, 3(1), 43-57. https://doi.org/10.1007/BF01114531

Crouch, A., \& Nimran, U. (1989). Perceived facilitators and inhibitors of work performance in an office environment. Environment and Behavior, 21(2), 206-226. https://doi.org/10.1177/0013916589212004

Cvitkovich, Y., \& Wister, A. (2001). A comparison of four person-environment fit models applied to older adults. Journal of Housing for the Elderly, 14(1/2), 1-25. https://doi.org/10.1300/J081v14n01_01

Davis, G. (1990). European research on olfactory context as a mediating influence. Presentation at Virginia Polytechnic Institute and State University, College of Architecture.

Denzin, N., \& Lincoln, Y. (2003). Introduction: The discipline and practice of qualitative research. In N. K. Denzin \& Y. S. Lincoln (Eds.), Strategies of qualitative inquiry (pp. 29-71). Thousand Oaks, CA: Sage.

Dobbs, S., Furnham, A., \& McClelland, A. (2011). The effect of background music and noise on the cognitive test performance of introverts and extraverts. Applied Cognitive Psychology, 25(2), 307-313. https://doi.org/10.1177/0305735617704300

Duvall-Early, K., \& Benedict, J. O. (1992). The relationships between privacy and different components of job satisfaction. Environment and Behavior, 24(5), 670-679. https://doi.org/10.1177/0013916592245006

Edwards, J. R., Caplan, R. D., \& Harrison, R. V. (1998). Person-environment fit theory: Conceptual foundations, empirical evidence, and directions for future research. In C. L. Cooper (Ed.), Theories of organizational stress (pp. 28-67). Oxford: Oxford University Press.

Engelen, L., Chau, J., Young, S., Mackey, M., Jeyapalan, D., \& Bauman, A. (2019). Is activity-based working impacting health, work performance and perceptions? A systematic review. Building Research E Information, 47(4), 468-479. https://doi.org/10.1080/09613218.2018.1440958

Evans, G. W., \& Stecker, R. (2004). Motivational consequences of environmental stress. Journal of Environmental Psychology, 24(2), 143-165. https://doi.org/10.1016/S0272-4944(03)00076-8

Fischer, C. T. (1971). Toward the structure of privacy: Implications for psychological assessment. In A. Giorgi, W. G. Fischer, \& R. Von Eckartsberg (Eds.), Duquesne studies in phenomenological psychology (pp. 149-163). Pittsburgh, PA: Duquesne University Press.

Flynn, D. (2014). The privacy crisis. 360 Magazine, 68, 13-35.

Flyvbjerg, B. (2006). Five misunderstandings about case-study research. Qualitative Inquiry, 12(2), 219-245. https://doi.org/10.1177/1077800405284363

Fried, Y., Slowik, L. H., Ben-David, H. A., \& Tiegs, R. B. (2001). Exploring the relationship between workspace density and employee attitudinal reactions: An integrative model. Journal of Occupational and Organizational Psychology, 74(3), 359-372. https://doi.org/10.1348/096317901167406 


\section{Privacy regulation theory}

Geen, R. G. (1984). Preferred stimulation levels in introverts and extroverts: Effects on arousal and performance. Journal of Personality and Social Psychology, 46(6), 1303-1312. https://doi.org/10.1037/ 0022-3514.46.6.1303

Geen, R. G., \& Gange, J. J. (1977). Drive theory of social facilitation: Twelve years of theory and research. Psychological Bulletin, 84(12), 1267-1288. https://doi.org/10.1037/0033-2909.84.6.1267

Goodrich, R. (1982). Seven office evaluations: A review. Environment and Behavior, 14(3), 353-378. https:// doi.org/10.1177/0013916582143006

Goodrich, R. (1986). The perceived office: The office environment as experienced by its users. In J. D. Wineman (Ed.), Behavioral issues in offices design (pp. 109-133). New York: Van Nostrand Reinhold.

Harding, J. R., \& Livesay, J. M. (1984). Anthropology and public policy. In G. McCall \& G. Weber (Eds.), Social science and public policy: The role of academic disciplines in public analysis (pp. 51-85). Port Washington, NY: Associated Faculty Press.

Haynes, B. P. (2007). The impact of the behavioural environment on office productivity. Journal of Facilities Management, 5(3), 158-171. https://doi.org/10.1108/14725960710775045

Haynes, B. P. (2008). The impact of office layout on productivity. Journal of Facilities Management, 6(3), 189-201. https://doi.org/10.1108/14725960810885961

Hedge, A. (1982). The open-plan office: A systematic investigation of employee reactions to their work environment. Environment and Behavior, 14(5), 519-542. https://doi.org/10.1177/0013916582145002

Hoendervanger, J. G., Ernst, A. F., Albers, C. J., Mobach, M. P., \& Van Yperen, N. W. (2018). Individual differences in satisfaction with activity-based work environments. PloS One, 13(3), e0193878. https:// doi.org/10.1371/journal.pone.0193878

Ittelson, W. H., Proshansky, H. M., \& Rivlin, L. G. (1970). Bedroom size and social interaction of the psychiatric ward. Environment and Behavior, 2(3), 255-270. https://doi.org/10.1177/001391657000200301

Johnson, V. W. (1991). Architectural correlates of privacy: The dynamics of privacy regulation [Unpublished doctoral dissertation]. Virginia Polytechnic Institute and State University, 1990.

Justa, F. C., \& Golan, M. B. (1977). Office design: Is privacy still a problem? Journal of Architectural Research, $6(2), 5-12$.

Kahana, E. (1982). A congruence model of person-environment interaction. In M. P. Lawton, P. G. Windley, \& T. O. Byerts (Eds.), Aging and the environment: Theoretical approaches (pp. 97-121). New York: Springer.

Keeling, T., Clements-Croome, D., \& Roesch, E. (2015). The effect of agile workspace and remote working on experiences of privacy, crowding and satisfaction. Buildings, 5(3), 880-898. https://doi. org/10.3390/buildings5030880

Kelvin, P. (1973). A socio-psychological examination of privacy. British Journal of Social and Clinical Psychology, 12, 248-296. https://doi.org/10.1111/j.2044-8260.1973.tb00065.x

Kim, J., \& de Dear, R. (2013). Workspace satisfaction: The privacy-communication trade-off in open-plan offices. Journal of Environmental Psychology, 36, 18-26. https://doi.org/10.1016/j.jenvp.2013.06.007

Klitzman, S., \& Stellman, J. (1989). The impact of the physical environment on the psychological well-being of office workers. Social Science \& Medicine, 29(6), 733-742. https://doi.org/10.1016/0277-9536(89)9 0153-6

Kupritz, V. W. (1998). Privacy in the workplace: The impact of building design. Journal of Environmental Psychology, 18(4), 341-356. https://doi.org/10.1006/jevp.1998.0081

Kupritz, V. W. (2000). Privacy management at work: A conceptual model. Journal of Architectural and Planning Research, 17(1), 47-63.

Kupritz, V. W. (2011). Individual and group privacy needs across job types: Phase 1 study. Journal of Architectural and Planning Research, 28(4), 292-313.

Kupritz, V. W., \& Haworth, Inc. (2005). Ethnographic assessment of individual and group privacy needs: Phase I and II studies. Haworth Research Paper.

Laurence, G. A., Fried, Y., \& Slowik, L. H. (2013). My space: A moderated mediation model of the effect of architectural and experienced privacy and workspace personalization on emotional exhaustion at work. Journal of Environmental Psychology, 36, 144-152. https://doi.org/10.1016/j.jenvp.2013.07.011

Lawton, M. P. (1987). Environment and the need satisfaction of the aged. Unpublished Paper.

Lawton, M. P., \& Nahemow, L. (1973). An ecological theory of adaptive behaviour and aging. In C. Eisdorfer \& M. P. Lawton (Eds.), The psychology of adult development and aging (pp. 657-667). Washington: American Psychological Association.

Leder, S., Newsham, G. R., Veitch, J. A., Mancini, S., \& Charles, K. E. (2016). Effects of office environment on employee satisfaction: A new analysis. Building Research E Information, 44(1), 34-50. https:// doi.org/10.1080/09613218.2014.1003176 


\section{Clara Weber et al.}

Le Poire, B. A., Burgoon, J. K., \& Parrott, R. (1992). Status and privacy restoring communication in the work place. Journal of Applied Communication Research, 20(4), 419-436. https://doi.org/10.1080/009098892093 65347

Lewin, K. (1951). Field theory in social science: Selected theoretical papers (D. Cartwright, Ed.). New York: Harper \& Brothers.

Maher, A., \& von Hippel, C. (2005). Individual differences in employee reactions to open-plan offices. Journal of Environmental Psychology, 25(2), 219-229. https://doi.org/10.1016/j.jenvp.2005.05.002

Margulis, S. T. (1977). Conceptions of privacy: Current status and next steps. Journal of Social Issues, 33, 5-21. https://doi.org/10.1111/j.1540-4560.1977.tb01879.x

Marshall, N. J. (1972). Privacy and environment. Human Ecology, 1(2), 93-110.

Medik, V. L., \& Stettina, C. J. (2014). Towards responsible workplace innovation: The rise of NWW in public knowledge organizations and their impact on governance. In International conference on engineering, technology and innovation. Bergamo, Italy. https://doi.org/10.1109/ICE.2014.6871538

Mehrabian, A. (1977). A questionnaire measure of individual difference in stimulus screening and associated differences in arousability. Environmental Psychology and Nonverbal Behaviour, 1(2), 89-103. https:// doi.org/10.1007/BF01145458

Newell, P. B. (1995). Perspectives on privacy. Journal of Environmental Psychology, 15(2), 87-104. https:// doi.org/10.1016/0272-4944(95)90018-7

Nunnally, J. C. (1967). Psychometric theory. New York: McGraw Hill.

Oldham, G. R. (1988). Effects of changes in workspace partitions and spatial density on employee reactions: A quasi-experiment. Journal of Applied Psychology, 73(2), 253-258. https://doi.org/10.1037/00 21-9010.73.2.253

Oldham, G. R., Cummings, A., Mischel, L. J., Schmidtke, J. M., \& Zhou, J. (1995). Listen while you work? Quasi-experimental relations between personal-stereo headset use and employee work responses. Journal of Applied Psychology, 80(5), 547-564. https://doi.org/10.1037/0021-9010.80.5.547

Oldham, G. R., Kulik, C. T., \& Stepina, L. P. (1991). Physical environments and employee reactions: Effects of stimulus-screening skills and job complexity. Academy of Management Journal, 34(4), 929-938. https://doi.org/10.2307/256397

O'Neill, M. J., \& Carayon, P. (1993). The relationship between privacy, control, and stress responses in office workers. Proceedings of the Human Factors and Ergonomics Society Annual Meeting, 37(7), 479-483. https://doi.org/10.1177/154193129303700702

Oseland, N. (2009). The impact of psychological needs on office design. Journal of Corporate Real Estate, 11(4), 244-254. https://doi.org/10.1108/14630010911006738

Pedersen, D. M. (1979). Dimensions of privacy. Perceptual and Motor Skills, 48(3), 1291-1297. https://doi. org/10.2466/pms.1979.48.3c.1291

Pedersen, D. M. (1999). Model for types of privacy by privacy functions. Journal of Environmental Psychology, 19(4), 397-405. https://doi.org/10.1006/jevp.1999.0140

Raffaello, M., \& Maas, A. (2002). Chronic exposure to noise in industry. Environment and Behavior, 34(5), 651-671. https://doi.org/10.1177/0013916502034005005

Rashid, M., \& Zimring, C. (2008). A review of the empirical literature on the relationships between indoor environment and stress in health care and office settings: Problems and prospects of sharing evidence. Environment and Behavior, 40(2),151-190. https://doi.org/10.1177/0013916507311550

Robertson, M. M., Huang, Y. H., O’Neill, M. J., \& Schleifer, L. M. (2008). Flexible workspace design and ergonomics training: Impacts on the psychosocial work environment, musculoskeletal health, and work effectiveness among knowledge workers. Applied Ergonomics, 39(4), 482-494. https://doi.org/10.1016/j. apergo.2008.02.022

Schoeman, F. D. (1984). Philosophical dimensions of privacy: An anthology. New York: Cambridge University Press.

Seddigh, A., Berntson, E., Bodin Danielsson, C., \& Westerlund, H. (2014). Concentration requirements modify the effect of office type on indicators of health and performance. Journal of Environmental Psychology, 38, 167-174. https://doi.org/10.1016/j.jenvp.2014.01.009

Shils, E. B. (1966). Privacy: Its constitution and vicissitudes. Law and Contemporary Problems, 31, 281-305.

Steele, F. I. (1986). Making and managing high-quality workplaces: An organizational ecology. New York: Teachers College Press.

Stokols, D., \& Scharf, T. (1990). Developing standardized tools for assessing employees' ratings of facility performance. In G. Davis \& F. Ventre (Eds.), Performance of buildings and serviceability of facilities, ASTM STP 1029 (pp. 55-79). Philadelphia, PA: American Society for Testing and Materials. 
Sundstrom, E. (1986). Privacy in the office. In J. D. Wineman (Ed.), Behavioral issues in office design (pp. 177203). New York: Van Nostrand.

Sundstrom, E., Herbert, R. K., \& Brown, D. (1982). Privacy and communication in an open plan office: A case study. Environment and Behavior, 14(3), 379-392. https://doi.org/10.1177/0013916582143007

Sundstrom, E., \& Sundstrom, M. G. (1986). Work places: The psychology of physical environment in offices and factories. Cambridge: Cambridge University Press.

Veitch, J. A., Bradley, J. S., Legault, L. M., Norcross, S. G., \& Svec, J. M. (2002). Masking speech in open-plan offices with simulated ventilation noise: Noise level and spectral compositing effects on acoustic satisfaction. Ottawa, Canada: NRC Institute for Research in Construction. https://doi.org/10.4224/20386334

Veitch, J. A., Charles, K. E., Farley, K. M. J., \& Newsham, G. R. (2007). A model of satisfaction with open-plan office conditions: COPE field findings. Journal of Environmental Psychology, 27(3), 177-189. https://doi.org/10.1016/j.jenvp.2007.04.002

Wallis, C., Steptoe, S., \& Cole, W. (2006). Help! I've lost my focus. Time, 167(3), 72-79.

Weber, C. (2019). Privacy fit in open-plan offices: Its appraisal, associated outcomes $\mathcal{E}$ contextual factors [Doctoral dissertation]. University of Surrey, SRI Publishing. https://doi.org/10.15126/thesis.00850409

Weber, C., \& Gatersleben, B. (in preparation). The measurement of privacy at work: Evaluation of the privacy at work inventory.

Webster, N. (1979). Webster's new twentieth century unabridged dictionary. New York: Publishers International.

Westin, A. F. (1970). Privacy and freedom. New York: Atheneum.

Wyllie, T., Green, M., Nagrath, R., \& Town, A. (2012). Activity based working. Retrieved from www.jll. com.au/australia/en-au/Documents/jll-au-activity-based-working-2012.pdf

Zagreus, L., Huizenga, C., Arens, E., \& Lehrer, D. (2004). Listening to the occupants: A web-based indoor environmental quality survey. Indoor Air, 14(8), 65-74. https://doi.org/10.1111/j.1600-0668.2004.00301.x

Zalesny, M., \& Farace, R. (1987). Traditional versus open offices: A comparison of sociotechnical, social relations, and symbolic meaning perspectives. Academy of Management Journal, 30(2), 240-259. https:// doi.org/10.5465/256272

Zeisel, J. (1984). Inquiry by design. Cambridge: Cambridge University Press.

Zijlstra, F. R. H., Roe, R. A., Leonora, A. B., \& Krediet, I. (1999). Temporal factors in mental work: Effects of interrupted activities. Journal of Occupational and Organizational Psychology, 72(2), 163-186. https://doi. org/10.1348/096317999166581 


\title{
7 \\ INFORMATION SPACE(S)
}

\author{
Mascha Will-Zocholl*
}

\section{Background}

The concept of the 'information space' was introduced in 1996 by Andrea Baukrowitz and Andreas Boes in the context of their reflections on virtual working environments, as they were to emerge in the context of the new phase of informatisation, now associated with the spread of new information and communication technologies and the internet (Baukrowitz \& Boes, 1996). They used the term to describe the consequences for work and its organisation as well as organisations. This information space is more than a technical infrastructure or 'data motorways', but "a space of social action enabling saving, handling or exchanging information and information objects" (Boes, Kämpf, Langes, \& Lühr, 2017, p. 153). The information space further refers to the blurring boundaries of work and private life, physical and virtual beings, places and spaces; in sum, the consequences of the digital transformation affect all areas of life (Boes, Kämpf, \& Ziegler, 2020b). When Baukrowitz and Boes published their considerations, the internet was still in its infancy. It was a relatively confusing virtual space, with no search engines and only reachable by slow and unreliable connection, with hardly any data volume provided. However, the use of personal computers at the workplace reached a significant level in the 1990s, when concrete ideas for a flexibilisation of places of work were discussed (see the first studies on the potential of telework in Huws, Krte, \& Robinson, 1990).

Therefore, even if the technologies themselves were not yet mature and powerful, they allowed projections on the future development of work: the emergence of the information space as a 'global space of production' (Boes \& Kämpf, 2007) that enables changing modes of production (especially in knowledge work), business models and the global division of labour. Their understanding of space is shaped by more recent versions of the sociology of space, which parts from the idea of space as built space and now understands 'space' as a socially produced space (see also Chapter 8 Social Constructionism Theory). This means working spaces only arise when people work together, regardless of where exactly they are located (Lefebvre, 1991; Löw, 2013). The concept goes even further, however, in that all computerised and digitalised spheres of our everyday life are (re)organised via the information space, that is, private and professional contexts overlap or can simultaneously be the object of action in the information space. To illustrate this distinction of multiple layers, it can be helpful to speak of information spaces that arise in the specific context of interaction rather than of a globally encompassing information space. Authors

*Corresponding author: mascha.will-zocholl@hfpv-hessen.de 


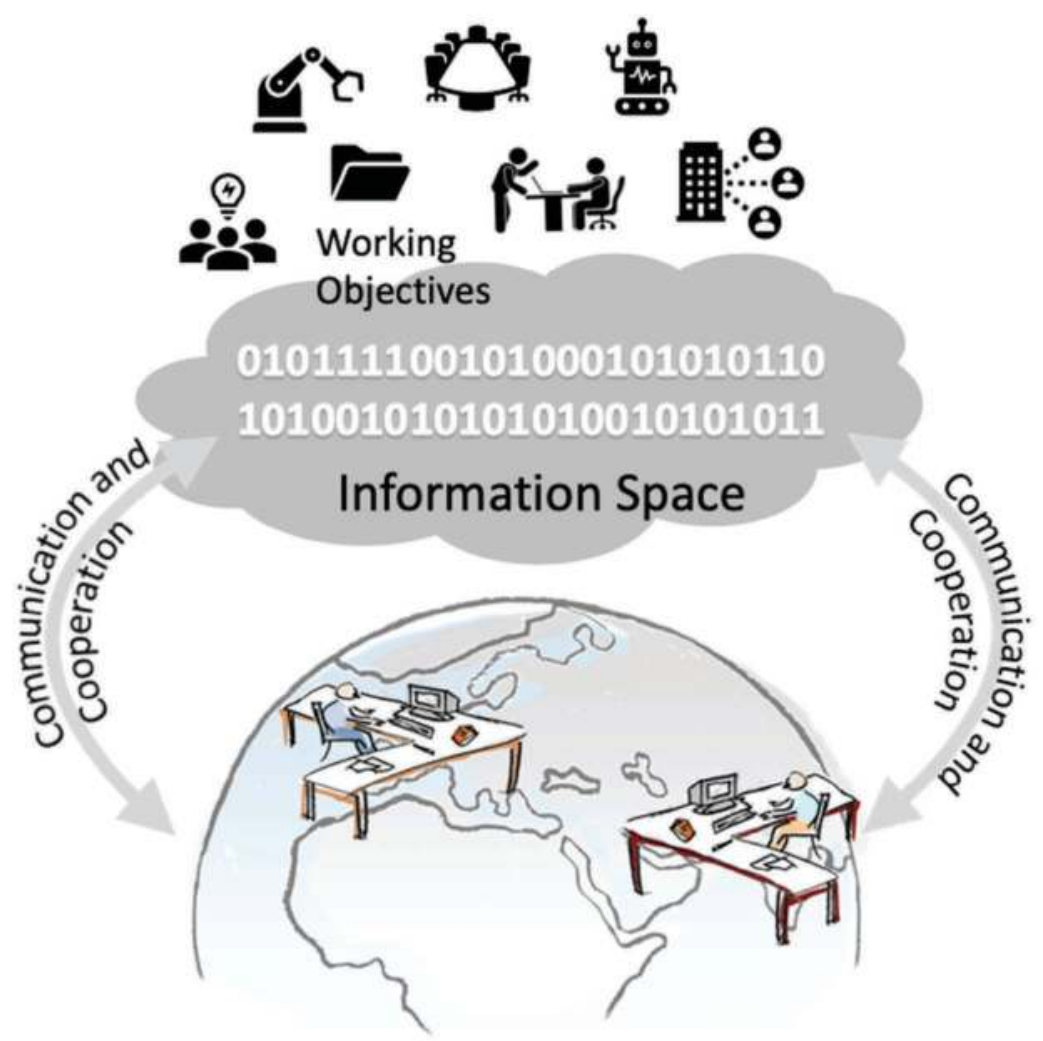

Figure 7.1 Information space (own figure, illustration ISF Munich)

covering the topic decided for certain reasons to use the singular to describe the world-spanning possibility space (Baukrowitz \& Boes, 1996; Boes et al., 2017). In this way, the differences can also be taken into account, for example with regard to the context, the specific topology of workplaces, locations, persons involved, time zones, local characteristics and cultural specifics.

The concept of 'information space' differed from others discussed at that time -like 'cyberspace' highlighting the social conditions of space instead of technical requirements - as it was in line with traditional spatial research and emphasised the flow of information as 'data highways', a mode of infrastructure, mainly discussed in the computer-supported-collaborative-work (CSCW) community. Some authors already thought ahead of the technological options of their time and dealt with broader concepts of information and media spaces that are today more topical than they were during the 1990s (e.g. Bley, Harrison, \& Irwin, 1993; Fitzmaurice, 1993; Streitz, Geißler \& Holmer, 1998).

With the shift of the work object into the information space, new possibilities of the division of labour become possible and realisable. A prerequisite for the emergence of an information space is the process of informatisation. What is it about? The term computerisation in the sense of the increasing spread of computer technologies is often associated with informatisation. However, this understanding does not go far enough, as it is based only on a technical development and covers a relatively short period. The sociological-historical process of informatisation, thus the process of generating and using information, opens up the view on a more systematic 
process of handling information and the use of information systems as part of the capitalist economic logic (Schmiede, 2006). The debate is further linked to Manuel Castells's diagnosis of an 'informational capitalism' (1996), in which classical means of production, capital and labour are replaced by information and knowledge. This means that by using technologies of information and knowledge, an information layer parallel to (work) processes is established to enhance transparency in working environments. The informatisation approach eases the embedding of the digitalisation issues into a historical context, which makes it easier to identify qualitative leaps about the new technologies in use. Information systems are part of societal productive forces, which address mental and cognitive processes of human work in particular (Boes et al., 2017). As Boes et al. explain,

we understand informatisation as a social process geared to rendering mental activities and their results accessible to others. Thus, informatisation means a process of externalising mental processes and their reification in media that can be used in a social context, beyond the individual.

(2017, p. 156)

From this point of view, informatisation enables information being available for the reorganisation of the division of labour.

The progressive digitisation of objects and processes marks a new phase in the informatisation process and now allows reorganising work through the information space. This means new possibilities to create workspaces (virtual workspaces, mobile workplaces), the international division of labour, new value chains (such as outsourcing and offshoring) and new business models (e.g. platform work) as well as a flexibilisation and multiplication of workplaces. During the last decades information handling extended as ever-larger amounts of information and data could be processed and are easily accessible in the information space. Informatisation not only considers the dimension of new information systems, but it also changes organisational structures, evolves new forms of control and a new quality of the utilisation of work and subjectivity as well as liberates and emancipates potentials.

Especially for today's knowledge workers, this development goes along with a multiplication of spatial scales they are working in: they can be sitting in an office with colleagues at the same time as chatting with teammates at home and emailing international customers. They participate in more than one social action space at the same time, virtually and physically. The integration of work through the information space often leads to the misleading assumption that place becomes unimportant. Flecker and Schönauer (2016) speak of the construction of 'placelessness' to foster the international division of labour. Nevertheless, evidence shows that even in the information space(s), places remain important levels of reference to which, for example, cultural understandings of work or competencies are linked. Further, local communities foster innovation, as Wenger (1998) emphasises in his conceptualisation of 'Communities of Practice'. It shows that the shift of the action level into the information space is not completely successful, as we can see from the increasing business travel activities (before the COVID-19 crisis) or the practice of assigning people on site to the client for the period of cooperation. Instead of 'placelessness', it is more a matter of linking physical places and virtual spaces for action (in the information space).

The consequences of inventing information space(s) are listed as follows:

1 From a macro-perspective, the already mentioned construction of 'placelessness', in terms of 'anyplace, anytime', is often used as a strategic component, for example to justify the reduction of permanently assigned jobs or to create pressure within the workforce between 
different locations or suppliers, nowadays no longer limited to low-skilled production work but all forms of knowledge work. It is reflected in concepts such as 'global engineering' (e.g. Continental, 2006; Will-Zocholl, 2016), 'global sourcing' strategies and 'shared service centres' (Howcroft \& Richardson, 2012), but also in reorganisation of value chains such as off- and nearshoring or crowdwork (e.g. Boes \& Kämpf, 2007; Flecker \& Schönauer, 2016; Hardy \& Hollinshead, 2011).

2 Further information space(s) enables new ways and a new quality of collaboration across different locations, on site and in informatised structures. Knowledge is shared and learning is possible by the documentation of former interaction of others, for example by the use of corporate wikis etc. Everything previously discussed, communicated and processed is now transparently accessible for everyone - even at a later date. The extensive use of the home office during the COVID-19 pandemic showed what is possible to do via information space(s). This new quality opens up scope for empowerment and emancipation potentials for employees to take over more self-organisation if they participate in the digital transformation process (Boes, Gül, Kämpf, \& Lühr, 2020a). ${ }^{1}$

3 The information space and the aspects mentioned under item 1 promote an 'industrialisation of knowledge work' (Boes et al., 2017, p. 163), that is, it becomes more and more similar to production work by standardising parts of the work, limiting the potential for action and tightening control. Rationalisation potential emerges, with the result that individual expertise loses value (Boes et al., 2017). This means that with an ongoing informatisation high-skilled work especially is affected by a revival of Tayloristic approaches. Beyond classical understandings of Taylorism, a new quality emerges in how subjective contributions of knowledge workers (like creativity, problem-solving) are integrated in industrialised work processes. $^{2}$

4 The production of 'placelessness' from a micro-perspective goes along with a loosening of the attachment (see also Chapter 16 Place Attachment) to certain places and thus a certain workplace, on the one hand. And a growing importance of physical places and workspaces (with all things connected to it) for the work itself and the individuals, on the other hand (see next section).

5 The simultaneity of work at physical workplaces and in the information space (and here the simultaneity of different workspaces in the information space), including border management at different levels (Roth-Ebner, 2015), needs to be managed by individuals. This is associated with higher demands on the subjectivity of the employees (self-organisation, selfcontrol, self-management). The situation of 'different people in different places in the same work contexts etc.' also brings new challenges at the management level, such as distributed leadership and disciplinary responsibility. The mixing and simultaneity of different spatial scales require that the design of virtual and of physical working worlds needs equal importance. For design, this means thinking through the information space: today, the office is no longer just about the office as a physical space but always about the office as part of the information space.

6 Greater global networking, a more international division of labour and more simultaneousness also lead to increasing complexity. This concerns on the one hand the work itself and on the other hand the work organisation and workplaces (e.g. in models in which fewer workplaces are kept than employees potentially working in the offices).

The emergence of a 'regime of availability' results from the transformation of the 'workplace' into an information object and its relocation into the information space vs. the claim to draw boundaries in order to reconcile work and life. These consequences show that far-reaching 
changes based primarily on a dominance of the information level accompany the emergence of the information space. This allows new social spaces of action to emerge, which have different connections to physical places and show new forms of cooperation, knowledge exchange and the use of mental productive forces. At the same time, the transparency of work processes, activities and communication is increasing - and so is the possibility of control and empowerment at the same time (Boes et al., 2017, 2020a). In view of the developments described previously, the question arises as to what is relevant for workplace studies.

\section{Applicability to workplace studies}

The theory of information space(s) is not a classical workplace theory, but it could make an important contribution to a better understanding of the impact of digitisation (and virtualisation) to/on workplaces, leadership and management and hint at the design of such workplaces. As it refers to the changing materiality of workplaces in the course of advancing use of technologies and digitalisation and especially to the emergence of new working spaces, this approach emphasises the matter of space as well as the challenges of parallel existing virtual spaces and places where people work. The embedding of the current developments of digitisation in a historical context also allows us to understand the increasing computerisation and emergence of the internet as a social process, which is leading to challenges for actors in the world of work, especially for working people.

Three aspects in particular (out of those already mentioned in Section 1) will be in the focus of attention here and will be explained in the following subsections:

1 The production of 'placelessness', or better referred to as the loosening of the attachment (see also Chapter 16 Place Attachment) to certain places and thus also a certain workplace, vs. the importance of physical places and the workplace (with all things connected to it) for the work itself.

2 The regime of availability resulting from the transformation of the 'workplace' into an information object and its relocation into the information space vs. the claim to draw boundaries in order to reconcile work and life.

3 The simultaneity of work at physical workplaces and the information space (and here the simultaneity of different workspaces in the information space) vs. serial work processes and fixed workplaces in offices.

\subsection{Production of 'placelessness'}

The emergence of an information space nourishes the idea that work can be organised regardless of place and location: 'anyplace, anytime'. This is taken up, for example, in concepts such as the 'digital nomad' (Makimoto \& Manners, 1997) or the 'digital bohemian' (Friebe \& Lobo, 2006), in which digitalised work is a prototype of translocal and mobile work, which appears detached from any temporal and local references. A look at the everyday life of digitised and translocal work makes it clear that there is a need to differentiate. Digitised work can be locally bound (e.g. parts of the administrative processing that has to be offered locally as face-to-face service), and translocal work can be less digitised (mobile service technicians, care workers etc.). Even in fields that at first glance appear to be 'placeless', empirical results point in other directions, so that doubts are justified about the assumption of 'placelessness' which does not simply occur, but is actively produced (Flecker \& Schönauer, 2016). Rather, the aforementioned studies show that location is indeed important. This starts with simple basic conditions (such as local time) 
and extends to cultural practices inscribed in the body, which are also effective in the information space.

These limitations of the assumption of 'placelessness' are also evident in the context of office workplaces. On the one hand, we tend to see a multiplication of places used for working, such as co-working spaces, the home office, the train, the car, etc. These places are not arbitrary but chosen carefully, as Liegl (2014) points out in his investigation of mobile work. In addition, individual knowledge workers are increasingly working from different places. On the other hand, one's own workplace in the office is not just a table, a chair and the technical equipment. It is a social space that expresses the recognition of one's own work (by the organisation, colleagues, clients etc.) and the centrality of work in peoples' lives. The latter is also the reason why flexible desk models are so controversial. People experience the loss of a private workplace as a loss of recognition and develop placing practices to mitigate this (e.g. Petendra, 2015).

\subsection{Availability regimes $v$ s. boundary setting}

The integration and distribution of work through the information space(s) and the construction of 'placelessness' is leading to a melange of consequences for the individual. More freedom in the organisation of work and the choice of place of work means that each individual has more decisions, boundaries and demarcations to make for oneself. This is one aspect of why the informatisation formulates new demands on employee subjectivity and points to a greater need for self-organisation. This capacity for self-organisation alone represents a major challenge for some employees. If the organisation gives the impression that drawing boundaries is undesirable, for example by criticising a lack of accessibility, this exacerbates the situation. When organisations fail to find binding rules for the work of their employees and implicit and explicit demands for availability increase, time and place sovereignty turns into a regime of availability, with all the negative consequences described in many studies on workload, challenges of demarcation and health effects. In order to avoid this, it is important for leadership and management to be clear about the expectations of work in the information space and especially about the situation where employees work outside the office, to create clear regulations and transparency about which parameters are in use, for example, to evaluate their work. Thinking about work and its different places through the information space opens a perspective to consider the design of local workplaces, the necessary structures and conditions.

\subsection{Simultaneity of work at places and spaces}

The current phase of working in information spaces is characterised by a simultaneity of the working processes in different work places and spaces (Roth-Ebner, 2016). By shifting the object of work into the information space, not only the processes change, but also the working methods and the nature of work, which require skills, competencies and resources (e.g. Boes, 2017; Roth-Ebner, 2015; Ryser, Angerer, Ganesh, \& Schulze, 2016). Dealing with simultaneous virtual spaces and places represents a major challenge for today's workers who work in such contexts. This 'being in one place' and being integrated into information spaces (not limited to professional ones) at the same time can currently be well observed in face of the COVID-19 crisis at the home office: simultaneous home-schooling activities while working.

But even outside the home office, simultaneity brings challenges - not least in the design of the workplace (see also Chapter 4 Task-Technology Fit Theory and its concept of technostress). How much simultaneity of virtual and physical presence is desirable? How do places structure 
work and help employees cope with the increasing simultaneity and complexity? These questions are also raised in terms of designing office spaces. The design of these can no longer be thought through solely in their material-objective components, that is, the built space, furniture, light, air, etc., but must also be thought through the lens of the information space. This is so particularly because it is already becoming apparent, through intelligent lighting control or sensor-based measurements (length of sitting time etc.), that essential best parts of the built space have also already reached an information level. It is also a matter of linking the built world and the desk with work in the virtual world and drawing concrete conclusions for design from this perspective.

\section{Methodology/research approach}

How does one explore the impact of information space(s)? From a macro-perspective, the theory of information space ${ }^{3}$ helps to clarify the disruptive potential of the digital transformation, which calls into question everything that has existed so far (see e.g. contributions in Will-Zocholl \& Roth-Ebner, 2021). It helps in developing an integrative perspective on organisational development, value chains and business models, for example in the IT branch, the automotive industry, platform work and call centre work (e.g. Boes et al., 2017; Flecker \& Schönauer, 2016; Vogl, 2018; Will-Zocholl, 2016).

From a micro-perspective, the changes in the nature of work (especially knowledge work) like industrialisation, standardisation and rationalisation of work processes are research outcomes (Boes et al., 2017; Kämpf, 2018; Schmiede \& Will-Zocholl, 2011) that further enhance the understanding of working on- and offline at the same time from different places (Roth-Ebner, 2016) and the spatial imaginations people working have. Finally, yet importantly, information space theory has helped in thinking about the qualifications and competencies of people working in those contexts (Boes, 2017; Roth-Ebner, 2015; Will-Zocholl, 2016).

Most of the previous studies used qualitative methods. These mainly consisted of industrial sociological case studies (Pongratz \& Trinczek, 2010), in which the organisation itself, its structures and functioning, are examined. In other studies, the work in mostly specific fields of activity or qualification is the focus. The methods in use are diverse:

1 Document analysis (e.g. Bowen, 2009), especially of internal documents, but also statistics, etc. to learn more about the structure and functioning of the organisation;

2 Participatory observation at the workplace that can provide important impulses about the use of technologies and practices in work, about their topologies of work and their interaction on a small scale;

3 Qualitative, mostly guided, interviews with employees, employee representatives or functionaries in the company to learn more about their individual and/or professional perspectives (e.g. Flick, 2018).

The combination of different approaches makes it possible to gain a comprehensive perspective of the phenomena, especially to gain insight into how the organisational level and the level of individual work merge. Other studies use different combinations of methods, for example a triangulation of drawing mental maps, qualitative interviews and a quantitative survey (RothEbner, 2016; Roth-Ebner, 2015). Mental maps in particular are very well suited for capturing the experience of space and place. In addition, the keeping of thematically structured diaries, the diary method, can provide important insights, for example about the use of certain technologies (e.g. Hyers, 2018). In addition, other research concepts such as organisational ethnographies (e.g. Ybema, Yanow, Wels, \& Kamsteeg, 2009) and action research approaches seem to be suitable. 
Nowadays huge amounts of data are generated and stored in IT systems in the course of daily work or could be recorded for evaluation purposes, for example how high the communication effort is or in how many contexts simultaneous participation takes place. The use of such data can be fruitful in the course of future research.

For future research in the context of information spaces and workplaces, it is important to integrate the perspective of the employees even more than before, since they have to make many decisions in their work organisation themselves. For example, an attempt could be made to identify situations in which employees would like certain spatial conditions or consider them helpful in organising their work, but also in order to distance themselves from their private lives or to stay in contact with colleagues or to feel attached to a company (or colleagues) even when locally separated. In addition, it is necessary to ascertain how and to what extent they use which tools, places and so on and to consider how these data can also be collected and analysed in a qualitative (in contrast to purely quantitative use) manner. This is important for learning more about the spatial practices that emerge when working in information space(s) in interaction with places, but also with people and in organisations.

\section{Limitations}

As universal as the theory may sound, it developed primarily in the context of - and according to - developments in manufacturing sectors, especially in the IT industry. This in turn has specific characteristics that make it a pioneer for future developments in other industries, but it also deals with a specific materiality of working objects: their transferability into the information space. For example, in software engineering the object of work is an information object without any compelling connection to build (material-objective) components. This means that the work can be broken down into any number of individual work packages and, accordingly, is distributed among people who come together in the information space at different locations around the world. In practice, limitations emerge as place is incorporated in the form of competences, habits and cultural practices. This extreme form of detachment from materialobjective things hardly occurs in other activities (most likely in management consultancy). In most other areas of knowledge work there is a connection between material-objective components and abstract parts of work, which evolves into the challenge of connecting the virtual and the analogue world (e.g. in engineering), in terms of working objects, people, places and virtual spaces.

The theory is limited to informatised work, which means that significant parts of work are transferable into the information space, which is obviously true for office work. But the COVID-19 pandemic shows that the areas reorganised by information space(s) continuously increase, and today it can be estimated that this is now already the case for about half the workforce in industrialised countries. The same also happens in corporal service and production work and even in schools. This occurs with gradations of the consequences described here, even if the working objects are not completely transformed.

\section{Theory relevance to practice}

The theory of information spaces may help to embed current developments into a broader frame. In particular, it contributes to the question of how people deal with being present in physical places and in different virtual spaces at the same time. The juggling of these different places and spaces in different spheres, both professionally and privately, is a fundamental necessity for the individual. It is important to understand this in order to find out the challenges and 
demands on subjectivity that these circumstances are associated with. The human being must be at the centre of attention in technologised working environments, including in the design of workplaces and spaces. This helps to explain informatisation and digitalisation as social processes rather than just focusing on 'technology' and understanding these developments solely as a technology-driven process, as the current digitalisation debate emphasises (critically: Boes \& Kämpf, 2007; Pfeiffer, 2017). This begins with understanding technological development itself as a social process, implemented by people and their ideas about function and modes of action that play just as much a role as their ideas about the future. Thus, digitisation is more than the transformation of analogue information into a digital form. It is also a social transformation process that is made, designed and desired, affects all areas of life, organisations and work, and fundamentally changes our relationships and networks - our lives (Boes et al., 2020b).

For the management of organisations this means actively involving employees in these change processes. Change management here means not only carrying out the already decided reorganisation or introduction of new IT without friction, but also letting employees participate in these decisions or increasing their scope of action instead of restricting it, as is often the case (keyword: empowerment). With view of office workplaces, it also presupposes that in the organisation, a detachment from the link between private office workplaces and recognition in work is promoted. This step is necessary if more flexible office work concepts are the goal to increase efficiency of office use and if these shall not - as in many cases - be experienced as degradation of one's own work. The same applies to rewarding presence, for example for promotions, and to recognising the problem that people who work in the information space from different locations have in fighting for visibility outside the information space, for example currently increasingly via social media (Twitter, LinkedIn etc.)

For corporate real estate management and facility management, it is essential that workspaces are not only thought of in their built form (office) or as a dichotomy of physical space and virtual space. It is also important that workspaces between people are only created when they work together, regardless of where they are located. For the office, this means that the people physically there do not only necessarily share a workspace with others who are physically there. At the same time they also work in information space(s) with others abroad, in their offices or at home. It is also possible that at certain times, they work from home alone without being part of neither a physical office nor information space(s). This development is linked to studies showing that employees no longer want to work in the office all the time (e.g.Nappi \& de Campos Ribeiro, 2021). The reason given for coming to the office is often that they want to feel part of a community, which is less successful in virtual teams. This also has consequences for the office as a place, as part of the built environment and the concepts that calculate, for example, the need for office workplaces or the design of spaces.

This is also a starting point for the work of facility management, which can support this need for community through appropriate services and activities and not just concentrate on the functioning of the spatial conditions. It is not so much a question of the equipment and function of a building, but whether it is possible (or not) to integrate the office workplace into the information space. The understanding of digitisation as a social process and the information space thesis can help corporate real estate management develop strategies for the future development of office workplaces, which consider for example more flexible uses, but also the integration of internal and external real estate solutions. The speed of the digital transformation shows that long-term planning is much more difficult than before. The extent to which office workplaces will continue to have weight and significance for employees (and external employees) in the future depends on the perceived benefits of the workplaces inside and outside the 'company'. 


\section{Further reading}

- Boes, A., Kämpf, T., Langes, B., \& Lühr, T. (2016). The disruptive power of digital transformation. In K. Briken, S. Chillas, S. M. Krzywdzinski, \& A. Marks (Eds.), The new digital workplace (pp. 153-175). London: Palgrave.

- Roth-Ebner, C. (2016): Spatial phenomena of mediatised work. In J. Flecker (Ed.), Space, place and global digital work (pp. 227-245). London: Palgrave Macmillan.

- Schmiede, R. (2006). Knowledge, work and subject in informational capitalism. In J. Berleur, I. Markku, I. Nurminen, \& J. Impagliazzo (Eds.), Social informatics - An information society for all? (pp. 333-354). Heidelberg: Springer Science and Business Media.

\section{Notes}

1 In the same way as new forms of collaboration evolve as 'coopetition', which means that even people (and organisations) who were originally competitors have to work together.

2 Whereas classical Taylorism is about switching off the mind and letting manual activities be carried out automatically, here it is about allowing (and claiming) for creativity but integrating it into objectified (i.e. measurable and scalable, standardised) processes, a kind of 'creativity on demand' under precisely defined conditions and structures.

3 Not all research that provides important insights into the notion of information spaces explicitly addresses this theory. Often topics dealing with new topologies of work leave the theory of space untreated. In this chapter, only examples that directly refer to information space theory and/or informatisation are given.

\section{References}

Baukrowitz, A., \& Boes, A. (1996). Arbeit in der "Informationsgesellschaft". In R. Schmiede (Ed.), Virtuelle Arbeitswelten. Arbeit, Produktion und Subjekt in der "Informationsgesellschaft" (pp. 129-158). Berlin: Edition sigma.

Bley, S., Harrison, S., \& Irwin, S. (1993). Media spaces: Bringing people together in a video, audio and computing environment. Communications of the ACM, 36(1), 28-47.

Boes, A. (2017). Qualifizieren für das Arbeiten im globalen Informationsraum. WSI Mitteilungen, 2017(2), 155-157.

Boes, A., Gül, K., Kämpf, T., \& Lühr, T. (Eds.). (2020a). Empowerment in der agilen Arbeitswelt. Analysen, Handlungsorientierungen und Erfolgsfaktoren. Freiburg: Haufe.

Boes, A., \& Kämpf, T. (2007). The nexus of informatisation and internationalisation: A new stage in the internationalisation of labour in globalised working environments. Work Organisation, Labour and Globalisation, 1(2), 193-208.

Boes, A., Kämpf, T., Langes, B., \& Lühr, T. (2017). The disruptive power of digital transformation. In K. Briken, S. Chillas, M. Krzywdzinski, \& A. Marks (Eds.), The new digital workplace (pp. 153-175). London: Palgrave.

Boes, A., Kämpf, T., \& Ziegler, A. (2020b). Arbeit im Informationsraum - Informatisierung als Perspektive für ein soziologisches Verständnis der digitalen Transformation. In S. Maasen \& J. H. Passoth (Eds.), Soziologie des Digitalen - Digitale Soziologie? (pp. 305-325). Soziale Welt - Sonderband 23. https://doi. org $/ 10.5771 / 9783845295008-305$

Bowen, G. (2009). Document analysis as a qualitative research method. Qualitative Research Journal, 9(2), 27-40. https://doi.org/10.3316/QRJ0902027

Castells, M. (1996). The rise of the network society: The information age - Economy, society and culture I. Oxford: Blackwell.

Continental (Ed.). (2006). In search of global engineering excellence: Educating the next generation of engineers for the global workplace. Hannover: Continental.

Fitzmaurice, G. (1993). Situated information spaces and spatially aware palmtop computers. Communications of the ACM, 36(7), 38-49.

Flecker, J., \& Schönauer, A. (2016). The production of 'placelessness': Digital service work in global value chains. In J. Flecker (Ed.), Space, place and global digital work (pp. 11-30). London: Palgrave Macmillan. 
Flick, U. (Ed.). (2018). The Sage handbook of qualitative data collection. London: SAGE. https://doi.org/10.4135/ 9781526416070

Friebe, H., \& Lobo, S. (2006). Wir nennen es Arbeit-die digitale Bohème oder: intelligentes Leben jenseits der Festanstellung. München: Heyne.

Hardy, J., \& Hollinshead, G. (2011). The embeddedness of software development in the Ukraine: An offshoring country perspective. European Planning Studies, 19(9), 1633-1650.

Howcroft, D., \& Richardson, H. (2012). The back office goes global: Exploring connections and contradictions in shared service centres. Work, Employment and Society, 26(1), 111-127.

Huws, U., Korte, W. B., \& Robinson, S. (1990). Telework: Towards the elusive office. New York: Wiley.

Hyers, L. (2018). Diary methods: Understanding qualitative research. London: Oxford University Press.

Kämpf, T. (2018). Lean and white-collar work: Towards new forms of industrialisation of knowledge work and office jobs? triple C.at. Journal for a Global Sustainable Information Society, 16(2), 901-918.

Lefebvre, H. (1991). The production of space. New York: Wiley.

Liegl, M. (2014). Nomadicity and the care of place: On the aesthetic and affective organization of space in freelance creative work. Computer Supported Cooperative Work, 23, 163-183.

Löw, M. (2013). The emergence of space through the interplay of action and structures. In D.A.: A handbook of design anthropology (pp. 714-727). Frankfurt: Peter Lang.

Makimoto, T., \& Manners, D. (1997): Digital nomad. New York: Wiley.

Nappi, I., \& de Campos Ribeiro, G. (2021). The duality of the physical and virtual worlds of work. In Will-Zocholl, M. \& Roth-Ebner, C. (Eds.), Topologies of digital work. How digitalisation and virtualisation shape working places and spaces (pp. 295-340). London: Palgrave.

Petendra, B. (2015). Räumliche Dimensionen von Büroarbeit. Eine Analyse des flexiblen Büros und seiner Akteure. Wiesbaden: Springer VS.

Pfeiffer, S. (2017). Industrie 4.0 in the making - Discourse patterns and the rise of digital despotism. In K. Briken, S. Chillas, M. Krzywdzinski, \& A. Marks (Eds.), The new digital workplace (pp. 21-41). London: Palgrave.

Pongratz, H. J., \& Trinczek, R. (2010). Industriesoziologische Fallstudien Entwicklungspotenziale einer Forschungsstrategie. Berlin: Edition sigma.

Roth-Ebner, C. (2015). The skills of the digicom-worker. Journal of Technologies and Human Usability, 11, 1-9.

Roth-Ebner, C. (2016). Spatial phenomena of mediatised work. In J. Flecker (Ed.), Space, place and global digital work (pp. 227-245). London: Palgrave Macmillan.

Ryser, T., Angerer, E., Ganesh, M. P., \& Schulze, H. (2016). Towards a model of collective competences for globally distributed collaborations. In J. Flecker (Ed.), Space, place and global digital work (pp. 201226). London: Palgrave Macmillan.

Schmiede, R. (2006). Knowledge, work and subject in informational capitalism. In J. Berleur, I. Markku, I. Nurminen, \& E. Impagliazzo (Eds.), Social informatics: An information society for all? (pp. 333-354). Wiesbaden: Springer Science and Business Media.

Schmiede, R., \& Will-Zocholl, M. (2011). Engineers work on the move. Challenges in automotive engineering in a globalized world. Engineering Studies, 3(2), 1-21.

Streitz, N. A., Geißler, J., \& Holmer, T. (1998). Roomware for cooperative buildings: Integrated design of architectural spaces and information spaces. In N. A. Streitz, S. Konomi, \& H. J. Burkhardt (Eds.), Cooperative buildings: Integrating information, organization, and architecture. CoBuild 1998. In Lecture Notes in Computer Science (p. 1370). Wiesbaden: Springer.

Vogl, E. (2018). Crowdsourcing-Plattfirmen als neue Marktplätze für Arbeit. Die Nenorganisation con Arbeit im Informationsraum und ihre Implikationen. München: Rainer Hampp.

Wenger, E. (1998). Communities of practice: Learning, meaning, and identity. Cambridge: Cambridge University Press.

Will-Zocholl, M. (2016). New topologies of work. Informatisation, virtualisation and globalisation in automotive engineering. In J. Flecker (Ed.), Space, place and global digital work (pp. 31-52). London: Palgrave Macmillan.

Will-Zocholl, M., \& Roth-Ebner, C. (Eds.) (2021). Topologies of digital work. How digitalisation and virtualisation shape working places and spaces. London: Palgrave.

Ybema, S., Yanow, D., Wels, H., \& Kamsteeg, F. (2009). Organizational ethnography: Studying the complexity of everyday life. Newcastle upon Tyne: Sage. 
8

\title{
SOCIAL CONSTRUCTIONISM THEORY
}

\section{Constructing the user experience of workplace}

\author{
Kaisa Airo*
}

\section{Background}

Peter Berger and Thomas Luckmann developed the theory of social construction of reality at the end of the 1960s (1966). It accelerated the narrative turn in social sciences, which pushed the research to concentrate more on how knowledge and meaning are constructed than on what actually is true. Issues such as power, discrimination, deviance, crime and media became popular topics of interest, and the focus shifted from statistical research to socio-linguistics and the use of language in a cultural sense.

The basic principle of social constructionism is that many of the things we perceive as objective truths are not but are constructed culturally or socially. For instance, gender roles, marriage or values are more culturally defined than factually there. Since the 1980 s social sciences have been interested in interpreting this objective reality from a critical point of view. Studies have been labelled for example as critical psychology, discourse analysis, deconstruction or critical sociology. However, all of these perspectives can be categorised under the vast umbrella of social constructionism theory (Burr, 2015).

Social constructionism refers to theory on reality and knowledge creation (see also Chapter 22 on knowledge creation theory), thus in principle it is ontological theory on what we consider real and true. On the other hand, it differs from philosophical theories of knowledge in a sense that it is interested in social processes of knowledge creation rather than on objective truth (Berger \& Luckmann, 1966).

Social constructionism is based on the idea that language does not mirror reality; rather, it constitutes it (Fairhurst \& Grant, 2010). It states that reality is both produced and interpreted in a social context through language and communication. Therefore, knowledge is profoundly social (Davenport \& Prusak, 2000). Not just all the abstract concepts but also all the material objects are then defined, valued and ultimately experienced in a social process. From the perspective of social constructionism, studying different aspects of language is crucial when aiming at understanding reality. From a social constructionism point of view, language is any kind of symbolic system that can be interpreted, not just ethnic or verbal language.

Social constructionism is based on two principles. The first emphasizes the role of language in constructing knowledge and the second elaborates the social nature of knowledge creation. The fundamental principles are overlapping since one would not exist without another, but they

*Corresponding author: kaisa.airo@laurea.fi 
do differ conceptually, as social networks are the nodes of human behaviour and language is the mean between the subjects.

Socially constructed workplace literature often concentrates on organisational theory. In management and organisation research, discursive articles discuss the general organisation communication theory (Bisel, 2009; Sillince, 2007) or segmented groups in work such as mothers or the elderly (e.g. Medved \& Kirby, 2005). In addition, social constructionism concentrates to workplace phenomena and analysing workplaces also as spatial language (O’Brien, 2020).

Social constructionism is intertwined with other similar sociolinguistic and discursive perspectives and methods. In this chapter the tradition of discourse analysis is presented. Discourse analysis refers to a number of different perspectives in analysing language. There are multiple usages and interpretations of the method, which can also be seen as a theory in itself. However, the term discourse analysis was introduced by Harris in the 1950s. In Britain in the 1970s Mulkay and his students developed the method further (Mulkay, Potter, \& Yearley, 1983). The term discourse is defined by Michel Foucault in The Archaeology of Knowledge (1969). More precisely, Foucault developed the concept of discourse by defining analysis as an archaeological method, which refers to the layered nature of language. By this, Foucault (1969) means that reality, as we perceive it, is a product of an ongoing discursive game in which defining concepts is the basic strategy of claiming a power position. Language both reflects and produces social reality.

The other perspective and method is narrative analysis, which accordingly claims that people's experience and memory are built upon stories and storyline structures. Hence analysing the topics of interest, such as actors, stages and goals, could be reconstructed in stories (Labov \& Waletzky, 1967).

\section{Applicability to workplace}

Workplace management research has not applied social constructionism extensively. In this chapter the theory and its implications are discussed based on the author's doctoral dissertation (Airo, 2014) with the addition of current literature, which suggests that the social construction is still a rare perspective in workplace management.

In workplace management research, social constructionism is mostly applied in researching organisational behaviour or employee experience, rather than the space or place itself. However, according to social constructionism, the built environment, including workspaces in their physical sense, is also the institutionalised object of a social process. This environment is experienced and perceived in a discursive process. Ideals, meanings and cultural assumptions govern the design, use and management of any built space. Ideals, meanings and cultural assumptions are overall discursive concepts, that is, they are derived from language. The built environment is not only constructed from physical things, it is also designed, understood and experienced discursively.

Markus and Cameron (2002) claim that the language used when speaking and writing about the built environment plays a significant role in shaping the environment and our responses to it. Additionally, they emphasise the idea that although the buildings themselves do not have a discursive form, people using them use language in interpreting the environment. People who design, build and talk about buildings always have an agenda, which is shown in the way buildings are designed, valued and used.

Socially constructed space refers both to the production of actual space and to our perception and ultimately the experience of the space. This process is elaborated through habitualised institutions, verbal language and visual symbols. The topic of space is considered a somehow indifferent attribute in constructing the concept of workplace, which is often seen as a network of social relationships rather than a tangible space with meaning. The workplace is not merely 
an activity container (Hillier \& Hanson, 1984) for paid work, but contains representations of all other major social places in contemporary society. This means that workplace reflects social status and organisation rather than just functions as a neutral stage for working. Cairns (2003) emphasizes, like other scholars before him, that the physical stage of the workspace becomes a place once it is occupied by people. Once it is occupied by people, it becomes a social construction, in which language plays a significant role.

Workplace phenomena such as bullying, change resistance (Airo, Rasila, \& Nenonen, 2012; Bryant, 2003, 2006; Jørgensen, 2004), contradiction (Whittle, Mueller, \& Mangan, 2008), identity construction (Holmes, 2005) and leadership (Fairhurst, 2008) have been studied using a discursive approach. Tracy, Lutgen-Sandvik and Alberts (2006) have studied workplace bullying using narrative interviews to reveal the metaphors used when describing the distress of bullying. Miller, Considine and Garner have used workplace narratives as a resource to map the terrain of workplace emotions (2007). Sonenshein (2006) has studied the manner in which individuals shape the meaning of social structure while using intentionally different language in private discussions and public discussion of issues. However, social constructionistic studies, combining both the physical nature and the social processes of workplace, are quite rare.

In recent decades, many organisations have begun to take a closer look at the workplace's strategic significance for organisational performance (Skogland \& Hansen, 2017). There is still confusion about the definition of workplace because the concepts of place and space are ambiguous. Gieryn explains how places differ from spaces by saying, "Space is what place becomes when the unique gathering of things, meanings, and values are sucked out" (Gieryn, 2000, p. 463). Spaces thus are physical entities, which lack all of the qualities stated by the ground rules, such as meaning, physical boundaries, an association with meaningful things and specific locations, and finitude. In this sense, workspace, for instance, is not just space, though neither it is a place, because place can be defined based on the aforementioned ground rules. Still, workspaces have some of the qualities of places. Workspace is considered the physical space in which the work takes place, and workplace is the social and organisational place where employees work (Price, 2012). However, workspace includes a gathering of things, meaning and value. Thus, it is not mere physical space. Rather, workplace also implies an organisational, abstract place where one can go, without going to a particular workspace. Thus, workplace is not as physical as the definition of place, which includes, for instance, a specific location. Conversely, workspace is more than just physical space. Lefebvre (1991) claims that when investigating space, it is more important to focus on the ways that space is categorised than to focus on the space itself, because space itself is only an abstract entity full of nothing. It becomes understandable only through restrictions and borders; in other words, the way that space is defined.

One stream of social constructionistic theories in organisations and the built environment focuses on how physical artefacts (including space) are used as a means of communication and role construction. For instance, Frers (2009) has used discourse analysis in demonstrating the way that the material world reaches into social interactions and consequently fills in mental maps of the social world with physical details. Sparkes, Brown and Partington have taken a similar perspective when studying how space can be and is used as a mean of constructing social identity among university students (2010). In addition, Ainsworth, Grant and Iedema (2009) have used discourse analysis to prove that the spatial imagery has a significant role in constructing the manager's identity. Managers used the concepts of mobility and locality and the idea of a social space to describe their role in the organisation. The concept of moving freely and accessing information was considered a symbol of power, whereas getting stuck or between the walls was considered as losing power. Thus, spatial imagery places a discursive function in describing the assumed position in an organisation. 
The use of discursive methods combining all of the attributes of workplace management, (a) management, (b) spatial issues and (c) discursive methods, seems to be non-existent (Airo, 2014). The challenges of multidisciplinary issues seem to hinder both disciplines. Still, everyday reality is neither partial nor segmented but instead is a holistic combination of the social and the physical. That is, because workplaces are social constructions, they are also physical entities that are connected to social behaviour. Because the academic tradition of workplace management is not only new but also focused on practical applications, the ontological and epistemological premises of the field are ambiguous (Cairns, 2003).

\section{Methodology}

Social constructive methods concentrate on language and more so the discursive structure of language rather than, for example, grammar. Social constructionist methods are not either qualitative or quantitative by nature. This is because they do not seek to find coherent synthesis. At least discourse analysis does not. The methods only point out that objective matter of facts are rarely matter of facts as such but instead are socially constructed. However, from the methodological point of view, social constructionistic methods resemble qualitative methods, which often enable multiple possible interpretations of the same data depending on the intuition, insights and scientific imagination of a researcher, perceiving all such interpretations to be potentially meaningful (Eriksson \& Kovalainen, 2008). This also applies to the discursive approach, in which a researcher's interpretations play a profound role. Accordingly, the aim of this type of methodology is more to understand how something works rather than what it truly is. Thus, the results are not ripe for generalisation. Two most typical discursive methods in social constructionism are discourse and narrative analysis, which both concentrate on deconstructing language.

Discourse can be narrowly defined as the practices of talking and writing (Woodilla, 1998). More precisely, discourse means the relations of talking, writing or otherwise producing a cultural text, which can also be a picture, photograph, artefact and so forth. Text is the basic unit of data for discourse analysis. It is also essential to acknowledge that texts are not meaningful individually but only through their interconnection with other texts (Phillips \& Hardy, 2002). Discourse is often confused with ordinary communication (Jones, 2005); however, discourse analysis examines the implicit cultural structures of communication rather than the explicit content of that communication.

Discourse analysis often aims to reveal underlying messages bound to culturally dependent values. By deconstructing these values, the researcher is able to find potentially hidden agendas behind the message of the subject. Discourse analysis and critical discourse analysis are traditionally used to study power relations within a society (Fairclough \& Wodak, 1997; Starks \& Brown Trinidad, 2007). A typical object of discourse analysis would be a politician's speech or a media text. Recently, discourse analysis has been used to study the ways in which people give meaning to their existing reality (e.g., work, parenting, gender, etc.) (e.g., Ashcraft, 2007).

Narrative analysis is connected to the idea of social constructionism, which means that our experiences are constructed in an ongoing social process, which embodies our subjective history and our present interactions with our environment. Narrative analysis was developed by Labov and Waletzky (1967), who define narrative as a story that has both a clear beginning and a clear end. Although the world and tangible reality exist all the time, everywhere, mental processes and verbal output are always constructed in a form of a narrative - a story. Thus, analysing the structure of the narratives that people present may reveal something possibly hidden about their experience of a subject. 
Rymes explains that in a narrative analysis, it is important to recognise that narrative in itself is not a portal to experience. At least, narrative is not a direct portal. Instead, narrative, in any form and by necessity, always involves narrating to someone and in some context. This means that narrative analysis depends on speech acts, which are inevitably related to speaking, context, meaning and subjective descriptions (2010). In other words, narrative analysis is concerned about the positioning of events, things and subjects rather than the stories themselves.

Social constructionism in research should be applied more in studying the language of the built environment and the language of the users of the space. In addition, the language that is used when publicly discussing space is very fruitful in analysing the attitudes, power structures or roles of different actors in the field of workplace management. For instance, Airo analysed the discourses of media about open-plan offices and claimed that our attitudes are highly influenced by words used in news reporting and discussions (2014). This kind of study would benefit from revealing the 'tone of voice' used in political and business-driven decisions.

The symbolism of space itself is also very useful and certainly an understudied topic in workplace and facility management. This perspective could benefit from the theories about nudging and deaf spaces as well as studies of visual language and usability. The visual language is complemented with the verbal language used. Studying discourses of change management might reveal hidden agendas of the different parties concerned with workplace change.

\section{Limitations}

A social constructionist approach in workplace management is still rare and ambiguous. Research on management and organisational behaviour acknowledges the perspective to some extent, but the research on the built environment seems to lack such a paradigm. It seems that journals that concentrate on social and cultural studies overlook the subjects of business and the workplace, whereas journals on management and the built environment do not extensively publish papers with discursive/socially constructive perspectives and/or methodology.

Although research based on social construction is often motivated by practical problems, it does not give recommendations or practical tools solving such issues. Additionally, theories developed based on socially constructed principles are in danger of becoming self-explaining. In other words, the results can be seen as circular, especially because they, as other qualitative methods, are subjective, since the researcher him/herself is bound to the empirical data he/she interprets and describes.

Another limitation in social constructionism is the relationship between empirical data and the theory. They both explain one another, which can conclude to the circular thinking, in which it is impossible to say which initiated the other. For instance, the general discourse on social construction itself has become an explaining force, but also a producing force of social institutions, such as modern school system or the media. This can be an ontological problem, but it is also an empirical example on how the philosophy of social constructionism embodies to practical reality.

\section{Applicability to practise}

Social constructionism does not take a stand on tangible reality. On the other hand, some practical problems are due to social construction. For instance, if certain problems are often discussed they might be perceived as problems, although they have not been perceived as such earlier. This process can work the other way as well. Verbalising issues influences the way they are perceived. 
Thus, social constructionism does not provide answers, but the pure existence of the perspective might change the way we perceive knowledge, which influences the way things really are.

Regardless of the limitations of social constructionism, facility managers should pay more attention to the communication strategies taking place in a workplace context. In order to develop a sufficient communicational strategy, one should understand how users communicate about the space. One should be aware of current sensemaking processes in order to develop and manage the facilities in the future. End users might pay attention to something completely different than what the managers are concentrating on. Additionally, the users and the manager consider issues as matters of facts, although they are socially constructed. For instance, the enclosed office is considered traditional, although in fact it is not as traditional a working space as an open-plan layout. Using words such as traditional gives a certain discursive value to the space, which in the end is just there. What we consider objective truth might be a matter of people constructing meaning in the social network. That is, using language. The whole reality the users experience is constructed with language.

All the stakeholders in workplace management, from designers to facility managers, should pay more attention to physical language, that is, the language of the space itself. People draw conclusions out of physical hints. This can be seen in research about the usability of workplaces or about event management. Physical language has been discussed through the concept of the deaf space. Sign language is based on visual and spatial attributes and is not verbal as such. The discussion about deaf architecture revolves around the idea that workplaces actually speak and communicate in their own right (O'Brien, 2020). Even though this is often discussed in the context of disability and inclusive environment, the thought of communicating environments could be applied more extensively such as in nudging environments or enhancing the employee experience in any workplace. The narratives and the symbolism of the space have a crucial role in navigation and sense of aesthetics. How users interpret physical hints is highly connected to socially constructed reality. Understanding physical language might make actual economic difference in designing more efficient facility services from cleaning to catering.

Undoubtedly, language about spaces is still an unknown territory, and as such it should be more extensively researched and applied. This should be acknowledged among all of the stakeholders in the fields of facility management and the built environment. Managing space not only as a physical asset but also as a source of conversation - is important. The workplace discourse is not disconnected: it takes place in relation to space and is an important channel to deepen the understanding not only of users' workplace experience, but also in designing, constructing or managing the workspace and -place.

\section{Further reading}

- Airo, K. (2014). Workplace and language - Constructing the user experience of office space. Espoo: Aalto Publications.

- Ajtony, Z., \& Pieldner, J. (2013). Discourses of space. New Castle upon Tyne: Cambridge Scholars Publishing.

- Berger, P., \& Luckmann, T. (1966). The social construction of reality: A treatise in the sociology of knowledge. Garden City, NY: Anchor.

- Burr, V. (2015). Social constructionism. London: Routledge.

- Cameron, D., \& Markus, T. (2003). Words between spaces. New York, NY: Routledge.

- Ryan, M., Foote, K., \& Azaryahu, M. (2016). Narrating space/Spatializing narrative: Where narrative theory and geography meet. Columbus, $\mathrm{OH}$ : The Ohio State University Press. 


\section{References}

Ainsworth, S., Grant, D., \& Iedema, R. (2009). 'Keeping things moving': Space and the construction of middle management identity in a post-NPM organization. Discourse and Communication, 3(1), 5-25. https://doi.org/10.1177/1750481308098762

Airo, K. (2014). Workplace and language: Constructing the user experience of office space. Espoo: Aalto Publications. Retrieved from http://urn.fi/URN:ISBN:978-952-60-5954-9

Airo, K., Rasila, H., \& Nenonen, S. (2012). Speech as a way of constructing change in space: Opposing and conforming discourses in workplace change process. Facilities, 30, (7/8), 289-301. https://doi. org/10.1108/02632771211220095

Ashcraft, K. L. (2007). Appreciating the 'work' of discourse: Occupational identity and difference as organizing mechanisms in the case of commercial airline pilots. Discourse and Communication, 1(1), 9-36. https://doi.org/10.1177/1750481307071982

Berger, P., \& Luckmann, T. (1966). The social construction of reality: A treatise in the sociology of knowledge. Garden City, NY: Anchor.

Bisel, R. S. (2009). On a growing dualism in organizational discourse research. Management Communication Quarterly, 22(4), 614-638. https://doi.org/10.1177/0893318908331100

Bryant, M. (2003). Persistence and silence: A narrative analysis of employee responses to organisational change. Sociological Research Online, 8(4), 246-258. https://doi.org/10.5153/sro.853

Bryant, M. (2006). Talking about change: Understanding employee responses through qualitative research. Management Decision, 44(2), 246-258. https://doi.org/10.1108/00251740610650229

Burr, V. (2015). Social constructionism. London: Routledge.

Cairns, G. (2003). Seeking a facilities management philosophy for the changing workplace, Facilities, 21(5/6), 95-105. https://doi.org/10.1108/02632770310476705

Davenport, T. H., \& Prusak, L. (2000). Working knowledge: How organizations manage what they know. Boston, MA: Harvard Business Press.

Eriksson, P., \& Kovalainen, A. (2008). Qualitative methods in business research. London: SAGE Publications.

Fairclough, N. L., \& Wodak, R. (1997). Critical discourse analysis. In T. A. van Dijk (Ed.), Discourse studies: A multidisciplinary introduction. Discourse as Social Interaction, 2 (pp. 258-284). London: Sage.

Fairhurst, G. T. (2008). Discursive leadership: A communication alternative to leadership psychology. Management Communication Quarterly, 21(4), 510-521. https://doi.org/10.1177/0893318907313714

Fairhurst, G., \& Grant, T. (2010). Social construction of leadership: A sailing guide. Management Communication Quarterly, 21(4), 171-210. https://doi.org/10.1177/0893318909359697

Foucault, M. (1969). The archaeology of knowledge. London and New York: Routledge.

Frers, L. (2009). Space, materiality and the contingency of action: A sequential analysis of the patient's file in doctor-patient interactions. Discourse Studies, 11(3), 285-303. https://doi.org/10.1177/1461445609102445

Gieryn, T. F. A. (2000). Space for Place in Sociology. Annual Review of Sociology, 26, 463-496. https://doi. org/10.1146/annurev.soc.26.1.463

Hillier, B., \& Hanson, J. (1984). The social logic of space. Cambridge: Cambridge University Press.

Holmes, J. (2005). Story-telling at work: A complex discursive resource for integrating personal, professional and social identities. Discourse Studies, 7(6), 671-700. https://doi.org/10.1177/1461445605055422

Jones, D. (2005). Spot the difference: Discourse in organizational communication, organizational studies, and workplace sociolinguistics. Management Communication Quarterly, 19(2), 288-298. https://doi.org/10.11 $77 / 0893318905278537$

Jørgensen, K. M. (2004). Creating value-based collaboration: Life forms and power in a change project, Management, 7(3), 85-107. Retrieved from www.cairn.info/journal-management-2004-3-page-85.htm

Labov, W., \& Waletzky, J. (1967). Narrative analysis: Essays on the verbal and visual arts, ed. J. Helm, $12-44$. Seattle: U. of Washington Press. Reprinted in Journal of Narrative and Life History, 7, 3-38. https://doi. org/10.1075/jnlh.7.02nar

Lefebvre, H. (1991). The production of space. Oxford: Blackwell Publishing.

Markus, T. A., \& Cameron, D. (2002). The words between the spaces: Buildings and language. London/New York: Routledge.

Medved, C. E., \& Kirby, E. L. (2005). Family CEOs: A feminist analysis of corporate mothering discourses. Management Communication Quarterly, 18(4), 435-478. https://doi.org/10.1177/0893318904273690

Miller, K. I., Considine, J., \& Garner, J. (2007). Let me tell you about my job: Exploring the terrain of emotion in the workplace. Management Communication Quarterly, 20(3), 231-260. https://doi.org/10.1177/089331 8906293589 


\section{Kaisa Airo}

Mulkay, M., Potter, J., \& Yearley, S. (1983). Why an analysis of scientific discourse is needed. In Science observed: Perspectives on the social study of science (pp. 171-203). London: Sage.

O'Brien, D. (2020). Negotiating academic environments: Using Lefebvre to conceptualise deaf spaces and disabling/enabling environments. Journal of Cultural Geography, 37(1), 26-45. https://doi.org/10.1080/ 08873631.2019 .1677293

Phillips, N., \& Hardy, C. (2002). Discourse analysis: Investigating processes of social construction. Thousand Oaks, CA: Sage Publications.

Price, I. (2012). The social construction of FM communities. In I. Price \& K. Alexander (Eds.), Managing organisational ecologies: Space, management and organisation. New York: Routledge.

Rymes, B. (2010). Why and why not? Narrative approaches in the social sciences. Narrative Inquiry, 20(2), 371-374. https://doi.org/10.1075/ni.20.2.07rym

Sillince, J. A. (2007). Organizational context and the discursive construction of organizing. Management Communication Quarterly, 20(4), 363-394. https://doi.org/10.1177/0893318906298477

Skogland, M. A. C., \& Hansen, G. K. (2017). Change your space, change your culture: Exploring spatial change management strategies. Journal of Corporate Real Estate, 19(2), 95-110. https://doi.org/10.1108/ JCRE-07-2016-0024Sonenshein, S. (2006). Crafting social issues at work. Academy of Management Journal, 49(6), 1158-1172. https://doi.org/10.5465/amj.2006.23478243

Sparkes, A., Brown, D. H. K., \& Partington, E. (2010). The jock body and the social construction of space: The performance and positioning of cultural identity. Space and Culture, 13(3), 333-347. https://doi. org/10.1177/1206331210365288

Starks, H., \& Brown Trinidad, S. (2007). Choose your method: A comparison of phenomenology, discourse analysis, and grounded theory. Qualitative Health Research, 17(10), 1372-1380. https://doi.org/10.1177/ 1049732307307031

Tracy, S. J., Lutgen-Sandvik, P., \& Alberts, J. K. (2006). Nightmares, demons, and slaves: exploring the painful metaphors of workplace bullying. Management Communication Quarterly, 20(2), 148-185. https:// doi.org/10.1177/0893318906291980

Whittle, A., Mueller, F., \& Mangan, A. (2008). In search of subtlety: Discursive devices and rhetorical competence. Management Communication Quarterly, 22(2), 99-122. https://doi.org/10.1177/08933189 08318515

Woodilla, J. (1998). Workplace conversations: The text of organizing. In D. Grant, T. Keenoy, \& C. Oswick (Eds.), Discourse and organization (pp. 31-50). London: Sage. 


\title{
9 \\ ECOLOGICAL SYSTEMS THEORY
}

\author{
Eunhwa Yang* and Bonnie Sanborn
}

\section{Background}

Ecological systems theory (EST) was devised by Urie Bronfenbrenner (1979) and explains that human development occurs based upon interactions between a growing human being and their environments. Before EST, researchers mostly focused on the human side of Lewin's equation (Lewin, 1936) that human behaviour was determined by a person's attributes in relation to the environment (see also Chapter 2 Person-Environment Fit Theory). Bronfenbrenner (1979) drew attention to the environmental side with clear categories for and interdependencies between environments and human behaviour. The origin of this theory can be traced to the biological and sociological sciences.

The term ecology was brought by Ernst Haeckel (1866), adopting Darwin's (1859) study of the complex interrelationships between organisms and their environments in the process of survival (Stauffer, 1957). In the 1920s, human ecology applied the theoretical scheme of plant and animal ecology to human communities (Hawley, 1950). Hawley (1950) claimed that human beings adapted their behaviour patterns for the environments and ecosystems in which they were involved. Changes in behaviour accumulated according to the impact of environmental changes; specifically, changes occurred in order to achieve equilibrium or homeostasis (Hawley, 1950). "The basic premises of ecological theory are that systems are dynamic, change is constant, and everything is connected to everything else" (Salazar \& Beaton, 2000, p. 471).

Bronfenbrenner (1979) considers that the development of a person is also driven by dynamic, changing, and connected interactions between a person and social and physical environments in which $\mathrm{s} /$ he is involved or not involved but indirectly linked. Bronfenbrenner's EST challenges an approach to human development focused on individual behaviours; it focuses on interconnection and interdependency between systems, emphasizing "examination of multi-person systems not limited to a single setting and must take into account aspects of the environment beyond the immediate situation containing the subject" (Bronfenbrenner, 1979, p. 21). Bronfenbrenner (1979) states that human development is affected by five different layers of environmental systems (see Figure 9.1):

1 Micro-systems: immediate setting or environment of the person (i.e., home, day care centre, playground, work)

*Corresponding author: eunhwa.yang@design.gatech.edu 


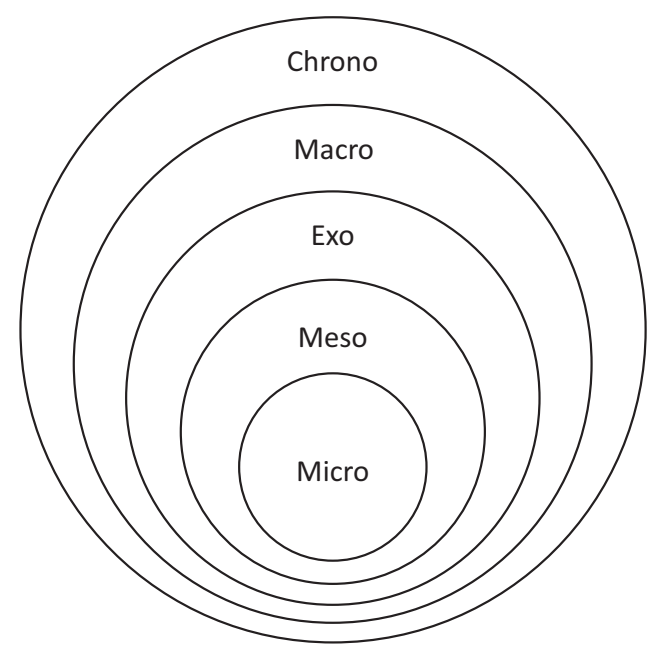

Figure 9.1 Bronfenbrenner's ecological systems (1979)

2 Meso-systems: interrelations between the settings containing the person (i.e., for a child, the relations among home, school, and neighbourhood peers; for an adult, the relations among family, work, and social groups)

3 Exo-systems: linkages between the environments that do not involve the person but influence the micro-systems (i.e., for a child, the parent's workplace, the parent's network or friends, and the sibling's school and friends; for an adult, the child's school and the spouse's workplace, network, and friends)

4 Macro-systems: culture and subcultures (i.e., political, economic, cultural, ethnic, religious)

5 Chrono-systems: time (i.e., human life span, changes in role and setting such as marriage and remarriage, divorce, having a child, and changing jobs)

The five layers are explained within widely understood contexts of child development. The microsystem can be home, school, or community of a child. The child is directly influenced by the immediate environments, such as the relationships with her/his parents, teachers, and friends at school. The meso-system is the relationship between the micro-systems, such as home and school; the parents' attitudes towards the child's teacher affects the child's behaviour at school. The exosystem is the relationships between two or more environments that indirectly influence the developing child. If one parent has a long business trip scheduled, the relationship between the child and the other parent will be changed by activity away from the home. The macro-system of culture and subcultures refers to varying perspectives and social consensus on education and work, which may have effects on child development. Lastly, the chrono-system is the ecological transition resulting from changes in roles or settings and consequent environmental changes. The development of a child is changes with achievement of milestones ordered in time, such as entering school, getting a new job, and getting married.

EST emphasizes the environmental influences and moderating effects of human attributes on corresponding consequences. The theory inspired many social scientists to expand and test it for children and adults evolving throughout their life spans. Bronfenbrenner (1986, p. 287) states,

studies of children and adults in real-life settings, with real-life implications, are now commonplace in the research literature on human development, both in the United 
States and, as this volume testifies, in Europe as well. This scientific development is taking place, I believe, not so much because of writings, but rather because the notions I have been promulgating are ideas whose time has come.

\section{Applicability to workplace studies}

The five main systems in EST emphasize the impact of physical and social environmental factors and their interrelations, including various types of settings in everyday life. Office settings can refer to both physical and social environments; physical environments include office layout, an arrangement of furniture, ergonomic furniture and devices, ambient environments such as temperature, humidity, acoustic, and light, whereas social environments include training or social events at the workplace, and formal and informal interactions with co-workers. The influence of social connections in open-plan offices becomes more frequent and complicated than in enclosed offices, for example, and the design of open-plan offices encourage serendipitous interactions among workers (Oldham \& Brass, 1979). Through an EST approach, human relationships and interactions in the workplace can be understood by considering different layers of systems (from micro- to chrono-) within and beyond the office setting.

\subsection{A conceptual framework for workplace research based on EST}

Workplace strategies and management styles can actually alter different systems of our lives, not just within the system to which the workplace - a micro-system - belongs. Workplace design and strategy influence social and environmental changes within the workplace, workers' perception of and satisfaction with the workplace - but also relationships that workers experience outside of the office, such as their family, their children's development, companies they later work for, and careers. For instance, changes in workplace policy on telecommuting may affect one's family dynamics and activities, emotional ability to socialize, and physical time to socialize. This interconnection of systems, from micro- to chrono-systems, should be considered when planning or measuring workplace strategies and management for comprehensive impact.

Workplace design and strategies can affect individuals' safety (Danna \& Griffin, 1999), health (Arundell et al., 2018; Danielsson \& Bodin, 2008; Thatcher \& Milner, 2014; Wijk, Bergsten, \& Hallman, 2020), and environmental perception and satisfaction (Arundell et al., 2018; Brunia, de Been, \& van der Voordt, 2016), often highly associated with their job satisfaction (Arundell et al., 2018; Bangwal \& Tiwari, 2019; Danielsson \& Bodin, 2008). Inadequate environmental support can result in diminished individual productivity (de Been \& Beijer, 2014; Thatcher \& Milner, 2014). For instance, providing ergonomic furniture and devices can prevent or reduce the risk of an individual's joint problems or chronic muscle fatigue (Robertson \& O’Neill, 2003).

Considering the impact of workplace strategies and management on different systems becomes crucial as the boundary of work and individual life becomes blurry. The intertwining of work and life has accelerated along with connectivity, so easily achieved by the internet and mobile technologies and now aggravated through increasing virtual social media connectivity. With this hyperconnectivity, a parent's work can be easily brought into home environments and intervene in family availability and behaviour.

Workplace design and strategies can also affect the process of work, collaborative productivity as a team, and workplace social climate and culture. Similarly, workplace climate and culture affect workplace design and strategy; companies requiring and emphasizing high security and safety practices may design their workplaces with high security and monitoring systems and have 
extensive safety training for their employees. These workplace systems and design in turn influence workplace security and safety climate and culture.

Collectively, workplace design and strategies can shape how the communities form through the networks and societal shifts of perception of how the workplace should look or which workplaces are preferred by employees and employers. Lastly, workplace design and strategies can serve different age groups at different periods of their lives, whether in times of physical or cognitive changes, change in marital status, having a child, or changing their jobs.

In this chapter, a simplified conceptual framework based on EST is proposed for previously completed workplace research (Figure 9.2). The framework emphasizes that the impacts of workplace interventions should be measured and analysed across multiple levels/systems (micro-, meso-, exo-, macro-, and chrono-systems), such as individuals, workplace, home, and community, with a longitudinal research design. Applying EST builds a holistic understanding of the impact of workplace interventions and supports theory-driven research.

The following paragraphs explain existing literature; the literature search was limited to studies that explicitly refer to EST. In order to understand how work and workplace affect different dimensions of our lives through the lens of EST, we summarize the literature by subtopics and related outcomes in different ecological levels. Interventions in the workplace can affect (1) workplace flexibility, (2) individual vitality, (3) work-family relationships, (4) workplace and organizational vitality, and (5) community vitality.

\subsection{Workplace flexibility}

Workplace flexibility is defined as "the ability of workers to make choices influencing when, where, and for how long they engage in work-related tasks" (Hill et al., 2008a, p. 166). Workplace flexibility is conceptualized as a mediating variable linking individual, home and family, workplace, and community characteristics as explanatory variables to individual, home and family, workplace, and community vitality as dependent variables, based on EST combined with a person-environment fit theory (Hill et al., 2008b). A part of Hill et al's (2008b) workplace flexibility framework based on EST, including workplace characteristics, workplace flexibility, and home and family, has been previously tested using a survey in the context of work-life conflict, depending on work hours and schedule flexibility (Hill, Erickson, Holmes, \& Ferris, 2010). Hill et al's 2010 study found that flexibility in work schedule, work hours, and the choice to work from home all contributed to positive outcomes for employees and the companies they work for. It appears that adding flexibility as a mediating factor allows individuals to use that flexibility to reduce conflict between the differing demands of their multiple contexts and processes, thereby reducing stress. There is a point at which, however, flexibility could not make up for the stress of working longer hours - over 50 hours a week still caused difficulty, despite flexibility and work-from-home options. Interestingly, employees with the option to work from home or flex their schedules were also able to give a few

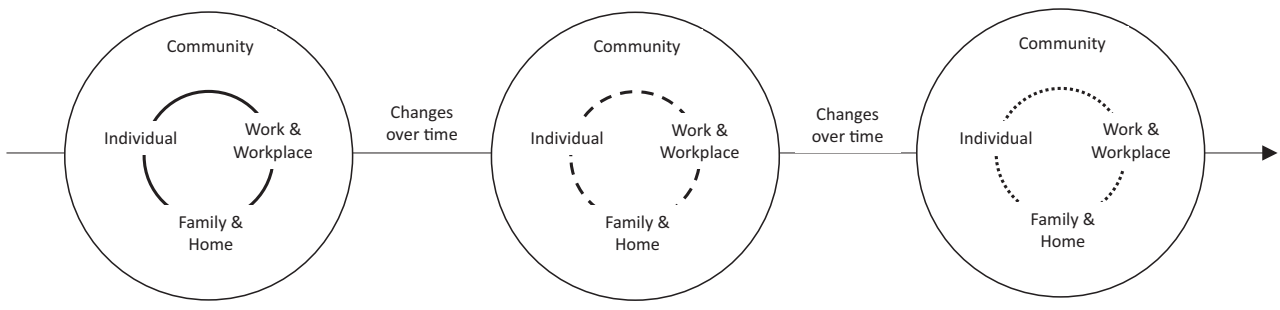

Figure 9.2 A conceptual framework for workplace research based on ecological systems theory 
more hours of productive work per week to their organization, creating a win-win outcome. Differences existed for individuals, especially women, with children at home under the age of 5 - a part of their micro-system - who had a lower 'break point' at 41 hours per week of productive work, and for respondents whose cultural context - their macro-system - exerts expectations about physical team presence at the office that cause conflicts which cannot be solved by workplace flexibility. These findings echo Hill's earlier work showing that gender and presence/age of children both factor into the imbalances in a person's work-life system, while workplace flexibility options can reduce that stress (Hill et al., 2008a, 2008b).

Skinner and Pocock (2011) also examined the association between flexibility in work hours and work-life interference, which was measured by general interference, work-related time strain with family or friends, work-to-community interference, satisfaction of work-life balance, and time pressure. Like other studies, Skinner and Pocock found that flexible work arrangements reduced work-life interference and slightly increased the productive hours per week an employee was able to work. An interesting outcome of this study was that men tended to request flexibility in their work less often than women did, despite being unhappy with their work arrangements, and of those who did request flexible arrangements the majority were women with children. The authors posit that this may be related to gender norms in their cultural context (macro-system) in which women's requests for flexibility were understandable given the women are viewed as primary caregivers and in charge of household (micro-system).

\subsection{Individual vitality}

There has been much theoretical exploration of individual vitality, such as employee health and attitudes (Cleveland, Byrne, \& Cavanagh, 2015), healthy eating strategies in the workplace (Quintiliani, Poulsen, \& Sorensen, 2010), workplace health promotion and well-being management (Bone, 2015), and occupational stress (Salazar \& Beaton, 2000). Cleveland et al. (2015) emphasized respect of humanity at work, especially in the human resource management field, and pointed to individuals as the centre of systems (i.e., engagement and well-being, talent acquisition and retention), the relationships between individuals and contexts (human resource communication and leadership, interpersonal relationship, and employee-organization dynamics), and the influence of larger contextual environments (i.e., environmentally sustainable or safe buildings, diversity and legal issues). In Cleveland et al.s (2015) application of EST in HR systems, multiple level systems included employees, organizational sustainability, and the organizationenvironment relation, where the latter two systems should support employee health and engagement to develop a human-centred workplace. Quintiliani et al.s (2010) review paper positioned healthy eating behaviours as a desired outcome, with relevant systems that influence such behavioural choices including individual, organizational and immediate social environments, physical environment settings (i.e., job sites), and macro-level context (i.e., social values and food marketing) (Quintiliani et al., 2010; Story, Kaphingst, Robinson-O’Brien, \& Glanz, 2008). Specifically, food availability at work, nutrition labelling, and promotional material at work positively affected employees' healthy eating behaviours across settings (Story et al., 2008).

Bone (2015) suggested multiple level systems as a theoretical approach to applying EST in workplace health promotion and management: (1) micro: workplaces as psychosocial settings and interpersonal relations at work, (2) meso: spatial and temporal work-life boundaries, (3) exo: governmental policies and codes and other social systems (i.e., federal governmental agencies, healthcare, unions), (4) macro: economic, societal, cultural contexts, and (5) chrono: time and events. Bone's (2015) approach was based on the concept of workplaces being a venue of facilitation for health promotion, rather than injury or illness prevention. Salazar and Beaton 
(2000) applied EST to understand occupational stresses as an outcome of the interconnection of multisystems. They propose four levels (micro, organizational, peri-organizational, and extraorganizational systems) and identify work-related stressors and perceived risk factors for each system level. Salazar and Beaton's (2000) ecological model of occupational stress provided a holistic view of different system levels, including moderating factors (i.e., age, gender, personalities, marital status), outcomes of stress responses, and ultimate health and well-being with detailed work stressors and risk factors. Their ecological occupational stress model can be expanded to understand other dimensions of individual vitality (i.e., performance, positive health outcomes, eating behaviours). All of these theoretical ecological models of workplaces put humans and respect for humanity in the centre of focus and laid out interventions or improvements that can be made at different levels of systems for human health and well-being.

\subsection{Work-family relationship}

Work-family relationships have been explored theoretically (Wayne, Grzywacz, Carlson, \& Kacmar, 2007) as well as through interviews (Grzywacz \& Marks, 1999), survey, and observation (Repetti \& Wood, 1997). This is a rich area for seeing applications of EST, because work-family relationships are established topics in the fields of family psychology and child development, linking work and family domains and investigating the moderating effects of personal characteristics (Wayne et al., 2007). Commonly addressed dimensions of work factors are organizational climate, social support, workloads, job autonomy, and interpersonal stress (Repetti \& Wood, 1997; Voydanoff, 2001).

Wayne et al. (2007) proposed a theoretical framework, the resource-gain-development (RGD) perspective, explaining how work, family, personal characteristics, environmental resources, and demand characteristics are related to work-family facilitation. Wayne et al. (2007, p. 64) defined work-family facilitation as "the extent to which an individual's engagement in one life domain (i.e., work/family) provides gains (i.e., developmental, affective, capital, or efficiency) which contribute to enhanced functioning of another life domain (i.e., family/work)". The RGD perspective emphasized that individual characteristics (i.e., self-efficacy, positive affectivity, work identity) and environmental resources (i.e., developmental opportunities, social support from co-workers and supervisors, family-friendly culture at the workplace) promoted positive employee experience both at work and at home (i.e., work-to-family facilitation).

Grzywacz and Marks (1999) found significant correlations of positive and negative spillover between work and family; for instance, decision latitude was significantly associated with positive work-family interface, both from work to family and from family to work, whereas spouse affectual support was strongly associated with a positive spillover from family to work - but not from work to family. These results confirmed that the work-family interface could be better understood through both work and family domains, not just personal characteristics or role occupations alone (Barnett, Marshall, \& Pleck, 1992; Grzywacz \& Marks, 1999). Increases in perceived workload and interpersonal stress at work were negatively associated with motherchild interactions in emotion and behaviour; furthermore, mothers who reported more psychological distress (i.e., depression, anxiety) or more Type A behaviour (i.e., time urgency, competition, easy aggression) showed greater parent-child behavioural and emotional withdrawal than those who did not (Repetti \& Wood, 1997).

\subsection{Workplace and organizational vitality}

Workplace and organizational vitality have also been explored theoretically (Allen, Stelzner, \& Wielkiewicz, 1999; Chandler, Kram, \& Yip, 2011; Johnson, 2011) and empirically in a randomized 
controlled true experiment (Cooley, Pedersen, \& Mainsbridge, 2014). Theoretical explorations of workplace and organizational vitality include various topics, such as Chandler et al.s 2011 mentoring at work. Their handbook focuses on the interdependent system of settings in participants' lives, pointing out ways in which a person's mentoring relationships at work impact other multisystems, adding nuances to their application of EST - such as the importance of dyadic exchange in the context of both the workplace micro-system and social network micro-systems. In a similar vein, Allen et al.'s (1999) theoretical approach to leadership points out ways in which leadership must transcend multiple levels if it is to have lasting impact on an organization, society, or global outcomes.

Interventions intended to improve workplace and organizational vitality outcomes have been created based on the idea that relationships and activities within the micro-system (workplace) have an effect on and interdependency with other layers. Cooley et al.s (2014) study provides an evaluation of a physical-activity-promoting workplace health intervention that resulted in impacts to multiple layers of the ecological system - within the office to beyond the workplace. Participants reported being more aware of their sedentary or active time across settings and changed non-work health habits, including diet and smoking (Cooley et al., 2014). A proposed intervention intended to address and reduce workplace bullying (Johnson, 2011) leverages this same concept in a framework to address the issue within the micro-system (office) while acknowledging ways in which bullying behaviour stems from meso- and exo-system influences, such as attitudes of others and societal stress or norms.

\subsection{Community vitality}

Community vitality is conceptualized in the context of work and family (Voydanoff, 2001) and workplace violence (Gillespie, Gates, \& Fisher, 2015). Work, family, and community are linked to one another; the combination performs a meso-system as a social context (Voydanoff, 2001). In a similar fashion to Johnson's 2011 exploration of a multisystem intervention to address workplace bullying, Voydanoff (2001) points out the systemic interconnectedness of work, family, and community micro-systems and the ways in which actions related to family or work, for example, take place within multiple layers of the system. Acknowledging this reality allows for an approach to community health that takes work into account; employers participate by recognizing the ways in which their workplace micro-system interacts with the community; health and healthy relationships in the home or community space necessarily stem from health and healthy relationships at the office. This is echoed by a review of recommendations for reducing violence and bullying in healthcare workplaces from Gillespie et al. (2015), including a summary of strategies with an EST approach to provide ideas for interventions in individual, relationship, community, and societal levels.

\section{Methodology/research approach}

\subsection{Data collection and analysis}

Ecological systems theory has been applied to topics across various disciplines, from workplace culture and community resilience to public policy (Baranowski, Cullen, Nicklas, Thompson, \& Baranowski, 2003; Boon, Cottrell, King, Stevenson, \& Millar, 2012; Johnson, 2011) with varying methods of research, data collection, and analysis. Some studies take an approach of theoretical exploration, while others focus on quantitative methodology. Data collection and analysis methods differ depending on the topic, but the main objectives of workplace-related studies 
are similar: identifying the relationship between work (or work environments) and (behavioural) consequences in the workplace, demonstrating the interconnection of interventions (or environmental factors) and other systems (i.e., family), and showing the influence of work and workplace environments in our lives.

Because EST provides five levels of systems, for data collection and analysis purposes, each system can be analysed separately without considering the other levels of the systems - or multiple systems can be explored simultaneously, to understand interactions and their outcomes. Therefore, it is important to consider the level of study and if it calls for within-level or across-level generalization (Onwuegbuzie, Collins, \& Frels, 2013). Within-level generalization refers to generalization made within the same level of the systems (wholly within the workplace). Across-level, on the other hand, means generalization combined with more than two levels of the systems (e.g., between the workplace and the home). Bronfenbrenner and Ceci (1994) developed a person-process-context model to use to propose research methodology for simultaneous investigation (e.g., birth weight, behavioural problems, the quality of infant-mother interaction, social-economic status); with the addition of a chronic system, the model is expanded to a process-person-context-time model (Tudge, Morkova, Hatfield, \& Karnik, 2009).

In summary, previous studies applying EST utilize several methods depending on the study objectives (see Table 9.1). Regardless of the level of systems, the most commonly used method is qualitative exploration (Allen et al., 1999; Bone, 2015; Chandler et al., 2011; Cleveland et al., 2015; Gillespie et al., 2015; Hill et al., 2008b; Johnson, 2011; Quintiliani et al., 2010; Salazar \& Beaton, 2000; Voydanoff, 2001; Wayne et al., 2007). These studies are theoretical, and most of them explain relationships between factors based on EST. Another set of studies propose new ecological systems based on EST by defining the level of systems according to the topic. Other methods of data collection are surveys (Hill et al., 2010), interviews (Grzywacz \& Marks, 1999; Skinner \& Pocock, 2011), observation (Repetti \& Wood, 1997), and controlled experiment (Cooley et al., 2014); data collected in the quantitative form are analysed using statistical analysis, such as descriptive analysis and regression analysis.

Table 9.1 Data collection and analysis methods: ecological systems theory and workplace studies

\begin{tabular}{|c|c|c|c|}
\hline Topic & Author(s) \& Year & Relevant systems in EST & Data collection and analysis methods \\
\hline \multirow[t]{3}{*}{$\begin{array}{l}\text { Workplace } \\
\text { flexibility }\end{array}$} & Hill et al., 2010 & Meso-system & $\begin{array}{l}\text { Survey, statistical analysis (descriptive } \\
\text { analysis, ordinary least square } \\
\text { (OLS) regression) }\end{array}$ \\
\hline & Hill et al., 2008b & $\begin{array}{l}\text { Micro-, meso-, exo-, } \\
\text { and macro-systems }\end{array}$ & $\begin{array}{l}\text { Theoretical approach, qualitative } \\
\text { exploration }\end{array}$ \\
\hline & $\begin{array}{l}\text { Skinner \& Pocock, } \\
2011\end{array}$ & $\begin{array}{l}\text { Micro- and } \\
\text { meso-systems }\end{array}$ & $\begin{array}{l}\text { Telephone interview, statistical } \\
\text { analysis }\end{array}$ \\
\hline \multirow[t]{4}{*}{$\begin{array}{l}\text { Individual } \\
\text { vitality }\end{array}$} & $\begin{array}{l}\text { Cleveland et al., } \\
2015\end{array}$ & $\begin{array}{l}\text { Micro-, meso-, and } \\
\text { exo-systems }\end{array}$ & $\begin{array}{l}\text { Theoretical approach, qualitative } \\
\text { exploration }\end{array}$ \\
\hline & $\begin{array}{l}\text { Quintiliani et al., } \\
2010\end{array}$ & $\begin{array}{l}\text { Exo- and } \\
\text { macro-systems }\end{array}$ & $\begin{array}{l}\text { Theoretical approach, qualitative } \\
\text { exploration }\end{array}$ \\
\hline & Bone, 2015 & $\begin{array}{l}\text { Micro-, meso-, exo-, } \\
\text { and macro-systems }\end{array}$ & $\begin{array}{l}\text { Theoretical approach, qualitative } \\
\text { exploration }\end{array}$ \\
\hline & $\begin{array}{l}\text { Salazar \& Beaton, } \\
\quad 2000\end{array}$ & $\begin{array}{l}\text { Micro-, meso-, exo-, } \\
\text { and macro-systems }\end{array}$ & $\begin{array}{l}\text { Theoretical approach, literature } \\
\text { review }\end{array}$ \\
\hline
\end{tabular}




\begin{tabular}{|c|c|c|c|}
\hline Topic & Author(s) \& Year & Relevant systems in EST & Data collection and analysis methods \\
\hline \multirow[t]{3}{*}{$\begin{array}{l}\text { Work-family } \\
\text { relationship }\end{array}$} & $\begin{array}{l}\text { Grzywacz \& } \\
\text { Marks, } 1999\end{array}$ & Micro-system & $\begin{array}{l}\text { Interview, statistical analysis } \\
\quad \text { (multivariate regression analysis) }\end{array}$ \\
\hline & Wayne et al., 2007 & $\begin{array}{l}\text { Micro- and } \\
\text { meso-systems }\end{array}$ & $\begin{array}{l}\text { Theoretical approach, qualitative } \\
\text { exploration }\end{array}$ \\
\hline & $\begin{array}{l}\text { Repetti \& Wood, } \\
1997\end{array}$ & Meso-system & $\begin{array}{l}\text { Observation, statistical analysis } \\
\text { (multiple regression) }\end{array}$ \\
\hline \multirow{4}{*}{$\begin{array}{l}\text { Workplace and } \\
\text { organizational } \\
\text { vitality }\end{array}$} & $\begin{array}{l}\text { Cooley et al., } \\
2014\end{array}$ & $\begin{array}{l}\text { Micro-, meso-, and } \\
\text { exo-systems }\end{array}$ & Controlled experiment \\
\hline & $\begin{array}{l}\text { Chandler et al., } \\
2011\end{array}$ & $\begin{array}{l}\text { Micro- and } \\
\text { macro-systems }\end{array}$ & $\begin{array}{l}\text { Theoretical approach, qualitative } \\
\text { exploration }\end{array}$ \\
\hline & Allen et al., 1999 & Macro-system & $\begin{array}{l}\text { Theoretical approach, qualitative } \\
\text { exploration }\end{array}$ \\
\hline & Johnson, 2011 & Multiple systems & $\begin{array}{l}\text { Theoretical approach, qualitative } \\
\text { exploration }\end{array}$ \\
\hline \multirow[t]{2}{*}{$\begin{array}{l}\text { Community } \\
\text { vitality }\end{array}$} & Voydanoff, 2001 & $\begin{array}{l}\text { Micro-, meso-, and } \\
\text { macro-systems }\end{array}$ & $\begin{array}{l}\text { Theoretical approach, qualitative } \\
\text { exploration }\end{array}$ \\
\hline & $\begin{array}{l}\text { Gillespie et al., } \\
2015\end{array}$ & $\begin{array}{l}\text { Micro-, meso-, exo-, } \\
\text { and macro-systems }\end{array}$ & $\begin{array}{l}\text { Theoretical approach, qualitative } \\
\text { exploration }\end{array}$ \\
\hline
\end{tabular}

\subsection{Research gaps in EST inspired workplace research}

Table 9.1 shows that there are three main research gaps in workplace studies regarding EST: (1) methodological limitation, (2) lack of integration of multiple levels, and (3) exclusion of built environments.

Most previous studies have focused on theoretical expansion of EST to workplace studies (Cleveland et al., 2015; Gillespie et al., 2015; Hill et al., 2008b; Voydanoff, 2002). Theoretical expansion allows for the adaptation of the theory for various topics related to the workplace but limits the methodology to qualitative exploration based on a literature review. There is a significant shortage of experimental studies using quantitative data (Cooley et al., 2014; Hill et al., 2008a; Törnquist Agosti, Bringsén, \& Andersson, 2017) to provide empirical evidence and validate the proposed models.

One of the advantages of EST that it encompasses multisystems and emphasizes interactions between levels. However, multiple levels of EST have not traditionally been tested simultaneously (Chandler et al., 2011; Grzywacz \& Marks, 1999), as most studies consider a single system in isolation. Considering multiple levels simultaneously (i.e., hierarchical linear modelling, structural equation modelling) allows testing for interdependence of the social-environmental systems of home, family, school, work, community, culture, and social infrastructures.

Lastly, even though environmental circumstances and surroundings are the key focuses of EST (Bronfenbrenner, 1979), the physical settings of workplace environments have not been fully considered as an environmental system in EST-inspired studies of workplace flexibility and work-family relations. The physical environment of workplaces can affect multisystems to varying degrees, such as individual behaviour, workplace vitality, work-family relationship, and community vitality. Some studies include workplace flexibility in work off-site (i.e., home office) (Hill et al., 2010; Skinner \& Pocock, 2011). Additionally, options to select where employees sit at their office with activity-based working and options to select different worksite locations (i.e., company's different locations, third places such as co-working spaces) should be included 
in the workplace EST model. In this way, the physical work environment can be tested as an independent, mediating, moderating, or dependent variable in future studies.

\section{Limitations}

It is challenging to test EST in a real-life context; this difficulty explains the lack of empirical studies in the existing literature. The limitation of applying EST to workplace studies lies in the complexity of dissecting interwoven relationships among different systems. First, measuring the impact of an intervention on different systems can be challenging, as it may require multidisciplinary or transdisciplinary approaches and collaboration among parties with different background knowledge and expertise. For instance, the investigation of an intervention in the physical workplace can be done with the collaboration of employees and their families, designers, facility managers, HR staff, psychologists, and managers from the ecological perspective. Second, the simultaneous measurements in multiple settings require deliberate research plans. The proposed framework in this chapter (see Figure 9.2) can help the process of scrutinizing the effect of workplace strategies and management on multiple levels over time but does not resolve challenges imposed by simultaneous measurements and the difficulty of random assignment, which can limit conclusions of research regarding causality or directionality of relationships. Additionally, the literature search of this chapter is limited to articles that explicitly refer to EST; workplace research that studied similar subjects but did not explicitly refer to or apply EST may be still applicable to the ecological systems of workplaces and even include analogous concepts.

To overcome such challenges, researchers can use quasi-experiments, mixed methods, various statistical modelling techniques (i.e., structural equation modelling, hierarchical linear modelling, factor analysis), and digital media methods. Convergent parallel mixed-methods designs (Creswell \& Plano Clark, 2011) and 'methodological triangulation' (Bruneel, Wit, Verhoeven, \& Elen, 2013) can be used to collect data in parallel strands and connect the results of different methods and multiple level systems. Social media methods, both qualitative and quantitative approaches of analysing user-generated contents on a large scale, have methodological benefits (Dominguez \& Hollstein, 2014; Sloan \& Quan-Haase, 2017; Snelson, 2016) and also potentially for workplace studies. These limitations also present the possibility that deeper understanding of EST may be gained through alternative research models, including participatory or generative design research.

Ecological systems theory is highly relevant to our personal lives and practices of workplace design, strategies, and management. The theory can be utilized as a tool to understand human behaviour in the workplace and the complex relationships between different dimensions of employees' lives. The holistic understanding of environmental changes in the workplace, beyond the workplace setting, also highlights the importance of the workplace environment in sustaining the interdependence of micro-, meso-, exo-, macro-, and chrono-systems. As longitudinal measurements in multiple settings require deliberate research plans and coordinated efforts, collaboration between academia and industry is essential to the success of EST-based workplace studies. To this end, professional associations and institutional community outreach centres can play an important role in connecting researchers and practitioners to overcome methodological and logistical challenges, acting as an effective knowledge-sharing and communication platform, and ultimately supporting the achievement of mutual goals.

\section{Theory relevance to practice}

Workplace managers can benefit from frameworks and interventions rooted in EST by seeing multiple inflection points at which their spatial or programming decisions can benefit employees. 
Understanding the underlying mechanics of interconnected systems and the reasons that a multiple level approach to workplace mentoring, wellness, or productivity may bear fruit allows managers to make decisions more effectively.

When asked to consider schedule flexibility, the pros and cons of wellness features offered in leased space, or a request from employees to change workspace or benefits, managers can use the concepts from EST to think through how they might respond to such requests in a way that touches not only the micro-system of the office but also interdependent systems. The benefits of using this approach can be seen in studies from the past 30 years that established stress from the commute can 'carry over' into the work day and impact morale and productivity (Costa, Pickup, \& Di Martino, 1988; Gottholmseder, Nowotny, Pruckner, \& Theurl, 2009; Stutzer \& Frey, 2008). Workplace managers reacted. It is now common to consider location relative to where employees live and modes of transit available to get to a potential new office space as a part of leasing criteria - even to consider working to improve transit options to desirable lease locations (Legrain, Eluru, \& El-Geneidy, 2015; Wener, Evans, Phillips, \& Nadler, 2003).

This relationship between levels is more relevant in a decade that has seen rapid expansion of remote work and work-from-home (WFH) programs; first seen as a way to attract employees through flexibility or enable employees to be more productive when traveling, remote work is now a fact of life for all organizations. Expanding the definition of the workplace to include mobility and amenities within the office, neighbourhood, and city necessitates acknowledging levels of an ecological system explicitly and addressing the ways in which they interact. New issues arise for employees when working remotely, ostensibly as a result of bringing more activities and relationships from one level (the micro-system of the physical workplace) into the mental, physical, social, and virtual spaces of other levels (Vartiainen \& Hyrkkänen, 2010).

For example, when an employee is more mobile through system levels and only in the main office a few days a week, they engage in 'micro-tasking' while on the go and begin to view the office as a home hub for meetings and longer periods of concentration (Koroma, Hyrkkänen, \& Vartiainen, 2014; Vartiainen \& Hyrkkänen, 2010). Workplace managers can react to these changing relationships with work outside the office and within it by shifting the amount and types of spaces available to meet shifting needs. For example, an ecosystem of services can be expanded within the community, rather than within the office, in order to keep employees connected to the food, exercise, wellness, and organizational culture that the office formerly provided.

Within the EST, findings from multiple disciplines, such as architecture and design, human development, psychology, environmental psychology, business and management, human resources, construction management, and project management, can be integrated. Having a theory that provides a framework to integrate findings from different fields, which often have their own silos of accumulative knowledge, can provide a holistic view of how workplace research and management affect our lives in the interdependent systems: micro-, meso-, exo-, macro-, and chrono-systems. Moreover, the integration of knowledge from diverse disciplines can foster effective evidencebased practices. In this sense, translational research based on the EST in workplace strategies and management can foster the application of findings from different disciplines into practice.

\section{Further reading}

- Bone, K. D. (2015). The bioecological model: Applications in holistic workplace well-being management. International Journal of Workplace Health Management, 8(4), 256-271. https:// doi.org/10.1108/IJWHM-04-2014-0010

- Bronfenbrenner, U. (1979). The ecology of human development: Experiments by nature and Design. Cambridge, MA: Harvard University Press. 


\section{Eunhwa Yang and Bonnie Sanborn}

- Hill, E. J., Jacob, J. I., Shannon, L. L., Brennan, R. T., Blanchard, V. L., \& Martinengo, G. (2008). Exploring the relationship of workplace flexibility, gender, and life stage to familyto-work conflict, and stress and burnout. Community, Work \& Family, 11(2), 165-181. https://doi.org/10.1080/13668800802027564

\section{References}

Allen, K. E., Stelzner, S. P., \& Wielkiewicz, R. M. (1999). The ecology of leadership: Adapting to the challenges of a changing world. Journal of Leadership Studies, 5(2), 62-82. https://doi.org/10.1177/1071 79199900500207

Arundell, L., Sudholz, B., Teychenne, M., Salmon, J., Hayward, B., Healy, G. N., \& Timperio, A. (2018). The impact of activity based working $(\mathrm{ABW})$ on workplace activity, eating behaviours, productivity, and satisfaction. International Journal of Environment Research and Public Health, 15(5), 1005. https://doi. org/10.3390/ijerph15051005

Bangwal, D., \& Tiwari, P. (2019). Workplace environment, employee satisfaction and intent to stay. International Journal of Contemporary Hospitality Management, 31(1), 268-284. https://doi.org/10.1108/ IJCHM-04-2017-0230

Baranowski, T., Cullen, K. W., Nicklas, T., Thompson, D., \& Baranowski, J. (2003). Are current health behavioural change models helpful in guiding prevention of weight gain efforts?. Obesity Research, 11(S10), 23S-43S. https://doi.org/10.1038/oby.2003.222

Barnett, R. C., Marshall, N. L., \& Pleck, J. H. (1992). Men's multiple roles and their relationship to men's psychological distress. Journal of Marriage and the Family, 54, 358-367.

Bone, K. D. (2015). The bioecological model: Applications in holistic workplace well-being management. International Journal of Workplace Health Management, 8(4), 256-271. https://doi.org/10.1108/ IJWHM-04-2014-0010

Boon, H. J., Cottrell, A., King, D., Stevenson, R. B., \& Millar, J. (2012). Bronfenbrenner's bioecological theory for modelling community resilience to natural disasters. Natural Hazards, 60(2), 381-408. https://doi.org/10.1007/s11069-011-0021-4

Bronfenbrenner, U. (1979). The ecology of human development: Experiments by nature and design. Cambridge, MA: Harvard University Press.

Bronfenbrenner, U. (1986). Recent advances in research on the ecology of human development. In R. Silbereisen, K. Eyferth, \& G. Fudinger (Eds.), Development as action in context (pp. 287-309). New York: Springer-Verlag.

Bronfenbrenner, U., \& Ceci, S. J. (1994). Nature-nurture reconceptualized in developmental perspective: A bioecological model. Psychological Review, 101(4), 568-586. https://doi.org/10.1037/0033-295X.101. 4.568

Brunia, S., de Been, I., \& van der Voordt, T. J. M. (2016). Accommodating new ways of working: Lessons from best practices and worst cases. Journal of Corporate Real Estate, 18(1), 30-47. https://doi.org/10.11 08/JCRE-10-2015-0028

Bruneel, S., Wit, K. D., Verhoeven, J. C., \& Elen, J. (2013). Facebook: When education meets privacy. Interdisciplinary Journal of E-Learning and Learning Objects, 9, 125-148.

Chandler, D. E., Kram, K. E., \& Yip, J. (2011). An ecological systems perspective on mentoring at work: A review and future prospects. The Academy of Management Annals, 5(1), 519-570. https://doi.org/10. 1080/19416520.2011.576087

Cleveland, J. N., Byrne, Z. S., \& Cavanagh, T. M. (2015). The future of HR is RH: Respect for humanity at work. Human Resource Management Review, 25(2), 146-161. https://doi.org/10.1016/j.hrmr.2015.01.005

Cooley, D., Pedersen, S., \& Mainsbridge, C. (2014). Assessment of the impact of a workplace intervention to reduce prolonged occupational sitting time. Qualitative Health Research, 24(1), 90-101. https://doi. org/10.1177/1049732313513503

Costa, G., Pickup, L., \& Di Martino, V. (1988). Commuting: A further stress factor for working people: Evidence from the European Community. I. A review. International Archives of Occupational and Environmental Health, 60(5), 371-376. https://doi.org/10.1007/bf00405673

Creswell, J. W., \& Plano Clark, V. L. (2011). Designing and conducting mixed methods research (2nd ed.). New York: SAGE Publications.

Danielsson, C. B., \& Bodin, L. (2008). Office type in relation to health, well-being, and job satisfaction among employees. Environment and Behavior, 40(5), 636-668. https://doi.org/10.1177/0013916507307459 
Danna, K., \& Griffin, R. W. (1999). Health and well-being in the workplace: A review and synthesis of the literature. Journal of Management, 25(3), 357-384. https://doi.org/10.1016/S0149-2063(99)00006-9

Darwin, C. (1859). On the origin of species by means of natural selection. London: Murray.

De Been, I., \& Beijer, M. (2014). The influence of office type on satisfaction and perceived productivity support. Journal of Facility Management, 12(2), 142-157. https://doi.org/10.1108/JFM-02-2013-0011

Dominguez, S., \& Hollstein, B. (Eds.). (2014). Mixed methods social networks research: Design and applications. Cambridge: Cambridge University Press.

Gillespie, G. L., Gates, D. M., \& Fisher, B. S. (2015). Individual, relationship, workplace, and societal recommendations for addressing healthcare workplace violence. Work, 51(1), 67-71. https://doi.org/10.3233/ WOR-141890

Gottholmseder, G., Nowotny, K., Pruckner, G. J., \& Theurl, E. (2009). Stress perception and commuting. Health Economics, 18(5), 559-576. https://doi.org/10.1002/hec.1389

Grzywacz, J. G., \& Marks, N. F. (1999). Family solidarity and health behaviours: Evidence from the National Survey of Midlife Development in the United States. Journal of Family Issues, 20(2), 243-268. https://doi.org/10.1177/019251399020002004

Haeckel, E. (1866). Generelle Morphologie der Organismen - Allgemeine Grundzüge der organischen Formen-Wissenschaft, mechanisch begründet durch die von Charles Darwin reformierte Descendenz-Theorie. Zweiter Band: Allgemeine Entwickelungsgeschichte der Organismen. Berlin: Verlag von Georg Reimer.

Hawley, A. H. (1950). Human ecology: A theory of community structure. New York: Ronald Press Company.

Hill, E. J., Erickson, J. J., Holmes, E. K., \& Ferris, M. (2010). Workplace flexibility, work hours, and work-life conflict: Finding an extra day or two. Journal of Family Psychology, 24(3), 349-358. https:// doi.org/10.1037/a0019282

Hill, E. J., Grzywacz, J. G., Allen, S., Blanchard, V. L., Matz-Costa, C., Shulkin, S., \& Pitt-Catsouphes, M. (2008b). Defining and conceptualizing workplace flexibility. Community, Work E Family, 11(2), 149-163. https://doi.org/10.1080/13668800802024678

Hill, E. J., Jacob, J. I., Shannon, L. L., Brennan, R. T., Blanchard, V. L., \& Martinengo, G. (2008a). Exploring the relationship of workplace flexibility, gender, and life stage to family-to-work conflict, and stress and burnout. Community, Work \& Family, 11(2), 165-181. https://doi.org/10.1080/13668800802027564

Johnson, S. L. (2011). An ecological model of workplace bullying: A guide for intervention and research. Nursing Forum, 46(2), 55-63. https://doi.org/10.1111/j.1744-6198.2011.00213.x

Koroma, J., Hyrkkänen, U., \& Vartiainen, M. (2014). Looking for people, places and connections: Hindrances when working in multiple locations: A review. New Technology, Work and Employment, 29(2), 139-159. https://doi.org/10.1111/ntwe.12030

Legrain, A., Eluru, N., \& El-Geneidy, A. M. (2015). Am stressed, must travel: The relationship between mode choice and commuting stress. Transportation Research Part F: Traffic Psychology and Behaviour, 34, 141-151. https://doi.org/10.1016/j.trf.2015.08.001

Lewin, K. (1936). Principles of topological psychology. New York: McGraw-Hill.

Oldham, G. R., \& Brass, D. J. (1979). Employee reactions to an open-plan office: A naturally occurring quasi-experiment. Administrative Science Quarterly, 24(2), 267-284. https://doi.org/10.2307/2392497

Onwuegbuzie, A. J., Collins, K. M., \& Frels, R. K. (2013). Foreword: Using Bronfenbrenner's ecological systems theory to frame quantitative, qualitative, and mixed research. International Journal of Multiple Research Approaches, 7(1), 2-8. https://doi.org/10.5172/mra.2013.7.1.2

Quintiliani, L., Poulsen, S., \& Sorensen, G. (2010). Healthy eating strategies in the workplace. International Journal of Workplace Health Management, 3(3), 182-196. https://doi.org/10.1108/17538351011078929

Repetti, R. L., \& Wood, J. (1997). Effects of daily stress at work on mothers' interactions with preschoolers. Journal of Family Psychology, 11(1), 90-108. https://doi.org/10.1037/0893-3200.11.1.90

Robertson, M. M., \& O'Neill, M. J. (2003). Reducing musculoskeletal discomfort: Effects of an office ergonomics workplace and training intervention. International Journal of Occupational Safety and Ergonomics, 9(4), 491-502. https://doi.org/10.1080/10803548.2003.11076585

Salazar, M. K., \& Beaton, R. (2000). Ecological model of occupational stress: Application to urban firefighters. Workplace Health \& Safety, 48(10), 470-479.

Skinner, N., \& Pocock, B. (2011). Flexibility and work-life interference in Australia. Journal of Industrial Relations, 53(1), 65-82. https://doi.org/10.1177/0022185610390297

Sloan, L., \& Quan-Haase, A. (Eds.). (2017). The SAGE handbook of social media research methods. London: SAGE Publications.

Snelson, C. L. (2016). Qualitative and mixed methods social media research: A review of the literature. International Journal of Qualitative Methods, 15(1). https://doi.org/10.1177/1609406915624574 


\section{Eunhwa Yang and Bonnie Sanborn}

Stauffer, R. C. (1957). Haeckel, Darwin, and ecology. The Quarterly Review of Biology, 32(2), $138-144$. https://doi.org/10.1086/401754

Story, M., Kaphingst, K. M., Robinson-O’Brien, R., \& Glanz, K. (2008). Creating healthy food and eating environments: Policy and environmental approaches. Annual Reviews of Public Health, 29, $253-272$. https://doi.org/10.1146/annurev.publhealth.29.020907.090926

Stutzer, A., \& Frey, B. S. (2008). Stress that doesn't pay: The commuting paradox. The Scandinavian Journal of Economics, 110(2), 339-366. https://doi.org/10.1111/j.1467-9442.2008.00542.x

Thatcher, A., \& Milner, K. (2014). Changes in productivity, psychological wellbeing and physical wellbeing from working in a 'green' building. Work, 49(3), 381-393. https://doi.org/10.3233/WOR-141876

Törnquist Agosti, M., Bringsén, Å., \& Andersson, I. (2017). The complexity of resources related to worklife balance and well-being: A survey among municipality employees in Sweden. The International Journal of Human Resource Management, 28(16), 2351-2374. https://doi.org/10.1080/09585192.2017.1340323

Tudge, J., Morkova, I., Hatfield, B. E., \& Karnik, R. B. (2009). Uses and misuses of Bronfenbrenner's bioecological theory of human development. Journal of Family Theory E Review, 1(4), 198-210. https:// doi.org/10.1111/j.1756-2589.2009.00026.x

Vartiainen, M., \& Hyrkkänen, U. (2010). Changing requirements and mental workload factors in mobile multi-locational work. New Technology, Work and Employment, 25(2), 117-135. https://doi.org/10.1111/ j.1468-005X.2010.00243.x

Voydanoff, P. (2001). Conceptualizing community in the context of work and family. Community, Work $\mathcal{E}$ Family, 4(2), 133-156. https://doi.org/10.1080/713658928

Voydanoff, P. (2002). Linkages between the work-family interface and work, family, and individual outcomes: An integrative model. Journal of Family Issues, 23(1), 138-164. https://doi.org/10.1177/01925 13X02023001007

Wayne, J. H., Grzywacz, J. G., Carlson, D. S., \& Kacmar, K. M. (2007). Work-family facilitation: A theoretical explanation and model of primary antecedents and consequences. Human Resource Management Review, 17(1), 63-76. https://doi.org/10.1016/j.hrmr.2007.01.002

Wener, R. E., Evans, G. W., Phillips, D., \& Nadler, N. (2003). Running for the 7:45: The effects of public transit improvements on commuter stress. Transportation, 30(2), 203-220. https://doi.org/10.1023/A:102 2516221808

Wijk, K., Bergsten, E. L., \& Hallman, D. M. (2020). Sense of coherence, health, well-being, and work satisfaction before and after implementing activity-based workplaces. International Journal of Environmental Research and Public Health, 17(14), 5250. https://doi.org/10.3390/ijerph17145250 


\title{
10
}

\section{TEMPERAMENT THEORY \\ Understanding people in a workplace context}

\author{
Mel Bull*
}

\section{Background}

To understand the use of temperament theory, one needs to grasp the historical context. This section explores the historical context of temperament/personality theory dating to the first use of the concept from Hippocrates in 460-370 BC, through to the 20th century with Steiner (1919), Jung's psychological types (1921), and Eysenck (1967) and to the use of this theory in the 21st century. To give definition to the concepts of 'temperament' and 'personality', Allport (1961) cited in Rothbart, Ahadi, and Evans (2000, p. 123) defined temperament as "the characteristic phenomena of an individual's emotional nature, including his susceptibility to emotional stimulation, his customary strength and speed of response and the quality of his prevailing mood, these phenomena being regarded as dependent up in constitutional make-up", whereas personality was defined as "the dynamic organization within the individual psychophysical systems that determine his unique adjustment to his environment". The use of temperaments has predominantly been used in psychology, particularly in child development, but also in modern business in $\mathrm{HR}$ as a development tool and in recruitment, using psychometric testing.

The concept of personality or temperament types is not new, and this chapter gives a chronological view of the development of temperament theory and its use in modern-day practice. Temperament, from the Roman 'temperamentum', originally referred to a mix of bodily 'humors' and was a fourfold typology (Rothbart et al., 2000); a concept which was created in approximately 400 BC by the Greek physician Hippocrates (460-370 BC). He created the concept of an innate temperament within everyone and the interrelation between bodily fluids (humors) and our emotions and behaviours. As described by Rothbart et al. (2000, p. 123), the humors related to aspects of the body:

The choleric individual, with a predominance of yellow bile is irritable and quick to anger; the melancholic individual with predominant black bile is sad and anxious; the sanguine individual with predominant blood, is positive and outgoing; and the phlegmatic individual with predominant phlegm is slow rising in emotion and action.

Immanuel Kant had an interest in temperament (1760s) from a psychological and physiological point of view. His explanation of the temperaments referred to them with two terms, feeling

*Corresponding author: mel.bull@sheffield.ac.uk 
and activity (Larrimore, 2001; Strelau, 1987). In his schema, the activity temperaments were the choleric with a temperament of intense but not persistent activity and phlegmatic as the polar opposite was inactive but enduring. In relation to the feeling temperaments, the sanguine and melancholic were also polar opposites, sanguine having strong and short-lasting feelings and melancholic having weak but longer-lasting feelings (Strelau, 1987; Lester, 1990; Stelmark \& Stalikas, 1991).

The use of temperaments or fourfold typologies had been limited up until the turn of the 20th century (Keirsey \& Bates, 1984; Merenda, 1987), when there was a resurgence of the concept from several academics, including Adickes (1907), Adler (1912), Kretschmer (1925) and Spränger (1928). All of these hold a strong link back to Hippocrates's four humors, but Rudolf Steiner, Austrian spiritual philosopher, offered the closest link to the four humors (see Table 10.1). He focused on the concept of temperaments in the early 1900s and later renamed his 'practice' as anthroposophy, meaning 'wisdom of the human being', founding the Anthroposophical Society in Germany in 1924 (Steiner, 1919, 2008). He found a significance for the four temperaments in relation to elementary education and hypothesised that temperament diminished as the personality developed after puberty. Whilst his theory was very similar to the origins of Hippocrates's ideas, he focused on a spiritual link: "Only when we hear what spiritual science has to say can we come closer to understanding these special colourings of the human personality" (Steiner, 2008, p. 3). Steiner suggested that there were four 'sheaths' to the human being. He then related these to the original four 'humors'. Notably Steiner refers to a predominant temperament, highlighting that we have the essence of all four within us. He discussed the need to be able to understand our temperaments and to embrace our own being, which then allows us an "immediacy of understanding to each human encounter" (Steiner, 2008, p. 24).

In modern parlance the work of Carl Jung, a Swiss psychologist and psychiatrist, is more commonly referred to and recognised through modern psychometric testing. Jung further developed the temperaments to psychological types by focusing on the opposite set of characteristics. He suggested, "the random variation in behaviour is actually quite orderly and consistent, due to basic differences in the way individuals prefer to use their perception and judgment" (Myers \& McCaulley, 1986, cited in Vincent \& Ross, 2001, p. 39). Jung's (1921 [1971], 1946) typologies were intricately linked with the physiological typologies of Greek medicine as highlighted earlier. Jung's basic model focused on a theory of primary and auxiliary functions, with a four-typology model of introversion/extraversion, sensation/intuition, thinking/feeling and rational/irrational functions. Jung believed that his theory could help to better explain personality but by no means does he suggest that an individual is a pure type. His theory is not one of

Table 10.1 Early 20th-century fourfold typologies

\begin{tabular}{|c|c|c|c|c|}
\hline $\begin{array}{l}\text { Adickes (1907) } \\
\text { Four world views }\end{array}$ & $\begin{array}{l}\text { Adler (1912) } \\
\text { Four mistaken } \\
\text { goals }\end{array}$ & $\begin{array}{l}\text { Steiner (1919) } \\
\text { Four sheaths linked to } \\
\text { Hippocrates's humors }\end{array}$ & $\begin{array}{l}\text { Kretschmer (1925) } \\
\text { Four character styles }\end{array}$ & $\begin{array}{l}\text { Spränger (1928) } \\
\text { Four value attitudes }\end{array}$ \\
\hline Innovative & Retaliation & $\begin{array}{l}\text { Sanguine (astral body } \\
\text { predominates) }\end{array}$ & Hypomanic & Artistic \\
\hline Doctrinaire & Recognition & Choleric (ego predominates) & Hyperesthetic & Religious \\
\hline Traditional & Service & $\begin{array}{l}\text { Melancholic (physical body } \\
\text { predominates) }\end{array}$ & Depressive & Economic \\
\hline Skeptical & Power & $\begin{array}{l}\text { Phlegmatic (etheric body } \\
\text { predominates) }\end{array}$ & Anesthetic & Theoretic \\
\hline
\end{tabular}


behaviour but of personality, as he focuses on the individual without the external stimuli. For example, an extravert is oriented to things and people whether they are in a crowd or on their own. However, Jung's model can be used as a tool to better understand who we are and how we generally function, and it subsequently allows us to assess our interactions with situations and people and to understand whether "our own actions truly reflected our judgements (thinking and feeling) and perceptions (sensation and intuition), and if not, why not?" (Sharp, 1987, p. 91). This further enhances the use of the temperaments model (Hippocrates, $400 \mathrm{BC}$ ) in being able to flex our behaviours to improve our communication with people.

When Jung's (1921) Psychological Types was translated to English in 1925, Katherine Briggs had already started to explore the importance of temperament in character development and stated that Jung's ideas corresponded with her own. The Myers-Briggs Type Indicator (MBTI), copyrighted in 1943, was created by her daughter Isobel Myers (nee Briggs) and was developed from Jung's typologies, delivering a 16-personality type model. The MBTI model allowed individuals to understand their own personality and how they engage with others, but it does not evidence ability (Kummerow, Barger, \& Kirby, 1997). This concept was further adopted in the 1950s by David Keirsey who adopted both Jung's (1921) theory of psychological types and the Myers-Briggs (1943) method of measuring types in the formation of the Kiersey Temperament Sorter in 1955. Kiersey also focused more on the concept of temperament as opposed to the pure Jungian view of functions. He named his personality types into four groupings - artisan, guardian, idealist and rational - and related these to the original temperaments intricately linked to the MBTI.

Through the development of temperament theories, there have been different levels of engagement with the role of emotion. Strelau (1987) focused on the concept of emotionality and temperament. The work linked with that of Allport (1938) and Eysenck (1970), specifically referring to 'affective behaviour'. Allport and Odbert's (1936) work led to the development of the five-factor model which focused on extraversion, openness to experience, agreeableness, consciousness, and emotional stability. This model has been further developed by academics (Goldberg, 1981; McCrae, Costa Jr, \& Busch, 1986; McCrae \& Costa, 2003). Eysenck (1967, 1997) and Eysenck and Eysenck (1985) focused on a three-traits model to include extraversion/ introversion, excitation/inhibition, and tough-mindedness/tender-mindedness. Goldsmith and Campos (1986, p. 231) cited in Strelau (1987) referred to the concept of temperament as "individual differences in emotionality" leading to Strelau's statement, "temperament is a synonym of the expression 'individual differences in emotional behaviour"” (Strelau, 1987, p. 513). Other terminology entered the frame; so for the extravert the other frames of reference were sensation seekers, low reactives and low arousability thus needing strong stimuli to gain the ideal level of arousal, but for introverts it was sensation avoiders or high reactives, and a lower level of stimuli was needed to keep an ideal level of arousal (Gray, 1964; Strelau, 1987). The concepts noted by Strelau (1987) still have a strong link to Jung's theory of introvert and extravert, but the significance being that emotion plays out in different ways depending on whether emotion is considered to be a "a trait, a process or a behavioral characteristic" (Strelau, 1987, p. 524).

From a practical level, moving through the 21 st century a multitude of temperament, personality or psychometric tests can be undertaken, including the MBTI, Insights Discovery ${ }^{\mathrm{TM}}$, The Enneagram and Keirsey's Temperament Sorter, to name a few. The aforementioned historical context has led to the creation and the theoretical underpinning for these models, but there are continued discussions about the validity of such tools and critiques on the concept of temperament theory. In the field of psychology and personality, debate in terms of temperament and trait psychology is ongoing (Clark \& Watson, 1999; Pervin \& John, 1999). We hope that this section has given the reader an idea of how the concept of temperament was born and how the 
varying scholars over the years have added elements to the initial concepts. This is not a chapter on the validity of temperament theory but more provides an understanding of how temperament theory can be utilised to understand ourselves and others. It also gives us the ability to understand our preferences and how we can learn to flex our behaviours to better relate and communicate with each other. Temperament theory does not evidence an ability to do a job, nor does it explain workplace dysfunctionality, but it is more a tool to understand and celebrate individual differences (Pederson, 2003). The following sections will focus on how to consider this temperament theory in the way we communicate, particularly through times of change, and may help to clarify the need to not take a one-size-fits-all approach. Because human beings are all different, we need to think about how our communication impacts at an individual level instead of trying to communicate en masse or providing a one-size-fits-all working environment.

\section{Applicability to workplace studies}

Linking to the concept of temperaments and the difference in individuals, Beard \& Price (2010) define the workplace as 'workspace plus culture'. If culture forms a strong part of our workplace, then there is a need to understand the people within this. Sundstrom (1984) provides an exploration into the psychologies of working environments and the impact these have on interpersonal relationships and communication. His focus is on outcomes: individual outcomes (satisfaction and performance), interpersonal outcomes (communications) and organisational outcomes (effectiveness). Sundstrom $(1984$, p. 7) defines the physical environment as that of "the individual's immediate surrounding during the workday which consist of a workspace or workstation and its ambient conditions". In a time of changing workplace requirements, rather than a blanket change of ways of working, the question needs to be asked whether we are considering the people within the space, their needs in terms of personality/temperament and the type of job to be undertaken in the space. Although the early theorists and authors of space recognised the need for improved communication, the issue of hierarchy and status was still as much of an issue as it is in today's workplace.

The use of psychometric testing is prevalent within human resource management (HRM) and, as facilities management strengthens its links with the HRM discipline, perhaps there needs to be greater consideration on how the space and place of work impacts on an individual's preferences (Jung, 1921, 1946). Pederson (2003) carried out a piece of research in the late 90s and focused on the role of an archivist/record keeper in Australia utilising Keirsey's temperament types to try to understand the type of person that took on this job specification. She found that the predominant Keirsey type for the role was that of a guardian, who is seen as someone who enjoys factual data. The results were limited to Australia, but by understanding the type of person in the role, Pederson suggested that archivists had "greater understanding of themselves and of how they perceive and are perceived by others; temperament awareness can improve the quality of our working relationships and our opportunities for professional achievement" (Pederson, 2003 , p. 362). If this is about understanding what we need from our workplace and relationships, then this could also help us to understand the space that individuals would prefer to work in, not just understanding the role they do.

Temperament theory could also offer a way of understanding staff needs when there is a potential workspace change. Pederson's (2003) research focused on the individual within the job role, and whilst they found a predominant Keirsey (Keirsey \& Bates, 1984) type, there was consideration of how this 'type' could improve their communication through better understanding of themselves and others. If you were leading a workplace change, then encouraging individuals to engage in the design of the space through open communication would be beneficial (Quirke, 
2008). Haynes (2012) refers to an asset alignment model containing eight elements, including planet, position, purpose, procurement, place, paradigm, process and people. The people element is often not focused on, with a greater emphasis on organisational need rather than psychological needs of the employees (Haynes, 2012; Oseland, 2009). Oseland (2009) critiques personality theory in terms of extrovert and introvert traits in terms of office space as being a consideration, but that it should not be the only one. There also needs to be further consideration of the "type of activity being conducted and mood" (Oseland, 2009, p. 245). Although Oseland does further discuss creating different spaces for different people, whether that be quiet space or social space, he also refers to giving people the choice of where they prefer to work and that the creation of workspace should consider "organisational and individual psychological needs" (Oseland, 2009, p. 253). Participative design can lead to occupants feeling committed to their workspace and could even create psychological attachment to it (see Chapter 16 Place Attachment). It may also lead to better environment design, using the experts (those living in it) to recognise how they use their own space, and finally it also shows a cooperation between workers irrelevant of status (Sundstrom, 1984, Oseland, 2009; Haynes, 2012; Bull \& Kortens, 2012).

Appel-Meulenbroek, Clippard, and Pfnür (2018) carried out a review of previous research on the effects of the physical office environment on employee outcomes. They found studies on the office layout focused more on "privacy, concentration and communication and again relatively less on health, comfort and emotional state" (Appel-Meulenbroek et al., 2018, p. 69). There appears to be a gap in the individualised focus on temperaments and the people working within a space. Hartog, Weijs-Perrée, and Appel-Meulenbroek (2018) conducted a quantitative study drawing on personality traits and workplace satisfaction in multi-tenant offices but also recognised that the link between personality and workplace research has been limited. Previous studies have focused on the personalisation of workspace (Laurence, Fried, \& Slowik, 2013) and on workplace design and the impact on cultural differences and preferences (Gan \& Haynes, 2012). The organisational workplace change carried out at Channel 4 (broadcasting company in the UK) engaged staff in creating a workspace to suit all types of people (Bull \& Kortens, 2012). Smollan, Matheny, and Sayers (2010) carried out a qualitative study on organisational change and the role that personality can play during this time. The research focused on engagement with change such as 'drive, accept or resist change' and personality traits, but also on how individuals understood their own predisposition to change. They found that personality traits impacted on how people engaged with change. This said, they focused specifically on the traits of "openness to experience, resilience, pragmatism, change self-efficacy and locus of control" (Smollan et al., 2010, p. 85) and not necessarily on temperament theory, but the traits are linked to the historical context of temperament. Deguchi et al. (2016) researched the impact of temperament on workplace stress and concluded that understanding temperaments can help to further the understanding of wellbeing and raise awareness of promoting social support from supervisors and colleagues. In the work by Bull and Brown $(2011,2012)$ on a workspace change in FinanceCo, they found the lack of effective communication mixed with a perceived lack of understanding of workplace needs had a negative impact on those staff involved. The research at FinanceCo did not focus on temperament theory, but perhaps by understanding individuals' personality preferences there would have been greater consideration of the type of communication used and the space to be provided, leading to the workplace change being better received.

As we have worked through the global pandemic, there has been a general change in how people have worked; for some working from home has been a dream and for others a nightmare. Allowing for other mitigating circumstances, one of the potential discrepancies in how people have enjoyed (or not) working from home could be down to their temperament. Whilst this chapter does not focus on COVID-19, we need to recognise, as the world moves towards the 
new norm that there may well be a need for a change in working practice, and a better understanding of people's preferences may aid the workplace design for the future.

\section{Methodology/research approach}

Research around temperament and workspace together is limited, but several research methodologies could be applied, depending on what the research was aiming to understand. An inference of our temperament type may also be made in how we choose to do our research. Working within the basic level of extrovert/introvert and thinking/feeling spectrums may lead people to research from different methodological positions. However, there does seem to be a predominance of positivist-based research in psychology.

If a researcher wanted to explore this through quantitative research taking a positivist position (Remenyi, Williams, Money, \& Swartz, 1998), a hypothesis could be tested in terms of the impact of temperament on satisfaction with workplace (for example), drawing on statistical analysis. A measurement tool to ascertain the temperament of the participants would be needed, followed by a survey focused on the workplace. This format could then be replicated in multiple spaces (Gill \& Johnson, 2002). From a more pragmatist position, a mixed-method approach could use a survey instrument and a measurement tool to ascertain the temperament of participants, but perhaps with a greater focus on the social actors' voices through the use of semi-structured interviews or focus groups (Tashakkori \& Teddlie, 2010). This could also be carried out as an organisational case study using similar data collection methods (Yin, 2017). In the qualitative realm researchers could use a narrative methodology (Clandinin \& Connelly, 2000; Clandinin, 2006) by asking people to create stories about their space, how they live and engage with it, and from this temperament type could be understood through the language used and the interpretation of the text (Georgakopoulou, 2006). This may give more of an insight into how people feel about their space though the language used (see also Chapter 8 Social Constructionism Theory).

There is not necessarily a one-size-fits-all methodology for this research. The research aims and objectives need to be considered, that is, whether the research is for practical implementation of space or theoretical context. There have been multiple accounts of research on traits and engagement with work satisfaction but minimal research on these concepts in alignment with workspace.

\section{Limitations}

Temperament and personality typologies have received varying critiques, depending on the research area. MBTI has been criticised as being unsubstantiated (Pittenger, 1993; Boyle, 1995) and misused as psychometric tools for recruitment, but as discussed earlier this is not about ability (Robbins, Judge, \& Campbell, 2010). In the field of psychology and personality, there is an ongoing debate in terms of temperament and trait psychology (Clark \& Watson, 1999). The potential limitations for workplace research could also include the adapted behaviour that is evidenced in the workplace as opposed to a true representation of self. Also, limited research exists that supports the use of temperament in understanding how people engage in their space, whilst being a limitation this may also be an opportunity to further current knowledge.

\section{Theory relevance to practice}

As practitioners it would be useful to understand changing workspace needs, the typologies of people within the space and how best to communicate any potential changes to workspace. In 
large organisations it may not always be possible to fully understand everyone's needs, but by understanding different personality types and their requirements this may lead to being able to provide a better overall space for people within the building to include quiet space, communal space and meeting space. As we will be returning to a "new normal" post COVID-19 and encouraging people back into the workplace, this may be a perfect time to understand what people require to do their job but also to satisfy the different temperament preferences. A onesize-fits-all workspace needs to be re-examined to understand the people that live within it.

\section{Further reading}

- Appel-Meulenbroek, R., Clippard, M., \& Pfnür, A. (2018). The effectiveness of physical office environments for employee outcomes. Journal of Corporate Real Estate, 20(1), 56-80. https://doi.org/10.1108/JCRE-04-2017-0012

- Hartog, L., Weijs-Perrée, M., \& Appel-Meulenbroek, R. (2018). The influence of personality on user satisfaction: Multi-tenant offices. Building Research \& Information, 46(4), 402-416. https://doi.org/10.1080/09613218.2017.1307015

- Oseland, N. (2009). The impact of psychological needs on office design. Journal of Corporate Real Estate, 11(4), 244-254. https://doi.org/10.1108/14630010911006738

- Pervin, L. A., \& John, O. P. (1999). Handbook of personality: Theory and research (2nd ed.). New York: The Guilford Press.

- $\quad$ Sharp, D. (1987). Personality types: Jung's model of typology. Toronto, Canada: Inner City.

\section{References}

Adickes, E. (1907). Charakter und Weltanschauung: Akademische Antrittsrede, gehalten am 12. Januar 1905. Tübingen: JCB Mohr (Paul Siebeck).

Adler, A. (1912). Praxis und Theorie der Individualpsychologie. Zeitschrift für die Gesamte Neurologie und Psychiatrie. Munich: J.F. Bergmann-Verlag.

Allport, G. W. (1938). Personality: A problem for science or a problem for art? Revista de Psihologie, 1, 488-502.

Allport, G. W. (1961). Pattern and growth in personality. New York: Holt, Rinehart \& Wilson.

Allport, G. W., \& Odbert, H. S. (1936). Trait-names: A psycho-lexical study. Psychological Monographs, 47(1), i. https://doi.org/10.1037/h0093360

Appel-Meulenbroek, R., Clippard, M., \& Pfnür, A. (2018). The effectiveness of physical office environments for employee outcomes. Journal of Corporate Real Estate, 20(1), 56-80. https://doi.org/10.1108/ JCRE-04-2017-0012

Beard, C., \& Price, I. (2010). Space, conversations, and place: Lessons and questions from organisational development. International Journal of Facility Management, 1(2). Retrieved from http://shura.shu.ac.uk/ id/eprint/2616.

Boyle, G. J. (1995). Myers-Briggs type indicator (MBTI): Some psychometric limitations. Australian Psychologist, 30(1), 71-74. https://doi.org/10.1111/j.1742-9544.1995.tb01750.x

Briggs, K. C. (1943). Myers-Briggs Type Indicator ${ }^{\circledR}$, form M. MBTI (Tm).

Bull, M., \& Brown, T. (2011). Implementing change. In E. Finch (Ed.), Facilities change management (pp. 108-122). Oxford: Blackwell Publishing Ltd.

Bull, M., \& Brown, T. (2012). Change communication: The impact on satisfaction with alternative workplace strategies. Facilities, 30(3/4), 135-151. https://doi.org/10.1108/02632771211202842

Bull, M., \& Kortens, J. (2012). Strategies for communication within facilities management. In K. Alexander \& I. Price (Eds.), Managing organizational ecologies: Space, management and organizations (pp. 196-206). London: Routledge.

Clandinin, D. J. (2006). Narrative inquiry: A methodology for studying lived experience. Research Studies in Music Education, 27(1), 44-54. https://doi.org/10.1177/1321103x060270010301

Clandinin, D. J., \& Connelly, F. M. (2000). Narrative inquiry: Experience and story in qualitative research. San Francisco, CA: John Wiley \& Sons. 
Clark, L. A., \& Watson, D. (1999). Temperament: A new paradigm for trait psychology. In L. A. Pervin \& O. P. John (Eds.), Handbook of personality: Theory and research (2nd ed., pp. 399-423). New York: Guildford Press.

Deguchi, Y., Iwasaki, S., Konishi, A., Ishimoto, H., Ogawa, K., Fukuda, Y., . . \& Inoue, K. (2016). The usefulness of assessing and identifying workers' temperaments and their effects on occupational stress in the workplace. PLoS One, 11(5), 1-12. https://doi.org/10.1371/journal.pone.0156339

Eysenck, H. J. (1967). The biological basis of personality. Springfield: Charles C. Thomas.

Eysenck, H. J. (1970). A dimensional system of psychodiagnosis. In A. R. Mahrer (Ed.), New approaches to personality classification (pp. 169-210). New York: Columbia University Press.

Eysenck, H. J. (1997). Personality and experimental psychology: The unification of psychology and the possibility of a paradigm. Journal of Personality and Social Psychology, 73(6), 1224-1237. https://doi. org/10.1037/0022-3514.73.6.1224

Eysenck, H. J., \& Eysenck, M. W. (1985). Personality and individual differences: A natural science approach. New York: Plenum.

Gan, Q., \& Haynes, B. (2012). Office occupiers: Cultural differences and preferences (No. eres2012_383). European Real Estate Society (ERES). Retrieved from https://ideasrepec.org/p/arz/wpaper/eres2012_383. html

Georgakopoulou, A. (2006). Thinking big with small stories in narrative and identity analysis. Narrative Inquiry, 16(1), 122-130. https://doi.org/10.1075/ni.16.1.16geo

Gill, J., \& Johnson, P. (2002). Research methods for managers (3rd ed.). London: Sage.

Goldberg, L. R. (1981). Language and individual differences: The search for universals in personality lexicons. In L. Wheeler (Ed.), Review of personality and social psychology (Vol. 2, pp. 141-166). Beverley Hills, CA: Sage Publications.

Goldsmith, H. H., \& Campos, J. J. (1986). Fundamental issues in the study of early temperament: The Denver Twin Temperament Study. In M. E. Lamb \& A. L. Brown (Eds.), Advances in developmental psychology (pp. 231-283). Hillsdale, NJ: Erlbaum.

Gray, J. A. (1964). Pavlov's typology. Oxford: Pergamon Press.

Hartog, L., Weijs-Perrée, M., \& Appel-Meulenbroek, R. (2018). The influence of personality on user satisfaction: Multi-tenant offices. Building Research \& Information, 46(4), 402-416. https://doi.org/10.1 080/09613218.2017.1307015

Haynes, B. (2012). Corporate real estate asset management: Aligned vision. Journal of Corporate Real Estate, 14(4), 244-254. https://doi.org/10.1108/JCRE-10-2012-0022

Jung, C. G. (1921 [1971]). Psychological types (H. G. Baynes, Trans.; revised by R. F. C. Hull). Volume 6 of the Collected Works of C. G. Jung. Princeton, NJ: Princeton University Press.

Jung, C. G. (1946). Psychological types, or the psychology of individuation. New York: Harcourt, Brace and Company.

Keirsey, D., \& Bates, M. (1984). Please understand me: Character and temperament types. Del Mar, CA: Gnosology Books Ltd.

Kretschmer, E. (1925). Physique and character. New York: Harcourt, Brace and Company.

Kummerow, J. M., Barger, N. J., \& Kirby, L. K. (1997). Work types. New York: Warner Books.

Larrimore, M. (2001). Substitutes for wisdom: Kant's practical thought and the tradition of the temperaments. Journal of the History of Philosophy, 39(2), 259-288. https://doi.org/10.1353/hph.2003.0103

Laurence, G. A., Fried, Y., \& Slowik, L. H. (2013). "My space": A moderated mediation model of the effect of architectural and experienced privacy and workspace personalization on emotional exhaustion at work. Journal of Environmental Psychology, 36, 144-152. https://doi.org/10.1016/j.jenvp.2013.07.011

Lester, D. (1990). Galen's four temperaments and four factor theories of personality: A comment on "toward a four-factor theory of temperament and/or personality". Journal of Personality Assessment, $54(1$ \& 2), 423-426. https://doi.org/10.1080/00223891.1990.9674007

McCrae, R. R., \& Costa, P. T. (2003). Personality in adulthood: A five-factor theory perspective. New York: Guilford Press.

McCrae, R. R., Costa Jr, P. T., \& Busch, C. M. (1986). Evaluating comprehensiveness in personality systems: The California Q-Set and the five-factor model. Journal of Personality, 54(2), 430-446. https:// doi.org/10.1111/j.1467-6494.1986.tb00403.x

Merenda, P. F. (1987). Toward a four-factor theory of temperament and/or personality. Journal of Personality Assessment, 51(3), 367-374. https://doi.org/10.1207/s15327752jpa5103_4

Myers, I. B., \& McCaulley, M. H. (1986). Manual: A guide to the development and use of the Myers-Briggs type indicator. Palo Alto, CA: Consulting Psychologists Press. 
Oseland, N. (2009). The impact of psychological needs on office design. Journal of Corporate Real Estate, 11(4), 244-254. https://doi.org/10.1108/14630010911006738

Pederson, A. (2003). Understanding ourselves and others: Australian archivists and temperament. Archival Science, 3(3), 223-274. https://doi.org/10.1007/s10502-004-4039-1

Pervin, L. A., \& John, O. P. (1999). Handbook of personality. Theory and research (2nd ed.). New York: The Guilford Press.

Pittenger, D. J. (1993). The utility of the Myers-Briggs type indicator. Review of Educational Research, 63(4), 467-488. https://doi.org/10.3102/00346543063004467

Quirke, B. (2008). Making the connections: Using internal communication to turn strategy into action. Aldershot: Gower Publishing, Ltd.

Remenyi, D., Williams, B., Money, A., \& Swartz, E. (1998). Doing research in business and management: An introduction to process and method. London: Sage Publications.

Robbins, S. P., Judge, T., \& Campbell, T. T. (2010). Organizational behaviour. Englewood Cliffs, NJ: Financial Times Prentice Hall.

Rothbart, M. K., Ahadi, S. A., \& Evans, D. E. (2000). Temperament and personality: Origins and outcomes. Journal of Personality and Social Psychology, 78(1), 122-135. https://doi.org/10.1037/0022-3514.78.1.122

Sharp, D. (1987). Personality types: Jung's model of typology. Toronto, Canada: Inner City.

Smollan, R. K., Matheny, J. A., \& Sayers, J. G. (2010). Personality, affect and organisational change: A qualitative study. In W. F. Zerbe, N. M. Ashkanasy, \& C. E. J. Hartel (Eds.), Research on emotions in organizations, Vol. 6, Emotions and organizational dynamism, (pp. 85-112). Bingley, UK: Emerald Insight.

Spränger, E. (1928). Types of men. New York: G.E. Stechert Company.

Steiner, R. (1919). Discussions with teachers. New York: Anthroposophic Press.

Steiner, R. (1944, 2008) The four temperaments. Forest Row: Rudolf Steiner Press

Stelmark, R. M., \& Stalikas, A. (1991). Galen and the humor theory of temperament. Journal of Personality and Individual Differences, 12(3), 255-263. https://doi.org/10.1016/0191-8869(91)90111-N

Strelau, J. (1987). Emotion as a key concept in temperament research. Journal of Research in Personality, 21(4), 510-528. https://doi.org/10.1016/0092-6566(87)90037-7

Sundstrom, E. (1984). Work places: The psychology of the physical environment in offices and factories. Cambridge: Cambridge University Press.

Tashakkori, A., \& Teddlie, C. (Eds.). (2010). Sage handbook of mixed methods in social \& behavioral research (2nd ed.). Thousand Oaks, CA: Sage.

Vincent, A., \& Ross, D. (2001). Personalize training: Determine learning styles, personality types and multiple intelligences online. The Learning Organisation, 8(1), 36-43. https://doi.org/10.1108/09696470110366525

Yin, R. K. (2017). Case study research and applications: Design and methods. Thousand Oaks, CA: Sage. 


\title{
TWO-PROCESS THEORY OF PERCEIVED CONTROL
}

\section{Changing the workspace and changing the self}

\author{
Daibin Xie*
}

\section{Background}

The two-process theory of perceived control (TTPC) was proposed by Rothbaum, Weisz and Snyder (1982). The theory incorporates cognitive development ideas (Piaget, 1970) and suggests that a feeling of control can be gained by two means - changing the world and changing the self. The two processes are often intertwined but prioritised differently according to circumstances. Since its introduction, the theory has attracted great attention in the field of psychological study as it challenges traditional Western understanding about control (Morling \& Evered, 2006).

Control has long been regarded as an important construct affecting people's psychological functioning (Skinner, 1996). Psychologists believe that humans have a universal desire to exert control over their environments or make choices in order to produce behaviour-event contingency (Heckhausen \& Schulz, 1995). A lack of control has been associated with learned helplessness (Seligman, 1975), self-denial (DeCharms, 1979), defects in 'self-efficacy' (Bandura, 1977) and negative emotions such as dissatisfaction, anxiety, depression and even anger (Mirowsky \& Ross, 1990). Because of this importance, control variables, in one form or another, underlie much theorising of environmental and organisational psychology. For example, Rotter's (1966) locus of control theory considers the person's beliefs about control as a key driver of behaviours, suggesting that those people who see external forces as controlling outcomes (external locus of control) are more likely to manifest inward behaviours such as passivity, withdrawal, submissiveness and depression than are those who believe in their own effort and ability to change the environment as controlling outcomes (internal locus of control). Seligman's (1975) learned helplessness model focuses on the effect of objective contingency between action and outcome on control agents (the individuals or groups who exert the control) and maintains that prolonged exposure to the situation failing to influence the environment produces cognitive, motivational and emotional deficits (Seligman, 1975). Karasek's (1979) job demands/control model (see Chapter 3 The Job Demands-Resources Model) sees the interaction of job demands and latitude as a determining factor of worker well-being.

The aforementioned three theories are often cited in social or occupational stress studies due to their lucid account of maladaptive behaviours. In each case individuals' ability to affect the environment or make choices/decisions is emphasised and inward behaviours are *Corresponding author: daibin.xie.13@alumni.ucl.ac.uk 
linked to relinquished control. However, Rothbaum et al. (1982) argued that those classical control theories have overlooked the important effect of cognitive mediation. According to cognitive development theorists, the goal of development is equilibration, involving assimilation and accommodation; both reflect strategies to optimise the individual's adaptation to the environment (Piaget, 1970; Rothbaum et al., 1982). As such, it is possible that perceived control increases when an individual is able to accommodate to reality (Averill, 1973).

Based on the assumption, Rothbaum et al. (1982) suggested that in addition to attempts to influence the environment and the abandonment of action, there is a third alternative - people sometimes flexibly adjust themselves to fit in with the existing reality. For instance, an individual may submerge self-sense in order to foster a sense of belonging at workplaces; some people lower their expectations to avoid disappointment when a task is perceived as difficult or impossible to finish. These responses signal a purpose to maintain perception of control in the form of enhancing group recognition or proactively managing negative effects. In essence, they have a positive nature.

Rothbaum et al. (1982) labelled processes of changing the environment to fit personal needs as primary control and attempts to align themselves with existing realities as secondary control. A key distinguishing characteristic of them is that actions are directed outward to the environment in primary control (e.g. personalise one's workstations) but inward to the individual's cognition in secondary control (e.g. accept having no assigned desk at work). According to Rothbaum et al. (1982), there are four types of secondary control. When people attribute outcomes to chances, for example, linking business success and failure to good or back luck, they may gain illusory control to enhance acceptance of their own fate. Vicarious control is sought when people attempt to create association or to sustain alignment with powerful others such as managers or supervisors to derive feelings of self-esteem. When people attribute negative outcomes to low ability or external constraints, for instance one's status within an organisation, they predict future outcomes and then adjust their expectations to reduce disappointments, which leads to predictive control. Finally, attempts to gain sense of meaning and understanding about existing realities may foster interpretive control (e.g. seeing life suffering as atonement).

The theory views the interaction between people and environment as a dynamic negotiation process involving both assimilation and accommodation. Rothbaum et al. (1982) argued that primary control and secondary control have similar functional values, although secondary control is often used as a back-up response to minimise losses and negative effects after efforts to exert primary control have been ineffective. Heckhausen and Schulz (1995, p. 286) further suggest, "secondary control not only helps in dealing with failures, but also fosters primary control directly by managing its selectivity." Although the primacy of primary control is often questioned by other researchers, the theory has opened a new window for psychological study about control. It has inspired a number of later researchers to derive new findings and develop new hypotheses.

For example, Heckhausen and Schulz (1995) developed a life-span theory of development based on the concept of primary and secondary control. They suggest, "trade-offs between primary and secondary control undergo systematic shifts across the life course in response to the opportunities and constraints encountered" (Heckhausen \& Schulz, 1995, p. 284). As people age, they are more able to regulate their emotions and thereby increase secondary control ability (Heckhausen \& Schulz, 1995; McConatha \& Huba, 1999).

Cross-cultural studies reported also that the trade-off between primary control and secondary control is culturally conditioned. It is suggested that, generally, East Asians show a stronger tendency for secondary control then do Americans or Europeans (Kim \& Markus, 1999; Peng \& Nisbett, 1999; Spector, Sanchez, Siu, Salgado, \& Ma, 2004; Weisz, Rothbaum, \& Blackburn, 1984). Leung (2001) elaborated that workers in collectivistic cultures are more unconditionally 
benevolent and are more likely to sacrifice certain personal interest to enhance in-group welfare to get group recognition.

\section{Applicability to workplace studies}

The control issue also resonates in the field of workplace research. In the literature, much has been written about the benefits of fulfilling user needs and providing more user control over the work environment. A core argument of workplace researchers is that the increase of perceived control brought about by more flexibility and more user engagement in workplace design and management can enhance employees' sense of belonging and ownership at the workplace and enable them to create an environment better fitting their task needs and personal expectations (Vischer, 2008).

Control variables often examined in the workplace literature are control over indoor environment qualities (e.g. ventilation, lighting, noise and temperature), personalisation, layout adjustability and flexibility, visual access, acoustic privacy, adjustable furniture, choice of time and location of work, user engagement in workplace design and ergonomics training to improve control (Huang, Robertson, \& Chang, 2004; Leaman, 1995; O’Neill, 2010; O’Neill \& Carayon, 1993; Robertson \& O’Neill, 1999; Veitch \& Newsham, 2000; Vischer, 2008). Vischer (2008) theorised that, in general, workplace control manifests itself in two layers: mechanical control and empowerment. Mechanical control involves direct behaviours changing the physical workplace settings such as lighting, temperature, acoustics, windows, furnishing, office layout, displays, personalisation, time and location of work, etc. Empowerment involves actions to increase opportunities for employees to participate in workspace decision-making.

The problem is, for most workplace users, they are rarely able to engage in the workplace design process or change the physical workplace optimally to suit them; rather, what they can do is accept what they find as 'givens' (Leaman, 2003). But ironically, this does not stop office workers continuously committing themselves to an undesirable workplace. Why?

According to the theoretical proposition of TTPC, it is reasonable to argue that some forms of positive effect have been caused by those self-adaptive behaviours. Telling evidence is found in the case study of Leaman (1995). It shows that in post-occupancy surveys in UK, offices rated as 'good' often are not those with the best physical conditions but are those with the highest forgiveness ratings. The measure 'forgiveness' is calculated by dividing the overall comfort/ satisfaction of occupants with the mean of measured workplace variables, reflecting occupants' tolerance level on space shortcomings. Leaman (1995, p. 18) explained that workplaces are total systems that consist of human systems and physical systems, and "where these systems correspond closest, there is a greater likelihood that the building will work well in total." Because of this, people are likely to forgive deficiencies and thus maintain a high overall workplace satisfaction when they know every effort has been made but there are difficulties in solving the problems (Leaman, 1995). Echoing Leaman (1995), Xie (2019) empirically found that office workers' workplace expectations are affected by workplace settings. When facing undesirable workplace conditions, office workers may accept the reality and lower their expectations, for instance, depressing the need for privacy in open-planning offices. Or they adjust their expectations and look for compensation to restore a perception of control, for example, by expecting to have more flexibility when the workstation is close to the supervisor. By contrast, the fulfilment of some needs may shift the attention of workspace users and make them forgive other shortcomings; or it may reinforce workplace users' brief of primary control and lead them to raise their work-life standard (Xie, 2019). 
These two examples clearly show the important influence of self-adaptation at workplaces. However, space users' self-adaptation has been largely overlooked by preceding researchers despite its importance and, so far, little is known about it.

The two-process theory of perceived control may be borrowed to fill the research gap as it provides a holistic view in examining the mutual influence between people and the physical work environment. Most importantly, the TTPC offers a dynamic perspective to view the role of workplace needs and control. In literature, various workplace researchers have emphasised that it is important to fulfil user needs and expectations in order to improve workplace satisfaction, productivity and well-being. The idea clearly reflects the mindset of primary control. But according to the TTPC, unfulfilment of needs and expectations does not necessarily lead to dissatisfaction or stress, as people may adapt their needs and expectations according to the context when they are unable to change the fixed physical settings. It appears that office workers' self-adaptation is coined to attempt creating or changing the workplace to fit user needs. Following the logic, researchers may rethink the relationship between workplace control and stress. Lacking personal control on the environment has been regarded as a stressor (McCoy \& Evans, 2005). Obviously, this relationship is doubtful from the standpoint of secondary control, because one of the main functions of secondary control is to help individuals avoid negative influences.

The TTPC stresses the importance of understanding individuals' adaptive patterns and underlying motivations in order to develop proper strategies to help individuals gain or restore a sense of control. The four types of secondary control presented by Rothbaum et al. (1982) provide guidance to crack the nut. They are applicable in workplace research and practice too. For instance, the example that office workers forgive the shortcomings of the workplace after knowing the difficulty to resolve them (Leaman, 1995) can be seen as a practice of predictive control. Following these patterns, researchers and practitioners are able to develop tools to test, predict and manage the outcomes of workplace provisions. For instance, in projects adopting innovation workplace concepts, for example activity-based working, change management agents can foster interpretive control by communicating the benefits of the new design to the company when they know it is an effective strategy to overcome office workers' resistance.

Another important finding of TTPC theorists is the cultural differences in the preferences for secondary control. According to the literature, secondary control appears to be more relevant and preferred in non-Western cultures (Weisz et al., 1984). In other words, direct control over the environment and empowerment may be less expected in those cultures (Fock, Hui, Au, \& Bond, 2013; Zhang \& Begley, 2011). This cultural difference may inspire workplace researchers to rethink the values of mechanical control and empowerment in a cross-cultural context.

Similarly, according to Heckhausen and Schulz (1995), from a life-span development perspective, age and experience play important roles in individuals' choices between primary control and secondary control. Relevant research findings and methodologies may feed workplace research relating to age and generational differences.

\section{Methodology/research approach}

The concept of 'contingency' is central in various control theories, including the TTPC. Setting out from this stance, psychological experiments to test individuals' reactions were widely deployed by early control researchers (Rothbaum et al., 1982). But fieldwork has received increasing attention in recent decades, especially in the field of organisational psychology. Unlike experimental studies in laboratories, individuals' mental schemes and psychological reactions to the environment are difficult to be recorded through well-designed props such as cards games or drawings in fieldwork. Therefore, questionnaire surveys are commonly used to capture 
respondents' psychological action and reaction in field studies with a TTPC viewpoint. Another benefit of using questionnaires is that it enables the quantitative analysis of psychological actions, whereas most experimental psychology studies are qualitative. The following measures are often incorporated in the study of organisational control.

- Work locus of control. The measure assesses briefs about internal/external control in the workplace. For instance, the Work Locus of Control Scale (Spector, 1988) measures whether the respondent believes he or she can control rewards at work through his or her own action. The result may indicate the extent to which the individual stresses primary control.

- Secondary control. Scales are often developed based on the four components of secondary control described by Rothbaum et al. (1982) to reflect respondents' adaptive patterns. For instance, a scale testing the preference for predictive control asks, 'do you agree that you would avoid accepting a task if you think it is overly difficult?'

- Job stressors. In organisational psychology, job stressors measured often are ambiguity of job design, role conflict, interpersonal conflict and lack of autonomy (Spector et al., 2004).

- Strains. For example, job/life dissatisfaction, work anxiety and resign intention.

These measures can be selectively borrowed in studies of workplace control to reflect the individual's motivation of control. But they are clearly insufficient for workplace studies, as workplace is a holistic system consisting of people and physical space. Workplace researchers need to further investigate physical workplace settings and workplace users' needs and expectations with multiple methodologies. Figure 11.1 describes a general process of a workplace study aiming to investigate space users' adaptive behaviours with a TTPC standpoint.

One-way analysis of variance (ANOVA) is often used in comparative studies of control briefs (Spector et al., 2004). Similar methodologies have been used by workplace researchers to investigate the differences in workplace needs and satisfaction between different groups. For instance, Langston, Song and Purdey (2008) examined the occupational differences in workplace satisfaction with a Kruskal-Wallis test (this test is usually used when a measurement variable does not meet the normality assumption of ANOVA). In studies from the standpoint of TTPC, the methodology is also useful for investigating changes in workplace expectations, for example, pre- and post-relocation comparisons.

For TTPC studies, an important task is to understand the effect of external constraints and personal traits (locus of control and preferences for secondary control) on adaptive behaviours. Correlation tests therefore are a powerful tool to conduct the investigation. Some highly interesting research findings have been generated by researchers through the approach, for example the aforementioned adaptive patterns posited by Xie (2019).

In general, the TTPC provides a valuable framework to decipher the complex interaction between people and the environment. For workplace researchers, four research topics in the context of control theory are worth exploring in the future. The first is the effects of workplace settings on workplace users' adaptive behaviours. The second is the comparative study of control preference between cultures, genders and different social groups. The third is the life-span development of control at workplaces - how age and experience affect the trade-off between primary control and secondary control. The final one is the long-term effect of secondary control at workplaces. People may temporarily accept or tolerate a workplace shortcoming, but how long they can tolerate it would be another issue. To address these research topics, researchers need to design their research methodologies carefully to measure office workers' psychology changes, to collect and compare data from different sample groups, and to enable longitudinal studies. 
Step 1. Identify research questions and develop research methodologies based on the research interests

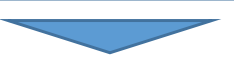

Step 2. Fieldworks: questionnaire survey / site tour to code workspace characteristics

\section{Step 3. Know the facts through descriptive data analysis}

- Identify the locus of control briefs and psychological adaptive patterns of respondents.

- Identify workplace needs / expectations and trace their changes / differences in different contexts.

- Trace changes occupants exert on the physical environment.

\section{Step 4. Get insights through interpretive data analysis}

- Examine the association between psychological adaptations and environmental settings and test related hypothesis.

- Examine the association between primary / secondary control patterns and outcomes of space / workplace expectations, and test related hypothesis.

\section{Step 5. Towards a user-cantred workplace}

Inform workplace design and management practice with insights about what occupants want, what they can possibly give up, how space provisions and deficits would affect them and how to manage their expectations.

Figure 11.1 Process of workplace studies guided with TTPC

\section{Limitation}

The two-process theory of perceived control has attracted great attention in psychology since its introduction because it counterintuitively frames maladaptive behaviours in positive ways and makes reasonable a variety of behaviours that seem maladaptive "from the perspective of an autonomously functioning Western person" (Morling \& Evered, 2006, p. 269). But at the same time, the theory is often faulted for its 'theoretical ambiguity' in regard to the primacy of primary control and the actual function of secondary control and inconsistent findings reported by later researchers. This to some extent would weaken the value of using the theory to interpret self-adaptive behaviours at workplaces. 
In addition, the theory mainly focuses on inward behaviours such as passivity and submissiveness and sees them as psychological strategies to fit in with the environment. Yet, changes of expectations associated with successful delivery of primary control are not addressed.

\section{Theory relevance to practice}

The two-process theory of perceived control as a framework sees the process of people trying to fit in with the environment as a negotiation process between the person and the environment involving assimilating and compromise. It 'vividly' mirrors what is happening in real practice. Insights and knowledge generated from workplace studies guided by the theory may allow workplace designers and managers to better understand what occupants want and what they can compromise on and to predict the effects of different workspace provision scenarios in order to make proper arrangements to better balance the needs of different stakeholders. These findings are also valuable for change management as they may inform change agents to develop more effective communication strategies and design more customised change roadmaps. This is especially important for the implementation of innovation workplace designs and policies such as flexible working, as one main challenge threatening workplace innovation is user resistance.

\section{Further reading}

- Morling, B., \& Evered, S. (2006). Secondary control reviewed and defined. Psychological Bulletin, 132(2), 269-296. https://doi.org/10.1037/0033-2909.132.2.269

- Rothbaum, F., Weisz, J. R., \& Snyder, S. S. (1982). Changing the world and changing the self: A two-process model of perception control. Journal of Personality and Social Psychology, 42, 5-37. https://doi.org/10.1037/0022-3514.42.1.5

- Skinner, E. A. (1996). A guide to constructs of control. Journal of Personality \& Social Psychology, 71(3), 549-570. https://doi.org/10.1037/0022-3514.71.3.549

\section{References}

Averill, J. R. (1973). Personal control over aversive stimuli and its relationship to stress. Psychological Bulletin, 80, 286-303. https://doi.org/10.1037/h0034845

Bandura, A. (1977). Self-efficacy: Toward a unifying theory of behavioural change. Psychological Review, 84, 191-215. https://doi.org/10.1016/0146-6402(78)90002-4

DeCharms, R. (1979). Personal causation and perceived control. In L. C. Perlmuter \& R. A. Monty (Eds.), Choice and perceived control (pp. 29-40). Hillsdale, NJ: Erlbaum.

Fock, H., Hui, M. K., Au, K., \& Bond, M. H. (2013). Moderation effects of power distance on the relationship between types of empowerment and employee satisfaction. Journal of Cross-Cultural Psychology, 44(2), 281-298. https://doi.org/10.1177/0022022112443415

Heckhausen, J., \& Schulz, R. (1995). A life-span theory of control. Psychological Reviews, 102, 284-384. https://doi.org/10.1037/0033-295X.102.2.284

Huang, Y., Robertson, M. M., \& Chang, K. (2004). The role of environmental control on environmental satisfaction, communication, and psychological stress: Effects of office ergonomics training. Environment and Behaviour, 36(5), 617-637. https://doi.org/10.1177/0013916503262543

Karasek, R. A. (1979). Job demands, job decision latitude, and mental strain: Implications for job redesign. Administrative Science Quarterly, 24, 285-308. https://doi.org/10.2307/2392498

Kim, H., \& Markus, H. (1999). Deviance or uniqueness, harmony or conformity? A cultural analysis. Journal of Personality and Social Psychology, 77, 785-800. https://doi.org/10.1037/0022-3514.77.4.785

Langston, C., Song, Y., \& Purdey, B. (2008). Perceived conditions of workers in different organisational settings. Facilities, 26(1/2), 54-67. https://doi.org/10.1108/02632770810840309 
Leaman, A. (1995). Dissatisfaction and office productivity. Facilities, 13(2), 13-19. https://doi.org/10.1108/ 02632779510078120

Leaman, A. (2003). User needs and expectations. In R. J. Cole \& R. Lorch (Eds.), Buildings, culture \& environment: Informing local \& global practices (pp. 154-176). Oxford: Blackwell.

Leung, K. (2001). Different carrots for different rabbits: Effects of individualism - Collectivism and power distance on work motivation. In M. Erez, U. Kleinbeck, \& H. Thierry (Eds.), Work motivation in the context of a globalising economy (pp. 329-339). New York: Lawrence Erlbaum Associates Publishers.

McConatha, J. T., \& Huba, H. M. (1999). Primary, secondary, and emotional control across adulthood. Current Psychology, 18(2), 164-170. https://doi.org/10.1007/s12144-999-1025-z

McCoy, J. M., \& Evans, G. W. (2005). Physical work environment. Thousand Oaks, CA: Sage.

Mirowsky, J., \& Ross, C. E. (1990). Control or defense? Depression and the sense of control over good and bad outcomes. Journal of Health and Social Behaviour, 31, 71-86. https://doi.org/10.2307/2137046

Morling, B., \& Evered, S. (2006). Secondary control reviewed and defined. Psychological Bulletin, 132(2), 269-296. https://doi.org/10.1037/0033-2909.132.2.269

O’Neill, M. J. (2010). A model of environmental control and effective work. Facilities, 28(3/4), 118-136. https://doi.org/10.1108/02632771011023104

O'Neill, M. J., \& Carayon, P. (1993). The relationship between privacy, control, and stress responses in office workers. Proceedings of the Human Factors and Ergonomics Society Annual Meeting, 3(3), 479-483. https://doi.org/10.1177/154193129303700702

Peng, K., \& Nisbett, R. E. (1999). Culture, dialectics, and reasoning about contradiction. American Psychologist, 54, 741-754. https://doi.org/10.1037/0003-066X.54.9.741

Piaget, J. (1970). Piaget's theory. In P. H. Mussen (Ed.), Carmicheal's manual of child psychology (3rd ed.). New York: Wiley.

Robertson, M. M., \& O’Neill, M. J. (1999). Effects of environmental control on stress, performance and group effectiveness. Proceedings of the Human Factors and Ergonomics Society Annual Meeting, 43(8), 552-556. https://doi.org/10.1177/154193129904300801

Rothbaum, F., Weisz, J. R., \& Snyder, S. S. (1982). Changing the world and changing the self: A twoprocess model of perception control. Journal of Personality and Social Psychology, 42, 5-37. https://doi. org/10.1037/0022-3514.42.1.5

Rotter, J. B. (1966). Generalised expectancies of internal versus external control of reinforcements. Psychological Monographs, 80(1), 1-28. https://doi.org/10.1037/h0092976

Seligman, M. E. P. (1975). Helplessness: On depression, development and death. San Francisco, CA: W. H. Freeman.

Skinner, E. A. (1996). A guide to constructs of control. Journal of Personality and Social Psychology, 71(3), 549-570. https://doi.org/10.1037/0022-3514.71.3.549

Spector, P. E. (1988). Development of the work locus of control scale. Journal of Occupational Psychology, 61, 335-340. https://doi.org/10.1111/j.2044-8325.1988.tb00470.x

Spector, P. E., Sanchez, J. I., Siu, O. L., Salgado, J., \& Ma, J. (2004). Eastern versus Western control beliefs at work: An investigation of secondary control, socioinstrumental control, and work locus of control in China and the US. Applied Psychology: An International Review, 53, 38-60. https://doi. org/10.1111/j.1464-0597.2004.00160.x

Veitch, J. A., \& Newsham, G. R. (2000). Exercised control, lighting choices, and energy use: An office simulation experiment. Journal of Environmental Psychology, 20(3), 219-237. https://doi.org/10.1006/ jevp.1999.0169

Vischer, J. C. (2008). Towards an environmental psychology of workspace: How people are affected by environments for work. Architectural Science Review, 51(2), 97-108. https://doi.org/10.3763/asre.2008.5114

Weisz, J. R., Rothbaum, F. M., \& Blackburn, T. C. (1984). Standing out and standing in: The psychology of control in America and Japan. American Psychologist, 39, 955-969. https://doi.org/10.1037/0003-06 6X.39.9.955

Xie, D. (2019). Cultural influence in Chinese workspaces: National, regional, industrial and organisational effects [Doctoral thesis]. London: University College London.

Zhang, Y., \& Begley, T. M. (2011). Power distance and its moderating impact on empowerment and team participation. The International Journal of Human Resource Management, 22(17), 3601-3617. https://doi.org/10.1080/09585192.2011.560877 
12

\title{
ORGANISATIONAL CULTURE THEORIES
}

\section{Dimensions of organisational culture and office layouts}

\author{
Kusal Nanayakkara* and Sara Wilkinson
}

\section{Background}

Typically, full-time employees spend eight hours a day at their workplaces and about half their active life at work during their working lives (Chatzitheochari \& Arber, 2009). The number of persons working 50 or more hours per week has risen dramatically over the last 15 years in some countries, including the USA and the UK (Cohen, 1992). As a result, the corporate culture of organisations affects both employees' work lives and their personal lives. Several disciplines, including human resources management, marketing, management, nursing and community health, emphasise the importance of appropriate organisational cultures (Bhaskaran \& Sukumaran, 2007; Ingelsson, Bäckström, \& Snyder, 2018; Nuutinen \& Lappalainen, 2012; Plimmer, Bryson, \& Teo, 2017). Studies have also examined the effect of organisational culture on various aspects of organisations, such as their profitability, employee satisfaction and productivity (Patterson, Maguin, Dulmus, \& Nisbet, 2013; Rashid, Sambasivan, \& Johari, 2003).

\subsection{What is organisational culture?}

One of the main objectives of an organisation is to achieve sustained profitability from its operations. The culture of an organisation in any industry is an intangible mechanism contributing to profitability (Cawood, 2008), and it has a significant influence on the long-term success of an organisation (Wiewiora, Trigunarsyah, Murphy, \& Coffey, 2013). With very few exceptions, every organisation develops a distinctive culture that is clearly identifiable by its key stakeholders and, if it is the right culture, it may be a legacy of an organisation (Bieliková, 2008). Organisational culture became a popular concept in the 1980s in academia and industry (Reiman \& Oedewald, 2002). Several studies emphasised the importance of studying organisational culture to understand the policies, practices and regional differences of an organisation (Budhwar \& Sparrow, 2002; Rajagopal \& Rajagopal, 2006; Wilkins \& Ouchi, 1983). Existing organisational and behavioural management literature discusses the significance of organisational culture for a company's intangible aspects such as its values, practices and assumptions extensively. However,

*Corresponding author: Hiniduma.Nanayakkara@alumni.uts.edu.au 
Fairs (2016) and Igo and Skitmore (2006) suggest that, until recently, limited attention had been paid to its impacts on a company's tangible aspects, such as its office layout, corporate logo and uniform.

Every organisation, from establishment, lives and operates within a certain cultural framework and gradually develops its own culture which is suited to the organisation in the long run (Ingelsson et al., 2018; McCarthy, 1998). Although there is no common definition of organisational culture (Chandler, Heidrich, \& Kasa, 2017; Denison \& Spreitzer, 1991), it can be categorised into four key areas (Martin, 1992; Martin \& Siehl, 1983). Firstly, it is an interpretation of the history of the organisation and provides guidance for members of the organisation on how to discipline themselves and how they are expected to behave in the organisation. Secondly, culture helps to enhance employees' commitment to the values of the organisation and its management philosophy; as a result, they feel that they work for values they believe in (Munter, 1993). Thirdly, organisational culture is a mechanism of organisational control and includes policies, procedures and norms (Chandler et al., 2017). Fourthly, it is a mechanism related directly to the performance, productivity and profitability of the organisation (Kinjerski \& Skrypnek, 2006; Wilkins \& Ouchi, 1983).

\subsection{Definitions of organisational culture}

Organisational culture is defined in management and organisational behaviour in different ways. For example, Schein (1992) defined organisational culture as:

a pattern of shared basic assumptions that a group learned as it solved its problems of external adaptation and internal integration that has worked well enough to be considered valid and, therefore, to be taught to new members as the correct way to perceive, think, and feel in relation to those problems.

The culture of an organisation can be identified by evaluating its mission statement, which answers three main questions: 'who are we?'; 'what do we do?'; and 'where are we headed?' The answers help to identify its corporate culture, as well as the company's philosophy, ethical policy, pathway and target destination (Hofstede, Hofstede, \& Minkov, 2010).

Martin (1992) argued that three perspectives are deployed by social scientists in studying organisational culture: integration, differentiation and fragmentation. The integration perspective considers an organisation as a whole and does not pay attention to its subcultures. It maintains consistency in relation to manifestations, which are artefacts such as office layouts, symbols and practices, while uncertainty is excluded. No consistency in manifestations can be observed in the differentiation perspective, and ambiguity is included to some extent. In contrast, ambiguity is the essence of the fragmentation perspective, and there is no clear consistency, or inconsistency, in relation to manifestations and no special focus is given to sub- or main cultures (Martin, 1992).

In addition, an organisational culture is made up of shared elements and common understandings in an organisation such as philosophies, behaviours, traditions, values, norms, assumptions, perceptions, ideologies, exceptions, sayings and heroes (Lau \& Ngo, 1996). These manifestations can be summarised into three categories: practices, artefacts and content (Martin \& Meyerson, 1988). Practices can be rules, procedures or norms, either formal or informal (Schein, 1992). A pattern of basic beliefs, assumptions and values shared by organisational members is part of organisational culture and identified as content in the management literature (Adler \& Jelinek, 1986; Calori \& Sarnin, 1991; Schein, 1992; Shekari, Rahmdel, \& Rajabian, 2012). Artefacts refer to the physical office layout, ceremonies, rites and rituals of the organisation (Martin \& 
Meyerson, 1988). In broader terms, organisational culture is described as a control and exchange mechanism (Wilkins \& Ouchi, 1983) or the theme (Martin \& Meyerson, 1988) of an organisation. Brunetto (2001) categorised all elements in organisational culture into two groups:

1 Shared assumptions, beliefs, attitudes, values and rituals which shape life in an organisation.

2 Behaviours, values and language which reflect the culture of the organisation.

In the next section, elements or theories relating to organisational culture are discussed in detail in order to have a better understanding of the concept of organisational culture.

\subsection{Elements of organisational culture}

Every organisation has its own culture, which may have developed over time by practices or behaviours which become normal, or 'norms', and then, de facto, become the culture of the organisation. Another way to establish an organisational culture is by adopting standard norms, behaviours and practices introduced by the leaders of the organisation, which become the culture of the organisation over time. Organisational culture is like an iceberg (Sackmann, 1991), where the visible part of the culture is very small compared to what lies below (see Figure 12.1).

Although organisational culture has many elements, three main parts of it are labelled: artefacts, espoused values and basic underlying assumptions (Sackmann, 1991).

Expanding Sackmann's (1991) analysis further, Schein (1992) analysed organisational culture at three levels in detail: artefacts, espoused values and basic underlying assumptions. As Figure 12.2 shows, the relationships between office layout and organisational culture are clearly illustrated in his study.

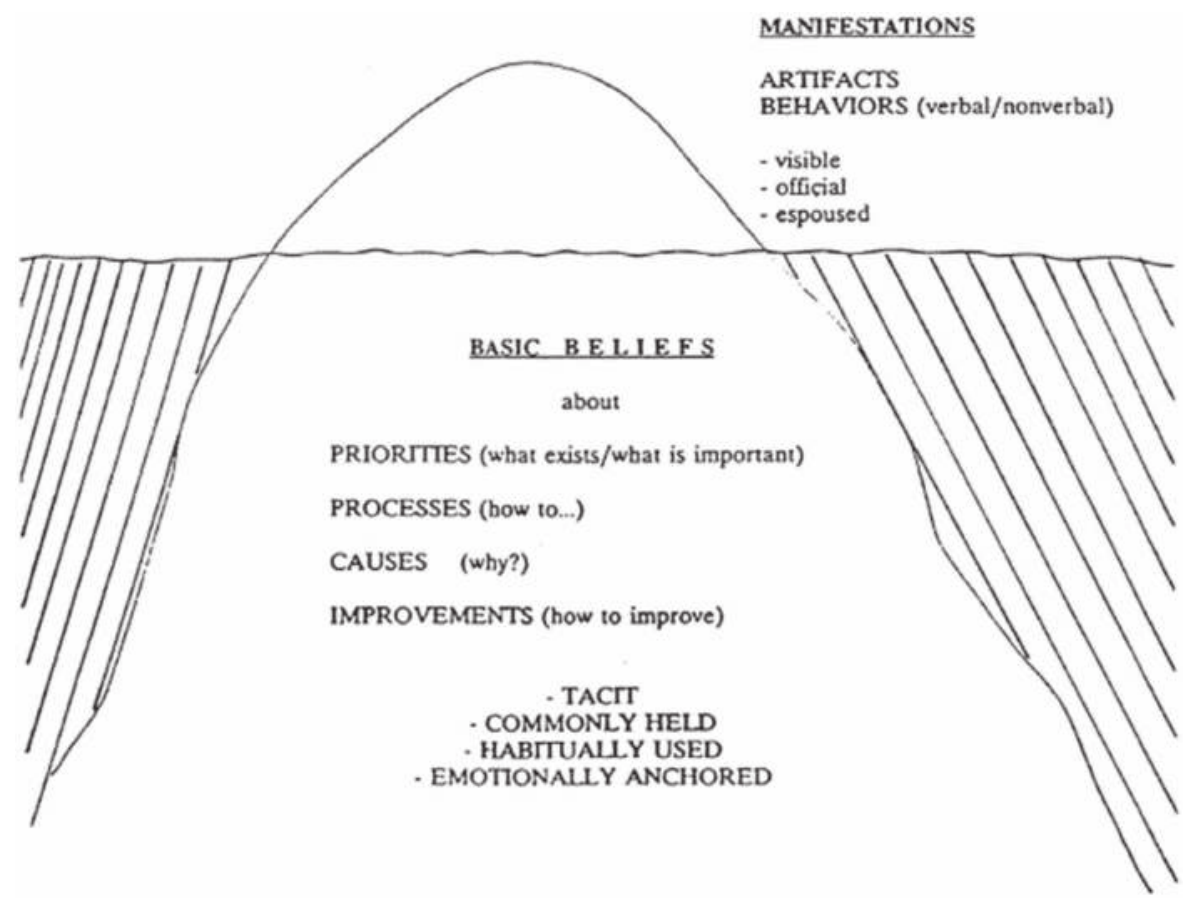

Figure 12.1 Iceberg model of culture (Sackmann, 1991) 


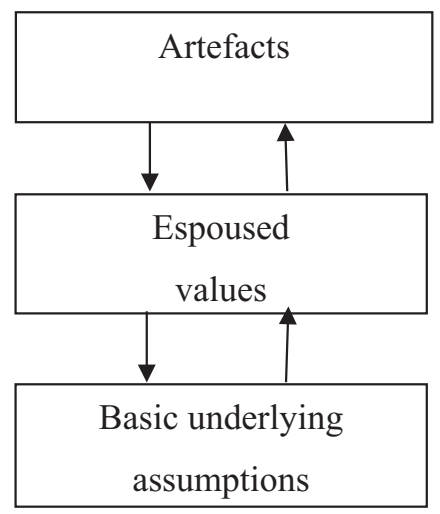

Figure 12.2 Levels of organisational culture (Schein, 1992)

\subsubsection{Artefacts}

Artefacts are observable features which represent the dominant culture of the organisation. These include the physical office layout, architectural design, publicly expressed lists of values, artistic creation of environment, observable ceremonies and rituals, technology and products, dress codes and uniforms, and emotional displays (Martin \& Siehl, 1983; Reiman \& Oedewald, 2002). These attributes are the most visible manifestations of organisational culture, which help to maintain an organisation's identity and image (Meissonier, Houzé, \& Bessière, 2013).

In addition to these clearly visible manifestations, the manner of addressing each other, the language used in the organisation, the myths and stories about the organisation and the behaviour of members are considered as artefacts (Calori \& Sarnin, 1991; Martin, 1992; Meissonier et al., 2013; Rajagopal \& Rajagopal, 2006). This level of organisational culture can be seen, felt and heard when entering office premises (Cawood, 2008; Schein, 1992).

However, although this level of culture is very easy to observe, it is difficult to interpret and may lead to misleading assumptions about the organisation (Engstrom, 2010; Schein, 1992). The artefacts send symbolic messages to employees in terms of what attitudes and behaviours are expected from them by the organisation (Brown, 1992). Artefacts such as office layouts, interior designs and rituals help to obtain a clear understanding of an organisation's deeper level of culture, even though it cannot be generalised (Calori \& Sarnin, 1991; Gagliardi, 1990; Martin, 1992). For example, organisations with casual dress codes and flexible work practices with unassigned workstations may give an inaccurate perception of inefficiency and unsatisfactory working layouts. In order to have a clear understanding of the culture of an organisation, it is essential to engage with, or live with, that culture to be able to analyse and understand the espoused values, norms and rules of that organisation (Munter, 1993). The objective of this research was to examine the effects of changes in artefacts, particularly office layouts, on the existing cultures of organisations.

\subsubsection{Espoused values}

Espoused values can be considered as the governing rules and perceptions of the organisation, which tend to be emotional rather than rational (Gagliardi, 1990). They can be categorised into two groups: declared values, which are displayed in charts and diagrams such as mission statements objectives, and organisational structures and discourses in the office, which are operational values used for day-to-day activities and problem-solving mechanisms (Meissonier et al., 2013). 


\subsubsection{Basic assumptions}

Basic assumptions are similar to theories-in-use (Argyris \& Schon, 1974; Mazur, 2015) which indicate to group members how to behave, think and feel about certain things. These basic assumptions are not challengeable, and therefore are extremely difficult to amend (Wilkins \& Ouchi, 1983). However, some professionals have autonomy to challenge the existing deeper values and beliefs in relevant activities. For example, some senior university academics have autonomy to challenge existing deeper values and beliefs in relevant teaching activities and research findings (Brunetto, 2001).

Adding another level to Schein's 'three level culture model', Martin and Siehl (1993) suggested that management practices are the fourth level of organisational culture. This term refers to common management practices such as work practices, training, performance appraisals, reward allocation and hiring.

\subsection{Theories (dimensions) of organisational culture}

Management literature includes several theories of organisational culture; however, the focus here is on theories which are relevant and useful to workplaces only. Three of the most relevant theories are discussed next.

\subsubsection{Competing value framework}

One of the most commonly accepted frameworks developed to distinguish dimensions, or theories, of organisational culture is the competing value framework (Fairs, 2016). This framework was initially introduced to understand the values underlying organisational effectiveness and was further developed to understand organisational forms, organisational life cycles and leadership roles (Quinn \& Rohrbaugh, 1981). This is a widely accepted theory of dimensions of organisational culture in management and behavioural studies (Black \& Mendenhall, 1989).

The competing value framework proposed by Cameron and Quinn (2006) is the most-used descriptive framework to identify different types of organisational culture (Corfield \& Paton, 2016; Chandler et al., 2017; Gupta, 2011; Suppiah \& Sandhu, 2011). This framework is rooted in considerable research in the organisational culture area and aligns with well-accepted cultural categorical themes - the way people think, their values, assumptions and how they process information (Harper, 2012) (Figure 12.3).

Cameron and Quinn (2006) identified four dimensions of organisational culture in the competing value framework as follows:

1 Hierarchy culture.

2 Market culture.

3 Clan culture.

4 Adhocracy culture.

\section{HIERARCHY/CONSISTENCY/BUREAUCRACY CULTURE}

This culture type emphasises uniformity and strong control of the organisation with empowering coordination, evaluation and internal efficiency (Cameron \& Quinn, 2006). The main focus is the internal organisation and stability of the organisation. Order, security, rules and regulations are common motivators while efficiency, control and stability measure the organisation's 


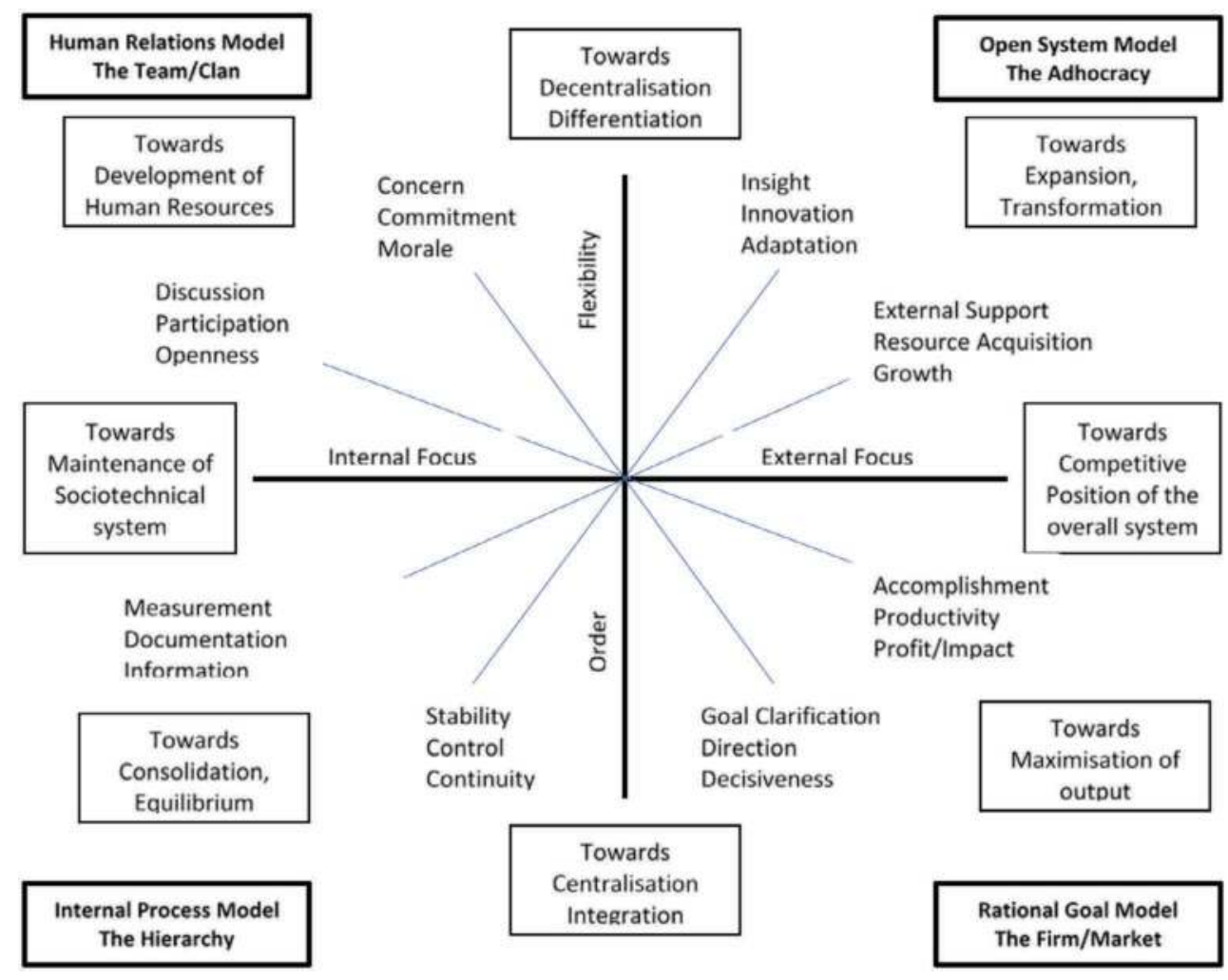

Figure 12.3 Competing value framework (adapted from Cameron and Quinn, 2006)

effectiveness (Hartley, 2002; San Park \& Kim, 2009). Implementation of rules and regulations is a key expectation of the leaders. Clearly defined decision-making procedures and well-established rules and regulations help to keep employees under control and accountable (Cameron \& Quinn, 2006; Übius \& Alas, 2009).

\section{MARKET/RATIONAL CULTURE}

In the late 1960s it was perceived that the hierarchy culture could not provide sufficient flexibility for organisations when meeting strong market competition, and the market/rational culture emerged as a result (Cameron \& Quinn, 2006). The achievement of well-defined objectives and goals are emphasised in this culture, which focuses mainly on the external layout instead of the internal functions (Denison, Haaland, \& Goelzer, 2004). The main focus is how to compete and reach set goals with unsupportive external factors, such as government regulations, license restrictions, customers' expectations, suppliers' limitations, external contractors and trade unions. Competition and successful achievement are the motivational factors, while control, efficiency and stability measure the effectiveness of the organisation (Denison \& Spreitzer, 1991). Increasing the market segment, profitability, customer base and targets are the primary focus of the organisation, and competitiveness and productivity are key values and attributes. 
The main focus of clan/group/involvement/consensual culture is maintaining better relationships and providing greater flexibility to employees to perform their job. Leaders of the organisation actively engage with employees and have concern for their well-being (Denison \& Spreitzer, 1991). Extensive support of staff and interaction between employees are encouraged in this culture. Trust, involvement, teamwork and corporate commitment to staff are the key characteristics of this dimension. Loyalty and tradition play an important role in clan culture, and customers are best thought of as partners. Collaboration is the main orientation of this culture, while leaders act as facilitators, mentors or team leaders (Denison et al., 2004). Employees feel that they have input into decision-making processes and can contribute to the organisation's goals.

\section{DEVELOPMENT/ADHOCRACY/ROLE CULTURE}

The development/adhocracy/role culture emerged when the developed world moved to the information age from the industrial age (Cameron \& Quinn, 2006). In this culture, most employees contribute to special committees or task forces which are dissolved once the task is complete. The main focus is creativity, innovation and resource acquisition (Fairs, 2016). Leaders are expected to take risks, as entrepreneurial and idealistic approaches are the keys to this dimension. Growth of the organisation, the acquisition of new resources, stimulation and development of a vision for the future are major concerns of this type of culture (Denison \& Spreitzer, 1991; San Park \&Kim, 2009). Individualism in the workplace is significant, as innovation is a major expectation in day-to-day tasks.

\subsubsection{Four core dimensions of organisational culture by Harrison and Stokes (1992)}

Harrison and Stokes (1992) introduced a theory of four core dimensions of organisational culture. They are:

1 Power-oriented culture: Power is the dominant feature of this dimension of culture and can be seen in organisations which have limited availability or limited access to resources. Control over people accessing resources, obtaining better working conditions, earning good money, accessing privileges, and having high job security are the main objectives of this dimension (McCarthy, 1998). The major incentive in this culture is rewards and excitement to be with high-ranking leaders who have the power to decide what is good for the organisation and staff (Rodriguez \& Gomez, 2009).

2 Role culture: This outlines a power-oriented culture and is underpinned by structures and procedures, which enable the management and control of large organisations. Although delegated responsibility and authority provide more efficiency for an organisation, along with justice and stability, this approach constrains innovation and rational decision-making. In particular, difficulties in changing current procedures and structures cause issues when there is high market competition (McCarthy, 1998).

3 Achievement orientation culture: This culture type assumes that members of the organisation are committed to work and want to make a significant contribution to the organisation. This culture is a combination of power-oriented culture and role culture and gives individual members opportunities to learn, grow, make decisions and be responsible for their 
own decisions (McCarthy, 1998). Recognition of individual work commitments, achievements, ongoing challenges, continuous learning and rewards are motivational factors for this culture (McCarthy, 1998).

4 Support and person-oriented culture: This type, based on mutual trust between the management and staff and mutual support by staff members of their co-workers, is the key feature. This culture is very useful for organisations to achieve their common goals, as individuals are personally committed to the workplace and high levels of collaboration and teamwork are involved (McCarthy, 1998).

\subsubsection{Three paradigms of organisational culture by Rodriguez and Gomez (2009)}

Rodriguez and Gomez (2009) introduced different dimensions of organisational culture, labelled the 'three paradigms of organisational culture' which are as follows:

1 Pessimistic/fatalistic paradigm: A dominant managerial style and a strong hierarchical structure are the main characteristics. All decisions are made by top management and others are expected to follow them. Individuals work under pressure and are rewarded based on their level of obedience and the nature of their relationship with higher management.

2 Optimistic/maniac paradigm: This type is most suitable for highly skilled professionals and individuals who have the ability and freedom to work efficiently and productively. Employees are encouraged to offer new ideas and innovations and are rewarded for their creativity and knowledge.

3 Pragmatic/bureaucratic paradigm: In this type of organisational culture individuals are expected to follow advice from management without question; formal rules, practices and procedures are commonplace. No teamwork or collaborative work practices are allowed, and interpersonal relationships are limited.

\subsection{Dimensions of organisational culture and types of organisations}

It would be useful to understand some specific characteristics and applications of each cultural dimension briefly.

Hierarchy culture: As implementing rules and regulations is a key expectation of leaders, clearly defined decision-making procedures and well-established rules and regulations help to keep employees under control and accountable. The main focus of this culture is the internal organisation and stability of the organisation. Order, security, rules and regulations are common motivators while efficiency, control and stability measure the effectiveness of the organisation. Military forces and police organisations are good examples of hierarchy cultures. Although this type of culture is common in the public sector, some private corporates adopt this culture.

Market culture: As increasing the market segment, profitability, the customer base and targets are the primary focus of the organisation, market culture can be observed in result-oriented workplaces such as insurance companies, telecommunication companies and sales-target-oriented business organisations.

Clan culture: Trust, involvement, teamwork and corporate commitment to staff are the key characteristics. Loyalty and tradition play an important role in clan culture and customers are best thought of as partners. As collaboration is the main characteristic, this culture can be found in organisations with modern management strategies, such as service organisations, banks, healthcare and insurance companies. 
Table 12.1 Cultures compared and organisation types

\begin{tabular}{lll}
\hline Culture & Characteristics & Organisation type adopting culture \\
\hline \multirow{2}{*}{ Hierarchy } & Uniformity & Military forces \\
& Strong control & Police \\
& Empowering coordination & Most government organisations \\
Market & Order, security, rules and regulations & \\
& Profitability & Insurance companies \\
& Customer base & Telecommunications \\
& Targets & Sales \\
Rlan & Results & Target-oriented organisations \\
& Trust & Service organisations \\
& Involvement & Banks \\
& Teamwork & Healthcare \\
& Corporate commitment to staff & Insurance companies \\
Adhocracy & Loyalty and tradition & \\
& Individualism & Research organisations \\
& Innovation & Software firms \\
& & Innovation and development projects
\end{tabular}

Adhocracy culture: Individualism in the workplace is significant, as innovation is a major expectation in day-to-day tasks. Therefore, this type of organisational culture is visible in industries such as research, software development, consulting and aerospace. Table 12.1 summarises the cultures, their characteristics and organisation types.

\section{Applicability to workplace studies}

Within property and real estate literature, organisational culture remains a relatively less researched area, despite its importance for the behaviour of property market practitioners, particularly within corporate real estate. Corporate real estate, more specifically office layout and design, has significant implications for the corporate culture of an organisation (Nanayakkara, 2019). It is important to examine various cultural aspects prevailing in organisations to obtain a deeper understanding of the effects of changes in office layout on the corporate culture of organisations (Chow, 2012).

For large corporates, the relationship between organisational culture and artefacts such as office layouts, architectural design and interiors, and the people who work in the office buildings is much more complicated. Furthermore, organisations which understand this relationship minimise problems related to recruitment, retention and motivation and achieve higher levels of employee productivity and satisfaction (Earle, 2003).

When workplace is discussed, it comprises three major parts: office layouts, interior designs and work practices. All are very much connected to the productivity and efficiency of dayto-day work and, ultimately, the output of the entire organisation. On the other hand, organisational culture is referred as an unforeseen mechanism to profitability (Cawood, 2008). It is important to see how organisational culture could be incorporated with office layouts, work practices and interior designs as this would provide a pleasant, productive and efficient workplace. The competing value framework proposed by Cameron and Quinn (2006) is useful in this context. 
Hierarchy culture: This culture type emphasises uniformity and strong control of the organisation with empowering coordination, evaluation and internal efficiency. Traditional or bureaucratic work practice is the common work practice. In terms of office layout arrangements, the traditional office layouts are the most appropriate since they facilitate strong hierarchical cultures within the organisation. Traditional office layouts refer to layouts that provide individual offices for high-ranking officers and depend on their level within the hierarchy of the organisation. All general staff are in open-plan offices with dedicated individual space.

Market culture: Organisations which adopt this culture mostly embrace high-involvement work practices as the most suitable work pattern. In relation to office space configurations, open-plan office layouts were introduced into large corporates to facilitate this type of culture in the late 1990s. Open-plan office layouts allow team members to meet, discuss, share their knowledge and collaborate with each other in order to maximise their performance at work.

Clan culture: Organisations could empower their individuals with clan culture. Employees feel that they are very valuable members of the organisation and they can contribute to the organisation's goals. Flexible work practices appear to be the most suitable for this cultural dimension as they provide various options to choose from according to the type of employees and the nature of their work. In addition to highly involved work practices (HIWP), flexible working is extensively used in this cultural dimension, since it provides flexibility and autonomy for skilled workers to carry out their work. Employees are encouraged to use activity-based working, flexi-time and teleworking practices, as they provide various financial and non-financial advantages to the organisation.

Adhocracy culture: In this culture, most employees contribute to special committees or task forces which are dissolved once the task is complete. The main focus is external layout and creativity, innovation, and resource acquisition. Leaders are expected to take risks, as entrepreneurial and idealistic approaches are key to this dimension. Growth of the organisation, the acquisition of new resources, stimulation and the development of a vision for the future are major concerns of this type of culture. Since it is important to provide quiet working spaces with minimum disturbances for work which requires intense concentration, large individual space allocation or individual offices for employees with sufficient spaces for team collaboration are considered suitable office layout arrangements for this type of culture. Table 12.2 summarises the culture type and preferred office layout found in the literature.

This chapter mostly discussed the relationship between organisational culture and office layout, and this is mainly due to the limited publications available which discuss this relationship. However, organisational culture is a powerful tool which influences many other areas in workplace. There is a relationship between organisational culture and office designs (Voordt, Meel, Smulders, \& Teurlings, 2003). Researchers further try to understand the relationship of type of building, interior atmosphere, furniture and colours associated with organisational culture type.

Some studies have identified that there is a positive relationship between organisational culture and company performance (Cawood, 2008; Ngo \& Loi, 2008). The market culture and

Table 12.2 Summary of cultures and preferred office layout

\begin{tabular}{ll}
\hline Culture & Characteristics \\
\hline Hierarchy culture & Traditional office layouts \\
Market culture & Open-plan office \\
Clan culture & Activity-based working \\
Adhocracy culture & Large individual space allocation or individual offices \\
\hline
\end{tabular}

Source: (Nanayakkara, 2019) 
adhocracy culture tend to outperform the clan and bureaucratic cultures in specific sectors (Deshpandé, Farley, \& Webster, 1993), and highly integrative cultures show the highest organisational performance followed by companies with market culture (Tsui, Wang, \& Xin, 2006). Organisational culture may affect the effectiveness of participation at different levels of management in the decision-making process (O'Connor, 1995). The existing studies have identified positive correlations between certain attributes of their corporate culture, such as their values, team spirit, quality, consistency, adaptation and work-related responsibilities (Calori \& Sarnin, 1991). The nature of the existing corporate culture in an organisation also has significant implications for employee commitment, their productivity and overall satisfaction (Green, 1988; Rashid et al., 2003). If managers cannot implement necessary psychological contacts with employees, this will cause significant negative impacts, such as high employee turnover, high levels of absenteeism and a demotivated workforce (Silverthorne, 2004).

Based on a study in China, Tsui et al. (2006) identified that employees working in highly and moderately integrated culture types, such as clan and adhocracy cultures, have the highest level of perceived organisational support and commitment to the company and the lowest level of turnover intention. From a study based in Taiwan, Silverthorne (2004) identified that bureaucratic culture causes the lowest level of organisational commitment, while innovative culture and supportive cultures cause the highest levels of commitment. It was also found that staff well-being, job satisfaction and organisational commitment were correlated significantly with organisational culture in business organisations in the UK (Santos, Hayward, \& Ramos, 2012). Communication between employees and any level of management is well established in Japanese companies, and it is a main part of the culture of Japanese organisations (Yuen \& Kee, 1993). Ngo and Loi (2008) confirmed that there is a direct effect of organisational culture on human resources practices and human resource-related performance. Several studies in the management discipline emphasise the influence of organisational culture on the efficiency and effectiveness of organisations (Alvesson, 1990; Calori \& Sarnin, 1991; Cawood, 2008; McCarthy, 1998; Schein, 1992).

Therefore, organisational culture is a very important tool which could influence many parts of the workplace. If it is used appropriately and carefully, organisational culture would be one of the most powerful and effective elements in organisational success.

\section{Methodology/research approach}

It is important to understand how to apply organisational culture theory to workplaces. No one single type of organisational culture exists in an organisation; instead, it is a mix of some or all of the culture types. When conducting a research in organisational culture, it is very important to identify the dominant culture type. It can be complicated, as different departments may have one dominant culture, while the organisation as a whole may have a different culture type. Therefore, it is important to ensure that your research sample represents the entire organisation.

Qualitative methodology is often used in organisational culture research, though mixed methods are helpful to analyse the cultural dimensions in detail. Different research methods could be used in collecting data to analyse the culture and its dimensions. In-depth interviews, questionnaire surveys and observations are effective data collection methods for this kind of research. Questionnaire data can be used to measure the dimensions of organisational culture, and interviews and observations can be used to analyse them in greater depth. It is important to evaluate culture from both management and employee perspectives, as they may have different views of the culture existing within an organisation.

If an organisation wants to change the existing culture, the first step is to measure the dimensions of the existing culture(s). Once the dimensions and level of changes required are identified, the 
process of introducing new elements of organisational culture can commence. This involves changes in work practices, office layouts, office design, employees behaviour, organisational rules and regulations, key performance indicators and attitudes. These changes are crucial for the organisation and need careful attention throughout the entire process, which can take some years to complete.

Organisational culture is a relatively novel area in the domain of corporate real estate research. Therefore, there are a number of new areas for future research to be undertaken. It would be interesting to see how different generations cope with organisational culture changes along with other changes such as those in work practices and office layouts. It would also be interesting to see how subcultures have been influenced due to changes in dimensions of main culture types. Furthermore, in 2020 the world has been gripped by economic and social change brought about by the COVID pandemic. This has caused many people to work remotely, and many predict that the likelihood of all employees returning to full-time office-based work after the pandemic is slim. Opportunities exist to research which of the four cultures thrive in the post-pandemic workplace and how workplaces are adapting.

\section{Limitations}

The previous analysis has identified and described the main cultures within organisations; however, some further iterations/factors can add more complexity in practice:

1 Some subcultures may co-exist within an organisation's main culture, and this theory does not address those subcultures.

2 National culture is an important cultural theory which exists within organisations, and this model does not discuss national culture and its impact at all.

3 It is difficult to understand the main organisational culture type that exists in an organisation. Therefore, management must evaluate the existing culture(s) and the culture which the organisation prefers to promote before designing a new workplace.

4 Organisational culture is a complicated theory and is connected to workplace and work practices. It is very important to understand the nature of the organisation and work practices that exist, in particular the organisational type, when conducting research on organisational culture.

5 It is necessary to use more than one method to collect the data to understand and measure the organisational culture. Those methods can include interviews, questionnaire surveys and participant observation. Selecting an appropriate sample from the research population is critically important too.

\section{Theory relevance to practice}

Leaders always look for possibilities to increase their organisation's profit. They attempt to do this by increasing income and reducing expenses. The largest expenditure source of any organisation is the salaries/wages of its employees. Improving productivity and efficiency is one way of increasing profitability. Large organisations introduce different work practices such as flexible working, collaborative working and high-involvement work practices to increase productivity and efficiency. New office layouts and design are introduced to support the new work practices. Similarly, large organisations tend to reduce their office spaces to minimise the cost of corporate real estate. Different work practices such as flexible working, teleworking, agile working, working from home and satellite offices are introduced to reduce office space without reducing the number of employees. 
However, most leaders do not understand the influence of changing work practices and how the workplace would influence the existing organisational culture. As mentioned earlier, organisational culture is an unseen mechanism to profitability for business organisations. If new office layouts and work practices do not support the preferred organisation culture, the ultimate impact on the bottom line would not be the one that management has anticipated. Therefore, understanding the theories and relationships between organisational culture, physical office environment and work practices is essential before making any changes to the workplace.

Since organisational culture is one of the biggest assets in an organisation, it is important to understand the type of organisational culture an organisation adheres to. In most cases, management believes that the organisation has their preferred culture type; however, it may not be the case in practice. Therefore, it is important to understand the existing organisational culture type and preferred organisational culture type, to see if there are differences before making any decision of changing office environment.

\section{Further reading}

- Nanayakkara, K. (2019). Understanding the influence of changes in physical office layouts on the organisational culture of large organisations. Retrieved from https://opus.lib.uts.edu.au/ handle/10453/140171

- Schein, E. H. (1992). How can organizations learn faster? The problem of entering the Green Room. MIT Sloan Management Review. Retrieved from https://sloanreview.mit.edu/ article/how-can-organizations-learn-faster-the-challenge-of-entering-the-green-room/

- Van der Voordt, T., van Meel, J., Smulders, F., \& Teurlings, S. (2003). Corporate culture and design. Environments by DESIGN, 4, 23-43.

\section{References}

Adler, N. J., \& Jelinek, M. (1986). Is organization culture culture bound? Human Resource Management, 25(1), 73-90. https://doi.org/10.1002/hrm.3930250106

Alvesson, M. (1990). On the popularity of organizational culture. Acta Sociologica, 33(1), 31-49.

Argyris, C., \& Schon, D. A. (1974). Theory in practice: Increasing professional effectiveness, San Francisco, CA: Jossey-Bass Publishers Inc.

Bhaskaran, S., \& Sukumaran, N. (2007). National culture, business culture and management practices: Consequential relationships? Cross Cultural Management: An International Journal, 14(1), pp. 54-67. https://doi.org/10.1108/13527600710718831

Bieliková, A. (2008). Corporate culture: The way of increasing the work quality in transport organisation. Promet - Traffic - Traffico, 20(1), 43-45.

Black, J. S., \& Mendenhall, M. (1989). A practical but theory-based framework for selecting crosscultural training methods. Human Resource Management, 28(4), 511-539. https://doi.org/10.1002/ hrm.3930280406

Brown, A. (1992). Organizational culture: The key to effective leadership and organizational development. Leadership \& Organization Development Journal, 13(2), 3-6. https://doi.org/10.1108/01437739210009545

Brunetto, Y. (2001). Mediating change for public-sector professionals. International Journal of Public Sector Management, 14(6), 465-481. https://doi.org/10.1108/09513550110408639

Budhwar, P. S., \& Sparrow, P. R. (2002). An integrative framework for understanding cross-national human resource management practices. Human Resource Management Review, 12(3), 377-403. https://doi. org/10.1016/S1053-4822(02)00066-9

Calori, R., \& Sarnin, P. (1991). Corporate culture and economic performance: A French study. Organization Studies, 12(1), 49-74. https://doi.org/10.1177/017084069101200104

Cameron, K. S., \& Quinn, R. E. (2006). Diagnosing and changing organizational culture: Based on the competing values framework (p. 294). San Francisco, CA: Jossey-Bass. 
Cawood, S. (2008). Company culture: The intangible pathway to profitability. Employment Relations Today, 34(4), 27-35. https://doi.org/10.1002/ert.20173

Chandler, N., Heidrich, B., \& Kasa, R. (2017). Everything changes? A repeated cross sectional study of organisational culture in the public sector. Evidence-based HRM: A Global Forum for Empirical Scholarship, 5(3), 283-296. Retrieved from https://ideas.repec.org/a/eme/ebhpps/ebhrm-03-2017-0018.html

Chatzitheochari, S., \& Arber, S. (2009). Lack of sleep, work and the long hours culture: Evidence from the UK Time Use Survey. Work, Employment and Society, 23(1), pp. 30-48. https://doi. org/10.1177/0950017008099776

Chow, I. H. (2012). The roles of implementation and organisational culture in the HR-performance link. International Journal of Human Resource Management, 23(15), 3114-3132. https://doi.org/10.1080/0958 5192.2011.639553

Cohen, G. L. (1992). Hard at work (the number of persons working 50 or more hours per week has risen dramatically over the last 15 years). Perspectives on Labour and Income, 4(1), 8-14. https://link.gale.com/ apps/doc/A30507998/AONE

Corfield, A., \& Paton, R. (2016). Investigating knowledge management: Can KM really change organisational culture? Journal of Knowledge Management, 20(1), 88-103 https://doi.org/10.1108/ JKM-12-2014-0502

Denison, D. R., Haaland, S., \& Goelzer, P. (2004). Corporate culture and organizational effectiveness: Is Asia different from the rest of the world? Organizational Dynamics, 33(1), 98-109. https://doi. org $/ 10.1016 /$ j.orgdyn

Denison, D. R., \& Spreitzer, G. M. (1991). Organizational culture and organizational development: A competing values approach. Research in Organizational Change and Development, 5(1), 1-21. Retrieved from www.denisonconsulting.com/sites/default/files/documents/resources/denison-1991-competingvalues-approach_0.pdf

Deshpandé, R., Farley, J. U., \& Webster, F. E., Jr. (1993). Corporate culture, customer orientation, and innovativeness in Japanese firms: A quadrad analysis. Journal of Marketing, 57(1), 23-37. Retrieved from www.jstor.org/stable/1252055

Earle, H. A. (2003). Building a workplace of choice: Using the work environment to attract and retain top talent. Journal of Facilities Management, 2(3), 244-257. https://doi.org/10.1108/14725960410808230

Engstrom, C. L. (2010). Rhetorical criticism as a method for examining cultural pressures on organisational form. Qualitative Research in Organisations and Management, 5(3), 259-279. https://doi. org/10.1108/17465641011089872

Fairs, M. (2016). Architecture and design an support or even change company culture. Retrieved from www. dezeen.com/2016/03/22/haworth-white-paper-research-how-to-create-a-successful-organisationalculture-working-styles-office-design

Gagliardi, P. (1990). Symbols and artifacts: Views of the corporate landscape. Berlin, New York: de Gruyter. https://doi.org/10.1515/9783110874143 p5-32.

Green, S. (1988). Strategy, organisational culture and symbolism. Long Range Planning, 21(4), 121-129. https://doi.org/10.1016/0024-6301(88)90016-7

Gupta, B. (2011). A comparative study of organizational strategy and culture across industry. Benchmarking: An International Journal, 18(4), 510-528. https://doi.org/10.1108/14635771111147614

Harper, S. (2012). The leader coach: A model of multi-style leadership. Journal of Practical Consulting, 4(1), 22-31. Retrieved from www.regent.edu/acad/global/publications/jpc/vol4iss1/JPC_Vol4Iss1_Harper.pdf

Harrison, R., \& Stokes, H. (1992). Diagnosing organizational culture (pp. 1-32). Hoboken, NJ: John Wiley \& Sons.

Hartley, J. (2002). Leading communities: Capabilities and cultures. Leadership \& Organisation Development Journal, 23(8), 419-429. https://doi.org/10.1108/01437730210449311

Hofstede, G., Hofstede, G. J., \& Minkov, M. (2010). Cultures and organisations: Software of the mind (3rd ed., pp. 3-48). New York, NY: McGraw-Hill London.

Igo, T., \& Skitmore, M. (2006). Diagnosing the organizational culture of an Australian engineering consultancy using the competing values framework. Construction Innovation: Information, Process, Management, 6(2), 121-139. https://doi.org/10.1108/14714170610710659

Ingelsson, P., Bäckström, I., \& Snyder, K. (2018). Strengthening quality culture in private sector and health care: What can we learn from applying soft measures? Leadership in Health Services, 31(3), 276-292. https://doi.org/10.1108/LHS-02-2018-0012

Kinjerski, V., \& Skrypnek, B. J. (2006). Measuring the intangible: Development of the spirit at work scale. In K. Mark Weaver (Ed.), Proceedings of the sixty-fifth annual meeting of the academy of management (pp. 2-16). Retrieved from https://www.kaizensolutions.org/sawscale.pdf 
Lau, C. M., \& Ngo, H. Y. (1996). One country many cultures: Organizational cultures of firms of different country origins. International Business Review, 5(5), 469-486. Retrieved from https://ideas.repec.org/a/ eee/iburev/v5y1996i5p469-486.html

Martin, J. (1992). Cultures in organizations: Three perspectives (pp. 25-185). Oxford: Oxford University Press.

Martin, J., \& Meyerson, D. (1988). Organizational cultures and the denial, channeling and acknowledgement of ambiguity (p. 126). New York, NY: John Wiley.

Martin, J., \& Siehl, C. (1983). Organizational culture and counterculture: An uneasy symbiosis. Organizational Dynamics, 12(2), pp. 52-64. https://doi.org/10.1016/0090-2616(83)90033-5

Mazur, M. (2015). Basic assumptions of organizational culture: In religiously diverse environments. International Journal of Contemporary Management, 14(3), 115-132. https://doi.org/10.4467/24498939I JCM.15.007.4309

McCarthy, E. (1998). The dynamics of culture, organisational culture and change. AI \& SOCIETY, 12(3), pp. 155-184. Retrieved from https://link.springer.com/article/10.1007/BF01206194

Meissonier, R., Houzé, E., \& Bessière, V. (2013). Cross-cultural frictions in information system management: Research perspectives on ERP implementation misfits in Thailand. International Business Research, 6(2), 150-159. Retrieved from http:// citeseerx.ist.psu.edu/viewdoc/download?doi=10.1.1.989.7110\& rep=rep1\&type $=$ pdf

Munter, M. (1993). Cross-cultural communication for managers. Business Horizons, 36(3), 69-78. Retrieved from https://go.gale.com/ps/anonymous?id=GALE\%7CA13183249\&sid=googleScholar\& $\mathrm{v}=2.1 \& \mathrm{it}=\mathrm{r} \&$ linkaccess $=$ abs\&issn $=00076813 \& \mathrm{p}=\mathrm{AONE} \& \mathrm{sw}=\mathrm{w}$

Nanayakkara, K. (2019). Understanding the influence of changes in physical office layouts on the organisational culture of large organisations. Retrieved from https://opus.lib.uts.edu.au/handle/10453/140171

Ngo, H., \& Loi, R. (2008). Human resource flexibility, organisational culture and firm performance: An investigation of multinational firms in Hong Kong. International Journal of Human Resource Management, 19(9), 1654-1666. https://doi.org/10.1080/09585190802295082

Nuutinen, M., \& Lappalainen, I. (2012). Towards service-oriented organisational culture in manufacturing companies. International Journal of Quality and Service Sciences, 4(2), 137-155. https://doi.org/ $10.1108 / 17566691211232882$

O'Connor, N. G. (1995). The influence of organisational culture on the usefulness of budget participation by Singaporean-Chinese managers. Accounting, Organisations and Society, 20(5), 383-403. https://doi. org/10.1016/0361-3682(94)00034-S

Patterson, D. A., Maguin, E., Dulmus, C. N., \& Nisbet, B. C. (2013). Individual worker level attitudes toward empirically supported treatments. Research on Social Work Practice, 23(1), 95-99. https://doi. org/10.1177/1049731512463442

Plimmer, G., Bryson, J., \& Teo, S. T. T. (2017). Opening the black box: The mediating roles of organisational systems and ambidexterity in the HRM-performance link in public sector organisations, Personnel Review, 46(7), 1434-1451. https://doi.org/10.1108/PR-10-2016-0275

Quinn, E. R., \& Rohrbaugh, J. (1981). A competing values approach to organisational effectiveness. Public Productivity Review, 5(2), 122-140. https://doi.org/10.2307/3380029

Rajagopal, \& Rajagopal, A. (2006). Trust and cross-cultural dissimilarities in corporate environment. Team Performance Management, 12(7), 237-252. https://doi.org/10.1108/13527590610711796

Rashid, M. Z. A., Sambasivan, M., \& Johari, J. (2003). The influence of corporate culture and organisational commitment on performance. Journal of Management Development, 22(8), 708-728. https://doi. org/10.1108/02621710310487873

Reiman, T., \& Oedewald, P. (2002). The assessment of organisational culture: A methodological study. VTT Technical Research Centre of Finland. VTT Tiedotteita - Research Notes No. 2140. Retrieved from www.vtt.fi/inf/pdf/tiedotteet/2002/T2140.pdf

Rodriguez, J. K., \& Gomez, C. F. (2009). HRM in Chile: The impact of organisational culture. Employee Relations, 31(3), 276-294. https://doi.org/10.1108/01425450910946479

Sackmann, S. A. (1991). Uncovering culture in organizations. The Journal of Applied Behavioral Science, 27(3), 295-317. https://doi.org/10.1177/0021886391273005

San Park, J., \& Kim, T. H. (2009). Do types of organizational culture matter in nurse job satisfaction and turnover intention? Leadership in Health Services, 22(1), 20-38. https://doi.org/10.1108/17511870910928001

Santos, A., Hayward, T., \& Ramos, H. M. (2012). Organisational culture, work and personal goals as predictors of employee well-being. Journal of Organisational Culture, Communications and Conflict, 16(1), 25-48.

Schein, E. (1992). Organizational culture and leadership (2nd ed., pp. 25-411). San Francisco, CA: Jossey-Bass Publishers. 


\section{Organisational culture theories}

Shekari, G., Rahmdel, H., \& Rajabian, E. (2012). Study of factors affecting improvement of organisational culture, based on the model's denison (case study: Agricultural bank branches in Mashhad). Interdisciplinary Journal of Contemporary Research in Business, 4(5), 790-798. Retrieved from https://journalarchieves23.webs.com/790-798.pdf

Silverthorne, C. (2004). The impact of organisational culture and person-organisation fit on organisational commitment and job satisfaction in Taiwan. Leadership \& Organisation Development Journal, 25(7), 592-599. https://doi.org/10.1108/01437730410561477

Suppiah, V., \& Sandhu, M. S. (2011). Organisational culture's influence on tacit knowledge-sharing behaviour. Journal of Knowledge Management, 15(3), 462-477. https://doi.org/10.1108/13673271111137439

Tsui, A. S., Wang, H., \& Xin, K. R. (2006). Organizational culture in China: An analysis of culture dimensions and culture types. Management and Organization Review, 2(3), 345-376. https://doi.org/10.1111/j. 1740-8784.2006.00050.x

Übius, Ü, \& Alas, R. (2009). Organizational culture types as predictors of corporate social responsibility. Inzinerine Ekonomika-Engineering Economics, 61(1), 90-99. Retrieved from https://inzeko.ktu.lt/index. $\mathrm{php} / \mathrm{EE} / \mathrm{article} / \mathrm{view} / 11597$

Voordt, T. J. M., van der, Meel. J., van, Smulders, F., \& Teurlings, S. (2003). Corporate Culture and Design. Environments by DESIGN, 4(2), 23-43. Retrieved from www.cfpb.nl/media/uploads/publicaties/upload/ voordt_2003_corporateculture.pdf

Wiewiora, A., Trigunarsyah, B., Murphy, G., \& Coffey, V. (2013). Organizational culture and willingness to share knowledge: A competing values perspective in Australian context. International Journal of Project Management, 31(8), 1163-1174. Retrieved from https://eprints.qut.edu.au/57104/

Wilkins, A. L., \& Ouchi, W. G. (1983). Efficient cultures: Exploring the relationship between culture and organizational performance. Administrative Science Quarterly, 28(3), 468-481. https://doi. org $/ 10.2307 / 2392253$

Yuen, E. C., \& Kee, H. T. (1993). Headquarters, host-culture and organisational influences on HRM policies and practices. MIR: Management International Review, 33(4), 361-383. Retrieved from www.jstor. org $/$ stable $/ 40228170$ 


\title{
THEORY OF ATTRACTIVE QUALITY
}

\section{Occupant satisfaction with indoor environmental quality at workplaces}

\author{
Quan Jin*, Holger Wallbaum, Jungsoo Kim, and Richard de Dear
}

\section{Background}

Satisfaction is dictionary-defined as the condition of having a desire or need to be fulfilled. The origin of the word can be backdated to eight centuries ago. The foundation for satisfaction lies in 'mankind's ability to learn' from previous experiences (Peyton \& Kamery, 2003). In the book Satisfaction, Oliver has provided a formal concept of satisfaction on the consumer perspective and elaborated that satisfaction is the fulfilment response and its pleasurable level of under- or over-fulfilment (Oliver, 1996). Satisfaction is a concept that has appeared in various disciplines, such as worker satisfaction in the industry, patient satisfaction in public health, and life satisfaction in sociology. Research on satisfaction generally sits upon a 'disconfirmation of expectation' theory; the feeling of satisfaction is formed through a cognitive process of comparing the perceived performance to expectations (Oliver, 1980). For instance, a perceived performance that exceeds expectations results in satisfaction (positive disconfirmation), whereas a performance below expectation results in dissatisfaction (negative disconfirmation).

One of the key features of satisfaction research is to understand the needs, identify and prioritise the determinants and optimise the process, since satisfaction reflects the emotion and behaviour which can be influenced by different attributes from the product or service. In 1984, Kano, Seraku, Takahashi, and Tsuji (1984) introduced the theory of attractive quality and the Kano model on product development and customer satisfaction, developed originally in the context of marketing. The theory has proposed two-dimensional quality as a relation between a subjective dimension of, for example, satisfaction and an objective dimension of, for example, physical attributes. For instance, the theory can be applied to study the relationship between customer satisfaction and product quality, or between employee satisfaction and job-related factors. The theory explains different relations between the satisfaction and the degree of fulfilment of a function with various quality attributes. In other words, it explicates when a quality attribute fulfils the function or fails to function, how it influences satisfaction and what categories the influence can be classified into. Traditionally, in the one-dimensional model, the level of satisfaction is assumed to be linearly correlated with product quality, that is, the better the quality,

*Corresponding author: quan.jin@chalmers.se 
the higher level the satisfaction. In contrast with the one-dimensional model, Kano's theory of attractive quality addresses the limitation by considering the non-linear and asymmetric relation between various quality attributes.

Therefore, the Kano model, which provides a bridge for putting the theory into practice, classifies customer preferences into five categories: must-be quality, one-dimensional quality, attractive quality, indifferent quality and reverse quality (Kano et al., 1984; Löfgren, Witell, \& Gustafsson, 2011). Figure 13.1 gives a general review of the Kano model and illustrates the five categories. It is based on recognising the feelings to be satisfied, dissatisfied or indifferent. The attractive quality of the first category contains the factors that have the highest and non-linear impact on satisfaction. It explains that the more the function is fulfilled, the greater the satisfaction is. However, it does not necessarily cause dissatisfaction when not fulfilled. The second category refers to the factors with one-dimensional quality. As was anticipated, satisfaction is linearly dependent upon these factors so that with the increase of fulfilment of the function, the satisfaction is also increased, and vice versa. The third category is the must-be quality. The factors in this category have the highest and non-linear influence on dissatisfaction. The failure of the performance of the factors leads to dissatisfaction, but the achievement of fulfilment does not necessarily result in satisfaction. The fourth category is socalled reversal quality, which means that the insufficiency of fulfilment promotes satisfaction, and vice versa. It is the opposite of the one-dimensional quality. The last category is indifference quality. The performance of fulfilment with various quality attribute does not influence satisfaction or dissatisfaction.

Attribute quality also may change over time, as indicated in Figure 13.1. With the development of the product or service, one attribute can change from an attractive feature to a must-be feature (Kano, 2001). For example, when the earliest air conditioning technology was

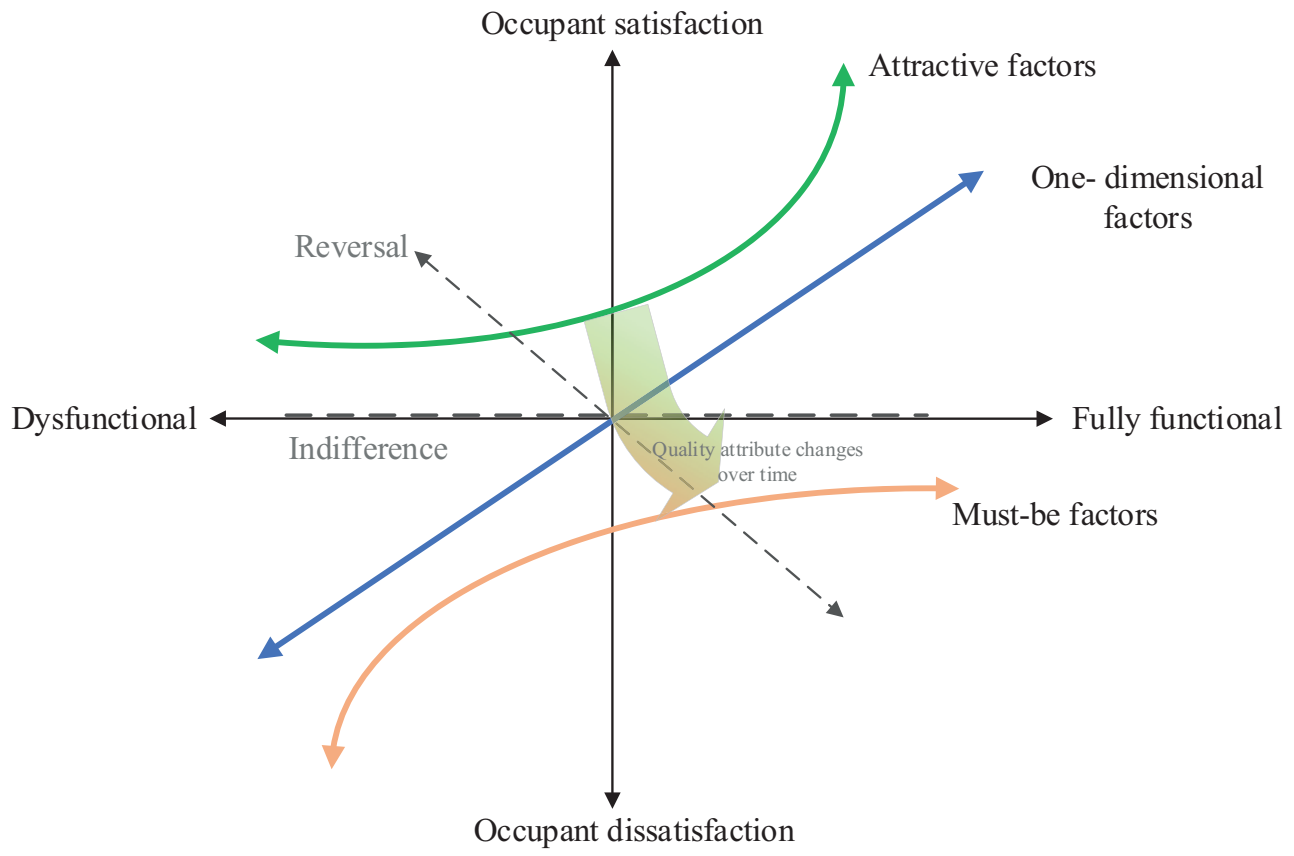

Figure 13.1 Kano's satisfaction model and categories of attribute quality (adapted from Kano et al., 1984) 
introduced in 1902, the air conditioner likely had an attractive quality. In modern society, an air conditioner has been widely implemented, and this attribute and the quality provided is perhaps assigned as a must-be or a one-dimensional quality.

During the past 20 years, the Kano theory and model has been increasingly utilised in different disciplines, from the traditional application in product development to other disciplines. For instance, the Kano model was integrated into the architectural design by suggesting subcategories for indifferent factors to better interpret various perceived design options (Ek \& Çıkış, 2015). The Kano model has also been applied in environmental quality science to clarify customer perceptions of an environmental attribute of a green product (Finster, Eagan, \& Hussey, 2001), such as packaging, recycling and energy consumption. The model has helped to create the incentives for environmental design and link to business value. In 2015, Luor, Lu, Chien and $\mathrm{Tu}$ further reviewed the Kano model in quality research by the publications from 1998 to 2012. It shows that the use of the Kano model has been increasing since 1998 as well as the times cited in academia. Thus far, the Kano model has been vastly applied in the four subject areas, including business economics, engineering, operation research management science and computer science. The Kano theory and model visualise the perceptions of a product, service or design and is of significance to identify the characteristics of various quality attributes. It triggers a continuous development of different disciplines to improve the concept and product by addressing and linking users' real needs.

\section{Application to workplaces}

Within the 17 UN Sustainable Development Goals (SDGs), Goal 3 on good health and wellbeing and Goal 8 on decent work and economic growth are closely related to the quality of indoor environments, where we spend more than $80 \%$ of our lives. This holds especially true for the millions of people working indoors. To achieve future positive and resilient workplaces, employees' needs and preferences should be put at the centre of building design, technology and service in terms of motivating and lifting their satisfaction to the environmental quality indoors.

\subsection{Occupant satisfaction with IEQ matters}

Indoor environmental quality (IEQ) simply refers to the quality of a building's environment. It should not only meet the basic needs of hygiene, physiology, sanitation and safety for the people who occupy the space but should also benefit occupant health and well-being. With the development of IEQ research over the past decades, there is growing awareness that IEQ is of high significance to guarantee a good quality of life and work for human beings and is one of the most significant aspects of concern in workplace design (World Green Building Council, 2014). IEQ is of major interest for occupants, employers and several other building-related stakeholders. It is commonly agreed that a comfortable and healthy indoor environment is vital for the well-being of occupants. A better IEQ reduces sick leave days and improves the productivity of employees (Fisk \& Rosenfeld, 1997). Research acknowledges that different factors of IEQ have direct effects on human comfort and health, and the direct links have been identified (Frontczak \& Wargocki, 2011; Wolkoff, 2013). Beyond comfort and health, the positive influence on the productivity of the occupants has also been reviewed and emphasised in green building research; for instance, the improved IEQ can lead to selfreported improvements in productivity (Singh, Syal, Grady, \& Korkmaz, 2010).

IEQ is a broad concept. The most important factors of IEQ for a building include thermal comfort, indoor air quality, acoustics and lighting (Buildings Performance Institute Europe, 
2018). The European standard EN 16798-1 also lists these IEQ factors and addresses building system design and energy performance. Apart from that, other non-environmental factors from architectural design and social perspective are also considered as part of IEQ and to be of significance for workplaces. These include office layout, view, colour, furnishings, cleanliness, maintenance and electromagnetic radiation (Malmqvist, 2008; Zagreus, Huizenga, Arens, \& Lehrer, 2004). Hence, when dealing with occupant satisfaction and expectation, which occurs through the relations among each of the IEQ factors, it becomes complex. Indeed, in real-life scenarios occupants would perceive the environment as a whole, making it extremely difficult to predict their attitude towards or their satisfaction with the building. Sometimes it is witnessed that poor IEQ does not necessarily harm occupant satisfaction, whereas on some other occasions an IEQ factor can trigger substantial criticism of a building. This gives us a hint that the significance of an IEQ factor can differ, depending on how it is perceived by an occupant.

\subsection{The Kano model for satisfaction research with IEQ}

Applying the Kano model to IEQ helps for better understanding the relationship between perceived building performance on specific indoor environmental factors and occupants' satisfaction with their workplaces. The Kano model of customer satisfaction is adapted for its utilisation on the subject of building occupants' satisfaction. Bringing the Kano theory and model into academia and research has triggered many studies using the model in environmental quality, and indoor environmental quality is one of the main disciplines to which the model has been applied.

The Kano model has been used to evaluate occupant satisfaction with IEQ in office buildings (Kim \& de Dear, 2012). The result is based on 43,021 post-occupancy evaluation questionnaires in 351 office buildings with natural ventilation, mechanical ventilation or mix-mode, and IEQ factors are categorised into basic, proportional and bonus factors. This three-factor structure of satisfaction, typically termed as the Kano model in the literature, categorises different qualities according to the direction of their effect on satisfaction. This study shows the following. First, for the basic factors, it includes temperature, noise, amount of space, visual privacy, adjustability of furniture, colours and textures, and workspace cleanliness. These are expected and are thus regarded as minimum requirements. Being predominantly associated with dissatisfaction, good quality on these factors doesn't necessarily improve satisfaction. Instead, they can cause dissatisfaction if they are deficient in some way. Second, proportional factors, which can affect satisfaction both positively and negatively, consist of air quality, amount of light, visual comfort, sound privacy, ease of interaction, comfort of furnishing, building cleanliness and building maintenance. Third, no bonus IEQ factors were recognised from the study, but there might exist possible bonus factors as the study has not covered all IEQ factors, for example daylight and external view. Bonus factors are not expected normally. Being predominantly associated with satisfaction, they can have a strong positive effect once they are fulfilled.

The Kano model can be viewed as an efficient and potential method for IEQ assessment related to satisfaction. For example, it can converge towards environmental quality and sustainability by combining with social cognitive theory (Dace, Stibe, \& Timma, 2020). It has also been shown to be the most suitable method to measure user satisfaction with adaptive behaviour in the indoor environment in energy-efficient buildings and can assist the design to integrate users' needs (Shafaghat et al., 2016). 


\section{Methodology/research approach}

\subsection{Examples of data collection from employees}

Data collection in the real world is a key approach for exploring the relations and interactions between indoor environment and employees' feelings about the quality of a building for both new building construction and existing building renovation. By collecting data on employees satisfaction and expectation, the Kano theory and model could be effectively applied and verified to recognise the key attributes in building design, operation and management. In parallel, the challenge of collecting data with employees in the organisation should not be overlooked since it often brings up the issues of resources and efforts allocated as well as the collaboration with the management group. Hence, a qualified data collection method and frame are of true significance for utilising and verifying the Kano model.

\subsubsection{Post-occupancy evaluation}

Post-occupancy evaluation (POE) can be defined as a systematic process of evaluating buildings that have been occupied for a certain period, focusing on building occupants and their needs (Preiser, Rabinowitz, \& White, 1988). Throughout the process of POE, data collection is an essential prerequisite to the development of useful knowledge. There are varieties of ways to collect building performance data, and they each have their level of difficulty and effort (i.e., amount of time, resources and the depth of evaluation). Conducting an occupant survey is probably the most prevalent method of collecting building performance data that can be found in studies in various disciplines. Different forms of POE questionnaire are in use around the world, but probably the best-known questionnaires focusing on office IEQ satisfaction are BUS (building use studies) and CBE (Center for the Built Environment). In the UK, the BUS survey questionnaire was adopted by and evolved throughout the PROBE (post-occupancy review of buildings and their engineering) research project that started in 1995 (Cohen, Standeven, Bordass, \& Leaman, 2001). In addition to the basic IEQ questions, the BUS system also collects detailed information about general topics such as building management, image of building, occupant's perceived productivity and health. In the USA, the CBE questionnaire was developed by the Center for the Built Environment at the University of California, Berkeley, and has been collecting occupant responses since 2000 (Zagreus et al., 2004). As a web-based survey, the participants are invited to the survey by e-mail and the survey results can be viewed through an automated online reporting tool. Occupants' satisfaction with seven core IEQ aspects is assessed on a seven-point rating scale. Branching questions are activated whenever a respondent indicates dissatisfaction with a certain IEQ aspect, which allows further investigation into the source of dissatisfaction. The BUS and CBE are implemented in various green building rating tools across the globe and are widely used survey tools for IEQ evaluation in the commercial building sector. It is also worth noting that although POE via BUS and CBE might have been superseded by the questionnaires behind some recent certification systems, for example, the WELL V2 certification (WELL, 2020), scientific evidence is still a challenge.

\subsection{2 'Furbish SSO' user insight approach}

'Furbish SSO' refers to the approach and tool for a deep user insight into smart and sustainable offices (Cobaleda-Cordero, Rahe, Wallbaum, Jin, \& Forooraghi, 2017; Jin, Wallbaum, Rahe, \& Forooraghi, 2019). It is a holistic mixed-method approach to collect employees' needs and feedback on the inner quality of a building and service during its life cycle including planning, design, operation 


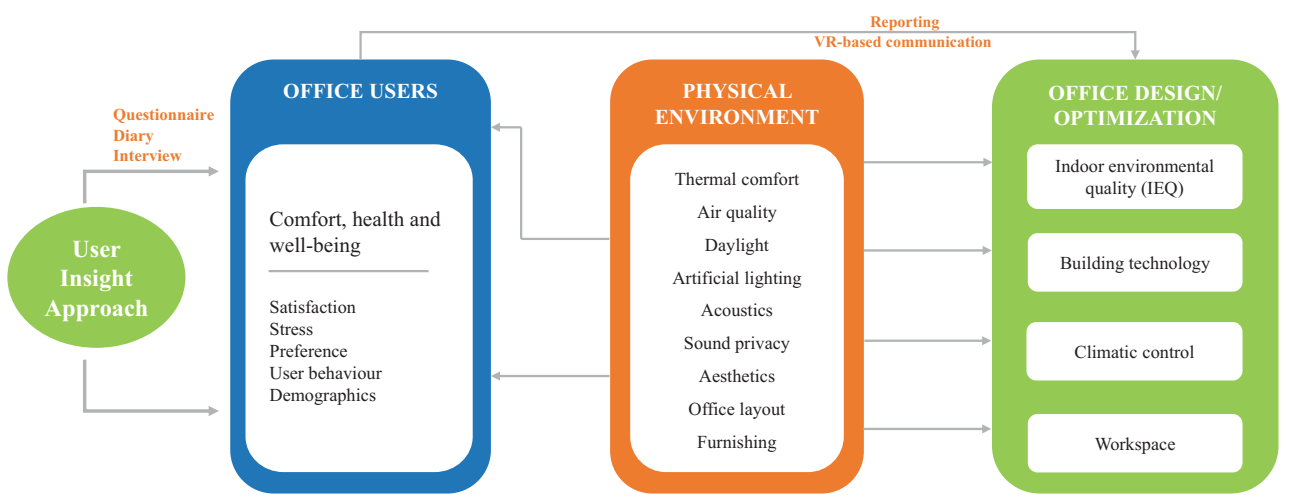

Figure 13.2 A mixed-method approach of qualitative and quantitative measures in smart and sustainable offices

and renovation. It aims to develop a strategy for the implementation of a new generation of useroriented and resilient building design solutions to provide empirical evidence for future office environments. One of the main focuses is to collect user experience and physical data on the specific indoor environment, including thermal comfort, air quality, daylight, lighting quality, acoustics, sound privacy, aesthetics, office layout and furnishings. Moreover, the social aspect is considered in this approach by assessing user demographics, user behaviour and energy use consciousness, as well as job-related satisfaction. The main components of the approach include a questionnaire, diary and focus group, as well as a number of individual interviews and a VR-based communication tool. The questionnaire maps a holistic picture of the user's general experience in the office environment, including satisfaction, stress and preference. The diary tracks the daily change of user satisfaction and behaviour, which allows the researchers to accurately relate the perceptions and measured physical environment. The semi-structured individual interviews and the focus-group interviews collect in-depth personal perspectives on the importance of the physical work environment characteristics and qualities in the office, along with the satisfaction with these characteristics and qualities. The VR tool supports a co-creation session with the users and planners to discuss and support indoor environmental design concepts following the preferences identified by applying the Furbish SSO approach. Based on the data collected of employees' perceptions of the office environment, the attractive features from a broad scope of physical work environment could be identified. Figure 13.2 shows the mixed-method approach with the main IEQ factors involved.

\subsection{Research gaps and the Kano model}

Attractive quality theory provides a way to explore the key features of satisfaction. Other theories also explain the origins of satisfaction, for instance users' satisfaction theories of assimilation theory (Festinger, 1957), contrast theory (Hovland, Harvey, \& Sherif, 1957) and negative theory (Anderson \& Fornell, 1994), which have been summarised by Aigbavboa and Thwala in 2013. However, comparing these theories, an advanced feature of the attractive theory includes the Kano model, which links the theory with practical use. The Kano model has been extensively used in marketing gaining perspective on customer satisfaction. Nevertheless, more applications to the studies in IEQ of building science are needed. Thus far, it is not sufficient for concluding which attractive key building attributes that employees value most at workplaces. Hence, the model should be applied to more populations and in various types of buildings and offices. 
As building technology and systems continue to develop, the model should address the dynamic nature of basic features, performance features and attractive features. Regarding the Kano model's function of specifying the attributes, for example to rank different attributes of the same quality for an overall evaluation of office satisfaction or to quantify the relation between each attribute and satisfaction, other methods of data mining could be further considered along with the Kano model, for example factor analysis, structural equation modelling, fuzzy modelling and Merenda and Gold's method (Bi, 2012; Dace et al., 2020; Gregory \& Parsa, 2013; Lee, Sheu, \& Tsou, 2008).

The attractive quality theory could be also further developed by verifying and testing in the real world. For example, coupling it with the empirical evidence gained from the IEQ field studies can help researchers and building professionals clarify the way to improve employees' satisfaction at workplaces. Aiming to shed light on the potential theory and model and to lift employees' satisfaction and achieve a sustainable working life in offices with high inner quality, in future research, subjective data need to be further aggregated at workplaces in different phases of a building's life cycle, especially with a longitudinal study enabling a critical test of pre-move and post-move to verify the Kano model on the key features of building attributes.

\section{Limitations}

A limitation of applying the Kano theory and model to workplaces in the field of IEQ exists in the possible bias of occupant perceptions of the building environment. The reliability and completeness of the subjective data collection and measurement cannot be neglected. Also, the influence of interactions between the various attributes on satisfaction is possibly lacking. The indoor environmental attributes are complex and relate to various aspects, including building physics, service engineering and building design. The relevant factors need to be holistically studied to identify key building attributes. More studies need to be conducted to verify the existing conclusions on potential quality categories. A limitation also exists in the further consideration of well-being at workplaces. For example, subjective perceptions of different environmental attributes with a focus on mental well-being have been measured by the Warwick-Edinburgh wellbeing scale (WARWICK, 2018). Concerns about the emotional responses on the health and mind and the economic impacts cannot be neglected either (see Chapter 14 Flourish Theory).

\section{Theory relevance to practice}

The application of the Kano model to the IEQ context indicates some IEQ factors' differential significance to occupant's overall environmental satisfaction. This has implications for those who operate a building, such as facilities managers. They must understand the relationship between occupant satisfaction and different IEQ factors before they make decisions for resource allocation. Those factors showing negative asymmetry (i.e., basic factors) such as 'thermal comfort' (Kim \& de Dear, 2012) will become more critical if they fail to meet occupant expectations, and even a substantial investment to improve a basic factor does not necessarily result in corresponding occupant satisfaction. Basic factors are regarded as 'must-have' elements, and therefore focusing on their negative aspects can be a strategic and a more efficient way to maintain occupant satisfaction to a certain level. In contrast, for those showing positive asymmetry (i.e., bonus factors) such as 'external view' (Kim \& de Dear, 2020) can be sources of occupants' delightful environmental experience, significantly contributing to enhancing overall satisfaction. Therefore, once basic factors have been delivered to a satisfactory level, it would be a rational strategy to focus on bonus factors to maximise occupant satisfaction. 


\section{Further reading}

- Clements-Croome, D. (Ed.). (2018). Creating the productive workplace: Places to work (3rd ed.). London: Routledge.

- Dace, E., Stibe, A., \& Timma, L. (2020). A holistic approach to manage environmental quality by using the Kano model and social cognitive theory. Corporate Social Responsibility and Environmental, 27, 430-443. https://doi.org/10.1002/csr.1828

- Kim, J., \& de Dear, R. (2012). Nonlinear relationships between individual IEQ factors and overall workspace satisfaction. Building and Environment, 49, 33-40. https://doi. org/10.1016/j.buildenv.2011.09.022

- Oliver, R. L. (1996). Satisfaction: A behavioral perspective on consumer. New York, NY: Prince Hill.

- Witell, L., Löfgren, M., \& Dahlgaard, J. J. (2013). Theory of attractive quality and the Kano methodology - The past, the present, and the future. Total Quality Management and Business Excellence, 24(11-12), 1241-1252. https://doi.org/10.1080/14783363.2013.791117

\section{References}

Aigbavboa, C., \& Thwala, W. (2013, December 17-18). A theoretical framework of users' satisfaction/ dissatisfaction theories [Paper presentation]. In 2nd international conference on arts, behavioral sciences and economics issues (ICABSEI'2013). Pattaya, Thailand. Retrieved from http://psrcentre.org/images/ extraimages/12\%201213003.pdf

Anderson, E. W., \& Fornell, C. (1994). A customer satisfaction research prospectus. In R. T. Rust \& R. Oliver (Eds.), Service quality: new directions in theory and practice (pp. 241-268). Thousand Oaks, CA: SAGE Publications.

Bi, J. (2012). A review of statistical methods for determination of relative importance of correlated predictors and identification of drivers of consumer liking. Journal of Sensory Studies, 27(2), 87-101. https:// doi.org/10.1111/j.1745-459X.2012.00370.x

Buildings Performance Institute Europe (BPIE). (2018). The inner value of a building. Retrieved from http:// bpie.eu/wp-content/uploads/2018/10/The-Inner-value-of-a-building-Linking-IEQ-and-energyperformance-in-building-regulation_BPIE.pdf

Cobaleda-Cordero, A., Rahe, U., Wallbaum, H., Jin, Q., \& Forooraghi, M. (2017). Smart and Sustainable Offices (SSO): Showcasing a holistic approach to realise the next generation offices. Informes de la Construcción, 69(548), e221. https://doi.org/10.3989/id55278

Cohen, R., Standeven, M., Bordass, B., \& Leaman, A. (2001). Assessing building performance in use 1: The probe process. Building Research and Information, 29(2), 85-102. https://doi.org/10.1080/096132 10010008018

Dace, E., Stibe, A., \& Timma, L. (2020). A holistic approach to manage environmental quality by using the Kano model and social cognitive theory. Corporate Social Responsibility and Environmental Management, 27(2), 430-443. https://doi.org/10.1002/csr.1828

Ek, F. İ., \& Çıkış, Ş. (2015). Integrating the Kano model into architectural design: Quality measurement in mass-housing units. Total Quality Management and Business Excellence, 26(3-4), 400-414. https://doi. org $/ 10.1080 / 14783363.2013 .835898$

Festinger, L. (1957). A theory of cognitive dissonance. Stanford, CA: Stanford Press.

Finster, M., Eagan, P., \& Hussey, D. (2001). Linking industrial ecology with business strategy: Creating value for green product design. Journal of Industrial Ecology, 5(3), 107-125. https://doi. org/10.1162/108819801760049495

Fisk, W. J., \& Rosenfeld, A. H. (1997). Estimates of improved productivity and health from better indoor environments. Indoor Air, 7(3), 158-172. https://doi.org/10.1111/j.1600-0668.1997.t01-1-00002.x

Frontczak, M., \& Wargocki, P. (2011). Literature survey on how different factors influence human comfort in indoor environments. Building and Environment, 46(4), 922-937. https://doi.org/10.1016/j. buildenv.2010.10.021

Gregory, A. M., \& Parsa, H. G. (2013). Kano's model: An integrative review of theory and applications to the field of hospitality and tourism. Journal of Hospitality Marketing and Management, 22(1), 25-46. https://doi.org/10.1080/19368623.2011.641073 
Hovland, C., Harvey. O., \& Sherif, M. (1957). Assimilation and contrast effects in reaction to communication and attitude change. Journal of Abnormal and Social Psychology, 55(7), 244-252. https://doi. org/10.1037/h0048480

Jin, Q., Wallbaum, H., Rahe, U., \& Forooraghi, M. (2019). SSO User Insight Toolbox for employees' health, well-being and productivity. REHVA Journal, 6, 58-63. Retrieved from www.rehva.eu/ rehva-journal/chapter/sso-user-insight-toolbox-for-employees-health-well-being-and-productivity

Kano, N. (2001, September 12-14). Life cycle and creation of attractive quality. In S. M. Park- Dahlgaard \& J. J. Dahlgaard (Eds.), Proceeding of the 4th international QMOD conference quality management and organizational development (pp. 18-36). Linköping, Sweden: Linköping University Electronic Press.

Kano, N., Seraku, N., Takahashi, F., \& Tsuji, S. (1984). Attractive quality and must be quality. Journal of the Japanese Society for Quality Control, 14(2), 147-156. https://doi.org/10.20684/quality.14.2_147

Kim, J., \& de Dear, R. (2012). Nonlinear relationships between individual IEQ factors and overall workspace satisfaction. Building and Environment, 49, 33-40. https://doi.org/10.1016/j.buildenv.2011.09.022

Kim, J., \& de Dear, R. (2020). Employee satisfaction and the quality of workplace environment. In O. B. Ayoko \& N. M. Ashkanasy (Eds.), Organizational behavior and the physical environment (pp. 13-36). London: Routledge.

Lee, Y. C., Sheu, L. C., \& Tsou, Y. G. (2008). Quality function deployment implementation based on Fuzzy Kano model: An application in PLM system. Computers and Industrial Engineering, 55(1), 48-63. https://doi.org/10.1016/j.cie.2007.11.014

Löfgren, M., Witell, L., \& Gustafsson, A. (2011). Theory of attractive quality and life cycles of quality attributes. The TQM Journal, 23(2), 235-246. https://doi.org/10.1108/17542731111110267

Luor, T., Lu, H. P., Chien, K. M., \& Tu, T. C. (2015). Contribution to quality research: A literature review of Kano's model from 1998 to 2012. Total Quality Management and Business Excellence, 26(3-4), $234-247$. https://doi.org/10.1080/14783363.2012.733264

Malmqvist, T. (2008). Environmental rating methods: Selecting indoor environmental quality (IEQ) aspects and indicators. Building Research E Information, 36(5), 466-485. https://doi.org/10.1080/ 09613210802075841

Oliver, R. L. (1980). A cognitive model of the antecedents and consequences of satisfaction decisions. Journal of Marketing Research, 17(4), 460-469. https://doi.org/10.1177/002224378001700405

Oliver, R. L. (1996). Satisfaction: A behavioral perspective on consumer. New York: Prince Hill.

Peyton, R. M., P. S., \& Kamery, R. H. (2003). Consumer Satisfaction/Dissatisfaction (CS/D): A review of the literature prior to the 1990s. Proceedings of the Academy of Organizational Culture, Communications and Conflict, 7(2), 41-46.

Preiser, W. F. E., Rabinowitz, H. Z., \& White, E. T. (1988). Post-occupancy evaluation. New York: Van Nostrand Reinhold.

Shafaghat, A., Keyvanfar, A., Muhd, M. Z., Lamit, H. B., Ahmad, M. H., Ferwati, M. S., \& Ghoshal, S. K. (2016). Methods for adaptive behaviors satisfaction assessment with energy efficient building design. Renewable and Sustainable Energy Reviews, 57, 250-259. https://doi.org/10.1016/j.rser.2015.12.133

Singh, A., Syal, M., Grady, S. C., \& Korkmaz, S. (2010). Effects of green buildings on employee health and productivity. American Journal of Public Health, 100(9), 1665-1668. https://doi.org/10.2105/ AJPH.2009.180687

WARWICK. (2018). The Warwick-Edinburgh Mental Wellbeing Scales - WEMWBS. Retrieved from https:// warwick.ac.uk/fac/sci/med/research/platform/wemwbs

WELL. (2020). WELL: Pre-approved programs. Retrieved from https://v2.wellcertified.com/resources/ preapproved-programs

Wolkoff, P. (2013). Indoor air pollutants in office environments: Assessment of comfort, health, and performance. International Journal of Hygiene and Environmental Health, 216(4), 371-394. https://doi. org/10.1016/j.ijheh.2012.08.001

World Green Building Council. (2014). Health, well-being \& productivity in offices: The next chapter for green building. Retrieved from www.worldgbc.org/news-media/health-wellbeing-and-productivityoffices-next-chapter-green-building

Zagreus, L, Huizenga, C, Arens, E, \& Lehrer, D. (2004). Listening to the occupants: A web-based indoor environmental quality survey. Indoor Air, 14(8), 65-74. https://doi.org/10.1111/j.1600-0668.2004.00301.x 


\title{
14 \\ FLOURISH THEORY
}

\section{A model for multisensory human-centric design}

\author{
Derek Clements-Croome*
}

\section{Background}

This chapter is based on an evolving body of research that is starting to account for non-optimised design in terms of health life years lost (Shrubsole et al., 2015), presents empirical studies that reveal the impact of poorly designed workplaces (British Council for Offices [BCO] studies, 2012; 2014; 2015; 2017; 2018) and makes links between the research and applied design thinking.

The flourish approach is rooted in the established conceptual theories of 'flourish' and 'wellbeing' (Barrett, Barrett, \& Zhang, 2015; Diener \& Biswas-Diener, 2008; Huppert \& So, 2013; Kim \& de Dear, 2012; Maslow, 1943; Seligman, 2011). The flourish model has been developed and is described in BSRIA (2019), Clements-Croome (2018, 2020), Clements-Croome, Turner and Pallaris (2019) and the UK Green Building Council [UKGBC] (2016, p. 14) on health and wellbeing in homes and by earlier viewpoints of the author and presented in the World Green Building Council publications (World Green Building Council [WGBC], 2014, p. 31).

Flourish goes beyond comfort and towards a more holistic understanding of how sensory change from stimuli diversity around us can help to stimulate health and wellbeing, which are the roots of human energy that fires creativity and productivity (Clements-Croome, 2018, 2020; BCO, 2017), The flourish approach was the framework for the BCO report called Wellness Matters (BCO, 2018). Flourishing refers to the experience of life going well. It is a combination of feeling good and functioning effectively. Flourishing is synonymous with a high level of mental wellbeing and epitomises mental health (Huppert \& So, 2013).

Fredrickson (2001) writes that flourishing is an optimal state of human functioning and all the positivity which is implied by that. Huppert and So (2013) describe a European survey - 43,000 subjects in 23 countries - which aimed to define what is meant by flourishing, and this resulted in defining 10 attributes of positive wellbeing or flourishing. These were competence, emotional stability, engagement, meaning, optimism, positive emotion, positive relationships, resilience, self-esteem and vitality.

One can see how these factors are part of personal motivation. Many of these attributes are described in the classic work of Maslow (1943) or Diener \& Biswas-Diener (2008) and Seligman (2011).

*Corresponding author: d.j.clements-croome@reading.ac.uk 


\subsection{The multisensory experience}

To design spaces that benefit our wellbeing requires knowledge of how the body and mind respond to the diversity of stimuli they receive from the environment. The nature of the stimuli can be people, work focus, objects, the look and feel of the space and the atmosphere that is created. The brain does not perceive environmental stimuli in isolation but rather embraces the whole pattern of stimuli as they change in time unless, particularly, extremes occur in any of the stimuli. The primary stimulus is the task being undertaken but the surroundings provide peripheral stimuli which we are aware of but not to the point of being distracted. As our attention waxes and wanes according to our mind fatigue patterns, these peripheral stimuli like colour or views out on to nature, for example, provide sensory contrast breaks from work focus. A mixture of sitting, standing and walking provide healthy movement for the body, so ways of doing this by walking in gardens, meditating or other means all add contrast in the sensory experience that people can enjoy.

Architecture is for humanity. The buildings it enshrines reflect the spirit of a particular age. At a basic level they shelter people from a range of climates and let them carry out an array of functions in their living and working lives. Often, they are judged for their functionality and their visual appearance. Beauty, however, is not only what the eyes see; it is also how the building interior affects the human senses in terms of feelings, emotions and affect. So sound, touch, smell and sight all react in particular ways and can result in a feeling of happiness, contentment or spiritual uplift if the architecture has been designed with imagination and respect for human sensory needs. Barbara Erwine (2017) in her book Creating Sensory Spaces writes about architecture of the invisible or what may be called a total sensory aesthetic. In her book Urban Smellscapes (2013), Victoria Henshaw writes about the reactions of people on smellwalks, and others have described soundwalks (Behrendt, 2018), but these reactions are explained as being like layers of the senses. You see something but smell, sound and touch elevate your feelings about it whether you are inside or outside a building.

A multisensory design approach termed synesthetic design offers an alternative to traditional visual sensory bias by providing the systematic incorporation of all five senses. The aim of synesthetic design is "to coordinate all sensations stimulated by an object in a manner that results in a pleasant, harmonious overall appearance while coinciding with the particular function(s) desired" (Haverkamp, 2012, p. 14).

\subsection{Empirical studies on workplace design}

The 2014 British Council for Offices survey of 2,000 UK office workers showed that one in four believed their work environment did not support their physical wellbeing (BCO, 2014). Dissatisfied respondents were particularly unhappy with a lack of colour (80\%), a lack of greenery (64\%) and a lack of art (61\%) in their workplaces (BCO, 2015). On a global scale, the Human Spaces Survey (Cooper \& Browning, 2015) found that 58\% of 7,600 office workers in 16 countries (of which $85 \%$ of offices surveyed were located in an urban environment) did not report having plants in the office and $47 \%$ reported no natural light. Just under half (47\%) reported having felt stressed in their workplace within the last three months and $28 \%$ of respondents reported that they did not have a quiet space to work in their office. The five elements most desired in the office revealed by the survey were inherently linked to nature and the sensory experience of the workplace and these were natural light, views on to natural landscapes, bright colours, indoor plants and quiet working spaces. 


\subsection{Beyond environmental comfort}

The word comfort is perhaps overused. It has a neutral but long-term durable quality. It is usually seen as a pleasant or relaxed state of a human being in relation to their environment, but surely that is only part of what we need for the concentrating mind. Is one highly attentive when comfortable, or is there a danger of being bored, losing attention or even falling asleep? Cabanac (2006) writes about pleasure and joy and their role in human life and indicates how transients are important in providing variety and contrast for the human sensory system to respond, to reiterate the description about multisensory environments given earlier. During the day we hope for and seek joyful moments - perhaps a tree in blossom, pleasant air movement or changing light patterns. There is an echo of this in Maslow's book Religions, Values, and Peak Experiences (1964) when he writes about peak experiences which can be transitory, momentary or longer term but can trigger happiness and uplift in mood. Cabanac (2006) introduced the term alliesthesia, which means a stimulus may give rise to a pleasant or unpleasant sensation depending on the internal state of the person (de Dear, 2011). Our experience of the environment is the result of an interplay of heat, light, sound and many other factors, not just of single elements like thermal comfort, for example. Buildings should provide a multisensory experience. The senses need stimulation to react to, otherwise boredom sets in.

Malnar and Vodvarka (2004) comment, "The problem with most of the research on the thermal environment is that it has centred on thermal comfort or thermal neutrality. They go to quote other work." Wilson (1984) states, "As with the auditory area of research, the approaches concentrate on preventing feelings of discomfort, rather than producing positive responses such as interesting, invigorating - to thermal conditions."

Human performance has been defined as depending on motivation, ability or competence and opportunity offered by amenities and support systems (Fogg, 2009). So here we can see the link between people's feelings and their work performance and how the environment in which they are located affects this.

Vitality is about human energy, and much has been written about how this can be sapped by poor atmospheres lacking good air quality, natural lighting or temperature control, for example. Drab environments devoid of colour, views or greenery lead to dull, unstimulating hours of work, however interesting that might be.

These findings underlie the flourish model.

\section{Applicability to workplace studies}

\subsection{The flourish model}

The aim is to create an environment in which people thrive. The author has based the reasoning for this model on the work of Zhang and Barrett (2012) and Kim and de Dear (2012), which goes beyond comfort and reaches out towards acquiring the ideal state of wellbeing as described by Diener \& Biswas-Diener (2008), Maslow (1943) and Seligman (2011). The model is based on three issues - the environmental factors, the perceptions and feelings people have in various environmental settings and the economic consequences of the environments created (WGBC, 2014, 2016).

The impact of the environment on people is difficult to predict because the environment has an effect which is more than the sum of its parts (Bluyssen, 2014; de Dear, 2011). Another complication is that sensory modalities interact. They also compensate one another, for example as happened with Evelyn Glennie, who although deaf became a world-class percussionist by 
sensing the vibrations through her feet, lower body and hands. A few years ago, at a seminar on multisensory dining held by Professor Charles Spence at Oxford University, he invited attendees to taste a ginger biscuit whilst gliding their hand over a smooth surface and then again over a rough surface. For the majority the ginger flavour was more intense when the hand was passed over the rough surface. Sense modalities interact.

Barrett (2018) believes that there is no real understanding of the holistic impacts of built spaces on people despite the huge amounts of knowledge there is on individual aspects like heat, light and sound. The outcome of his Holistic Evidence and Design (HEAD) project is the SIN model, which has three main dimensions - stimulation level, individualisation and naturalness.

Stimulation arises from the amount of information in the setting in which stimulants such as colour, aromas, greenery or things that are changing such as formal or informal social contacts or changes in the natural setting give variety, context and interest. An example of a building designed to be enjoyable and uplifting is the atrium in the Kajima office in Tokyo described by Takenoya (2006), in which aroma and bio-music are used intermittently to provide variety and stimulation. Complexity, colour and texture, for example, give contrast and make the environment more interesting. Overstimulation can give confusing and hectic signals which can increase stress levels, whereas too little stimulation can be boring (Bluyssen, 2014).

Individualisation is the occupants' personal environment and includes factors like personal control, flexibility and one's identity with a space. Naturalness is the basic environmental setting, and this where the comfort backdrop forms an important foundation. The holistic multisensory experience is the interplay between these three dimensions of stimulation, individualisation and naturalness.

Kano, Seraku, Takahashi and Tsuji (1984) proposed a model of product and service satisfaction in the 1980s which defines three essential attributes (see also Chapter 13 The Theory of Attractive Quality):

- Threshold attributes: customers expect these as a fundamental set of requirements (comfort criteria).

- Performance attributes: these increase customers' enjoyment, though some may not be absolutely necessary.

- Excitement attributes: these provide the extra sense of surprise and enjoyment (bonus factors).

These are a dynamic, interactive set of attributes.

Kim and de Dear (2012) adapted these and described Kano et al.'s (1984) classification in terms of basic factors, bonus factors and proportional factors. From their survey of 351 different office buildings, they identified basic and proportional factors, which are adapted here to suit the COVID-19 pandemic situation in 2020:

- Basic factors: levels of temperature and sound, amount of space, visual privacy, flexible furniture, colours and textures and workplace cleanliness. These are minimal requirements, but with the COVID-19 virus we need to add infection risk, which affects spacing, layout and patterns of air distribution, cleaning processes and maintenance.

- Proportional factors: air quality, light, visual comfort, sound privacy, ease of interaction, ergonomic comfort of furniture, cleanliness and building maintenance. Satisfaction tends to increase linearly as these elements improve.

- Bonus factors: colour, social climate, greenery, views and changing daylight. 
These factors act like triggers that can impact mood and add pleasure to one's experience. Other factors are aesthetics and décor, which give the look and feel of a space.

One can see a connection here with the thinking behind the SIN model as the stimulating element corresponds to the bonus factors in the Kano et al. (1984) model; naturalness corresponds to the basic factors; individualisation corresponds to the proportional factors and includes personal control. The first is a normal layer featuring standard comfort health and safety guidelines for temperature, sound, light and ventilation (for the waking and sleeping states). Various codes, guides and handbooks prescribe these. Design and operation of ventilation is now a critical factor in dealing with infection risk so is undergoing deep scrutiny since COVID-19 appeared worldwide. The second layer is one which recognises that people prefer to have some degree of personal control over their environmental settings. Also, there is a relationship between health and some of the factors we are dealing with in a proportional way. For example, as ventilation increases from $8 \mathrm{l}$ /s person to $25 \mathrm{l} / \mathrm{s}$ person, illnesses decrease as the research shown by Fanger (1970, 2002), Wargocki et al. (2006) and Wargocki and Wyon (2007). So there is not a single number or narrow band to choose for design like temperature, for example, but rather an individual or proportional layer in which a choice has to be made. In selecting a figure, one has to study the evidence for offices, schools, retail outlets or homes. Often the decision is made on low energy and cost, but this has to be offset by the savings accrued by better health and productivity as evidenced by less absenteeism and presenteeism, and now infection risk has become a primary concern.

Third, there is the sparkle or ' $w o w$ ' layer which includes things like views on nature, daylight, colour, décor, layout, aesthetics and green space around the building. These features are mainly non-quantifiable but still important. These seemingly small factors can suddenly make one feel better in spirit - a bit like getting up in the morning and feeling a little sluggish then opening the curtains on to a beautiful sunny morning and feeling quivers of happiness. Some of the research is beginning to give some design data such as for biophilic design (Browning, 2012) (see also Chapter 15 The Biophilia Hypothesis), but in general we should consider the sparkle factors in design even though they are 'soft' metrics and not quantifiable. We do know, however, that homes with sea or country views, for example, fetch premium prices. Buildings in cities are particularly challenging but with careful creative thought they can be lovable, joyful and soulful places for people to live and work.

We need to capture all three layers if we are going to provide buildings in which people thrive and flourish for living or work. Figure 14.1 (Clements-Croome, 2016, 2018, 2020) shows the advantages of using the flourish model for various stakeholders. How occupants feel in the environmental setting they occupy influences their motivational energy to do work and make decisions (Clements-Croome, 2018).

Figure 14.2 shows how objective and subjective factors impact people's feelings and as a consequence the economics of the workplace. Flourish echoes the checklists proposed by Dolan and Bernheimer. In his book Happiness by Design (2014), Dolan proposes the SALIENT mnemonic:

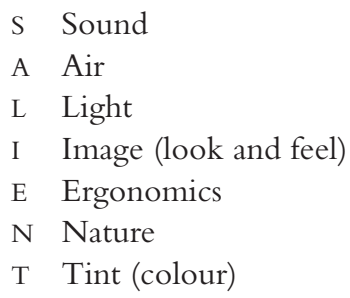




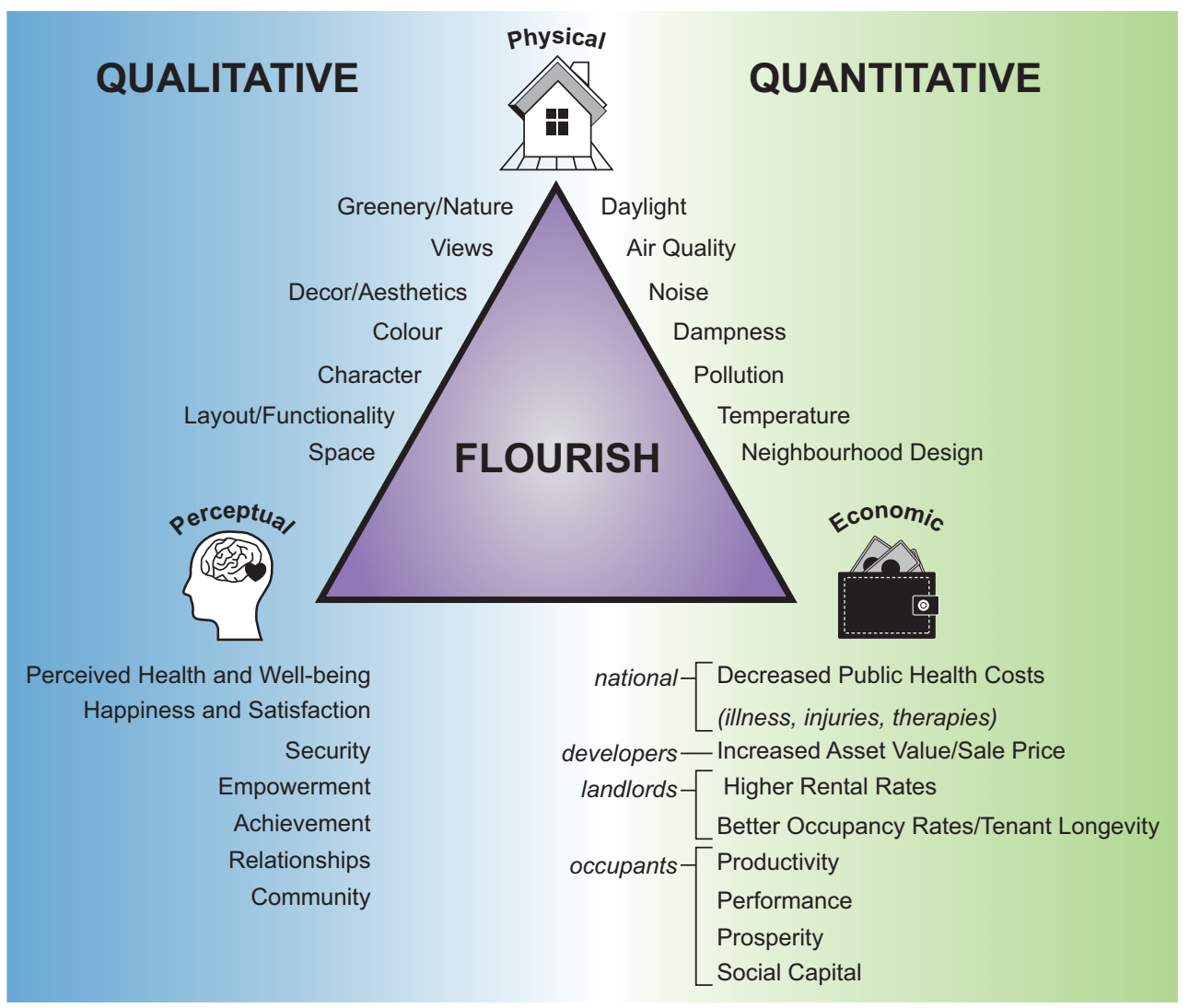

Figure 14.1 Flourish model (Clements-Croome, 2018, 2020)

Bernheimer in her book The Shaping of Us (2017) proposes a BALANCED space checklist.

B Biophilia - natural materials, views and patterns

A Atmospheric - light, air quality, temperature and smell

L Layout - space quality, circulation

A Amenities - nutrition, movement, ergonomics

$\mathrm{N}$ Noise

C Cohesion - community, communication

E Energy - resources and waste

D Design - colour, shape, materials, proportions, detail and style

The WELL version 2 rating system has 10 factors to consider for health and wellbeing:

- Air

- Water

- Light

- Nourishment

- Movement

- Thermal comfort

- Sound 
- Materials

- Mind

- Community

These three independent total environment user-centric approaches have many similar aspects and add support to the underlying aims of the flourish model. To reiterate - the evidence for flourish is rooted mainly in the psychology research of Maslow (1943, 1964), Cabanac (2006), Diener and Biswas-Diener (2008), Huppert and So (2013) and Seligman (2011), together with later evidence described by Dolan (2014) and Bernheimer in Clements-Croome (2018, 2020). It is important to realise that the findings from this work can enrich architectural design and make workplaces better for health and wellbeing. The aim is to go beyond the traditional comfort approach and achieve environments in which people thrive, benefiting both creativity and productivity. Two case studies demonstrating the flourish approach are cited later.

\section{Methodology}

Using flourish involves several steps:

- Work with client mapping needs with flourish.

- Use a sample survey of occupants using questions based on the flourish wheel in Figure 14.2.

- Work with human resources (HR) on economic factors like sickness absence and staff retention rates.

- Use Kansei or other multifactor decision-making approaches (Huda \& Hadiana, 2020).

- Analyse results and derive a predesign flourish map using the flourish wheel.

- At the post-occupancy evaluation (POE) stage, collect data from the physical environment, HR on absenteeism and staff retention rates, and people's psychological and physiological responses via questionnaires and wearables.

- $\quad$ Reiterate the analysis.

- Recommend any changes.

Figure 14.2 shows how objective and subjective factors can affect people's feelings and consequently the economics of the workplace. The flourish model can be used in setting and evaluating success criteria for projects besides aiding POE. BSRIA BG 74/2019 Success Criteria for Soft Landings provides more information on success criteria. Human Resources departments can provide data for the economic quadrant on the economic area.

Data is derived from questionnaires which are based on the following general factors as described in $\operatorname{BCO}(2017,2018)$ and Clements-Croome (2020):

- Type of work - range of work.

- Location - city/rural, nature, accessibility.

- HR data on absenteeism, staff turnover rates, medical problems.

- Physical data plus facilities managers (FM) experience.

- Occupants feedback plot on flourish wheel.

- Simple rating scales for health/wellbeing (see Appendix in Clements-Croome, 2020).

- Other factors that arise in interviews with users.

The workplace is ever changing and has implications for how we should design the next generation of workplaces. Whether in old refurbished buildings or new ones, health and wellbeing 


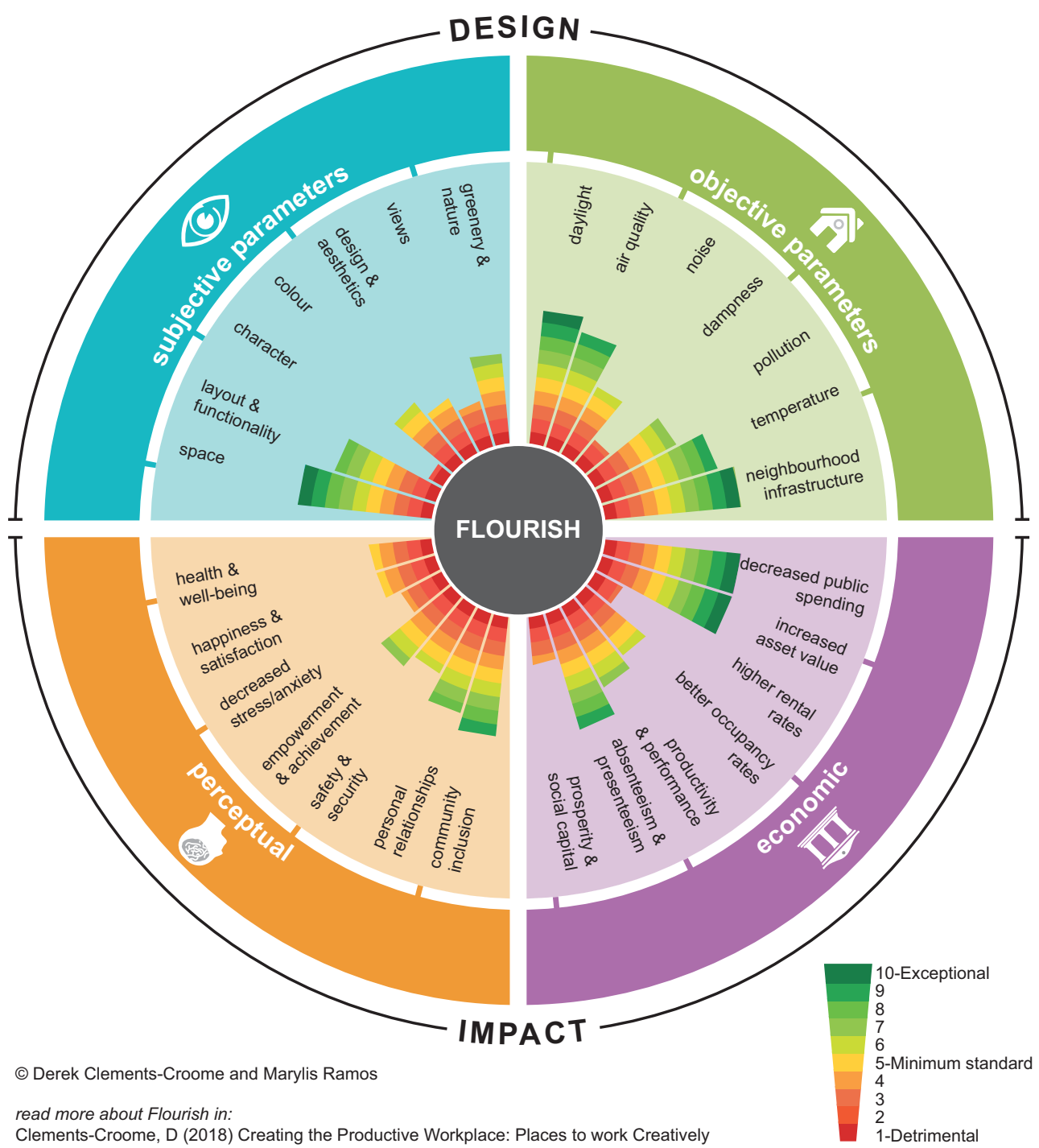

Figure 14.2 The flourish wheel

will be emphasised in architectural design and will continue into the construction and operation of buildings in practice. The responses of office workers in various surveys by the BCO suggest that even current practice and value sets are not realising the creativity and productivity potentials that workplace design can yield. The roots of productivity are in health and wellbeing, and these determine the energy we each have to work and live.

There is already a wealth of knowledge about the sensory response of the human body. Wearable technology offers the opportunity for further enhancing our knowledge of how design decisions affect employees' physiological and psychological wellbeing, at both the individual and the collective level. Such technology will have implications for the way we design, refurbish and build workplaces, placing an even greater emphasis on the human-centric, experiential 
perspective, a perspective embedded at the heart of a multisensory approach to workplace design (Clements-Croome, Aguilar, \& Taub, 2015).

\section{Limitations}

The model relies on collecting data. It is easy to measure factors like air quality and temperature using traditional instrumentation. Assessing subjective environmental data involves interviewing and administering questionnaires. Currently the use of wearables enables the assessment of many factors that affect people physiologically and psychologically. However, the compiling of economic data on absenteeism, presenteeism and staff retention rates is more difficult and depends on how effective HR departments are at gathering this.

\section{Theory relevance to practice: case studies}

Employers are realising that greater consideration of their staff within workplace design has multiple rewards, enabling them to provide a healthier working environment whilst simultaneously improving profitability and staff retention. After the COVID-19 pandemic, we will perhaps see greater flexibility between home and office working besides taking a much more human health-centred approach to planning for lower occupancy densities, ventilation and air movement patterns, cleaning routines and processes, and maintenance.

Designing with this sensory approach in mind might at first encounter cost hurdles. This approach can be seen as potentially resulting in higher investment requirements, with higher design fees allocated for additional employee engagement and for other elements of office redesign. However, health and wellbeing is not a luxury; it is an investment. Beyond this, ignoring infection risk, for example, can cause deaths. We know that indoor and outdoor pollution can contribute to deaths too. A traditional workplace valuation approach considers costs in terms of occupancy per square footage. This approach is no longer viable.

The flourish model offers an impacts framework against which design considerations can be assessed and the resulting outcomes evaluated. If the workplace is not delivering the productive, enticing, healthy environment they need to undertake their work, employees will have a well-informed basis upon which to express dissatisfaction and act. Also, illness absenteeism can increase and staff retention rates decrease with poor environments. The workplace of the future must rapidly transition to incorporate environments conducive to our sense of wellbeing. This can only be achieved by creating workplaces that enable employees to flourish. Measurement will be key in obtaining the data we need to deepen our understanding.

\subsection{The biophilic classroom, Putney High School, London, by Clare Bowman, RCZM Architects}

The following is a study into the restorative benefits of biophilic design through the role of nature in a space and nature's analogue patterns (Gillis \& Gatersleben, 2015) to support health and wellbeing. The research is based on the flourish model theory of creating natural and harmonious environments to stimulate the alpha brain waves (high relaxation) and lower the beta brain waves (high stress), with the aim to calm the mind to improve attention and create the space for the imagination to thrive (Clements-Croome, 2018, 2020).

'Nature in space' was introduced to a maths classroom in the form of plants and visual 'natural analogue' in the form of a woodlands photo mural to an English classroom. Comfort was monitored for temperature, humidity, $\mathrm{CO}_{2}$, various particles and gases. User surveys included perception of 
design, comfort, health, attention, and cognitive and emotional wellbeing. Further observational studies of attention and engagement used the Leuven scale for wellbeing developed by Professor Ferre Laevers at Research Centre for Experiential Education at Leuven University in 2005.

Internal air quality results revealed that the maths classroom with plants improved air quality by an average of $10 \%$ and humidity by $8 \%$ above the English classroom. The study also found consistency of comfort and freshness with the passive ventilation system set to $750 \mathrm{ppm}$.

Occupant surveys revealed plants had a closer association with cognitive wellbeing and the mural of nature had a stronger relationship with emotional wellbeing. Head Mistress Suzie Longstaff stated, "The findings have shown that the subtle reintroduction of nature can enhance the quality of learning environments to benefit health, productivity, cognitive and emotional wellbeing."

\subsection{The biophilic workplaces: "second home" by Youmna Dmour}

The Second Home Company have regenerated an old building in East London, which is an appropriate case to study the impact of the biophilic design features in workplaces as it recognises the advantages to health and wellbeing of having internal landscaping. This workspace is quoted in AnOther magazine as a place "where nature acts as a catalyst for creative sanctuary and innovation" (Hawkins, 2016).

Buildings in large densely populated cities are challenging, but with creative and imaginative thinking, they can be joyful, cheerful and soulful spaces for people to live and work. If the designer is going to deliver buildings in which individuals thrive and flourish for living or work, there is a need to capture the holistic environment of the building design as well as the user experience. The flourish model is a way of achieving a holistic design.

This research interviewed 10 occupants in the Second Home Spitalfields building in East London and generated a matrix that explains, first, the factors of indoor environmental quality (IEQ) in the office environment that mostly affected occupant's wellness. Second, these factors, which include biophilia, also show their impact on feelings that occupants perceive besides the economic benefits such as reduced absenteeism. The interviews in this study focused on the occupants' perceptions and some economic issues, so this research will present a holistic view of the building both physically and psychologically.

In conclusion, it was clear that using biophilic design made a huge difference in the occupants' satisfaction and wellness. The occupants' responses show two main points. The first one is that using biophilic design features alone are not enough to reach the best environmental quality for health and wellbeing. The second point is to integrate biophilic features with the ability to control the indoor environment quality for satisfactory thermal, air, lighting and sound conditions together with a suitable spatial layout of the office. This has been especially important since March 2020, when the COVID-19 virus began posing a risk of severe infection. Biophilic design enhances and adds great value to a holistic environmental design.

\section{Further reading}

- Barrett, P., \& Barrett, L. (2010). The potential of positive places: Senses, brain and spaces. Intelligent Buildings International, 2(3), 218-228. https://doi.org/10.3763/inbi.2010.0042

\section{Acknowledgments}

The author thanks Clare Bowman of RCZM Architects and Youmna Dmour at Brunel University for their case studies demonstrating the use of the flourish approach and Gulay Ozkan for editing. 


\section{References}

Barrett, P. (2018). Lessons from schools for productive office environments: The SIN Model. In D. J. Clements-Croome (Ed.), Creating the productive workplace: Places to work creatively (pp. 111-124). Abingdon: Routledge.

Barrett, P., Barrett, L., \& Zhang, Y. (2015). Teachers' views of their primary school classrooms, Intelligent Buildings International, 8(3), 176-191. https://doi.org/10.1080/17508975.2015.1087835

BCO. (2012, September 3), Making art work in the workplace. International Art Consultants and British Council for Offices. Retrieved from http://bco.org.uk/nmsruntime/saveasdialog.aspx?IID=513

BCO. (2014, July 18). Making the business case for well-being: The 2014 well-being at work study. British Council for Offices and Morgan Lovell and Hatch. Retrieved from http://cdn.morganlovell.co.uk/pdfs/ Morgan-Lovell-Making-the-business-case-for-wellbeing-2014.pdf

BCO. (2015, May 12), Putting people first: Designing for health and wellbeing in the built environment. Retrieved from http://derekcroome.com/Document\%20Files/Healthyworking.pdf

BCO. (2017, November 29). Improving productivity in the workplace: Lessons learnt and insights from the Whole Life Performance Plus project. Retrieved from www.emcoruk.com/workplace_productivity.pdf

BCO. (2018, June 11). Wellness matters. British Council for Offices.

Behrendt, F. (2018). Soundwalking. In M. Bull (Ed.), The Routledge companion to sound studies (pp. 249257). Routledge.

Bernheimer, L. (2017). The shaping of us: How everyday spaces structure our lives, behaviour, and well-being (1st ed.). San Antonio, TX: Trinity University Press.

Bluyssen, P. M. (2014). The healthy indoor environment: How to assess occupants' well-being in buildings. London: Routledge.

Browning, W. (2012). The economics of biophilia - Why designing with nature in mind makes financial sense. New York: Terrapin Bright Green, LLC.

BSRIA. (2019). The flourish model to enhance wellbeing. DELTA T, 8-9, Building Services Research and Information Association. Retrieved from www.bsria.com/uk/news/article/the-flourish-model-to-enhancewellbeing/

Cabanac, M. (2006). Pleasure and joy, and their role in human life. In D. J. Clements-Croome (Eds.), Creating the productive workplace (pp. 40-50). London: E \& FN Spon.

Clements-Croome, D. J. (2016, March 4). Intelligent liveable buildings: Health and well-being perspectives. Lecture, Bath University, School of Architecture and Civil Engineering.

Clements-Croome, D. J. (2018). Effects of the built environment on health and well- being. In D. J. Clements-Croome (Eds.), Creating the productive workplace: Places to work creatively (3rd ed., pp. 3-40). London: Routledge.

Clements-Croome, D. J. (2020). Designing buildings for people: Sustainable liveable architecture. Marlborough, UK: The Crowood Press Ltd.

Clements-Croome, D. J., Aguilar, A. M., \& Taub, M. (2015, May). Putting people first: Designing for health and wellbeing in the built environment. Briefing Paper, British Council for Offices.

Clements-Croome, D. J., Turner, B., \& Pallaris, K. (2019). Flourishing workplaces: A multi-sensory approach to design and POE. Intelligent Buildings International Journal, 11(3-4), 131-144. https://doi.org/10.1080/ 17508975.2019.1569491

Cooper, C., \& Browning, W. (2015). The global impact of biophilic design in the workplace. Human Spaces. Retrieved from https://greenplantsforgreenbuildings.org/wp-content/uploads/2015/08/Human-SpacesReport-Biophilic-Global_Impact_Biophilic_Design.pdf

De Dear, R. (2011). Revisiting an old hypothesis of human perception: Alliesthesia. Building Research and Information, 39(2), 108-117. https://doi.org/10.1080/09613218.2011.552269

Diener, E., \& Biswas-Diener, R. (2008). Happiness: Unlocking the mysteries of psychological wealth. Hoboken, NJ: Wiley-Blackwell. https://doi.org/10.1002/9781444305159

Dolan, P. (2014). Happiness by design: Change what you do, not how you think. New York: Avery Pub Group.

Erwine, B. (2017). Creating sensory spaces: The architecture of the invisible. London: Routledge.

Fanger, P. O. (1970). Thermal comfort: Analysis and applications in environmental engineering. Copenhagen: Danish Technical Press.

Fanger, P. O. (2002). Human requirements in future air-conditioned environments. In M. Anson, J. M. Ko, \& E. S. S. Lam (Eds.), Advances in building technology, 1, (pp. 29-38). Elsevier.

Fogg, B. (2009). A behavior model for persuasive design. In Persuasive 2009; Proceedings of the 4th international conference on persuasive technology, Article No. 40 (pp. 1-7). Claremont, CA. https://doi. org/10.1145/1541948.1541999 
Fredrickson, B. L. (2001). The role of positive emotions in positive psychology: The broaden-and-build theory of positive emotions. American Psychologist, 56(3), 218-226. https://doi.org/10.1037/0003-066X. 56.3.218

Gillis, K., \& Gatersleben, B. (2015). A review of psychological literature on the health and wellbeing benefits of biophilic design. Buildings, 5(3), 948-963. https://doi.org/10.3390/building5030948

Haverkamp, M. (2012). Synesthetic design: Handbook for a multi-sensory approach. Berlin, Basel: Birkhäuser.

Hawkins, L. (2016, August 30). The evolution of pioneering workspace, second home. AnOther. Retrieved from www.anothermag.com/design-living/9004/the-evolution-of-pioneering-workspace-second-home

Henshaw, V. (2013). Urban smellscapes understanding and designing city smell environments. New York: Routledge. https://doi.org/10.4324/9780203072776

Huda, C. N., \& Hadiana, A. (2020). Kansei analysis using analytical hierarchy process. In Proceedings of the international conference on business, economic, social science, and humanities - Economics, business and management track (ICOBEST-EBM 2019) (pp. 218-223). Paris, France: Atlantis Press. https://doi.org/10.2991/ aebmr.k.200108.050

Huppert, F. A., \& So, T. T. (2013). Flourishing across Europe: Application of a new conceptual framework for defining well-being. Social Indicators Research, 110(3), 837-861. https://doi.org/10.1007/ s11205-011-9966-7

Kano, N., Seraku, N., Takahashi, F., \& Tsuji, S. (1984). Attractive quality and must-be quality. Journal of the Japanese Society for Quality Control, 14(2), 39-48.

Kim, J., \& de Dear, R. (2012). Nonlinear relationships between individual IEQ factors and overall workspace satisfaction. Building and Environment, 49(1), 33-40. https://doi.org/10.1016/j.buildenv.2011.09.022

Malnar, J. M., \& Vodvarka, F. (2004). Sensory design. Minnesota: University of Minnesota Press.

Maslow, A. H. (1943). A theory of human motivation. Psychology Review, 50(4), 370-396. https://doi. org $/ 10.1037 / \mathrm{h} 0054346$

Maslow, A. H. (1964). Religions, values, and peak-experiences. Columbus, OH: Ohio State University Press.

Ong, B. L. (2013). Beyond environmental comfort. London: Routledge.

Seligman, M. E. P. (2011). Flourish: A visionary new understanding of happiness and well-being. New York: Free Press.

Shrubsole, C., Das, P., Milner, J., Hamilton, G., Spadaro, J. V., Oikonomou, E., \& Wilkinson, P. (2015). A tale of two cities: Comparative impacts of $\mathrm{CO} 2$ reduction strategies on dwellings in London and Milton Keynes. Atmospheric Environment, 120, 100-108. https://doi.org/10.1016/j.atmosenv.2015.08.074

Takenoya, H. (2006). Air conditioning systems of the K I Building, Tokyo. In D. J. Clements-Croome (Eds.), Creating the productive workplace (2nd ed., pp. 334-347). London and New York: Taylor and Francis.

UKGBC. (2016, July). Health and wellbeing in homes. UK Green Building Council, London. Retrieved from www.ukgbc.org/wp-content/uploads/2017/12/Healthy-Homes-Full-Report.pdf

Wargocki, P., Seppänen, O., Andersson, J., Boerstra, A., Clements-Croome, D., Fitzner, K., \& Hanssen, S. O. (2006). Indoor climate and productivity in offices: How to integrate productivity in life-cycle cost analysis of building services. REHVA Guidebook No. 6. Finland: REHVA.

Wargocki, P., \& Wyon, P. (2007). The effects of moderately raised classroom temperatures and classroom ventilation rate on the performance of schoolwork by children (RP-1257). HVAC\&R Research, 13(2), 193-220. https://doi.org/10.1080/10789669.2007.10390951

WGBC. (2014, September 24). Health, wellbeing and productivity in offices: The next chapter for green building. Health, Wellbeing and Productivity in Retail: The Impact of Green Buildings on People and Profit. Retrieved from www.worldgbc.org/sites/default/files/compressed_WorldGBC_Health_Wellbeing_ Productivity_Full_Report_Dbl_Med_Res_Feb_2015.pdf

WGBC. (2016). Health, wellbeing and productivity in retail: The impact of green buildings on people and profit. World Green Building Council and UK Green Building Council. Retrieved from www.worldgbc.org/ sites/default/files/FinalReport-Jan2016New.pdf

Wilson, F. (1984). A graphic survey of perception and behaviour for the design professions. New York: Van Nostrand Reinhold.

Zhang, Y., \& Barrett, P. S. (2012). Teachers view on the design of their primary schools. Facilities, 28(13/14), 641-656. 


\title{
15 \\ BIOPHILIA HYPOTHESIS \\ The benefits of nature in the workplace
}

\author{
Sven Wolf Ostner*
}

\section{Background}

The term biophilia stems from Greek and translates as 'love of nature'. It was initially used by social psychologist Erich Fromm (1973, p. 366) to depict "the passionate love of life and of all that is alive". The definition has changed since then. At first biologist Edward O. Wilson (1984, p. 1) described in his book Biophilia the concept as "the innately emotional affiliation of human beings to other living organisms" and "the innate tendency to focus on life and life-like processes". Some authors redefined the hypothesis later on. Kellert and Wilson (1993, p. 42) saw it as "the innate need to relate deeply and intimately with the vast spectrum of life about us".

Biophilia and its interpretation is still in the process of development. It is therefore referred to as a hypothesis rather than a theory. As Joye and De Block (2011) rightly point out, some aspects of the interpretation of biophilia are problematic. Biophilia is embedded and overlaps with other fields of research. It is therefore difficult to define limitations to it. The limitation to "life and life-like processes" is in the light of many findings certainly inconclusive because of the positive effects of natural materials, water, scent etc. which are not alive.

We have therefore seen that the definition of biophilia has changed over time. Heerwagen (2008, p. 227) defined biophilia as the "human need to connect with nature". This is a much sounder approach but also less specific. That can lead sometimes to a very broad interpretation of its meaning. Some authors see, for instance, a connection to sustainability and conservation of nature or even an ethical dimension (Benyus, 2008; Joye \& De Block, 2011 Krcmárová, 2009). There is an obvious risk that biophilia loses its specific meaning if applied too widely. Certainly, the ethical interpretation is questionable. It is important to remain detached from judgments of value and morality in order not to get into naturalistic fallacy (Roberts \& Van Vugt, 2012). In other words, nature is not positive or negative in absolutes. Nature just has settings that are positive relative to non-natural environments, as we will see. From an evolutionary perspective the 'normal' natural environment is just the better neural fit. Humans are a part of nature and therefore susceptible to it. A natural environment is our default situation.

The human body is in all its aspects biologically encoded and therefore suited to live in a certain range of natural habitats. "Nature is not merely 'nice'. It is not just a matter of improving one's mood, rather it is a vital ingredient in healthy human functioning" (Kaplan, 1992, p. 141). This is true despite the fact that humans can adapt to new circumstances. The quantity

*Corresponding author: sven.ostner@awlark.se 
and quality of changes in the last 10,000 years are just too numerous for a sufficient adaption in a short time, in evolutionary terms (Buss, 2008). It is within this context not too far-fetched to assume that even the human brain is formed for a more natural context. It is therefore not surprising that biophilia provides a better mental fit to our predisposition than do environments without biophilia. The system of the human being as a whole has a predisposition for natural conditions. The underlying principles are beyond personal characteristics and cultural differences. They touch on the very nature of humankind. There is a coherence between environmental settings in nature and positive reactions of humans.

Biophilia can therefore be regarded as embedded in evolutionary psychology (see also Chapter 17 Evolutionary Psychology Theory). Both views share the assumption that evolutionary processes have shaped the human body and the brain and therefore even the psychological mechanisms and the behaviour associated with it. However, biophilia does not advocate biological determinism. The metaphor that compares the brain with a computer is too simplistic for a system of organic complexity (Epstein, 2016).

Biophilia is today influential in many fields, for instance in developmental psychology (Kahn, 1997), preventive medicine (Frumkin, 2001) and architectural theory (Hildebrand, 2008). The value of nature to humans is most obvious if there is a lack of it, like in urban settlements. Biophilia is a tool to dampen the neurological effects of nature deprivation and to calibrate our contact to nature. That it is necessary and valuable is undisputed and demonstrated by a large body of research.

\section{Applicability to workplace studies}

The extensive observation and testing of all kinds of human reactions to natural elements has led to recommendations on how to implement the findings to workplace design. Biophilic design is based on the understanding that the spatial conditions have a highly relevant influence on our mental state and that nature is important to human well-being, as we will see. Space can be described as a cluster of symbolic and sensual codes. The contextual sum of this 'neuronal landscape' has a profound, but mostly unconscious, influence on us. Kühn et al. (2017, p. 1) point out, "research on brain plasticity supports the notion that our environment can shape brain structures as well as function." It is therefore important to design the workplace environment in the best possible way for people's well-being and business objectives.

But, "current workplaces are designed to focus on efficiency rather than psychological welfare" (Fitzgerald \& Danner, 2012, p. 772). The mismatch between the human preconditioning and the novelty of our modern environment can be sometimes problematic. This clash of environmental settings, even referred to as the mismatch hypothesis (Cofnas, 2016; Lloyd, Sloan Wilson, \& Sober, 2011), has countless consequences for our modern lives (Gluckman, Hanson, \& Low, 2019), not least for the workplace (Norman, Van Vugt, \& Colarelli, 2017). But the paradox offers even a great potential for architectural design, if we introduce elements of biophilia which are beneficial to us. That means, in consequence, that we need to enrich our built environment with conditions that meet our inherited spatial preferences. Biophilia can be a guideline to evaluate and enhance the settings of a workplace against our original natural habitat.

Browning, Ryan and Clancy (2014) describe biophilic settings in 14 different patterns (see Table 15.1)

The implementation of these biophilic patterns can be structured into three parts (Browning et al., 2014):

1 Incorporation of nature: Hereby 'real' nature is introduced into the office space with the help of natural components like water, sunlight, plants, animals and natural materials (see 
Figure 15.1; applied principles: visual connection with nature, non-visual connection with nature, non-rhythmic sensory stimuli, biomorphic forms and patterns, material connection to nature, complexity and order, mystery).

2 Mimicking of nature: The next approach is to use analogues and simulations of nature represented in pattern, form, pictures, colour, light and scent (see Figure 15.2; applied principles: non-rhythmic sensory stimuli, biomorphic patterns, complexity and order).

3 Use of natural principles: A third way is to design the space itself with abstract references to nature and to use architectural composition and organisation, information richness and variability in order to facilitate biophilic effects (see Figure 15.3; applied principles: mystery, refuge, prospect, material, non-visual connection).

Table 15.1 Biophilic features

\begin{tabular}{ll}
\hline Biophilic features & Examples \\
\hline $\begin{array}{l}\text { Visual connection with nature } \\
\text { Non-visual connection with nature } \\
\text { Non-rhythmic sensory stimuli }\end{array}$ & $\begin{array}{l}\text { windows with a view to nature, in-house plants } \\
\text { scent, sound, touch } \\
\text { natural pattern, plants, elements interacting with nature (e.g. } \\
\text { wind and sun) } \\
\text { openable windows, variation of indoor climate, access to the } \\
\text { outside (balconies etc.) }\end{array}$ \\
Presence of water & outdoors or indoors (aquarium, fountains, water walls, etc.) \\
daylight, human-centric lighting, flexible control, variation of & light settings \\
Dynamic and diffused light & water cycle, access to green areas and gardens, experience of \\
Connection to natural systems & seasons \\
organic shapes, natural colours, fractals & wooden surface, stone, leather, wool, etc. \\
Biomorphic forms and patterns & spatial composition and layout, workstation design, pattern on \\
Material connection to nature & floors and walls, colour scheme \\
Complexity and order & views, elevated planes \\
protection from behind (e.g. furniture) bay windows, arcades, & elevated planes, canopies \\
Prospect & winding paths, partly concealed views \\
Refuge & heights, passing under a dominant object, slide or ramp \\
Mystery &
\end{tabular}

Source: (Browning et al., 2014)

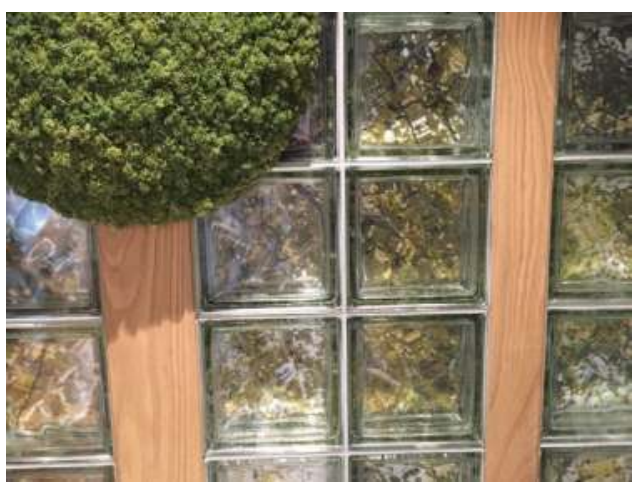

Figure 15.1 WC-wall at House of Innovation, Stockholm School of Economics, Stockholm 


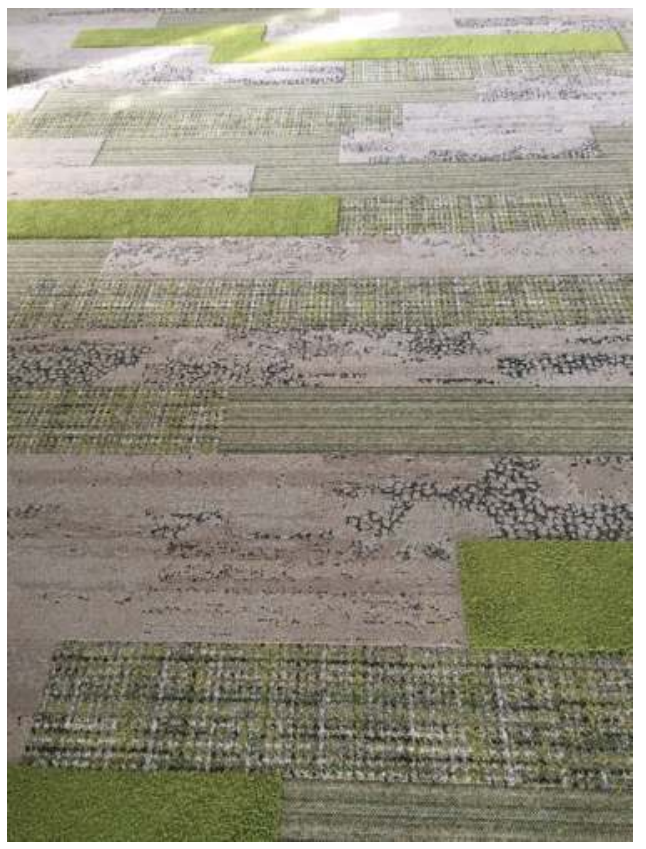

Figure 15.2 Floor at Lufthansa's local HQ in Stockholm

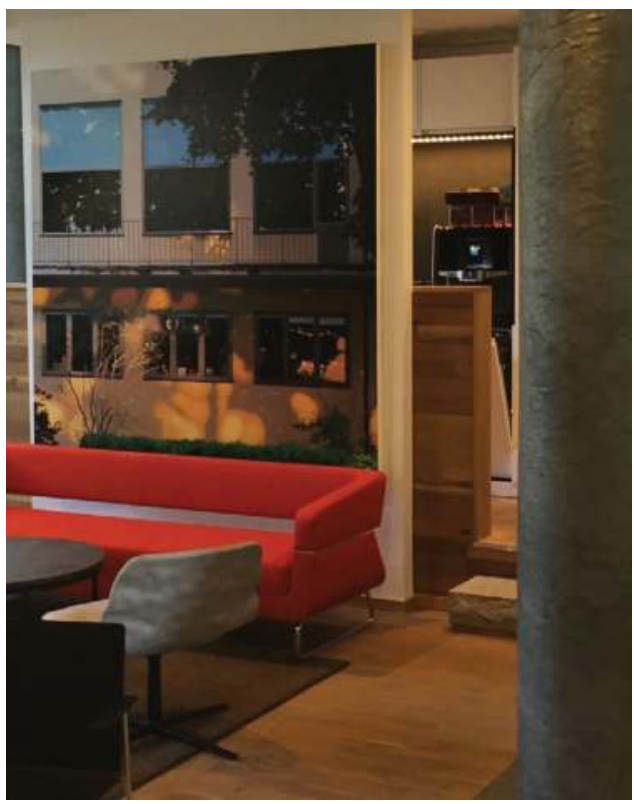

Figure 15.3 Lounge and kitchenette at Stockholm School of Economics, Stockholm 
The approach of biophilic design enables us to create space which causes less strain to the brain. The observed results range from reduced stress and increased well-being to better health and higher job satisfaction (Martyn \& Brymer, 2014). As Ulrich puts it:

for stressed individuals, restorative influences of viewing nature involve, among other responses, a broad shift in feelings towards a more positively-toned feeling state, positive changes in activity levels in different physiological systems, and that these changes are accompanied by moderately high levels of sustained attention.

(Ulrich, 1997, p. 8)

The described and highly desirable mental state results even in a significantly higher level of productivity. Table 15.2 summarises some findings regarding the possible increase of productivity related to biophilic design. It is noteworthy that aspects like general acoustics, air quality, artificial light settings, thermal comfort, social context and colour all can influence productivity, but they are generally not regarded as part of a biophilic design approach and therefore not included in the table.

\section{Methodology/research approach}

Productivity in a workplace, as shown in Table 15.2, can be measured indirectly by the number of repetitive activities in a workplace within a certain time. It is also possible to record absentee rates, hours worked, safety rule violations, number of sick days, staff retention, employee turnover, job performance (mental stress/fatigue) and learning rates. The results related to workplace design show a very positive and highly relevant role for biophilia regarding all measures

Table 15.2 Productivity gains with biophilic workplace design

\begin{tabular}{|c|c|c|}
\hline Effect on productivity & Biophilic design strategy & Source \\
\hline$+6 \%$ to $12 \%$ & Indoor plants & $\begin{array}{l}\text { Lohr, Pearson-Mims, and } \\
\text { Goodwin (1996) }\end{array}$ \\
\hline$+15 \%$ & Daylight & Romm \& Browning (1998) \\
\hline$+13.2 \%$ & Daylight & Romm \& Browning (1998) \\
\hline$+15 \%$ to $23 \%$ & Daylight & Heschong Mahone Group (1999) \\
\hline Increase & Leafy indoor plants & Shibata \& Suzuki (2002) \\
\hline$+7 \%$ to $13 \%$ & Daylight and window views & Heschong Mahone Group (2003) \\
\hline Increase & $\begin{array}{l}\text { Right number of indoor } \\
\text { plants in view }\end{array}$ & $\begin{array}{l}\text { Bringslimark, Hartig, and Grindal } \\
\quad \text { Patil (2007) }\end{array}$ \\
\hline$+5 \%$ & Natural daylight & Painter \& Goodman (2007) \\
\hline $\begin{array}{l}\text { Improved cognitive } \\
\text { performance }\end{array}$ & Pictures of nature & $\begin{array}{l}\text { Berman, Jonides, and Kaplan } \\
\text { (2009) }\end{array}$ \\
\hline$+10 \%$ to $14 \%$ & Presence of plants & Daly, Burchett, and Torpy (2010) \\
\hline Increase & Wooden surface & Fraser (2011) \\
\hline Increase & Pleasant sounds from nature & Fitzgerald \& Danner (2012) \\
\hline$+20 \%$ to $26 \%$ & Daylight & Terrapin Bright Green (2012) \\
\hline$+38 \%$ & Office plants & Knight (2013) \\
\hline$+15 \%$ & Enriched office with plants & $\begin{array}{l}\text { Nieuwenhuis, Knight, Postmes, \& } \\
\text { Haslam (2014) }\end{array}$ \\
\hline$+6 \%$ & $\begin{array}{l}\text { View of the outdoor } \\
\text { environment }\end{array}$ & Cooper (2017) \\
\hline
\end{tabular}


(Romm \& Browning, 1998, Thomson \& Bruk-Lee, 2019). But in order to understand the reason why biophilia is so beneficial for office design, it is necessary to have a broader approach. Besides the indirect method to measure productivity, it is possible to research more direct physical reactions of participants.

Evidence for the viability of the biophilia hypothesis can be obtained in various ways. Besides employee surveys recording work satisfaction, employee comfort and mental well-being, there are controlled laboratory studies with focus on attention, vigilance, memory, creativity and comprehension or motivation. Participants are hereby exposed to elements of biophilic character, like plants, images or pets, and it is observed if there is a significant change in behaviour. There are also field experiments not only with questionnaires but also with physiological tests like blood samples, measures of the electrical activity of the heart with electrocardiography (EKG) and electroencephalography (EEG), heart rate variability (HRV), and heart rate or near-infrared spectroscopy (NIRS). There are furthermore surveys with neuroimaging with functional magnetic resonance imaging (fMRI). The latter shows that "different landscapes affected regional brain activity differently" (Jo, Song, \& Miyazaki, 2019, p. 13), not only regarding urban and natural settings but even between various types of landscapes. Observed brain activity with this method is "indicating that a nature-oriented lifestyle is inherently preferred" (Jo et al., 2019, p. 13).

Most prominent are the significant health benefits systematically observed in hospitals (Ulrich, 1984). A variety of physical effects tend to be noted when patients were exposed to nature settings, in comparison to urban settings with a lack of nature: substantial decline in skin conductance response (SCR) and decline in muscle tension (measured using electromyography EMG) (Ulrich, 2008). These results are associated with lower stress levels and therefore conditions beneficial to health and regeneration. Patients with window views to nature and sunlight recovered much quicker, had lower pulse and blood pressure and needed even less medication (Malenbaum, Keefe, Williams, Ulrich, \& Somers, 2007, Ulrich, 2008). In other words, the environment had mental and even physical effects on humans.

Another well-documented field of biophilic research is Shinrin-yoku, so-called forest bathing. Research shows that spending time in a forest can decrease blood glucose in diabetic patients by almost $40 \%$ in comparison to only $21 \%$ when walking indoors (Ohtsuka, Yabunaka, \& Takayama, 1997). Even hormonal secretion and autonomic nervous function are stabilised (Morita et al., 2007), which can be related to a lower risk for stress-related disease.

It can be concluded that biophilia has indeed positive effects on humans. Effects besides the one mentioned earlier are lower concentration of cortisol, associated with a lower stress level; greater parasympathetic nerve activity, linked to relaxation; and lower sympathetic nerve activity, indicating decreased stress. Contact with nature is even beneficial for mental health because of improved mood; reduced psychological tension, depression, anger, fatigue and confusion; and moreover enhanced psychological robustness and energy (Park, Tsunnetsugu, Kasetani, Kagawa, \& Miyazaki, 2009). Most relevant to work performance is the fact that biophilic design is associated with less stress, increased concentration, lower anxiety and an increase of prosocial behaviours (Fitzgerald \& Danner, 2012).

However, it should be noted that the results for indoor plants are not always conclusive regarding the support of productivity (Shibata \& Suzuki, 2002). The number and density of plants are relevant, as well as the size and even the shape, when measuring effects. Plants with rounded leaves are perceived as mentally more beneficial than leaves with sharp and narrow shape (Augustin, 2009). This is coherent with findings regarding the reactions to abstract art with sharp forms compared with the attitude towards art depicting natural motives: sharp and abstract shapes are perceived as negative (Ulrich, 2008). But even natural motives can have an ambivalent effect. In general, pictures of nature do have a positive effect on humans, but pictures 
of a spatially enclosed and shadowy forest setting have no effect (Ulrich, 2008). There are furthermore proven mental benefits from the company of dogs, but the opposite is true for snakes (Joye \& De Block, 2011). There is not just biophilia but also biophobia (Hinds \& Sparks, 2011; Ulrich, 2008; Olivos-Jara, Segura-Fernández, Rubio-Pérez, \& Felipe-Gracia, 2020). That does explain why views of landscapes with traces of human intervention are rated higher than pure nature (Augustin, 2009). Elements of human presence in nature can refer to a social aspect and imply a sense of comfort and control (Joye \& De Block, 2011).

The effects of biophilia are mostly measured directly as previously shown. But it is also valuable to notice that a variety of indirect, more circumstantial facts strengthen the hypothesis. The degree of human adaption to nature is also reflected in other fields of research. Examples are that our metabolism and mental health are dependent on a certain degree of movement (Hansen, 2016), our microbiome is not suited for all modern food (Gundry, 2017; Price, 1939), we need exposure to sunlight in order to generate sufficient vitamin D (Spitz, 2018; Ulrich, 2008), and we are affected by a circadian rhythm (Zivkovic, 2012). One example, which is mainly overlooked, makes this point very clear, as Berg, Mahnert and Moissl-Eichinger (2014, p. 2) explain: "Plants provide beneficial bacteria for indoor rooms and therefore can positively influence human health." Enclosed environments like offices have a reduced microbial diversity compared to the outdoor environment. "A reduction in microbial diversity is well known to facilitate dominant proliferations of certain strains, which might bear the risk to have a negative effect towards our health."

These findings are only a few examples, but they show that very different fields of research like medicine, cognitive neuroscience, behavioural genetics, evolutionary biology, environmental science, biological anthropology and biochemistry are involved. They all contribute to a better understanding of the complex system that human beings are and show that biophilia is indeed only a part of a bigger picture, rather than a detached theoretical model. In any case, further research required. Partly because it is still unclear if, and in this case, to what extent the human body, including the brain, can adapt to novel environments. The current evidence of a civilisatory mismatch is indisputable, but anthropology tells us that the human body, at least in the Western world, has changed significantly within the very short time of the last 150 years because of novel food patterns (Vonderach, 2015). It can therefore not be ruled out that even the brain has changed during a shorter course of time than earlier anticipated, not only because of the well-established evolutionary mechanisms but also due to rapid epigenetically changes we do not yet fully understand (Kegel, 2009).

\section{Limitations}

Researching biophilia is complex and only understandable within a larger context. However, that context sometimes adds even further questions. First, there is a general uncertainty regarding all kinds of research observing preferences and behaviour. Preferences can vary depending on mood, age, culture, health, personality and experience. (Ulrich, 1993 p. 94; see also Chapter 10 Temperament Theory). Some findings, therefore, do sometimes have a lightly episodical character because of unclear contextual influences. For instance, "To the degree that workplace plants are psychologically beneficial because they promote restoration, they will be less potent if the workers in question generally have modest restoration needs" (Bringslimark et al., 2007, p. 5).

Kuo $(2015$, p. 6) points out that there are "a multiplicity of mechanisms by which contact with nature might promote health", for example chemical and biological agents, negative air ions, microorganism, sights, sounds, moderate temperature and the absence of air pollution as well as physical activity, just to name a few. The choice of test environments or the kind of 
visual images used also have a profound influence on the results. Associated with this problem is the indifferent use of the description 'urban setting', which can indeed be used for very diverse environments (Kuo, 2015; Sandal, Thorlund, Ulrich, Dieppe, \& Roos, 2015). The human brain functions only contextually and it is therefore extremely difficult to identify scientific proof from the observation of isolated aspects. Even the findings on productivity gains are not entirely conclusive, partly because of the vague definition of productivity (Sullivan, Baird, \& Donn, 2013) and partly because of the wide range of results for the same aspect. "Clearly, there may be other factors which are playing a role, and these are not fully understood" (Bell, Mabb, Garcia-Hansen, Bergman, \& Morawska, 2003, p. 2).

The fact that observed outcomes can have multiple causes does not render the results of the research invalid. But it is beneficial to take into account a wider spectrum of related findings in order to understand how and why biophilia works. It requires an evaluation on a meta-level. It is therefore desirable to develop the hypothesis into a sound theory in conjunction with other fields of research concerning evolutionary conditioning. In this way could the large amount of significant evidence be better evaluated, and self-referencing avoided.

\section{Theory relevance to practice}

Nature has been shown to contribute to recovery from mental fatigue resulting from sustained directed attention.

"Mentally fatigued individuals suffer from (a) a lowered ability to concentrate, think clearly, and solve problems; (b) heightened irritability and a disinclination to be helpful or even civil; (c) an inability to get along in the world; and (d) a tendency to be accident-prone. Lowering levels of mental fatigue by exposing oneself to nature would thus be expected to reduce levels of frustration and anger."

(Kweon, Ulrich, \& Tassinary, 2008, p. 360)

Too much stress is not only a health risk, but it also reduces productivity and creativity. It hinders social interaction and communication. Health and well-being have therefore a role to play regarding engagement and innovation. The promotion of well-being with the help of biophilia makes it easier to accomplish common business objectives as required for office work. Berman et al. $(2009$, p. 6) state, "To consider the availability of nature as merely an amenity fails to recognize the vital importance of nature in effective cognitive functioning."

Biophilia can be a potent strategy for human capital management. A biophilic human-centric workplace can increase job satisfaction and is therefore useful for attracting new and retaining existing employees (Thomson \& Bruk-Lee, 2019; Walden, 2008). That in itself can represent a cost savings. Considering the share of salary payments on the overall budget of a company of about $80 \%$ (Walden, 2008), it becomes clear that a significant increase in productivity and efficiency, as demonstrated with biophilic concepts, are a very cost-efficient way to create monetary value that can be expressed in revenue, billable hours, net income or market share gained. "Disregarding human's inclination towards nature is simultaneously denying potential for positive financial growth" (Terrapin Bright Green, 2012, p. 9). A biophilic office should therefore be part of a company's business strategy. If optimised for its use with biophilic insights, office space can be regarded a business asset rather than a cost. Biophilia deserves to be considered as a valuable method to increase the employee's well-being and business performance. It should even go hand in hand with business consulting. In contrast to intellectually framed business theories applied in order to improve a company's operations, biophilic design is based on unconscious 
affinity. It is therefore a much stronger stimulus, and its effects do not rely on explanations in order to show positive effects.

We need to calibrate our view and consider nature as the 'old normal'. We describe biophilia as positive because we regard our urban environment as the default condition. It might be that the opposite is true.

\section{Further reading}

- Browning, W., Ryan, C., \& Clancy, J. (2014). 14 patterns of biophilic design. Terrapin Bright Green. Retrieved from www.terrapinbrightgreen.com/reports/14-patterns/

- Kaplan, R., \& Kaplan, S. (1989). The experience of nature: A psychological perspective. Cambridge: Cambridge University Press.

- Kellert, S. R., Heerwagen, J. H., \& Mador, M. L. (2008). Biophilic design: The theory, science, and practice of bringing buildings to life. Hoboken, NJ: John Wiley \& Sons.

- $\quad$ Kellert, S. R., \& Wilson, E. O. (1993). The biophilia hypothesis. Washington, DC: Island Press.

- Terrapin Bright Green LLC. (2012). The economics of biophilia. Retrieved from www.terrapin brightgreen.com/report/economics-of-biophilia/

\section{References}

Augustin, S. (2009). Place advantage: Applied psychology for interior architecture. Hoboken, NJ: John Willey \& Sons.

Bell, J., Mabb, J., Garcia-Hansen, V., Bergman, B., \& Morawska, L. (2003). Occupant health and productivity: An Australian perspective. In CIB 2003 international conference on smart and sustainable built environment (SASBE). Brisbane. Retrieved from www.semanticscholar.org/paper/Occupanthealth-and-productivity-\%3A-an-Australian-Bell-Bergman/7f06ce094c69997c4c11130159e4ecdd $94 \mathrm{f} 72994$

Benyus, J. (2008). A good place to settle: Biomimicry, biophilia, and the return of nature's inspiration to architecture. In S. R. Kellert, J. H. Heerwagen, \& M. L. Mador (Eds.), Biophilic design: The theory, science, and practice of bringing buildings to life (pp. 38-40). Hoboken, NJ: John Wiley \& Sons.

Berg, G., Mahnert, A., \& Moissl-Eichinger, C. (2014). Beneficial effects of plant-associated microbes on indoor microbiomes and human health? Frontiers in Microbiology, 5(15), 1-5. https://doi.org/10.3389/ fmicb.2014.00015

Berman, M. G., Jonides, J., \& Kaplan, S. (2009). The cognitive benefits of interacting with nature. Psychological Science, 19(12), 1207-1212. https://doi.org/10.1111\%2Fj.1467-9280.2008.02225.x

Bringslimark, T., Hartig, T., \& Grindal Patil, G. (2007). Psychological benefits of indoor plants in workplaces: Putting experimental results into context. Hort Science, 42(3), 581-587. https://doi. org/10.21273/HORTSCI.42.3.581

Browning, W. D., Ryan, C. O., \& Clancy, J. O. (2014). 14 patterns of biophilic design. Terrapin Bright Green LLC. Retrieved from www.terrapinbrightgreen.com/reports/14-patterns/

Buss, D. M. (2008). Evolutionary psychology. London: Routledge.

Cofnas, N. (2016). A teleofunctional account of evolutionary mismatch. Cambridge: Department of History and Philosophy of Science, University of Cambridge, Springerlink.com. https://doi.org/10.1007/ s10539-016-9527-1

Cooper, G. (2017). Human space report: Biophilic design in the workplace. Retrieved from www.p-plus.nl/ resources/articlefiles/Human-Spaces-report-web-res-3.pdf.pdf

Daly, J., Burchett, M., \& Torpy, F. (2010). Plants in the classroom can improve student performance. Centre for Environmental Sustainability, Faculty of Science, University of Technology, Sydney (UTS). Retrieved from www.wolvertonenvironmental.com/Plants-Classroom.pdf

Epstein, R. (2016). The empty brain. Aeon. Retrieved from https://aeon.co/essays/your-brain-doesnot-process-information-and-it-is-not-a-computer

Fitzgerald, C., \& Danner, K. (2012). Evolution in the office: How evolutionary psychology can increase employee health, happiness, and productivity. Evolutionary Psychology, 10(5), 770-778. https://doi.org/ 10.1177\%2F147470491201000502 
Fraser, S. (2011). Health benefits of wood, plants and nature in the human environment: An analysis of the past 15 years of research and its application potential. FRST 497. Retrieved from https://open.library.ubc.ca/ cIRcle/collections/undergraduateresearch/52966/items/1.0075512

Fromm, E. (1973). The anatomy of human destructiveness. New York: Holt, Rinehart and Winston.

Frumkin, H. (2001). Beyond toxicity: Human health and the natural environment. American Journal of Preventive Medicine, 20(3), 234-240. https://doi.org/10.1016/S0749-3797(00)00317-2

Gluckman, P. D., Hanson, M. A., \& Low, F. M. (2019). Evolutionary and developmental mismatches are consequences of adaptive developmental plasticity in humans and have implications for later disease risk. Philosophical Transactions B, 374(1770), 20180109. https://doi.org/10.1098/rstb.2018.0109

Gundry, S. R. (2017). The plant paradox. New York: Harper Collins.

Hansen, A. (2016). Hjärnstark. Stockholm, Sweden: Fitnessförlaget.

Heerwagen, J. H. (2008). Biophilia and sensory aesthetic. In S. R. Kellert, J. H. Heerwagen, \& M. L. Mador (Eds.), Biophilic design: The theory, science, and practice of bringing buildings to life. Hoboken, NJ: John Wiley \& Sons.

Heschong, L. (1999). Daylighting in Schools: An investigation into the relationship between daylight and human performance. Heschong, L. Mahone Group. https://doi.org/10.13140/R G.2.2.31498.31683

Heschong, L. (2003). Windows and offices: A study of workers performance and the indoor environment. Heschong L. Mahone Group. Retrieved from http://h-m-g.com/downloads/Daylighting/A-9_Windows_Offices_ 2.6.10.pdf

Hildebrand, G. (2008). Biophilic architectural space. In S. R. Kellert, J. H. Heerwagen, \& M. L. Mador (Eds.), Biophilic design: The theory, science, and practice of bringing buildings to life (pp. 263-275). Hoboken, NJ: John Wiley \& Sons.

Hinds, J., \& Sparks, P. (2011). The affective quality of human-natural environment relationships. Evolutionary Psychology, 9(3), 451-469. https://doi.org/10.1177\%2F147470491100900314

Jo, H., Song, C., \& Miyazaki, Y. (2019). Physiological benefits of viewing nature: A systematic review of indoor experiments. International Journal of Environmental Research and Public Health, 16(23), 4739. https://doi.org/10.3390\%2Fijerph16234739

Joye, Y., \& De Block, A. (2011). Nature and I are two: A critical examination of the biophilia hypothesis. Environmental Values, 20(2), 189-215. ISM University of Management of and Economics, KU Leuven. https://doi.org/10.3197/096327111X12997574391724

Kahn, P. H. (1997). Developmental psychology and the biophilia hypothesis: Children's affiliation with nature. Developmental Review, 17, 1-61. https://doi.org/10.1006/drev.1996.0430

Kaplan, S. (1992). The restorative environment: Nature and human experience: The role of horticulture in human wellbeing and social development. Timber Press. Retrieved from https://deepblue.lib.umich.edu/bitstream/ handle/2027.42/150712/1992_Kaplan_The_restorative_environment.pdf?sequence =1\&isAllowed=y

Kegel, B. (2009). Epigenetik (p. 313). Köln, Germany: DuMont Buchverlag.

Kellert, S. R., \& Wilson, E. O. (1993). The biophilia hypothesis. Washington, DC: Island Press. https://doi. org/10.1177\%2F027046769501500125

Knight, C. (2013). Office plants boost well-being at work. University of Exeter's Psychology Department. Retrieved from https://phys.org/news/2013-07-office-boost-well-being.html

Krcmárová, J. (2009). E. O. Wilson's concept of biophilia and the environmental movement in the USA. Klaudyán: Internet Journal of Historical Geography and Environmental History, 6(1-2), 4-17.

Kühn, S., Düzel, S., Eibich, P., Krekel, C., Wüstemann, H., Kolbe, J., . . . \& Lindenberger, U. (2017). In search of features that constitute an "enriched environment" in humans: Associations between geographical properties and brain structure. Scientific Reports, 7(1), 11920. https://doi.org/10.1038/ s41598-017-12046-7

Kuo, M. (2015). How might contact with nature promote human health? Promising mechanisms and a possible central pathway. Frontiers in Psychology, 6, 1093. https://doi.org/10.3389/fpsyg.2015.01093

Kweon, B.-S., Ulrich, R. S., \& Tassinary, L. G. (2008). Anger and stress: The role of landscape posters in an office setting. Environment and Behaviour, 40(3), 355-381. https://doi.org/10.1177/001391650 6298797

Lloyd, E., Sloan Wilson, D., \& Sober, E. (2011). Evolutionary mismatch and what to do about it: A basic tutorial. Evolutionary Applications. National Evolutionary Synthesis Center (NESCent). Retrieved from https://evolution-institute.org/wp-content/uploads/2015/08/Mismatch-Sept-24-2011.pdf

Lohr, V. I., Pearson-Mims, C. H., \& Goodwin, G. K. (1996). Interior plants may improve workers productivity and reduce stress in a windowless environment. Department of Horticulture and Landscape Architecture, Washington State University, Pullman, WA 99164-6414. https://doi.org/10.24266/0738-2898-14.2.97 
Malenbaum, S., Keefe, F. J., de C. Williams, A. C., Ulrich, R., \& Somers, T. J. (2007). Pain in its environmental context: Implications for designing environments to enhance pain control. Pain, 134(3), 241-244. https://doi.org/10.1016/j.pain.2007.12.002

Martyn, P., \& Brymer, E. (2014). The relationship between nature relatedness and anxiety. Journal of Health Psychology, 21(7), 1436-1445. https://doi.org/10.1177/1359105314555169

Morita, E., Fukuda, S., Nagano, J., Hamajima, N., Yamamoto, H., Iwai, Y., . . . \& Shirakawa, T. (2007). Psychological effects of forest environments on healthy adults: Shinrin-yoku (forest-air bathing, walking) as a possible method of stress reduction. Journal of the Royal Institute of Public Health, 121, 54-63. https://doi.org/10.1016/j.puhe.2006.05.024

Nieuwenhuis, M., Knight, C., Postmes, T., \& Haslam, S. A. (2014). The relative benefits of green versus lean office space: Three field experiments. Journal of Experimental Psychology: Applied, 20(3), 199. https://doi.org/10.1037/xap0000024

Norman, P. L., Van Vugt, M., \& Colarelli, S. M. (2017). The evolutionary mismatch hypothesis: Implications for psychological science. Current Directions in Psychological Science, 27(1), 38-44. https://doi. org/10.1177/0963721417731378

Ohtsuka, Y., Yabunaka, N., \& Takayama, S. (1997). Shinrin-yoku (forest-air bathing and walking) effectively decreases blood glucose levels in diabetic patients. International Journal of Biometeorology, 41, 125127. https://doi.org/10.1007/s004840050064

Olivos-Jara, P., Segura-Fernández, R., Rubio-Pérez, C., \& Felipe-Gracia, B. (2020). Biophilia and Biophobia as emotional attribution to nature in children of 5 years old. Frontiers in Psychology, 11, 511. https://doi.org/10.3389/fpsyg.2020.00511

Painter, S., \& Goodman, S. (2007). Office of the future, sustainable design and workplace productivity: A research review. AC Martin Partners. Retrieved from www.acmartin.com/sites/default/files/ACMResearchSustDesign-WorkplProd-L.pdf

Park, B.-J., Tsunnetsugu, Y., Kasetani, T., Kagawa, T., \& Miyazaki, Y. (2009). The physiological effects of Shinrin-yoku (taking in the forest atmosphere or forest bathing): Evidence from field experiments in 24 forests across Japan. Environmental Health and Preventive Medicine, 15(1), 18-26. https://doi.org/10.1007/ s12199-009-0086-9

Price, W. (1939). Nutrition and physical degeneration. La Mesa, CA: The Price-Pottenger Nutrition Foundation.

Roberts, C., \& van Vugt, M. (2012). Evolutionary psychology in the modern world: Applications, perspectives, and strategies. Evolutionary Psychology, 10(5), 762-769. https://doi.org/10.1177\%2F147470491201000501

Romm, J. J., \& Browning, W. D. (1998). Greening the building and the bottom Line: Increasing productivity through energy-efficient design. Rocky Mountain Institute. Retrieved from http://library.uniteddiversity. coop/Ecological_Building/Greening_the_Building_and_the_Bottom_Line.pdf

Sandal, L. F., Thorlund, J, B., Ulrich, R. S., Dieppe, P. A., \& Roos, E. M. (2015). Exploring the effect of space and place on response to exercise therapy for knee and hip pain: The CONEX trial. BMJ Open, 9. https://doi.org/10.1136/bmjopen-2015-007701

Shibata, S., \& Suzuki, N. (2002). Effects of the foliage plant on task performance and mood. Journal of Environmental Psychology, 22, 265-271. https://doi.org/10.1006/jevp.2002.0232

Spitz, J. (2018). Vitamin-D-Mangel. Vienna, Austria: Verlagshaus der Ärzte.

Sullivan, J., Baird, G., \& Donn, M. (2013). Measuring productivity in the office workplace. Centre for Building Performance Research, Victoria University of Wellington. Retrieved from www.scribd.com/ document/261452305/measuring-productivity-in-the-office-workplace-docx

Terrapin Bright Green LLC. (2012). The Economics of biophilia. Retrieved from www.terrapinbrightgreen. $\mathrm{com} / \mathrm{report} /$ economics-of-biophilia/

Thomson, A., \& Bruk-Lee, V. (2019). Naturally! Examining nature's role in workplace strain reduction. Occupational Health Science, 3(1), 23-43. https://doi.org/10.1007/s41542-019-00033-5

Ulrich, R. S. (1984). View through a window may influence recovery from surgery. Science, New Series, 224(4647), 420-421. https://doi.org/10.1126/science.6143402

Ulrich, R. S. (1993). Biophilia, biophobia, and natural landscapes (pp. 73-137). Island Press. Retrieved from www.researchgate.net/publication/284655696_Biophilia_biophobia_and_natural_landscapes

Ulrich, R. S. (1997). A theory of supportive design for healthcare facilities. Journal of Healthcare Design: Proceedings from the .. . Symposium on Healthcare Design, 9, 3-7.

Ulrich, R. S. (2008). Biophilic theory and research for healthcare design. In S. R. Kellert, J. H. Heerwagen, \& M. L. Mador (Eds.), Biophilic design: The theory, science, and practice of bringing buildings to life (pp. 87-106). Hoboken, NJ: John Wiley \& Sons.

Vonderach, A. (2015). Anthropologie Europas (pp. 183-187). Graz, Austria: Ares Verlag. 


\section{Sven Wolf Ostner}

Walden, R. (2008). Architekturpsychologie: Schule, Hochschule und Bürogebäude der Zukunft. Lengerich, Germany: Pabst Science Publishers.

Wilson, E. O. (1984). Biophilia. Cambridge, MA: Harvard University Press.

Zivkovic, B. (2012). Clocks, metabolism, evolution: Towards an integrative chronobiology. Scientific American. Retrieved from https://blogs.scientificamerican.com/a-blog-around-the-clock/clocks-metabolismevolution-toward-an-integrative-chronobiology/ 


\title{
16 \\ PLACE ATTACHMENT THEORY
}

\author{
Goksenin Inalhan, Eunhwa Yang, and Clara Weber*
}

\section{Background}

Place attachment has consistently been used to describe the phenomenon whereby people form emotional bonds to physical environments (e.g., Altman \& Low; 1992; Giuliani \& Feldman, 1993; Hidalgo \& Hernandez, 2001; Lewicka, 2005, 2010; Low \& Altman, 1992), despite the high variability of conceptualisations of place attachment across various disciplines of the social sciences (e.g., Lewicka, 2011b). Indicative of this variability is the range of labels that has been used to refer to the emotional bond between person and place, such as place attachment, rootedness, sense of place, and urban attachment (Hernández, Hidalgo, \& Ruiz, 2014). Due to the interdisciplinary nature of the subject, various epistemological and theoretical influences have been drawn on, leading to disagreement on how to define, conceptualise, and assess place attachment (e.g., Giuliani, 2003; Hernández et al., 2014; Lewicka, 2011a, 2011b; Patterson \& Williams, 2005; Scannell \& Gifford, 2010; Turton, 2016). For example, definitions of place attachment vary by the focus; either the focus is on the quality of the people-place bond (e.g., Altman \& Low, 1992; Low \& Altman, 1992), on the outcome associated with those bonds (e.g., state of psychological well-being, Giuliani \& Feldman, 1993; psychological and behavioural investment, e.g., Hummon, 1992), or on related constructs, such as place identity (e.g., Moore \& Graefe, 1994; Speller, 1996). As a result, no accepted overarching theoretical framework has been agreed on to date (Lewicka, 2011b; Turton, 2016).

Regardless of theoretical disagreements, the significance of the research on people-place bonds becomes apparent by its popularity in various social science disciplines and its application in numerous research contexts, such as 'social housing policy' (Manzo \& Perkins, 2006), neighbourhood design (Hester, 1984; Romice \& Uzzell, 2005), health and well-being (Bogdan, Rioux, \& Negovan, 2012; Wilson, DeJoy, Vandenberg, Richardson, \& Mcgrath, 2004), natural resource management (Kil, Holland, Stein, \& Ko, 2012; Lee \& Shen, 2013), tourism (Cui \& Ryan, 2011), regional planning (Kruger, 2008), and pro-environmental engagement (Devine-Wright, 2011; Jones, Orr, \& Eiser, 2011; Scannell \& Gifford, 2010; Turton, 2016, p. 20; Vaske \& Kobrin, 2001).

Several models of people-place relationships have been put forward, including the 'structural alternative model' (Gerson, Stueve, \& Fischer, 1977), the 'model of place dependence' (Stokols \& Shumaker, 1981), and the 'place identity model' (Proshansky, 1978). Based on limited empirical

*Corresponding author: weec@zhaw.ch 
tests, these models seek to provide a framework for how people develop ties to places. Based on a recent systematic review on the phenomenon's definitional ambiguity, place attachment has been presented as a multidimensional construct where affect is central to the relationship between people and place but which also incorporates cognitive and behavioural components (Turton, 2016). This view is relatively consistent with a recent theoretical advancement made by Scannell and Gifford (2010), who proposed the person-process-place (PPP) model, a tripartite framework of place attachment. The PPP framework attempts to organise the various conceptualisations of place attachment and identifies three distinct but interrelated dimensions: (1) the person dimension, (2) the psychological process dimension, and (3) the place dimension.

1 The person dimension differentiates between individual- and group-determined meanings of place.

2 The psychological process dimension differentiates between components that are involved in the process of being attached. These components are affect (emotion), (proximity-maintaining) behaviour, and cognition (thoughts).

3 The place dimension differentiates between the physical and socially bound characteristics of a place, contributing to the people-place bond.

Although the tripartite framework captures contributing variables in the attachment process, the saliency of variables may depend upon the scale and type of environment (e.g., Lewicka, 2011a, 2011b; Scannell \& Gifford, 2010). For example, city neighbourhoods (e.g., Bonaiuto, Aiello, Perugini, Bonnes, \& Ercolani, 1999) involve markedly different variables to studies of recreational areas (e.g., Kyle, Graefe, Manning, \& Bacon, 2004). Hence, variables that are salient in one type of setting may not be relevant in another type of setting: predictors cannot be treated as universally important to the attachment process (Turton, 2016). Therefore, the authors suggest that place attachment should not be considered as a generalisable phenomenon but should be contextualised (Turton, 2016).

\section{Applicability to workplace studies}

Understanding people's affective (emotion), cognitive (attitude), and behavioural reactions to place loss should inform prevalent organisational change management strategies (e.g., Harrison, Wheeler, \& Whitehead, 2004). Stakeholders in the workplace and the building industry should be aware of the impact workplace change can have on workers who may feel threatened and resistant to changes in the workplace (e.g., Fried, 2000; Inalhan, 2009; Manzo \& Perkins, 2006). Given that facility managers, designers, and planners have a significant responsibility for workers' psychological well-being, redesign and relocation processes should be undertaken in a manner informed by principles of workplace attachment research.

\subsection{Workplace attachment models}

The concept of workplace attachment is a recent one that has gained popularity in workplace research over the last few decades. Workplace attachment has been the subject of several studies that have examined workplace attachment associations with various socio-environmental and psychosocial variables (see Scrima, Rioux, \& Guarnaccia, 2019). Workplace attachment has been broadly defined as the emotional bond between a person and the physical work environment(s) of their associated organisation (e.g., Milligan, 1998, 2003a, 2003b; Rioux, 2006). Three theoretical models of workplace attachment have been acknowledged in the 
literature to date: (1) a unidimensional model of workplace attachment by Rioux (2006), (2) a transfer of the PPP model to the workplace (Ardalan, 2019; Grady, Grady, McCreesh, \& Noakes, 2020; Inalhan, 2009), and (3) a model by Inalhan (2009), which emphasises place loss and resulting emotion, attitudes, and behaviours relevant for workplace change processes.

\subsubsection{The unidimensional model of workplace attachment}

Rioux's (2006) model of workplace attachment is grounded in Shumaker and Taylor's (1983) unidimensional understanding of place attachment. As such, the emphasis lies in the affective component of the person-work environment relationship. Consequently, the derived measure, the Workplace Attachment Scale (WAS)/Echelle d'Attachement au lieu de travail (ÉALT), is a one-dimensional, seven-item scale based on the Neighborhood Attachment Scale by Bonnes, Bonaiuto, Aiello, Perugini, and Ercolani (1997). ${ }^{1}$ In their book, Manzo and Devine-Wright (2014) also highlight this approach as being quantitative because it relies on the Likert scale. Several studies (Le Roy \& Rioux, 2012; Rioux \& Pignault, 2013b; Velasco \& Rioux, 2010) have found that employees who are more attached to their workplace are more satisfied, show a lower tendency to leave their jobs, and improve their job performance compared with those who are less attached (Dinç, 2007).

\subsubsection{The PPP model in a workplace context}

The PPP model proposes a three-dimensional person-process-place organising framework that structures the varied definitions in the place attachment literature (Scannell \& Gifford, 2010, 2014). This framework is instructive in explaining workplace attachment as a multidimensional concept involving person, psychological process, and place dimensions (see Figure 16.1).

(1) The person dimension: Who is attached? To what extent is the attachment based on individually and collectively held meanings? In the workplace, place attachment occurs at both the individual (employee) and group levels (working groups), and although definitions of the term tend to emphasise one over the other, the two may overlap (Ardalan, 2019). At the individual level, it involves the personal connections that one has to the workplace. Place attachment is stronger for settings that evoke personal memories, and this type of place attachment is thought to contribute to a stable sense of self (Ardalan, 2019; Scannell \& Gifford, 2014). At the group level, attachment is comprised of the symbolic meanings of a place that are shared among working group members (Ardalan, 2019; Scannell \& Gifford, 2014). This kind of attachment has been described as a community process in which groups become attached to areas wherein they

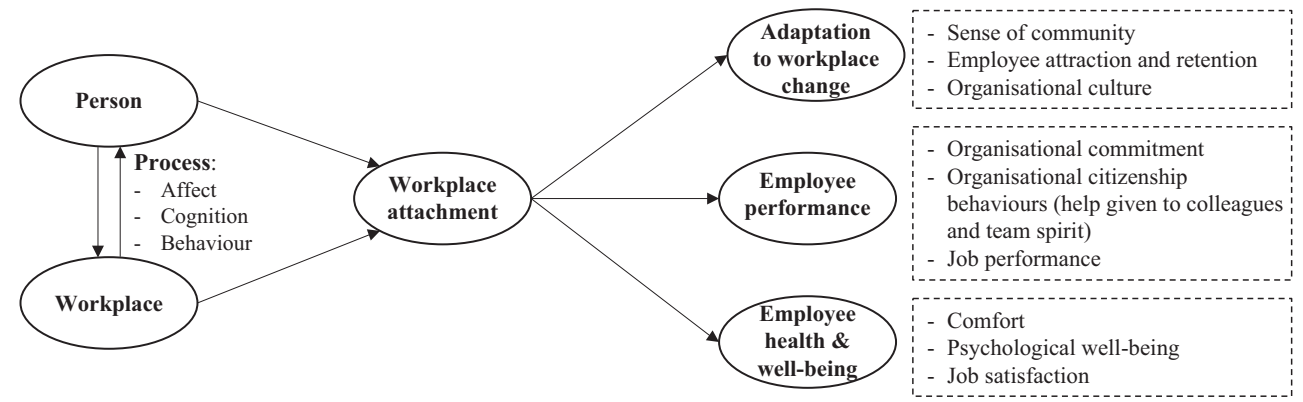

Figure 16.1 A framework of workplace attachment: person, place, process, and desired outcomes 
may practice, and thus preserve their organisational culture (Ardalan, 2019) (see also Chapter 12 on organisational culture theory). Culture links members to place through shared historical experiences, values, and symbols. Therefore, in workplace studies, the group and individual levels of place attachment are not entirely independent (Ardalan, 2019).

(2) The psychological process dimension: How are affect, cognition, and behaviour manifested in the attachment? This dimension concerns the way that individuals and groups relate to a workplace and the nature of the psychological interactions that occur in the work environments that are important to them. The three psychological aspects of place attachment are affect, cognition, and behaviour.

Workplace attachment as affect: The central role of affect in person-place bonding at work is an emotional investment in a place or feelings of pride and a general sense of well-being. Some evidence that attachment to a place is grounded in emotion comes from the literature on displacement when individuals must leave their places, such as in the event of an office relocation (e.g., individual employees or a full office relocation; Ardalan, 2019).

Workplace attachment as cognition: The memories, beliefs, meaning, and knowledge that individuals associate with their central settings make them personally important in workplaces. Place attachment as cognition involves the construction of, and bonding to, place meaning (see also Chapter 8 Social Constructionism Theory), as well as the cognitions that facilitate closeness to a place.

Workplace attachment as behaviour: Place attachment behaviours are not necessarily territorial, although the two may overlap, given that place use is an element of both. Territoriality is based on ownership, control of space, and the regulation of access to self, but attachment to places is an affective, proximity-maintaining bond that can be expressed without an underlying purpose of control (Manzo \& Devine-Wright, 2014).

(3) The place dimension: This dimension concerns the object of the attachment: the place itself and its characteristics. What is it about the place that instils a sense of attachment? It should be stressed that both physical and social characteristics of place influence the overall bond and that the spatial level should be considered when measuring place attachment.

Physical characteristics of place: Certain physical features, such as density, proximity, and the presence of amenities and other social arenas influence these interactions (see also Chapter 21 Space Syntax).

Social characteristics of place: When the attachment is directed towards others who live in the place rather than to aspects of the place itself, it is considered to be a socially based place bond because it is sometimes compared to, or conflated with, the sense of community (Inalhan, 2013). Furthermore, research gives some indication of the predictors of workplace attachment. Dinç (2007) found correlational evidence suggesting that atmospheric qualities and aesthetics (e.g., attractive, beautiful, and peaceful space), as well as functional qualities (e.g., room size and adequacy of the fit-out for work tasks), predict workplace attachment in personalised private offices. Interaction effects between environmental qualities, personalisation, and attachment are likely (Laurence, 2013). Of note, the ability to personalise one's workspace and having a private office are related to workplace design, management, and policy. Personalised enclosed offices have become less common with more organisations implementing open-plan offices or activity-based workplaces. Considerations of spatial efficiency, employee communication, and collaboration have prompted these innovations, although the benefits are frequently disputed. 


\subsubsection{The workplace attachment-and-disruption model}

Inalhan's (2009) workplace attachment model is grounded in Brown and Perkins's (1992) understanding of place attachment. Brown and Perkins (1992) postulate that place attachment only becomes apparent when place separation or place loss takes place. To investigate workers' reactions to workplace changes, Inalhan's (2009) workplace attachment model utilises Brown and Perkins's (1992) four attachment-and-disruption reaction patterns:

Phase 1 captures the development of attachment to the workplace environment.

Phase 2 captures the (work)place loss.

Phase 3 captures coping with lost attachment.

Phase 4 captures the development of attachment to a new workplace environment.

It has been postulated that the stage of coping with place loss (Phase 3) is challenging for both individual employees and management in terms of duration and identifying useful coping/recon ciliation strategies (Brown \& Perkins, 1992; Inalhan, 2009). In this sense, it has been suggested that the quality of attachment (Phase 1) is indicative of the severity of negative affect and attitudes experienced in Phase 2 and the variability in required coping/reconciliation strategies to handle place loss experienced in Phase 3 (Brown \& Perkins, 1992; Inalhan, 2009). With regard to the antecedents of successful coping (individual) and reconciliation (organisation) strategies in prior phases, Nicholson (1990) outlines establishing conditions that can support states of readiness for change.

\subsection{Desired outcomes of workplace attachment}

Place attachment can be thought of as both a process (i.e., reasons for attachment) and a product/ outcome (i.e., feeling attached; Giuliani, 2003). It is clear from the literature review that the concept can be operationalised in both ways. As a process, place attachment is the appropriation of space via involvement with the local area. It is a continuous, dynamic process. As a product, place attachment is an emotional bond with a specific place. The experience of feeling attached and belonging to a place can serve three desired outcomes of place attachment in workplace design and management:

1 adaptation to workplace change,

2 employee performance, and

3 employee well-being (see Figure 16.1).

\subsubsection{Adaptation to workplace change}

Even though recent interest in affect in workplace has been intense, opportunities and challenges remain on the emotional significance of the physical environment for employees (Inalhan, 2006, 2009).

The increased diversity and variety of working practices, work locations, and types of workplaces bring out key dilemmas to resolve. As the choices increase with regard to where and how people can work, the social component of the office grows in importance. Therefore, the future demands a higher level of facility management skills to evaluate the effectiveness of the workplace to support organisation strategies and individuals. Although workplace redesign and relocation have been used as a catalyst by many organisations to introduce myriad elements of 
organisational change, little thought has been given to the ways such changes may be viewed by the employees and the employee workspace attachment (Inalhan, 2006). The symbolism attached to place is a powerful force that works against locational flexibility. It is argued that many organisations have failed to implement new workplaces due to overwhelming employee resistance to change (Stegmeier, 2008).

Inalhan and Finch (2004) suggest that the physical environment could be used as a way to increase an employee's sense of attachment to the workplace. Good workspace design should seek to maintain those characteristics that are familiar and meaningful to employees; at the same time, it should constantly contribute to improving their attachment to the workplace (Ujang \& Zakariya, 2015). Therefore, the study of place attachment in the workplace environment contributes to developing and sustaining the attraction and the meaning of office settings. The degree to which a particular environment satisfies the needs and goals of an employee determines their judgment of its quality, and this judgment regulates the attachment to a place (Dinç, 2007; Stokols \& Shumaker, 1981; Zenker \& Rütter, 2014). Thus, workspace attachment is a consequence of the personal interactions between employees and their organisational environment (Milligan, 1998; Scrima, 2015). When a place provides the resources required for goal attainment (e.g., survival and security, temporal or personal continuity, etc.) and the use of those resources is frequent, attachment occurs (Inalhan \& Finch, 2004, 2012; Stokols \& Shumaker, 1981).

\subsubsection{Employee performance and organisational commitment}

Velasco and Rioux (2010) found a positive relationship between attachment to the workplace and affective commitment. According to the authors, employees who are emotionally attached to their workplace are more likely to develop a positive emotional connection to their organisation. Rioux and Pavalache-Ilie (2013) found that workplace attachment is a good predictor of two dimensions of organisational citizenship behaviours: 'help given to colleagues' and 'team spirit'. Specifically, the authors argue that the more employees are attached to the workplace, the more they will show citizenship behaviours towards their colleagues and contribute to the proper functioning of the team. In addition, employees attached to their workplace will show higher levels of job satisfaction than their colleagues with a low level of attachment (Rioux \& Pignault, 2013a, 2013b).

\subsubsection{Employee well-being and job satisfaction}

Workplace attachment is considered to be an important aspect of quality of work life (e.g., Scrima, Moffat, \& Rioux, 2016) because of its diverse impact on individual and worker-related outcomes such as worker well-being (e.g., Rioux, 2005, 2006), satisfaction (e.g., Scrima et al., 2019), comfort (c.f., Rioux, 2017), perception of team spirit and helping behaviour (Rioux \& Pavalache-Ilie, 2013), and employee retention (Rioux, 2006, 2011).

\section{Methodology/research approach}

\subsection{Employing mixed methods in place attachment research}

Combining quantitative and qualitative methods in place attachment research is critical to understand a phenomenon and its story. Quantitative methods can find 'how much' (Lewicka, 2011 b, p. 222) the importance of the relationship between people and places is, and qualitative 
methods can discover 'what the places mean to people' (Turton, 2016, p. 29). Thus, a mixedmethods approach provides analytical strengths from each method in a study, allowing researchers to uncover the full story of research problems (Creswell, 2015). Quantitative methods allow researchers to investigate the statistical significance of the relationship between people and places; inferential statistics provide the benefit of using a sample (a subset of the entire target population) to generalise the research findings to the target population. Qualitative methods can then determine why such relationships occur by providing details and context; additional factors that are not included in quantitative methods can be found through qualitative methods (Turton, 2016).

In studies of residential environments, quantitative methods have been used more extensively than qualitative methods. However, even in a quantitative study with a survey method, researchers often include interviews to add context to explain the results of the survey (Turton, 2016, p. 30). In qualitative residential studies, place attachment can provide important insights, such as how attachment changes over time (Lewicka, 2011b), the importance of social ties (Aiello, Barrat, Cattuto, Ruffo, \& Schifanella, 2010; Rollero \& De Piccoli, 2010), and the importance of matching environment with one's preference (Feldman, 1996; Twigger-Ross \& Uzzell, 1996). Specifically, Livingston, Bailey, and Kearns's (2008) qualitative study suggests that individual perception of welcoming and friendly neighbours is associated with higher residential place attachment. During in-depth semi-structured interviews, residents have reported higher residential place attachment when neighbourhood improvements occurred over time (Twigger-Ross \& Uzzell, 1996). Likewise, social, environmental, and economic aspects of residential areas can be better understood through a mixed-methods approach. Quantitative and qualitative methods can compensate for each other. Qualitative methods can answer 'why' and 'how' questions related to the findings of quantitative methods, and together, they can provide a more comprehensive understanding of a research problem.

\subsection{Potential moderators of workplace attachment}

In her review of the evidence, Turton (2016) indicates that length of residence is one of the most reliable predictors of place attachment in a residential context (see, for example, Bailey, Kearns, \& Livingston, 2012; Lewicka, 2008, 2010, 2011a; Williams et al., 2010). However, in her own work Turton (2016) observes that the effect of length of residence on attachment may be moderated by other factors; namely, social cohesion and type of environment. These factors may also be relevant to workplace attachment. Social cohesion is positively related to residential place attachment (Turton, 2016). Extrapolating from this evidence, spending more time in a workplace and participating to a greater extent in the workplace community may lead to greater social connections and greater attachment. Turton (2016) also found that length of residence was only a positive and significant predictor of place attachment in more urbanised environments, whereas social cohesion was a consistent predictor across different types of environments, including those that are more rural. In the context of attachment to workplace settings, research should not neglect the role of social connectedness in informing attachment relationships.

Future research should investigate the influence of organisational commitment by introducing other attitudes, such as job involvement and job satisfaction, along with the attachment to the workplace. This endeavour should involve an examination of their contribution and their respective roles in achieving organisational citizenship behaviours. It would also be interesting to conduct studies incorporating other dimensions from environmental psychology that could help enrich the work on understanding organisational citizenship behaviours.

The studies of attachment to the workplace so far have taken the relational approach (focusing on Bowlby's theory), the organisational approach (based on the organisational commitment 
model; Allen \& Meyer, 1990), and the environmental approach (focusing on place attachment as an emotional connection between an individual and a given place). However, very few studies to date have analysed the possible overlaps between these three approaches, although several studies have highlighted the relationship between affective commitment and workplace attachment (Velasco \& Rioux, 2010), between affective commitment and attachment style in the workplace (Neustadt, Chamorro-Premuzic, \& Furnham, 2011), and between workplace attachment and attachment style in the workplace (Scrima, 2014).

There are widespread variations in the definitions and functions ascribed to place attachment; they suggest that place attachment is a set of related phenomena rather than a singular phenomenon (Harris, 1998; Low \& Altman, 1992). Many researchers use the terms attachment, territoriality, and satisfaction with the workplace interchangeably without defining these concepts. There is a confusion regarding whether place attachment can be differentiated from other person-place terms such as territoriality and satisfaction with the place. Some researchers (Stokols \& Altman, 1987) have theorised that the concepts are intertwined, possibly with attachment either subsuming or being subsumed by the other two. Giuliani and Feldman (1993) suggest that a fruitful research direction would be to consider the plurality of emotional bonds with a place, by emphasising the distinctions between affective bonds and operationalising their specific effects.

\section{Limitations}

Certain characteristics of the previous works make it evident that place attachment studies have focused almost exclusively on home environments and neighbourhoods, while work environments have been neglected. The drive for undertaking workplace research comes from the fact that while the speed of change in work environments is much higher than in residential environments, there is a disparity in knowledge. Scant empirical work has been carried out using the qualitative methods, and little consensus has been reached in the area of operationalising the concept of place attachment. There is a pressing need for an effective conceptual approach that can be applied to facilities management (Inalhan, 2006).

Place attachment can be thought of as both a process (being an experience) and an outcome (being a product of an experience). The existing theory on 'place attachment' is incomplete and may not be applicable in all types of work environments.

Scrima (2015) examines the convergent discriminant validity of three scales: the Workplace Attachment Scale, the Adult Attachment Style in the Workplace Scale, and the Affective Commitment Scale. These three forms of emotional attachment to a specific place, to colleagues, and to the organisation seem to have a positive effect on quality of life at work. The discrimination between these three constructs may help researchers create functional models, explain employees' behaviour in the workplace, and enable human resource managers to design comfortable and customised spaces. Such measures may improve the quality of relationships between employees, enabling them to get to know and share values, opinions, and views of their organisation, thereby contributing to better workplace relationships and improved performance (Scrima, 2014). Specifically, these three levels of emotional attachment to the workplace, to colleagues, and to the organisation seem to be important resources for improving the quality of work life.

\section{Theory relevance to practice}

All of these studies underline the importance of attachment to the workplace in human resource management. Based on these theoretical contributions, human resource managers could 
implement organisational interventions geared towards employees' comfort, with the ultimate goal of developing commitment, encouraging organisational citizenship behaviours, and thereby increasing the performance of workers. Place attachments held by employees to the physical site of an organisation go unrecognised by the management involved in transition processes (Milligan, 1998, 2003a, 2003b). Ignoring the emotional charge given by these employees has the potential to undermine adaptation to workplace changes, employee performance, and employee health and well-being.

A complex relationship exists between workplace attachment and positive organisational behaviours like organisational 'civism' and organisational commitment. The ethical behaviour at work holds a privileged position in the preoccupations of organisations: civic organisational behaviour is highly valued. Workplace attachment and organisational commitment have proven to be strong predictors of organisational citizenship behaviour (Rioux \& Pavalache-Ilie, 2013) - a good reason for managers to stimulate the development of workspace appropriation (PavalacheIlie, 2016).

Scrima (2015) suggests that allowing employees to customise their office would increase attachment at work (Dinç, 2007). Specific training could be offered to improve the quality of relationships between colleagues with the aim of increasing confidence and improving communication (Ronen \& Mikulincer, 2012). Finally, involvement in organisational life could increase the bond between the employee and the organisation. The strong link between workplace attachment and adult attachment style should suggest to human resource (HR) practitioners the possibility to activate a virtuous cycle via organisational development practices aimed at improving employee attitude towards their established workplace. These practices, therefore, are of potential importance for influencing the sense of belonging to the work environments and this, in turn, may influence employees' health and well-being.

Personalisation of a workspace is usually possible when employees have designated workstations. Unassigned seating/hoteling systems are more evident in open-plan and activity-based offices, where increased space utilisation is important. While the office of the future requires designers and facility managers to think in terms of space and time rather than about desks and chairs, employees still continue to act upon the old person-place metaphor (Nutt \& McLennan, 2000). How do people develop a sense of place attachment in the 'hot swappable' work environment? How can modern workplaces be examined in the context of workplace attachment? Are there different degrees of place attachment according to spatial types (i.e., assigned enclosed offices, assigned workstation in an open area, unassigned workstation in an open area, kitchen, lounge, or overall attachment to the workplace as a whole)? In the era of the mobile worker, can place attachment continue to play its role as a pivotal source of identity and social cohesion?

Many organisations refer to 'the death of the office' as the COVID-19 pandemic leaves offices around the world empty, with many observers asking what the point of them was anyway (Nixey, 2020). While change and innovation can be uppermost in the minds of organisations today, they still struggle to implement it. For a sustainable future, workplace studies should address several questions:

1 The creative knowledge worker as a mobile person - does high mobility change the modes of identification of creative knowledge workers? Do workers develop new hybrid identification patterns in relation to places, jobs, and social roles? How can we create workplaces where every voice matters, everyone thrives and finds meaning, and change and innovation happen naturally (Di Masso et al., 2019; Nadler, 2014)? It is important to understand how creative knowledge workers orientate in physical and social space: do they still develop a routine of orientation in social and physical space? What do these people do 
while travelling? How do they perceive and use the transit time and transit spaces (third places) between their various places (Oldenburg, 1989)?

2 The creative knowledge worker as a locating person - how do such workers appropriate new places to make them a part of their own life? Do they develop specific routines to appropriate new places? How do they become members of local communities and cultural contexts abroad? To which scale do they feel they belong? Are places equally important, or are there certain hierarchies at play for creative knowledge production (Hirst, 2011; Nadler, 2014)?

3 The creative knowledge worker in relation to places - places not only influence creative knowledge workers and their lives, but these workers also reciprocally influence the places in which they live. What does the dialectic of physical absence and presence then mean to the places themselves? What do people significantly lack and long for in the workplace (Nadler, 2014)?

\section{Further reading}

- Fried, M. (1963). Grieving for a lost home. In L. J. Duhl (Ed.), The urban condition people and policy in the metropolis (pp. 124-152). New York: Basic Books.

- Giuliani, M. V. (1991). Towards an analysis of mental representation of attachment to the home. Journal of Architectural Planning Research, 8(2), 133-146. Retrieved from www.jstor. org/stable/43029028

- Sennett, R. (1999). Corrosion of character: Personal consequences of work in the new capitalism. New York: W.W. Norton Publications.

- Steele, F. (1981). Sense of place. Boston, MA: CBI Publishing.

- Sundstrom, E. (1986). Workplaces: The psychology of the physical environment in offices and factories. New York: Cambridge University Press.

\section{Note}

1 Although the scale has been used extensively with workers in different settings such as workplace staff (e.g., Rioux \& Pignault, 2013b; Scrima et al., 2016), hospital staff (Velasco \& Rioux, 2010) and school staff (Rioux \& Pignault, 2013a), it has limitations, which are indicated in the methods section.

\section{References}

Aiello, L. M., Barrat, A., Cattuto, C., Ruffo, G., \& Schifanella, R. (2010). Link creation and profile alignment in the aNobii social network. 2010 IEEE Second International Conference on Social Computing, Minneapolis, MN, pp. 249-256.

Allen, N. J., \& Meyer, J. P. (1990). The measurement and antecedents of affective, continuance and normative commitment to the organization. Journal of Occupational Psychology, 63(1), 1-18. https://doi. org/10.1111/j.2044-8325.1990.tb00506.x

Altman, I., \& Low, S. M. (Eds.). (1992). Place attachment. New York: Plenum.

Ardalan, K. (2019). Equity home bias in international finance: A place-attachment perspective. New York: Routledge.

Bailey, N., Kearns, A., \& Livingston, M. (2012). Place attachment in deprived neighbourhoods: The impacts of population turnover and social mix. Housing Studies, 27(2), 208-231. https://doi.org/10.10 80/02673037.2012.632620

Bogdan, C., Rioux, L., \& Negovan, V. (2012). Place attachment, proactive coping and well-being in a university environment. Procedia - Social and Behavioral Sciences, 33, 865-869. https://doi.org/10.1016/j. sbspro.2012.01.245 
Bonaiuto, M., Aiello, A., Perugini, M., Bonnes, M., \& Ercolani, A. P. (1999). Multidimensional perception of residential environment quality and neighbourhood attachment in the urban environment. Journal of Environmental Psychology, 19(4), 331-352. https://doi.org/10.1006/jevp.1999.0138

Bonnes, M., Bonaiuto, M., Aiello, A., Perugini, \& M., Ercolani, A. P. (1997). A transactional perspective on residential satisfaction. In C. Després \& D. Piché (Eds.), Housing surveys. Advances in theory and methods (pp. 75-99). Quebec: Centre de recherche en aménagement et développement, Université de Laval.

Brown, B., \& Perkins, D. D. (1992). Disruptions in place attachment In I. Altman \& S. Low (Eds.), Place attachment (pp. 279-304). New York: Plenum.

Creswell, J. W. (2015). A concise introduction to mixed methods research. Thousand Oaks, CA: Sage.

Cui, X., \& Ryan, C. (2011). Perceptions of place, modernity and the impacts of tourism: Differences among rural and urban residents of Ankang, China: A likelihood ratio analysis. Tourism Management, 32(3), 604-615. https://doi.org/10.1016/j.tourman.2010.05.012

Devine-Wright, P. (2011). From backyards to places: Public engagement and the emplacement of renewable energy technologies. In P. Devine-Wright (Ed.), Renewable energy and the public: From NIMBY to participation (pp. 577-574). London: Earthscan.

Di Masso, A., Williams, D. R., Raymond, C. M., Buchecker, M., Degenhardt, B., Devine-Wright, P., . . \& \& von Wirth, T. (2019). Between fixities and flows: Navigating place attachments in an increasingly mobile World. Journal of Environmental Psychology, 61, 125-133. https://doi.org/10.1016/j.jenvp.2019.01.006

Dinç, P. (2007). Spatial and behavioral variables that affect "emotional attachment" of users: A multidimensional approach for private offices. Gazi University Journal of Science, 20(2), 41-50.

Feldman, R. M. (1996). Constancy and change in attachments to types of settlements. Environment and Behaviour, 28(4), 419-445. https://doi.org/10.1177/0013916596284001

Fried, M. (2000). Continuities and discontinuities of place. Journal of Environmental Psychology, 20(3), 193205. https://doi.org/10.1006/jevp.1999.0154

Gerson, K., Stueve, A., \& Fischer, C. S. (1977). Attachment to place. In C. S. Fisher, R. M. Jackson, C. A. Stueve, K. Gerson, L. M. Jones, \& M. Baldassare (Eds.), Network and places: Social relations in the urban setting (pp. 139-161). New York: Free Press.

Giuliani, M. V. (2003). Theory of attachment and place attachment. In M. Bonnes, T. Lee, \& M. Bonaiuto (Eds.), Psychological theories for environmental issues (pp. 137-170). Farnham: Ashgate.

Giuliani, M. V., \& Feldman, R. (1993). Place attachment in a developmental and cultural context. Journal of Environmental Psychology, 13(3), 267-274. https://doi.org/10.1016/S0272-4944(05)80179-3

Grady, J., Grady, V., McCreesh, P., \& Noakes, I. (2020). Workplace attachments: Managing beneath the surface. New York: Routledge.

Harris, J. (1998). Real estate and the future. In J. Worthington (Ed.), Reinventing the workplace (pp. 50-60). Oxford: Architectural Press.

Harrison, A., Wheeler, P., \& Whitehead, C. (Eds.). (2004). The distributed workplace: Sustainable work environments. London: Spon Press.

Hernández, B., Hidalgo, M. C., \& Ruiz, C. (2014). Theoretical and methodological aspects of research on place attachment. In L. C. Manzo \& P. Devine-Wright (Eds.), Place attachment: Advances in theory, methods and applications (pp. 125-137). New York: Routledge.

Hester, R. T., Jr. (1984). Planning neighborhood space with people. New York: Van Nostrand Reinhold.

Hidalgo, M. C., \& Hernandez, B. (2001). Place attachment: Conceptual and empirical questions. Journal of Environmental Psychology, 21(3), 273-281. https://doi.org/10.1006/jevp.2001.0221

Hirst, A. (2011). Settlers, vagrants and mutual indifference: Unintended consequences of hot-desking. Journal of Organizational Change Management, 24(6), 767-788. https://doi.org/10.1108/09534811111175742

Hummon, D. M. (1992). Community attachment: Local sentiment and sense of place. In I. Altman \& S. M. Low (Eds.), Place attachment (pp. 253-278). New York: Plenum.

Inalhan, G. (2006). The role of place attachment on employees' resistance to change in workplace accommodation projects [Unpublished doctoral dissertation]. Reading, UK: Reading University.

Inalhan, G. (2009). Attachments: The unrecognised link between employees and their workplace (in change management projects). Journal of Corporate Real Estate, 11(1), 17-37. https://doi.org/10.1108/14630010 910940534

Inalhan, G. (2013). Quitter le confort du familier - L'attachement social au lieu de travail [Leaving the comfort of the familiar-social attachment to workplace]. In L. Rioux, J. Le Roy, L. Rubens, \& J. Le Conte (Eds.), Le confort au travail: Que nous apprend la psychologie environnementale? [Comfort in the workplace: What does environmental psychology teach us?] (pp. 174-216). Quebec: Les Presses de L'Université Laval. 
Inalhan, G., \& Finch, E. (2004). Place attachment and sense of belonging. Facilities, 22(5/6), 120-128. https://doi.org/10.1108/02632770410540333

Inalhan, G., \& Finch, E. (2012). Change and attachment to place. In E. Finch (Ed.), Facilities change management (pp. 155-174). Honoken, NJ: Wiley-Blackwell Publishing.

Jones, C. R., Orr, B. J., \& Eiser, J. R. (2011). When is enough, enough? Identifying predictors of capacity estimates for onshore wind-power development in a region of the UK. Energy Policy, 39(8), 4563-4577. https://doi.org/10.1016/j.enpol.2011.04.044

Kil, N. K., Holland, S. M., Stein, T. V., \& Ko, Y. J. (2012). Place attachment as a mediator of the relationship between nature-based recreation benefits and future visit intentions. Journal of Sustainable Tourism, 20(4), 603-626. https://doi.org/10.1080/09669582.2011.610508

Kruger, L. E. (2008). An introduction to place-based planning. In J. O. Farnum \& L. E. Kruger (Eds.), Place-based planning: Innovation and applications from four western forests. General Technical Report PNWGTR-741 (pp. 1-6). Portland, OR: USDA Forest Service, Pacific Northwest Research Station.

Kyle, G., Graefe, A., Manning, R., \& Bacon, J. (2004). Effects of place attachment on users' perceptions of social and environmental conditions in a natural setting. Journal of Environmental Psychology, 24(2), 213-225. https://doi.org/10.1016/j.jenvp.2003.12.006

Laurence, J. (2013). "Hunkering down or hunkering away?" The effect of community ethnic diversity on residents' social networks. Journal of Elections, Public Opinion and Parties, 23(3), 255-278. https://doi.org/ 10.1080/17457289.2013.808641

Lee, T. H., \& Shen, Y. L. (2013). The influence of leisure involvement and place attachment on destination loyalty: Evidence from recreationists walking their dogs in urban parks. Journal of Environmental Psychology, 33, 76-85. https://doi.org/10.1016/j.jenvp.2012.11.002

Le Roy, J., \& Rioux, L. (2012). The mediating role of workplace attachment in the relationship between organizational commitment and organizational citizenship behavior. Revue Internationale de Psychologie Sociale, 25(3), 211-233.

Lewicka, M. (2005). Ways to make people active: The role of place attachment, cultural capital, and neighborhood ties. Journal of Environmental Psychology, 25(4), 381-395. https://doi.org/10.1016/j. jenvp.2005.10.004

Lewicka, M. (2008). Place attachment, place identity, and place memory: Restoring the forgotten city past. Journal of Environmental Psychology, 28(3), 209-231. https://doi.org/10.1016/j.jenvp.2008.02.001

Lewicka, M. (2010). What makes neighborhood different from home and city? Effects of place scale on place attachment. Journal of Environmental Psychology, 30(1), 35-51. https://doi.org/10.1016/j. jenvp.2009.05.004

Lewicka, M. (2011a). On the varieties of people's relationships with places: Hummon's typology revisited. Environment and Behavior, 43(5), 676-709. https://doi.org/10.1177/0013916510364917

Lewicka, M. (2011b). Place attachment: How far have we come in the last 40 years? Journal of Environmental Psychology, 31(3), 207-230. https://doi.org/10.1016/j.jenvp.2010.10.001

Livingston, M., Bailey, N., \& Kearns, A. (2008). People's attachment to place: The influence of neighbourhood deprivation. Project report. York: Chartered Institute of Housing/Joseph Rowntree Foundation.

Low, S. M., \& Altman, I. (1992). Place attachment: A conceptual inquiry. In I. Altman \& S. M. Low (Eds.), Place attachment (pp. 1-12). New York: Plenum.

Manzo, L. C., \& Devine-Wright, P. (Eds.). (2014). Place attachment: Advances in theory, methods, and applications. New York: Routledge.

Manzo, L. C., \& Perkins, D. D. (2006). Finding common ground: The importance of place attachment to community participation and planning. Journal of Planning Literature, 20(4), 335-350. https://doi. org/10.1177/0885412205286160

Milligan, J. M. (1998). Interactional past and potential: The social construction of place attachment. Symbolic Interaction, 21(1), 1-33. https://doi.org/10.1525/si.1998.21.1.1

Milligan, J. M. (2003a). Loss of site: Organizational site moves as organizational deaths. International Journal of Sociology and Social Policy, 23(6-7), 115-152. https://doi.org/10.1108/01443330310790615

Milligan, J. M. (2003b). Displacement and identity discontinuity: The role of nostalgia in establishing new identity categories. Symbolic Interaction, 26(3), 381-403. https://doi.org/10.1525/si.2003.26.3.381

Moore, R. L., \& Graefe, A. R. (1994). Attachments to reaction settings: The case of rail-trail users. Leisure Sciences, 16(1), 17-31. https://doi.org/10.1080/01490409409513214

Nadler, R. (2014). Plug E play places: Lifeworlds of multilocal creative knowledge workers. Warsaw: De Gruyter Open. 


\section{Place attachment theory}

Neustadt, E. A., Chamorro-Premuzic, T., \& Furnham, A. (2011). Attachment at work and performance. Attachment \& Human Development, 13(5), 471-488. https://doi.org/10.1080/14616734.2011.602254

Nicholson, N. (1990). The transition cycle: Causes, outcomes, processes and forms. In S. Fisher \& C. L. Cooper (Eds.), On the move: The psychology of change and transition (pp. 83-108). Hoboken, NJ: John Wiley and Sons. https://doi.org/10.1002/smi.2460070413

Nixey, C. (2020, April 29). Work: Death of office. The Economist, 1843 Magazine. Retrieved from www.1843magazine.com/features/death-of-the-office

Nutt, B., \& McLennan, P. (2000). Facility management risk and opportunities. Oxford: Blackwell Science.

Oldenburg, R. (1989). The great good place: Cafes, coffee shops, bookstores, bars, hair salons and other hangouts at the heart of a community. New York: De Capo Press.

Patterson, M. E., \& Williams, D. R. (2005). Maintaining research traditions on place: Diversity of thought and scientific progress. Journal of Environmental Psychology, 25(4), 361-380. https://doi.org/10.1016/j. jenvp.2005.10.001

Pavalache-Ilie, M. (2016). Workspace appropriation and attachment. Bulletin of the Transilvania University of Braşov, 9(2), 27-34.

Proshansky, H. M. (1978). The city and self-identity. Environment and Behavior, 10(2), 147-169. https:// doi.org/10.1177/0013916578102002

Rioux, L. (2005). Approche psychosociale de l'attachement aux lieux de travail [Psychosocial approach to workplace attachment: A study carried out among hospital staff]. Working Paper No. 2005-2. Orléans: Université d'Orléans.

Rioux, L. (2006). Construction d'une échelle d'attachementau lieu de travail: Une démarche exploratoire [Construction of a scale of attachment to the workplace: An exploratory approach]. Revue Canadienne des Sciences du Comportement [Canadian Journal of Behavioural Science], 38(4), 325-336. https://doi. org/10.1037/cjbs2006018

Rioux, L. (2011). Workplace attachment and request for professional transfer: Study of a population of French employees. Bulletin of the Transylvania University of Braşov, 4(53), 91-96.

Rioux, L. (2017). Comfort at work: An indicator of quality of life at work. In G. Fleury-Bahi, E. Pol, \& O. Navarro (Eds.), Handbook of environmental psychology and quality of life research. International handbooks of quality-of-life (pp. 401-419). Basel: Springer. https://doi.org/10.1007/978-3-319-31416-7_22

Rioux, L., \& Pavalache-Ilie, M. (2013). Workplace attachment and organizational commitment: Are they predictors of organizational citizenship behavior? Annals of Alexandru Ioan Cuza University of Iasi, Psychology Series, 1, 5-18.

Rioux, L., \& Pignault, A. (2013a). Workplace attachment and meaning of work in a French secondary school. Spanish Journal of Psychology, 16(E23), 1-14. https://doi.org/10.1017/sjp.2013.42

Rioux, L., \& Pignault, A. (2013b). Apego al lugar de trabajo, apropiación del lugar de trabajo, y satisfacción laboral [Workplace attachment, workspace appropriation, and job satisfaction]. Psyecology: Revista Bilingüe de Psicología Ambiental - Bilingual Journal of Environmental Psychology, 4(1), 39-65. https://doi. org/10.1174/217119713805088342

Rollero, C., \& De Piccoli, N. (2010). Does place attachment affect social well-being? European Review of Applied Psychology, 60(4), 233-238. https://doi.org/10.1016/j.erap.2010.05.001

Romice, O., \& Uzzell, D. (2005). Community design studio: A collaboration of architects and psychologists. Centre for Education in the Built Environment Transactions, 2(1), 73-88. https://doi.org/10.11120/ $\operatorname{tran} .2005 .02010073$

Ronen, S., \& Mikulincer, M. (2012). Predicting employees' satisfaction and burnout from managers' attachment and caregiving orientations. European Journal of Work and Organizational Psychology, 21(6), 828-849. https://doi.org/10.1080/1359432X.2011.595561

Scannell, L., \& Gifford, R. (2010). Defining place attachment: A tripartite organizing framework. Journal of Environmental Psychology, 30(1), 1-10. https://doi.org/10.1016/j.jenvp.2009.09.006

Scannell, L., \& Gifford, R. (2014). The psychology of place attachment. In R. Gifford (Ed.), Environmental psychology: Principles and practice (5th ed., pp. 272-300). Victoria: Optimal Books.

Scrima, F. (2014). Comprendre l'attachement au travail pour agir sur le confort au travail [Understanding workplace attachment to act on comfort in the workplace]. Psychologie du Travail et des Organisations, 20(3), 295-310. https://doi.org/10.1016/S1420-2530(16)30031-0

Scrima, F. (2015). A three-factor structure of comfort in the workplace: An exploratory investigation. Paper presented at Groupe de Psychologie Environnementale de Paris Ouest Nanterre (GREPON), University of Paris Ouest Nanterre La Defense, Paris, France. 


\section{Inalhan, Yang, and Weber}

Scrima, F., Moffat, E., \& Rioux, L. (2016). The relationship between environmental satisfaction in the workplace and job satisfaction. A reciprocal longitudinal model. Psicologia Sociale, 11(2), 141-157.

Scrima, F., Rioux, L., \& Guarnaccia, C. (2019). A study of the relationship between workplace attachment and job satisfaction. TPM: Testing, Psychometrics, Methodology in Applied Psychology, 26(2), 209-220. https://doi.org/10.4473/TPM26.2.3

Shumaker, S. A., \& Taylor, R. B. (1983). Toward a clarification of people-place relationships: A model of attachment to place. In N. R. Feimer \& E. S. Geller (Eds.), Environmental psychology: Directions and perspectives (pp. 219-251). New York: Praeger.

Speller, G. (1996). Community in transition [Unpublished doctoral dissertation]. Guildford, UK: University of Surrey.

Stegmeier, D. (2008). Innovations in office design: The critical influence approach to effective work environments. Hoboken, NJ: John Wiley \& Sons.

Stokols, D., \& Altman, I. (Eds.). (1987). Handbook of environmental psychology (vols. 1 and 2). New York: Wiley.

Stokols, D., \& Shumaker, S. A. (1981). People in places: A transactional view of settings. In J. Harvey (Ed.), Cognition, social behaviour and environment (pp. 441-488). Hillsdale, NJ: Erlbaum.

Turton, C. J. (2016). Defining residential place attachment and exploring its contribution to community and personal environmental actions [Unpublished doctoral dissertation]. Guildford, UK: University of Surrey.

Twigger-Ross, C. L., \& Uzzell, D. L. (1996). Place and identity processes. Journal of Environmental Psychology, 16(3), 205-220. https://doi.org/10.1006/jevp.1996.0017

Ujang, N., \& Zakariya, K. (2015). Place attachment and the value of place in the life of the users. ProcediaSocial and Behavioral Sciences, 168(9), 373-380. https://doi.org/10.1016/j.sbspro.2014.10.243

Vaske, J. J., \& Kobrin, K. C. (2001). Place attachment and environmentally responsible behavior. The Journal of Environmental Education, 32(4), 16-21. https://doi.org/10.1080/00958960109598658

Velasco, L., \& Rioux, L. (2010). Enfoque psicosocial del “apego al lugar de trabajo”. Estudio realizado con personal hospitalario [Psychosocial approach to workplace attachment: A study carried out among hospital staff]. Estudios de Psicologia, 31(3), 309-323. https://doi.org/10.1174/021093910793154385

Williams, A., Kitchen, P., DeMiglio, L., Eyles, J., Newbold, B., \& Streiner, D. (2010). Sense of place in Hamilton, Ontario: Empirical results of a neighborhood-based survey. Urban Geography, 31(7), 905-931. https://doi.org/10.2747/0272-3638.31.7.905

Wilson, M. G., DeJoy, D. M., Vandenberg, R. J., Richardson, H. A., \& Mcgrath, A. L. (2004). Work characteristics and employee health and well-being: Test of a model of healthy work organization. Journal of Occupational and Organizational Psychology, 77, 565-588. https://doi.org/10.1348/0963179042596522

Zenker, S., \& Rütter, N. (2014). Is satisfaction the key? The role of citizen satisfaction, place attachment and place brand attitude on positive citizenship behavior. Cities, 38, 11-17. https://doi.org/10.1016/j. cities.2013.12.009 


\title{
EVOLUTIONARY PSYCHOLOGY THEORY
}

\author{
Can I ever let go of my past?
}

\author{
Young Lee*
}

\section{Background}

\subsection{Human psychological mechanisms explained through evolutionary psychology}

Owing the theoretical foundation to Darwin's theory of evolution, evolutionary psychology (EP) is a theory or approach in psychology that attempts to explain human behaviours with innate psychological drivers based on the evolutionary perspective. Evolutionary psychologists attribute the current human psychological traits to evolved adaptations for natural selection. According to EP, current human behaviours are due to psychological adaptations acquired to survive and reproduce in the ancestral environment (Confer et al., 2010). The EP theory is influenced by many other disciplines, including evolutionary biology, cognitive psychology, behavioural ecology, ethology, and anthropology, and is most substantially influenced by sociobiology and ethology (Schacter \& Addis, 2007; Griffiths, 2008).

While EP is not free of criticisms, the theory of EP shows merits when explaining human innate psychological mechanisms deeply rooted in human nature behind certain common behaviours such as environmental preferences that have consistently exhibited in multiple studies. Due to these merits, the EP theory and research findings have influenced various disciplines such as environment, management, health, economics, law, and politics (Dunbar \& Barret, 2007). They have also contributed to the development of specific theories in psychology related to perception and cognitive biases, including auditory looming bias, visual descent illusion, and error management theory (Buss, 2009). While topics in EP encompass various subjects related to survival and reproduction, this chapter mainly discusses a set of topics in survival most relevant and applicable to the workplace. These EP topics include attachment and territoriality, cognitive and perceptive biases, biophilia and cognitive restoration, prospect and refuge, complexity and mystery, and spatial biases. The following explains each topic in further detail.

\footnotetext{
*Corresponding author: young.lee@innovativeworkplaceinstitute.org
} 


\subsection{Topics of EP related to workplace}

\subsubsection{Attachment and territoriality}

Attachment explains the emotional attachment and proximity-seeking behaviours of children towards caregivers such as parents for survival (Bowlby, 2005). Children feel safe and secure when in a close proximity with such caregiving attachment figures. In separation from them, children develop negative psychologies such as separation anxiety. This tendency continuously exhibits in an attachment to places. Similar to interpersonal attachments, place attachment also shows similar proximity-seeking behaviours to a place of security and safety (Scannell \& Gifford, 2010). In many cases, these places are related to or reminiscent of childhood memories of familiar, safe places such as home, neighbourhood, and landscape, where children are protected with personal care and develop a social bond with caregiving attachment figures. In separation from such a place, people develop negative psychologies such as homesickness. This is an adaptive behaviour observed in many species attached to their own habitats. This behaviour is developed to maintain their innate lifestyle to protect them from threats, secure food, and create a safe breeding territory (see also Chapter 16 Place Attachment). Territory, meaning a defended area within a boundary, is in general associated with attachment and exclusiveness (Gold, 1982).

\subsubsection{Cognitive and perceptive biases}

EP uses the term 'modularity' to refer to functionally specialised human organ systems and brain mechanisms that play a specific role for the purpose of natural selection instead of a general role (Fodor, 1983). For instance, the role of human visual or auditory systems is not to simply deliver arbitrary visual scenes or sounds around us, but to specifically analyse information to generate the percept to solve adaptive problems related to survival and reproduction such as identifying threats, avoiding predators, and finding food and shelter. According to the error management theory, human cognitive and perceptive mechanisms rather favour adaptive biases under uncertain circumstances where judging a situation as a false negative (e.g. deciding something as not a threat while it is a threat) will yield a greater loss than a false positive (e.g. deciding something as a threat while it is not a threat) in evolutionary history (Buss, 2019). Due to this reason, humans exhibit cognitive and sensory biases (see also Chapter 18 Behavioural Economics Theory) such as looming sound bias where our brain processes looming sounds louder and closer than they actually are for a better chance of escaping from dangers (Neuhoff, 2016). Furthermore, our peripheral visual system is tuned to detecting movement and low light in the dark for protection from threats. The auditory system also shows evidence of evolutionary adaptation by being preferably tuned to acoustic frequencies of not only airborne sounds for threat detection but also sounds of conspecific calls to communicate within the same species to sound an alarm to the presence of threats and danger among themselves (Schrode \& Bee, 2015).

\subsubsection{Biophilia and cognitive restoration}

Biophilia refers to an intrinsic human psychological bond with nature (see also Chapter 15 The Biophilia Hypothesis). Our psychological orientation towards nature is due to an adaptive behaviour evolved from living in the ancestral environment of savannahs where our ancestors found food, water, and shelters (Wilson, 1984). The impact of natural elements 
on elevated mood, reduced stress and anxiety, physical healing, and cognitive restoration is well documented (Yin, Zhua, MacNaughtona, Allen, \& Spenglera, 2018; Yin et al., 2019). It is evident that natural elements, such as air and water, are necessities for physical survival of humans from the evolutionary biological perspective. Beyond biological needs, humans' psychological orientation towards natural elements, such as desires for greenery, daylight, and the sound of nature, can be further explained by EP. People have shown a propensity of preferring natural landscape over urban/built hardscape (Kaplan \& Kaplan, 1989; Ulrich, 1983). Various preferential elements of nature comprise many sensory-stimulating elements such as visual presence of natural elements (e.g. vegetation or body of water), sounds of nature (e.g. bird songs or spring water sound), smell of nature (e.g. forest smell or flower scent), natural light, views to nature, and fresh air movement. In addition to the physical elements of nature, abstracted properties of natural elements are also preferred since these are perceived as representations of nature, including shapes and patterns, materials, and colours associated with natural elements. Many studies have highlighted benefits of these natural elements on emotional and cognitive functions. Stress recovery theory (Ulrich, 1983) and attention restoration theory (Kaplan \& Kaplan, 1989) explain these two types of restorative experiences associated with natural elements. People feel psychologically relaxed, restore from negative emotions fast, and recover from mental fatigue easily when being in nature due to their adaptive EP towards nature.

\subsubsection{Prospect and refuge}

Prospect and refuge theory is one of the most well-known environmental preference theories that explain humans' adaptive behaviours favouring certain landscapes reminiscent of ancestral savannah-like habitats. Originated from Darwin's habitat theory (Darwin, 1958), prospect and refuge theory explains that people feel safe and secure in places that provide an open view for outlook in the front (prospect) to be able to easily observe danger and, simultaneously, an enclosure from the back (refuge) to protect themselves from any intrusions (Appleton, 1975). Prospect spaces are related to a sense of openness for obtaining visual information about sources of danger and other relevant information for survival. Refuge spaces are related to a sense of hiding for enhanced privacy and safety for protection. This concept of being able to see around us without being seen by others is commonly observed in predators' hunting as well as shelterseeking behaviours in many species.

\subsubsection{Complexity and mystery}

Investigatory or exploratory behaviour is another common adaptive behaviour frequently observed in animals, including humans. This behaviour is to find optimal conditions for better survival by understanding environments (Appleton, 1975). Investigatory/exploratory behaviour offers the foundation of complexity and mystery theory. Complexity refers to various environmental elements in a view (Berlyne, 1971) and mystery, a view cuing surprisingly pleasant elements hidden in the next view (Kaplan \& Kaplan, 1989). When a view is associated with a higher level of complexity, people tend to feel more aesthetically pleased from the view. And they feel more curious to further explore beyond the current viewpoint when the view presents mystery exhibiting environmental cues for more interesting components awaiting. Both complexity and mystery have shown to be the predictors of preferred environments in natural environments, while mystery has shown more consistent results in both indoor and outdoor environments (Kaplan \& Kaplan, 1989). 


\subsubsection{Spatial biases}

People exercise controls over spaces between theirs and others, especially when they are with others in the same space. They exhibit behaviours, often non-verbal communicative cues, to express their discomfort when these invisible boundaries are violated by others. According to proxemics, a theory proposed by Hall (1966), people have an innate urge to regulate spatial distances between themselves and others. This is an adaptive behaviour intended to protect one's own habitat by setting up a distance to separate between kin and non-kin (Hediger, 1955). While related to the concept of territoriality, proxemics further argues that this behaviour is also derived from an intent for co-survival within the same group by maintaining a certain social distance between them while protecting oneself in a private shelter. This is to be able to easily both communicate vital information and regulate density for the distribution of resources such as food and a better chance of survival in case of danger and threats. Since regulating density was for the purpose of better survival, people exhibit negative psychologies related to high density and overcrowding in a space. High density and overcrowding have been associated with a feeling of unease from lack of controllability and availability of fewer resources (Stokols, 1978), and even cognitive overload in the brain function (Esser, 1973).

The social brain hypothesis argues that the evolution of human cognition is rather a response to surviving and reproducing in a social context (Dunbar, 1998). Dunbar suggests a close relationship between human cognitive capacity and the number of social relationships, attributing the limited number in a social group to the neocortex size in the brain. According to Dunbar's circles of acquaintanceship, humans have several layers of social relationships from highly intimate (close tie) to fairly casual (weak tie): support clique (3-5 most intimate people), sympathy group (12-20 close friends), bands (30-50 friends), and clan (150 casual friends) (Dunbar, 1993). The hierarchical order of circles indicates that the strength of bond in relationships with others decreases as the circles get bigger. The support clique circle is referred to the size of kin, sympathy group to people with special ties, bands to overnight hunting and gathering groups, and clan to traditional small societies (Dunbar, 2014).

The next section explains how these behaviours occur in the workplace, offering insights on psychological mechanisms underlying certain behaviours related to the workplace. This is to take advantage of the perspective of EP to understand and explain why we see certain behaviours in the workplace when these behaviours can be explained by EP the most. However, the ultimate goal of examining the EP theory for the application to the workplace in this chapter is neither to simply understand 'why' nor to explain the entire workplace human psychology based on EP. It is to offer insights for potential design and management solutions to reinforce positive behaviours and transform inadequate behaviours into adequate ones in more effective, systematic ways by better understanding human innate psychological nature.

\section{Application to workplace behaviours}

The application of EP to the workplace is in its infancy. However, there has been a growing interest in certain topics of EP, especially those aforementioned, in explaining particular behaviours persistently observed in the workplace. Some behaviours seem harmless common natural inclinations among people, but other behaviours may cause conflicts between people or violations within the rules and boundaries of the workplace. The contemporary work environment is significantly different from the ancestral environment of hunter-gatherers. It is mostly climate-controlled indoors; has different purposes of functions and types of tasks; is established within further systematically organised networks of people; and uses different types of tools and 
devices to accomplish tasks. The predominant contemporary open-plan offices, especially, have a particular configuration that may not accommodate human innate psychological mechanisms that were adapted and acquired since hunter-gatherer societies. In open-plan offices, people with certain personality traits may adapt faster and more easily to the environment of no personal boundaries (Lindberg, Tran, \& Banasiak, 2016). However, others may feel too uncomfortable to cope with the open environment that does not support their innate psychological programmes.

The greatest benefit of looking into the workplace behaviours through the lenses of EP is that it allows us to understand workplace behaviours based on a scientific framework; thus, to more easily identify issues and come up with solutions in a more systematic way. Some of the topics discussed here may have a common ground with other known discoveries such as in the environmental preference theory. Using the psycho-evolutionary model, environmental psychologists attribute particular environmental preferences commonly observed across various groups to human intrinsic psychology to protect and survive (Ulrich et al., 1991). Or, these topics may be frequently observed human behaviours but considered rather individual issues, such as territoriality or noise perception, than a human innate psychology across people that needs to be addressed in a more systematic way in the workplace.

\subsection{Attachment and territoriality}

The tendency of place attachment is often shown in the behaviours of personalisation within the personal spaces and boundaries at work. Furthermore, in activity-based working offices where people do not have assigned seats, people have shown a propensity of persistently preferring the same spots despite various seating options available (see Figure 17.1). Oftentimes, they feel uncomfortable or uneasy when other people take their usual spots. As place attachment is associated with a concept of exclusive boundary, this behaviour is related to territoriality. Territoriality is often observed in the workplace. Since workplace territoriality was recognised as an organisational behavioural issue in early 2000s, its research has expanded to cover human spatial behaviours derived from the psychology of territoriality. As territoriality is related to a feeling of ownership and attachment, an individual feeling of territoriality for one's own work has shown a link to positive attitudes and higher commitments to the organisation (Brown, Crossley, \& Robinson, 2014).

However, from a social relationship viewpoint among co-workers, a feeling of territoriality of individuals can lead to conflicts with others and non-cooperative conduct as a team member if it elevates to a higher level of exclusiveness, protectiveness, and confrontation against sharing and accessing one's work, office items, and spaces. Territorial behaviours at work can occur as either a claiming behaviour for the territory, marking physical boundaries of one's own, or an anticipatory defence behaviour, locking the drawers and hiding items and information related to jobs (Brown et al., 2014). While personalisation and controllability of individual workspaces should be provided to individuals to a certain level to increase positive attitudes, personal comfort, and productivity, undesirable territorial behaviours ought to be immediately mediated to maintain healthy organisational cultures and interpersonal dynamics for cooperative collegiality.

\subsection{Cognitive and perceptive biases}

While human visual and auditory systems are evolved to fit the ancestral environment, our current workplace environments are vastly different from such an environment. This 


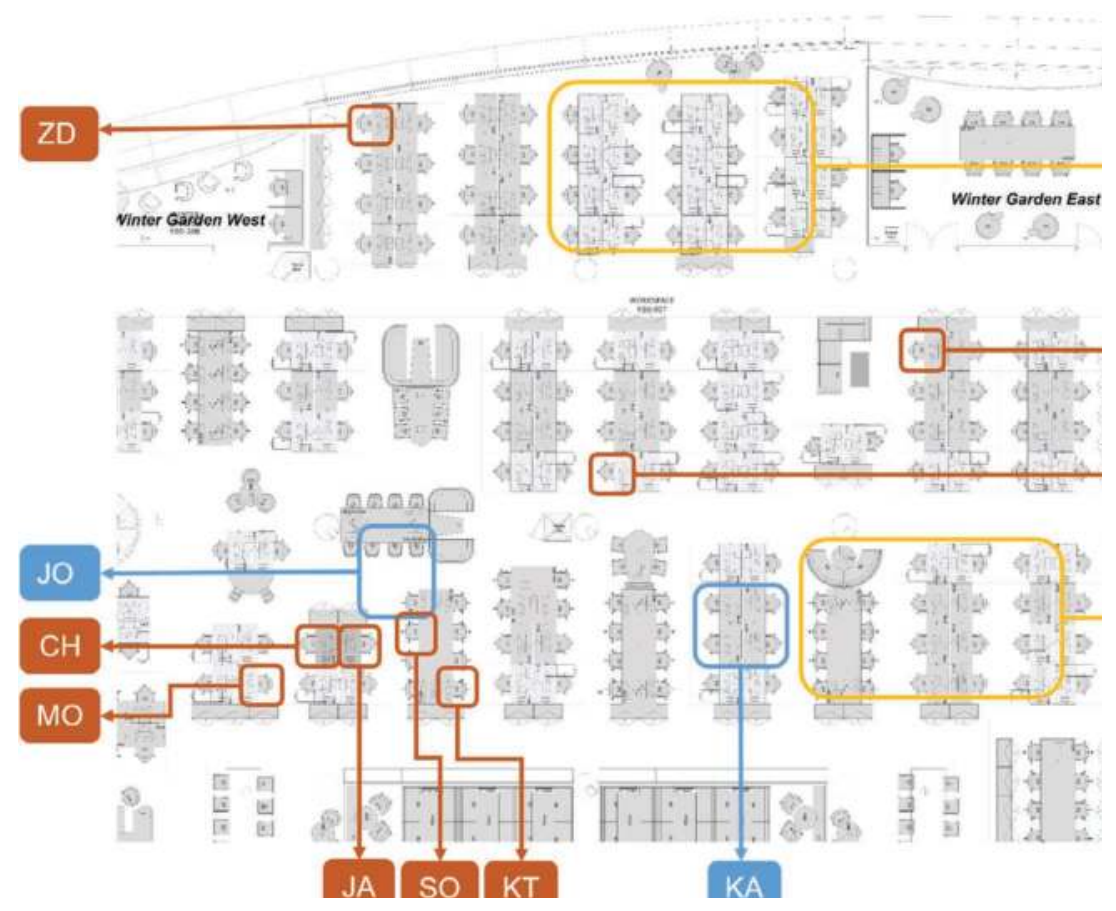

Figure 17.1 Attachment behaviour in an activity-based working office with no assigned seats in London

creates a mismatch between the way that our visual and auditory systems are tuned to the environment and the way that the contemporary work environments stimulate our visual and auditory systems. Most complaints in open-plan offices are associated with visual and auditory distractions (see also Chapter 6 Privacy-Regulation Theory). Human peripheral vision is sensitive to detecting speedy motions and flickering conditions (McKee \& Nakayama, 1984). Thus, people in open-plan offices are frequently distracted by various movements and activities of other people as well as by blinking lights from diverse office and personal devices. The main sources of noises in the workplace are known to be people: co-workers talking nearby and talking on the phone (Lee \& Guerin, 2009). As we are tuned to the voices of our own kind and our auditory system predominantly filters human voices over other sounds, we tend to be more distracted by voices of other people in the workplace.

In addition, our cognitive mechanisms are built to decipher whether these external visual and auditory stimuli are threats or not. Thus, these distractions constantly consume our cognitive resources and interfere with knowledge work tasks that require the same cognitive resources. To reduce visual and auditory distractions in the workplace, the following strategies can be useful: breaking down a large open space into smaller clusters, turning the desk orientation from face-to-face to face away, staggering desks, using plants for visual and acoustic privacy, providing small enclosed spaces for phone calls and conversations away from major individual workspaces, reinforcing noise-mitigating materials and construction details, and implementing workplace etiquette policy (Lee, 2020a, 2020b). 


\subsection{Biophilia and cognitive restoration}

Biophilic elements of nature have many benefits in workplace culture, behaviours, and productivity by contributing to reducing stress and anxiety, encouraging desirable behaviours, and improving cognitive restoration and function (Söderlund \& Newman, 2017). As most contemporary knowledge workplaces require cognitive tasks, integrating natural elements into the workplace can help with faster mental restoration and lower stress for employee health and wellbeing. Among various elements of nature, two most wanted elements at work are daylight and plants (Cooper, 2015; Lee, 2020c). Daylight, particularly, has shown a link to not only individual health and wellbeing but also organisational human analytics metrics such as job satisfaction and loyalty to the organisation (Lee, 2020c).

Biophilic elements applicable to the workplace can include sensory elements of nature (e.g. plants, water, sounds and smells of nature, views to outdoors, and daylight) as well as representations of nature (e.g. 2D/3D artwork depicting natural elements) or representative elements of nature applied to interior spaces or materials (e.g. shapes, forms, patterns, materials, and colours of nature) (Lee, 2019). When applying these elements in the workplace, one must be cognisant of the complex impact of biophilic elements on human psychology and cognitive performance in both short and long terms. While the benefits of biophilic elements may be clearer with regard to individual health and wellbeing, it may not be the same case for various cognitive tasks in the workplace. For instance, biophilic elements such as plants and natural views outside windows may contribute to decreasing stress and increasing creative thinking but also distract from attention (Yin et al., 2019). Thus, careful planning is necessary to determine the purpose of biophilic elements and which elements to apply where among various spaces of the workplace.

\subsection{Prospect and refuge}

Prospect and refuge behaviours, derived from outdoor living, can also be easily observed in seating preferences in the workplace. People tend to gravitate to heavy and large physical structures, preferring to sit next to walls or columns. This is to afford an open view to the main central space of action from a corner of the room, making sure that no threats emerge from the back or side. Research in the prospect and refuge theory has mainly examined either psychological aspects (preferential or perceptual attributes) or spatial aspects (geometric attributes) of views. Known attributes related to prospect include either preferential/perceptual attributes of outlook, depth of view, spaciousness, and openness or geometric attributes of isovist area and maximum radial line length in views. Attributes related to refuge include either preferential/perceptual attributes of enclosure and safety or geometric attributes of occlusion and minimum radial line length (Dosen \& Oswald, 2016). However, a caution needs to be exercised when implementing the prospect and refuge theory to the workplace, as contemporary workplaces are far more complex than ancestral outdoor living environments. In indoor work environments, people have shown relatively consistent seating/spatial preferences for open spaces in prospect-requiring circumstances, but less-consistent preferences in refuge-requiring circumstances (Dosen \& Oswald, 2016; Keszei, Halász, Losonczi, \& Dúll, 2019).

This may be because the perceived sense of safety in the indoor environment of the contemporary workplace relaxes pursuits for safer and more secure private spaces that were once essential in the savannah-like environment. In addition, the complexity of the current workplace, such as various environmental settings (e.g. window seat vs. corner seat), relationships (e.g. seat next to favourite co-worker vs. boss), work modes (e.g. focused vs. collaborative), and activities 
(individual work vs. interactive work) can also contribute to less consistent seating/spatial preferences for refuge-requiring circumstances. Refuge-requiring environments may be more important to certain personality traits (see also Chapter 10 Temperament Theory). There are many anecdotal stories on introverts disadvantaged in open-plan offices due to their tendency to turn inwards when responding to external stimuli. Thus, they tend to prefer less stimulation, fewer social interactions, and being in their own spaces. In order to provide more refuge-like spaces in open-plan offices for introverts, offering adjustable translucent (for visual privacy) or acoustic screens (for acoustic privacy) and implementing designated quiet or retreat spaces (Figure 17.2) may be helpful in addition to the strategies previously discussed to reduce visual and auditory distractions.

\subsection{Complexity and mystery}

Often examined together with prospect and refuge attributes of views, complexity and mystery are considered two other attributes that influence environmental preferences of the indoors. In research, the attributes associated with complexity are the amount of information presented, the

(a)
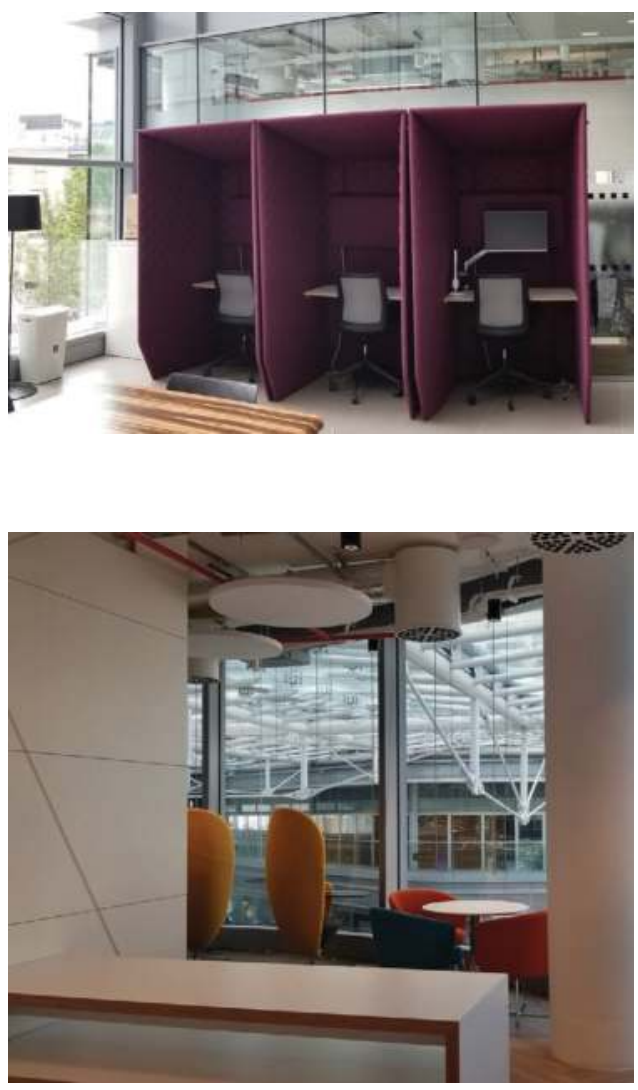

(C) (b)

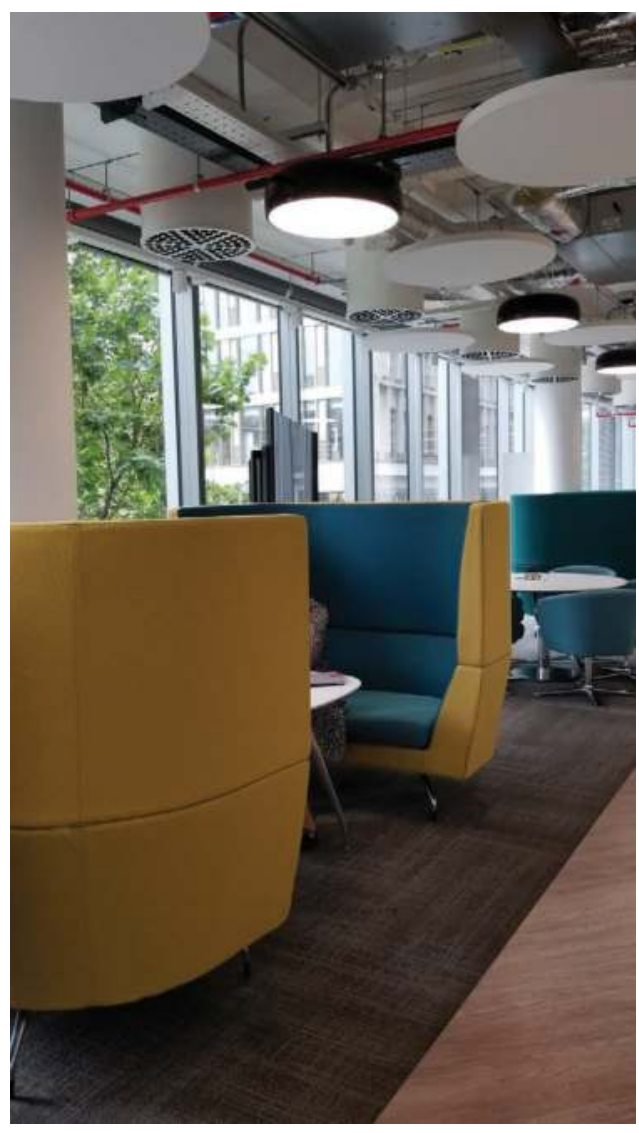

Figure 17.2 Various quiet and retreat spaces provided along the corners in an open-plan office of a real estate company in London 
level of jaggedness, and the number of occluding edges (vertices). The mystery attributes linked to complexity include the levels of luminosity and occlusivity between spaces (Dosen \& Oswald, 2016). Studies in general show that people prefer a view with a certain level of complexity. However, preferences for complexity in indoor environments are not as consistent as those in outdoor environments (Dosen \& Oswald, 2016). This may be due to the literal interpretation and application of the complexity and mystery theory prevalent in the natural environment to the indoor environment. As complexity and mystery are related to a human desire to further understand and explore their environments beyond the immediate surroundings, the components of complexity and mystery in contemporary workplaces may be more suitable in the areas where people are willing to further invest time and effort to learn more about the environmental elements. For instance, these components may be more appreciated when integrated to places where these elements do not interfere with the efficiency of performing job functions and tasks for the most urgent survival instinct. These places include lounges, rest areas, hangout spaces, cafeterias, or dining spaces. The strategies promoting complexity and mystery can also be implemented to encourage more physical movement for workplace health and wellbeing. These comprise providing options for various types of spaces, using curvilinear paths rather than straight paths, partial views in circulation paths, and small windows to other spaces with interesting components (Lee, 2019).

\subsection{Spatial biases: control and crowding}

People's behaviours related to space control in the workplace have been discussed as part of communication issues, especially non-verbal communications. As humans express over $90 \%$ of meanings via non-verbal communication channels (Bhardwaj, Sharma, \& Deepshikha, 2017), behaviours of proxemics that regulate interpersonal spaces become important for the effective communications within organisations. A clear expectation for interpersonal spaces needs to be established in the workplace since an encroachment of interpersonal spaces can be perceived as such unintended conduct as intimidation, attention, or threat (Bonaccio, O’Reilly, O'Sullivan, \& Chiocchio, 2016). Another topic of interest related to proxemics in organisations is social interactions in groups within particular spaces. As non-verbal cues of expression, people employ spatial positions and orientations for space control in interactions with others. This is called socio-spatial formation, known as Kendon's facing formation (F-formation), where people tend to jointly form a transactional space of a round shape (O-shape) (Setti, Russell, Bassetti, \& Cristani, 2015). This transactional space is constantly modified normally in forms of circular shapes, when the number in the group fluctuates, to maintain the direction and equal access to other people. Examining spatial patterns based on F-formations and behaviours of space control can offer valuable information to assist spatial design and planning for better communications in organisations. Furthermore, flexible furniture design and configurations can be developed to enable better interactions in groups by integrating such behavioural patterns.

Despite these natural human behaviours to regulate spaces per distance and intimacy, the contemporary workplace practice has pushed the personal boundaries to smaller sizes. Increased social density contributes to crowding which is associated with such negative feelings as frustration, lack of controllability, helplessness, and low motivation (Veitch, 2011). Increased social density and spatial density can make the work environment not only physically and psychologically uncomfortable but also vulnerable to easy transmission of contagious diseases, as shown in the incident of the deadly spread of COVID-19 in 2020 (Lee, 2020b). With human spatial behaviours and underlying psychologies in mind, some of the strategies mentioned earlier can 
also help to address this issue, including breaking down a large open space into smaller clusters, employing a face-away orientation of desks, staggering desks, and placing plants or physical screens along the clusters or major aisles. In addition, integration of the concept of flexible offices such as working from home and virtual office can also alleviate issues of crowding and density in the workplace.

\section{Methodology/research approach}

As EP is a theory or approach in psychology, it shares similar research methods used in other divisions of psychology or broadly in social science. These include subjective methods, objective methods, and a combination of these two. Subjective methods can include surveys or interviews. Objective methods comprise observations, experiments (both laboratory and field), and simulations. Due to the advancement of technology, recent studies have employed various medical devices and equipment, including devices examining biomarkers such as blood pressure, body temperature, and skin conductance, as well as devices looking into the brain activities such as functional magnetic resonance imaging (fMRI). A combination of subjective and objective methods, instead of relying on only a single type of method, is often recommended as a comprehensive approach to better understanding of the outcomes.

Particular methods can be utilised for specific environmental attributes of EP topics. Computational methods such as space syntax can be used when analysing geometries and spatial configurations in prospect and refuge, complexity and mystery, and proxemics (see also Chapter 21 Space Syntax). Space syntax, possible with either manual or computer-aided methods, analyses visibility and accessibility within the layout of spaces, which allows examinations of social interactions and spatial uses of users (Hillier, 1996). Space syntax can be employed to understand environmental preferences either via an observation of actual spaces (Psathiti \& Sailer, 2017) or virtual reality (VR) spaces (Keszei et al., 2019). VR is also often utilised in biophilic studies examining the impact of natural elements to control variables in the spaces (Yin et al., 2019). When conducting observations of interactions or spatial uses in groups, camera surveillance can be incorporated to more accurately record the incidences. However, the issue with privacy invasion should carefully be reviewed in such a case.

Currently, inexpensive innovative wearable technologies are becoming available at the medical grade. These technologies integrate biomarker sensors, including electroencephalography (EEG) and electrodermal activity (EDA), to simpler and more practical devices. Implementing these devices can allow researchers to collect more accurate physiological reactions to a specific external stimulus that can be further interpreted as cognitive or emotional states. Thus, it is a good idea to integrate these sensors as a complementary method to traditional psychometric measures and other subjective measures to better explain human responses towards either environmental stimuli or interactions with others in EP. For instance, EDA/ EEG sensors can be used in conjunction with cognitive tests/experiments and/or subjective surveys/interviews to understand the comprehensive impact on emotional states or cognitive functions by natural sound (see Figure 17.3) (Lee, Nelson, Flynn, \& Jackman, 2020) or natural views (Yin, Zhua, MacNaughtona, Allen, \& Spenglera, 2018). In conjunction with inexpensive innovative wearable technologies available for research in behavioural science, further advanced technologies in environmental sensors and data collection are also becoming available in building science research. It is recommended to take a methodologically comprehensive approach to examine human behaviours in EP by further integrating building data, such as temperature, indoor air quality, acoustics, and daylight to name a few, with physiological data and psychometric data. 
(a)

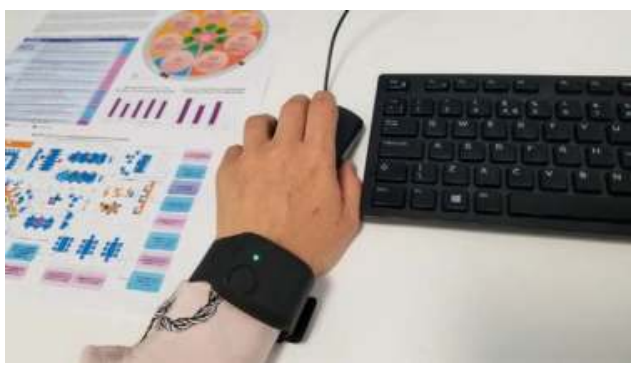

(b)

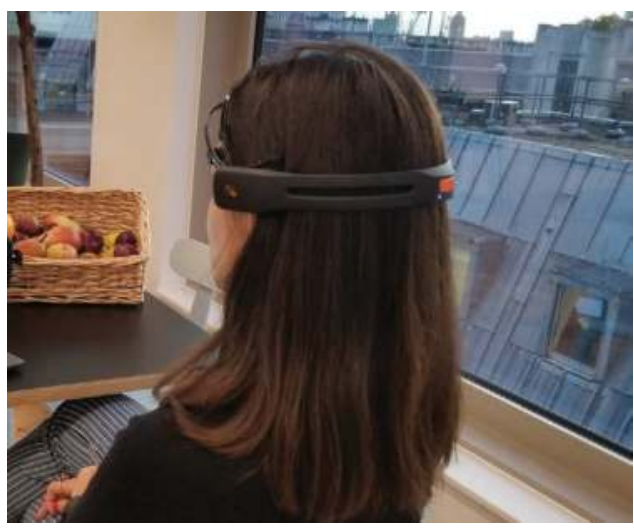

Figure 17.3 Integrating EDA (left) and EEG (right) devices to environmental stimuli experiments

\section{Limitations}

As mentioned earlier, EP is not free of criticisms. Since it applies behavioural patterns observed in animals to humans, and attributes human behaviours to natural adaptedness, it may promote biological determinism believing that human behaviours are simply determined by genes and biological traits. It may also promote panadaptionism that all human behaviours and physiological evolution such as brain size are attributed to the human need for survival. These ideas may lead to discrediting other aspects of complex human development affected by the physical environment, social context, cultural progression, and human autonomy. If solely relying on EP for explanations for human behaviours, it may be easy to dismiss potentially better-suited explanations and theories. Furthermore, it may use human adaptation as a defence or justification for undesirable human behaviours in the modern human society such as domination, sexism, hierarchy, and territorialism. Thus, one must be aware that some behaviours but not all are better explained by EP when applying it to the workplace. More importantly, even if certain behaviours may be better explained by EP, moral and ethical judgments must be exercised to evaluate those behaviours. The topics discussed in this chapter are the ones that may be better explained by EP. While presented in separate topics, some behaviours are related to each other. Thus, it may be best to address them simultaneously in the real workplace. Design and facility management strategies provided in this chapter can be used to steer people towards positive behaviours and away from inadequate behaviours to better fit the current functions and lifestyles to create healthy workplaces.

\section{Theory relevance to practice}

This chapter discussed six topics in EP as they are commonly observed behaviours in the workplace: attachment and territoriality, cognitive and perceptive biases, biophilia and cognitive restoration, prospect and refuge, complexity and mystery, and spatial biases. These behaviours are considered hard-wired adaptive behaviours driven from the innate survival instinct in the ancestral environment. These behaviours are exhibited in forms of preferences desiring certain features for comfort, modifications altering the environment to fit their needs, or complaints in the absence of these components. By understanding human innate psychological mechanisms, 
workplace practitioners can provide an environment that better accommodates these hard-wired needs and resolves interpersonal conflicts by considering these behaviours as collective behaviours instead of individual behaviours. When implementing specific solutions for various topics aforementioned, one must be aware of the dynamics among these topics. Even if solutions for a specific topic are sought, it is best to examine it with relevant topics together to afford better solutions by understanding potential synergic benefits and trade-offs. Spatial regulation issues need to be examined together, including personal/interpersonal space, proxemics, territoriality, and crowding. Environmental preference issues also need to be looked at together, including prospect and refuge, complexity and mystery, and biophilia.

Finding solutions between certain topics may be complicated in practice due to their conflicting natures, such as personal spaces for individuals and social interactions for groups. Differences in gender, generations, and cultures must be considered in seeking appropriate spatial distances and socially accepted intimacy. Many of the theoretical components discussed in this chapter are based on Western cultures. Thus, it is necessary to understand these behaviours under the certain cultural context that is being examined. Lastly, it is important to understand that each workplace is unique. It may not be effective to simply adopt research findings from experiments or other organisations without considering specific spaces, people, organisational cultures, and leadership styles of a particular workplace. While general evidence of these behaviours exist, there is a vast discrepancy in research findings in terms of consistency and replicability, especially in spatial and architectural attributes (Dosen \& Oswald, 2016). The best approach to applying these EP topics to the workplace would be balancing out among the various issues such as personal space, visual privacy, acoustical comfort, social interaction, open vs. enclosed spaces, certain spatial features of complexity and mystery, and biophilic elements for the overall wellbeing of people.

\section{Further reading}

- Colarelli, S. M., \& Arvey, R. D. (2015). The biological foundations of organizational behavior. Chicago, IL: The University of Chicago Press.

- Dosen, A. S., \& Ostwald, M. J. (2016). Evidence for prospect-refuge theory: A metaanalysis of the findings of environmental preference research. City Territory and Architecture, 3(4), 1-14.

- Fitzgerald, C. J. (2012). Evolution in the office: How evolutionary psychology can increase employee health, happiness, and productivity. Evolutionary Psychology, 10(5), 770-781.

- Lee, Y. (2020, May 29). Don't stand so close to me: Creating the resilient workplace. Retrieved from Worktech Academy: www.worktechacademy.com/dont-stand-so-close-to-me-creatingthe-resilient-workplace/

- Saad, J. (2011). Evolutionary psychology in the business sciences. New York, NY: Springer.

\section{References}

Appleton, J. (1975). The experience of landscape. London: Wiley.

Berlyne, D. E. (1971). Aesthetics and psychobiology. New York: Appleton-Century-Crofts.

Bhardwaj, S., Sharma, V., \& Deepshikha. (2017). Study on managerial communication in multicultural workplace. Journal of Management Research, 9(1), 60-65.

Bonaccio, S., O’Reilly, J., O'Sullivan, S., \& Chiocchio, F. (2016). Nonverbal behavior and communication in the workplace: A review and an agenda for research. Journal of Management, 42(5), 1044-1074. https://doi.org/10.1177/0149206315621146

Bowlby, J. (2005). The making and breaking of affectional bonds. New York: Routledge Classics. 
Brown, G., Crossley, C., \& Robinson, S. L. (2014). Psychological ownership, territorial behaviour, and being perceived as a team contributor: The critical role of trust in the work environment. Personnel Psychology, 67, 463-485. https://doi.org/10.1111/peps.12048

Buss, D. M. (2009, May). Darwin's influence on modern psychological science. Psychological Science Agenda. Retrieved from www.apa.org/science/about/psa/2009/05/sci-brief

Buss, D. M. (2019). Evolutionary psychology: The new science of the mind (6th ed.). New York: Routledge.

Confer, J. C., Easton, J. A., Fleischman, D. S., Goetz, C. D., Lewis, D. M., Perilloux, C., \& Buss, D. M. (2010). Evolutionary psychology: Controversies, questions, prospects, and limitations. The American Psychologists, 65(2), 110-126.

Cooper, C. (2015). Human spaces: The global impact of biophilic design in the workplace. Retrieved from https:// greenplantsforgreenbuildings.org/wp-content/uploads/2015/08/Human-Spaces-Report-BiophilicGlobal_Impact_Biophilic_Design.pdf

Darwin, C. (1958). The origin of species. Amherst, NY: Prometheus.

Dosen, A. S., \& Oswald, M. J. (2016). Evidence for prospect-refuge theory: A meta-analysis of the findings of environmental preference research. City, Territory and Architecture, 3(4), 1-14. https://doi. org/10.1186/s40410-016-0033-1

Dunbar, R. (1993). Coevolution of neocortex size, group size and language in humans. Behavioral Brain Science, 16(4), 681-694. https://doi.org/10.1017/S0140525X00032325

Dunbar, R. (1998). The social brain hypothesis. Evolutionary Anthropology: Issues, News, and Reviews, 6(5), 178-190. https://doi.org/10.1002/(SICI)1520-6505(1998)6:5<178::AID-EVAN5>3.0.CO;2-8

Dunbar, R. (2014). The social brain: Psychological underpinnings and implications for the structure of organizations. Current Directions in Psychological Science, 23(2), 109-114. https://doi.org/10.1177/09637 21413517118

Dunbar, R., \& Barret, L. (2007). The Oxford handbook of evolutionary psychology. Oxford: Oxford University Press.

Esser, A. H. (1973). Cottage fourteen: Dominance and territoriality in a group of institutionalized boys. Small Group Behavior, 4(2), 131-146. https://doi.org/10.1177/104649647300400201

Fodor, J. (1983). Modularity of mind: An essay on faculty psychology. Cambridge, MA: MIT Press.

Gold, J. R. (1982). Territoriality and human spatial behaviour. Progress in Human Geography, 6(1), 44-67. https://doi.org/10.1177/030913258200600102

Griffiths, P. E. (2008). Ethology, sociobiology and evolutionary psychology. In S. Sarkar \& A. Plutynski (Eds.), A companion to philosophy of biology (pp. 393-414). New York: Blackwell.

Hall, T. (1966). The hidden dimension. New York: Doubleday and Co.

Hediger, H. (1955). The psychology and behavior of animals in zoos and circuses. New York: Dover.

Hillier, B. (1996). Space is the machine: A configurational theory of architecture. Cambridge: Cambridge University Press.

Kaplan, R., \& Kaplan, S. (1989). The experience of nature: A psychological perspective. Cambridge: Cambridge University Press.

Keszei, B. K., Halász, B., Losonczi, A., \& Dúll, A. (2019). Space syntax’s relation to seating choices from an evolutionary approach. Periodica Polytechnica Architecture, 50(2), 115-123. https://doi.org/10.3311/ PPar. 14251

Lee, Y. (2019). PROWELL PLUS: Workplace health and wellbeing assessment tool. New York: Innovative Workplace Institute.

Lee, Y. (2020a). Acoustic planning to improve workplace health, wellbeing and performance: What works. In Health and wellbeing at work. Birmingham: Health and Wellbeing at Work.

Lee, Y. (2020b, May 29). Don't stand so close to me: creating the resilient workplace. Retrieved from Worktech Academy: www.worktechacademy.com/dont-stand-so-close-to-me-creating-the-resilient-workplace/

Lee, Y. (2020c). IWI-UCL workplace health and wellbeing research: The impact of workplace health and wellbeing on organizational outcomes at Land Securities Head Office. New York: Innovative Workplace Institute. Retrieved from https://innovativeworkplaceinstitute.org/assets/publications/Report_UCLIWI\%20Workplace\%20Health\%20\&\%20Wellbeing\%20Study\%20@\%20LandSec\%20summary\%20 report.pdf

Lee, Y., \& Guerin, D. (2009). Indoor environmental quality related to occupant satisfaction and performance in LEED-certified buildings. Indoor Built Environment, 18(4), 293-300. https://doi.org/10.1177/ 1420326X09105455

Lee, Y., Nelson, E., Flynn, M. J., \& Jackman, J. S. (2020). Exploring soundscaping options for the cognitive environment in an open-plan office. Building Acoustics, 1-18. https://doi.org/10.1177/1351010X20909464 
Lindberg, C. M., Tran, D. T., \& Banasiak, M. A. (2016). Individual differences in the office: Personality factors and work-space enclosure. Journal of Architectural and Planning Research, 33(2), 105-120.

McKee, S. P., \& Nakayama, K. (1984). The detection of motion in the peripheral visual field. Vision Research, 24(1), 25-32. https://doi.org/10.1016/0042-6989(84)90140-8

Neuhoff, J. G. (2016). Looming sounds are perceived as faster than receding sounds. Cognitive Research: Principles and Implications, 1(15), 1-9. https://doi.org/10.1186/s41235-016-0017-4

Psathiti, C., \& Sailer, K. (2017). A prospect-refuge approach to seat preference: Environmental psychology and spatial layout. In 11th space syntax symposium (pp. 137.1-137.16). Lisbon: Space Syntax Symposium.

Scannell, L., \& Gifford, R. (2010). Defining place attachment: A tripartite organizing framework. Journal of Environmental Psychology, 30(2010), 1-10. https://doi.org/10.1016/j.jenvp.2009.09.006

Schacter, D. L., \& Addis, D. R. (2007). The cognitive neuroscience of constructive memory: Remembering the past and imagining the future. Philosophical Transactions, 362, 773-786. https://doi.org/10.1098/ rstb.2007.2087

Schrode, K. M., \& Bee, M. A. (2015). Evolutionary adaptations for the temporal processing of natural sounds by the anuran peripheral auditory system. Journal of Experimental Biology, 218, 837-848. https:// doi.org/10.1242/jeb.115014

Setti, F., Russell, C., Bassetti, C., \& Cristani, M. (2015). F-formation detection: Individuating free-standing conversational groups in images. PLoS One, 10(9), e0123783. https://doi.org/10.1371/journal.pone.01 39160

Söderlund, J., \& Newman, P. (2017). Improving mental health in prisons through biophilic design. The Prison Journal, 97(6), 750-772. https://doi.org/10.1177/0032885517734516

Stokols, D. (1978). A typology of crowding experience. In A. Baum \& Y. M. Epstein (Eds.), Human response to crowding (pp. 219-255). Hillsdale, NJ: Erlbaum.

Ulrich, R. S. (1983). Aesthetic and affective response to natural environment. In I. Altman \& J. F. Wohlwill (Eds.), Behavior and the natural environment (pp. 85-125). New York: Plenum Press.

Ulrich, R. S., Simons, R., Losito, B. D., Fiorito, E., Miles, M. A., \& Zelson, M. (1991). Stress recovery during exposure to natural and urban environments. Journal of Environmental Psychology, 11(3), 201-230. https://doi.org/10.1016/S0272-4944(05)80184-7

Veitch, J. A. (2011). Workplace design contributions to mental health and well-being. HealthcarePapers, 11(Sp), 38-46. https://doi.org/10.12927/hcpap.2011.22409

Wilson, E. O. (1984). Biophilia. Cambridge, MA: Harvard University Press.

Yin, J., Arfaei, N., MacNaughton, P., Catalano, P. J., Allen, J. G., \& Spengler, J. D. (2019). Effects of biophilic interventions in office on stress reaction and cognitive function: A randomized crossover study in virtual reality. Indoor Air, 29(6), 1028-1039. https://doi.org/10.1111/ina.12593

Yin, J., Zhua, S., MacNaughtona, P., Allen, J. G., \& Spenglera, J. D. (2018). Physiological and cognitive performance of exposure to biophilic indoor Environment. Building and Environment, 132(2018), 255-262. https://doi.org/10.1016/j.buildenv.2018.01.006 


\title{
BEHAVIOURAL ECONOMICS THEORY
}

\section{Masters of deviations, irrationalities, and biases}

\author{
Young Lee*
}

\section{Background}

\subsection{Understanding how we, Homo sapiens, really behave}

Based on the utility concept, traditional economics models were created by the premise of impeccably rational humans when making decisions. These classical models have assumed that normal people, Homo sapiens, would behave the same way that Homo economicus (economic person) exercises infinite rationalities and self-control for the best benefits of themselves (Thaler, 2000). Thus, they were unable to grasp the psychology or cognition of normal Homo sapiens who has flaws in their reasoning and uses heuristics, instinct, and emotions in decision-making instead of perfect logic to calculate probability for the best utility after exhausting all comparisons between pros and cons of economic options. Behavioural economists suggest that humans have bounded rationality, in which people make decisions based on various cognitive limitations (Simon, 1957). Thus, unlike the traditional utility economic models, the premise of BE builds upon understanding common cognitive biases, irrationalities, and deviations that normal people exhibit, which often drive them to make decisions that are not in their best interest or beneficial to them.

BE pays special attention to three aspects of human behaviours: use of immediate cognitive resources such as heuristics in decision-making, temporal aspect of judgments, and social influence on individual decision-making (Samson, 2014). Heuristics are mental shortcuts used to make fast and easy decisions under limited information and time (Gilovich, Griffin, \& Kahneman, 2002). Rule of thumb, educated guess, and trial and error are heuristics that people frequently rely on and exercise for quick decision-making. These are known to work well in general but also are subject to errors, especially in more complex situations (Sunstein, 2017). In many cases, heuristics are exercised based on previous experiences, easily available memory, and initially obtained information (Zhang \& Highhouse, 2018). When heuristics induce systematic errors in judgment, biases tend to occur. When examining common human biases, $\mathrm{BE}$ also brings attention to human evaluations and judgments that are susceptible to time and social context. BE acknowledges that people are more perceptive to the present time and are constantly influenced by the social context and norms, introducing a temporal dimension and a social dimension in addition to cognitive dimension to the depth of the theoretical framework (Samson, 2014).

*Corresponding author: young.lee@innovativeworkplaceinstitute.org 
The core ideas of BE have already been exercised in consumer-oriented fields such as marketing, advertising, and television game shows in practice before BE. However, the world-renowned Nobel Prize recipient in economics Thaler, along with Kahneman and Tversky, has developed theoretical frameworks and established BE as a recognised division of mainstream economics. By integrating cognitive psychology to economics, these behavioural economists intended to understand the way that human cognition really works in economic decision-making and discover the common cognitive biases underlying irrational behaviours. BE has been applied to various fields beyond economics and finance, including social psychology, organisational psychology, business management, human resources, politics, and crime science, to understand social and organisational psychology as well as to implement strategies for easy motivation of people towards desired options (Samson, 2017). Often, these discoveries in BE are used to develop strategies and solutions to prevent shortcomings of the natural cognitive process of decision-making in various fields, such as public policy, HR, and public health to name a few.

\subsection{Cognitive, temporal, and social biases of $B E$}

Among many common cognitive biases in decision-making discussed in BE, this chapter focuses on the ones more relevant and applicable to the workplace. While not an exhaustive list, these comprise status quo bias, loss aversion, optimism bias, overconfidence, planning fallacy, herd behaviour, social norm, and reciprocity. Due to the relevance between these topics, certain topics are explained together below: (1) status quo bias and loss aversion focusing on heuristics and biases; (2) optimism bias, overconfidence, and planning fallacy on the temporal dimension; and (3) herd behaviour, social norm, and reciprocity on the social dimension of BE.

\subsubsection{Status quo bias and loss aversion}

It is easy to observe people's propensity for maintaining the default or the same previous settings in various devices such as cell phones or computers without changing them. These behaviours often sustain even in the events of vast improvements for their comfort, health, productivity, and financial benefits by changing these settings. The status quo bias means the preference of no changes or remaining the same status as before even if it requires only little efforts or costs, or people are aware of the benefits from the changes (Samuelson \& Zeckhauser, 1988). Inertia and procrastination may be the drivers of this behaviour. However, people tend to resort to no changes in situations of too much cognitive thinking involved or highly uncertain consequences of new options (Dean, Kibris, \& Masatlioglu, 2017). According to Samuelson and Zeckhauser (1988), three main reasons for status quo bias are cognitive misperceptions, psychological commitment, and difficulty with rational evaluation when costs and/or uncertainty are involved. Uncertainty, especially, drives people to gravitate to already known safe methods and circumstances to avoid risks (see also Chapter 17 Evolutionary Psychology Theory). People also tend to regret more when the results are bad from their new actions than from no actions (Kahneman \& Tversky, 1982). This is due to people's innate negativity bias, in which they naturally place more emphasis on negative consequences than positive consequences of their decisions (Baumeister, Bratslavsky, Finkenauer, \& Vohs, 2001).

The negativity bias leads people to evaluate loss and gain unequally. People tend to perceive losses more regrettably than they appreciate the same amount of gains from a decision, called the loss aversion bias (Kahneman \& Tversky, 1979). According to the loss aversion bias, people tend to commit to the potential gain only when it doubles the potential loss (Samson, 2014). This means that people are not motivated enough to change or select a new option without 
sufficient incentives that outweigh the potential loss from the change. Due to this concern with loss, when information is presented in a negative (loss) frame instead of a positive (gain) frame, people may perceive the consequences more seriously (Meyerowitz \& Chaiken, 1987). An example would be ' $10 \%$ rate of operations failure' versus ' $90 \%$ rate of operations success'. This is called framing effect, referring to a tendency of people whose decisions are affected by how the information is presented to them (Plous, 1993). When exercising framing effect in practice, a caution is necessary as the effect can yield different outcomes among different age groups due to a higher susceptibility to the automatic affect heuristic among certain age groups with a declining cognitive capacity (Thomas \& Millar, 2011). In addition, persuasiveness via the gain-loss frame to encourage/discourage certain behaviours may result in unexpected/ unintended outcomes, depending on topics and circumstances (Baek \& Yoon, 2017). Lastly, ethical questions may rise with regard to influencing people's decisions by manipulating how information is presented and perceived.

\subsubsection{Optimism bias, overconfidence, and planning fallacy}

People's evaluations and judgments on gains and losses are time dependent. People are presentbiased, weighing the present time significantly heavier than the past. Due to this tendency, people focus more on their present emotions, experiences, and circumstances than on how their past events of similar incidents actually turned out. When people evaluate the probability of positive vs. negative consequences of an event, they tend to become more optimistic regardless of the past experiences, called the optimism bias (Samson, 2017). An example of the optimism bias is that people tend to believe that they are less likely to cause a car accident despite their radical driving habits. This bias occurs regardless of past experiences and abundant information readily available (Kahneman \& Tversky, 1973). The optimism bias can exhibit from both a positive incident (e.g. believing to live longer due to eating organic foods) and a negative incident (e.g. believing their unlawful conduct to be unnoticed). However, people tend to feel more optimistic in negative incidents (Gouveia \& Clarke, 2001).

The optimism bias leads people to be overconfident when evaluating their own capability. Overconfidence becomes problematic when people overrate their performance and commit to certain plans above their true ability, warranting frequent failures to adhere to the original plans. Overconfidence is typically measured by overestimation, overplacement, and overprecision (Moore \& Healy, 2008). According to Moore and Healy (2008), people tend to falsely believe that their ability and performance are better than they actually are (overestimation), their ability and performance are better than others (overplacement), and their knowledge or information is more accurate than it really is (overprecision). Both optimism and overconfidence biases drive people to commit to planning fallacy that people underestimate time, cost, and risks (Lovallo \& Kahneman, 2003). The important aspect of planning fallacy is that this tendency occurs not because of lack of information available from the past failures in similar circumstances (Kahneman \& Tversky, 1973). Potential reasons for this tendency may be the inability to recognise the similarities between circumstances or comparing the circumstance to non-equivalent circumstances (Kahneman \& Tversky, 1979).

\subsubsection{Herd behaviour, social norm, and reciprocity}

$\mathrm{BE}$ focuses on the concept of herd behaviour to understand how individuals are affected by other people's opinions and social trends in forming their own opinions and making decisions. Instead of being independent decision makers, people, as social animals, tend to conform 
within the group that they belong to. Herd behaviour can be as innocent as trying to eat the same healthy foods as colleagues eat or as irrational as toilet paper stockpiling seen during the COVID-19 pandemic in early 2020 that was motivated by collective irrationality of fear and uncertainty. Social norms play a significant role in forming herd behaviours. Social norms are generally accepted and expected behaviours in a group or society (Dolan, Hallsworth, Halpern, King, \& Vlaev, 2010). The members in the group or society feel not only pressured to follow the shared social norms, but also feel shame or guilt when not conforming to those norms. Since social norms define what behaviours are appropriate within a group, they tend to be specific to the culture of the group.

Reciprocity is an interesting concept as a social norm since it emphasises a human nature beyond pure self-interest. Reciprocity is an in-kind exchange, not an economic exchange, responding to an action of others with the same kind of action, such as returning a favour (Samson, 2017). The famous old saying of 'an eye for an eye' is a direct example of reciprocity, showing how essential this concept is as a principle of social conduct deeply embedded in a human society. According to the reciprocity principle, people tend to be nicer and more cooperative when requested nicely. This cooperative propensity towards others is called positive reciprocity while the retaliatory behaviour in 'an eye for an eye' is called negative reciprocity. Reciprocity has been greatly examined in people's behaviours with tax compliance, voting, and fundraising (Malmendier, te Velde, \& Weber, 2014). While a small percentage of people exhibit no concept of reciprocity by acting solely based on pure self-interest, people in general conduct themselves per reciprocity in a society. Due to this reason, such topics as incentives and voluntary cooperative reciprocity, reciprocal behaviours and organisational outcomes, and incivility and retaliatory reciprocity have become of particular interest in the workplace.

\section{Applicability to workplace studies}

Since theories in economics are closely tied with business management, topics related to BE have been actively discussed in organisational management. Workplace policies and HR practices have, especially, sought strategies and tactics in BE to encourage desired behavioural changes within the organisation. These behaviours vary, including energy saving, healthier habits, job performance, or compliance to ethics (Ilieva \& Drakulevski, 2018). This adoption in business management was to take advantage of low to no cost associated with $\mathrm{BE}$ implications such as utilising negative framing by changing wording in a message. The majority of earlier adopters of BE in the built environment side of the workplace were in occupational health and safety, where the physical environment of the workplace could cause serious illnesses and injuries if not intuitive or straightforward to employee heuristics and cognitive procedural limitations (Seabury, Reville, Rhodes, \& Boden, 2005). Recently, workplace designers, facility managers, and workplace strategists have started recognising the potential of BE as a framework to facilitate workplace health and wellbeing (Lee, 2019). Expounding upon the aforementioned biases related to three dimensions of BE, this section further discusses the relevance of them to the workplace.

\subsection{Status quo bias and loss aversion}

A good example of the status quo bias in the workplace is maintaining the same environmental settings already in place, instead of changing them to optimise the environment to respond to the fluctuating external stimuli (see Figure 18.1). For instance, a reason for imbalance in daylight penetration into the workplace is due to people's inertia behaviour - once they close the shades to block out too much glare from daylight in the morning, they leave the window shades closed 
later in the day even if there is not enough daylight in their workplace (Steverson, 2017). Inertia behaviours, persisting to existing conditions and functions, are harmless in general but become problematic when the current conditions and functions are inefficient (Polites \& Karahanna, 2012). While the previous example is actively decided by individuals as a choice of no change/ action, many other decisions in the workplace are made for individuals by others as defaults, and individuals passively accept them ( $\mathrm{Lu} \&$ Xie, 2014). Office layouts and desk locations are decided by designers and facility managers, computer default settings by IT, and defaults in retirement account options by HR. Mandating a new change, without understanding the keen relationship between the status quo bias and cognitive misperceptions, can frequently end up as a failure in persuading employees to adopt a new change (Jasperson, Carter, \& Zmud, 2005). In providing resolutions for the status quo bias and inertia behaviours, some researchers focus on choosing the default options for the best interest of employees or utilising framing effect to direct them to more desirable decisions for their own interest. Others focus on how to promote individual competency in decision-making. For instance, Lu and Xie (2014) highlighted that the status quo bias could be mediated by evaluating gains and losses of a change with a more balanced set of queries and listing gains before losses to intervene with the negativity bias and the loss aversion bias (see Section 5 for these two approaches). While not a BE strategy, participatory design, utilised in architectural and workplace design integrating employees' suggestions for their own workspaces and workstyles to the overall workplace planning, can provide opportunities for employee involvement in decision-making, instead of forcing them to be passive adopters.

The status quo bias accelerates under the circumstances of uncertainty and difficulty with accurately judging gains and losses from a choice. These situations are the particular concerns of occupational safety and health professionals. This is because worker capability of collecting and processing information on risks is critical in these situations to prevent workplace injuries and reduce workers' compensation (Seabury et al., 2005). In this regard, many researchers focus on two issues: (1) cognitive process and individual biases in perceiving risks and deciding a choice such as overestimating vs. underestimating risks and (2) cost-benefit analysis of workplace safety

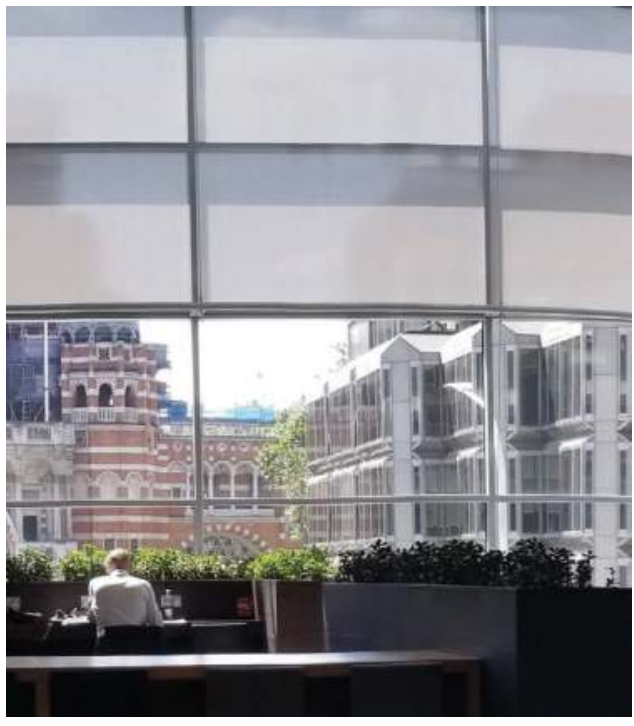

Figure 18.1 Window shades half closed all day without changes to control the amount of daylight 
to understand the comprehensive evaluation between costs and benefits. Cost-benefit analysis is also often used to understand at which costs people are willing to accept a new change, examining the degree of loss aversion between the willingness to pay and the willingness to accept an alternative option (Dauth \& Haller, 2020). With the recent workplace health and wellbeing trend, people's tendency of the status quo and inertia habits, such as prolonged sitting, has become a further concern (Das et al., 2016). To break up people's status quo tendency to promote workplace health and wellbeing, it is important to improve spatial and environmental elements and provide alternative options to promote physical movement. In addition, automated controls can provide necessary adjustments for constantly fluctuating environmental factors, such as daylight, temperature, or indoor air quality, without cumbersome human interventions throughout a day.

\subsection{Optimism bias, overconfidence, and planning fallacy}

Optimism, generally harmless, becomes a problematic issue in the workplace when it is accompanied by overconfidence. This is because overconfidence leads to inaccurate judgments and projections in organisational planning. The majority of research in overconfidence focuses on overestimation. Researchers have discovered that people tend to underestimate their ability when tasks are easy or they are well experienced with the tasks, but overestimate it when tasks are rather difficult (Michailova \& Katter, 2014). This is known as the hard-easy effect in cognitive psychology (Lichtenstein \& Fischhoff, 1977). Experiences are also associated with overconfidence in a similar manner to the hard-easy effect: people tend to be overconfident when less experienced with the business type (Hayward, Shepherd, \& Griffin, 2006). Many studies confirm people's tendency with overplacement (Beer \& Hughes, 2010). Known as the better-than-average belief, overplacement is prevalent despite objective performance standards available in organisations (Benoît, Dubra, \& Moore, 2015). A wishful thinking of expecting to be better than others may lead people to the overplacement belief. Overprecision, judgmental overconfidence, is most widespread but least studied and understood among the three types of overconfidence in organisational behaviours (Moore \& Schatz, 2017). While overprecision may be derived from a lack of knowledge or experiences, studies also show that a higher level of accuracy in business is associated with higher confidence in the knowledge (Ilieva, Brudermann, \& Ljubomir, 2018). Ilieva et al. (2018) also found that people making decisions alone, highly relying on their own knowledge and judgment without consulting others, tend to be overconfident. However, overconfidence is not always negative in the workplace. Such an attitude can lead people to be more innovative and persuasive, not to mention increased subjective wellbeing about one's own self.

The attitude of solely relying on only one source of information can easily lead to planning errors in organisations. Since people are unaware of the full scope of situations, they tend to underestimate the probability of obstacles and risks. Planning fallacy can happen in underestimations of various resources. An infamous example is a construction time and cost underestimation in Sydney Opera House, in which the six-year project with an initial cost of \$7 million in 1957 ended up opening in 1973 with an over budget of $\$ 102$ million (Buehler, Griffin, \& Ross, 2002). It is argued that over $50 \%$ of the projects are underestimated in budget (Love, Ika, \& Sing, 2019). Time underestimations can also range from 30\% less time than the actual time required for easy to moderate projects to $50 \%$ for complex projects as shown in Microsoft's internal analysis of their delayed projects (Beshears \& Gino, 2015). Planning fallacy is shown in many mega structures and novel projects such as the London Wembley Stadium, in which the initial projection of time and cost was difficult due to no precedent cases and the complexity of the scope. However, planning fallacy tends to exhibit even when the information on precedents is available. This is because 
people take an inside view where they focus on the uniqueness of the task/project and disregard past experiences, as opposed to an outside view where they contemplate other factors when predicting time and budget to complete a task/project (Buehler et al., 2002). Since planning fallacy is persistent regardless of precedent information and outside views available, it may be wise for organisations to embrace the bias and focus on modifying the projection of required resources by establishing a standardised procedure of adding safety margins or incorporating other available information in determining necessary resources. Examining past projects is a good resolution to planning fallacy by understanding typical estimation errors within the organisation and adding more accurate safety margins for future project estimations.

\subsection{Herd behaviour, social norm, and reciprocity}

The concept of social norms has recently been utilised as a cost-effective approach to motivating people to engage in behavioural changes for sustainability and health promotion in the workplace. For instance, presenting one's energy consumption trend compared to others stimulates her/his motivation to stick to the similar trend of others' energy use (Allcott, 2011). Worksite health and wellness promotion programs are also known to be more effective in sustaining healthy behavioural changes when accompanied with changes in workplace norms (Carnethon et al., 2009). In addition, utilising descriptive social norm messages has shown to promote daily healthy behaviours by indicating how other people commit to healthy behaviours. Displaying signs near elevators to encourage stair climbing instead of using elevators (see Figure 18.2) showed nearly $50 \%$ of people switching to using stairs from elevators (Burger \& Shelton, 2011). Displaying posters with a social norm message on vegetable choice by others also increased vegetable selection at workplace restaurants (Thomas et al., 2017). This is because people consider other people's behaviours as a guide in deciding their behaviours, which explains why people within the same social group such as family often exhibit the same dietary preferences. While simple methods as social norm messages can influence healthy behaviours, promoting a healthy lifestyle at work is more complex and requires more than simple BE tactics. In order to change and promote workplace norms related to health and wellbeing, a combination of supports from various disciplines is necessary. This is because solving a complex problem requires a multidimensional approach since a singular approach has failed too many times. To make health promotion a social norm in the workplace, supports in physical environment, policy, and educational programmes would be simultaneously necessary (Lee, 2019).

Reciprocity in the workplace, both cooperative and retaliatory, between the organisation and employees or among employees is of particular interest to organisational behavioural researchers. People have shown a tendency to return a favour by working harder in response to a company paying a higher or fair wage (Akerlof, 1982). This kind of behaviour, called gift exchange, is often examined in terms of employee willingness to work harder for non-monetary gifts such as holidays. Unlike many economists' belief that non-monetary gifts are less efficient than money, non-monetary gifts have shown to be of higher value than are monetary gifts (Kube, Maréchal, \& Puppe, 2012). Kube et al. (2012) also suggested that employees may reciprocate a company's kind offer with various options beyond simple productivity, including reduced absenteeism and higher retention and loyalty. Retaliatory reciprocity is also frequently observed in the workplace. Employee thefts of company properties have shown to increase after a wage decrease decision by the company (Giacalone \& Greenberg, 1997). Commonly observed personal retaliatory behaviours against other colleagues range from active retaliatory behaviours (e.g. sabotaging one's work) to passive ones (e.g. not coming to work). While the severity level tends to match between misconducts and retaliatory reactions (e.g. mild misconducts followed 


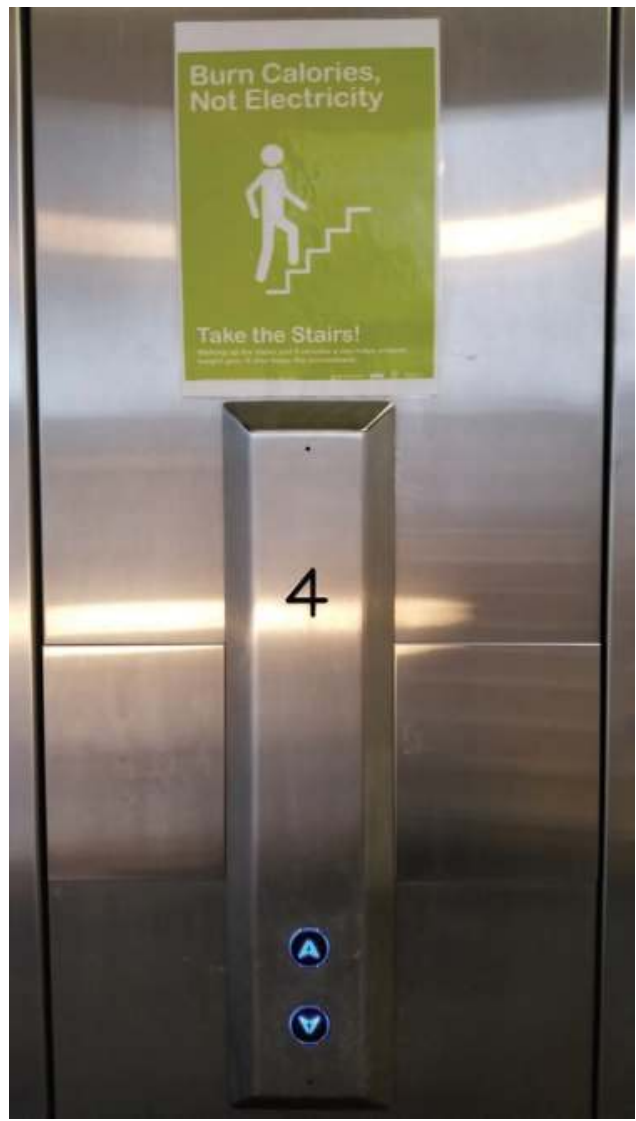

Figure 18.2 A descriptive message encouraging to use stairs instead of elevators

by mild retaliatory reactions and severe misconducts by severe retaliatory responses), individual personality differences exist (e.g. severe retaliatory reactions for mild misconducts or mild retaliatory reactions for severe misconducts) (Greco, Whitson, O’Boyle, Wang, \& Kim, 2019). Furthermore, most people, up to $60 \%$, tend to choose reciprocal reactions, but $20 \%$ to $30 \%$ of them act in pure self-interest (Gächter \& Falk, 1999). While individual personality differences affect the decision of reciprocal responses, organisational cultures also have a tremendous impact on deviant behaviours (Di Stefano, Scrima, \& Parry, 2019). Such deviant and retaliatory behaviours can harm not only interpersonal relationships but also organisational efficiency, function, and morale. It is important to prevent undesirable retaliatory behaviours, but also reward collaborative reciprocal behaviours with proper policy implications.

\section{Methodology/research approach}

Many studies applying BE theories and biases to workplace-related topics use research methods available in behavioural science. Researchers examine how a choice/decision is made, focusing on emotional, cognitive, temporal, and social dimensions in human biases and decision-making processes. Or, they investigate the consequences of decisions or behaviours committed based on these biases. The studies focusing on decision-making processes trace steps of decision-making, utilising various 
techniques, including computational modelling and simulations in more recent studies (Zhang \& Highhouse, 2018). When examining which choice/decision is made, observations have frequently been utilised to understand specific choice behaviours. These studies often compare different scenarios to see changes in choice behaviours. Some researchers investigate behavioural patterns in individuals, while others in the issues of organisational behaviours and associated impacts on organisations.

Surveys are also heavily utilised to understand choice behaviours by directly asking the participants. Many overconfidence studies measure participants' estimates as self-assessment. The self-reported results can be analysed between people's various ratings on their own subjective capability or by comparing their subjective ratings to the actual data to understand the gap between these two. Lastly, secondary or publicly available data can be utilised to understand habitual behavioural patterns within or across organisations. For future studies, it is recommended to strengthen studies incorporating subjective measures with further standardised measurements due to the weaknesses associated with subjective measures. Studies also need to be conducted in more controlled circumstances to be able to offer more consistent suggestions to other organisations. Otherwise, these studies become anecdotal stories only specific to an organisation, since human biases are time- and social context-dependent.

\section{Limitations}

$\mathrm{BE}$ is criticised for overly focusing on understanding the limitations of human cognition and deviated behaviours from the traditional economic theories, not the underlying reasons why we behave the way we behave. Since it is not able to answer the fundamental reasons behind our behaviours, it has difficulty of generalisation and consistent application to various subjects. In addition, there is a cultural difference in how reasoning is defined and accepted as being appropriate (Etzioni, 2011). Since, in some cultures, religious or social norms more heavily affect reasoning, it may be difficult to expect the same outcomes observed in other cultures. Ethics has always been questioned in exercising BE. It can easily manipulate our perception with an intent of taking advantage of our natural weakness for undesired outcomes to us by those imposing BE on us. Thus, BE should only be used under three conditions: transparency, easy to opt out, and only employed for the benefit of users (Thaler \& Sunstein, 2008). BE research in the workplace often utilises subjective ratings, exhibiting a methodological weakness. For instance, evaluating overplacement by self-assessment can be problematic due to ambiguous performance standards in people's subjective minds, since people may define differently what work performance means and what to consider to estimate their own subjective ability (Meikle, Tenney, \& Moore, 2016). How questions are structured and worded also tend to influence people's answers in surveys and interviews. In addition to the methodological limitations, certain topics and biases have shown mixed results in different circumstances. This may be due to human biases being context-dependent.

\section{Theory relevance to practice}

$\mathrm{BE}$ has the potential to offer workplace professionals a consistent framework to (1) understand limitations in human decision-making; (2) implement plans to support the natural cognitive process as well as prevent cognitive shortcomings; and (3) evaluate policies, environments, and cultures of organisations to encourage positive behaviours and resolve conflicts between individuals. In general, motivating people towards more desired directions can be done in two approaches. One way is to structure and present desired choices to easily appeal to heuristics, intuitions, and emotions. The other way is to create mechanisms and tools to encourage a concerted effort to deliberate for the best decisions. The former is called choice architecture, 
and this approach of motivating people to choose desired decisions is called nudging (Thaler \& Sunstein, 2008) (see also Chapter 19 on nudging theory). The latter approach is called boosting (Grüne-Yanoff \& Hertwig, 2016).

However, it may not be straightforward in practice how to implement strategies to overcome our own limitations and become wise decision makers in the workplace. We humans are complex beings whose perceptions and judgments are constantly influenced by our physical and social environments. Thus, we should not assume that perfect predictions of human behaviours and behavioural modelling are possible to offer the one-size-fits-all type of strategy for workplace behaviours. Instead, we should focus on understanding our own cognitive limitations to implement workplace strategies that will lead to actual behavioural changes. In doing so, we have to be mindful of two things to be successful: individual variation and multidimensional approach. We are born with natural variations within a spectrum (e.g. introverted vs. extroverted or hypersensitive vs. hyposensitive). Certain personality traits tend to be more prominently associated with particular behavioural patterns than others (see also Chapter 10 Temperament Theory). However, personality traits alone cannot predict our behaviours. We are continuously influenced by physical and social environments while shaping new opinions and experiences, not to mention our own capacity to learn and grow to become a more competent decision maker. This brings up the importance of a multidimensional approach. A multidimensional approach is advantageous in (1) simultaneously addressing various facets of a circumstance and (2) bringing diverse strategies that appeal to individuals with various preferences and cognitive processes. When planning behavioural changes in the workplace, it is necessary to watch out for inadvertent consequences of complex human psychologies such as the licensing effect, in which people justify their undesirable behaviour after doing a desired behaviour such as eating junk food after exercising. Furthermore, it is always wise to target longer-term outcomes for sustainable behavioural changes, as there is a tendency for people to resort back to old habits once short-term interventions are finished, as shown in the yo-yo effect.

\section{Further reading}

- Hertwig, R., \& Grüne-Yanoff, T. (2017). Nudging and boosting: Steering or empowering good decisions. Perspectives on Psychological Science, 12(6), 973-986.

- Hoffman, E., McCabe, K. A., \& Smith, V. L. (1998). Behavioral foundations of reciprocity: Experimental economics and evolutionary psychology. Economic Inquiry, 35(3), 335-352.

- Hollingworth, C., \& Barker, L. (2016). How to apply behavioural science with success: Learning from application around the world. In A. Samson (Ed.), The behavioral economics guide 2016 (pp. 30-36). Retrieved from https://www.behavioraleconomics.com

- Ilieva, V., \& Drakulevski, L. (2018). Applying behavioral economics insights at the workplace. Journal of Human Resource Management, 21(2), 40-48.

- Lee, Y. (2019). Workplace health and its impact on human capital: Seven key performance indicators of workplace health. In O. Korhan (Ed.), Indoor environment and health (pp. 1-29). London: IntechOpen. www.intechopen.com/books/indoor-environment-and-health/work place-health-and-its-impact-on-human-capital-seven-key-performance-indicators-ofworkplace-healt

\section{References}

Akerlof, G. A. (1982). Labor contracts as partial gift exchange. Quarterly Journal of Economics, 97, 543-569. https://doi.org/10.2307/1885099 
Allcott, H. (2011). Social norms and energy conservation. Journal of Public Economics, 95(5), $1982-2095$. https://doi.org/10.1016/j.jpubeco.2011.03.003

Baek, T. H., \& Yoon, S. (2017). Guilt and shame: Environmental message framing effects. Journal of Advertising, 46(3), 440-453. https://doi.org/10.1080/00913367.2017.1321069

Baumeister, R. F., Bratslavsky, E., Finkenauer, C., \& Vohs, K. D. (2001). Bad is stronger than good. Review of General Psychology, 5, 323-370.

Beer, J. S., \& Hughes, B. L. (2010). Neural systems of social comparison and the "above-average" effect. Neuroimage, 49(3), 2671-2679. https://doi.org/10.1016/j.neuroimage.2009.10.075

Benoit, J. P., Dubra, J., \& Moore, D. A. (2015). Does the better-than-average effect show that people are overconfident?: Two experiments. Journal of the European Economic Association, 13(2), 293-329. https:// doi.org/10.1111/jeea.12116

Beshears, J., \& Gino, F. (2015, May). Leaders as choice architects. Harvard Business Review.

Buehler, R., Griffin, D., \& Ross, M. (2002). Inside the planning fallacy: The causes and consequences of optimistic time predictions. In T. Gilovich, D. Griffin, \& D. Kahneman (Eds.), Heuristics and biases: The psychology of intuitive judgment (pp. 251-270). Cambridge: Cambridge University Press.

Burger, J. M., \& Shelton, M. (2011). Changing everyday health behaviors through descriptive norm manipulations. Social Influence, 6(2), 69-77. https://doi.org/10.1080/15534510.2010.542305

Carnethon, M., Whitsel, L. P., Franklin, B. A., Kris-Etherton, P., Milani, R., Pratt, C. A., \& Wagner, G. R. (2009, October 27). Worksite wellness programs for cardiovascular disease prevention. Circulation, 120(17), 1725-1741.

Das, B. M., Mailey, E., Murray, K., Phillips, S. M., Torres, C., \& King, A. C. (2016). From sedentary to active: Shifting the movement paradigm in workplaces. Work, 54(2), 481-487. https://doi. org/10.3233/WOR-162330

Dauth, W., \& Haller, P. (2020). Is there loss aversion in the trade-off between wages and commuting distances? Regional Science and Urban Economics, 83(C). https://doi.org/10.1016/j.regsciurbeco.2020.103527

Dean, M., Kibris, O., \& Masatlioglu, Y. (2017). Limited attention and status quo bias. Journal of Economic Theory, 169(C), 93-127. https://doi.org/10.1016/j.jet.2017.01.009

Di Stefano, G., Scrima, F., \& Parry, E. (2019). The effect of organizational culture on deviant behaviours in the workplace. International Journal of Human Resource Management, 30(17), 2482-2503. https://doi. org/10.1080/09585192.2017.1326393

Dolan, P., Hallsworth, M., Halpern, D., King, D., \& Vlaev, I. (2010). MINDSPACE: Influencing behaviour through public policy. London: Cabinet Office.

Etzioni, A. (2011). Behavioral economics: Next steps. Journal of Consumer Policy, 34(3), 277-287. https:// doi.org/10.1007/s10603-011-9160-y

Gächter, S., \& Falk, A. (1999). Reputation or reciprocity? Zurich, Germany: Institute for Empirical Research in Economics at University of Zurich.

Giacalone, R., \& Greenberg, J. (1997). Antisocial behavior in organizations. Thousand Oaks, CA: Sage Publications.

Gilovich, T., Griffin, D., \& Kahneman, D. (2002). Heuristics and biases: The psychology of intuitive judgment. Cambridge: Cambridge University Press.

Gouveia, S. O., \& Clarke, V. (2001). Optimistic bias for negative and positive events. Health Education, 101(5), 228-234. https://doi.org/10.1108/09654280110402080

Greco, L. M., Whitson, J. A., O’Boyle, E., Wang, C. S., \& Kim, J. (2019). An eye for an eye? A meta-analysis of negative reciprocity in organizations. Journal of Applied Psychology, 104(9), 1117-1143. https://doi.org/ 10.1037/apl0000396

Grüne-Yanoff, T., \& Hertwig, R. (2016). Nudge versus boost: How coherent are policy and theory? Minds E Machines, 26(2016), 149-183. https://doi.org/10.1007/s11023-015-9367-9

Hayward, M., Shepherd, D. A., \& Griffin, D. (2006). A Hubris theory of entrepreneurship. Management Science, 52(2), 160-172. https://doi.org/10.1287/mnsc.1050.0483

Ilieva, V., Brudermann, T., \& Ljubomir, D. (2018). "Yes, we know!” (Over)confidence in general knowledge among Austrian entrepreneurs. PLoS One, 13(5), 1-15. https://doi.org/10.1371/journal.pone.0197085

Ilieva, V., \& Drakulevski, L. (2018). Applying behavioral economics insights at the workplace. Journal of Human Resources Management, 21(2), 40-48.

Jasperson, J. S., Carter, P. E., \& Zmud, R. W. (2005). A comprehensive conceptualization of post-adoptive behaviors associated with information technology enabled work systems. MIS Quarterly, 29(3), 525-557.

Kahneman, D., \& Tversky, A. (1973). On the psychology of prediction. Psychological Review, 80(4), 237251. https://doi.org/10.1037/h0034747 
Kahneman, D., \& Tversky, A. (1979). Prospect theory: An analysis of decision under risk. Econometrica, 47(2), 263-291. https://doi.org/10.2307/1914185

Kahneman, D., \& Tversky, A. (1982). The psychology of preference. Scientific American, 246(1), $160-173$. https://doi.org/10.1038/scientificamerican0182-160

Kube, S., Maréchal, M. A., \& Puppe, C. (2012). The currency of reciprocity: Gift exchange in the workplace. American Economic Review, 102(4), 1644-1662. https://doi.org/10.1257/aer.102.4.1644

Lee, Y. (2019). Workplace health and its Impact on human capital: Seven key performance indicators of workplace health. In O. Korhan (Ed.), Indoor environment and health (pp. 1-29). London: IntechOpen. Retrieved from https://www.intechopen.com/books/indoor-environment-and-health/workplacehealth-and-its-impact-on-human-capital-seven-key-performance-indicators-of-workplace-healt

Lichtenstein, S., \& Fischhoff, B. (1977). Do those who know more also know more about how much they know? Organizational Behavior and Human Decision Processes, 20(2), 159-183. https://doi. org/10.1016/0030-5073(77)90001-0

Lovallo, D., \& Kahneman, D. (2003). Delusions of success: How optimism undermines executives' decisions. Harvard Business Review, 56-63.

Love, P., Ika, L. A., \& Sing, M. (2019). Does the planning fallacy prevail in social infrastructure projects? Empirical evidence and competing explanations. In IEEE transactions on engineering management (pp. 1-15). San Mateo, CA: Institute of Electrical and Electronics Engineers.

Lu, J., \& Xie, X. (2014). To change or not to change: A matter of decision maker's role. Organizational Behavior and Human Decision Processes, 124(1), 47-55. https://doi.org/10.1016/j.obhdp.2013.12.001

Malmendier, U., te Velde, V. L., \& Weber, R. A. (2014). Rethinking reciprocity. Annual Review of Economics, 6, 849-874. https://doi.org/10.1146/annurev-economics-080213-041312

Meikle, N. L., Tenney, E. R., \& Moore, D. A. (2016). Overconfidence at work: Does overconfidence survive the checks and balances of organizational life? Research in Organizational Behavior, 36, $121-134$. https://doi.org/10.1016/j.riob.2016.11.005

Meyerowitz, B. E., \& Chaiken, S. (1987). The effect of message framing on breast self-examination attitudes, intentions, and behavior. Journal of Personality and Social Psychology, 52(3), 500-510. https://doi. org/10.1037/0022-3514.52.3.500

Michailova, J., \& Katter, J. (2014). Quantifying overconfidence in experimental finance. International Journal of Behavioural Accounting and Finance, 4(4), 351-367. https://doi.org/10.1504/IJBAF.2014.067629

Moore, D. A., \& Healy, P. J. (2008). The trouble with overconfidence. Psychological Review, 115(2), 502517. https://doi.org/10.1037/0033-295X.115.2.502

Moore, D. A., \& Schatz, D. (2017). The three faces of overconfidence. Social and Personality Psychology Compass, 11(8), 1-12. https://doi.org/10.1111/spc3.12331

Plous, S. (1993). The psychology of judgment and decision making. ISBN 978-0-07-050477-6. New York: McGraw-Hill.

Polites, G., \& Karahanna, E. (2012). Shackled to the status quo: The inhibiting effect of incumbent system habit, switching costs, and inertia on new system acceptance. MIS Quarterly, 36(1), 21-42. https://doi. org/10.2307/41410404

Samson, A. (2014). An introduction to behavioral economics. In A. Samson (Ed.), The behavioral economics guide 2014 (pp. 1-12). Behavioral Economics Group. Retrieved from www.behavioraleconomics.com

Samson, A. (2017). Behavioral economics: Expanding boundaries. In A. Samson (Ed.), The behavioral economics guide 2017 (pp. 1-17). Behavioral Economics Group. Retrieved from www.behavioraleconomics.com

Samuelson, W., \& Zeckhauser, R. J. (1988). Status quo bias in decision making. Journal of Risk and Uncertainty, 1, 7-59. https://doi.org/10.1007/BF00055564

Seabury, S. A., Reville, R. T., Rhodes, H. J., \& Boden, L. I. (2005). How can behavioral economics inform research on workplace injuries? In K. Roberts, J. F. Burton, \& M. M. Bodah, Workplace injuries and diseases: Prevention and compensation (pp. 219-252). Kalamazoo, MI: W.E. Upjohn Institute for Employment Research.

Simon, H. A. (1957). Models of man. New York: John Wiley.

Steverson, B. (2017). Circadian light for your health. Chicago, IL: US GSA Office of Federal High-Performance Buildings.

Sunstein, C. (2017). Don't tell me what I can't do: On the intrinsic value of control. In A. Samson (Ed.), The behavioral economics guide 2017 (pp. V-XII). Retrieved from https://www.behavioraleconomics.com.

Thaler, R. (2000). From Homo economicus to Homo sapiens. Journal of Economic Perspectives, 14(1), $133-141$. https://doi.org/10.1257/jep.14.1.133 


\section{Behavioural economics theory}

Thaler, R., \& Sunstein, C. (2008). Nudge: Improving decisions about health, wealth and happiness. New Haven, CT: Yale University Press.

Thomas, A. K., \& Millar, P. R. (2011). Reducing the framing effect in older and younger adults by encouraging analytic processing. The Journals of Gerontology Series B: Psychological Sciences and Social Sciences, 67B (2), 139-149. https://doi.org/10.1093/geronb/gbr076

Thomas, J. M., Ursell, A., Robinson, E. L., Aveyard, P., Jebb, S. A., Herman, C. P., \& Higgs, S. (2017). Descriptive social norm to increase vegetable selection in workplace restaurant settings. Health Psychology, 36(11), 1026-1033. https://doi.org/10.1037/hea0000478

Zhang, D. C., \& Highhouse, S. (2018). Judgment and decision making in the workplace. In D. S. Ones, N. Anderson, C. Viswesvaran, \& H. K. Signangil (Eds.), The SAGE handbook of industrial, work E organizational psychology: Personnel psychology and employee performance (pp. 611-633). London, UK: Sage Publication Ltd. 


\title{
NUDGING IN THE WORKPLACE
}

\section{Facilitating desirable behaviour by changing the environment}

\author{
Tina Venema* and Laurens van Gestel
}

\section{Background}

In 2008, behavioural economist Richard Thaler and lawyer Cass Sunstein published their book Nudge: Improving Decisions about Health, Wealth, and Happiness. Nudging was introduced as a behaviour change tool that acknowledges that people have bounded rationality and therefore cannot be expected to carefully deliberate all their decisions. To be more precise, nudges are changes to the environment in which people are presented with choice options (i.e., choice architecture) designed to steer them towards a particular 'sensible' choice, without restricting alternative options or changing financial incentives (Thaler \& Sunstein, 2008). For example, footprints towards the staircase might decrease elevator use in favour of the stairs by making them more salient (Van Nieuw-Amerongen, Kremers, De Vries, \& Kok, 2011), or employees could be automatically enrolled in a retirement savings plan set up by their employer when signing their contract so they do not miss out due to procrastination (Thaler \& Bernartzi, 2004). Nudge interventions come in all shapes and sizes, but one thing they all have in common is that they capitalize on psychological processes that guide our interactions with our environment.

To explain how choice architecture can influence decisions, Thaler and Sunstein rely on the dual systems theory, which later received much attention outside of academia with Kahneman's book Thinking, Fast and Slow (Kahneman, 2011). This theory posits that there are two systems that govern all human behavioural decision-making (see also Chapter 18 Behavioural Economics Theory). One system is quick, automatic, intuitive, unconscious, and efficient (system 1). The other system is slow, deliberate, reasoned, conscious, and effortful (system 2). Albeit thorough, the second system is mentally taxing and people cannot use it for every decision. Imagine grocery shopping while meticulously deliberating about every product. In most cases, the amount of information to incorporate in a decision would simply be overwhelming (Schwartz \& Ward, 2004). Instead, system 1 is proposed as the default operating modus, with which the majority of decisions are made (Epstein, 2003; Thompson, 2009; Thompson, Turner, \& Pennycook, 2011). In this modus, people might often unintentionally use 'rules of thumb', also called heuristics, to guide their decisions. To illustrate, tourists might assume that, after disembarking from a train, the direction in which the majority of people are walking must be where the exit is located. However, due to these (mental) shortcuts and impulses, they may also end up making

*Corresponding author: a.g.venema@psy.au.dk 
decisions that would have been different when having had the opportunity to consider them carefully (e.g., Baumeister, Sparks, Stillman, \& Vohs, 2008; Evans, 2003; Lichtenstein \& Slovic, 2006). Small changes to the choice architecture that make use of these shortcuts can therefore change the outcome of people's choices considerably (Dolan et al., 2012). There are abundant examples of this type of influence, and marketers have long discovered this presentation tactic. For example, the placing of premium brands at eye level in supermarkets to increase profits and the automatic renewal of magazine subscriptions ensuring a steady customer base are just two common manifestations. Thaler and Sunstein (2008) argued that since the environment has such a great influence on our decisions, policy makers should be aware of this influence and use it to help people make sensible decisions.

For many policy makers, the appeal of nudges as policy tools stems primarily from the fact that they are a softer alternative to strict rules and regulations (e.g., Halpern, 2015). For years, the two most common ways to influence the behaviour of the public were either prohibition by law, thereby removing the decision from the public, or education to provide the public with more information to improve their decisions (Bemelmans-Videc, Rist, \& Vedung, 2011; Christen \& Lægreid, 2002). ${ }^{1}$ Prohibition is often not the preferred policy tool (in democratic societies) because it is likely to meet resistance and requires continuous enforcement. An example of this is the instalment of smoking bans in public spaces (Bell, McCullough, Salmon, \& Bell, 2010). Education campaigns are more popular, because they leave the freedom of choice intact. However, the effectiveness to change behaviour has been limited, making it not always a cost-effective policy tool either. For example, people can learn that women need on average 2,000 kilocalories a day, and men 2,500, to maintain their current weight. Note that for this knowledge to result in actual behaviour change, people need to read labels in the supermarket and monitor their intake, which has shown to be a quite effortful barrier (Teixeira et al., 2015). The enthusiasm for nudges can largely be explained because Thaler and Sunstein made a compelling case why nudges overcome all of these issues: they are easy and cheap to implement, while leaving alternative choices intact (e.g., OECD, 2017). To illustrate, when the environment is designed in such a way that low-calorie food products are more easily accessible than high-calorie products, people might make better choices even without knowledge about the recommended number of calories.

On a political spectrum, nudges are considered as libertarian paternalism. Paternalism, because it is based on the idea that certain choices are better than others to improve well-being in the long run. This is what distinguishes nudges from marketing 'tricks' - the intention behind the design. One of the underlying assumptions of nudging is that people are in agreement with the goals represented by these nudge interventions, that is, they have provided hypothetical consent (see also Van de Veer, 1986). Therefore, it rests on the premise that people generally would like to be healthy, good to the environment, and good to other people (Thaler \& Sunstein, 2008). The 'libertarian' aspect requires that the 'desirable' choices are not enforced but rather suggested; alternative options should still be attainable. However, nudges have not invoked only praise; nudge critics from diverse academic fields (e.g., philosophy and governmental science) fear that people will be manipulated because they argue that nudges mostly rely on processes that people are not aware of (Bovens, 2009; Hansen \& Jespersen, 2013; Hertwig \& Ryall, 2019; Selinger \& Whyte, 2011). It has been suggested that nudges limit people's autonomy to evaluate, deliberate, and choose for themselves (e.g., Gigerenzer, 2015; Glod, 2015; Hausman \& Welch, 2010) and that nudges therefore have no place in public policy (e.g., Leggett, 2014). While heated debates are fought out through editorial commentary and review articles (e.g., Huang \& Baum, 2012; Welch, 2013), it is important to note that the arguments on both sides of the debate are primarily based on theoretical principles and concerns. What is more, an important, but overlooked, assumption held by both proponents and opponents of nudging is that nudges are indeed effective in steering behaviour. 


\subsection{Empirical research on nudges}

Now, more than a decade after the introduction of nudges, a handful of meta-analyses and systematic reviews have appeared in the nudge literature that bring some nuance to the debate (e.g., Arno \& Thomas, 2016; Bucher et al., 2016; Cadario \& Chandon, 2020; Hummel \& Maedche, 2019; Szaszi, Palinkas, Palfi, Szollosi, \& Aczel, 2018). Although many meta-analyses focus on one specific type of nudge or one particular behavioural domain (e.g., healthy eating, sustainability, financial decision-making, etc.), their conclusions align with those that take a broader scope. For example, Hummel and Maedche (2019) cover multiple behavioural domains and multiple types of nudges, including 100 empirical articles in their meta-analysis. They found that $62 \%$ of nudging interventions resulted in a statistically significant change in behaviour. Across all included studies, the average percentual change on the outcome measure (e.g., the number of calories consumed or the number of participants that selected a particular option) between a nudge intervention group and a control group was 21\%. Most meta-analyses show that even though the majority of nudge interventions work, the effect sizes are small, suggesting they are not effective for everyone (Olejnik \& Algina, 2000).

Nudge researchers and policy makers should be aware that nudge interventions, in terms of effectiveness, target mainly 'the inconsistent choosers' (Goldin, 2015): those individuals who do not have strong and specific a priori preferences (based on their goals and values) and who are therefore more likely to be affected by the choice architecture. The few empirical articles that looked into moderators of the effectiveness of nudge interventions found that strong attitudes, habits, and intentions mitigate the behavioural change due to the nudge (e.g., Murtagh et al., 2013; Trudel, Murray, Kim, \& Chen, 2015; Venema, Kroese, De Vet, \& De Ridder, 2019; Venema, Kroese, Verplanken, \& De Ridder, 2020; Vetter \& Kutzner, 2016). For example, thirsty participants could not be steered towards a smaller - and less caloric - portion size of soda with a position nudge (Venema et al., 2019). Nor was an opt-out default nudge that automatically transferred people's tax refunds into a savings account effective for people who already had plans to spend their refunds (Bronchetti, Dee, Huffman, \& Magenheim, 2013). Supermarket customers who habitually bought white bread simply went looking for their preferred product when the bread section was rearranged to make whole wheat bread more salient (De Wijk et al., 2016). These examples demonstrate that when people hold strong and specific nudge-incongruent preferences (i.e., a preference for an alternative option), nudges are unlikely to manipulate them into decisions that they do not want. Moreover, these findings stipulate that nudges are a promising behaviour change tool especially in situations where people do not have strong preferences (Venema, Kroese, Benjamins, \& De Ridder, 2020). Examples of these situations are when people are indifferent to the behaviour at hand, when they have good intentions that they forget about, when they experience conflicting preferences, and in novel choice contexts where people do not know what to do. In the remainder of this chapter we will discuss how nudging has been implemented in the workplace thus far, some points of attention when implementing a nudge intervention, and finally some limitations of nudges.

\section{Applicability to workplace studies}

Even though nudges were initially introduced as a governmental policy instrument, it also piqued the interest of management teams (e.g., Beshears \& Gino, 2015; Haugh, 2017; Thaler \& Sunstein, 2008). Much like the traditional governmental practices to change behaviour, organizations typically aim to change undesirable behaviours of employees through education or 
sanctions, with similarly small results (e.g., Staddon, Cycil, Goulden, Leygue, \& Spence, 2016; Thompa, Trevithick, \& McLeod, 2007). Moreover, the paternalistic nature of many workplace health promotion (WHP) interventions is known to invoke low participation in these programs and even reactance (e.g., Hannon, Hammerback, Garson, Harris, \& Sopher, 2012; Röttger et al., 2017). Nudge interventions, which require little to no effort or time on the part of the employees, therefore fill this research gap and provide a refreshing alternative to traditional organizational intervention policies. This chapter highlights three major domains in which companies can use nudging: (1) supporting physical health of employees, (2) decreasing impact of the company on the environment, and (3) facilitating adherence to company rules.

\subsection{Physical and health of employees}

Employee well-being is related to increased productivity at work and reduced absenteeism, while employee sickness even can directly increase costs for companies in the US in the form of hospital bills (Goetzel \& Ozminkowski, 2008; Soler et al., 2010; Ybema, van Vuuren, \& van Dam, 2020). This explains why companies welcome cost-effective solutions, such as nudges, to help their employees make healthier choices. For example, reducing the time spent sitting during the workday has been shown to have important health benefits (Straker \& Mathiassen, 2009). A considerable number of employers, with Google and Facebook as well-known examples, have therefore invested in sit-stand desks (SSDs) to provide their employees with the possibility to work standing up (Carlton, 2011). However, research has found that SSDs are mostly used for sitting after the novelty wears off, and people simply forget to stand (e.g., De Cocker et al., 2015; Pronk, Katz, Lowry, \& Payfer, 2012; Wilks, Mortimer, \& Nylén, 2006). A recent longitudinal study found that a nudge intervention that placed the SSDs by default at standing height increased stand-up working rates by approximately seven times compared to baseline observations (Venema, Kroese, \& De Ridder, 2018). Also, stair usage is a frequently targeted behaviour of nudge interventions to increase physical activity in the workplace, for example by placing footsteps leading to the staircase or displaying the number of potential calories burned at the point of choice (Bellicha et al., 2015; Van der Meiden, Kok, \& Van der Velde, 2019).

Besides physical activity, large health gains can be won by improving diets. It is therefore not surprising that healthy eating behaviour is the most targeted domain in the nudge literature (Szaszi et al., 2018). Self-serving canteens are especially important areas in the workplace where employers can nudge employees towards a healthier lifestyle (Schliemann, \& Woodside, 2019; Velema, Vyth, Hoekstra, \& Steenhuis, 2018). Recent meta-analyses on nudging healthy food choices revealed the most promise for nudges that influence convenience, such as repositioning healthy options to more prominent places (e.g., at the cash register, Van Gestel, Kroese, \& De Ridder, 2018; at the start of a buffet, Flores, Reimann, Castaño, \& Lopez, 2019) and using smaller cutlery (e.g., Cadario \& Chandon, 2020; James, Maher, Biddle, \& Broom, 2018; Skov, Lourenço, Hansen, Mikkelsen, \& Schofield, 2013). In contrast, nudges that provided caloric information and labelling products as healthy were less influential (Cadario \& Chandon, 2020). One explanation could be that since hungry people are less interested in the healthiness of food (Siep et al., 2009), health information becomes a less relevant factor in food choices compared to its convenience (Hoefling \& Strack, 2010). Whereas nudges are mostly used to change behaviours that are directly beneficial to employees' well-being, they can also be used to encourage behaviours that benefit individuals indirectly through clean and safe environments. 


\subsection{Sustainability}

It has become more important for companies to be CO2 neutral, also referred to as 'corporate greening' (Raineri \& Paillé, 2016). In the workplace, many factors can contribute to achieve these organizational goals, such as recycling behaviour, energy conservation, waste reduction, and employees' mode of transport (e.g., Stringer, 2010). In line with observations about the role of a priori preferences in the nudge literature (Venema, Kroese, Benjamins et al., 2020), research has found that organizational norms and practices concerning environmentally friendly behaviours are particularly effective among employees with weak individual environmental concerns (Dumont, Shen, \& Deng, 2017; Raineri \& Paillé, 2016). Nudges therefore provide a promising behaviour change tool to help employees behave in line with the company's sustainability goals (Schubert, 2017). For example, changing the default printer settings to double-sided printing led to a 15\% reduction in paper waste (Egebark \& Ekström, 2016). Likewise, a systematic review found that desk-based electricity use is most effectively reduced - up to $50 \%$ - by relying on people's inertia (i.e., the tendency to make no active decision) by programming devices to automatically switch off after a period of non-activity (Staddon et al., 2016). Environmentally friendly behaviours that do require active decisions, such as recycling, are best served by nudges that emphasize social norms to act environmentally friendly (Abrahamse \& Steg, 2013). For example, a dynamic norm nudge - 'more and more customers are switching from to-go cups to a sustainable alternative' - led to a $17.3 \%$ switch from disposable cups to reusable ceramic mugs at a worksite café (Loschelder, Siepelmeyer, Fischer, \& Rubel, 2019).

\subsection{Adherence to company rules}

Companies make rules about behaviours in the realm of safety, hygiene, and liability that are too harmful when people are left to their own devices. Non-adherence to these rules can be a great source of frustration, but nudges have the potential to address the causes (Haugh, 2017; Lindhout \& Reniers, 2017). For example, non-adherence to cybersecurity policies is primarily caused by habits and cognitive biases concerning the reality of the risk (Sommestad, Karlzén, \& Hallberg, 2019). However, nudges that influence the threat appraisal alone (e.g., pop-up warnings and framing of the risk) are not enough; a sense of ownership of what is under attack is crucial for a successful intervention (Briggs, Jeske, \& Coventry, 2017; Renaud \& Zimmermann, 2019). In fact, several studies have shown that employees who feel part of the workplace community (i.e., high social cohesion) are more likely to adhere to safety rules (e.g., Kwok, Harris, \& McLaws, 2017; Leach, 2003). Therefore, nudge interventions that target social aspects of the desirable behaviour are particularly promising to improve adherence. To illustrate, although employees in health care, food, and agriculture sectors know that they should wash their hands (i.e., it is the injunctive norm - what people should do; Kallgren, Reno, \& Cialdini, 2000), there is hardly any social control in the privacy of the bathroom where the behaviour should take place (Oldfield, 2017). A study in a hospital showed that medical staff engaged more often in hand hygiene behaviours when they were overtly observed (Wu et al., 2018). Changing the choice architecture in such a way that the desirable behaviour becomes visible (i.e., boosting the descriptive norm - what people actually do) may thus be an effective solution. Another cause of non-compliance to company rules is 'sludge' - unnecessary lengthy procedures in administration (Sunstein, 2019). Nudges that simplify forms and procedures have been shown effective for tax compliance (e.g., John \& Blume, 2018) and also show great promise for companies. For example, removing non-essential questions in an application procedure led to lower voluntary dropout of high-quality applicants (Linos \& Riesch, 2020). To summarize, nudge interventions 
show promise to help improve employees' physical health, reach companies' sustainability goals, and increase adherence to company rules. However, more high-quality empirical research is necessary (Szaszi et al., 2018).

\section{Methodology/research approach}

Several toolboxes are available that provide a step-by-step guide to implement nudge interventions (see Further Reading section), but these are mostly created with practitioners in mind. This section therefore particularly addresses common pitfalls that nudge researchers encounter, to help improve the quality of empirical nudge research. The first three are practical issues that one may encounter when designing a nudge, creating a research design, or implementing a nudge. The fourth pitfall concerns the semantic discussion of what qualifies as a nudge.

The first pitfall is to copy and paste nudge interventions from one context to another. Nudge researchers might be tempted to start with a nudge type that they want to investigate (e.g., a default nudge) and go in search of a suitable context to do so. However, as the starting point of nudge research, we strongly advocate a 'diagnostic approach', in which the undesirable decision or behaviour is identified and the choice architecture is mapped to specify the exact physical location (where), the timing of the decision (when), and the causes of the undesirable behaviour (why; e.g., Hansen, 2018). Short surveys or focus groups concerning the reasons for the undesirable behaviour provide input to select a nudge type that addresses the most pressing cause of the undesirable behaviour, such as poor social norms, convenience, cognitive biases, habits, etc. (e.g., Murtagh et al., 2013; Venema et al., 2018). The importance of considering the where and when is illustrated by a study in which employees were provided with feedback on their desk energy usage (Murtagh et al., 2013). Engagement with the feedback had to be initiated by clicking on a desktop icon. The feedback intervention did not lead to a considerable drop in energy use. Afterwards the data showed that $41 \%$ of the employees did not access their feedback even once. In this particular case, the decision to engage with the feedback preceded the decision to reduce energy usage, unintentionally creating another choice context.

The second pitfall pertains to the research design. Despite the popularity of randomized control trials, also by governmental organizations (Feitsma \& Schillemans, 2019), pre and post measures are often more suitable when it comes to nudge interventions. As nudges are implemented in specific contexts, this may complicate finding good control conditions that are, apart from the implementation of the nudge, identical to the intervention condition. Notable exceptions are online nudges and nudges in letters (e.g., Meeker et al., 2014). Longitudinal within-subject designs where the impact of the nudge intervention is followed over a prolonged period especially provide valuable knowledge (Bucher et al., 2016; Van Gestel et al., 2018; Velema et al., 2018).

The third pitfall is not being transparent to the key stakeholders in the nudge intervention. It is important to be transparent with the workforce about the nudge and to create support. Proper briefing of management and employees who are directly responsible for the choice environment (e.g., canteen employees, cleaners, IT personnel, etc.) has been found crucial to the success of nudge interventions (Schliemann \& Woodside, 2019). Transparency and disclosure of the implementation and intention of the nudge are important contributors to acceptance of nudging (Steffel, Williams, \& Pogacar, 2016). Moreover, current evidence suggests that it does not come at the cost of effectiveness (Bang, Shu, \& Weber, 2018; Bruns, Kantorowicz-Reznichenko, Klement, Jonsson, \& Rahali, 2018).

The fourth pitfall relates to the semantic discussion of what counts as a nudge (and what does not). Oftentimes, interventions are labelled as nudges because the term inspires or enthuses those who wish to implement an intervention, but the use of the term has become too widespread. 
To improve the quality of empirical knowledge on nudges, researchers are urged to be mindful when using the term nudge (e.g., Osman et al., 2020; Wilson, Buckley, Buckley, \& Bogomolova, 2016). Marketing strategies (that aim to improve profits - not the well-being of the decision maker) and financial incentives, such as taxes and bonuses (e.g., Cornwell \& Krantz, 2014), clutter the nudge literature (Marchiori, Adriaanse, \& De Ridder, 2017). Apart from this, there are other examples of interventions that change the environment to improve well-being but that are not considered nudges.

First, merely introducing a healthy choice where previously there was none would not be considered a nudge. However, increasing the variety of healthy options is considered a nudge. For example, ensuring that $70 \%$ of soda vending machine options consist of beverages that fall under healthy nutrition guidelines does count as a nudge (e.g., Kocken et al., 2012; Van Kleef, Otten, \& van Trijp, 2012) and taps into availability heuristics and salience. Second, environmental interventions that do not target decisions do not qualify as nudges. For example, it has been shown that having green plants in the office helps with restoring attention after fatiguing tasks (Raanaas, Evensen, Rich, Sjøstrøm, \& Patil, 2011). Although this may have promising effects on employee well-being, this does not meet the definition of nudges as no actual choice or decision is affected. Third, a key feature of nudges is that they change the environment in which the decision is made (i.e., the choice architecture). To illustrate, employees might indicate that they do not like to bike to work because they are afraid that their bike will be stolen while at work (e.g., Biernat, Buchholtz, \& Bartkiewicz, 2018). When the company then builds a bicycle shed, it removes the foreseen barrier by making changes in the environment. However, since the decision to go by bike is made at the homes of the employees, this would not be considered choice architecture and hence the intervention is not a nudge. To sum up, when researchers design nudge intervention studies, they are advised to adopt a diagnostic approach before implementation, use within-subject experimental designs, be transparent about the aim of the intention to stakeholders, and be mindful when classifying their intervention as a 'nudge'.

\section{Limitations}

Even when taking precautions, the success of nudge interventions is not a guarantee, and it is important to be aware of the limitations of nudges. First, despite the prominent place of the dual systems theory in the origin of nudges, there is little empirical proof that these systems are actually distinct (i.e., Melnikoff \& Bargh, 2018; Mugg, 2016) and that this distinction poses implications for the effectiveness of nudges (Lin, Osman, \& Ashcroft, 2017; Osman et al., 2020). To illustrate, a recent experiment demonstrated that a default nudge that stimulated sustainable behaviour was equally effective among those who had plenty or little cognitive resources available (Van Gestel, Adriaanse, \& De Ridder, 2020). Moreover, the effectiveness of default nudges has been explained by inertia and loss aversion (explanations based on system 1), but people also stick with the default because they want to save time or because they see the default as a recommendation from the authorities (i.e., rational system 2 explanations) (Huh, Vosgerau, \& Morewedge, 2014; Jachimowicz, Duncan, Weber, \& Johnson, 2019). Not only has relying on the dual process theory caused ample confusion in defining what is and what is not a nudge (Berthet \& Ouvrard, 2019), the presumed uncontrollability of system 1 is the source of many ethical debates on nudges. ${ }^{2}$ Letting go of the dual process theory in relation to nudges is shifting the nudging literature back to the field of psychology to uncover through which mechanisms the choice environments influence individual decisions (e.g., De Ridder et al., 2020).

Finally, it is important to point out that there are several outstanding questions about nudging. As nudges are changes within a specific choice architecture, effects are to be expected 
in this exact situation. It is currently unclear if nudges have the potential to lead to spillover effects in other contexts (i.e., from work to home life) and if nudges remain effective in the long term. It should also be pointed out that nudges are not a panacea, but rather an instrument that has promise - if implemented with appropriate care and consideration. Some problematic behaviours are better addressed with other measures, such as strict agreements, salary bonuses (Mols, Haslam, Jetten, \& Steffens, 2015), or with an eye for the systematic circumstances (i.e., political climate) rather than solely focusing on individual decisions (Meder, Fleischhut, \& Osman, 2018).

\section{Theory relevance to practice}

In the workplace, employees' main priorities lie with performing well on their job, sometimes at the expense of behaviours that support performance in the long run, impacting employees' health and well-being (e.g., Maslach, Schaufeli, \& Leiter, 2001). Nudging is a valuable behaviour change tool with the potential to facilitate desirable behaviours that are insufficiently addressed with traditional policy tools, such as educational workshops and financial incentives (Thaler \& Sunstein, 2008). The incremental value of the concept of nudges to the workplace lies in the understanding that choice architecture influences individual decision-making. Nudge interventions use this influence to encourage desirable behaviour, while leaving the freedom of choice intact. Moreover, organizations can use the concept of nudges to have a critical look at their current choice environment, for example to reflect on which defaults are currently in place, which norms are conveyed by the environment, and how objects (e.g., recycling bins) are positioned in the space where they need to be used. When developing nudges, however, one should be careful and conscientious in finding the critical environmental trigger, create appropriate research designs, and not omit being transparent with those at the receiving end of the nudge intervention. Yet, when taking these common pitfalls into consideration, nudges offer a practical solution to a wide variety of behaviours in the workplace.

\section{Further reading}

- Hansen, P. G. (2019). Tools and ethics for applied behavioural insights: The BASIC toolkit. Organisation for Economic Co-operation and Development, OECD. https://doi.org/10.1787/ 9ea76a8f-en

- Hummel, D., \& Maedche, A. (2019). How effective is nudging? A quantitative review on the effect sizes and limits of empirical nudging studies. Journal of Behavioral and Experimental Economics, 80, 47-58. https://doi.org/10.1016/j.socec.2019.03.005

- Lamprell, K., Tran, Y., Arnolda, G., \& Braithwaite, J. (2020). Nudging clinicians: A systematic scoping review of the literature. Journal of Evaluation in Clinical Practice, 27(1), 175-192. https://doi.org/10.1111/jep.13401

- $\quad$ Lindhout, P., \& Reniers, G. (2017). What about nudges in the process industry? Exploring a new safety management tool. Journal of Loss Prevention in the Process Industries, 50, 243-256. https://doi.org/10.1016/j.jlp.2017.10.006

\section{Notes}

1 A third commonly used policy tool is increasing taxes, which is also regarded as an unpopular measure.

2 For a discussion on what the field of behavioural economics (cf. Chapter 18 Behavioural Economics Theory) should do with the dual process theory, see Grayot (2020). 


\section{References}

Abrahamse, W., \& Steg, L. (2013). Social influence approaches to encourage resource conservation: A metaanalysis. Global Environmental Change, 23(6), 1773-1785. https://doi.org/10.1016/j.gloenvcha.2013. 07.029

Arno, A., \& Thomas, S. (2016). The efficacy of nudge theory strategies in influencing adult dietary behaviour: A systematic review and meta-analysis. BMC Public Health, 16, 676. https://doi.org/10.1186/ s12889-016-3272-x

Bang, H. M., Shu, S. B., \& Weber, E. U. (2018). The role of perceived effectiveness on the acceptability of choice architecture. Behavioural Public Policy, 1-21. https://doi.org/10.1017/bpp.2018.1

Baumeister, R. F., Sparks, E. A., Stillman, T. F., \& Vohs, K. D. (2008). Free will in consumer behavior: Selfcontrol, ego depletion, and choice. Journal of Consumer Psychology, 18, 4-13. https://doi.org/10.1016/j. jcps.2007.10.002

Bell, K., McCullough, L., Salmon, A., \& Bell, J. (2010). "Every space is claimed”: Smokers' experiences of tobacco denormalisation. Sociology of Health E Illness, 32(6), 914-929. https://doi.org/10.1111/j.14679566.2010.01251.x

Bellicha, A., Kieusseian, A., Fontvieille, A. M., Tataranni, A., Charreire, H., \& Oppert, J. M. (2015). Stair-use interventions in worksites and public settings: A systematic review of effectiveness and external validity. Preventive Medicine, 70, 3-13. https://doi.org/10.1016/j.ypmed.2014.11.001

Bemelmans-Videc, M. L., Rist, R. C., \& Vedung, E. O. (Eds.). (2011). Carrots, sticks, and sermons: Policy instruments and their evaluation (Vol. 1). New Brunswick, NJ: Transaction Publishers.

Berthet, V., \& Ouvrard, B. (2019). Nudge: Towards a consensus view? Psychology and Cognitive Science Open Journal, 5, 1-5. https://doi.org/10.17140/PCSOJ-5-143

Beshears, J., \& Gino, F. (2015, May) Leaders as decision Architects. Harvard Business Review. Retrieved from www.organisationalpsychology.nz/content/150817HBR_Leaders_as_Decision_Architects_R1505C.PDF

Biernat, E., Buchholtz, S., \& Bartkiewicz, P. (2018). Motivations and barriers to bicycle commuting: Lessons from Poland. Transportation Research Part F: Traffic Psychology and Behaviour, 55, 492-502. https:// doi.org/10.1016/j.trf.2018.03.024

Bovens, L. (2009). The ethics of nudge. In T. Grüne-Yanoff \& S. O. Hansson (Eds.), Preference change: Approaches from philosophy, economics and psychology (pp. 207-219). New York: Springer.

Briggs, P., Jeske, D., \& Coventry, L. (2017). Behavior change interventions for cybersecurity. Behavior Change Interventions for Cybersecurity, 115-136. https://doi.org/10.1016/B978-0-12-802690-8.00004-9

Bronchetti, E. T., Dee, T. S., Huffman, D. B., \& Magenheim, E. (2013). When a nudge isn't enough: Defaults and saving among low-income tax filers. National Tax Journal, 66(3), 609-635. https://doi. org/10.3386/w16887

Bruns, H., Kantorowicz-Reznichenko, E., Klement, K., Jonsson, M. L., \& Rahali, B. (2018). Can nudges be transparent and yet effective? Journal of Economic Psychology, 65, 41-59. https://doi.org/10.1016/j. joep.2018.02.002

Bucher, T., Collins, C., Rollo, M. E., McCaffrey, T. A., De Vlieger, N., Van der Bend, D., . . . \& PerezCueto, F. J. (2016). Nudging consumers towards healthier choices: A systematic review of positional influences on food choice. British Journal of Nutrition, 115(12), 2252-2263. https://doi.org/10.1017/ S0007114516001653

Cadario, R., \& Chandon, P. (2020). Which healthy eating nudges work best? A meta-analysis of field experiments. Marketing Science, 39(3), 465-486. https://doi.org/10.1287/mksc.2018.1128

Carlton, J. (2011, September). Standing desks are on the rise. Wall Street Journal. Retrieved from www.wsj. com/articles/SB10001424053111904199404576541011003270644

Christensen, T., \& Lægreid, P. (2002). New public management: Puzzles of democracy and the influence of citizens. Journal of Political Philosophy, 10(3), 267-295. https://doi.org/10.1111/1467-9760.00153

Cornwell, J. F., \& Krantz, D. H. (2014). Public policy for thee, but not for me: Varying the grammatical person of public policy justifications influences their support. Judgment and Decision Making, 9(5), 433.

De Cocker, K., Veldeman, C., De Bacquer, D., Braeckman, L., Owen, N., Cardon, G., \& De Bourdeaudhuij, I. (2015). Acceptability and feasibility of potential intervention strategies for influencing sedentary time at work: Focus group interviews in executives and employees. International Journal of Behavioral Nutrition and Physical Activity, 12, 22. https://doi.org/10.1186/s12966-015-0177-5

De Ridder, D., Feitsma, J., van den Hoven, M., Kroese, F., Schillemans, T., Verweij, M., ... \& de Vet, E. (2020). Simple nudges are not so easy. Behavioural Public Policy. https://doi.org/10.1017/bpp.2020.36 


\section{Nudging in the workplace}

De Wijk, R. A., Maaskant, A. J., Polet, I. A., Holthuysen, N. T., van Kleef, E., \& Vingerhoeds, M. H. (2016). An in-store experiment on the effect of accessibility on sales of wholegrain and white bread in supermarkets. PLoS One, 11(3), e0151915. https://doi.org/10.1371/journal.pone.0151915

Dolan, P., Hallsworth, M., Halpern, D., King, D., Metcalfe, R., \& Vlaev, I. (2012). Influencing behaviour: The mindspace way. Journal of Economic Psychology, 33, 264-277. https://doi.org/10.1016/j. joep.2011.10.009

Dumont, J., Shen, J., \& Deng, X. (2017). Effects of green HRM practices on employee workplace green behavior: The role of psychological green climate and employee green values. Human Resource Management, 56(4), 613-627. https://doi.org/10.1002/hrm.21792

Egebark, J., \& Ekström, M. (2016). Can indifference make the world greener? Journal of Environmental Economics and Management, 76, 1-13. https://doi.org/10.1016/j.jeem.2015.11.004

Epstein, S. (2003). Cognitive-experiential self-theory of personality. Handbook of Psychology, 159-184. https://doi.org/10.1002/0471264385.wei0507

Evans, J. S. B. (2003). In two minds: Dual-process accounts of reasoning. Trends in Cognitive Sciences, 7(10), 454-459. https://doi.org/10.1016/j.tics.2003.08.012

Feitsma, J., \& Schillemans, T. (2019). Behaviour experts in government: From newcomers to professionals? In Handbook of behavioural change and public policy. Cheltenham, UK: Edward Elgar Publishing. https:// doi.org/10.4337/9781785367854.00015

Flores, D., Reimann, M. C., Castaño, R., \& Lopez, A. (2019). If I indulge first, I will eat less overall: The unexpected interaction effect of indulgence and presentation order on consumption. Journal of Experimental Psychology: Applied, 25(2), 162-176. https://doi.org/10.1037/xap0000210

Gigerenzer, G. (2015). On the supposed evidence for libertarian paternalism. Review of Philosophy and Psychology, 6(3), 361-383. https://doi.org/10.1007/s13164-015-0248-1

Glod, W. (2015). How nudges often fail to treat people according to their own preferences. Social Theory and Practice, 41(4), 599-617. https://doi.org/10.5840/soctheorpract201541433

Goetzel, R. Z., \& Ozminkowski, R. J. (2008). The health and cost benefits of work site health- promotion programs. Annual Review of Public Health, 29, 303-323. https://doi.org/10.1146/annurev.publhealth.29. 020907.090930

Goldin, J. (2015). Which way to Nudge: Uncovering preferences in the behavioral age. Yale Law Journal, 125, 226-270. https://doi.org/10.2139/ssrn.2570930

Grayot, J. D. (2020). Dual process theories in behavioral economics and neuroeconomics: A critical review. Review of Philosophy and Psychology, 11, 105-136. https://doi.org/10.1007/s13164-019-00446-9

Halpern, D. (2015). Inside the nudge unit: How small changes can make a big difference. Random House.

Hannon, P. A., Hammerback, K., Garson, G., Harris, J. R., \& Sopher, C. J. (2012). Stakeholder perspectives on workplace health promotion: a qualitative study of midsized employers in low-wage industries. American Journal of Health Promotion, 27(2), 103-110. https://doi.org/10.4278/ajhp.110204-QUAL-51

Hansen, P. G. (2018). What are we forgetting? Behavioural Public Policy, 2(2), 190-197. https://doi. org/10.1017/bpp.2018.13

Hansen, P. G., \& Jespersen, A. M. (2013). Nudge and the manipulation of choice: A framework for the responsible use of the nudge approach to behavior change in public policy. The European Journal of Risk Regulation, 1, 3-28. https://doi.org/10.1017/S1867299X00002762

Haugh, T. (2017). Nudging corporate compliance. American Business Law Journal, 54(4), 683-741.

Hausman, D. M., \& Welch, B. (2010). Debate: To nudge or not to nudge. Journal of Political Philosophy, 18, 123-136. https://doi.org/10.1111/j.1467-9760.2009.00351.x

Hertwig, R., \& Ryall, M. D. (2019). Nudge versus boost: Agency dynamics under libertarian paternalism. The Economic Journal, 130(629), 1-32. https://doi.org/10.1093/ej/uez054

Hoefling, A., \& Strack, F. (2010). Hunger induced changes in food choice: When beggars cannot be choosers even if they are allowed to choose. Appetite, 54(3), 603-606. https://doi.org/10.1016/j. appet.2010.02.016

Huang, C. J., \& Baum, M. L. (2012). Nudge ethics: Just a game of billiards? The American Journal of Bioethics, 12(2), 22-24. https://doi.org/10.1080/15265161.2011.634955

Huh, Y. E., Vosgerau, J., \& Morewedge, C. K. (2014). Social defaults: Observed choices become choice defaults. Journal of Consumer Research, 41(3), 746-760. https://doi.org/10.1086/677315

Hummel, D., \& Maedche, A. (2019). How effective is nudging? A quantitative review on the effect sizes and limits of empirical nudging studies. Journal of Behavioral and Experimental Economics, 80, 47-58. https://doi.org/10.1016/j.socec.2019.03.005 
Jachimowicz, J. M., Duncan, S., Weber, E. U., \& Johnson, E. J. (2019). When and why defaults influence decisions: A meta-analysis of default effects. Behavioural Public Policy, 3(2), 159-186. https://doi. org/10.1017/bpp.2018.43

James, L. J., Maher, T., Biddle, J., \& Broom, D. R. (2018). Eating with a smaller spoon decreases bite size, eating rate and ad libitum food intake in healthy young males. British Journal of Nutrition, 120(7), 830-837. https://doi.org/10.1017/S0007114518002246

John, P., \& Blume, T. (2018). How best to nudge taxpayers? The impact of message simplification and descriptive social norms on payment rates in a central London local authority. Journal of Behavioral Public Administration, 1. https://doi.org/10.30636/jbpa.11.10

Kahneman, D. (2011). Thinking, fast and slow. New York: Farrar, Straus, and Giroux.

Kallgren, C. A., Reno, R. R., \& Cialdini, R. B. (2000). A focus theory of normative conduct: When norms do and do not affect behavior. Personality and Social Psychology Bulletin, 26(8), 1002-1012. https:// doi.org/10.1177/01461672002610009

Kocken, P. L., Eeuwijk, J., Van Kesteren, N. M., Dusseldorp, E., Buijs, G., Bassa-Dafesh, Z., \& Snel, J. (2012). Promoting the purchase of low-calorie foods from school vending machines: A clusterrandomized controlled study. Journal of School Health, 82(3), 115-122. https://doi.org/10.1111/j.17461561.2011.00674.x

Kwok, Y. L. A., Harris, P., \& McLaws, M. L. (2017). Social cohesion: The missing factor required for a successful hand hygiene program. American Journal of Infection Control, 45(3), 222-227. https://doi. org/10.1016/j.ajic.2016.10.021

Leach, J. (2003). Improving user security behaviour. Computers \& Security, 22(8), 685-692. https://doi. org/10.1016/S0167-4048(03)00007-5

Leggett, W. (2014). The politics of behaviour change: Nudge, neoliberalism and the state. Policy \& Politics, 42, 3-19. https://doi.org/10.1332/030557312X655576

Lichtenstein, S., \& Slovic, P. (Eds.). (2006). The construction of preference. Cambridge: Cambridge University Press.

Lin, Y., Osman, M., \& Ashcroft, R. (2017). Nudge: Concept, effectiveness, and ethics. Basic and Applied Social Psychology, 39(6), 293-306. https://doi.org/10.1080/01973533.2017.1356304

Lindhout, P., \& Reniers, G. (2017). What about nudges in the process industry? Exploring a new safety management tool. Journal of Loss Prevention in the Process Industries, 50, 243-256. https://doi. org/10.1016/j.jlp.2017.10.006

Linos, E., \& Riesch, N. (2020). Thick red tape and the thin blue line: A field study on reducing administrative burden in police recruitment. Public Administration Review, 80, 92-103. https://doi.org/10.1111/ puar.13115

Loschelder, D. D., Siepelmeyer, H., Fischer, D., \& Rubel, J. A. (2019). Dynamic norms drive sustainable consumption: Norm-based nudging helps café customers to avoid disposable to-go-cups. Journal of Economic Psychology, 75, 102146. https://doi.org/10.1016/j.joep.2019.02.002

Marchiori, D. R., Adriaanse, M. A., \& De Ridder, D. T. (2017). Unresolved questions in nudging research: Putting the psychology back in nudging. Social and Personality Psychology Compass, 11, e12297. https:// doi.org/10.1111/spc3.12297

Maslach, C., Schaufeli, W. B., \& Leiter, M. P. (2001). Job burnout. Annual Review of Psychology, 52, 397422. https://doi.org/10.1146/annurev.psych.52.1.397

Meder, B., Fleischhut, N., \& Osman, M. (2018). Beyond the confines of choice architecture: A critical analysis. Journal of Economic Psychology, 68, 36-44. https://doi.org/10.1016/j.joep.2018.08.004

Meeker, D., Knight, T. K., Friedberg, M. W., Linder, J. A., Goldstein, N. J., Fox, C. R., . . \& \& Doctor, J. N. (2014). Nudging guideline-concordant antibiotic prescribing: A randomized clinical trial. JAMA Internal Medicine, 174(3), 425-431. https://doi.org/10.1001/jamainternmed.2013.14191

Melnikoff, D. E., \& Bargh, J. A. (2018). The mythical number two. Trends in Cognitive Sciences, 22(4), 280-293. https://doi.org/10.1016/j.tics.2018.02.001

Mols, F., Haslam, S. A., Jetten, J., \& Steffens, N. K. (2015). Why a nudge is not enough: A social identity critique of governance by stealth. European Journal of Political Research, 54, 81-98. https://doi. org/10.1111/1475-6765.12073

Mugg, J. (2016). The dual-process turn: How recent defenses of dual-process theories of reasoning fail. Philosophical Psychology, 29(2), 300-309. https://doi.org/10.1080/09515089.2015.1078458

Murtagh, N., Nati, M., Headley, W. R., Gatersleben, B., Gluhak, A., Imran, M. A., \& Uzzell, D. (2013). Individual energy use and feedback in an office setting: A field trial. Energy Policy, 62, 717-728. https:// doi.org/10.1016/j.enpol.2013.07.090 


\section{Nudging in the workplace}

OECD. (2017). Behavioural insights and public policy lessons from around the world. Paris: OECD Publishing.

Oldfield, K. (2017). The social aspects of hand washing in American restaurants: An administrative approach to reducing public and private health care costs. Administration E Society, 49(5), 753-771. https://doi. org/10.1177/0095399716638121

Olejnik, S., \& Algina, J. (2000). Measures of effect size for comparative studies: Applications, interpretations, and limitations. Contemporary Educational Psychology, 25(3), 241-286. https://doi.org/10.1006/ ceps. 2000.1040

Osman, M., Radford, S., Lin, Y., Gold, N., Nelson, W., \& Löfstedt, R. (2020). Learning lessons: How to practice nudging around the world. Journal of Risk Research, 23, 11-19. https://doi.org/10.1080/1366 9877.2018.1517127b

Pronk, N. P., Katz, A. S., Lowry, M., \& Payfer, J. R. (2012). Reducing occupational sitting time and improving worker health: The take-a-stand project, 2011. Preventing Chronic Disease, 9, 110323. https:// doi.org/10.5888/pcd9.110323

Raanaas, R. K., Evensen, K. H., Rich, D., Sjøstrøm, G., \& Patil, G. (2011). Benefits of indoor plants on attention capacity in an office setting. Journal of Environmental Psychology, 31(1), 99-105. https://doi. org/10.1016/j.jenvp.2010.11.005

Raineri, N., \& Paillé, P. (2016). Linking corporate policy and supervisory support with environmental citizenship behaviors: The role of employee environmental beliefs and commitment. Journal of Business Ethics, 137, 129-148. https://doi.org/10.1007/s10551-015-2548-x

Renaud, K., \& Zimmermann, V. (2019). Nudging folks towards stronger password choices: Providing certainty is the key. Behavioural Public Policy, 3(2), 228-258. https://doi.org/10.1017/bpp.2018.3

Röttger, S., Maier, J., Krex-Brinkmann, L., Kowalski, J. T., Krick, A., Felfe, J., \& Stein, M. (2017). Social cognitive aspects of the participation in workplace health promotion as revealed by the theory of planned behavior. Preventive Medicine, 105, 104-108. https://doi.org/10.1016/j.ypmed.2017.09.004

Schliemann, D., \& Woodside, J. V. (2019). The effectiveness of dietary workplace interventions: A systematic review of systematic reviews. Public Health Nutrition, 22(5), 942-955. https://doi.org/10.1017/ S1368980018003750

Schubert, C. (2017). Green nudges: Do they work? Are they ethical? Ecological Economics, 132, 329-342. https://doi.org/10.1016/j.ecolecon.2016.11.009

Schwartz, B., \& Ward, A. (2004). Doing better but feeling worse: The paradox of choice. In P. A. Linley \& S. Joseph (Eds.), Positive psychology in practice (pp. 86-104). Hoboken, NJ: John Wiley \& Sons Inc.

Selinger, E., \& Whyte, K. (2011). Is there a right way to nudge? The practice and ethics of choice architecture. Sociology Compass, 5(10), 923-935. https://doi.org/10.1111/j.1751-9020.2011.00413.x

Siep, N., Roefs, A., Roebroeck, A., Havermans, R., Bonte, M. L., \& Jansen, A. (2009). Hunger is the best spice: An fMRI study of the effects of attention, hunger and calorie content on food reward processing in the amygdala and orbitofrontal cortex. Behavioural Brain Research, 198, 149-158. https://doi. org/10.1016/j.bbr.2008.10.035

Skov, L. R., Lourenco, S., Hansen, G. L., Mikkelsen, B. E., \& Schofield, C. (2013). Choice architecture as a means to change eating behaviour in self-service settings: A systematic review. Obesity Reviews, 14(3), 187-196. https://doi.org/10.1111/j.1467-789X.2012.01054.x

Soler, R. E., Leeks, K. D., Razi, S., Hopkins, D. P., Griffith, M., Aten, A., . . . \& Pronk, N. P. (2010). A systematic review of selected interventions for worksite health promotion: The assessment of health risks with feedback. American Journal of Preventive Medicine, 38(2), S237-S262. https://doi.org/10.1016/j. amepre.2009.10.030

Sommestad, T., Karlzén, H., \& Hallberg, J. (2019). The theory of planned behavior and information security policy compliance. Journal of Computer Information Systems, 59(4), 344-353. https://doi.org/10.10 80/08874417.2017.1368421

Staddon, S. C., Cycil, C., Goulden, M., Leygue, C., \& Spence, A. (2016). Intervening to change behaviour and save energy in the workplace: A systematic review of available evidence. Energy Research E Social Science, 17, 30-51. https://doi.org/10.1016/j.erss.2016.03.027

Steffel, M., Williams, E. F., \& Pogacar, R. (2016). Ethically deployed defaults: Transparency and consumer protection through disclosure and preference articulation. Journal of Marketing Research, 53(5), 865-880. https://doi.org/10.1509/jmr.14.0421

Straker, L., \& Mathiassen, S. E. (2009). Increased physical work loads in modern work: A necessity for better health and performance? Ergonomics, 52(10), 1215-1225. https://doi.org/10.1080/00140130903039101

Stringer, L. (2010). The green workplace: Sustainable strategies that benefit employees, the environment, and the bottom line. New York, NY: Palgrave MacMillan. 
Sunstein, C. R. (2019). Sludge audits. Behavioural Public Policy, 1-20. https://doi.org/10.1017/bpp.2019.32

Szaszi, B., Palinkas, A., Palfi, B., Szollosi, A., \& Aczel, B. (2018). A systematic scoping review of the choice architecture movement: Toward understanding when and why nudges work. Journal of Behavioral Decision Making, 31(3), 355-366. https://doi.org/10.1002/bdm.2035

Teixeira, P. J., Carraça, E. V., Marques, M. M., Rutter, H., Oppert, J. M., De Bourdeaudhuij, I., . . . \& Brug, J. (2015). Successful behavior change in obesity interventions in adults: A systematic review of self-regulation mediators. BMC Medicine, 13, 84. https://doi.org/10.1186/s12916-015-0323-6

Thaler, R. H., \& Benartzi, S. (2004). Save more tomorrow ${ }^{\text {TM}: ~ U s i n g ~ b e h a v i o r a l ~ e c o n o m i c s ~ t o ~ i n c r e a s e ~}$ employee saving. Journal of Political Economy, 112(S1), S164-S187. https://doi.org/10.1086/380085

Thaler, R. H., \& Sunstein, C. R. (2008). Nudge: Improving decisions about health, wealth, and happiness. New Haven, CT: Yale University Press.

Thompson, V. A. (2009). Dual-process theories: A metacognitive perspective. In J. S. B. T. Evans \& K. Frankish (Eds.), In two minds: Dual processes and beyond (pp. 171-195). Oxford: Oxford University Press. https://doi.org/10.1093/acprof:oso/9780199230167.003.0008

Thompson, V. A., Turner, J. A. P., \& Pennycook, G. (2011). Intuition, reason, and metacognition. Cognitive Psychology, 63(3), 107-140. https://doi.org/10.1016/j.cogpsych.2011.06.001

Tompa, E., Trevithick, S., \& McLeod, C. (2007). Systematic review of the prevention incentives of insurance and regulatory mechanisms for occupational health and safety. Scandinavian Journal of Work, Environment \& Health, 85-95. https://doi.org/10.5271/sjweh.1111

Trudel, R., Murray, K. B., Kim, S., \& Chen, S. (2015). The impact of traffic light color-coding on food health perceptions and choice. Journal of Experimental Psychology: Applied, 21(3), 255. https://doi. org/10.1037/xap0000049

Van de Veer, D. (1986). Paternalistic intervention: The moral bounds on benevolence. Princeton: Princeton University Press.

Van der Meiden, I., Kok, H., \& Van der Velde, G. (2019). Nudging physical activity in offices. Journal of Facilities Management, 17(4), 317-330. https://doi.org/10.1108/JFM-10-2018-0063

Van Gestel, L. C., Adriaanse, M. A., \& De Ridder, D. T. D. (2020). Do nudges make use of automatic processing? Unraveling the effects of a default nudge under type 1 and type 2 processing. Comprehensive Results in Social Psychology. https://doi.org/10.1080/23743603.2020.1808456

Van Gestel, L. C., Kroese, F. M., \& De Ridder, D. T. D. (2018). Nudging at the checkout counter: A longitudinal study of the effect of a food repositioning nudge on healthy food choice. Psychology $\&$ Health, 33(6), 800-809. https://doi.org/10.1080/08870446.2017.1416116

Van Kleef, E., Otten, K., \& van Trijp, H. C. (2012). Healthy snacks at the checkout counter: A lab and field study on the impact of shelf arrangement and assortment structure on consumer choices. BMC Public Health, 12, 1072. https://doi.org/10.1186/1471-2458-12-1072

Van Nieuw-Amerongen, M. E., Kremers, S. P. J., De Vries, N. K., \& Kok, G. (2011). The use of prompts, increased accessibility, visibility, and aesthetics of the stairwell to promote stair use in a university building. Environment and Behavior, 43, 131-139. https://doi.org/10.1177/0013916509341242

Velema, E., Vyth, E. L., Hoekstra, T., \& Steenhuis, I. H. (2018). Nudging and social marketing techniques encourage employees to make healthier food choices: A randomized controlled trial in 30 worksite cafeterias in the Netherlands. The American Journal of Clinical Nutrition, 107(2), 236-246. https://doi. org/10.1093/ajcn/nqx045

Venema, T. A. G., Kroese, F. M., Benjamins, J. S., \& de Ridder, D. T. D. (2020). When in doubt, follow the crowd? Responsiveness to social proof nudges in the absence of clear preferences. Frontiers in Psychology, 11, 1385. https://doi.org/10.3389/fpsyg.2020.01385

Venema, T. A. G., Kroese, F. M., \& De Ridder, D. T. (2018). I'm still standing: A longitudinal study on the effect of a default nudge. Psychology \& Health, 33(5), 669-681. https://doi.org/10.1080/0887044 6.2017 .1385786

Venema, T. A. G., Kroese, F. M., de Vet, E., \& de Ridder, D. T. D. (2019). The one that I want: Strong personal preferences render the center-stage nudge redundant. Food Quality and Preference, 78, 103744. https://doi.org/10.1016/j.foodqual.2019.103744

Venema, T. A. G., Kroese, F. M., Verplanken, B., \& de Ridder, D. T. D. (2020). The (bitter) sweet taste of nudge effectiveness: The role of habits in a portion size nudge, a proof of concept study. Appetite, 104699. https://doi.org/10.1016/j.appet.2020.104699

Vetter, M., \& Kutzner, F. (2016). Nudge me if you can-how defaults and attitude strength interact to change behavior. Comprehensive Results in Social Psychology, 8-34. https://doi.org/10.1080/23743603. 2016.1139390 
Welch, B. F. (2013). Shifting the concept of nudge. Journal of Medical Ethics, 39(8), 497-498. https://doi. org/10.1136/medethics-2012-101111

Wilks, S., Mortimer, M., \& Nylén, P. (2006). The introduction of sit-stand worktables; aspects of attitudes, compliance and satisfaction. Applied Ergonomics, 37(3), 359-365. https://doi.org/10.1016/j. apergo.2005.06.007

Wilson, A. L., Buckley, E., Buckley, J. D., \& Bogomolova, S. (2016). Nudging healthier food and beverage choices through salience and priming: Evidence from a systematic review. Food Quality and Preference, 51, 47-64. https://doi.org/10.1016/j.foodqual.2016.02.009

Wu, K. S., Lee, S. S. J., Chen, J. K., Chen, Y. S., Tsai, H. C., Chen, Y. J., . . . \& Lin, H. S. (2018). Identifying heterogeneity in the Hawthorne effect on hand hygiene observation: A cohort study of overtly and covertly observed results. BMC Infectious Diseases, 18, 369. https://doi.org/10.1186/ s12879-018-3292-5

Ybema, J. F., van Vuuren, T., \& van Dam, K. (2020). HR practices for enhancing sustainable employability: Implementation, use, and outcomes. The International Journal of Human Resource Management, 31(7), 886-907. https://doi.org/10.1080/09585192.2017.1387865 


\title{
20
}

\section{ACTIVITY THEORY}

\section{A framework for understanding the interrelations between users and workplace design}

\author{
Maral Babapour*, Antonio Cobaleda-Cordero, and \\ MariAnne Karlsson
}

\section{Background}

Activity theory (AT) has its origins in the sociocultural tradition of Russian psychology and psychologists such as Lev Vygotsky (in the 1920s) and later (in the 1970s), Aleksei Leont'ev. In contrast with theories which objectify the mind and consider activity as a response to a stimulus, activity theory was built on the notion that consciousness and activity are one and the same and that the mind develops through activity (Leont'ev, 1978) by interacting with the world and through the construction of artefacts. According to AT, humans have needs which lead them to carry out activities (that is, interact with objects in the world) to satisfy their needs. These objects, which may be tangible or intangible, motivate and direct activities. This is why understanding human activities necessitates an understanding of objects (Kaptelinin \& Nardi, 2009). Humans may carry out activity as individuals or among and in collaboration with other humans as collective activity. However, the structure of the activity can only be considered and understood in a sociocultural context. This context comprises the motives and goals for the activity as well as its methods and tools (Leont'ev, 1978).

Human activities are organised into three hierarchical layers (Leont'ev, 1978), illustrated in Figure 20.1. The highest level, activity, is oriented towards a motive, corresponding to a need. The motive is that object which the human (or subject) needs to attain (Kaptelinin \& Nardi, 2009). One activity may have more than one motive, originating from different areas of life. Motives are often tacit or unarticulated. This makes them difficult to elicit because without motive, there is no activity. Each activity is, in turn, conducted through actions, which are conscious processes with specific goals (and sub-goals). These actions must be undertaken to fulfil the object. One or more actions may contribute to the same activity, and a single action may contribute to multiple activities. However, even though actions have their own goals, it is the activity which gives meaning to the various actions. Actions are implemented through a series of operations, which are unconscious processes triggered by the specific physical and social conditions present at that moment. Although activity, action and operation form a hierarchy, the hierarchy is not fixed. Transformation takes place constantly.

Furthermore, human activity is mediated by one or more physical and psychological tools that shape the way a human being interacts with the world and through which they achieve

*Corresponding author:maral@chalmers.se 

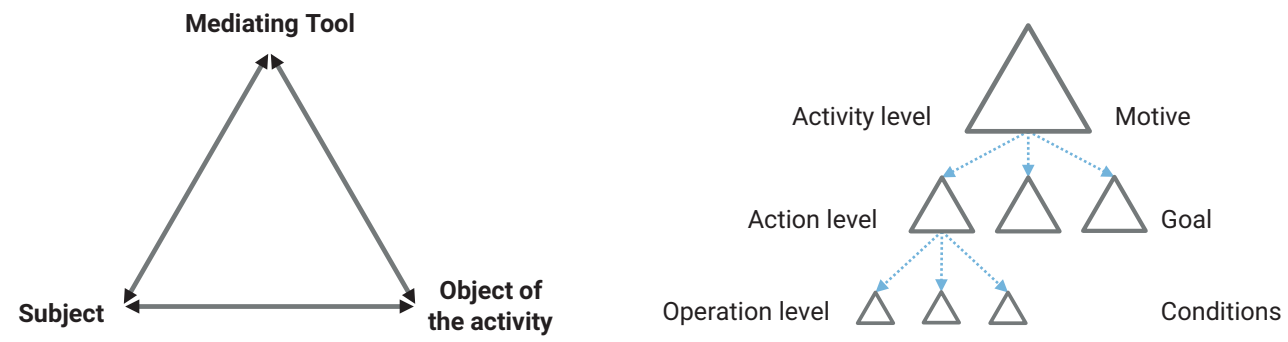

Figure 20.1 Constituents and hierarchical layers of activities

their goals. Examples of physical tools are hand tools, computers, furniture and so on. However, tools may also include place and space. A well-functioning mediating tool allows the user to focus on the object. Conversely, a tool that does not work well causes breakdowns and draws the user's focus towards the tool per se. Artefacts that are used regularly by users in a given activity constitute the current artefact ecology and shape the user's perception when appropriating new artefacts.

The basic unit of analysis in AT is the activity system. This has been defined as a collective, artefact-mediated, object-orientated system (Engeström, Miettinen, \& Punamäki, 1999); a group of people sharing a common object and motive over time, plus the tools they need to act on the object (Kain \& Wardle, 2014). In most complex situations, many dynamic interrelated activities form what could be seen as a system of activities. To understand activity systems, we need to consider how they have developed over time, their past and present and their dialectic character, in that changes to one aspect of a system may change other aspects in response.

Leont'ev played an important role in developing the original theory, adding to Vygotsky's ideas by arguing that activities were composed of actions and operations and, perhaps more importantly, depended on the division of labour. These ideas were later embraced by Engeström (1987) in his extended activity system, in which an activity is mediated, not only by tools, but also by a community, the rules of that community and a division of labour.

The use of AT has grown and is now applied within different fields, not least as an analytical tool in fields such as educational research (Scanlon \& Issroff, 2002; Roth, 2004), in studies of organisational learning (e.g. Engeström, 2006) and studies of information systems (e.g. Bødker \& Klokmose, 2011; Kaptelinin \& Nardi, 2009; Kuutti, 1996). Common themes involve understanding collective work and tensions and contradictions within and between activity systems. More recently, other areas have also started to acknowledge the theory, for example as a tool for analysing the relationship between users and technical products as a basis for user-oriented product design (Engelbrektsson, 2004; Hiort, 2010; Karlsson, 1996; Rexfelt, 2008), for understanding barriers to, and enablers of, sustainable behaviour (Renström, 2019; Selvefors, 2017; Strömberg, 2015) and for workplace research, as described in this chapter (Babapour, 2019a; Cobaleda-Cordero, 2019).

\section{Application to workplace studies}

The main object of inquiry in activity theory is to understand human activity in natural situations and examine the role of tools in everyday activities. AT provides a holistic and fairly open view of human activities; it provides insights significant to workplace research, from both theoretical and applied standpoints. Applying an AT perspective in workplace research requires employees' everyday work situations and workplaces to be considered the main object of inquiry. From this viewpoint, employees are seen as users of workplaces and workplaces are seen as an 
artefact ecology, with a constellation of different workstations, office furniture and technical equipment that mediates users' activities.

Organisations worldwide are increasingly implementing flexible workplace solutions that entail changes in employees' artefact ecologies. These changes are made in the hope of realising strategic goals such as increased collaboration, productivity and work environment satisfaction, plus reduced occupancy costs and energy consumption (e.g. Appel-Meulenbroek, Groenen, \& Janssen, 2011; Rolfö, 2018; Van der Voordt, 2004). Activity theory has been applied in studies of flexible offices to investigate how well these innovations support employees' work and wellbeing. Several implementations of flexible offices in Sweden were thoroughly examined from an AT standpoint by the authors (Babapour, 2019a; Cobaleda-Cordero, Babapour, \& Karlsson, 2020). This section describes the unique foci of AT, provides arguments for the relevance and benefits of applying AT in workplace studies and outlines how the authors have applied AT in workplace research.

\subsection{Emphasis on the situatedness and contextual nature of employees' activities}

Employee activities take place within, and as a part of, the local circumstances of an organisation and rely on exploitation of available tools and resources in the work environment. Workplaces and the tools which mediate employees' activities are culturally situated. They are the result of historical, economic and technological developments and follow societal trends, norms, values and governing policies. Similarly, the ways in which employees use workplaces are socially situated. They are developed during a process whereby employees are not isolated but, rather, belong to a workgroup that develops and shares routines (Daniellou \& Rabardel, 2005). Sometimes the use of workplaces is formalised by information passed on between employees and internalised through, say, training, instructions or manuals. Applying an AT perspective in workplace research requires an understanding of the influence of the social organisation and the cultural context in which workplaces and their constituent resources and tools are developed.

In studying the implications of flexible offices, the authors identified a variety of organisational preconditions which influence employees' activity systems, both pre- and post-relocation (Babapour, 2019a; Cobaleda-Cordero et al., 2020). Examples include the quality of the physical and psychosocial work environment prior to relocation; the reasons and triggers behind the relocation; the resources available for implementing the office innovation and post-relocation improvements; the degree of employee involvement in decision processes when designing and improving the premises; and ongoing organisational changes. These preconditions influence the way employees experience and perceive the extent of improvement in their activity systems after relocating to a flexible office.

\subsection{A simultaneously holistic and granular understanding of employees' activities}

The hierarchical structure of activities encompasses different levels of abstraction: activity, action and operation levels (Leont'ev, 1978). This quality allows employees' activities to be approached as holistic systems of substantial complexity and with the prospect of analytical depth. Similarly, one may focus on individual or collective activities within an organisation (Engeström, 2000). The authors adopted this perspective to examine employees' activities in detail in several case studies of flexible offices (for detailed examples see Babapour, 2019a). Analysis of the hierarchies of employees' activities helped identify the goals and objects of the activities and the different 
actions, as well as the new actions and operations introduced into employees' activity systems because of the new workplace solution. This granularity is beyond the otherwise general and reductive operationalisations of office work as a combination of 'meetings and concentrative work'. It allowed for understanding why, in which situations and for which actions and operations flexible offices work. In addition, analysis of typical activities of individuals with different roles and responsibilities allowed identification of workplace requirements on individual, group and organisational levels and the dynamics between them.

\subsection{Understanding employees' experiences and subjective grasp of their contexts}

In activity theory, the emphasis is on capturing the activities of individuals with different values, prior experiences, motivations, personal preferences, physical capabilities and limitations, skills and training (Leont'ev, 1978). These individual preconditions are an integral part of human activities; they are formed as a result of the interactions within and between individuals' current and former activities (ibid.). Applied to workplace research, AT accounts for employees' experiences using workplaces, subjectively and individually as well as collectively. The authors outline various personal circumstances, prior experiences, preferences and physical or cognitive capabilities and limitations among employees that influence their experience of working in flexible offices (Babapour, 2019a; Cobaleda-Cordero, 2019). These individual preconditions played an essential role in employees' activities and the way they experience the workplace with respect to different functional, social, emotional, symbolic and aesthetic qualities of the environment (cf. Babapour, Harder, \& Bodin Danielsson, 2020). It is the employees, as workplace users, who give meaning to the tools and resources available in a workplace, based on their individual preconditions. Therefore, when studying workplaces, it is strongly recommended that the subjective experiences of employees should be accounted for.

\subsection{Mediating roles that workplaces play as tools in employees' everyday activities}

The resources and tools available in the workplace constitute an ecology of artefacts for employees. These artefact ecologies are analysed, not just as spaces or things, but also for the way in which they mediate employees' activities. Workplace solutions have different intrinsic qualities and constraints which contribute to employees' actions by defining a space for action possibilities; in other words, the activities, actions and operations which the workplace enables and allows for. The constraints in workplace solutions may lead to mismatches between either (i) possibilities or capacities of the workplace and what employees want to do or (ii) the workplace and employees' preconditions, preferences, physical conditions and training (see Chapter 2 Person-Environment Fit Theory). The analysis of how workplace solutions mediate employees' activities covers the hierarchical layers activities and may involve levels of abstraction varying from addressing a workplace as a technical system with various tools and resources to considering its tools or workstations in isolation.

Applying an AT perspective in the study of flexible offices showed that the office usage and the way it mediated employees' activities varied within and between different cases (Babapour, 2019a; Cobaleda-Cordero et al., 2020). The differences in usage related to sharing practices, the use and/or non-use of the different zones and workstations and the immediate tools such as data-entry devices. Three types of matches and/or mismatches were identified in employees' activity systems: Employee $\leftrightarrow$ Office, Activity $\leftrightarrow$ Office and Employee $\leftrightarrow$ Activity (see Figure 20.2). 


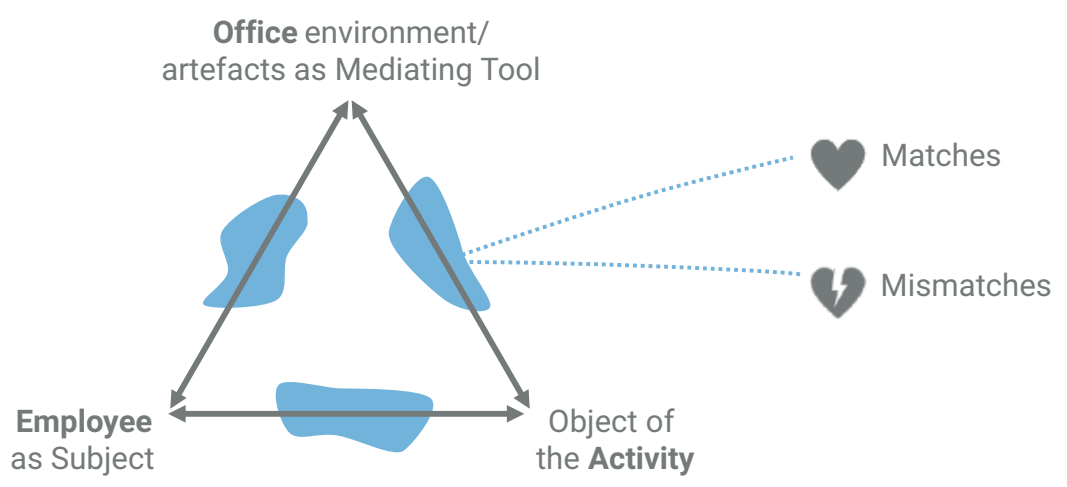

Figure 20.2 Activity systems in the office context

It is also important to note different matches and mismatches were identified on the activity, action and operation levels. In general, the abundance or lack of mismatches in the activity systems explained why some employees were satisfied with flexible offices while others were dissatisfied. Successful offices were designed to facilitate the activities of individuals, groups and the organisation on different hierarchical levels. They also supported the shared use of resources, whilst matching employees' personal circumstances and preferences for wellbeing and enjoyment.

\subsection{Temporal aspects and the developmental process of appropriating new workplaces}

Organisations continually improve and optimise their workplace solutions by introducing new tools or relocating to entirely new workplaces. The introduction of new tools into a given situation allows old problems to be solved, but it changes the nature of the activities and provides learning and improvement opportunities (Karlsson, 1996). The way individuals use tools may be seen as utilisation schemes, developed both individually, as repertoires or automated and wellmastered ways of doing things, and socially, as groups' common ways of doing things (Daniellou \& Rabardel, 2005). Sometimes, the same usage schemes may be applied to a new tool or workplace. In situations which are very new to individuals, entirely new usage schemes must be formed; this temporarily makes the appropriation process predominant. AT allows the processes by which individuals (or groups) explore, interpret, use and transform new workplace solutions to be captured; this is a necessary condition for reaching efficiency in those individuals' activities.

Applying AT to the study of flexible offices helped describe the phases of, and differences between, employees' post-relocation appropriation processes. Flexible offices require employees to share resources such as desks, tables and data-entry devices. The sharing dimension and new workplace design in flexible offices entail a re-mediation of employees' activities, providing new functionalities and requiring new usage schemes. The different phases involved familiarisation, exploration and routinisation (Babapour, Karlsson, \& Osvalder, 2018). However, these phases had different characteristics within and between the studied workplaces. Apart from changes within usage schemes, the appropriation process also involved changes within the workplaces. This allowed employees and organisations to improve the properties of the workplace, making them a better fit for the different levels of their activities (Babapour, 2019a, 2019b). Figure 20.3 shows that three types of appropriation were identified among the employees. These were 
Familiarisation; testing the desk-sharing rule and the new workplaces; resolution of initial problems.

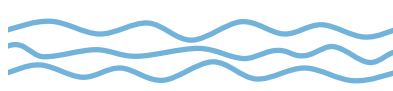

Fruitful symbiosis and stable phase; lack of mismatches in employees' activity systems with respect to the flexible office; facilitation of employees' work and promotion of their wellbeing.

Periodical rejection of desksharing rule; disruptions in employees' activity systems.

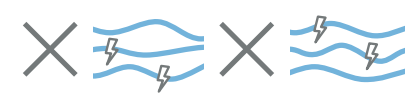
Instability; lingering mismatches and emergence of new problems due to the sub-optimal design of the workspaces and limited improvements.

Familiarisation; testing the desk-sharing rule and the new workplaces; identification of needs for improvements.

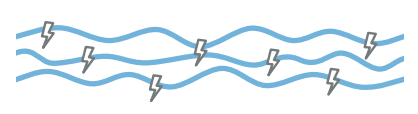

Resigned symbiosis; lingering mismatches due to the sub-optimal design of the workspaces and the limited improvements; development of coping strategies to reach a stable phase.

Figure 20.3 Different phases and types of appropriation after relocation to flexible offices

(i) an appropriation that led to a fruitful symbiosis and stable phase, in which the new office did not entail mismatches in the studied activity systems but rather supported employees' work and wellbeing; (ii) an appropriation that entailed lingering and emergent mismatches, without achieving stability in the studied activity systems; and (iii) an appropriation that led to a resigned symbiosis, in which employees had found ways to cope with the lingering mismatches in their activity systems.

\subsection{Informing a use(r)-centred workplace design and development}

Activity theory provides a framework for capturing users' needs in their everyday activities. Applying an AT perspective in design processes requires usage to be considered as an integral part of these processes (Ehn, 1989). Employees must often compensate for difficulties stemming from inadequate and sub-optimal workplace design solutions. The inadequacy of workplace design solutions is due to failure in, and difficulties with, anticipating the usage and specificities of a use situation. Using AT as a starting point in design processes allows the ongoing dynamics in use situations to be captured. It also allows the different levels of an activity system to be addressed to align the design solutions with users' activities (Bødker \& Klokmose, 2011). This requires a dialogical, iterative process (rather than a linear one) to capture the users' expertise in, and knowledge of, use and their activities.

Analysing the implications of flexible offices from an AT viewpoint has led to the identification of successful and sub-optimal design features of such workplace solutions (Babapour, 2019a; Cobaleda-Cordero et al., 2020). The in-depth understanding of employees' activities and the mapping of matches and mismatches helped identify success factors and sub-optimal features relating to the design of workspaces, furniture and other tools in flexible offices. These insights are then used as design recommendations for consideration both during the design processes and after relocation, thus allowing the design of these work environments to be modified (Babapour et al., 2020). Adopting an AT view facilitates anticipation of usage dynamics relating to future solutions and may be used as a resource for workplace designers and decision makers.

\subsection{The unique foci of activity theory}

Activity theory provides a multidimensional system view with a rigorous set of concepts and a well-defined unit of analysis. This has fundamental implications for workplace research by addressing the otherwise neglected situation-based questions within workplace studies that relate to (i) the technological and sociocultural context influencing the development of workplaces 
within an organisation; (ii) employees' goal-oriented actions and object-oriented activities and routinised operations; (iii) the different ways employees use available tools and resources in a workplace; (iv) ways in which the workplace mediates employees' activities and fulfils employees' needs; (v) the contradictions within and between activity systems and how they drive change and development of workplaces; and (vi) short- and long-term impacts of workplace changes on employees' activity systems.

As mentioned previously, the application of AT in the context of workplace research is limited to a few recent studies, mainly focusing on flexible offices such as activity-based offices and combi offices. AT has also been applied to investigate other workplace contexts and is recommended as a basis for the study of human work in the field of design and ergonomics sciences (Bedny \& Karwowski, 2004). Examples of other areas of application are healthcare environments (Engeström, 2000) or manufacturing operations (Bedny, Karwowski, \& Kwon, 2001). Therefore, the study of different office types or other types of work environments may also benefit from adopting this theoretical framework.

\section{Research approach for adopting activity theory in workplace research}

The study of office workplaces from an activity theoretical viewpoint involves a number of methodological considerations for data collection and analysis. The concept of mediation is central in AT and due to the "endless mutual transformation" of the activity and things in response to each other (Miettinen, 2006, p. 396), it is important to examine employees' activities in context. Therefore, contextual inquiries involving qualitative and ethnographical methods are recommended when studying the conditions of activities in real-world situations.

\subsection{Considerations for data collection from an activity theoretical viewpoint}

A variety of methods have been used to conduct contextual inquiries and capture the interrelations between different elements of employees' activity systems (Babapour, 2019a; CobaledaCordero, 2019). Interviews and focus groups are commonly used in studies with an AT viewpoint, allowing a diversity of themes to be addressed in depth and the elicitation of user insights into cumulative experiences in the office. Activity and experience-mapping tools may be used during interviews and focus groups to acquire insights into employee experiences, activities and routines over specified timeframes (Babapour \& Cobaleda-Cordero, 2020). Furthermore, observations of the office environment and spatial walkthroughs may be used to, say, collect data on the spaces which are most and least popular, or the artefacts and tools which people use (ibid.). In addition, collecting secondary data may provide complementary information about workplaces' configuration and design. Examples of secondary data include building documentation, organisations' protocols and workflows for facilities and occupational health management.

Evidently, the outlined data collection methods are not specific to activity theory. These methods may be used with specific questions that address and explore the different elements of employees' activity systems and their interrelations. Each method captures the elements and levels of activity systems to different extents (Figure 20.4). However, it is important to note that capturing the intentionality, motivations of activities and employees' experiences are essential from an AT perspective. This requires a commitment to comprehensively understand users' insights and context (Miettinen, 2006; Nardi, 1996). Therefore, methods which allow for a dialogue between researchers and the people they study and which enable people to reflect and 


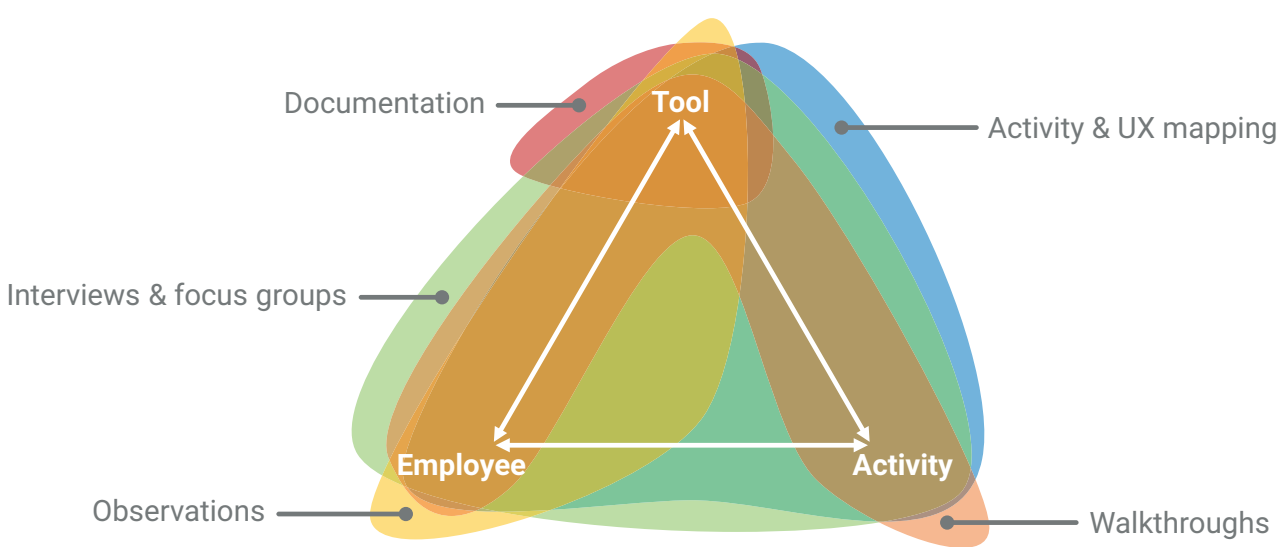

Figure 20.4 Coverage of the methods in relation to the study of activity systems

elaborate on their activities, preferences and experiences with their workspaces should be prioritised. A triangulation of multiple methods is recommended for a comprehensive and nuanced understanding of activity systems from an AT viewpoint.

\subsection{Analytical considerations from an activity theoretical viewpoint}

When conducting workplace studies using activity theory as an analytical framework, several steps and considerations should be considered, for both data collection and analysis. The authors propose a step-by-step guide for applying AT in workplace studies (see Figure 20.5), based on their application of the theory in various contexts. It is not necessary to follow the proposed steps in consecutive order. Rather, the application of AT requires an iterative and dialectic approach, and the process may vary depending on the context of the study.

The rich user insights, contextual data and methods triangulation help ensure confirmability and reliability of results when analysing activity systems from an AT perspective in workplace studies. The emphasis on qualitative methods requires researchers to closely examine the data to find trends, patterns and argumentations rather than correlations and causality. This implies that the diverse data inputs may converge, diverge, contradict or confirm each other and is the reason a sound ability to cross-interpret data is key. A suitable strategy for content analysis is to conduct both inductive and deductive coding processes involving at least two researchers, to enable discussion, avoid biases and ensure credibility of findings. Further, respondent validation strategies such as getting feedback from the participants are recommended to confirm findings and to ensure the quality and credibility of conclusions.

Activity theory provides a system view for the study of workplaces and may help address the otherwise neglected situation-based questions within workplace studies such as: What technological, social and cultural factors influence the development of workplaces within an organisation? What are the employees' goal-oriented actions and object-oriented activities and routinised operations within their roles and responsibilities? How do employees use workplaces? How do workplaces mediate employees' activities and fulfilment of their needs? What are the contradictions within and between different activity systems within a workplace and how do they drive change and development of workplaces? What are the short- and long-term impacts of workplace changes on employees' activity systems? 
Consider the context-specific circumstances of the workplace, covering previous and present resources, motives behind workplace changes, and norms, values and governing policies within the workplace.

Step 1 The sociocultural context

- Identify the significant activities of the system to be investigated plus each activity's subject(s), object and purpose.

- Identify the goal-directed actions and routinised operations in employees' activities.

- Consider activities of individuals and different groups within the organisation.

Step 2 The activity and its hierarchical layers

Consider users' personal circumstances, preferences, values, skills, capabilities and limitations.

- Identify the actions and mediating tools of the activity or activities, where tools can be primary, secondary or tertiary with different qualities and limitations.

- Identify the usage schemes and dynamics and tensions interrelations within and between the identified activity systems, specifically matches and mismatches between employees, the identified constellation of tools and activities, actions and operations.

- Identify the dynamics and tensions between the identified activity systems, by comparing the activity systems of different employees or groups.

\section{Step 4 Mediating tools and dynamics in activity systems}

Consider a timeframe that is long enough to capture the changing nature of activities that occurs as a result of adopting, developing and using new tools.

\section{Step 5 Appropriation}

Inform and steer a use(r)-centred design and development of workplaces based on the insights acquired from the preceding steps and by bringing together employees as participants and co-creators with decision makers in workplace design processes.

\section{Step 6 Towards a use(r) centred workplace design}

Figure 20.5 Guidance for application of activity theory in workplace studies

\section{Limitations and challenges}

The application of activity theory in workplace studies requires fieldwork which relies on gaining access to a particular organisation. This involves securing entry, ensuring that employees within that organisation will participate as informants for data collection and be able to return to the organisation to collect complementary data or present results. As outlined in the methodological implications, a triangulation of qualitative methods may be required to gain a thorough understanding of employees' activity systems. In this sense, both the data collection and the analysis of the subsequent datasets are costly and time-consuming. The three main challenges 
in applying AT in workplace research concern access, time and resources. It is also important to highlight that AT is not a predictive theory and that its application does not reveal causality. Rather, AT helps find patterns and interrelations between the three components of an activity system and within different activity systems.

\section{Relevance to practice}

Activity theory as a framework takes peoples' practices as its starting point and enables practitioners to understand employees' activities, needs and preferences at work, as well as the reasons underlying the use of office spaces and artefacts. This knowledge is fundamental to informing and steering design interventions and innovations. A wide range of stakeholders may benefit from the insights provided by adopting an AT perspective, for example, (i) facilities managers, for planning and maintenance; (ii) architects and interior designers during the design processes; (iii) product developers, such as designers of furniture or computer equipment intended for office environments; (iv) procurement managers who influence the type of artefacts and tools purchased in workplaces; (v) administrative managers who may influence changes in the work environment; and (vi) occupational health and safety professionals who advise on changes and improvements in workplaces. AT has been used to (re-)design and evaluate the physical environment in workplaces, providing opportunities to bring together employees as participants and co-creators with decision makers in design processes.

\section{Further reading}

- Babapour, M. (2019). The quest for the room of requirement - Why some activity-based flexible offices work while others do not [Doctoral Thesis]. Division Design \& Human Factors, Chalmers University of Technology (Sweden). Retrieved from https://research.chalmers.se/en/ publication/509482

- Cobaleda-Cordero, A. (2019). Office landscapes for well-being [Licentiate Thesis]. Division Design \& Human Factors, Chalmers University of Technology (Sweden). Retrieved from https://research.chalmers.se/en/publication/512797

- Cobaleda-Cordero, A., Babapour, M., \& Karlsson, M. (2020). Flexible office, flexible working? A post-relocation study on how and why university employees use a combi-office for their activities at hand. International Journal of Human Factors and Ergonomics, 7, 26-54. https://doi.org/10.1504/IJHFE.2020.107286

- Engeström, Y., Miettinen, R., \& Punamäki, R. L. (1999). Perspectives on activity theory. Cambridge: Cambridge University Press.

\section{References}

Appel-Meulenbroek, R., Groenen, P., \& Janssen, I. (2011). An end-user's perspective on activity-based office concepts. Journal of Corporate Real Estate, 13(2), 122-135. https://doi.org/10.1108/14630011111136830

Babapour, M. (2019a). The quest for the room of requirement-Why some activity-based flexible offices work while others do not [Doctoral thesis]. Division Design \& Human Factors, Chalmers University of Technology (Sweden). Retrieved from https://research.chalmers.se/en/publication/509482

Babapour, M. (2019b). From fading novelty effects to emergent appreciation of activity-based flexible offices: Comparing the individual, organisational and spatial adaptations in two case organisations. Applied Ergonomics, 81, 102877. https://doi.org/10.1016/j.apergo.2019.102877

Babapour, M., \& Cobaleda-Cordero, A. (2020). Contextual user research methods for eliciting user experience insights in workplace studies. In A. Kämpf-Derm \& M. Will-Zocholl (Eds.), Future workspaces: 
Proceedings of transdisciplinary workplace research conference 2020 (pp. 265-275). Frankfurt am Main, 17-18 September 2020.

Babapour, M., Harder, M., \& Bodin Danielsson, C. (2020). Workspace preferences and non-preferences in activity-based flexible offices: Two case studies. Applied Ergonomics, 83(2020), 102971. https://doi. org/10.1016/j.apergo.2019.102971

Babapour, M., Karlsson, M., \& Osvalder, A.-L. (2018). Appropriation of an activity-based flexible office in daily work. Nordic Journal of Working Life Studies, 8(S3), 71-94. https://doi.org/10.18291/njwls. v8iS3.105277

Bedny, G. Z., \& Karwowski, W. (2004). Activity theory as a basis for the study of work. Ergonomics, 47(2), 134-153. https://doi.org/10.1080/00140130310001617921

Bedny, G. Z., Karwowski, W., \& Kwon, Y. G. (2001). A methodology for systemic-structural analysis and design of manual-based manufacturing operations. Human Factors and Ergonomics in Manufacturing, 11(3), 233-255. https://doi.org/10.1002/hfm.1012

Bødker, S., \& Klokmose, C. N. (2011). The Human-Artifact Model: An activity theoretical approach to artifact ecologies. Human - Computer Interaction, 26(4), 315-371. https://doi.org/10.1080/07370024. 2011.626709

Cobaleda-Cordero, A. (2019). Office landscapes for well-being [Licentiate thesis]. Division Design \& Human Factors, Chalmers University of Technology (Sweden). Retrieved from https://research.chalmers.se/ en/publication/512797

Cobaleda-Cordero, A., Babapour, M., \& Karlsson, M. (2020). Flexible office, flexible working? A post-relocation study on how and why university employees use a combi-office for their activities at hand. International Journal of Human Factors and Ergonomics, 7(1), 26-54. https://doi.org/10.1504/IJHFE.2020.107286

Daniellou, F., \& Rabardel, P. (2005). Activity-oriented approaches to ergonomics: Some traditions and communities. Theoretical Issues in Ergonomics Science, 6(5), 353-357. https://doi.org/10.1080/146392205000 78351

Ehn, P. (1989). Work-oriented design of computer artifacts [Doctoral thesis]. Department of information Processing, Umeå University (Sweden).

Engelbrektsson, P. (2004). Enabling the user: Exploring methodological effects on user requirements elicitation [Doctoral thesis]. Division Design \& Human Factors, Chalmers University of Technology (Sweden). Retrieved from https://research.chalmers.se/en/publication/4308

Engeström, Y. (1987). Learning by expanding: An activity theoretical approach to developmental research. Helsinki: Orienta-Konsultit Oy. Retrieved from http://lchc.ucsd.edu/mca/Paper/Engestrom/Learningby-Expanding.pdf

Engeström, Y. (2000). Activity theory as a framework for analyzing and redesigning work. Ergonomics, 43(7), 960-974. https://doi.org/10.1080/001401300409143

Engeström, Y. (2006). Activity theory and expansive design. In S. Bagnara \& G. Crampton Smith (Eds.), Theories and practice of interaction design (pp. 3-23). Boca Raton, FL: CRC Press. https://doi. org/10.1201/9781482269536

Engeström, Y., Miettinen, R., \& Punamäki, R. L. (1999). Perspectives on activity theory. Cambridge: Cambridge University Press. https://doi.org/10.1017/CBO9780511812774

Hiort, V. (2010). The significance of things: Affective user-artefact relations [Doctoral thesis]. Division Design \& Human Factors, Chalmers University of Technology (Sweden). Retrieved from https://research. chalmers.se/en/publication/129033

Kain, D., \& Wardle, E. (2014): Activity theory: In introduction for the writing classroom. In E. Wardle \& D. Downs (Eds.), Writing about writing: A college reader. Boston, NY: Bedford/St Martin's.

Kaptelinin, V., \& Nardi, B. A. (2009). Acting with technology: Activity theory and interaction design. Cambridge, MA: MIT Press.

Karlsson, M. (1996). User requirements elicitation: A framework for the study of the relation between user and artefact [Doctoral thesis]. Department of Consumer Technology, Chalmers University of Technology (Sweden). Retrieved from https://research.chalmers.se/en/publication/1135

Kuutti, K. (1996). Activity theory as a potential framework for human computer interaction research. In B. A. Nardi (Ed.), Context and consciousness: Activity theory and human-computer interaction. Cambridge, MA: MIT Press.

Leont'ev, A. N. (1978). Activity, consciousness, and personality. Englewood Cliffs, NJ: Prentice-Hall.

Miettinen, R. (2006). Epistemology of transformative material activity: John Dewey's pragmatism and cultural-historical activity theory. Journal for the Theory of Social Behaviour, 36(4), 389-408. https://doi. org/10.1111/j.1468-5914.2006.00316.x 


\section{Activity theory}

Nardi, B. A. (1996). Context and consciousness: Activity theory and human-computer interaction. Cambridge, MA: MIT Press.

Renström, S. (2019). Participating in energy systems through everyday designs: Exploring roles for households in a more sustainable energy future [Doctoral thesis]. Division Design \& Human Factors, Chalmers University of Technology (Sweden). Retrieved from https://research.chalmers.se/en/publication/510208

Rexfelt, O. (2008). User-centred design and technology-mediated services: Identifying and addressing challenges by analysing activities [Doctoral thesis]. Division Design \& Human Factors, Chalmers University of Technology (Sweden). Retrieved from https://research.chalmers.se/en/publication/67664

Rolfö, L. V. (2018). Activity-based flexible office work environments: Design and implementation processes and outcomes [Doctoral thesis]. KTH Royal Institute of Technology (Sweden). Retrieved from www.diva-portal. org/smash/record.jsf?pid=diva2\%3A1265084\&dswid= $=454$

Roth, W.-M. (2004). Activity theory and education: An introduction. Mind, Culture, and Activity, 11(1), 1-8. https://doi.org/10.1207/s15327884mca1101_1

Scanlon, E., \& Issroff, K. (2002). Using technology in higher education: An activity theory perspective. Journal of Computer Assisted Learning, 18(1), 77-83. https://doi.org/10.1046/j.0266-4909.2001.00213.x

Selvefors, A. (2017). Design beyond interventions: Supporting less energy-reliant activities in the everyday [Doctoral thesis]. Division Design \& Human Factors, Chalmers University of Technology (Sweden). Retrieved from https://research.chalmers.se/en/publication/249056

Strömberg, H. (2015). Creating space for action: Supporting behaviour change by making sustainable transport opportunities available in the world and in the mind [Doctoral thesis]. Division Design \& Human Factors, Chalmers University of Technology (Sweden). Retrieved from https://research.chalmers.se/en/ publication/222635

Van der Voordt, T. J. M. (2004). Productivity and employee satisfaction in flexible workplaces. Journal of Corporate Real Estate, 6(2), 133-148. https://doi.org/10.1108/14630010410812306 


\title{
SPACE SYNTAX THEORY
}

\section{Understanding human movement, co-presence and encounters in relation to the spatial structure of workplaces}

\author{
Kerstin Sailer* and Petros Koutsolampros
}

\section{Background}

Space syntax as a theory aims to identify the link between spatial configuration and human behaviour, and, more specifically, examine how different parameters of the built environment affect different sets of behaviours such as movement and unplanned encounters. At its core, space syntax primarily employs spatial networks allowing for the study of local effects such as co-visibility and co-presence, but also building-wide effects, such as its overall level of depth and the overall distance to the entrance and other facilities.

\subsection{An interdisciplinary theory across spatial scales and settings}

The theory has its roots in the study of settlements and houses, where it was developed as a way to formalise spatial ordering principles by measuring the geometric properties of space and thus allowing for comparison to social behaviour. Essentially, the theory proposes to understand space in its own right - neither as a flowing entity, nor as the leftover between buildings or walls - but as a system of parts (e.g. rooms, corridors) and their interconnections (e.g. doors, staircases, elevators). Inspired by mathematics and linguistics (hence the term 'syntax' alluding to how elements can be joined together and combined in different ways by rules), the theory was pioneered in the 1970s at University College London, UK, by Bill Hillier, Julienne Hanson and colleagues. The theoretical base was first articulated in a 1976 paper simply called 'Space Syntax' (Hillier, Leaman, Stansall, \& Bedford, 1976) and more fully in The Social Logic of Space by Hillier and Hanson (1984), along with an initial set of methods and techniques to capture both spatial configuration and human behaviour.

It is worth noting that from the beginning space syntax worked across the scales. Early examples in Hillier and Hanson (1984) included small settlements and villages, but also simple houses, palaces and even temporary accommodations such as the Mongolian yurt, elaborating how spatial principles of access and separation of spaces by social spheres (e.g. between males and females, visitors and inhabitants) constituted a system of presence and encounters.

Since its origins, space syntax has grown into a worldwide community of researchers, practitioners and consultants studying a wide spectrum of phenomena. Applications include

*Corresponding author: k.sailer@ucl.ac.uk 
architecture (Peponis, Bafna, Dahabreh, \& Dogan, 2015) and urban planning (Karimi, 2012), but also embrace truly interdisciplinary contributions to fields as diverse as archaeology (Dawson, 2002), history (Griffiths, 2012), sociology (Liebst \& Griffiths, 2019), management (Thomas, 2019), neuroscience (Javadi et al., 2016) and biology (Varoudis, Swenson, Kirkton, \& Waters, 2018), to name a few.

Due to its prolific output and significant contribution to our understanding of the inner workings of cities, space syntax is sometimes mistaken as an urban theory, yet this is far from true. While The Social Logic of Space mainly focused on the analysis of simple settlements and houses, the relevance of the theory for the study of offices and other complex building types such as museums, hospitals, schools and so on was already manifest. For example, Hillier and Hanson (1984) reflected on the move of an organisation from cellular space to open plan, which was described as a move from status differences and power (cellular) to synchronicity and control (open plan). The first full implementation of space syntax in workplace settings was published by Hillier and Grajewski (1990), where a set of seven offices from the UK, the US and Scandinavia were examined. This lay the foundation for a rich research programme on office layouts and space syntax, with universities in the UK, the US and Sweden being at the heart of research efforts to understand the relationship between workplace design parameters and organisational outputs such as chance encounters, collaboration and productivity.

\subsection{Assumptions and representations common to space syntax theory}

Before focusing on workplace applications and findings in the next section, it is useful to understand more about the way space syntax represents and measures spatial qualities. Workplace examples will be used throughout to illustrate the space syntax approach.

The core assumption of the theory is that space is meaningful in the way different parts are linked to form an interconnected spatial system that humans inhabit and move through. By treating space as a complex network of interconnected parts (such as rooms and corridors), the approach allows for measuring how important (or central) a room or corridor is in a whole system, such as a building. The theory then predicts how frequently different parts of a space will be used depending on how central the space is in the overall network: highly integrated spaces will be used more intensively, while more segregated spaces will be quieter by nature. Space usage patterns are typically observed in space syntax research through direct observation methods in order to test and verify the predictive power of the theory (see details in Section 3 below).

Therefore, space as an infinite flowing entity needs to be cut into distinct 'chunks' for the theory to be applicable. Various representations have been suggested over the years, such as axial and segment line maps pronouncing the linear quality of human movement and spatial experience; convex maps which partition space into two-dimensional convex elements (where each point is intervisible with all others), expressing the qualities of human co-presence; but also most recently, more complex and nuanced representations, such as visibility graphs which tessellate a space into grid cells and take human visual fields into account.

Two of these spatial representations have been primarily used for workplace studies, axial/segment models and visibility graph analysis (VGA, originally described by Turner, Doxa, O'Sullivan, \& Penn, 2001), both sharing a common base: a spatial network (see Figures 21.1a and 21.2a).

Axial and segment models are based on lines following potential movement paths through a space (as shown in Figure 21.1a). Wherever lines intersect, a connection is made between one space (line) and another. Segment models are more fine-grained, cutting off long lines, for instance in corridors, into shorter segments at each intersection. 
(a)

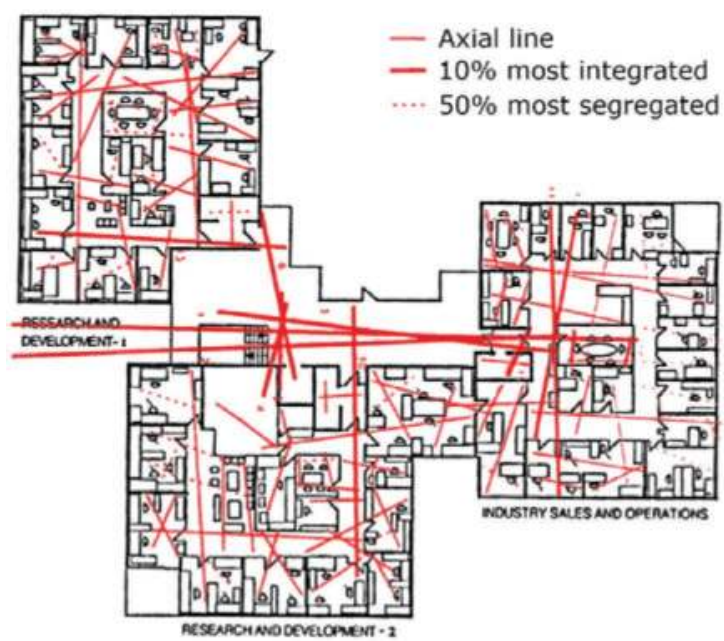

(b)

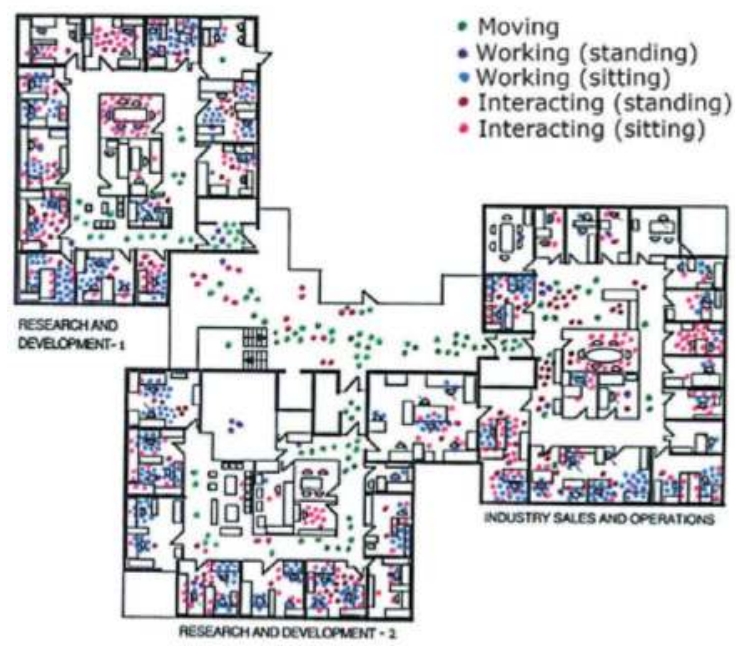

Figures 21.1 Axial map (a) and snapshot data (b) from Hillier and Grajewski (1990) and Grajewski (1992)

These resulting networks can then be described mathematically and quantitatively with the help of graph theory. The two main theoretical constructs used in space syntax are (1) connections and (2) depth. Connectivity is a local metric, for instance how many doors a room has or how many offices are accessible from one stretch of corridor. Depth, in contrast, is a form of distance metric. Step depth for example describes how many steps lie between one spatial element and another (such as from one cellular office to another via two corridors). Taken further, path lengths can be calculated from one point of interest (entrance) to another (desks), but also from any point to all other points, which gives a measure of the overall 'integration' of a spatial system. These constructs are comparable to degree and closeness centrality metrics used in other network-related disciplines.

The calculations employed in axial or segment maps can also be used in any other representation. The second commonly used workplace model, a VGA (as shown in Figure 21.2a) is based 
(a)

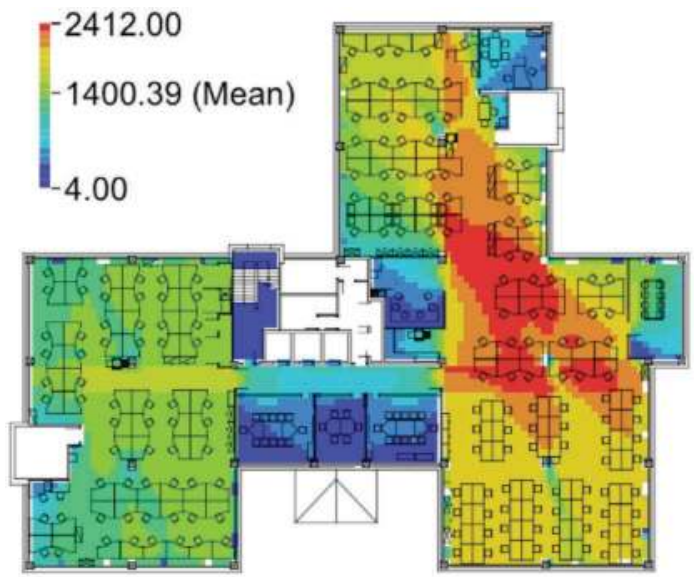

(b)

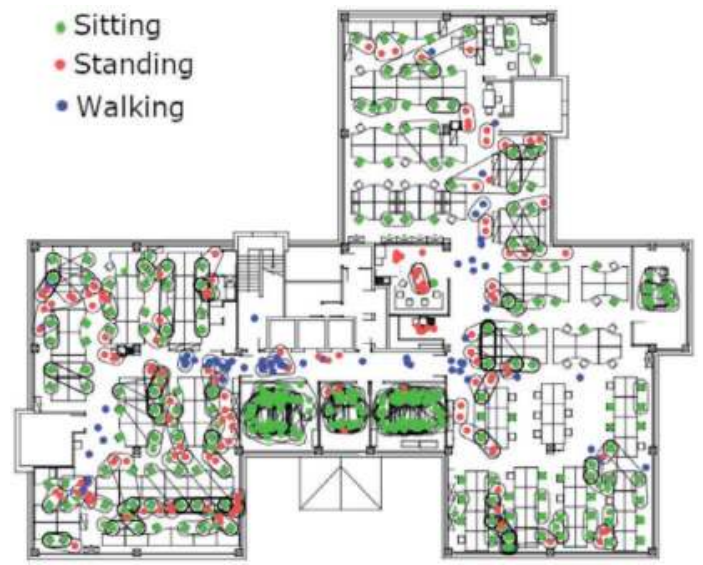

Figure 21.2 Connectivity in visibility graph analysis (a) and respective snapshot data (b)

on a regular grid superimposed on the plan, creating thousands of micro-locations, often called 'pixels', that represent a human potentially standing in that spot. From each pixel an isovist is created, described by Benedikt (1979) as the visible area on the plan from that vantage point. A visibility graph connects isovists and calculates, among a plethora of other parameters (Koutsolampros, Sailer, Varoudis, \& Haslem, 2019), visual integration (i.e. path length), which represents how often someone would have to 'look around the corner' from a given point to have seen all other spaces from there.

\section{Applicability to workplace studies}

The aim of most applications of space syntax theory in the workplace has been to explore how spatial configuration affects behaviours such as movement and encounters. To reach this aim, most studies identified the occurrence, frequency and location of different activities and brought this together with configurational properties of locations. By examining how spaces with different configurations attracted people to specific locations, the studies were able to suggest specific elements of design that might affect each behaviour. 
Following the core space syntax assumptions, the study by Hillier and Grajewski (1990) confirmed that more integrated parts of offices showed higher levels of both movement and interaction compared with more segregated places in offices. This showed that the basic assumptions of the theory applied well to buildings and particularly to workplaces as ways to highlight the locations of movement, occupancy and interaction.

\subsection{Workplace phenomena across scales}

In line with the origins of the theory, workplace studies developed different metrics to describe the qualities of a space within a network, alternating between micro-scales (for instance how space is experienced from one particular vantage point), meso-scales (how human experience unfolds between two points of interest) and macro-scales (how the location of a particular place in the overall spatial system contributes to its usage). These different scales could also be described on a range from egocentric analyses (depth from one place) to allocentric ones (from any place to all others).

Table 21.1 gives an overview of exemplary workplace research studies, showing the breadth of space syntax workplace research approaches. On a micro-scale, visibility from a particular point of interest was studied; the meso-scale covered patterns of inter-visibility of desks, or distance paths between all co-workers; while the macro-scale highlighted the centrality of a room or place in relation to the building as a whole.

An underlying shared principle of all these approaches is the search for a patterning, where spatial properties of a location, place or building as a whole can be used to explain the occurrence and prevalence of activities and human space usage behaviours. A spatial layout in this sense can be seen as a generator of a 'field of probabilistic encounter' (Hillier, Burdett, Peponis, \& Penn, 1987). This means that some spatial characteristics, such as the integration of a location, make it more likely for certain activities to occur, such as increased levels of encounter.

\subsection{Overview of workplace research findings on offices}

Building on initial findings, workplace studies in space syntax established the relationship between configuration and behaviours, highlighting how more integrated spaces and buildings

Table 21.1 Exemplary workplace research studies across scales using space syntax

\begin{tabular}{|c|c|c|}
\hline & Constructs & Study \\
\hline \multirow[t]{2}{*}{ Micro-scale } & Visibility from a point of interest & $\begin{array}{l}\text { Alavi, Verma, Mlynar, and Lalanne } \\
\text { (2018) }\end{array}$ \\
\hline & Local visibility while walking & Backhouse and Drew (1992) \\
\hline \multirow[t]{3}{*}{ Meso-scale } & $\begin{array}{l}\text { Patterns of visibility between } \\
\text { desks }\end{array}$ & Beck (2015) \\
\hline & Distances between co-workers & $\begin{array}{l}\text { Sailer and McCulloh (2012), } \\
\text { Wineman, Hwang, Kabo, } \\
\text { Owen-Smith, and Davis (2014) }\end{array}$ \\
\hline & Paths from desks to facilities & $\begin{array}{l}\text { Sailer (2007), Owen-Smith, } \\
\text { Kabo, Levenstein, Price, } \\
\text { and Davis (2012) }\end{array}$ \\
\hline Macro-scale & Centrality of a particular place & $\begin{array}{c}\text { Hillier and Grajewski (1990), Penn, } \\
\text { Desyllas, and Vaughan (1999) }\end{array}$ \\
\hline
\end{tabular}


accounted for higher densities of movement and interaction. It was shown, for example, that office workers in more integrated workspaces showed higher degrees of satisfaction with interaction support as well as a higher sense of community (Wineman \& Adhya, 2007). Research also established, however, that a large degree of variation in activities such as interaction was due to functional allocations and was predominantly found next to workstations (Rashid, Kampschroer, Wineman, \& Zimring, 2006; Steen, Blombergsson, \& Wiklander, 2005), regardless of their position or spatial characteristics such as integration.

Further studies underlined the importance of configurational aspects of workplaces for innovation by showing how the spatial configuration of integrated workplaces generated random contacts and unplanned encounters required for innovation (Penn et al., 1999). The relationship between spatial integration and generativity, that is, the ability to create new ideas and relationships in workplaces, was confirmed using a larger sample of office buildings (Sailer, Pomeroy, Raheem, Budgen, \& Lonsdale, 2012). This was built upon in a more recent study arguing that not just integrated layouts but also the distribution of teams made a difference to the innovative capacity of organisations by bringing diverse sets of people together in day-to-day work (Sailer \& Thomas, 2019). While the previous studies used qualitative evidence to infer innovation, more explicit and quantitative links to innovation were made in a few studies bringing together workplace layout, random encounters and innovative outputs such as patents and publications of scientists (Penn et al., 1999; Toker \& Gray, 2008; Wineman et al., 2014).

A similar argument was made for the supportive role of an integrated and easily readable workplace layout, which was shown to relate to interaction networks, but also to organisational productivity and knowledge work using billable hours as a proxy (Peponis et al., 2007). Studies focusing on corporate real estate also pointed out that there is potential for the measurements provided by space syntax to act as measurements for organisational performance (Appel-Meulenbroek \& Feijts, 2007).

Finally, studies also explored the relationship between spatial layouts and perceptions of privacy. While one study found no relations (Wineman \& Adhya, 2007), another reported that workers in larger open, more integrated areas tended to find concentration more difficult (Hong \& Yoo, 2010). The relationship between openness and privacy was also shown in studies in the micro-scale (Alavi et al., 2018), where the visual fields of specific staff members were found to relate to seat preference (staff preferred less-exposed seats), especially in rooms designated for quiet work.

In addition to exploring more complex behavioural constructs, eventually researchers started incorporating other aspects of workspace beyond pure geometric configuration such as attractors (Sailer, 2007; Owen-Smith et al., 2012) and organisational cultures (Peponis, 1985). The effect of attractors has in fact been shown to be non-negligible, especially in understanding movement, and in some cases a more important parameter than integration (Sailer, 2007). For interaction and chance encounter, however, the simulation of actual paths to attractors was found to be a highly effective predictor (Kabo, Hwang, Levenstein, \& Owen-Smith, 2015; Owen-Smith et al., 2012). It was specifically shown that if the paths of researchers in two university buildings had common zones, there was a higher likelihood that those scientists would collaborate as co-authors in publications and grant applications.

\subsection{Overview of workplace research findings in other settings}

Due to its wide range of applications, space syntax has contributed to our understanding of different settings other than traditional, corporate offices, since those can be considered workplaces, too.

Early studies in the space syntax domain explored laboratory buildings (Hillier \& Penn, 1991; Serrato \& Wineman, 1999; Wineman \& Serrato, 1997), arguing that proximity and integration 
afforded scientific knowledge creation. The spatial culture of factories arguably also touches upon work processes (Peponis, 1985). Work processes in hospitals such as communication patterns between caregivers in wards have long been studied using space syntax methods as well, showing how visibility in corridors enhanced professional communication (Pachilova \& Sailer, 2020) and how the workflow patterns of doctors and nurses differed according to visibility cues (Lu \& Zimring, 2012). Types of buildings with more diverse and complex workflow patterns such as universities have also been examined (Major et al., 2019) with promising but not strongly predictive results yet. Even studies in primary schools could be seen as workplace studies, for instance highlighting how high levels of integration in classrooms made it more difficult for teachers to adapt their teaching styles (Kishimoto \& Taguchi, 2014).

\section{Methodology/research approach}

Space syntax researchers typically analyse spatial structures in relation to human activities, hence this section clarifies methodological considerations for each of those aspects, but also how to bring them together.

\subsection{Spatial structure}

Detailed floor plans are an essential data source when studying workplaces following a space syntax approach. Axial or segment models require a researcher to draw lines of movement (for example in a CAD program or in a GIS system). A VGA requires a cleaned-up dxf file (with separate layers for walls, partitions, furniture, glass, etc.). These drawings are then imported into specialised open source software, such as depthmapX (depthmapX development team, 2019) to run the calculations. A manual by Al-Sayed, Turner, Hillier, Iida, and Penn (2014) can give details. An alternative software specifically for isovist and visibility analysis is called isovist (McElhinney, 2020), which reads dxf and svg file formats of plans.

The aforementioned apps create both visualisations and calculate the underlying metrics, which can be exported as csv files for further statistical analysis. A workflow in $\mathrm{R}$ has recently been developed (Koutsolampros \& Kostourou, 2019).

\subsection{Human activity}

For examining the locations of human behaviour, most studies employed either direct observations of where people perform various activities (so-called snapshots, as described by Vaughan, 2001) or questionnaires asking staff about their working practices and experiences of a workspace. Questionnaires in this tradition often involve asking staff about satisfaction with the workplace, their usage of facilities, but also their relationships to colleagues (e.g. who knows whom, who talks to whom). In some cases, this relational information was developed into a full analysis of the social network relations of staff, allowing for delving deeper into how spatial layouts afford human connections (Sailer \& McCulloh, 2012). Social network analysis was also applied to co-authorship networks in academic workplaces, linking collaborative work practices to the underlying campus building layout (Wineman, Kabo, \& Davis, 2009).

\subsection{Bringing space and usage together}

With space syntax being a quantitative method, human behaviour needs to be captured in quantifiable ways in order to overlap the two. While early studies in the 1980 s relied on paperdrawn maps and hand-counted methods, most commonly today researchers import both syntax 
maps and human activity data as locational maps into a GIS system, such as QGIS, in order to perform spatial queries (for example how many people use a certain space and which syntactical qualities that same space has). In detail, in cases where axial lines were used (Hillier \& Grajewski, 1990) the locations of human behaviour were converted to counts on each individual line based on distance (i.e. how many people moving were close to each line), while in cases where VGA was used the researchers either counted the number of observations in each cell (Dell, 2012) or retrieved the spatial configuration parameters at the location of each observation (AppelMeulenbroek, 2009). For the actual comparison and to understand whether the relationship was significant, most studies relied on simple statistical models such as Pearson correlation, where the spatial configuration parameters (integration, connectivity etc.) were treated as independent variables and the human behaviour parameters (numbers of people moving/interacting, questionnaire responses) as dependent variables. Where human behaviour was measured as responses to questionnaires or properties of a social network, the comparison unit (i.e. the unit of analysis) chosen was typically a person or a pair of people, instead of a line or a grid cell. In these cases, the statistical models would compare the spatial configuration properties of the location of that person or pair (location integration or pair distance) against the questionnaire responses or social network properties.

\subsection{Future research possibilities}

Space syntax can look back to a history of almost half a century of research efforts, yet compared to more established sciences it can still be considered a young and emerging field. Specifically, in the field of workplace research, there are plenty of open questions to be answered.

Recent developments in the broader space syntax domain have been to diversify user groups and consider the ways in which one building or space may affect different demographics in a variety of ways based on their personal preferences, skills or individualities (Carlson, Hölscher, Shipley, \& Conroy Dalton, 2010; Griffiths \& Netto, 2015; Sailer, 2015). In the context of workplaces this could include a new focus on visitor and staff experiences, for example.

Since space syntax research on workplace layouts has only just begun to reach out to social network analysis, organisational theory, industrial sociology, environmental psychology and other such neighbouring fields, inter- and transdisciplinary approaches provide interesting opportunities (see for example Sailer \& Thomas, 2020b).

Further research possibilities lie in exploiting computational power and the existence of larger data sets to explore the emergence of generic patterns, as for example highlighted by recent papers comparing decision-making speed across 72 workplaces (Sailer \& Thomas, 2020a) and the study of travel concentration across 216 floors (Koutsolampros, Sailer, \& Haslem, 2020).

\section{Limitations}

There are a few limitations for the applicability of space syntax to workplace studies. Firstly, the hypothesis of central places attracting the majority of human usage frequency assumes that origins and destinations of movements are randomly distributed. While that is the case for large urban systems or in building types based predominantly on exploratory behaviour such as museums, workplaces could be described as targeted movement systems (from entrance to desk, from desk to meeting room/kitchen and so on). This resulted in partially contradictory findings across early studies but was addressed by later work taking attractor-based movement into account (Sailer, 2007). 
With its foundation in the analysis of plans, the third dimension is only slowly addressed (Conroy Dalton \& Dalton, 2015; Varoudis \& Psarra, 2014), and arguably that matters in workplaces, for instance in foyers or atria.

The biggest challenge for the field in general, however, is replicability and consistency of results. Various researchers (Kegel, 2018; Sailer, 2010) highlighted that extant research examined small samples, mostly of up to three cases with only few exceptions studying up to 10 cases. Additionally, studies employed vastly differing techniques and metrics at times but also proceeded with varying rigour. As a result, contradictory findings emerged, for instance on the relationship between movement and spatial integration, which was not consistently shown (Sailer, 2007). Thus, while the theory has been applied successfully, that is, to connect specific behaviours to certain elements of spatial configuration for some cases, establishing generalisable findings valid for large samples of workplaces is still underway (Koutsolampros, 2021).

\section{Theory relevance to practice}

The techniques and methods within the space syntax domain can play an important role for evidence-based design, which is defined as the conscientious and explicit use of current best evidence in taking decisions (Sailer, Budgen, Lonsdale, Turner, \& Penn, 2008). Over the last decades, this approach of an evidence-based practice originating from medicine has become popular in a variety of professional contexts, among them management, HR and design. The majority of evidence-based design applications lie in healthcare design (Ulrich, Quan, Zimring, Joseph, \& Choudhary, 2004; Ulrich et al., 2008), however with a relative scarcity of approaches in workplace design. The need for an evidence-based design practice is underlined by a survey of 420 practitioners in which $80 \%$ reported a desire to use evidence in their work, yet only $5 \%$ of practitioners collected some kind of data themselves (EBD Journal, 2015).

Space syntax theories can be incorporated in an evidence-based design practice in two different ways: firstly, to support the design process for new workplaces, and secondly, to examine the potentials and limitations of existing office spaces.

As part of the design process, the methods allow for measuring how integrated and connected a suggested office floor plan is, and thus highlighting desirable solutions among a series of options and enabling a systematic comparison of alternative layouts. For example, a case study of a radio station design in Ireland highlighted the integrative benefits of a large central staircase (Sailer, Budgen, Lonsdale, Turner, \& Penn, 2007). This way, designs may be iterated upon using evidence on their potential effectiveness in affecting office activities such as movement and interaction. The final designs may then adhere to specific targets, such as balancing the need for serendipitous interaction (i.e. for the dissemination of new ideas) and the requirement for quiet spaces to facilitate concentrated work, all the while retaining ease of movement through the building. Evidence created by use of space syntax tools also provides means to communicate and visualise the differences between design options to clients. Existing workplaces can also benefit from the application of the methods as evaluation tools to identify potential workflow bottlenecks, such as very central and important departments located at segregated spaces reducing the potential for collaboration. Examples for both applications are provided from the reflective practice of Spacelab architects in London (Sailer, Pomeroy, \& Haslem, 2015).

\section{Further reading}

- Al-Sayed, K., Turner, A., Hillier, B., Iida, S., \& Penn, A. (2014). Space syntax methodology. The Bartlett School of Architecture, UCL. 
- Hillier, B., \& Grajewski, T. R. (1990). The application of space syntax to work environments inside buildings: Second phase: Towards a predictive model. In Unit for architectural studies. London: The Bartlett School of Architecture and Planning, University College London.

- Hillier, B., \& Hanson, J. (1984). The social logic of space. Cambridge: Cambridge University Press (CUP).

- Koutsolampros, P., Sailer, K., Varoudis, T., \& Haslem, R. (2019). Dissecting visibility graph analysis: The metrics and their role in understanding workplace human behaviour. Paper presented at the 12th International Space Syntax Symposium. Beijing, China.

- Sailer, K. (2010). The space-organisation relationship. On the shape of the relationship between spatial configuration and collective organisational behaviours [Doctoral Dissertation]. Germany: TU Dresden.

\section{Acknowledgments}

Both authors contributed equally to writing this chapter.

\section{References}

Al-Sayed, K., Turner, A., Hillier, B., Iida, S., \& Penn, A. (2014). Space syntax methodology. Bartlett School of Architecture, UCL. Retrieved from http://discovery.ucl.ac.uk/1415080/

Alavi, H. S., Verma, H., Mlynar, J., \& Lalanne, D. (2018). The hide and seek of workspace: Towards human-centric sustainable architecture. In Proceedings of the 2018 CHI conference on human factors in computing systems (pp. 1-12). Montreal QC, Canada: Association for Computing Machinery. https://doi. org/10.1145/3173574.3173649

Appel-Meulenbroek, R. (2009). Knowledge sharing in research buildings and about their design. Proceedings of the 7 th international space syntax symposium. Retrieved from http://www.sss7.org/Proceedings/04\%20 Building\%20Morphology\%20and\%20Emergent\%20Performativity/004_AppelMeulenbroek.pdf

Appel-Meulenbroek, R., \& Feijts, B. (2007). CRE effects on organizational performance: Measurement tools for management. Journal of Corporate Real Estate, 9(4), 218-238.

Backhouse, A., \& Drew, P. (1992). The design implications of social interaction in a workplace setting. Environment and Planning B: Planning and Design, 19, 573-573.

Beck, M. P. (2015). Slicing the cake: An isovist-based analysis of computerised workplace configuration. Proceedings of the 10th international space syntax symposium. Presented at the 10th international space syntax symposium, London, UK. Retrieved from http://www.sss10.bartlett.ucl.ac.uk/wp-content/ uploads/2015/07/SSS10_Proceedings_014.pdf

Benedikt, M. L. (1979). To take hold of space: Isovists and isovist fields. Environment and Planning B: Planning and Design, 6(1), 47-65. https://doi.org/10.1068/b060047

Carlson, L. A., Hölscher, C., Shipley, T. F., \& Conroy Dalton, R. (2010). Getting lost in buildings. Current Directions in Psychological Science, 19(5), 284-289. https://doi.org/10.1177/0963721410383243

Conroy Dalton, R., \& Dalton, N. (2015). The problem of representation of 3D isovists. Paper presented at the 10th International Space Syntax Conference, London, UK.

Dawson, P. C. (2002). Space syntax analysis of Central Inuit snow houses. Journal of Anthropological Archaeology, 21(4), 464-480. https://doi.org/10.1016/s0278-4165(02)00009-0

Dell, T. L. (2012). The life of the lab: Creating collaborative workspaces for scientists [Doctoral dissertation]. University of Michigan, US.

EBD Journal. (2015, August 22). The knowledge problem. As architects and designers, what do we know about people? Retrieved from https://ebdjournal.com/blog/general-design/the-knowledge-problem

Grajewski, T. R. (1992). Spatial configurations and interaction patterns within office buildings. [Doctoral dissertation]. University College London (University of London), UK.

Griffiths, S. (2012). The use of space syntax in historical research: Current practice and future possibilities. Paper presented at the 8th International Space Syntax Symposium, Santiago, Chile.

Griffiths, S., \& Netto, V. M. (2015). Open Syntaxes: Towards new engagements with social sciences and humanities: Guest editorial. The Journal of Space Syntax, 6(1), i-v. 
Hillier, B., Burdett, R., Peponis, J., \& Penn, A. (1987). Creating life: Or, does architecture determine anything? Architecture \& Comportement/Architecture \& Behaviour, 3(3), 233-250.

Hillier, B., \& Grajewski, T. R. (1990). The application of space syntax to work environments inside buildings: Second phase: Towards a predictive model. In Unit for architectural studies. London: The Bartlett School of Architecture and Planning, University College London.

Hillier, B., \& Hanson, J. (1984). The social logic of space. Cambridge: Cambridge University Press.

Hillier, B., Leaman, A., Stansall, P., \& Bedford, M. (1976). Space syntax. Environment and Planning B: Planning and Design, 3(2), 147-185. https://doi.org/10.1068/b030147

Hillier, B., \& Penn, A. (1991). Visible colleges: Structure and randomness in the place of discovery. Science in Context, 4(1), 23-50. https://doi.org/10.1017/S0269889700000144

Hong, Y.-K., \& Yoo, U.-S. (2010). Workspace visibility graph analysis (VGA) for concentration privacy and group relations in the open-plan office environment. Architectural Research, 12(1), 9-14. https://doi. org/10.5659/AIKAR.2010.12.1.9

Javadi, A.-H., Emo, B., Howard, L., Zisch, F., Yu, Y., Knight, R., . . . \& Spiers, H. J. (2016). Hippocampal and prefrontal processing of network topology to simulate the future. Nature Communications, 8(1), 14652. https://doi.org/10.1038/ncomms14652

Kabo, F., Hwang, Y., Levenstein, M., \& Owen-Smith, J. (2015). Shared paths to the lab a sociospatial network analysis of collaboration. Environment and Behavior, 47(1), 57-84.

Karimi, K. (2012). A configurational approach to analytical urban design: "Space syntax" methodology. Urban Design International, 17(4), 297-318. https://doi.org/10.1057/udi.2012.19

Kegel, P. (2018). The impact of the physical work environment on organizational outcomes: A structured review of the literature. Journal of Facility Management Education and Research, 1(1), 19-29. https://doi. org/10.22361/jfmer/76637

Kishimoto, T., \& Taguchi, M. (2014). Spatial configuration of Japanese elementary schools: Analyses by the space syntax and evaluation by school teachers. Journal of Asian Architecture and Building Engineering, 13(2), 373-380.

Koutsolampros, P. (2021). Human behaviour in office environments-Finding patterns of activity and spatial configuration in large workplace datasets [Doctoral dissertation]. University College London, London, UK.

Koutsolampros, P., \& Kostourou, F. (2019). rdepthmap: R and depthmapX CLI interface (Version 0.1.0). Retrieved from https://github.com/orange-vertex/rdepthmap

Koutsolampros, P., Sailer, K., \& Haslem, R. (2020). Travel concentration: The effects of attractor bound movement on workplace activity. Paper presented at the 2nd Transdisciplinary Workplace Research Conference, Frankfurt, Germany.

Koutsolampros, P., Sailer, K., Varoudis, T., \& Haslem, R. (2019). Dissecting visibility graph analysis: The metrics and their role in understanding workplace human behaviour. Paper presented the 12th International Space Syntax Symposium, Beijing, China.

Liebst, L. S., \& Griffiths, S. (2019). Space syntax theory and Durkheim's social morphology: A reassessment. Distinktion: Journal of Social Theory, 21(2), 1-21. https://doi.org/10.1080/1600910X.2019.1641121

Lu, Y., \& Zimring, C. (2012). Can intensive care staff see their patients? An improved visibility analysis methodology. Environment and Behavior, 44(6), 861-876. https://doi.org/10.1177/0013916511405314

Major, M., Indraganti, M., Ahmad, A., Tannous, H. O., Al-Marri, A., Alnoaimi, L., \& Al-Obaidan, M. (2019). Comfort and use in building evaluation: Information modelling and post-occupancy in the built environment. Paper presented at the 12th International Space Syntax Symposium, Beijing, China.

McElhinney, S. (2020). The Isovist_App: A basic user guide (version v1.6). Retrieved from https://isovists.org

Owen-Smith, J., Kabo, F., Levenstein, M., Price, R., \& Davis, G. (2012). A tale of two buildings: Socio-spatial significance in innovation. Ann Arbor, MI: University of Michigan.

Pachilova, R., \& Sailer, K. (2020). Providing care quality by design: A new measure to assess hospital ward layouts. The Journal of Architecture, 25(2), 186-202. https://doi.org/10.1080/13602365.2020.1733802

Penn, A., Desyllas, J., \& Vaughan, L. (1999). The space of innovation: Interaction and communication in the work environment. Environment and Planning B: Planning and Design, 26(2), 193-218. https://doi. org/10.1068/b4225

Peponis, J. (1985). The spatial culture of factories. Human Relations, 38(4), 357-390. https://doi. org/10.1177/001872678503800405

Peponis, J., Bafna, S., Bajaj, R., Bromberg, J., Congdon, C., Rashid, M., . . . \& Zimring, C. (2007). Designing space to support knowledge work. Environment and Behavior, 39(6), 815-840. https://doi. org/10.1177/0013916506297216 
Peponis, J., Bafna, S., Dahabreh, S. M., \& Dogan, F. (2015). Configurational meaning and conceptual shifts in design. The Journal of Architecture, 20(2), 215-243.

Rashid, M., Kampschroer, K., Wineman, J., \& Zimring, C. (2006). Spatial layout and face-to-face interaction in offices: A study of the mechanisms of spatial effects on face-to-face interaction. Environment and Planning B: Planning and Design, 33(6), 825-844. https://doi.org/10.1068/b31123

Sailer, K. (2007). Movement in workplace environments - Configurational or programmed? Proceedings of the 6 th international space syntax symposium. Paper presented at the 6th international space syntax symposium, Istanbul, Turkey.

Sailer, K. (2010). The space-organisation relationship: On the shape of the relationship between spatial configuration and collective organisational behaviours [Doctoral dissertation]. Germany: TU Dresden.

Sailer, K. (2015). The dynamics and diversity of space use in the British Library. ITU A $\mid Z$ Journal of the Faculty of Architecture, 12(3), 23-39.

Sailer, K., Budgen, A., Lonsdale, N., Turner, A., \& Penn, A. (2007). Effective workplaces: Bridging the gap between architectural research and design practice. Poster presented at the 6th International Space Syntax Symposium, Istanbul, Turkey.

Sailer, K., Budgen, A., Lonsdale, N., Turner, A., \& Penn, A. (2008). Evidence-based design: Theoretical and practical reflections of an emerging approach in office architecture. Paper presented the Undisciplined! Design Research Society Conference 2008, Sheffield Hallam University, Sheffield, UK.

Sailer, K., \& McCulloh, I. (2012). Social networks and spatial configuration: How office layouts drive social interaction. Social Networks, 34(1), 47-58. https://doi.org/10.1016/j.socnet.2011.05.005

Sailer, K., Pomeroy, R., \& Haslem, R. (2015). Data-driven design: Using data on human behaviour and spatial configuration to inform better workplace design. Corporate Real Estate Journal, 4(3), 249-262.

Sailer, K., Pomeroy, R., Raheem, A., Budgen, A., \& Lonsdale, N. (2012). The generative office building. Proceedings of the 8th international space syntax symposium. Paper presented at the 8th international space syntax symposium, Santiago, Chile.

Sailer, K., \& Thomas, M. (2019). Correspondence and non-correspondence: Using office accommodation to calculate an organization's propensity for new ideas. Paper presented at the 12th International Space Syntax Symposium, Beijing, China.

Sailer, K., \& Thomas, M. (2020a). From Saint Jerome's study to workplace seismographs: The role of spatial layouts in decision-making speed across different industries. Paper presented at the 2nd Transdisciplinary Workplace Research Conference, Frankfurt, Germany.

Sailer, K., \& Thomas, M. (2020b). Socio-spatial perspectives on open-plan versus cellular offices. Journal of Managerial Psychology, Forthcoming. https://doi.org/10.1108/JMP-10-2019-055

Serrato, M., \& Wineman, J. (1999). Spatial and communication patterns in research $\mathcal{E}$ development facilities. Paper presented at the 2nd International Space Syntax Symposium, Brasília, Brazil.

Steen, J., Blombergsson, M., \& Wiklander, J. (2005). Useful buildings for office activities. Facilities, 23(3/4), 176-186. https://doi.org/10.1108/02632770510578548

Thomas, M. (2019). How space affects emergent strategy: A study of the role physical space plays in the generation of social interactions in organisations [Doctoral dissertation]. Lancaster University.

Toker, U., \& Gray, D. O. (2008). Innovation spaces: Workspace planning and innovation in U.S. university research centers. Research Policy, 37(2), 309-329. https://doi.org/10.1016/j.respol.2007.09.006

Turner, A., Doxa, M., O’Sullivan, D., \& Penn, A. (2001). From isovists to visibility graphs: A methodology for the analysis of architectural space. Environment and Planning B: Planning and Design, 28(1), 103-121. https://doi.org/10.1068/b2684

Ulrich, R. S., Quan, X., Zimring, C., Joseph, A., \& Choudhary, R. (2004). The role of the physical environment in the hospital of the 21st century: A once-in-a-lifetime opportunity. Concord, CA: The Center for Health Design.

Ulrich, R. S., Zimring, C., Zhu, X., DuBose, J., Seo, H.-B., Choi, Y.-S., . . Joseph, A. (2008). A review of the research literature on evidence-based healthcare design. HERD: Health Environments Research $\mathcal{E}$ Design Journal, 1(3). https://doi.org/10.1177/193758670800100306

Varoudis, T., \& Psarra, S. (2014). Beyond two dimensions: Architecture through three dimensional visibility graph analysis. The Journal of Space Syntax, 5(1), 91-108.

Varoudis, T., Swenson, A. G., Kirkton, S. D., \& Waters, J. S. (2018). Exploring nest structures of acorn dwelling ants with X-ray microtomography and surface-based three-dimensional visibility graph analysis. Philosophical Transactions of the Royal Society B: Biological Sciences, 373(1753). https://doi.org/10.1098/ rstb.2017.0237 


\section{Kerstin Sailer and Petros Koutsolampros}

Vaughan, L. (2001). Space syntax observation manual (2001 unpublished revised ed.). London: Space Syntax Ltd. Wineman, J., \& Adhya, A. (2007). Enhancing workspace performance. Paper presented at the 6th International Space Syntax Symposium, Istanbul, Turkey.

Wineman, J., Hwang, Y., Kabo, F., Owen-Smith, J., \& Davis, G. F. (2014). Spatial layout, social structure, and innovation in organizations. Environment and Planning B: Planning and Design, 14, 1-14.

Wineman, J., Kabo, F. W., \& Davis, G. F. (2009). Spatial and social networks in organizational innovation. Environment and Behavior, 41(3), 427-442. https://doi.org/10.1177/0013916508314854

Wineman, J., \& Serrato, M. (1997). Enhancing communication in lab-based organisations. Paper presented at the 1st International Space Syntax Symposium, London, UK. 


\title{
22
}

\section{ORGANISATIONAL KNOWLEDGE CREATION THEORY AND KNOWLEDGE WORKPLACES}

\author{
Mervi Huhtelin* and Suvi Nenonen
}

\section{Background}

The paradigm of work in the knowledge society is different from the industrial society. The change can be seen with the increasing interest in researching knowledge work from different perspectives. The term 'knowledge worker' was first coined by Peter Drucker (1959) in the discipline of management. Knowledge work occurs primarily because of mental processes rather than physical labour. Knowledge work and knowledge workers are dealing with different types of knowledge, knowledge creation and sharing processes, and knowledge management in organisations.

Organisational management includes the fields of knowledge management and organisational learning (Clegg, Kornberger, \& Pitsis, 2011), where knowledge management is linked to two distinct streams, one from psychology and one from a more technical approach to management information. Papers on learning and knowledge in organisations have been published in journals about management studies, organisation studies and organisation science (Hislop, 2013). Drucker (1959) defined knowledge workers as high-level workers who apply theoretical and analytical knowledge, acquired through formal training, to develop products and services. $\mathrm{He}$ noted that knowledge workers would be the most valuable assets of a 21 st-century organisation because of their high level of productivity and creativity. Since the term was coined, the number of knowledge workers has continued to grow as organisations move towards a collaborative workplace that gives more autonomy to their employees.

\subsection{Activities connected to knowledge creation}

Knowledge work includes several activities connected to new knowledge (Clegg et al., 2011; Dierkes, Berthoin Antal, Child, \& Nonaka, 2001; Hislop, 2013; Polanyi, 1962). One can either create new knowledge by doing research or product development, or one can acquire new knowledge by practising and gaining experience, that is, 'learning by doing'. One can also create new knowledge in knowledge workers' everyday activities.

Knowledge work tasks include knowledge acquisition, participation in shared activities and knowledge creation in various everyday activities. Questioning and criticising existing practices, analysing and modelling new solutions, experimenting and implementing solutions,

*Corresponding author: mervi.huhtelin@sykoy.fi 
evaluating and reflecting results, and consolidating new practices (Rantavuori, Engeström, \& Lipponen, 2016) are examples of knowledge work activities. Although knowledge work is perceived as high-level cognitive work, it also includes mundane tasks such as storing and retrieving information and composing and responding to e-mail (Suchman, 2000). By its very nature, knowledge work is both highly cognitive and highly social. Workers need time alone to think and develop ideas, drawing on their own memory, insight and analytical skills. They also need 'hassle-free' time for non-conscious processing that aids creativity and imagination (Claxton, 2000). Yet, for ideas and concepts to become useful to an organisation, they must be made available to others for scrutiny and further development. Thus, knowledge work also involves conversation and interaction allowing thoughts embedded in one person's mind to be externalised and accessible to others through writing, speech or graphic visualisation. This transfer happens through social networks as people encounter one another throughout the normal working day in both formal and informal settings (Allen, 1977; Backhouse \& Drew, 1992; Brown \& Duguid, 2000).

\subsection{Knowledge-sharing and creation process}

One of the most influential and widely referenced theories in the knowledge management field is Nonaka's theory of knowledge creation (Hislop, 2013), and it emphasises the importance of knowledge sharing. Knowledge sharing is a process in which individuals mutually exchange knowledge and jointly create new knowledge (De Vries, Van den Hooff, \& De Ridder, 2006). Some studies labelled knowledge sharing as 'knowledge transfer' (Maurer, Bartsch, \& Ebers, 2011; Van Wijk, Jansen, \& Lyles, 2008). Knowledge sharing has been linked to knowledge transfer from individual level to organisational level (Ipe, 2003).

In 1995 Nonaka and Takeuchi presented their theory of organisational knowledge creation. The knowledge creation process can be operationalised to the phases of 'socialisation', 'externalisation', 'combination' and 'internalisation' (SECI). The core of the knowledge creation process is the mobilisation of tacit knowledge by converting it to explicit knowledge (Nonaka \& Takeuchi, 1995). A process model of knowledge creation develops on the critical presupposition that individual knowledge is created and enlarged by means of a social interaction between tacit and explicit knowledge, where the 'tacit knowledge' refers to personal knowledge, involving an active comprehension of things known (Polanyi, 1962). This interaction is called knowledge conversion, where 'conversion' refers to the process of changing or causing something to change from one form to another.

Nonaka and Takeuchi (1995) present a SECI Model, which includes four phases:

- Socialisation: Sharing of tacit knowledge to tacit knowledge. Knowledge is passed on through practice, guidance, imitation, observation and empathising. Tacit knowledge is shared through common, hands-on experiences, for example via apprenticeship. Interaction is mainly individual, face-to-face interaction. Knowledge used is mainly experiential, skills and know-how of individuals, involving energy, passion, tension, love, care and trust.

- Externalisation: Converting tacit knowledge to explicit knowledge. This is deemed as a difficult and often important conversion mechanism. Explicit knowledge is articulated through images, symbols and language. Concept creation in new product development is linked in this phase. Tacit knowledge is codified into documents, manuals, etc. so that it can spread more easily throughout the organisation. Since tacit knowledge can be virtually impossible to codify, the extent of this knowledge conversion mechanism is debatable. The use of metaphor is cited as an important externalisation mechanism. Interaction is mainly collective, 
peer-to-peer and face-to-face interaction. Knowledge used in mainly conceptual and can include the creation of product concepts, design and brand equity.

- Combination: Combining explicit knowledge into more complex and systematic sets of explicit knowledge. This phase of knowledge creation process is seen to be the simplest one; codified knowledge sources (e.g. documents) are combined to create new systemised and packaged explicit knowledge via collective, group-to-group kind of virtual and collaborative interaction. Knowledge used in this phase are mainly documents, manuals, database, patents and product specifications.

- Internalisation: Converting explicit knowledge to tacit knowledge. Tacit knowledge is routinised and embedded in actions and practices. Internalisation is closely related to learning by doing. As explicit sources are used and learned, the knowledge is internalised, modifying the user's existing tacit knowledge including reflection through action. 'Trying to understand' is vital in this phase. To conduct experiments and share results with the entire department is important. Interaction is individual or virtual or it takes place on site, sharing both time and space. Knowledge used in this phase are mainly know-how in daily operations, organisational routines and culture, practical knowledge and mass production.

In this model, knowledge is continuously converted and created as individual practice, collaboration, interaction and learning. The process should be seen as a continuous, dynamic swirl of knowledge rather than a static model. It is basically a visual representation of overlapping, continuous processes that take place - or should take place - in an organisation. This model is based on the theory that knowledge is created by individuals and then transmitted to the organisation (Finley \& Sathe, 2013; Rai, 2011).

\subsection{Workplace as a foundation for knowledge-sharing and creation process}

New approaches towards workplace and its ability to support knowledge creation processes started in the early 2000s (Danivska, 2018). The research is often based on Nonaka's concept ' $\mathrm{Ba}$ '. $\mathrm{Ba}$ is the shared context and the place where knowledge is created. It can be physical (e.g. office, dispersed business space), virtual (e.g. email, teleconference), mental (e.g. shared experiences, ideas, ideals) or any combination of them. Ba provides a platform for advancing individual and/or collective knowledge. There are four types of $\mathrm{Ba}$ that correspond to the four phases of the SECI model, each Ba especially suited to each of the four knowledge conversion phases. Next is a description of different Bas (adapted from Huhtelin \& Nenonen, 2015; Nenonen, 2005; Nonaka \& Konno, 1998; Nonaka \& Takeuchi, 1995; Nonaka, Toyama, \& Byosière, 2001):

'Originating Ba', supporting Socialisation: Originating Ba supports individual face-to-face interaction, which is the only way to capture the full range of physical senses and psychoemotional reactions, such as ease or discomfort, which are important elements in sharing tacit knowledge. Individuals share feelings, emotions, experiences and mental models. From Originating $\mathrm{Ba}$ emerge care, love, trust and commitment, which form the basis for knowledge conversion among individuals. Informal social meetings with competitors outside the firm or wandering inside the firm are used to gather knowledge needed in business development. Peers understand expertise through practice and demonstrations by a master.

'Dialoguing $B a$ ', supporting Externalisation: Dialoguing $\mathrm{Ba}$ is defined by collective peer-topeer and face-to-face interaction with conceptual knowledge, product concepts and 
design. Individuals' mental models and skills are shared, converted into common terms and articulated as concepts. The individual can profit from the creativity-producing synthesis of rationality and intuition. Metaphor, metonymy and synecdoche are used when converting tacit knowledge to explicit knowledge.

'Systemising Ba', supporting Combination: Systemising $\mathrm{Ba}$ is defined by collective and virtual interactions, rather than real time and space, so it is also called 'cyber Ba'. It is where new systemic, explicit knowledge is created through a combination of various elements of explicit knowledge. Interaction is collective, group-to-group in virtual platforms supporting access to databases, patents and product specifications. It is supported in a collaborative environment utilising information technology, such as online networks, documentation and databanks. Clear, articulated language is used.

'Exercising Ba' supporting Internalisation: The place where the conversion of explicit knowledge into tacit knowledge is facilitated. Exercising $\mathrm{Ba}$ is defined by individual, onsite or virtual interaction. Expertise in daily operations and practical knowledge are used, and organisational routines and culture are present for individuals to embody explicit knowledge that is communicated through virtual media, such as written manuals. Continuous learning and self-refinement through on-the-job training are stressed in order to communicate knowledge. Exercising Ba synthesises the transcendence and reflection through action. The internalisation of knowledge is constantly enhanced, using explicit knowledge in real life or in simulated applications.

Figure 22.1 shows the connection of each phase of knowledge creation process and each $\mathrm{Ba}$ supporting that phase.

Nevertheless, critique has also occurred (Amin \& Cohendet, 2004; Gourlay, 2006; Tsoukas, 2005). Amin and Cohendet (2004) have pointed out that Nonaka's understanding of Ba and the descriptions of four relational spaces are simplified. Additionally, scholars question the sequential steps of the four Bas in the knowledge conversion process and find Nonaka's view on the relational spaces restricting: each $\mathrm{Ba}$ is capable of doing more than what Nonaka's model (Nonaka \& Konno, 1998) permits. Additionally, the SECI model's universal applicability (Hislop, 2013)

\begin{tabular}{|c|c|c|c|}
\hline $\begin{array}{l}\text { Sharing of tacit } \\
\text { knowledge to tacit } \\
\text { knowledge }\end{array}$ & $\begin{array}{l}\text { Knowledge creation phase: "Socialisation" } \\
\text { Empathising: Tacit knowledge shared through } \\
\text { common, hands-on experiences, apprenticeship. }\end{array}$ & $\begin{array}{l}\text { Knowledge creation phase: "Externalisation" } \\
\text { Articulating: Explicit knowledge articulated } \\
\text { through images, symbols, and language. Concept } \\
\text { creation in new product development. }\end{array}$ & $\begin{array}{l}\text { Converting tacit } \\
\text { knowledge to } \\
\text { explicit knowledge }\end{array}$ \\
\hline $\begin{array}{l}\text { Individual } \\
\text { face-to-face } \\
\text { interaction } \\
\text { with skills and } \\
\text { know-how }\end{array}$ & $\begin{array}{l}\quad \text { "Originating Ba" } \\
\text { Ba supports individuals sharing feelings, emotions, } \\
\text { experiences, and mental models. Care, love, trust, } \\
\text { and commitments emerges. }\end{array}$ & $\begin{array}{l}\text { "Dialoguing Ba" } \\
\text { Ba supports reflection and dialogue amongst } \\
\text { participants. Mental models and skills possessed by } \\
\text { individuals are shared, converted into common } \\
\text { terms, and articulated as concepts. }\end{array}$ & $\begin{array}{l}\text { Collective, peer-to- } \\
\text { peer and face-to- } \\
\text { face interaction } \\
\text { with conceptual } \\
\text { knowledge }\end{array}$ \\
\hline $\begin{array}{l}\text { Individual, on site } \\
\text { or virtual } \\
\text { interaction with } \\
\text { knowhow and } \\
\text { practical knowledge }\end{array}$ & $\begin{array}{l}\text { "Exercising Ba" } \\
\text { Continuous learning through on-the-job training or } \\
\text { active participation are stressed in order to } \\
\text { communicate knowledge, with know-how, practical } \\
\text { knowledge, organizational routines and culture. }\end{array}$ & $\begin{array}{l}\text { "Systemising Ba" } \\
\text { New systemic, explicit knowledge is created } \\
\text { through a combination of various elements of } \\
\text { explicit knowledge with databases, patents and } \\
\text { product specifications. }\end{array}$ & $\begin{array}{l}\text { Collective, group- } \\
\text { to-group, virtual } \\
\text { interaction for } \\
\text { collaboration with } \\
\text { explicit knowledge }\end{array}$ \\
\hline
\end{tabular}

Figure 22.1 SECI model and Ba (adapted from Nonaka \& Takeuchi, 1995; Nonaka \& Konno, 1998; Huhtelin \& Nenonen, 2015) 
has been questioned and studied (Magnier-Watanabe \& Benton, 2013). However, Nonaka and Krogh (2009) have responded to the criticism by clarifying that their theory is focused on the knowledge creation used by organisations, where beliefs are true to the extent that they can be justified by the individual organisational member at certain moments and by using various mental models. They emphasised that the SECI model is not based on the assumption that all tacit knowledge can be transferred to explicit knowledge. Additionally, they clarified the tacit explicit distinction along the continuum, yet emphasised that it is still important to distinguish tacit knowledge from explicit knowledge in the knowledge creation process.

Overall, the research has shown the importance of the physical work environment as a mechanism that stimulates knowledge sharing within organisations (Chevez \& Aznavoorian, 2014). The physical infrastructure (i.e. design of the building, spaces and facilities) is also determined as one of the main dimensions of knowledge management infrastructure (Becerra-Fernandez \& Sabherwal, 2010).

\section{Applicability to workplace studies}

When seeking comprehension of workplace management research, knowledge creation theory and the concept $\mathrm{Ba}$ are useful frameworks. One can understand the knowledge work activities and diverse requirements for workplaces supporting those activities. In this chapter, first a study connected to the process of knowledge creation is presented, focusing on the knowledgesharing behaviour in connection with the places. This is followed by a description of two studies that provide insights into how the concept $\mathrm{Ba}$ can be used by analysing different phases of knowledge creation. Finally, the study about the nature of workplace for knowledge creation is presented, with two use cases. The last two studies apply the study of the nature of the workplace for knowledge creation as a framework to support the analysis of the data collected about the requirements for workplaces.

\subsection{Knowledge creation process and knowledge-sharing behaviour in workplaces}

Weijs-Perrée (2019) studied the influence of the physical work environment on business centre users' propensity to share different types of knowledge. She based her study on Nonaka's knowledge creation process (SECI model) and the different types of places (Bas) for knowledge sharing. She analysed the different types of shared knowledge and the places where it was shared, through face-to-face interaction patterns. Based on her results, tacit knowledge is shared more frequently during discussions/debates, during formal meetings and when receiving or giving advice. Weijs-Perrée's study showed relations between the physical work environment, knowledge sharing and networking behaviour. Other studies, for example by Weijs-Perrée, Buck, Appel-Meulenbroek, and Arentze (2019), have been conducted to understand where people engage in face-to-face interaction.

\subsection{Knowledge co-creation and knowledge workplace}

Huhtelin and Nenonen (2015) have studied what kinds of places support knowledge sharing and knowledge co-creation in university-industry collaboration, describing the requirements for the place. It turned out that Originating $\mathrm{Ba}$, which supports informal interaction, is a place where tacit knowledge can be co-created (Huhtelin \& Nenonen, 2015). They state that the place supporting the beginning of the university-industry collaboration should be one in which 
individuals share feelings, emotions, experiences and mental models. Originating Ba should be open to external connections, supporting networking and being informal as a nature as Nenonen (2005) describes in her research. Additionally, Dialoguing Ba is also important for knowledge co-creation in university-industry collaboration (Huhtelin \& Nenonen, 2015).

Another study focusing on knowledge sharing and knowledge co-creation in university industry collaboration is focused on business incubators. This study investigated the sharing of the knowledge developed in a university in the context of incubation centres (Strid, 2006). Both studies aim to understand the requirements supporting collaboration between university and industry by using the concept Ba. Even though the result was not completely aligned, both studies indicated that two Bas - Originating $\mathrm{Ba}$ and Dialoguing $\mathrm{Ba}$ - are important when facilitating knowledge sharing between universities and companies. The university-industry collaboration has been approached in the context of both incubation centres and collaboration platforms among more established industry actors.

\subsection{The nature of the workplace for each phase of knowledge creation}

Nenonen has studied the nature of the workplace, which is supporting all phases of the knowledge creation as a physical, social and virtual environment (Nenonen, 2005). The explorative research states that we have been designing workplaces for explicit knowledge creation, but the places for tacit knowledge creation are not taken into account evenly. She presents four knowledge workplace concepts: 'connective place', 'structural place', 'formal place' and 'reflective place'. Each of them is different by atmosphere and also represent different kinds of knowledge work processes. Figure 22.2 illustrates how the concepts are integrated into the knowledge process circle. The following list, adapted from Nenonen (2005) and Huhtelin and Nenonen (2016, 2019), describes the concepts:

The connective place is an environment that supports the exchange of tacit knowledge in the socialisation phase of knowledge creation. The place is open to the external world, easy

\begin{tabular}{|c|c|c|c|}
\hline $\begin{array}{l}\text { Sharing of tacit } \\
\text { knowledge to tacit } \\
\text { knowledge }\end{array}$ & $\begin{array}{l}\text { "Socialisation" / "Originating Ba" } \\
\text { Tacit knowledge is shared through common, hands-on } \\
\text { experiences, apprenticeship. Individual face-to-face } \\
\text { interaction with skills, passion, energy, know-how. }\end{array}$ & $\begin{array}{l}\text { "Externalisation" / "Dialoguing Ba" } \\
\text { Explicit knowledge articulated through images, symbols, } \\
\text { and language. Collective, peer-to-peer, face-to-face } \\
\text { interaction with conceptual knowledge. }\end{array}$ & $\begin{array}{l}\text { Converting tacit } \\
\text { knowledge to explicit } \\
\text { knowledge }\end{array}$ \\
\hline $\begin{array}{l}\text { Place is open for } \\
\text { external world, } \\
\text { supporting } \\
\text { collaboration and } \\
\text { informal interaction }\end{array}$ & $\begin{array}{l}\text { The connective place } \\
\text { The nature of the workplace is open and welcoming. It is } \\
\text { easy to access and approach. The atmosphere is warm, } \\
\text { inspiring, cosy, and there is a sense of hospitality. Entrance } \\
\text { halls or marketplaces are an example of the connective } \\
\text { place. }\end{array}$ & $\begin{array}{l}\text { The structural place } \\
\text { The nature of the workplace is functional, dynamic, } \\
\text { organised and it might be conservative. The clear structure } \\
\text { and the social atmosphere helps concentration to the task } \\
\text { and collaboration. The formal meeting room and the } \\
\text { traditional rooms for executives are examples of the } \\
\text { structural place. }\end{array}$ & $\begin{array}{l}\text { Place is open for } \\
\text { external world, } \\
\text { dedicated to meetings } \\
\text { and task-oriented } \\
\text { formal working }\end{array}$ \\
\hline $\begin{array}{l}\text { Closed space for } \\
\text { privacy, peaceful } \\
\text { reflecting, sharing of } \\
\text { experiences and } \\
\text { informal interaction }\end{array}$ & $\begin{array}{l}\text { The reflective place } \\
\text { The nature of the workplace is cosy, peaceful and a shared } \\
\text { place. The dynamic atmosphere is based on a sense of the } \\
\text { workplace belonging to everyone. An example of the } \\
\text { reflective place is a coffee area or informal meeting place } \\
\text { with the feeling of a living room. }\end{array}$ & $\begin{array}{l}\text { The formal place } \\
\text { The place is offering privacy, silence and concentration. } \\
\text { The office layout with a chain of individual, cell offices, is } \\
\text { an example of the formal place. The workstation for } \\
\text { individual work without disturbance is also an example. }\end{array}$ & $\begin{array}{l}\text { Closed space for } \\
\text { concentration, privacy } \\
\text { and task-oriented } \\
\text { formal work }\end{array}$ \\
\hline $\begin{array}{l}\text { Converting explicit } \\
\text { knowledge to tacit } \\
\text { knowledge }\end{array}$ & $\begin{array}{l}\text { "Internalisation" / "Exercising Ba" } \\
\text { Embodying explicit knowledge into tacit knowledge. } \\
\text { Individual, on site or virtual interaction with e.g. know- } \\
\text { how, practical knowledge. }\end{array}$ & $\begin{array}{l}\text { "Combination" / "Systemising Ba or Cyber Ba" } \\
\text { Converting explicit knowledge into more systemised } \\
\text { explicit knowledge. Collective, group-to-group, virtual } \\
\text { interaction for collaboration with e.g. databases, } \\
\text { documents. }\end{array}$ & $\begin{array}{l}\text { Combining explicit } \\
\text { knowledge to explicit } \\
\text { knowledge }\end{array}$ \\
\hline
\end{tabular}

Figure 22.2 Nature of the workplace (adapted from Nenonen, 2005; Huhtelin \& Nenonen, 2016, 2019) 
to access and approach, and supports collaboration and informal interaction. It is a platform for new, fresh tacit knowledge and the sharing of it with people inside and outside the organisation. The atmosphere is warm and welcoming, inspiring and cosy, and there is a sense of hospitality. The ownership belongs to all people. Entrance halls or marketplaces are an example of the connective place.

The structural place is an environment that supports the conversion of tacit knowledge into explicit knowledge (the externalisation phase). The place is open to the external world, dedicated to meetings and collaboration, and supports task-oriented formal working. The functionality of the place is high. The dynamic atmosphere of the place might be conservative and dedicated to task performance, like that of a formal meeting room and the traditional rooms for executives.

The formal place is an environment that supports the analysis of explicit knowledge in the combination phase of knowledge creation. This place is a closed space; it is more for individual and private work performances and supports concentration and task orientation. The atmosphere can be tense, and the place is difficult to approach. The virtual workplace is dedicated for information, and it is faceless. The use of it is based on norms and rules, which are not transparent. The office layout, with a chain of individual, cell offices, is an example of the formal place. The workstation for individual work without disturbance is also an example.

The reflective place is an environment that supports the sharing of explicit knowledge and transforming it into tacit knowledge (the internalisation phase). This place is a closed and cosy space for privacy, peaceful reflecting, sharing of experiences and informal interaction. Internal privacy is respected while the dynamic atmosphere is based on a sense of the workplace belonging to everyone. The place empowers reflection and relaxation. The virtual workplace facilitates the sharing of information and the transformation of it into new knowledge. An example of the reflective place is a coffee area or informal meeting place with soft couches and the feeling of a living room. The virtual workplace facilitates the sharing of information and the transformation of it for knowledge.

\subsection{Knowledge creation phases as a framework in studies of academic workplaces}

Huhtelin and Nenonen (2016, 2019) have studied places supporting knowledge work and knowledge creation in the university context. They were interested in understanding the differences in knowledge work in terms of demography or different disciplines. They used the data gathered via a survey questionnaire and analysed it with the framework connected to the knowledge creation phases. They found that older researchers also required external connections to be able to connect their knowledge to other fields of research (Huhtelin \& Nenonen, 2016). In their next study (Huhtelin \& Nenonen, 2019) the findings indicated that researchers from different disciplines have different requirements for the place supporting each phase of knowledge creation. That result was aligned to the description of the nature of different disciplines. The framework that was used clarified the analysing process of the data in both studies.

\section{Methodology/research approach}

The approach used in the presented research projects is mostly qualitative, however some quantitative approaches have also been chosen. The descriptive and explorative nature of the research is 
common. Methods include case study, literature reviews and interviews as well as surveys. Some papers are published with qualitative data based on content analysis.

The focus in different studies has varied also in terms of sample. Knowledge workers from organisations, business incubators and business-centre-type environments as well as university campuses were included. The organisational knowledge creation process (SECI model) and knowledge creation places (concept $\mathrm{Ba}$ ) have proven to be useful when seeking to understand the requirements for workplaces, in the context of both universities and private sector organisations. The research is also inspired by the user-centric approach - the results provide contributions both to practice and to research by understanding the demand of knowledge workers and knowledge creation processes.

There are some research gaps which knowledge creation theories can overcome. Knowledge work and its requirements are easier to analyse by following the knowledge creation process phases. However, the physical work environment is only one aspect in facilitating the knowledge creation process, as much of the knowledge creation takes place on digital and virtual platforms. The integration of these two entities is still lacking in research. Additionally, how space is used can be an important determinant. Office etiquette or the lack of it should also be studied in connection with physical and digital work environments. One also needs to integrate the servicescape with the supporting and required factors for supporting knowledge work.

\section{Limitations}

Even though the knowledge creation theory provides a possibility to increase understanding of knowledge work, it has some limitations. The most challenging limitation is the cultural aspect. The Japanese concept $\mathrm{Ba}$ is descriptive. The ideas of transcending boundaries of oneself and knowledge conversion can be interpreted differently in European or in US contexts (Magnier-Watanabe \& Benton, 2013). This limitation is discussed also in studies by Senoo, Magnier-Watanabe, and Salmador (2007).

Additionally, the theory can be interpreted differently based on the research tradition of different disciplines. The knowledge creation theory with four different phases (SECI) as well as the Bas are most likely understood, defined and investigated based on interpretation of the background of the researcher(s). The frameworks are theoretical descriptions of a real-world phenomenon and hence are not capable of capturing all the elements and nuances of the organisational knowledge creation practices. However, these limitations challenge researchers to work more closely in transdisciplinary teams. The comparison and integration of different perspectives will validate the interpretation and provide richer results.

\section{Theory relevance to practice}

The increased understanding of the knowledge creation process can help to develop organisational practices and processes. It provides a tool for designers to capture user-centred requirements for knowledge workplaces, for example for activity-based work environments. It provides a way to identify the work based on explicit knowledge as well as the work based on tacit knowledge. All these work activities require different kinds of environments - physical, digital or even mental realities. This means that new kinds of space typologies for the design of offices is needed.

Depending on the main goal of an organisation, its knowledge workers' work profiles differ, some being mainly focused in combining explicit knowledge, some having greater aspiration in enhancing personal skills and know-how, connected to tacit knowledge. For example, the work of an accountant consists primarily of combining explicit knowledge to existing explicit 
knowledge, and the work of a director in an advertising agency consists primarily of socialisation with clients, trying to understand their profession, and tacit knowledge embedded in their experience about their business. Further, when the need to be able to socialise and understand tacit knowledge of the clients has been identified, practitioners can apply existing research about places that enhance networking behaviour and face-to-face interaction known to facilitate tacit knowledge sharing (Weijs-Perrée, 2019; Weijs-Perrée et al., 2019).

The digital work environment and its use can also be more thoroughly understood by using the knowledge creation process phases and characteristics of spaces as the reflection point: how we can collaborate and share tacit knowledge and how we can focus on explicit knowledge alone or together in digital platforms and spaces. The hybrid working environments include both physical and digital solutions. The more integrated they are, the more potential is provided for the knowledge workers of today and the future.

\section{Further reading}

- Nonaka, I., \& Konno, N. (1998). The concept of "Ba": Building foundation for knowledge creation. California Management Review, 40(3), 40-54. Retrieved from www.semanticscholar. org/paper/The-Concept-of-\%22-Ba-\%22-\%3A-BUILDING-A-FO-Nonaka-Konn/b6b 340a3186c28646b8518f7ae6d82543aa26ea2?p2df

- $\quad$ Petrulaitiene, V., Rytkönen, E., Nenonen, S., \& Jylhä, T. (2017). Towards responsive work places - Identifying service paths for time-and place independent work. Journal of Corporate Real Estate, 19(3), 144-156. https://doi.org/10.1108/JCRE-10-2016-0034

- Senoo, D., Magnier-Watanabe, R., \& Salmador, M. P. (2007). Workplace reformation, active $\mathrm{Ba}$ and knowledge creation: From a conceptual to a practical framework. European Journal of Innovation Management, 10(3), 296-315. https://doi.org/10.1108/14601060710776725

\section{References}

Allen, T. J. (1977). Managing the flow of technology: Technology transfer and the dissemination of technical information within RED organizations. Cambridge, MA: MIT Press.

Amin, A., \& Cohendet, P. (2004). Architectures of knowledge: Firms, capabilities, and communities. New York: Oxford University Press.

Backhouse, A., \& Drew, P. (1992). The design implications of social interaction in a workplace setting. Environment and Planning B Planning and Design, 19, 573-584. https://doi.org/10.1068/b190573

Becerra-Fernandez, I., \& Sabherwal, R. (2010). Knowledge management: Systems and processes. Armonk, NY: M.E. Sharpe.

Brown, J. S., \& Duguid, P. (2000). The social life of information. Boston, MA: Harvard Business School Press.

Chevez, A., \& Aznavoorian, L. (2014). Space as a knowledge management tool. Work \& Place, 4, 11-14. Retrieved from https://workandplace.com/space-as-a-knowledge-management-tool/

Claxton, G. (2000). Hare brain, tortoise mind: How intelligence increases when you think less. New York: HarperCollins.

Clegg, S. R., Kornberger, M., \& Pitsis, T. S. (2011). Managing E organizations: An introduction to theory and practice (3rd ed.). London: SAGE Publications.

Danivska (Petrulaitiene), V. (2018). From walls to experiences workplace transformation from physical office space to 'workplace-w s-a-service' model [Doctoral dissertation]. Aalto University publication series doctoral dissertations $(158 / 2018)$.

De Vries, R. E., Van den Hooff, B., \& De Ridder, J. A. (2006). Explaining knowledge sharing: The role of team communication styles, job satisfaction, and performance beliefs. Communication Research, 33(2), 115-135. https://doi.org/10.1177/0093650205285366

Dierkes, M., Berthoin Antal, A., Child, J., \& Nonaka, I. (2001). Handbook of organizational learning and knowledge. Oxford: Oxford University Press.

Drucker, P. (1959). Landmarks of tomorrow. New York: Harper. 
Finley, D., \& Sathe, V. (2013). Nonaka's SECI framework: Case study evidence and an extension. Kindai Management Review, 1, 59-68. Retrieved from www.semanticscholar.org/paper/Nonaka\%E2\%80\%99sSECI-Framework\%3A-Case-Study-Evidence-and-an-FinleySath\%C3\%A9/1dfcd378df22dc40c53d2f6 $30903 \mathrm{e} 423 \mathrm{be} 8 \mathrm{e} 6 \mathrm{c} 41$

Gourlay, S. (2006). Conceptualizing knowledge creation: A critique of Nonaka's theory. Journal of Management Studies, 43(7), 1415-1436. https://doi.org/10.1111/j.1467-6486.2006.00637.x

Hislop, D. (2013). Knowledge management in organizations: A critical introduction (3rd ed.). Oxford: Oxford University Press.

Huhtelin, M., \& Nenonen, S. (2015). A co-creation centre for university-industry collaboration: A framework for concept development. Elsevier Procedia Economics and Finance, 21, 137-145. https://doi. org/10.1016/S2212-5671(15)00160-4

Huhtelin, M., \& Nenonen, S. (2016). The workplace for researchers - Enhancing concentration and face-to-face interaction. In K. Kähkönen \& M. Keinänen (Eds.), Proceedings of the CIB world building congress 2016: Volume I - Creating built environments of new opportunities (pp. 753-764). Tampere University of Technology. Department of Civil Engineering. Retrieved from http://urn.fi/ URN:ISBN:978-952-15-3741-7

Huhtelin, M., \& Nenonen, S. (2019). The workplaces of researchers in different disciplines. Journal of Corporate Real Estate, 21(1), 36-54. https://doi.org/10.1108/JCRE-11-2017-0043

Ipe, M. (2003). Knowledge sharing in organizations: A conceptual framework. Human Resource Development Review, 2(4), 337-359. https://doi.org/10.1177/1534484303257985

Magnier-Watanabe, R., \& Benton, C. (2013). Enablers of knowledge management across borders: A structural approach. International Journal of Innovation and Technology Management, 10(4), 1350012-1-135001221. https://doi.org/10.1142/S0219877013500120

Maurer, I., Bartsch, V., \& Ebers, M. (2011). The value of intra-organizational social capital: How it fosters knowledge transfer, innovation performance, and growth. Organization Studies, 32(2), 157-185. https://doi.org/10.1177/0170840610394301

Nenonen, S. (2005). The nature of the workplace for knowledge creation [Doctoral dissertation] Retrieved from Turku University of Applied Sciences, ISBN: 9525596338.

Nonaka, I., \& Konno, N. (1998). The concept of "Ba": Building foundation for knowledge creation. California Management Review, 40(3), 40-54. Retrieved from www.semanticscholar.org/paper/TheConcept-of-\%22-Ba-\%22-\%3A-BUILDING-A-FO-Nonaka-Konn/b6b340a3186c28646b8518f7ae6 d82543aa26ea2?p2df

Nonaka, I., \& Tackeuchi, H. (1995). The knowledge-creating company. New York: Oxford University Press.

Nonaka, I., Toyama, R., \& Byosière, P. (2001). A theory of organizational knowledge creation: Understanding the dynamic process of creating knowledge. In M. Dierkes, A. Berthoin Antal, J. Child, \& I. Nonaka (Eds.), Handbook of organizational learning and knowledge (pp. 491-517). Oxford: Oxford University Press.

Nonaka, I., \& von Krogh, G. (2009). Tacit knowledge and knowledge conversion: Controversy and advancement in organizational knowledge creation theory. Organization Science, 20(3), 635-652. https://doi.org/10.1287/orsc. 1080.0412

Polanyi, M. (1962). Personal knowledge: Towards a post-critical philosophy. London: Routledge.

Rai, R. K. (2011). Knowledge management and organizational culture: A theoretical integrative framework. Journal of Knowledge Management, 15(5), 779-801. https://doi.org/10.1108/13673271111174320

Rantavuori, J., Engeström, Y., \& Lipponen, L. (2016). Learning actions, objects and types of interaction: A methodological analysis of expansive learning among pre-service teachers. Frontline Learning Research, 4(3), 1-27. https://doi.org/10.14786/flr.v4i3.174

Senoo, D., Magnier-Watanabe, R., \& Salmador, M. P. (2007). Workplace reformation, active Ba and knowledge creation: From a conceptual to a practical framework. European Journal of Innovation Management, 10(3), 296-315. https://doi.org/10.1108/14601060710776725

Strid, M. (2006). Rum för entreprenörskap. En studie av universitetsbaserade företagsinku-batorer $i$ Västsverige [Doctoral dissertation]. Chalmers University of Technology, Architecture and Civil Engineering: 2006:02 New series $\mathrm{Nr} 2443$.

Suchman, L. (2000). Making a case: Knowledge and routine work in document production. In P. Luff, J. Hindmarsh, \& C. Heath (Eds.), Workplace studies: Recovering work practice and informing system design (pp. 29-45). Cambridge: Cambridge University Press.

Tsoukas, H. (2005). Do we really understand tacit knowledge? In Handbook of organizational learning and knowledge. Blackwell. Retrieved from www.researchgate.net/publication/2528222_Do_We_Really_ Understand_Tacit_Knowledge 
Van Wijk, R., Jansen, J. P., \& Lyles, M. A. (2008). Inter- and intra-organizational knowledge transfer: A meta-analytic review and assessment of its antecedents and consequences. Journal of Management Studies, 45, 815-838. https://doi.org/10.1111/j.1467-6486.2008.00771.x

Weijs-Perrée, M. (2019). The users'value of business center concepts for knowledge sharing and networking behavior within and between organizations [Doctoral dissertation]. Eindhoven University of Technology urn:nbn:nl:ui:25-2ed6fc49-56cb-499c-826b-ea0bec676b66

Weijs-Perrée, M., Buck, L., Appel-Meulenbroek, R., \& Arentze, T. (2019). Location choices of face-toface interactions in academic buildings: An experience sampling approach. Ergonomics, 62(12), 14991514. https://doi.org/10.1080/00140139.2019.1660419 


\title{
TOWARDS AN INTERDISCIPLINARY EMPLOYEE- WORKPLACE ALIGNMENT THEORY
}

\author{
Rianne Appel-Meulenbroek*, Susanne Colenberg, \\ and Vitalija Danivska
}

\section{Introduction}

The 21 theories discussed in this book have in common that they address people's ability to do their job in a certain work environment. Some focus more on explaining why people behave the way they do (the psychosocial environment), while others take the physical and/or digital work environment (the workplace) quality as a starting point to explain certain employee outcomes. But they all work towards increased alignment between person and work environment. The end goal of employee-workplace alignment should be happy, healthy, productive and engaged employees, which has also been called thriving (Kleine, Rudolph, \& Zacher, 2019). Kleine et al. (2019, p. 973) state, "thriving exhibits small, albeit incremental predictive validity above and beyond positive affect and work engagement, for task performance, job satisfaction, subjective health, and burnout." It is a crucial mechanism for facilitating short-term individual functioning (e.g. job satisfaction) and long-term human sustainability (e.g. health and development) at work (Spreitzer, Porath, \& Gibson, 2012). All theories in this book emphasise that the alignment between the physical, digital and psychosocial work environment and the person plays a role in certain aspects of employee thriving at work. In general, three main employee outcomes can be distinguished: attitudes (job satisfaction and organisational commitment), health (mental and physical) and performance (Edwards \& Shipp, 2007).

The degree of alignment between a person and his/her workplace determines whether their interaction leads to positive employee outcomes and thus contributes to thriving at work. In turn, employee thriving is likely to lead to positive outcomes for the organisation as a whole. On the other hand, suboptimal alignment results in stress, through either the perception of insufficiency of workplace supplies to fulfil the person's needs (Edwards, Caplan, \& Harrison, 1998) or a person's inability to meet the demands of the workplace (Edwards \& Shipp, 2007). Such an appraisal provides the motivation and direction for coping with the misalignment (Dewe, Cox, \& Ferguson, 1993). There is no overall agreement in literature on the best classification of coping strategies, but Skinner, Edge, Altman and Sherwood (2003) argued well that so-called

*Corresponding author: h.a.j.a.appel@tue.nl 
action-type classifications are the best, and that the distinction of primary versus secondary control is the most common one (see also Chapter 11 Two-Process Theory of Perceived Control). Several other chapters in this book have also addressed these kind of adaptive employee behaviours in a way.

Although satisfactory, healthy and productive workplaces are in everybody's best interest and are receiving increased attention in practice, research on improving the alignment between office employees and their physical workplace has not yet addressed all employee outcomes sufficiently (Appel-Meulenbroek, Clippard, \& Pfnür, 2018). Appel-Meulenbroek et al. also showed that it is scattered across many disciplines (e.g. psychology, architecture, real estate, economy, engineering and ergonomics). Because of this, the available scientific insights are spread over many different (micro) theories. This book was an attempt to bring some of the important theories together, with this chapter taking a first step towards integrating them into an overall framework towards developing a grand EWA theory. According to Brown (2013, p. 484), for a theory to qualify as 'grand', it should have "implications beyond the immediate discourse within which it was created". Given the interdisciplinary integration attempt here, it would appear to qualify for the term.

The previous chapters in this book have addressed many characteristics of people and environments that should be considered to optimise EWA. For example, at the side of the person, characteristics such as personality (see Chapter 10), privacy needs (see Chapter 6) and other needs stemming from the evolutionary development of our brains (see Chapter 17) must be considered. While at the side of the environment, characteristics such as digital technology (see Chapter 4), indoor environmental quality (see Chapter 13), layout (see Chapter 21), and biophilia (see Chapter 15) influence alignment. This book clearly shows that there is a lot of theoretical knowledge that could enrich attempts for evidence-based design towards creating a supportive office workplace aligned to the employees. However, it seems that available scientific knowledge is either not clear, inaccessible for workplace designers/managers in practice, or not ready to be implemented in practice, judging from the data produced by the Leesman index (see Leesmanindex.com) about workplace satisfaction. From a sample of over 600,000 office employees worldwide, their database shows that while $85 \%$ agree that workplace design is important to them, only one-third is satisfied about basic design/environmental features such as temperature control, noise levels, quiet rooms, plants and greenery, and the variety of different types of workspaces (Leesman review 29).

\subsection{An EWA theory}

To further the advancement of the workplace research field by integrating existing knowledge, this chapter starts with the development of a grand EWA theory dedicated to office workplace design. Here, workplace design refers to physical and digital characteristics of the work environment and the psychosocial conditions stemming from them. As quoted in Chapter 1, such

a theory should select and define constructs of interest, describe how the constructs relate to one another, explain why the focal constructs were chosen and why they relate as predicted by the theory, and specify boundaries that denote the conditions under which the predictions of the theory should hold.

(Edwards, 2008, p. 171)

Obviously, this would require an interdisciplinary approach to the identification of the constructs, followed by a transdisciplinary approach to test the relationships between these constructs and how they hold in different contextual conditions in living labs and other experiments. In 
Table 23.1 Theories in the book in alphabetical order

Action regulation theory

Activity theory

Attractive quality theory

Behavioural economics theory

The biophilia hypothesis

Ecological systems theory

Evolutionary psychology theory

Flourish theory

Information space

The job demands-resources model

Knowledge creation theory

Nudging theory

Organisational culture theories

Person-environment fit theory

Place attachment theory

Privacy regulation theory

Social constructionism theory

Space syntax theory

Task-technology fit theory

Temperament theory

Two-process theory of perceived control

this chapter we discuss a first step towards development of this new grand EWA theory, by identifying the focal constructs that Edwards mentioned across all 21 theories described in this book (see Table 23.1). These theories stem from a broad variety of disciplines, and integrating them would thus create the necessary interdisciplinary framework.

This chapter takes a first step into the integration of the assumptions of these theories by delivering a preliminary framework that provides a system overview (Nilsen, 2015) of EWA. To accomplish this, the most important tacit knowledge underlying the theories was made explicit to capture the essence of each theory. Then commonalities between the theories were identified, creating the focal constructs. The constructs were used to connect the theories in a preliminary framework. In the future, this framework could be developed into an EWA theory by connecting the constructs with empirical data.

The next section will explain the empirical approach (a concept mapping study) that was taken to create the focal constructs, followed by its results, a discussion of the implications of findings for workplace research and practice, and identification of the necessary further step to completely develop this framework into a grand theory on EWA.

\section{Concept mapping}

Integration of knowledge in the context of interdisciplinarity is defined by Repko (2012, p. 263) as "the cognitive process of critically evaluating disciplinary insights and creating common ground among them to construct a more comprehensive understanding”. To reveal such thematic commonalities and differences in the theories in this book, concept mapping (Kane \& Trochim, 2007) was applied, also known as 'group concept mapping', to distinguish it from mind mapping techniques such as Novakian concept mapping (Kane \& Rosas, 2018). This 


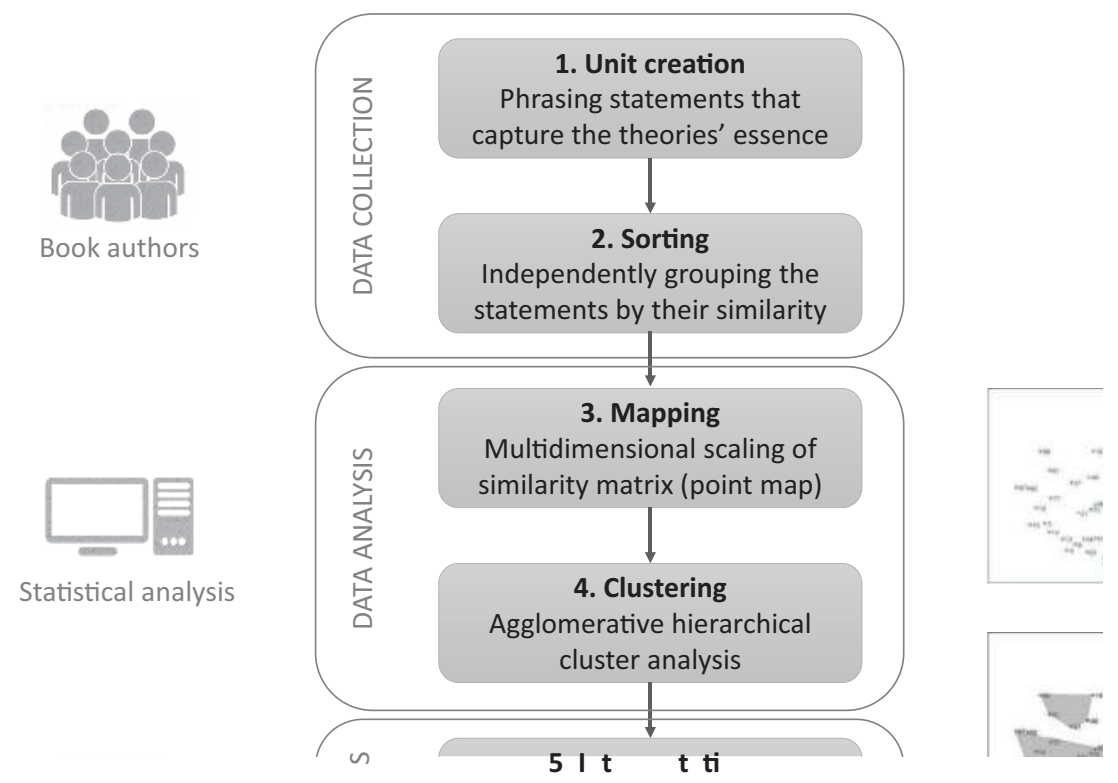

Figure 23.1 Applied concept mapping procedure in five steps

machine-driven content analysis method aggregates and integrates knowledge, creating a structure of ideas, values or opinions. Having evolved from educational planning and evaluation, it now has been used all over the world in a high diversity of disciplines (Trochim, 2017) for purposes such as text analysis, defining priorities and developing theoretical frameworks (Kane \& Rosas, 2018).

Group concept mapping is a mixed-method approach to extracting knowledge that resides among a group of individuals, the 'wisdom of the crowd'. Technically, the concept mapping process is a combination of brainstorming, card sorting (possibly accompanied by rating), statistical analysis and data visualisation (see Figure 23.1). Rosas and Kane (2012) showed that the method yields strong internal representational validity and very strong sorting reliability estimates.

Since the quested group wisdom was residing in the minds of the book chapter authors living all over the world, the data collection had to be done online. The concept mapping process was led by the research team, consisting of the three authors of this chapter.

\subsection{Unit creation by book chapter authors}

The first step of the concept mapping procedure included the creation of units that could refer to possible commonalities and differences between the theories. To keep a balance between the method's reliability and the sorters' burden, the aim was a maximum of around 100 units, as suggested by (Kane \& Rosas, 2018). All 38 authors of this volume have been requested by email to grasp the essence of their chapter's theory into three to five statements, meeting the following criteria:

- describing essential characteristics or assumptions of the theory, capturing its essential phenomena and relationships; 
- making theoretical statements, not phrasing recommendations that follow from the theory or empirical results;

- containing a maximum of 15 words each (virtually fitting on a post-it);

- $\quad$ easy to understand for authors from other disciplines;

- clear and comprehensible on its own, even when it is placed between statements about other theories;

- $\quad$ avoiding the theory's name if possible, to reduce recognition of the statement sets.

To further clarify the criteria, the authors were told that the statements "could be, for instance, a definition of the main phenomena, their composition or mutual relationships, the main propositions, assumptions, or values related to the theory, or anything else essential for the theory".

For 16 theories, the statements were initially created by the chapter authors, while for the remaining five theories the editors have phrased statements based on the author's chapter draft to keep the research from delay. In all cases, statements have been discussed between the chapter authors and the three members from the concept mapping research team until they were approved. The members of the research team have individually tested the collected statements by their fit with the aforementioned criteria, discussing the results together. Statements were rephrased if needed to increase their comprehensibility, and similar statements within one theory were deleted. There was no aim for a same amount of statements per theory, since one theory naturally might have more facets than another. Changes to the original statements were presented to the concerning authors for approval. In the end a total of 102 units, ranging between four and six (average $=4.9$ ) statements per theory, was created and stored in an Excel file.

\subsection{Grouping the statements}

First, the 102 statements were randomised by sorting them alphabetically, after which they were numbered to create the ability to reconnect them to their theory after the sorting. The numbered statements were entered into the remote card sort tool of UsabiliTEST, a Texas-based company providing tools for testing usability and improving information architecture, used by companies and universities worldwide. With this online software, a user test was created for open-ended card sorting, allowing participants to create their own groups according to their logic instead of providing categories beforehand in a closed sort. An open sort is ideal for collecting user-generated ideas for logical content groupings.

All 38 authors were invited to participate in sorting the statements, by sending them an email containing a link to the card sort test which they could not share with others. They were instructed to arrange the cards into groups that made the most sense to them and that they could create as many groups as they wanted, as long as they did not make a miscellaneous group such as a category 'other' or 'mixed'. They were able to pause the sorting and to continue at a later moment before submitting their contribution to the database. Two weeks before closing the test, a reminder was sent to those who did not yet submit a contribution. To each participant the cards were randomly presented by the system. While authors might still recognise their own statements, tending to put them together, this effect was mitigated by the other sorters' grouping.

Although methodological criteria have not been established yet, it looks like a number of at least 11 sorters is required for reliable results, and while more sorters is better, their added value decreases beyond 20 (Rosas \& Kane, 2012). When the card sort test was closed, eight weeks 
after the invitation was sent, 22 authors had participated in the sorting with an average completion rate of between $90 \%$ and $100 \%$ of the statements. One sorter has been excluded from the data analysis because the completion rate was below $20 \%$, as this would not contribute much to the discriminant validity of the concept mapping. On average the included sorters created 11.3 content groups with a mean of nine statements per group. One of the sorters commented: "It was a nice exercise! Quite a lot of statements to keep a good overview, but it was doable."

\subsection{Statistical analysis and concept map generation}

First, the raw data from the included sorters were exported from the UsabiliTEST system as an Excel file containing all groups that were created by the sorters and the names they had given them. These data were cleaned by deleting two miscellaneous groups (labelled e.g. 'misc' or 'A'), since these statements were not grouped based on content similarity and therefore including these groups would distort the analysis. On this cleaned file, R-CMap (Bar \& Mentch, 2017) was run, a piece of open-source software in $\mathrm{R}$ programming language. The first step of the analysis involved mapping (see Figure 23.1, step 3), using non-metric multidimensional scaling to transform the multidimensional data into a two-dimensional representation of the relative distances between the statements. This resulted in a point map, where each point represented a statement and the distance between them represented their content difference (the closer, the more similar). The second step (Figure 23.1, step 4) involved agglomerative hierarchical clustering, subsequently merging the two clusters at shortest distance, determined by the closest pair of points.

Since there was no desired number of clusters to aim for, the dendrogram was viewed to indicate the useful range of cluster amounts to consider. In this tree representation of the clustering process, the length of stems represented the distance between two merged clusters while corresponding to the within-cluster variance. Based on the dendrogram, the cluster analysis iterations ranging from five to 15 clusters were studied closely by each member of the research team to decide at what point the next merging was not logical or did not contribute to clarity of the themes. This resulted in the preference for eight clusters.

\section{Results}

\subsection{Identified concepts and regions of meaning}

The concept mapping revealed an eight-themed structure underlying the 21 theories present in this book. Figure 23.2 shows the 102 statements plotted into two-dimensional space and grouped into eight clusters based on their similarity as judged by the sorters. The closer the points or clusters appear on the map, generally the more similar they are according to the sorters, although the translation to two dimensions means it will always include some noise due to randomisation. Cluster names were chosen by the research team, based on the statements' content and inspired by group labels that were created by the sorters. In this decision process the content of the statements in the centre of the cluster was of greater weight than that of statements at the edges, and distances to other cluster were also taken into account.

At a higher level of abstraction, three regions of meaning (represented by the dotted lines in Figure 23.2) were identified based on the iteration of the cluster analysis where the eight clusters had been merged into three. These regions refer to (1) aligning workplace supplies to fit with employee needs, (2) human cognition and behaviour towards reaching alignment, and (3) the organisational context, which will now be discussed in more detail. 


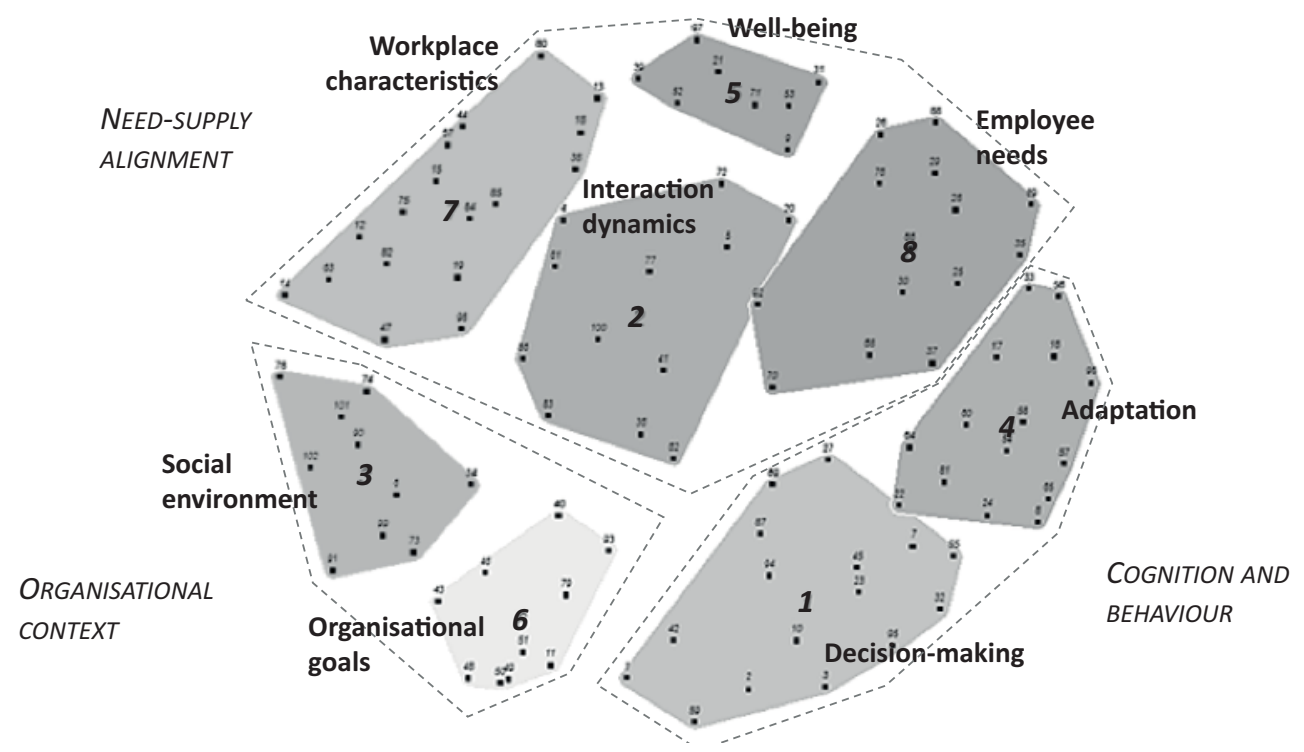

Figure 23.2 Clustering of the 102 theoretical statements into eight themes and three regions of meaning

\subsubsection{Need-supply alignment}

Four clusters form the region of meaning that comprises statements on alignment of workplace supplies to individual user needs. Cluster 7, labelled 'Workplace characteristics', contains both physical and digital office design aspects and represents the environmental 'supplies' that should be aligned to employee needs by workplace managers. Obviously, this cluster obtained statements from theories on environmental qualities (the theory of attractive quality and flourish) and on fit (action regulation theory, information space, the job demands-resources model, tasktechnology fit). The 17 statements in this cluster make it the largest one. Together they indicate that the workplace either functions as a resource, positively impacting employee outcomes, or as a demand, if not aligned well with employees' needs. Especially dealing with the digital/virtual and physical workplace simultaneously represents a major challenge for employees. The workplace clearly is a complex system of characteristics that often cannot be perceived in isolation. Additionally, alignment attempts by workplace managers do not only influence employee outcomes, but also steer their activities in and their use of the office. Typical statements in this cluster are "The physical environment can be divided into environmental demands and environmental resources" and "Workplaces are a constellation of tools that mediate employees' activities".

The 'Employee needs' cluster (cluster 8) on the other side of this region represents the employee in the person-environment relationship. The statements in this cluster all focus on user needs, emphasising that the degree of EWA is higher (and thus more likely to improve employee thriving) when the environment supports the most important needs of users. Some also show that people have inherited spatial preferences to settings similar to our ancestral environment and are psychologically oriented towards natural elements. Statements in this cluster include "Whether environmental stimuli are pleasant depends on the internal state of being" and "Person-environment interaction is optimal when the environment supports the most important needs of users". 
In addition, statements on the process of interaction between people and their workplace were clustered together in cluster 2, labelled 'Interaction dynamics'. Statements in this cluster imply that users and their workplace continuously interact with each other and that this interaction creates a bond. They also indicate that perception of workplace quality changes over time. If continuous mutual alignment is successful, this leads to occupant satisfaction, workplace experience, health, wellbeing and economic benefits, because, as one of the statements says, "Perception of the workplace quality is just as important as actual workplace quality", and another explains, "Attractive workplace aspects lift occupant satisfaction and workplace experience." Alignment is thus not a one-time process, nor should there be a one-size-fits-all approach. Statements include, "Perceived quality of a workplace attribute can change over time" and "Workplaces shape their users as well as the users shape their workplace."

Last, cluster 5 is labelled 'Wellbeing'. It is the smallest one and refers to psychological health and wellbeing and to feeling safe as basic conditions for performance. For instance, people need the right amount of stimulation and protection (physical openness) to function well. This cluster indicates potential consequences of top-down workplace realignment attempts. When people have become 'attached' to their current workplace, it may be difficult for them to accept changes. When place separation or place loss are experienced due to changes, workplace attachment becomes apparent and can have negative consequences for employee outcomes. Typical statements include "Scarcity of resources in the face of challenge can lead to stress, exhaustion and burnout" and "Coping with place loss is difficult for employees."

\subsubsection{Cognition and behaviour}

The second region of meaning shows that alignment of employees and their workplace is not just a matter of providing a 'theoretically' optimal workplace. Both clusters in this region show that alignment can also suffer or benefit from peoples' cognitive processes and adaptive behaviours.

Cluster 1, labelled 'Decision-making', contains statements explaining how employees' preferences, needs or group norms influence their decision-making and behaviour in dealing with the work environment, and how they purposely interact with the environment to achieve desired outcomes. Some statements emphasise that humans are biased in how they perceive the environment, which steers their behaviour in and use of the environment in a certain direction. As one of the statements summarises: "cognitive processes mediate the effects of physical conditions on human behaviour." Examples of other statements in this cluster are "Adoption of technology depends on users acknowledging this technology improves executing tasks", "Humans are biased in how they perceive visual and auditory distractions" and "People do not always make decisions that are in their own best interest."

Cluster 4 is based on statements similar to those in the adjacent cluster 1; however, it refers more strongly to the need for control, the role of personality and ecological systems in employees' attempts to adapt their behaviour to their work environment, and therefore is labelled 'Adaptation'. If people cannot change the environment to cope with misalignment, they compromise their needs by adapting themselves to the environment (secondary control). The statements in this cluster tell that, in general, people tend to maintain the same environmental settings instead of changing them to optimise the environment to their needs, especially if they have too many options to choose from, and that consideration of personality traits may help to understand individual preferences and behaviour in the workplace. They explain, "Employees have an innate need to control their environment" and "Workers strive to achieve the best possible fit between their actual and desired levels of input and output." 


\subsubsection{Organisational context}

Alignment of workplace supplies with employee needs, perception and dealing with misalignment all take place within an organisational context. The two clusters in this region describe the social setting of the workplace. Cluster 3, labelled 'Social environment', contains statements about workplaces being more than just physical space and digital support, referring to a psychosocial dimension. They indicate that workplaces are defined, valued and experienced in a social context through a process of individual and joint reasoning, making them objects of a social process. As one of the statements summarises, "Workspace is physical, workplace is the social and organisational work environment." Examples of other statements in this cluster are "Where people work together, a social workspace arises regardless of where they are located" and "Both workspace and workplace are socially and discursively constructed with language."

Cluster 6 comprises several statements on organisational culture, corporate goals and possibilities for regulation and knowledge creation, and it is labelled 'Organisational goals'. Its statements indicate that organisational culture might be unseen but is one of the most powerful elements in an organisation. It can be incorporated into office layouts, work practices and interior designs, and it connects people to the workplace through shared experiences and values. In addition, workplace relates to other organisational goals, such as knowledge sharing and sustainability. Typical statements are "Organisational culture can be seen, felt and heard when entering office premises" and "Culture connects members to place through shared historical experiences, values and symbols."

\subsection{Relations between theories}

Based on the statements in each cluster it is possible to detect which theories are represented in the clusters and to what extent (see Table 23.2). This shows that for some theories all statements congregate in one cluster where they strongly define such a cluster, while others are distributed over many different clusters. When looking at those theories that have more than half of their statements in one cluster (e.g. privacy-regulation theory, social constructionism, the biophilia hypothesis), a possible explanation might be that these are micro-theories that explain a certain phenomenon (see Chapter 1 for a discussion on types of theories). Those theories that have statements in four or five clusters (e.g. action regulation theory, theory of attractive quality, flourish, and evolutionary psychology) could be considered grand or mid-range theories with broader theoretical perspectives.

Next, Table 23.2 is visualised for the three regions of meanings, to provide a more direct view of which theories appear to relate to each other as well (see Figure 23.3). In this visualisation, one alteration to the table has been made, based on interpretation of the statements by the research team. Namely, although one statement of the biophilia hypothesis ("Space can be considered as a cluster of symbolic and sensual codes") grouped with cluster 3 "Social environment', it does not appear to fit well with the meaning of the rest of the statements in this cluster. Therefore, this statement's position in that region of meaning is not included in Figure 23.3. The figure shows that only a few micro-theories are focused on only one of the three regions and most are on the intersections of the circles. The location of the micro-theories in the outskirts of the circles seems logical: organisational culture theory and social constructionism indeed explain the 'Organisational context', while the biophilia hypothesis, space syntax theory, and the theory of attractive quality relate to 'Need-supply alignment'. Additionally, privacy regulation theory fits the 'Cognition and behaviour' region well. All intersections between regions of meaning have at least one theory dedicated to it. Knowledge creation theory is the only one in 
Table 23.2 Theories represented in the eight themes by less than $(\bullet)$, exactly half $(\bullet \bullet)$ or more than half $(\bullet \bullet \bullet)$ of their four to six statements

\begin{tabular}{|c|c|c|c|c|c|c|c|c|}
\hline & \multicolumn{4}{|c|}{ Need-supply alignment } & \multicolumn{2}{|c|}{ Cognition and behaviour } & \multicolumn{2}{|l|}{ Organisational context } \\
\hline & $\begin{array}{l}\text { 7. Workplace } \\
\text { characteristics }\end{array}$ & 8. Employee needs & $\begin{array}{l}\text { 2. Interaction } \\
\text { dynamics }\end{array}$ & 5. Wellbeing & 1. Decision-making & 4. Adaptation & 3. Social environment & 6. Organisational goals \\
\hline Person-environment fit & & $\bullet$ & $\bullet \bullet$ & & & $\bullet$ & & \\
\hline Job demands-resources & $\bullet \bullet$ & & & $\bullet$ & & & & $\bullet$ \\
\hline Action regulation & $\bullet$ & $\bullet$ & & & $\bullet$ & $\bullet$ & & $\bullet$ \\
\hline Privacy regulation & & & & & $\bullet \bullet \bullet$ & $\bullet$ & & \\
\hline Task-technology fit & $\bullet \bullet \bullet$ & & & & $\bullet$ & & & \\
\hline Information space & $\bullet \bullet$ & & $\bullet$ & & & & $\bullet$ & \\
\hline Social constructionism & & & & & & & $\bullet \bullet \bullet$ & \\
\hline Ecological systems & & $\bullet$ & & & & $\bullet$ & $\bullet \bullet$ & \\
\hline Temperament & & $\bullet$ & $\bullet$ & & & $\bullet$ & & \\
\hline Control & & $\bullet$ & & & $\bullet$ & $\bullet \bullet$ & & \\
\hline Organisational culture & & & & & & & & $\bullet \bullet \bullet$ \\
\hline Attractive quality & $\bullet$ & $\bullet$ & $\bullet$ & $\bullet$ & & & & \\
\hline Flourish & $\bullet$ & $\bullet$ & $\bullet$ & $\bullet$ & & $\bullet$ & & \\
\hline Biophilia & & $\bullet \bullet \bullet$ & & & & & $\bullet$ & \\
\hline Attachment & & & $\bullet$ & $\bullet \bullet \bullet$ & & & & $\bullet$ \\
\hline Evolutionary psychology & & $\bullet$ & & $\bullet$ & $\bullet$ & $\bullet$ & & \\
\hline Behavioural economics & & & $\bullet$ & & $\bullet$ & $\bullet \bullet$ & & \\
\hline Nudging & & & $\bullet$ & & $\bullet \bullet$ & $\bullet$ & & \\
\hline Activity & $\bullet$ & & & & $\bullet \bullet \bullet$ & & & \\
\hline Space syntax & $\bullet \bullet \bullet$ & & & & & & & \\
\hline Knowledge creation & & & & & $\bullet$ & & $\bullet$ & $\bullet \bullet$ \\
\hline
\end{tabular}




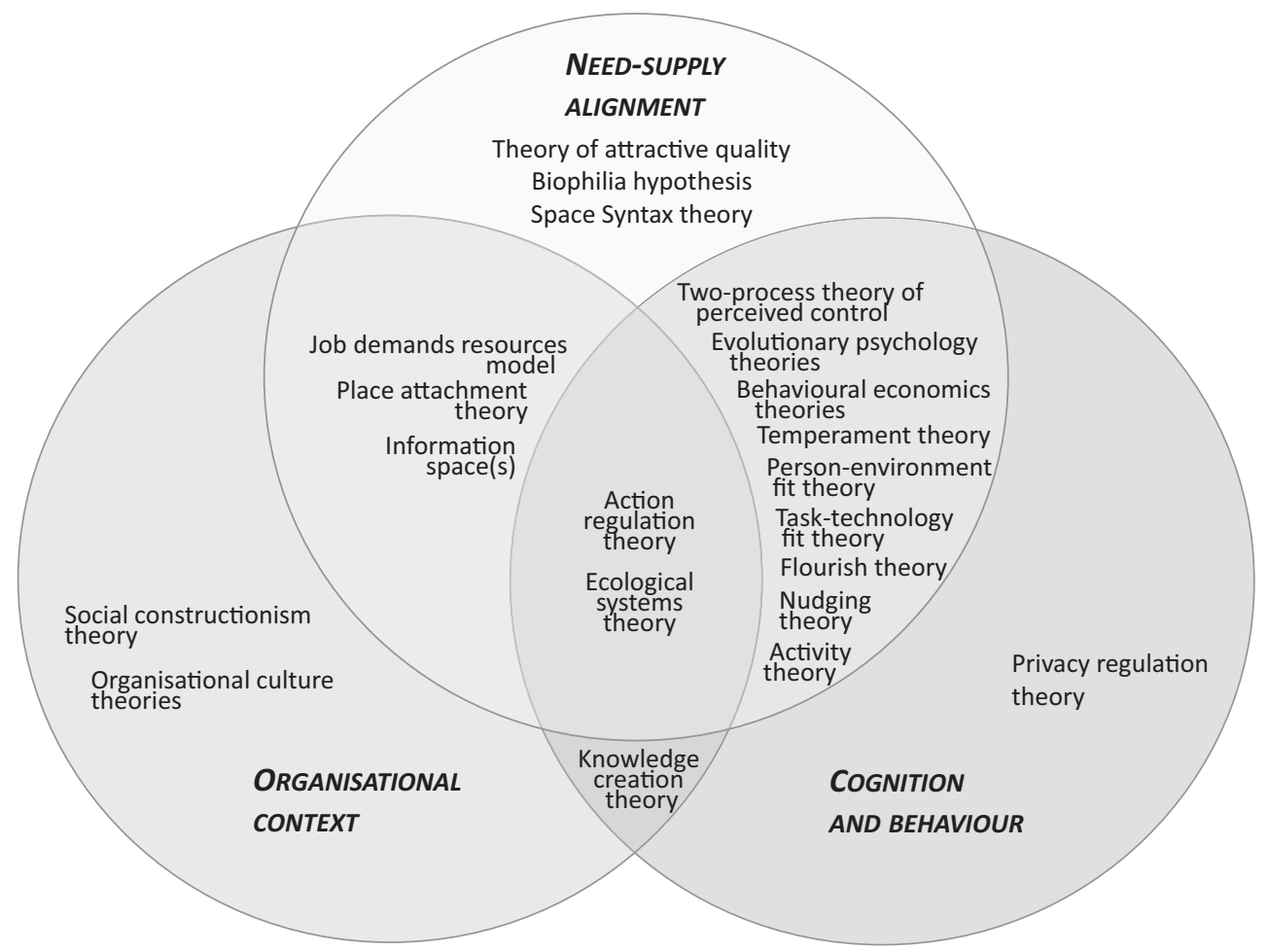

Figure 23.3 How the theories relate to the three regions of meaning

the intersection of cognition and behaviour with the organisational context, where its assumptions fit really well. The largest number of theories is located in the intersection of need-supply alignment with cognition and behaviour. This shows the width of the psychology field with its very many theories that are or could be applied to EWA. Three theories are on the intersection of need-supply alignment and the organisational context: the job demands-resources model, place attachment theory, and information space. Indeed, they all approach alignment on a more organisational level than the other psychological theories, which makes it logical that they are positioned here. Last, action regulation theory and ecological system theory ended up in the middle of the figure at the intersection of all three circles. Both theories appear to be more of a grand theory, providing a systematic overview of the nature of knowledge in both fields. Perhaps this is why their assumptions are linked to many other theories and why they ended up in many concepts. Overall, there are no theories showing up in an illogical place in the concept mapping results, confirming the validity of the outcome of this method.

\section{Discussion}

\subsection{Towards a new grand theory on EWA}

This chapter has taken a first step towards the development of a grand theory on workplaceemployee alignment. It has selected and defined the constructs of interest (the eight concepts) that such a theory could include and shows the framework created out of this. Future steps will 
have to define how these concepts relate to each other and why this is the case. This requires more research within each region of meaning and between the three regions. Figure 23.4 shows the EWA framework that came forward from the concept mapping data. All relationships are portrayed with two-directional arrows, as the exact relationships are yet to be determined with future research, including how all concepts explain employee thriving.

The 'Need-supply alignment' construct shows a clear confirmation of P-E fit theory, where the environment and person need to fit to each other to achieve positive employee outcomes and behaviours; with the hope and expectation that positive employee outcomes lead to positive organisational outcomes. Edwards and Shipp (2007) concluded from reviewing P-E fit studies that subjective needs-supplies fit is the most important type of fit to obtain positive employee attitudes and optimised employee wellbeing (both being part of thriving). Although $\mathrm{P}-\mathrm{E}$ fit theory is largely focused on the psychosocial work environment, there is also a lot of research on satisfaction with the physical workplace to support the attitude part of this claim for the physical workplace too. Such studies are mostly based on satisfaction surveys (AppelMeulenbroek et al., 2018), thus measuring subjective needs-supplies alignment and the attitude resulting from it (satisfaction). However, research on the physical workplace and wellbeing (including subjective wellbeing) is in a nascent state with a focus on preventing physical health issues rather than enhancing mental wellbeing (Colenberg, Jylhä, \& Arkesteijn, 2020; Van der Voordt \& Jensen, 2018), so the wellbeing part of the claim is so far less supported by evidence to extend it to physical workplaces. In addition, a downside of most workplace design studies is that they generally focus on measuring the workplace characteristics and ignore measuring employee needs (Budie, Appel-Meulenbroek, Kemperman, \& Weijs-Perrée, 2019). So, to get more insight into employee-workplace dynamics and how this creates and/or is influenced by workplace attachment and wellbeing, more research on these topics is necessary. In addition, less important needs that are fulfilled by the office environment might not raise satisfaction and wellbeing as much as when very important needs are met. Similarly, the effects of stress resulting from a needs-supply misfit is probably larger when this regards important needs for a person. So, it is first necessary to identify the most important needs that a workplace should align to.

Regarding the task performance outcome of thriving, Edwards and Shipp (2007, p. 31) concluded for the psychosocial work environment that "the effects of demand-abilities fit and

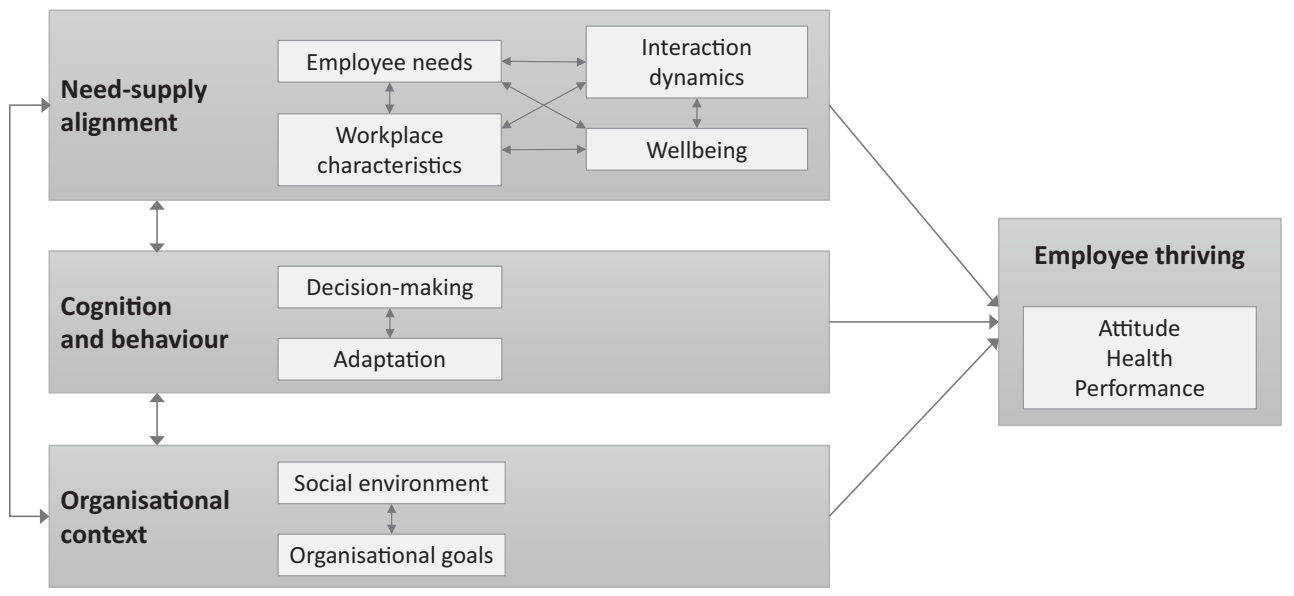

Figure 23.4 An employee-workplace alignment framework 
needs-supplies fit are interactive, such that both types of fit are required for task performance to occur." Demand-abilities fit regards whether people are not under- or overqualified for their job; whether they have what it takes to meet the environmental demands (Edwards et al., 1998). Extending this to the physical workplace, one could think of the ability to deal with noise and other environmental demands. What Edwards and Shipp suggest is that when such demands could be internalised as desires, this would improve the perceived fit between needs and supplies. To stick with the same example: if employees that are annoyed by the amount of noise in their workspace from brief conversations could be convinced of the value of such conversations to the extent that they start seeing it as an essential need for themselves, they might have more understanding for it. This would then increase subjective alignment of their need to concentrate and the ability to do so in the office. In the framework this type of behaviour is represented in the statements on 'Cognition and behaviour', which also relate to literature on job crafting: "a specific form of proactive behaviour in which the employee initiates changes in the level of job demands and job resources" (Tims \& Bakker, 2010, p. 1). Just like employees might customise their jobs to their individual needs and preferences (Berg, Dutton, \& Wrzesniewski, 2008), they can also do this with their office workplace. In this case it would probably better be called 'workplace crafting', where the employee exerts control, if possible, to make changes to the physical workplace that better fit his/her needs. Luong, Peters, Von Hippel, and Dat (2019) already used this term to refer to personalisation behaviour in the workplace, when employees felt insufficient fit between their own identity and that of their individual workspace. This is a way of actively coping with misalignment that has been observed by others as well (e.g. Babapour, Karlsson, \& Osvalder, 2018). Tims and Bakker (2010) suggest that crafting increases wellbeing and could thus set the stage for thriving. But what brings people to engage in crafting has not yet been studied sufficiently. Sticking with the previous noise example, research has shown that many employees do not opt for such an active approach in the office, but rather try to ignore it (e.g. trying harder to concentrate) even though they know this will be less effective (Appel-Meulenbroek, Steps, Wenmaekers, \& Arentze, 2020). Research could find out why this is the case. And if active control of the workplace is not possible, employees tend to adjust themselves to the environment to improve alignment by so-called secondary control (see Chapter 11 Two-Process Theory of Perceived Control). This also deserves more research on the reasoning behind this form of adaptation.

In workplace studies, data collection on the 'Organisational context' is often limited to perceptions of employees in a one or two organisations. It therefore remains unclear how the social environment and long-term organisational goals are related to workplace alignment processes. Nevertheless, some research on organisational culture and workplace design has been conducted. For example, Van der Voordt and Van Meel (2016) described dimensions such as hierarchy, formality and individuality that can be visualised and supported through the workplace. But, as they state, it remains unclear how physical workplaces can create cultural changes and vice versa. The achievement of other organisational goals such as sustainability and knowledge sharing through EWA would also benefit from more scientific evidence behind such mechanisms. As workplaces appear to be defined, valued and experienced through a process of individual and joint reasoning, more research into such social processes is necessary as well. Studies on participatory design processes suggest that this might convince those who oppose a workplace intervention to ultimately agree with it (Rolfö, 2018). Perhaps it can also aid in increasing demands-abilities fit, as workplace managers are able to explain the benefits of certain unpleasant demands of the environment (like noise) to employees in the process. In addition, it seems a logical way to identify which needs to focus on as well. But why should researchers and organisations only study or apply participatory processes in case of workplace interventions? They might also identify 
interesting input for EWA theory development on workplace experience throughout time in established work environments.

\subsection{Limitations and future steps}

Overall, the eight concepts for an EWA theory show that alignment of a workplace and an employee is interactive, personal, social and not a one-time effort. Especially the latter two have not yet received much attention in research on the physical and digital workplace and thus need further elaboration to be able to develop a full EWA theory. Qualitative research methods could provide insight into the identified processes of individual and joint reasoning about the workplace amongst employees and what this means for their perceptions and eventual thriving. Regarding the continuous effort to keep alignment over time, studies on the CRE strategy level are already calling for agility and dynamic alignment (e.g. Cooke, Appel-Meulenbroek, \& Arentze, 2019). This chapter shows that several theories suggest that it is highly relevant at the more operational employee-workplace alignment level as well and thus deserves more research. In addition, the first holistic studies on employee wellbeing suggest that satisfaction outcomes of EWA might support the other two types of outcomes (wellbeing and performance). For example, Appel-Meulenbroek, Van der Voordt, Aussems, Arentze, and LeBlanc (2020) found that perceived alignment of indoor environmental qualities, such as temperature and lighting, to employees' needs did not directly decrease stress or increase performance, but instead it increased feelings of recognition and appreciation, which in turn increased involvement which decreased exhaustion and increased efficacy. So, this suggests a complicated and mediated multi-stage mechanism of alignment to achieve thriving, which needs much more research to be able to complete an EWA theory. Figure 23.3 informs researchers which theories to incorporate in future research if they want to further develop specific concepts or interactions between concepts. Some theories might come from other disciplinary fields and might thus not be familiar to them yet. Hopefully, further integration of theories across disciplines helps researchers cross existing disciplinary boundaries to further develop EWA theory.

An important limitation of the framework in this chapter is that it is based on 21 theories that were selected in an uncontrolled manner, by soliciting suggestions for relevant theories within the editors' networks. A first important future step would thus be to verify this framework with the assumptions of potential other relevant theories from these and other disciplinary fields, to see whether the eight identified concepts cover everything or maybe still miss some aspects of EWA. For example, the social psychology field is extensive and might not have been fully represented with the few theories here to fully define the social environment cluster. In addition, the assumptions extracted from the theories for this concept mapping exercise could change if authors from different disciplinary fields that also use this theory would create them. So, it would be good to discuss the concepts and their essence, for example through a Delphi method approach, with a group of representatives from many different disciplinary backgrounds, and also by including workplace managers in practice.

The second step towards EWA theory development would be to develop scales for testing relations between the eight concepts, as this is another limitation of this chapter. As Edwards and Shipp (2007) point out, it is important to develop items that measure the person and the environment on the same level (global, domain, facet) and have both nominal and scale equivalence (respectively meaning that they are described by the same terms, for example desired and perceived privacy, and assessed on the same response scale). As physical workplace design research is a relatively young discipline, so far it has not created measurement scales that have been widely 
adopted either to measure workplaces or to measure employee needs. Instead, researchers generally create their own scales for each individual study. As Carpenter (2018, p. 25) pointed out, "The linking of measurement indicators to a concept is a complex process" that consists of 10 steps. So far, much of the workplace research has not gone through such a rigorous method of scale development and thus has a long way to go.

Once appropriate scales are created and tested, the third and final step would be to collect data in living labs and other field experiments to describe how the eight concepts relate to one another and to employee thriving outcomes and why. Repeating such studies in many different organisational and office contexts should then specify the conditions (and boundaries) under which the predictions of the EWA theory should hold. Only then would the EWA theory that has begun to develop in this chapter meet all criteria for a theory as put forward by Edwards (2008).

\section{Implications for practice}

This chapter of the book largely aims at further theoretical development of the workplace research field. Nonetheless, the developed framework also shows important take-aways for workplace managers in practice. The concepts in the 'Need-supply alignment' part of the framework suggest that managers should not only look for an objective needs-supplies fit, but work on achieving subjective alignment of the workplace as well. As decision-making and adaptation behaviour show clear individual differences in how to achieve alignment, it is important to identify what type of employees work for the organisation and what their main needs are. This could be very different between different teams and/or departments, and of course also depends on their activities, so this is not an easy task. Also, most employees will have previous experiences with one or more office types within other organisations or in their current job. This means that they could experience loss differently when their work environment changes. It is thus important not to overlook feelings of place attachment in change processes. Participatory design can help prevent or at least decrease stress and thus deserves more attention in workplace management in practice.

Workplace managers generally do not have a background in psychology and are not located within a department with colleagues that do. So, including the essence of the 'Cognition and behaviour' part of the framework in their daily practices might be difficult. If increasing workplace experience and employee wellbeing are important goals of the organisation, it might make sense to seek further training in this area. With the right training, workplace managers could, for example, observe coping behaviours in the office that indicate employees' stress and perceived lack of control. These might indicate perceived misalignment of the workplace to individual needs and could be a nice addition to the custom employee satisfaction surveys that are mostly used to identify employee satisfaction up till now. Such insights could then be used to discuss potential workplace interventions with employees and search for further optimisations.

The 'Organisational context' is an obvious aspect of a workplace, nevertheless it does not always receive attention in workplace strategy and interventions. Organisational culture is often depicted as an iceberg and is thus not very visible and explicit. Workplace managers could benefit from more awareness of how workplace design influences company culture and other organisational goals, and they could check more regularly whether those goals are supported by the workplace design. Especially if workplace interventions are based on efficiency reasoning, managers might overlook the consequences for employee thriving. Given that the workplace is also a social system, what happens in the workplace relates to other systems beyond the workplace, so that could cost the organisation much more than was saved by space reduction. 


\section{Closing words}

In practice, there appears to be an increased focus among office organisations and their workplace managers on user-centred design solutions and healthy workplaces, through which they aim to support user needs to reach employee thriving at work. Nonetheless, there are still too many organisations that have invested a lot of money in designing what they feel has become a wonderful office, ending up with a series of consistent complaints from employees. Although they were willing to create a high-quality environment and perhaps succeeded to do so in an objectively measured way (meeting norms, maybe obtaining certificates like WELL or BREEAM), they fall short in reaching subjective alignment and thus in supporting their employees optimally. We hope that further development of the EWA theory introduced in this chapter will improve alignment in practice as well. However, this will require lots of future research as discussed.

This is only the first book to appear in this Transdisciplinary Workplace Research and Management book series. The next book in this series (available at approximately the same time as this first volume) discusses theories on corporate real estate, facility and workplace management processes and strategy formation, and extracts a framework of concepts from them in the same way as done here. This will provide more insight into how to create an optimal workplace experience for all stakeholders in the organisation in the long term and achieve alignment on the strategic level as well.

\section{References}

Appel-Meulenbroek, R., Clippard, M., \& Pfnür, A. (2018). The effectiveness of physical office environments for employee outcomes: An interdisciplinary perspective of research efforts. Journal of Corporate Real Estate, 20(1), 56-80. https://doi.org/10.1108/JCRE-04-2017-0012

Appel-Meulenbroek, R., Steps, S., Wenmaekers, R. H. C., \& Arentze, T. (2020). Coping strategies and perceived productivity in open-plan offices with noise problems. Journal of Managerial Psychology, Aheadof-Print. https://doi.org/10.1108/JMP-09-2019-0526

Appel-Meulenbroek, R., Van der Voordt, T., Aussems, R., Arentze, T., \& LeBlanc, P. (2020). Impact of activity-based workplaces on burnout and engagement dimensions. Journal of Corporate Real Estate, 22(4), 279-296. https://doi.org/10.1108/JCRE-09-2019-0041

Babapour, M., Karlsson, M., \& Osvalder, A. L. (2018). Appropriation of an activity-based flexible office in daily work. Nordic Journal of Working Life Studies, 8(S3), 71-94. https://doi.org/10.18291/njwls. v8iS3.105277

Bar, H., \& Mentch, L. (2017). R-CMap: An open-source software for concept mapping. Evaluation and Program Planning, 60, 284-292. https://doi.org/10.1016/j.evalprogplan.2016.08.018

Berg, J. M., Dutton, J. E., \& Wrzesniewski, A. (2008). What is job crafting and why does it matter. Retrieved from https://positiveorgs.bus.umich.edu/wp-content/uploads/What-is-Job-Crafting-and-Why-Doesit-Matter1.pdf

Brown, C. (2013). The poverty of grand theory. European Journal of International Relations, 19(3), 483-497. https://doi.org/10.1177/1354066113494321

Budie, B., Appel-Meulenbroek, R., Kemperman, A., \& Weijs-Perrée, M. (2019). Employee satisfaction with the physical work environment: The importance of a need based approach. International Journal of Strategic Property Management, 23(1), 36-49. https://doi.org/10.3846/ijspm.2019.6372

Carpenter, S. (2018). Ten steps in scale development and reporting: A guide for researchers. Communication Methods and Measures, 12(1), 25-44. https://doi.org/10.1080/19312458.2017.1396583

Colenberg, S., Jylhä, T., \& Arkesteijn, M. (2020). The relationship between interior office space and employee health and well-being: A literature review. Building Research \& Information, 1-15. https://doi. org/10.1080/09613218.2019.1710098

Cooke, H., Appel-Meulenbroek, R., \& Arentze, T. (2019). Is the much discussed agility of Corporate Real Estate visible in practice? An empirical study of the relationship between business metrics and surplus property. International Journal of Strategic Property Management, 23(4), 227-243. https://doi.org/10.3846/ ijspm.2019.8029 
Dewe, P., Cox, T., \& Ferguson, E. (1993). Individual strategies for coping with stress at work: A review. Work \& Stress, 7(1), 5-15. https://doi.org/10.1080/02678379308257046

Edwards, J. R. (2008). Person-environment fit in organizations: An assessment of theoretical progress. Academy of Management Annals, 2(1), 167-230. https://doi.org/10.1080/19416520802211503

Edwards, J. R., Caplan, R. D., \& Van Harrison, R. (1998). Person-environment fit theory: Conceptual foundations, empirical evidence, and directions for future research. In C. L. Cooper (Ed.), Theories of organizational stress (pp. 28-67). Oxford: Oxford University Press.

Edwards, J. R., \& Shipp, A. J. (2007). The relationship between person-environment fit and outcomes: An integrative theoretical framework. In C. Ostroff \& T. A. Judge (Eds.), Perspectives on organizational fit (pp. 209-258). San Francisco, CA: Jossey-Bass.

Kane, M., \& Rosas, S. (2018). Conversations about group concept mapping: Applications, examples, and enhancements. Los Angeles, CA: SAGE Thousand Oaks.

Kane, M., \& Trochim, W. M. K. (2007). Concept mapping for planning and evaluation. Los Angeles, CA: ProQuest Sage.

Kleine, A. K., Rudolph, C. W., \& Zacher, H. (2019). Thriving at work: A meta-analysis. Journal of Organizational Behavior, 40(9-10), 973-999. https://doi.org/10.1002/job.2375

Leesman. (2020). The Leesman review 29. Retrieved from www.leesmanindex.com/leesman-review/ leesman-review-editions/review-29/

Luong, M., Peters, K., von Hippel, C., \& Dat, M. (2019). Fitting into the workplace. In O. B. Ayoko \& N. M. Ashkanasy (Eds.), Organizational behaviour and the built environment (pp. 113-127). London: Routledge.

Nilsen, P. (2015). Making sense of implementation theories, models and frameworks. Implementation Science, 10(1), 53-79. https://doi.org/10.1186/s13012-015-0242-0

Repko, A. F. (2012). Interdisciplinary research: Process and theory (2nd ed.). London, New Delhi, Thousand Oaks, and Singapore: Sage.

Rolfö, L. (2018). Activity-based flexible office work environments: Design and implementation processes and outcomes [Dissertation]. Stockholm: KTH Royal Institute of Technology. Retrieved from www.diva-portal.org/ smash/get/diva2:1265084/FULLTEXT02.pdf

Rosas, S. R., \& Kane, M. (2012). Quality and rigor of the concept mapping methodology: A pooled study analysis. Evaluation and Program Planning, 35(2), 236-245. https://doi.org/10.1016/j.evalprogplan.2011. 10.003

Skinner, E. A., Edge, K., Altman, J., \& Sherwood, H. (2003). Searching for the structure of coping: A review and critique of category systems for classifying ways of coping. Psychological Bulletin, 129(2), 216-269. https://doi.org/10.1037/0033-2909.129.2.216

Spreitzer, G., Porath, C. L., \& Gibson, C. B. (2012). Toward human sustainability: How to enable more thriving at work. Organizational Dynamics, 41(2), 155-162. https://doi.org/10.1016/j.orgdyn.2012.01.009

Tims, M., \& Bakker, A. B. (2010). Job crafting: Towards a new model of individual job redesign. SA Journal of Industrial Psychology, 36(2), 1-9. https://doi.org/10.4102/sajip.v36i2.841

Trochim, W. M. (2017). Hindsight is 20/20: Reflections on the evolution of concept mapping. Evaluation and Program Planning, 60, 176-185. https://doi.org/10.1016/j.evalprogplan.2016.08.009

Van der Voordt, T. J., \& Jensen, P. A. (2018). Measurement and benchmarking of workplace performance. Journal of Corporate Real Estate, 22(2), 95-112. https://doi.org/10.1108/JCRE-10-2017-0032

Van der Voordt, T. J., \& Van Meel, J. (2016). Culture. In P. A. Jensen \& T. van der Voordt (Eds.), Facilities management and corporate real estate management as value drivers: How to manage and measure added value. London: Routledge. 


\section{INDEX}

Note: Page numbers in italic indicate a figure and page numbers in bold indicate a table on the corresponding page.

abilities: and privacy regulation theory 74

academic workplaces 267

achievement orientation culture 138

action regulation 60

action regulation theory: action regulation and

stress 60; applicability to workplace studies

60, 61; background 54; basic principles of

55 ; hierarchical-sequential model of action regulation 55, 55; limitations 64; methodology/ research approach 63 ; regulation requirements and regulation possibilities 58,59 ; theory relevance to practice 64

action research: TTF theory 46

activity-based flexible work (A-FOs) 17, 21

activity-based working environments: and

activity theory 243; design and social factors

in 72; and ecological systems theory 109 and evolutionary psychology theory 199, 200; and organisational knowledge creation theory 268; and person-environment fit theory 15-17; and place attachment theory 183, 188; and privacy regulation theory 71; and two-process theory of perceived control 126

activity theory (AT): analytical considerations 243, 244; application to workplace studies 237; background 236, 237; considerations for data collection 242, 243; emphasis on the situatedness and contextual nature of employees' activities 238; informing a use(r)-centred workplace design and development 241; limitations and challenges 244; mediating roles that workplaces play as tools in employees' everyday activities 239 , 240 ; relevance to practice 245 ; research approach for adopting AT in workplace research 242; simultaneously holistic and granular understanding of employees' activities 238 ; temporal aspects and the developmental process of appropriating new workplaces 240 , 241; understanding employees' experiences and subjective grasp of their contexts 239; the unique foci of 241 adaptation to workplace change 185 adaptive coping mechanisms 50 adhocracy culture 136 appropriation 240, 241 artefacts 135

assessment: and work privacy 74

assumptions 136, 249

attachment 196, 199, 200; see also place attachment theory

attribute quality 148, 149

authors $9, \mathbf{1 0}$

availability regimes 87

awareness 49

Ba 263, 264, 265, 265, 267

basic assumptions 136

behaviour 279

behavioural economics theory: applicability

to workplace studies 212; background 209; cognitive, temporal, and social biases of 210; herd behaviour, social norm, and reciprocity 211, 215 , 216; and human behaviours 209; limitations 217; methodology/research approach 216; optimism bias, overconfidence, and planning fallacy 211 , 214; status quo bias and loss aversion 210, 212, 213; theory relevance to practice 217 
bias 196, 198

biophilia: and cognitive restoration 196, 201

biophilia hypothesis: applicability to workplace studies 170, 171, 171; background 169

limitations 175; methodology/research approach 173, 173; theory relevance to practice 176

biophilic classroom 166

biophilic workplaces 166; productivity gains 173

boundary setting 87

bureaucracy culture 136

BUS (building use studies) 152

case studies: flourish theory 165

chrono-systems 102, 103, 110, 111

clan culture 136

cognition 279

cognitive bias 196, 199, 210

cognitive restoration 196, 201

combination see SECI (socialisation,

externalisation, combination, internalisation)

model

comfort 159

community vitality 107

company rules 226

competing value framework 136, 137

complexity 197, 202, 202

concept mapping 274, 275, 277, 278

connective place 266

connectivity $249,250,254$

consensual culture 138

consistency culture 136

context 238, 280

control 203

coping: adaptive coping mechanisms 49; with unsupportive technology 42, 44; see also transactional theory of stress and coping

COVID-19 pandemic: and behavioural economics theory 211; and evolutionary psychology theory 203; and flourish theory 159, 165, 166; and information space $82,87,89$; and organisational culture theories 142; and place attachment theory 188; and temperament theory 118,120

crowding 203

cyclicle unit 55,55

data collection and analysis: activity theory 242-243, 242-243; ecological systems theory 107, 108; theory of attractive quality 152

decision making 136-138, 139, 209-210, 216, 217

design factors: in activity-based working environments 72 ; and work privacy fit 71

developmental process 240

development culture 138

ecological systems theory (EST): applicability to workplace studies 103; background 101, 102; and community vitality 107 ; conceptual framework for workplace research based on
103; data collection and analysis 107, 108; and individual vitality 105; limitations 110 ; methodology/research approach 107; research gaps 109; theory relevance to practice 110; and work-family relationship 106; and workplace flexibility 104, 104; and workplace and organisational vitality 106

electrodermal activity (EDA) 204, 205

electroencephalography (EEG) 174, 204, 205

emotional exhaustion: and privacy regulation theory 73

empirical studies: workplace design 158

employee performance 186

employee well-being 186

employee-workplace alignment (EWA) 1, 272 ,

274, 287; as a complex problem 2; concept mapping and regions of meaning 274-277; towards a grand new theory on 282, 283; implications for practice 286; limitations and future steps 285; relations between theories 274, 280, 281; relevant terminologies 8; theories, models, and frameworks 4-7; and transdisciplinarity 3

environmental comfort 159

environmental crafting 31

environmental demands 29, 30

environmental demands-resources (ED-R) model 27-34, 30

environmental resources 30

espoused values 135

evolutionary psychology theory: application

to workplace behaviours 198; attachment and territoriality 196, 199; background 195; biophilia and cognitive restoration 196, 201; cognitive and perceptive biases 196, 199, 200; complexity and mystery 197, 202; human psychological mechanisms explained through 195; limitations 205; methodology/research approach 204, 205; prospect and refuge 197, 201; spatial biases 198, 203; theory relevance to practice 205; topics related to workplace 195 exo-systems 102, 104, 107, 110-111 experiences 239

externalisation see SECI (socialisation, externalisation, combination, internalisation) model

family see work-family relationships flourish theory: applicability to workplace studies 159, 162; background 157; biophilic classroom 165; biophilic workplaces 166; empirical studies on workplace design 158; beyond environmental comfort 159; limitations 165; methodology 163, 164; and the multisensory experience 158; theory relevance to practice 165

formal place 277

framework 7 
functional magnetic resonance imaging (fMRI) 173, 204

Furbish SSO 152

GIS system 254255

granular understanding 238

group culture 138

health 225

herd behaviour 211, 215

hierarchical-sequential model 55, 55

hierarchy culture 136

holistic understanding 238

human activity 254

human flourishing: relationship of JD-R model to 31,31

individual vitality 105

indoor environmental quality (IEQ): Kano model for satisfaction research with 151; occupant satisfaction with 150

information space: applicability to workplace studies 86 ; availability regimes vs. boundary setting 87 ; background 82,82 ; limitations 89 ; methodology/research approach 88 ; and the production of 'placelessness' 86 ; simultaneity of work at places and spaces 87 ; theory relevance to practice 89

interdisciplinary theory $249,273,282$; concept mapping and regions of meaning 274-277; implications for practice 28.6; relations between theories 280

internalisation see SECI (socialisation, externalisation, combination, internalisation) model

involvement culture 138

job demands-resources (JD-R) model: applicability to workplace studies 29; background 27; environmental crafting 31; environmental demands 29; environmental resources 30 ; limitations 33; methodological/research approaches 33 ; outline of 27,28 ; relationship to human flourishing 31 ; theory relevance to practice 34

job satisfaction 186

job task 74

job type 74

Kano model 148-154, 149

knowledge co-creation 265

knowledge creation 261; as a framework in studies of academic workplaces 267; knowledge co-creation 265; and knowledge-sharing 262; the nature of the workplace for each phase of 266; workplace as a foundation for 263; in workplaces 265 ; see also organisational knowledge creation theory knowledge-sharing 262; workplace as a foundation for 263; in workplaces 265

knowledge workplaces: activities connected to knowledge creation 261; applicability to workplace studies 265; background 261; knowledge co-creation and knowledge workplace 265; knowledge creation phases as a framework in studies of academic workplaces 267; knowledge creation process and knowledgesharing behaviour in workplaces 265 ; knowledge-sharing and creation process 262; limitations 268; methodology/research approach 267; the nature of the workplace for each phase of knowledge creation 277; theory relevance to practice 268; workplace as a foundation for knowledge-sharing and creation process 263

loss aversion 210, 212

macro-systems 102, 104, 105, 110-111

market culture 136

meaning 277, 278, 282

mediating roles 239

mental fatigue: and privacy regulation theory 73 meso-systems 102, 104, 107, 110-111

methodology: action regulation theory 63 ; behavioural economics theory 216; biophilia hypothesis 173; ecological systems theory 107 ; evolutionary psychology theory 204; flourish theory 163; JD-R model 33; information space 88 ; nudges 227 ; organisational culture theories 142; organisational knowledge creation theory 267; P-E fit 19; place attachment theory 186 ; privacy regulation theory 75 ; social constructionism theory 96 ; space syntax theory 254 ; temperament theory 120; theory of attractive quality 152 ; TTF theory 46; TTPC 127

Meyers-Briggs Type Indicator (MBTI) 117, 120

micro-systems 103, 110-111

mixed methods 186

model 7

moderators of workplace attachment 187

multisensory experience 158

mystery 197, 202, 203

need-supply alignment 278

negative affect: and privacy regulation theory 73 nudging: and adherence to company rules 226 ; applicability to workplace studies 224 ; background 222; empirical research on 224; limitations 228 ; methodology/research approach 227; and physical health of employees 225 ; and sustainability 226 ; theory relevance to practice 229

office work 61, 62, 89, 176, 238

open plan 15, 19; and ecological systems theory

103; and evolutionary psychology theory 198; 
and job demands-resources model 17; and place attachment theory 182, 188; and privacy regulation theory $71,74,75,76$; and social constructionism theory 96,97 ; and space syntax theory 248

optimism bias 211, 214

organisational commitment 186

organisational context 278

organisational culture 132-134, 134, 140;

dimensions of 139,140

organisational culture theories 132

organisational knowledge creation theory: activities connected to knowledge creation 261; applicability to workplace studies 265 ; background 261; knowledge co-creation and knowledge workplace 265; knowledge creation phases as a framework in studies of academic workplaces 267; knowledge creation process and knowledge-sharing behaviour in workplaces 265; knowledge-sharing and creation process 262; limitations 268; methodology/research approach 267; the nature of the workplace for each phase of knowledge creation 277, 277; theory relevance to practice 268 ; workplace as a foundation for knowledge-sharing and creation process 263

organizational vitality 106

organisations, types of $139, \mathbf{1 4 0}$

outcomes: of workplace attachment 70

overconfidence 211, 214

participatory action research (PAR) 46

perceptive bias 196, 199

person-environment fit (P-E fit) theory:

applicability to workplace studies 15 ;

background 14; and the digital workplace 17;

limitations 21; methodology/research approach

19 ; and the physical workplace 17; and post-

occupancy evaluations 19; relevance to practice

21; and subjective wellbeing measures 20

physical health 225

place attachment theory: adaptation to workplace change 185; applicability to workplace studies 182; background 181; desired outcomes of workplace attachment 185; employee performance and organisational commitment 186; employee will-being and job satisfaction 186; employing mixed methods in research 186; limitations 188; methodology/research application 74 potential moderators of workplace attachment 187; the PPP model in a workplace context 183, 183; theory relevance to practice 188; the unidimensional model of workplace attachment 185; the workplace attachment-and-disruption model 185; workplace attachment models 182 placelessness 86 planning fallacy 211, 214

post-occupancy evaluations (POEs) 19, 152

power-oriented culture 138

PPP model 183

privacy see privacy regulation theory; work privacy privacy regulation theory: applicability to

workplace studies 69; background 68;

consequences of poor privacy fit 72 ; design

and social factors 71-72; job type and task

74; limitations 76; methodology 74; new

conceptualisations of work privacy by Weber

70; predictors of individual differences in privacy desires 73; predictors of work privacy fit

71; prior conceptualisations of work privacy 6.9; qualitative methods 75 ; quantitative methods 75 ; research gaps 76; satisfaction 72 ; stress, negative affect, and emotional exhaustion 73 theory relevance to practice 76 ; traits and abilities 74 ; work performance and mental fatigue 73

productivity gains $\mathbf{1 7 3}, 175$

prospect and refuge theory 197, 201

psychology 195; see also evolutionary psychology theory

rational culture 137

reciprocity 211,215

reflective place 277

regions of meaning $277,277,280$

regulation 58, 59; problems in office work 62; see also action regulation theory

representations 249

research: action regulation theory 63 ; activity

theory 242; behavioural economics theory 216

biophilia hypothesis 173 ; ecological systems theory 103, 104, 107; empirical research on nudges 224; evolutionary psychology theory 204; information space 88; JD-R model 33; nudges 227; organisational culture theories 142; organisational knowledge creation theory 267 P-E fit 19; place attachment theory 186; space syntax theory 254 ; temperament theory 120; theory of attractive quality 152 ; TTF theory 46; TTPC 127; see also action research; research gaps

research gaps: and ecological systems theory 109; and the Kano model 153; and privacy regulation theory 76

role culture 138

rules 226

satisfaction 72, 148; 'Furbish SSO' user insight approach 152; with IEQ matters 150; Kano's satisfaction model 149,151, 153; post-

occupancy evaluation 33; theory relevance to practice 154

SECI (socialisation, externalisation, combination, internalisation) model 262-263, 264, 265, 268 
SHINE (Sustainability and Health Initiative for

Net-Positive Enterprise) model 32, 32, 33-34

simultaneity 87

situatedness 238

social bias 210

social constructionism theory: applicability to practice 97; applicability to workplace 94; background 93; limitations 97; methodology 96 social factors: in activity-based working environments 72; and work privacy fit 71 socialisation see SECI (socialisation, externalisation, combination, internalisation) model

social norms 211, 215

space syntax theory: applicability to workplace studies 251; assumptions and representations common to space syntax theory 249,249 ; background 248; bringing space and usage together 254; future research possibilities 255; human activity 254; an interdisciplinary theory across spatial scales and settings 248; limitations 255; methodology/research approach 254; overview of workplace research findings on offices 252, 252; overview of workplace research findings in other settings 253; spatial structure 254; theory relevance to practice 256 ; workplace phenomena across scales 252

spatial biases 198, 203

spatial scales and settings 248

spatial structure 254

status quo bias 210,212

stress 42, 44; and action regulation 60; and privacy regulation theory 73 ; see also transactional theory of stress and coping

structural place 277

subjective wellbeing (SWB) measures 20

subjectivity 239

support and person-oriented culture 138

sustainability 226

Sustainable Development Goals (SDGs) 150

task-technology fit (TTF) theory: applicability to workplace studies 45; background 39; building awareness 49; and coping with unsupportive technology 42, 44; embracing adaptive coping mechanisms 49; interacting elements of 40; limitations 48; measurement components 50; methodology/research approach 46, 46; participatory changes in the daily practices 46; and utilisation 40; and technostress 45, 49 theory relevance to practice 49 ; and transactional theory of stress and coping 42 technology, unsupportive 42

technostress 41

techno-stressors 49

temperament theory: background 115, 116; applicability to workplace studies 118 ; limitations 120; methodology/research approach 120; theory relevance to practice 120

temporal aspects 240

temporal bias 210

terminologies 8

territoriality 196, 199

test-operate-test-exit (TOTE) unit 55, 55

theories 1, 9, 10; a complex problem 1; defined

7; relevant terminologies 8 ; selecting 4;

transdisciplinarity 3; see also specific theories

theory of attractive quality: application to

workplaces 150; background 148, 149;

examples of data collection from employees 152;

'Furbish SSO' user insight approach 152, 153;

the Kano model for satisfaction research with

IEQ 151; limitations 33; methodology/research approach 152; occupant satisfaction with IEQ

matters 150; post-occupancy evaluation 152;

research gaps and the Kano model 29; theory

relevance to practice 34

traits: and privacy regulation theory 74

transactional theory of stress and coping (TTSC)

42, 43

transdisciplinarity 3

two-process theory of perceived control (TTPC):

applicability to workplace studies 126 ;

background 124; limitations 129; methodology/ research approach 127,129 ; theory relevance to practice 130

unidimensional model of workplace attachment 183 unit creation 275

UN Sustainable Development Goals 150

UsabiliTEST 276-277

user-centred workplace design and development 241

user insight 152

utilisation: TTF theory 39

values see espoused values

virtual reality (VR) 153, 204

visibility graph analysis (VGA) 249, 254, 255

well-being 186

work-family relationships 106

work-from-home (WFH) programs 111

work performance: and privacy regulation theory 73

workplace: applicability of social constructionism

theory to 94; applicability of theory of attractive quality to 150 ; appropriating new workplaces 241,241 ; as a foundation for knowledgesharing and creation process 263, 277, 277; mediating roles of 239; and organizational vitality 106; PPP model in 182; topics of evolutionary psychology related to 196; usercentred design and development 241; see also knowledge workplaces 
workplace, digital 17

workplace, physical 17

workplace attachment: desired outcomes of 185 ; see also place attachment theory

workplace attachment-and-disruption model 185

workplace attachment models 182, 183

workplace behaviours: application of evolutionary

psychology theory to 198

workplace change: adaptation to 185

workplace design: empirical studies 158

workplace flexibility 104

workplace studies: action regulation theory 61 ; activity theory 237, 243; behavioural economics theory 212; biophilia hypothesis 170 ; ecological systems theory to 103 ; flourish theory 159 ; information space to 86 ; JD-R model to 29 ; nudges to 224; organisational culture theories to 140,141 ; organisational knowledge creation theory 265; P-E fit theory to 15; place attachment theory 182; privacy regulation theory to 69; space syntax theory 252, 252; temperament theory to 118 ; TTF theory to 45 ; TTPC to 126,129

work privacy: assessment methods of 74; consequences of poor fit 72; new conceptualisations of 70 ; predictors of fit 71 ; predictors of individual differences in privacy desires 73; prior conceptualisations of 69 